\title{
Artificial Metalloenzymes: Reaction Scope and Optimization Strategies
}

Fabian Schwizer, ${ }^{1, \ddagger}$ Yasunori Okamoto, ${ }^{1, \ddagger}$ Tillmann Heinisch, ${ }^{1, \ddagger}$ Yifan Gu, ${ }^{2, \ddagger}$ Michela M. Pellizzoni, ${ }^{1, \ddagger}$ Vincent Lebrun, ${ }^{1, \pm}$ Raphael Reuter, ${ }^{1, \pm}$ Valentin Köhler, ${ }^{1, \ddagger}$ Jared C. Lewis ${ }^{2, *}$ and Thomas R. Ward ${ }^{1, *}$

${ }^{1}$ Department of Chemistry, Spitalstrasse 51, University of Basel, $\mathrm{CH}-4056$ Basel, Switzerland.

${ }^{2}$ Searle Chemistry Laboratory, University of Chicago, 5735 S. Ellis Ave., Chicago, IL 60637, USA.

$\ddagger$ equal contribution

address correspondance to jaredlewis@uchicago.edu or thomas.ward@unibas.ch.

Acknowledgements. TRW thanks the Swiss National Science Foundation and more recently the NCCR "Molecular Systems Engineering" for generously funding his research on artificial metalloenzymes. JCL similarly thanks the David and Lucile Packard Foundation, the U.S. Army Research Office (62247-LS), and the NSF (CHE-1351991).

\begin{abstract}
The incorporation of a synthetic, catalytically competent metallocofactor into a protein scaffold to generate an artificial metalloenzyme (ArM) has been explored since the late 1970s. Progress in the ensuing years was limited by the tools available for both organometallic synthesis and protein engineering. Advances in both of these areas, combined with increased appreciation of the potential benefits of combining attractive features of both homogeneous catalysis and enzymatic catalysis, led to a resurgence of interest in ArMs starting in the early 2000s. Perhaps the most intriguing of potential ArM properties is their ability to endow homogeneous catalysts with a genetic memory. Indeed, incorporating a homogeneous catalyst into a genetically-encoded scaffold offers the opportunity to improve ArM performance by directed evolution. This capability could, in turn, lead to improvements in ArM efficiency similar to those obtained for natural enzymes, providing systems suitable for practical applications and greater insight into the role of second coordination sphere interactions in organometallic catalysis.
\end{abstract}

Since its renaissance in the early 2000s, different aspects of artificial metalloenzymes have been extensively reviewed and highlighted. Our intent is to provide a comprehensive overview of all work in the field up to December 2016, organized according to reaction class. Because of the wide range of non-natural reactions catalyzed by ArMs, this was done using a functional-group transformation classification. The review begins with a summary of the proteins and the anchoring strategies used to date for the creation of ArMs, followed by a historical perspective. Then follows a summary of the reactions catalyzed by ArMs and a concluding critical outlook. This analysis allows for comparison of similar reactions catalyzed by ArMs constructed using 
different metallocofactor anchoring strategies, cofactors, protein scaffolds, and mutagenesis strategies. These data will be used to construct a searchable website on ArMs that will be updated regularly by the authors. 


\section{Table of Contents}

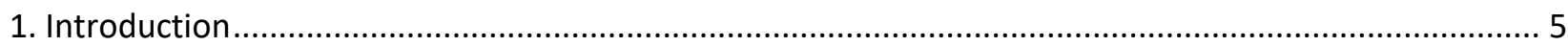

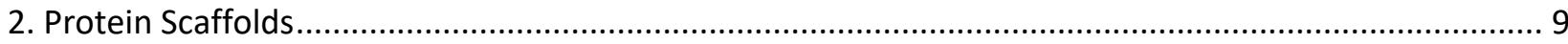

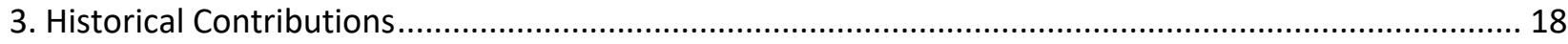

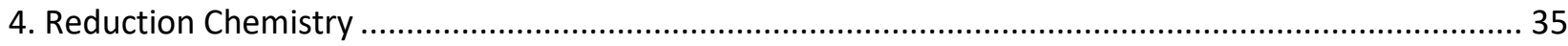

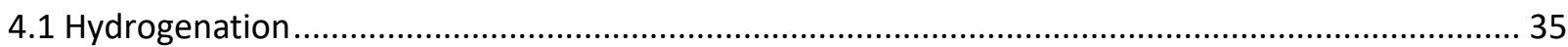

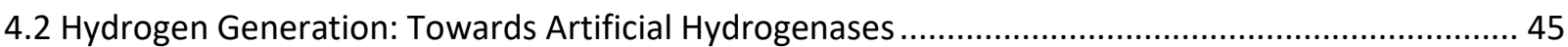

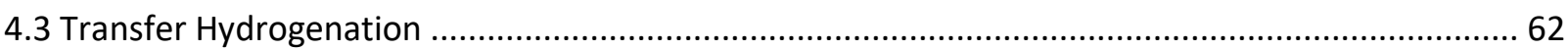

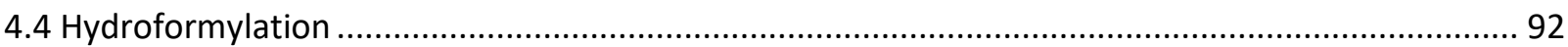

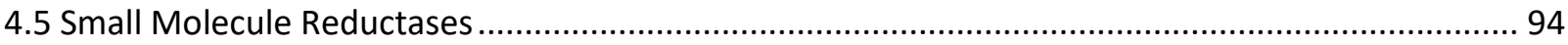

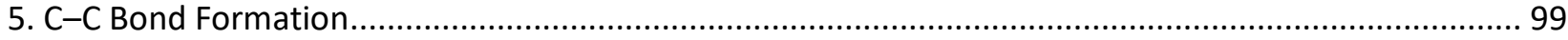

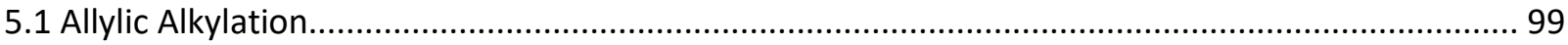

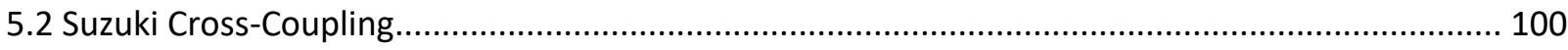

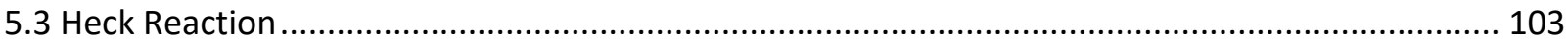

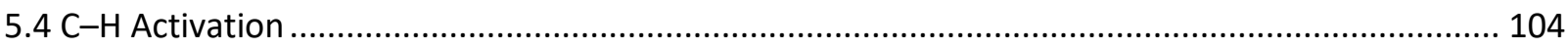

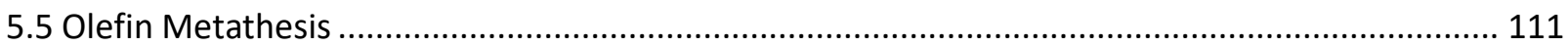

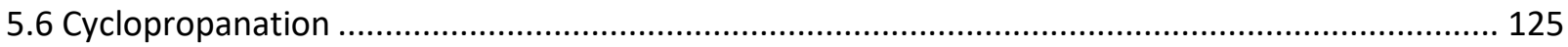

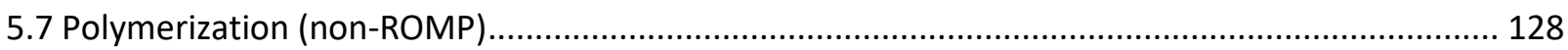

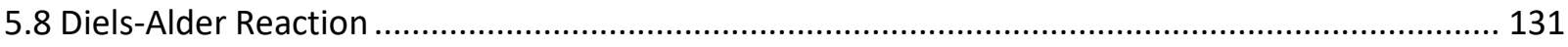

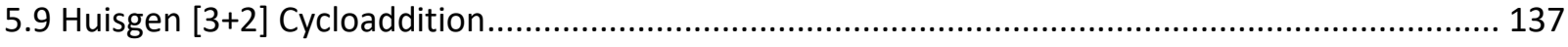

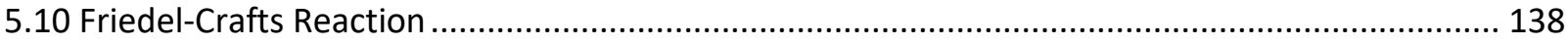

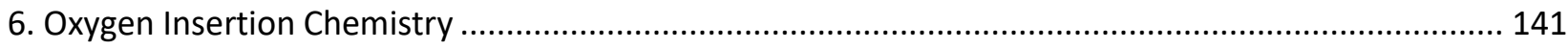

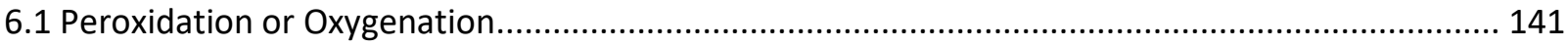

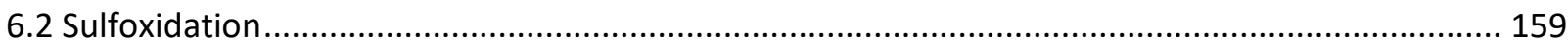

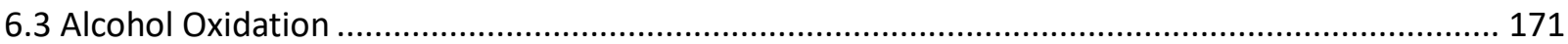

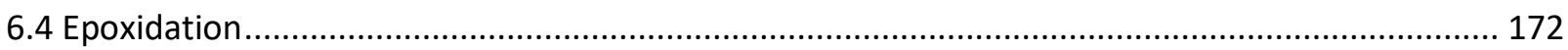

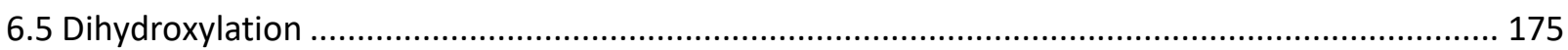

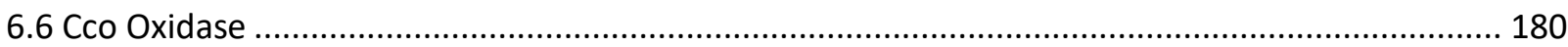

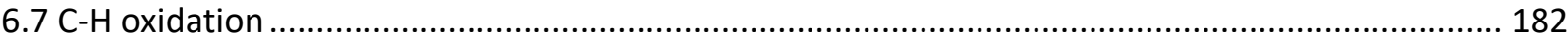

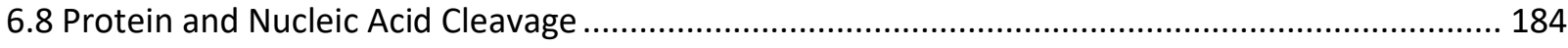

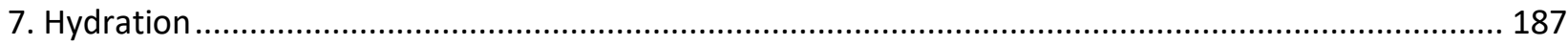

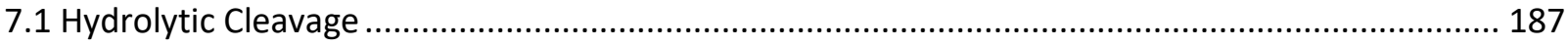

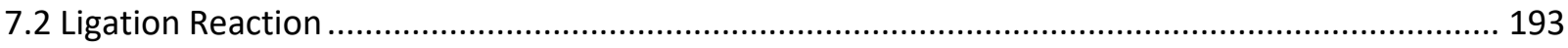

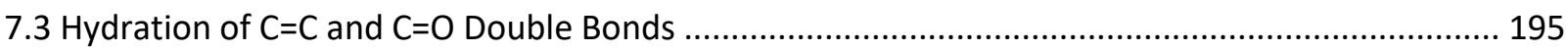




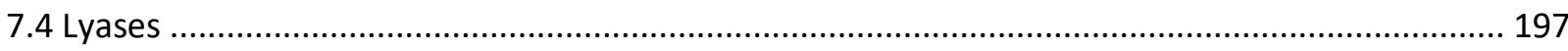

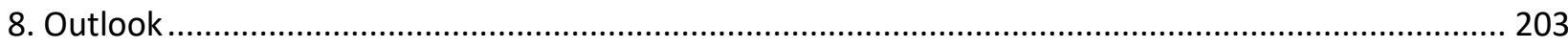

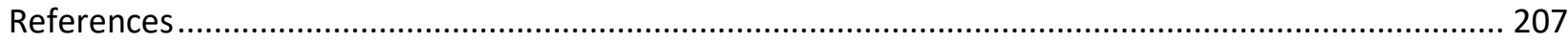




\section{Introduction}

Artificial metalloenzymes (ArMs) result from the incorporation of a catalytically competent metallocofactor into a protein scaffold. Initial attempts to construct ArMs were reported by Wilson and Whitesides as well as Kaiser and coworkers in the late 1970s. ${ }^{1-2}$ Despite several fascinating aspects of these hybrid catalysts, Whitesides concluded his article by stating "the catalytic system (...) is not a practical asymmetric catalyst." 2 Unfortunately, following this pronouncement, relatively little progress was made toward ArM development until the new millennium. Setting aside the question of whether practicality should dictate the course of scientific inquiry, it is certainly the case that ArM construction in those early days was limited by the tools available for both organometallic synthesis and protein engineering. Significant progress in these areas contributed to the revival in ArM research that continues to this day.

The resurgence of interest in ArMs was also driven by increased appreciation of the potential benefits of combining attractive features of both homogeneous catalysis and enzymatic catalysis. For example, the ArM secondary coordination sphere could interact with metal catalysts, substrates, or intermediates to facilitate reactions or to discriminate similarly reactive sites on substrates. ArMs could also be generated from protein scaffolds with inherent functionality (e.g. catalytic activity, substrate binding, redox properties, etc.) that could be used to augment ArM function. Perhaps more intriguingly, ArMs could endow homogeneous catalysts with a genetic memory. Indeed, incorporating a homogeneous catalyst within a genetically-encoded scaffold (i.e. the genetic memory of the ArM) offers the opportunity to improve the ArM performance by mutagenesis. This enables to apply Darwinian evolution schemes for ArM optimization. Introduced in the early nineties by Frances Arnold and Pim Stemmer, ${ }^{3-4}$ directed evolution has had a revolutionary impact on biotechnology, ${ }^{5-7}$ leading to catalysts that 
have supplanted well-established large-scale processes based on homogeneous catalysts. ${ }^{8}$ This technique relies on the efficient high-throughput screening of genetic diversity to identify and characterize functionally evolved mutants. Similar optimization of ArMs could ultimately lead to systems suitable for practical applications, and provide greater insight into the role of second coordination sphere interactions in organometallic catalysis.

Four complementary strategies have been pursued to localize metallocofactors within a well defined second coordination sphere environment, provided by the host protein: i) covalent, ii) supramolecular, iii) dative and iv) metal substitution, Figure 1.

i) Covalent anchoring, reminiscent of the well-established bioconjugation techniques, ${ }^{9}$ involves a high-yielding and irreversible reaction between cofactors bearing a reactive functional group and an amino acid side-chain on the protein scaffold. Common reactions used for ArM formation include: a) nucleophilic attack by cysteine or another uniquely activated residue on an electrophilic moiety (maleimide, $\alpha$-halocarbonyl, etc.) on the cofactor, b) disulfide bond formation between cysteine and a cofactor substituted with an electrophilic sulfur moiety, and c) Huisgen [3+2]-cycloaddition between an unnatural amino acid bearing a terminal alkyne or azide with an azide- or alkynesubstituted cofactor. ${ }^{10}$

ii) Supramolecular anchoring exploits the high affinity that proteins may display for a limited set of non-covalent inhibitors, natural cofactors, or substrates. Covalent modification of these with the cofactor may, in some cases, maintain a high affinity, thus ensuring quantitative localization of the cofactor within the host protein.

iii) Dative anchoring relies on the coordination of a nucleophilic amino acid residue (His, Cys, Glu, Asp, Ser etc.) to a coordinately unsaturated metal center. This type of 
anchoring and activation of the metal often complements either covalent or supramolecular strategies.

iv) Metal substitution builds upon the unique reactivity of non-native metals combined with the exquisitely tailored active site of natural metalloenzymes. Upon substituting the metal, new-to-nature reactivities can be introduced in the ArM's repertoire. ${ }^{11}$ This strategy builds upon the very elegant enzyme repurposing approach introduced by Frances Arnold in 2013. ${ }^{12-14}$ Because enzyme repurposing does not involve metal substitution (and all of the challenges associated with it), it is not covered here but is instead presented by Fasan and coworkers elsewhere in this issue of Chemical Reviews.

a)

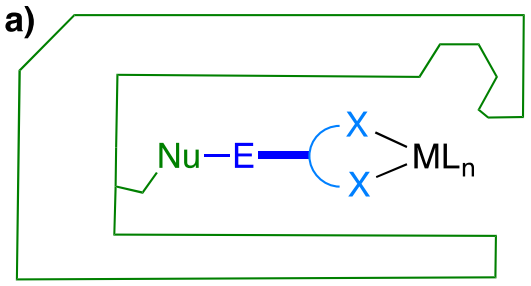

c)

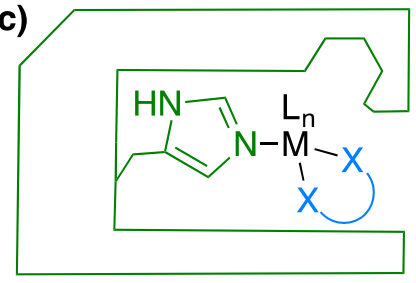

b)

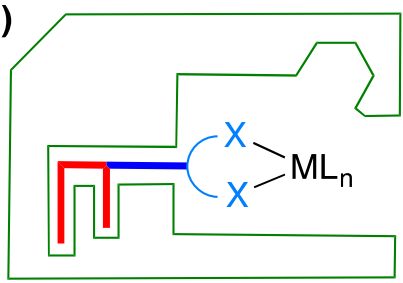

d)

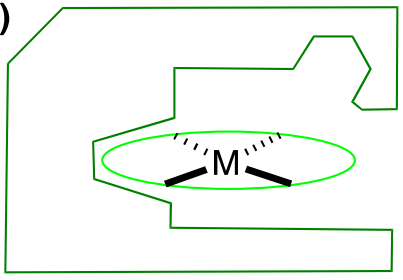

Figure 1. Four anchoring strategies allow to firmly localize an abiotic cofactor within a protein scaffold: a) covalent, b) supramolecular, c) dative, and d) metal substitution. The following colour codes apply: protein and natural cofactor (green), supramolecular anchor (red), variable spacer and ligand (blue) and abiotic metal (black).

Since its renaissance in the early 2000s, the field of artificial metalloenzymes has been extensively reviewed and highlighted. ${ }^{15-95}$ With catalytic applications in mind, the present review summarizes the progress in ArM according to the reaction they catalyze.

The authors' initial intention was to classify the reactions according to the enzyme class system (EC) from the International Union of Biochemistry and Molecular Biology: oxidoreductase, transferase, hydrolase, lyase, isomerase and ligase. It rapidly became evident that the EC system is not best suited to ArM as the reactions these catalyze are 
often non-natural: in what EC would one assign to an artificial metathase or Suzukiase? We thus followed a more classical functional-group transformation classification.

In view of the focus on catalysis, artificial metalloproteins with no catalytic function are not covered comprehensively. ${ }^{34-35}$ The same applies to the fascinating fields of DNAand RNAzymes as well as metallopeptides with less than one hundred amino acids (an arbitrary length set for inclusion in this review). These DNA/RNAzymes and metallopeptides have been reviewed recently by key players in the field. ${ }^{70,96-98}$

This review begins with a summary of the proteins and the anchoring strategies used to date for the creation of ArMs (chapter 2), followed by a historical perspective (chapter 3). Then follows a summary of the reactions catalyzed by ArMs (reduction chemistry, C-C bond-formation, oxygen insertion and hydration: chapters $4-7)$. This review ends with a critical outlook (chapter 8).

The authors have invested significant effort to cover all artificial metalloenzymes published to date, albeit with the restrictions outlined above. Despite the care for the detail and the search tools available, there is no doubt that we have missed some articles. We strive to apply a fair ethics of citation and thus wish to apologize for any unintentional omission. ${ }^{99}$ In addition, this review served as a basis to set up a fullysearchable website on ArM that will be updated regularly by the authors. ${ }^{100}$ 


\section{Protein Scaffolds}

The table presented below summarizes all the protein scaffolds that have been used to date to create artificial metalloenzymes as well as relevant data including i) the anchoring strategy, ii) whether mutants have been tested, iii) the reaction that the resulting ArM catalyzes etc. Protein scaffolds that have been subjected to mutagenesis to optimize the performance of the ArMs are displayed throughout the article where most relevant.

Table 1 Summary of protein scaffolds reported to date for the creation of artificial metalloenzymes.

\begin{tabular}{|c|c|c|c|c|c|c|c|c|c|c|c|}
\hline Entry & Name & PDB-code & Protein Fold ${ }^{a}$ & $\begin{array}{l}\text { Oligomeric } \\
\text { state }^{b}\end{array}$ & $\begin{array}{c}\mathbf{M}_{\mathbf{w}} \\
{[\mathrm{kDa}]}\end{array}$ & $\begin{array}{l}\text { Anchoring } \\
\text { Mode }^{c}\end{array}$ & $\mathrm{PI}^{\mathrm{d}}$ & Native Function & Stability & $\begin{array}{l}\text { Mutants } \\
\text { tested }^{f}\end{array}$ & Reactions $^{g}$ \\
\hline 1 & $\alpha_{3} D$ peptide & 2A3D & $\begin{array}{l}\text { Designed single } \\
\text { chain three- } \\
\text { helix bundle }\end{array}$ & Monomer & 8 & D & 5.8 & $\begin{array}{l}\text { De novo-designed } \\
\text { protein }\end{array}$ & n.d & + & $\mathrm{H} 2 \mathrm{O}$ \\
\hline 2 & $\alpha$-chymotrypsin & $1 \mathrm{YPH}$ & $\begin{array}{l}\text { Trypsin-like } \\
\text { serine protease }\end{array}$ & Homo dimer & 25 & $D, C$ & 8.7 & Endopeptidase & +/++ & WT & $\mathrm{DO}, \mathrm{M}$ \\
\hline 3 & B-lactamase & 2FU7 & $\begin{array}{l}\text { Metallo- } \\
\text { hydrolase/oxido } \\
\text { reductase }\end{array}$ & Monomer & 29 & $\mathrm{D}$ & 6.2 & $\begin{array}{l}\text { Hydrolysis of } B- \\
\text { lactams }\end{array}$ & +/++ & + & $\mathrm{CO}, \mathrm{H} 20$ \\
\hline 4 & B-lactoglobulin & $3 N P O$ & Lipocalins & Monomer & 18 & $S, C$ & 4.8 & Transport & ++ & WT & $\mathrm{TH}, \mathrm{SO}$ \\
\hline 5 & $\begin{array}{l}\text { 6-Phospho- } \\
\text { gluconolactonase } \\
\text { (6-PGLac) }\end{array}$ & 4TM8 & $\begin{array}{l}\text { NagB/RpiA/CoA } \\
\text { transferase-like }\end{array}$ & Monomer & 27 & D & 4.7 & Hydrolase & ++ & + & PE \\
\hline 6 & $\begin{array}{l}\text { Adipocyte lipid } \\
\text { binding protein } \\
\text { (ALBP) }\end{array}$ & $1 \mathrm{~A} 18$ & Lipocalins & Homo dimer & 15 & C & 8.6 & $\begin{array}{l}\text { lipid binding } \\
\text { protein }\end{array}$ & $+/++$ & + & HYD, TA \\
\hline 7 & $\begin{array}{l}\text { Alcohol } \\
\text { dehydrogenase } \\
\text { (ADH) }\end{array}$ & $5 E N V$ & GroES-like & $\begin{array}{l}\text { Homo } \\
\text { tetramer }\end{array}$ & 141 & D & 5.4 & Oxidoreductase & +/++ & WT & DO \\
\hline
\end{tabular}




\begin{tabular}{|c|c|c|c|c|c|c|c|c|c|c|c|}
\hline Entry & Name & PDB-code & Protein Fold ${ }^{a}$ & $\begin{array}{l}\text { Oligomeric } \\
\text { state }^{b}\end{array}$ & $\begin{array}{c}\mathbf{M}_{\mathbf{w}} \\
{[\mathrm{kDa}]}\end{array}$ & $\begin{array}{l}\text { Anchoring } \\
\text { Mode }^{c}\end{array}$ & $\mathrm{Pl}^{\mathrm{d}}$ & Native Function & Stability & $\begin{array}{l}\text { Mutants } \\
\text { tested }^{f}\end{array}$ & Reactions $^{g}$ \\
\hline 8 & Antibody 03-1 & n.d & $\begin{array}{l}\text { Immunoglobulin } \\
\text { like B sandwich }\end{array}$ & n.d & n.d & S & n.d & Immune response & n.d & WT & PE \\
\hline 9 & Antibody $12 \mathrm{E} 11 \mathrm{G}$ & n.d & $\begin{array}{l}\text { Immunoglobulin } \\
\text { like B sandwich }\end{array}$ & n.d & n.d & S & n.d & Immune response & n.d & WT & PE \\
\hline 10 & Antibody $13 \mathrm{G} 10$ & 4AMK & $\begin{array}{l}\text { Immunoglobulin } \\
\text { like B sandwich }\end{array}$ & Hetero dimer & 46 & $S$ & 8.1 & Immune response & n.d & WT & PE \\
\hline 11 & Antibody $14 \mathrm{H} 7$ & 4AT6 & $\begin{array}{l}\text { Immunoglobulin } \\
\text { like B sandwich }\end{array}$ & Hetero dimer & 45 & $\mathrm{~s}$ & 6.5 & Immune response & n.d & WT & PE \\
\hline 12 & Antibody $1 \mathrm{G} 8$ & n.d & $\begin{array}{l}\text { Immunoglobulin } \\
\text { like B sandwich }\end{array}$ & n.d & n.d & S & n.d & Immune response & n.d & WT & $\mathrm{H}$ \\
\hline 13 & Antibody $28 \mathrm{~F} 11$ & n.d & $\begin{array}{l}\text { Immunoglobulin } \\
\text { like B sandwich }\end{array}$ & Hetero dimer & 45 & S & n.d & Immune response & n.d & WT & PEP \\
\hline 14 & Antibody 2B4 & n.d & $\begin{array}{l}\text { Immunoglobulin } \\
\text { like B sandwich }\end{array}$ & n.d & n.d & $S$ & n.d & Immune response & n.d & WT & PE \\
\hline 15 & Antibody 33F12 & $1 \mathrm{AXT}$ & $\begin{array}{l}\text { Immunoglobulin } \\
\text { like B sandwich }\end{array}$ & Hetero dimer & 47.5 & C & 8.5 & Immune response & +/++ & WT & ALD \\
\hline 16 & Antibody $38 \mathrm{C}^{\mathrm{m}}$ & n.d & $\begin{array}{l}\text { Immunoglobulin } \\
\text { like B sandwich }\end{array}$ & n.d & n.d & C & n.d & Immune response & $+/++$ & WT & ALD, HYD \\
\hline 17 & Antibody $3 \mathrm{~A} 3$ & n.d & $\begin{array}{l}\text { Immunoglobulin } \\
\text { like B sandwich }\end{array}$ & n.d & n.d & S & n.d & Immune response & n.d & WT & $\mathrm{PE}, \mathrm{SO}, \mathrm{PN}$ \\
\hline 18 & Antibody 7A3 & n.d & $\begin{array}{l}\text { Immunoglobulin } \\
\text { like B sandwich }\end{array}$ & n.d & n.d & S & n.d & Immune response & n.d & WT & PE, SO, EO \\
\hline
\end{tabular}




\begin{tabular}{|c|c|c|c|c|c|c|c|c|c|c|c|}
\hline Entry & Name & PDB-code & Protein Fold ${ }^{a}$ & $\begin{array}{l}\text { Oligomeric } \\
\text { state }^{b}\end{array}$ & $\begin{array}{c}\mathbf{M}_{\mathrm{w}} \\
{[\mathrm{kDa}]}\end{array}$ & $\begin{array}{l}\text { Anchoring } \\
\text { Mode }^{c}\end{array}$ & $\mathrm{PI}^{\mathrm{d}}$ & Native Function & Stability & $\begin{array}{l}\text { Mutants } \\
\text { tested }\end{array}$ & Reactions $^{g}$ \\
\hline 19 & Antibody 7G12 & n.d & $\begin{array}{l}\text { Immunoglobulin } \\
\text { like B sandwich }\end{array}$ & n.d & n.d & $S$ & n.d & Immune response & n.d & WT & PE \\
\hline 20 & Antibody 84A3 & n.d & $\begin{array}{l}\text { Immunoglobulin } \\
\text { like B sandwich }\end{array}$ & n.d & n.d & $S$ & n.d & Immune response & n.d & WT & HYD \\
\hline 21 & Antibody SN37.4 & n.d & $\begin{array}{l}\text { Immunoglobulin } \\
\text { like B sandwich }\end{array}$ & n.d & n.d & $S$ & n.d & Immune response & $+/++$ & WT & SO \\
\hline 22 & Avidin (Av) & 1VYO & Streptavidin-like & $\begin{array}{l}\text { Homo } \\
\text { tetramer }\end{array}$ & 60 & $S$ & 10.4 & Biotin-binding & +++ & WT & $\mathrm{H}, \mathrm{M}$ \\
\hline 23 & $\begin{array}{l}\text { Binding domain of } \\
\text { Rabenosyn (Rab4) }\end{array}$ & $1 Y Z M$ & Long $\alpha$-hairpin & Monomer ${ }^{*}$ & 6 & D & 5.6 & $\begin{array}{l}\text { Membrane } \\
\text { trafficking } \\
\text { regulatory protein }\end{array}$ & n.d & + & $\mathrm{H} 2 \mathrm{O}$ \\
\hline 24 & \begin{tabular}{|l} 
Carbonic \\
anhydrase II \\
Bovine (CA)
\end{tabular} & 1V9E & $\begin{array}{l}\text { Carbonic } \\
\text { anhydrase }\end{array}$ & Monomer & 29 & MS & 6.4 & $\mathrm{CO}_{2}$ hydration & + & + & $\mathrm{EO}, \mathrm{H}, \mathrm{PE}$ \\
\hline 25 & $\begin{array}{l}\text { Carbonic } \\
\text { Anhydrase II } \\
\text { Human (hCAIl) }\end{array}$ & $1 \mathrm{CA} 2$ & $\begin{array}{l}\text { Carbonic } \\
\text { anhydrase }\end{array}$ & Monomer & 29 & $\mathrm{D}, \mathrm{MS}$ & 6.9 & $\mathrm{CO}_{2}$ hydration & ++ & +++ & $\begin{array}{l}\text { TH, H, HF, } \\
\text { EO, M,PE }\end{array}$ \\
\hline 26 & $\begin{array}{l}\text { Carboxypeptidase } \\
\text { A }\end{array}$ & $1 \mathrm{M} 4 \mathrm{~L}$ & $\begin{array}{l}\text { Phosphorylase/ } \\
\text { hydrolase-like }\end{array}$ & Monomer & 34.4 & $D$ & 6.3 & Protease & +++ & WT & $\mathrm{H} 2 \mathrm{O}, \mathrm{HYD}, \mathrm{O}$ \\
\hline 27 & $\begin{array}{l}\text { Catabolite activator } \\
\text { protein from E. coli }\end{array}$ & 2CGP & $\begin{array}{l}\text { DNA/RNA- } \\
\text { binding 3- } \\
\text { helical bundle }\end{array}$ & Homo dimer & 47 & $\mathrm{D}, \mathrm{Z}$ & 8.4 & $\begin{array}{l}\text { DNA binding, } \\
\text { regulation of } \\
\text { catabolite }\end{array}$ & $+/++$ & + & PE \\
\hline 28 & $\begin{array}{l}\text { C-terminal domain } \\
\text { of Calmodulin }\end{array}$ & $2 \mathrm{KZ2}$ & EF Hand-like & Monomer & 17 & $D$ & 4.1 & $\begin{array}{l}\text { Messenger, } \mathrm{Ca}^{2+} \\
\text { binding protein }\end{array}$ & $+/++$ & + & $\mathrm{H} 2 \mathrm{O}$ \\
\hline 29 & Cutinase & 1CEX & $\alpha / \beta$ hydrolase & Monomer & 21 & C & 7.8 & Cutin hydrolase & + & WT & $\mathrm{H}, \mathrm{M}$ \\
\hline
\end{tabular}




\begin{tabular}{|c|c|c|c|c|c|c|c|c|c|c|c|}
\hline Entry & Name & PDB-code & Protein Fold ${ }^{a}$ & $\begin{array}{l}\text { Oligomeric } \\
\text { state }^{\mathrm{b}}\end{array}$ & $\begin{array}{c}\mathbf{M}_{\mathbf{w}} \\
{[\mathrm{kDa}]}\end{array}$ & $\begin{array}{l}\text { Anchoring } \\
\text { Mode }^{c}\end{array}$ & $\mathbf{P l}^{\mathrm{d}}$ & Native Function & Stability & $\begin{array}{l}\text { Mutants } \\
\text { tested }\end{array}$ & Reactions $^{g}$ \\
\hline 30 & Cytochrome $b_{562}$ & 1QPU & $\begin{array}{l}\text { Four-helical up- } \\
\text { and-down } \\
\text { bundle }\end{array}$ & Monomer & 11 & MS & 7.9 & Electron transport & ++ & + & $\mathrm{H} 2$ \\
\hline 31 & Cytochrome $\mathrm{C}_{552}$ & 1DT1 & Cyt $c_{8}$ family & Monomer & 9 & MS & 9.6 & Nitrite reduction & +++ & M61A & $\mathrm{H} 2$ \\
\hline 32 & Cytochrome $\mathrm{cb}_{562}$ & $2 \mathrm{BC} 5$ & $\begin{array}{l}\text { Four } \\
\alpha \text {-helix bundle }\end{array}$ & Monomer ${ }^{\mathrm{h}}$ & 12 & $\mathrm{D}, \mathrm{S}$ & 5.0 & Oxidoreductase & +/++ & +++ & $\mathrm{H} 2 \mathrm{O}$ \\
\hline 33 & $\begin{array}{l}\text { Cytochrome P450 } \\
\text { (CYP119) }\end{array}$ & 1107 & $\begin{array}{l}\text { Cytochrome } \\
\text { P450 }\end{array}$ & Monomer & 43 & S, D & 6.1 & Oxidoreductase & $++/+++$ & +++ & $\mathrm{CH}$ \\
\hline 34 & $\begin{array}{l}\text { Cytochrome P450- } \\
\text { BM3 }\end{array}$ & 2IJ2 & $\begin{array}{l}\text { Cytochrome } \\
\text { P450 }\end{array}$ & Monomer & 118 & S & 5.2 & Oxidoreductase & + & + & $\mathrm{CP}$ \\
\hline 35 & Due Ferro 1 & $1 \mathrm{EC} 5$ & $\begin{array}{l}\text { Designed four- } \\
\text { helix bundle } \\
\text { protein }\end{array}$ & Homo dimer & 12 & D & 4.8 & $\begin{array}{l}\text { De novo-designed } \\
\text { protein }\end{array}$ & $+/++$ & + & PE \\
\hline 36 & Ferredoxin $(\mathrm{Fd})$ & $1 \mathrm{~A} 70$ & $\begin{array}{l}\text { B-Grasp } \\
\text { (ubiquitin-like) }\end{array}$ & Monomer & 13 & $C, D$ & 9.6 & Electron transport & ++ & WT & $\mathrm{H} 2$ \\
\hline 37 & Ferritin (Fr) & 1DAT & Ferritin-like & Homo 24-mer & 480 & $\mathrm{D}$ & $5-5.7$ & Iron storage & $+/++$ & + & $\mathrm{PO}, \mathrm{S}$ \\
\hline 38 & FhuA $\Delta$ CVF $^{\text {tev }}$ & $1 \mathrm{BY} 3$ & $\begin{array}{l}\text { Trans } \\
\text { membrane } \\
\text { B-barrels }\end{array}$ & Monomer & 64 & C & n.d & $\begin{array}{l}\text { Ferric } \\
\text { hydroxamate } \\
\text { uptake }\end{array}$ & $+/++$ & + & $\mathrm{DA}, \mathrm{M}$ \\
\hline 39 & Flavodoxin (Fld) & $1 \mathrm{CZL}$ & Flavodoxin fold & Monomer & 19 & MS & 4.0 & Electron transport & ++ & WT & $\mathrm{H} 2$ \\
\hline 40 & $\begin{array}{l}\text { Glyoxalase II } \\
\text { (Human) }\end{array}$ & 1QH5 & $\begin{array}{l}\text { Metallo- } \\
\text { hydrolase/oxido } \\
\text { reductase }\end{array}$ & Homo dimer & 58 & $\mathrm{D}$ & 6.9 & $\begin{array}{l}\text { Hydroxyacyl- } \\
\text { glutathione } \\
\text { hydrolase }\end{array}$ & $+/++$ & +++ & $\mathrm{H} 2 \mathrm{O}$ \\
\hline
\end{tabular}




\begin{tabular}{|c|c|c|c|c|c|c|c|c|c|c|c|}
\hline Entry & Name & PDB-code & Protein Fold ${ }^{a}$ & $\begin{array}{l}\text { Oligomeric } \\
\text { state }^{b}\end{array}$ & $\begin{array}{c}\mathbf{M}_{\mathbf{w}} \\
{[\mathrm{kDa}]}\end{array}$ & $\begin{array}{l}\text { Anchoring } \\
\text { Mode }^{c}\end{array}$ & $\mathrm{PI}^{\mathrm{d}}$ & Native Function & Stability & $\begin{array}{l}\text { Mutants } \\
\text { tested }\end{array}$ & Reactions $^{g}$ \\
\hline 41 & $(\mathrm{gp} 27-\mathrm{gp} 5)_{3}$ & $1 \mathrm{~K} 28$ & $\begin{array}{l}\text { Phage tail } \\
\text { OB-fold }\end{array}$ & $\begin{array}{l}\text { Hetero } \\
\text { hexamer }\end{array}$ & $>300$ & C & 5.4 & $\begin{array}{l}\text { Needle of } \\
\text { bacteriophage T4 }\end{array}$ & ++ & WT & so \\
\hline 42 & {$\left[(g p 5 ß f)_{3}\right]_{2}$} & $3 \mathrm{~A} 1 \mathrm{M}$ & OB-fold & $\begin{array}{l}\text { Homo } \\
\text { hexamer }\end{array}$ & 88 & C & 4.8 & $\begin{array}{l}\text { Needle of } \\
\text { bacteriophage T4 }\end{array}$ & ++++ & + & $\mathrm{ER}, \mathrm{CL}, \mathrm{CR}$ \\
\hline 43 & $\begin{array}{l}\text { Heme Oxygenase } \\
\text { (HO) }\end{array}$ & 1IW0 & $\begin{array}{l}\text { Heme } \\
\text { oxygenase-like }\end{array}$ & Monomer & 24 & $S, D$ & 5.5 & $\begin{array}{l}\text { Heme } \\
\text { oxygenation }\end{array}$ & +/++ & + & $\mathrm{H} 2, \mathrm{OR}$ \\
\hline 44 & Hemoglobin & 2DN1 & Globin-like & $\begin{array}{l}\text { Hetero } \\
\text { tetramer }\end{array}$ & 61.9 & C & 8.3 & $\mathrm{O} 2$ transport & ++ & WT & 0 \\
\hline 45 & $\begin{array}{l}\text { Hen egg white } \\
\text { Lysozyme } \\
\text { (HEWL) }\end{array}$ & 2VB1 & Lysozyme-like & Monomer & 14 & D & 11.4 & $\begin{array}{l}\text { Hydrolysis B-(1- } \\
\text { 4)- peptidoglycan }\end{array}$ & $++/+++$ & WT & $\mathrm{DO}, \mathrm{TH}^{\mathrm{i}}$ \\
\hline 46 & $\begin{array}{l}\text { Horseradish } \\
\text { Peroxidase (HRP) }\end{array}$ & $1 \mathrm{~W} 4 \mathrm{~W}$ & $\begin{array}{l}\text { Heme- } \\
\text { dependent } \\
\text { peroxidases }\end{array}$ & Monomer & 44 & S & 5.6 & Peroxidase & ++ & WT & PE, PO \\
\hline 47 & $\begin{array}{l}\text { Human retinoid-X- } \\
\text { receptor (hRXR } \alpha)\end{array}$ & $1 \mathrm{RXR}$ & $\begin{array}{l}\text { Glucocorticoid } \\
\text { receptor-like }\end{array}$ & Monomer & 10 & D & 9.6 & DNA binding & $+/++$ & +++ & L \\
\hline 48 & HydA & $3\llcorner X 4$ & n.d & Monomer & 49 & D & 5.9 & Hydrogenase & + & WT & $\mathrm{H} 2$ \\
\hline 49 & $\begin{array}{l}\text { Intestinal fatty acid } \\
\text { binding protein } \\
\text { (IFABP) }\end{array}$ & $1 \mathrm{ICM}$ & Lipocalins & Monomer & 15 & C & 6.9 & $\begin{array}{l}\text { lipid binding } \\
\text { protein }\end{array}$ & n.d & + & HYD, TA \\
\hline 50 & Laccase & $1 G Y C$ & Cupredoxin-like & Monomer & 53.6 & MS & 5.8 & Oxidoreductase & ++/+++ & WT & DO \\
\hline 51 & Lipase (C. rugosa) & $1 \mathrm{GZ7}$ & $\begin{array}{l}\alpha / \beta \text { hydrolase } \\
\text { fold }\end{array}$ & Monomer & 67 & D & 4.6 & Lipase & $+/++$ & WT & DO \\
\hline
\end{tabular}




\begin{tabular}{|c|c|c|c|c|c|c|c|c|c|c|c|}
\hline Entry & Name & PDB-code & Protein Fold ${ }^{a}$ & $\begin{array}{l}\text { Oligomeric } \\
\text { state }^{\mathrm{b}}\end{array}$ & $\underset{[\mathrm{kDa}]}{\mathrm{M}_{\mathrm{w}}}$ & $\begin{array}{l}\text { Anchoring } \\
\text { Mode }^{c}\end{array}$ & $\mathbf{P l}^{\mathbf{d}^{\mathrm{d}}}$ & Native Function & Stability & $\begin{array}{l}\text { Mutants } \\
\text { tested }\end{array}$ & Reactions ${ }^{g}$ \\
\hline 52 & $\begin{array}{l}\text { Lipase B from } C \text {. } \\
\text { antarctica (CALB) }\end{array}$ & $4 \mathrm{~K} 6 \mathrm{G}$ & $\alpha / \beta$ hydrolases & Monomer & 33 & C & 5.8 & $\begin{array}{l}\text { Hydrolysis of } \\
\text { triglycerides }\end{array}$ & +++ & WT & $\mathrm{H}, \mathrm{HK}$ \\
\hline 53 & $\begin{array}{l}\text { Lipase from } G \text {. } \\
\text { thermocatenulatus } \\
\text { (GTL) }\end{array}$ & $2 W 22$ & Rossmann fold & Monomer & 43 & C & 6.4 & Lipase & +++ & + & DA \\
\hline 54 & LmrR & 4ZZD & n.d & Homo dimer & 13.5 & C, S & 6.6 & $\begin{array}{l}\text { Transcriptional } \\
\text { repressor }\end{array}$ & n.d & + & $\mathrm{DA}, \mathrm{H} 2 \mathrm{O}, \mathrm{FC}$ \\
\hline 55 & $\begin{array}{l}\text { Mouse adenosine } \\
\text { deaminase }\end{array}$ & $1 \mathrm{~A} 4 \mathrm{~L}$ & TIM $\beta / \alpha$-barrel & Monomer & 40 & D & 5.5 & $\begin{array}{l}\text { Adenosine } \\
\text { deamination }\end{array}$ & ++ & +++ & $\mathrm{H} 2 \mathrm{O}$ \\
\hline 56 & $\begin{array}{l}\text { Myoglobin (Mb) } \\
\text { (Horse heart) } \\
\text { (Sperm whale) }\end{array}$ & $\begin{array}{l}2 \mathrm{~V} 1 \mathrm{~K}(\mathrm{HH}) \\
1 \mathrm{MBI}(\mathrm{SW})\end{array}$ & Globin-like & Monomer & 18 & S, D, MS & $\begin{array}{l}7.4(\mathrm{HH}) \\
8.7(\mathrm{SW})\end{array}$ & Oxygen transport & $+/++$ & +++ & $\begin{array}{l}\mathrm{PE}, \mathrm{SO}, \mathrm{CH}, \\
\mathrm{H} 2, \mathrm{CP}, \mathrm{DA} \text {, } \\
\mathrm{NO}\end{array}$ \\
\hline 57 & $\begin{array}{l}\text { Neocarzinostatin } \\
\text { (Variant 3.24) }\end{array}$ & 2CBM & $\begin{array}{l}\text { Immunoglobulin } \\
\text {-like B- } \\
\text { sandwich }\end{array}$ & Monomer & 14 & $\mathrm{~S}$ & 4.2 & Enediyne binding & + & WT & SO, DA, TE \\
\hline 58 & NikA & $4 I 9 D$ & $\begin{array}{l}\text { Periplasmic } \\
\text { binding protein- } \\
\text { like II }\end{array}$ & Monomer & 56 & $\mathrm{~S}$ & 10.0 & Nickel transport & + & WT & so \\
\hline 59 & Nitrobindin $(\mathrm{Nb})$ & 3EMM & Lipocalins & Monomer & 19 & C & 8.7 & NO transport & $+/++$ & + & $\begin{array}{l}\mathrm{H} 2, \mathrm{DA}, \mathrm{PO} \text {, } \\
\mathrm{EO}, \mathrm{CH}, \mathrm{M}\end{array}$ \\
\hline 60 & Papain (PAP) & 1PPP & $\begin{array}{l}\text { Cysteine } \\
\text { proteinases }\end{array}$ & Monomer & 23 & C & 8.8 & Protease & $+/++$ & WT & $\begin{array}{l}\text { TH, DA, H, } \\
\text { EO,O }\end{array}$ \\
\hline 61 & $\begin{array}{l}\text { Photoactive Yellow } \\
\text { Protein (PYP) }\end{array}$ & $2 \mathrm{PHY}$ & Profilin-like & Monomer & 14 & C & 4.8 & Photoreceptor & + & WT & $\mathrm{H}, \mathrm{AAm}$ \\
\hline 62 & $\begin{array}{l}\text { Photosystem I } \\
\text { (PSI) }\end{array}$ & $1 \mathrm{JBO}$ & Globin-like & Monomer & 215 & U & 5.3 & $\begin{array}{l}\text { Photochemical } \\
\text { energy conversion }\end{array}$ & + & WT & $\mathrm{H} 2$ \\
\hline
\end{tabular}




\begin{tabular}{|c|c|c|c|c|c|c|c|c|c|c|c|}
\hline Entry & Name & PDB-code & Protein Fold ${ }^{a}$ & $\begin{array}{l}\text { Oligomeric } \\
\text { state }^{b}\end{array}$ & $\begin{array}{c}\mathbf{M}_{\mathbf{w}} \\
{[\mathrm{kDa}]}\end{array}$ & $\begin{array}{l}\text { Anchoring } \\
\text { Mode }^{c}\end{array}$ & $\mathrm{Pl}^{\mathrm{d}}$ & Native Function & Stability & $\begin{array}{l}\text { Mutants } \\
\text { tested }\end{array}$ & Reactions $^{g}$ \\
\hline 63 & Phytase & $1 \mathrm{IHP}$ & $\begin{array}{l}\text { Phosphoglycera } \\
\text { te mutase-like }\end{array}$ & Monomer & 48.2 & $C, D$ & 4.9 & Phosphatase & $+/++$ & + & $\mathrm{SO}, \mathrm{CP}$ \\
\hline 64 & $\begin{array}{l}\text { Prolyl } \\
\text { oligopeptidase } \\
\text { (POP) }\end{array}$ & $1 \mathrm{QFS}^{\mathrm{n}}$ & $\begin{array}{l}\text { 7-bladed beta- } \\
\text { propeller }\end{array}$ & Monomer & 80 & C & 5.5 & $\begin{array}{l}\text { Prolyl } \\
\text { oligopeptidase }\end{array}$ & +++ & +++ & $\mathrm{CP}$ \\
\hline 65 & Proteinase- $\mathrm{K}$ & $5 A V K$ & Subtilisin-like & Monomer & 28.9 & $\mathrm{D}$ & 8.9 & Protease & $+/++$ & WT & DO \\
\hline 66 & Ribonuclease S & 2RNS & RNase A-like & Monomer & 14 & D & 8.6 & RNA cleavage & ++ & + & $\mathrm{TH}$ \\
\hline 67 & Rubredoxin (Rd) & $6 \mathrm{RXN}$ & $\begin{array}{l}\text { Rubredoxin-like } \\
\text { Zinc-ribbon fold }\end{array}$ & Monomer & 5.5 & MS & 4.6 & Electron transport & ++ & WT & $\mathrm{H} 2$ \\
\hline 68 & $\begin{array}{l}\text { Serum Albumin } \\
\text { Bovine (BSA) }\end{array}$ & $4 \mathrm{~F} 5 \mathrm{~S}$ & $\begin{array}{l}\text { Serum albumin- } \\
\text { like }\end{array}$ & Monomer & 66.5 & $D, S$ & 4.7 & $\begin{array}{l}\text { Plasma carrier, } \\
\text { oncotic pressure } \\
\text { regulator }\end{array}$ & +/++ & WT & $\begin{array}{l}\text { DO, DA, H, } \\
\text { PO, SO }\end{array}$ \\
\hline 69 & $\begin{array}{l}\text { Serum albumin } \\
\text { Chicken-egg (CSA) }\end{array}$ & $1 \mathrm{UHG}$ & $\begin{array}{l}\text { Serum albumin- } \\
\text { like }\end{array}$ & Monomer & 43 & $\mathrm{~S}$ & 4.5 & $\begin{array}{l}\text { Plasma carrier, } \\
\text { oncotic pressure } \\
\text { regulator }\end{array}$ & + & WT & DA, SO \\
\hline 70 & $\begin{array}{l}\text { Serum albumin } \\
\text { Porcine (PSA) }\end{array}$ & n.d & $\begin{array}{l}\text { Serum albumin- } \\
\text { like }\end{array}$ & Monomer & 67 & $\mathrm{~s}$ & 5.8 & $\begin{array}{l}\text { Plasma carrier, } \\
\text { oncotic pressure } \\
\text { regulator }\end{array}$ & + & WT & $\mathrm{DA}, \mathrm{SO}$ \\
\hline 71 & $\begin{array}{l}\text { Serum albumin } \\
\text { Rabbit (RSA) }\end{array}$ & 3V09 & $\begin{array}{l}\text { Serum albumin- } \\
\text { like }\end{array}$ & Monomer & 66 & S & 5.7 & $\begin{array}{l}\text { Plasma carrier, } \\
\text { oncotic pressure } \\
\text { regulator }\end{array}$ & + & WT & $\mathrm{DA}, \mathrm{SO}$ \\
\hline 72 & $\begin{array}{l}\text { Serum Albumin } \\
\text { Human (HSA) }\end{array}$ & 3JRY & $\begin{array}{l}\text { Serum albumin- } \\
\text { like }\end{array}$ & Monomer & 65 & $\mathrm{~s}$ & 4.7 & $\begin{array}{l}\text { Plasma carrier, } \\
\text { oncotic pressure } \\
\text { regulator }\end{array}$ & +/++ & WT & $\mathrm{SO}, \mathrm{DA}, \mathrm{HF}$ \\
\hline 73 & $\begin{array}{l}\text { Serum albumin } \\
\text { Sheep (SSA) }\end{array}$ & 4LUF & $\begin{array}{l}\text { Serum albumin- } \\
\text { like }\end{array}$ & Monomer & 66 & $\mathrm{~s}$ & 5.6 & $\begin{array}{l}\text { Plasma carrier, } \\
\text { oncotic pressure } \\
\text { regulator }\end{array}$ & + & WT & $\mathrm{DA}, \mathrm{SO}$ \\
\hline
\end{tabular}




\begin{tabular}{|c|c|c|c|c|c|c|c|c|c|c|c|}
\hline Entry & Name & PDB-code & Protein Fold ${ }^{a}$ & $\begin{array}{l}\text { Oligomeric } \\
\text { state }^{\mathrm{b}}\end{array}$ & $\begin{array}{c}\mathrm{M}_{\mathrm{w}} \\
{[\mathrm{kDa}]}\end{array}$ & $\begin{array}{l}\text { Anchoring } \\
\text { Mode }^{c}\end{array}$ & $\mathbf{P l}^{\mathbf{d}^{\mathrm{d}}}$ & Native Function & Stability & $\begin{array}{l}\text { Mutants } \\
\text { tested }^{\dagger}\end{array}$ & Reactions $^{g}$ \\
\hline 74 & $\begin{array}{l}\text { Small heat shock } \\
\text { protein }(M . \\
\text { jannaschii) }\end{array}$ & 1SHS & $\begin{array}{l}\text { HSP-20 like } \\
\text { chaperones }\end{array}$ & Homo 24-mer & 16.5 & C & 5.0 & Thermotolerance & +++ & + & $M$ \\
\hline 75 & $\begin{array}{l}\text { Staphylococcus } \\
\text { nuclease }\end{array}$ & 2SNS & OB-fold & Monomer & 16.8 & C & 9.6 & $\begin{array}{l}\text { DNA and RNA } \\
\text { hydrolysis }\end{array}$ & $+/++$ & WT & HYD (native) \\
\hline 76 & $\begin{array}{l}\text { Sterol Carrier } \\
\text { Protein (SCP) }\end{array}$ & $1 \mathrm{IKT}$ & SCP-like & Monomer & 12.5 & C & 9.5 & Sterol carrier & n.d & + & DA \\
\hline 77 & Streptavidin (Sav) & $2 \mathrm{BC} 3$ & Streptavidin-like & $\begin{array}{l}\text { Homo } \\
\text { tetramer }\end{array}$ & 64 & $\mathrm{~S}, \mathrm{~S}+\mathrm{D}, \mathrm{U}$ & 6.4 & Biotin-binding & ++++ & +++ & $\begin{array}{l}\text { H, TH, M, S, } \\
\text { AA, CH, AO, } \\
\text { SO, DO, MA }\end{array}$ \\
\hline 78 & $\begin{array}{l}\text { Thermosome } \\
\text { (THS) }\end{array}$ & $1 \mathrm{~A} 6 \mathrm{D}$ & $\begin{array}{l}\text { GroEL equat.+ } \\
\text { The "swivelling" } \\
\text { B/B/ } \alpha \text { domains }\end{array}$ & Hetero 16-mer & 117 & C & $\begin{array}{l}5.9(\alpha) \\
5.1(B) \\
\text { domains }\end{array}$ & Chaperonin & +++ & + & PO \\
\hline 79 & tHisF & 1THF & TIM $\beta / \alpha$ - barrel & Homo dimer & 28 & C, D & 5.2 & $\begin{array}{l}\text { imidazole glycerol } \\
\text { phosphate } \\
\text { synthase }\end{array}$ & +++ & + & $\begin{array}{l}\text { EO, CP, DA, } \\
\text { Si-I }\end{array}$ \\
\hline 80 & TRI peptide & $\begin{array}{l}\text { 3PBJ } \\
\text { (structure } \\
\text { analogue) }\end{array}$ & $\begin{array}{l}\text { Three-helix } \\
\text { bundles }\end{array}$ & Homo trimer & 10 & D & 6.8 & $\begin{array}{l}\text { De novo-designed } \\
\text { protein }\end{array}$ & n.d & + & $\mathrm{H} 2 \mathrm{O}, \mathrm{NR}$ \\
\hline 81 & Trypsin & 1S81 & $\begin{array}{l}\text { Trypsin-like } \\
\text { serine } \\
\text { proteases }\end{array}$ & Monomer & 23.5 & D & 8.3 & Protease & +++ & + & PEP \\
\hline 82 & Xylanase A (XIn) & $1 \mathrm{E} 0 \mathrm{X}$ & TIM B/ $\alpha$-barrel & Monomer & 51 & S & 6.2 & $\begin{array}{l}\text { Glycoside } \\
\text { hydrolysis }\end{array}$ & + & WT & PE, SO, EO \\
\hline 83 & $\begin{array}{l}\text { Zif268 zinc-finger } \\
\text { protein }\end{array}$ & $1 Z A A$ & $\begin{array}{l}\beta-\beta-\alpha \text { zinc } \\
\text { fingers }\end{array}$ & Trimer & 33 & $\mathrm{D}, \mathrm{Z}$ & 10.1 & $\begin{array}{l}\text { DNA binding, } \\
\text { mammalian } \\
\text { transcription factor }\end{array}$ & n.d & +++ & DNA binding \\
\hline
\end{tabular}


a based on Structural Classification of Proteins (SCOP). http://scop.mrc-Imb.cam.ac.uk

b based on PDBe classification.

${ }^{\mathrm{C} S}=$ supramolecular, $\mathrm{D}=$ dative, $\mathrm{C}=$ covalent, $\mathrm{MS}$ = metal substitution, $\mathrm{Z}$ = non-natural aminoacid, $\mathrm{U}=$ undefined

d Theoretical PI calculated with ProtParam based on the amino acid sequence of the natural/de novo-designed protein.

${ }^{e}++++$ very high stability against chaotropic agents, $+++\mathrm{Tm}>80^{\circ} \mathrm{C},++\mathrm{Tm}>60^{\circ} \mathrm{C},+\mathrm{Tm}>40^{\circ} \mathrm{C}$, n.d no data available.

$+++>50$ mutants tested, $++>10$ mutants tested, WT: only wild-type tested

${ }_{9} \mathrm{AA}=$ allylic alkylase, $\mathrm{AAm}=$ allylic aminase, $\mathrm{ALD}=$ aldolase, $\mathrm{AO}=$ alcohol oxidase, $\mathrm{CH}=\mathrm{C}-\mathrm{H}$ activase $, \mathrm{CL}=\mathrm{clickase}, \mathrm{CO}=\mathrm{catecohol}$ oxidase, $\mathrm{CP}=$ cyclopropanase, $\mathrm{CR}=\mathrm{CO}_{2}$ reductase, $\mathrm{DA}=$ Diels-Alderase, $\mathrm{DO}=$ dihydroxylase, $\mathrm{EO}=$ epoxidase, $\mathrm{ER}=$ epoxide Ring Opening, $\mathrm{FC}=\mathrm{Friedel}-\mathrm{Crafts}$ alkylase, $\mathrm{H}$ = hydrogenase, $\mathrm{H} 2$ = dihydrogenase, $\mathrm{HF}=$ hydroformylase, $\mathrm{HK}=$ heckase, $\mathrm{HYD}=$ hydrolase, $\mathrm{H} 2 \mathrm{O}=$ hydratase, $\mathrm{L}=$ ligase, $\mathrm{M}=$ metathase, $\mathrm{MA}=\mathrm{Michael}$ addase, $\mathrm{NR}=$ nitrite reductase, $\mathrm{NO}=\mathrm{NO}$ reductase, $\mathrm{NU}=$ nuclease, $\mathrm{O}=$ Oxidase, $\mathrm{OR}=$ oxygen reductase, $\mathrm{PO}=$ polymerase, $\mathrm{PE}=$ peroxidase, $\mathrm{PEP}=$ peptidase, $\mathrm{PN}=$ phenol nitratase, $\mathrm{S}=$ Suzukiase, $\mathrm{Si}-\mathrm{I}=\mathrm{Si}-\mathrm{H}$ insertion, $\mathrm{SO}=$ sulfoxidase, $\mathrm{TA}=$ transaminase, $\mathrm{TE}=$ transesterase, $\mathrm{TH}=$ transfer hydrogenase

${ }^{\mathrm{h}}$ Tezcan et al. used a Zn(II)-mediated tetramer of cytochrome cb562 (with a mass of $~ 50 \mathrm{kDa}$ )

' Ueno et al. used as tetragonal and orthorhombic crystal.

I Kuhlman et al. used the dimer of the Rab4 binding domain of Rabenosyn (with a mass of $\sim 12 \mathrm{kDa}$ ).

m Commercially available.

n POP from Pyrococcus furiosus (PDB : 5T88), submitted. 


\section{Historical Contributions}

The aim of this section is to cover work on artificial metalloenzymes dating from the earliest studies on hybrid metal-protein catalysts to those completed around the year 2000. As noted in the introduction, around this date, modern tools of molecular biology began making a significant impact on ArM research. Presumably as a result of this, the five-year average number of publications on ArM research each year increased substantially in the early 2000's (Chart 1). These early studies are presented in chronological order to highlight how different advances were made using different scaffolds and ArM formation strategies at the time of the original reports.

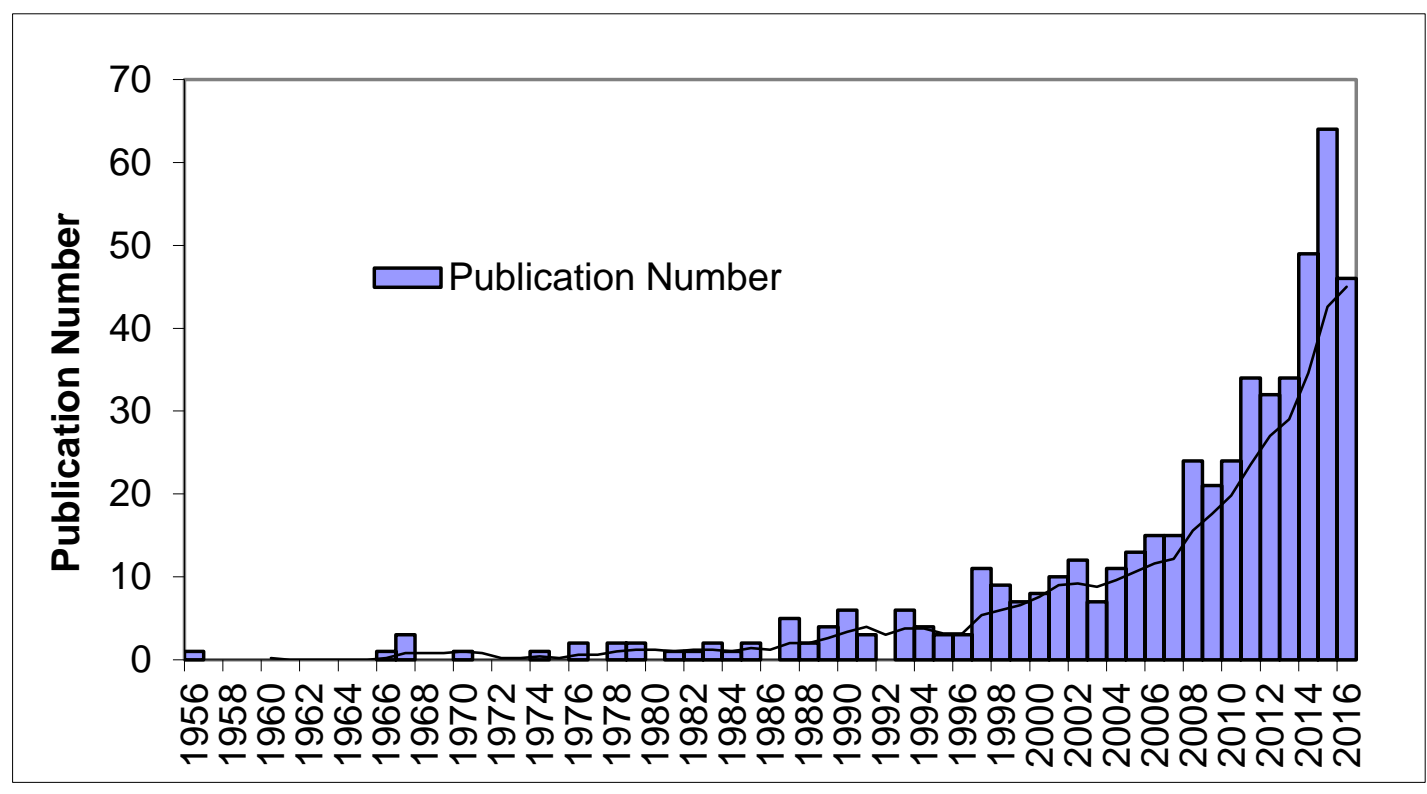

Chart 1. Number of publications and the five-year moving average of this number plotted versus publication year for publications cited in this review.

The first example of transition metal-catalyzed asymmetric synthesis, reported in 1956, also constitutes the first realization of a protein-modified transition metal catalyst. ${ }^{101-102} \mathrm{~S}$. Akabori et al. adsorbed palladium chloride on silk fibroin fibres and reduced the resulting material with hydrogen, likely resulting in the formation of Pd-nanoparticles embeded within an enantiopure protein environment. ${ }^{103}$ The protein-immobilized palladium 
catalyzed asymmetric hydrogenation of dehydroaminoacid derivatives $1-3$ to provide products 4 and 5 with significant enantiomeric excess (Scheme 1). The reduction of $\alpha$ benzildioxime, however, led to variable results, suggesting that the catalyst was poorly defined. Despite reproducibility issues, ${ }^{101-102}$ this initial study has sparked research in biopolymer-immobilized $\mathrm{Pd}$, sometimes termed bio-palladium. ${ }^{104} \mathrm{Pd}$-nanoparticles have recently also attracted attention for in vivo applications. ${ }^{105-106}$

Scheme 1. Asymmetric hydrogenation of dehydroaminoacid derivatives with silk-fiber modified palladium reported in 1956.

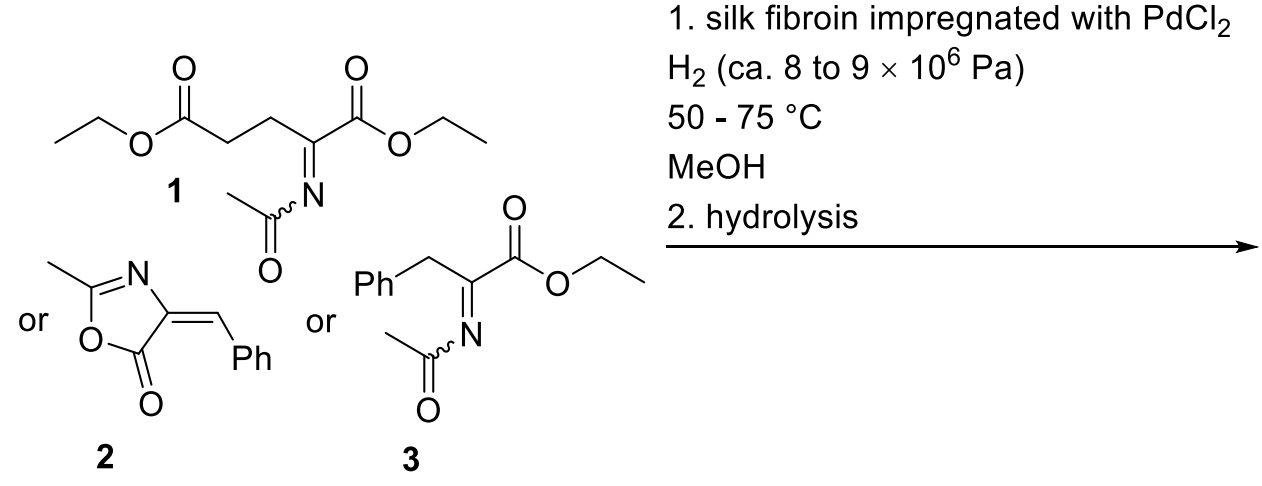<smiles>NC(Cc1ccccc1)C(=O)O</smiles>

5

Metal substitution has been used for the study of natural metalloenzymes since the late 1960s. ${ }^{107-108}$ Metal-exchange studies often aimed at introducing spectroscopically observable metals as a means to elucidate structural details but did not focus on catalysis. ${ }^{109-110}$ J. E. Coleman, however, observed that the $\mathrm{CO}_{2}$ hydration activity of carbonic anhydrase remains roughly half when $\mathrm{Zn}(\mathrm{II})$ is exchanged for $\mathrm{Co}(\mathrm{II})$, whereas the esterase activity increased after metal exchange for carbonic anhydrase B. ${ }^{108}$ In the same year (1967), P. Cuatrecasas et al. reported the replacement of $\mathrm{Ca}(\mathrm{II})$ for $\mathrm{Sr}(\mathrm{II})$ in a staphylococcal nuclease. Whereas the $\mathrm{Ca}(\mathrm{II})$-dependent enzyme catalyzed both DNA and RNA cleavage, the Sr(II) exchanged nuclease cleaved DNA exclusively. ${ }^{107}$

Although not catalytic, the potential of metal-ion exchange to impact enzyme function was convincingly demonstrated in the activation of the zymogen trypsinogen by trypsin in 1970. ${ }^{111}$ Trypsinogen contains two latent metal binding sites, the lower affinity of 
which is located at the cleaved $N$-terminus. ${ }^{112} \mathrm{Ca}(\mathrm{II})$-ions bound to this site led to a lowering of the $K_{m}$ for the trypsin-trypsinogen interaction. Bound $\mathrm{Nd}(\mathrm{III})$ leads to a much more pronounced lowering of the $K_{\mathrm{m}}$ compared to $\mathrm{Ca}(\mathrm{II})$, even at a 100 fold lower concentration of metal ions.

The first example where alternative catalytic function was introduced through metalexchange in a metalloprotein was reported by K. Yamamura and E. T. Kaiser in $1976 .^{1}$ Carboxypeptidase A was converted to an oxidase by substitution of $\mathrm{Zn}$ (II) for $\mathrm{Cu}$ (II) (Scheme 2). Limiting $K_{c a t}$ and $K_{m}$ values of $k_{c a t}=6 \mathrm{~min}^{-1}$ and $K_{\mathrm{m}}=0.24 \mathrm{mM}$ where determined for the oxidation of ascorbic acid 6 to dehydroascorbic acid 7 .

Scheme 2. Oxidation of ascorbic acid by carboxypeptidase A (CPA) after substitution of $\mathrm{Zn}(\mathrm{II})$ for $\mathrm{Cu}(\mathrm{II})$.<smiles>O=C1O[C@H](C(O)CO)C(O)=C1O</smiles>

6

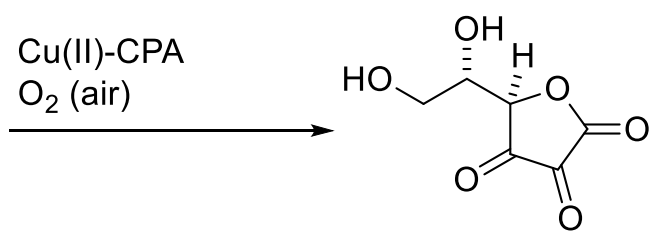

7

In 1978, Wilson and Whitesides were the first to anchor an abiotic cofactor inside a protein cavity. ${ }^{2}$ Exploiting the remarkable affinity of biotin for avidin, the biotinylated $\mathrm{Rh}(\mathrm{I})$-diphosphine moiety 9 was employed for the hydrogenation of $\alpha$-acetamidoacrylic acid 8 in the presence of avidin (Scheme 3). The system showed significant, albeit moderate, stereoinduction in aqueous phosphate buffer and, importantly, a definite increase in activity when compared to the protein-free cofactor. Avidin is a homotetrameric protein that can bind up to 4 equivalents of biotin. One equivalent of the biotinylated catalyst precursor vs. biotin binding sites led to a higher enantiomeric excess than 0.5 equivalents indicating that the cofactors interact with each other when localized in adjacent binding sites.

Scheme 3. Asymmetric hydrogenation of a dehydroamino acid derivative by a biotinylated $\mathrm{Rh}(\mathrm{I})$-complex upon binding to avidin. 


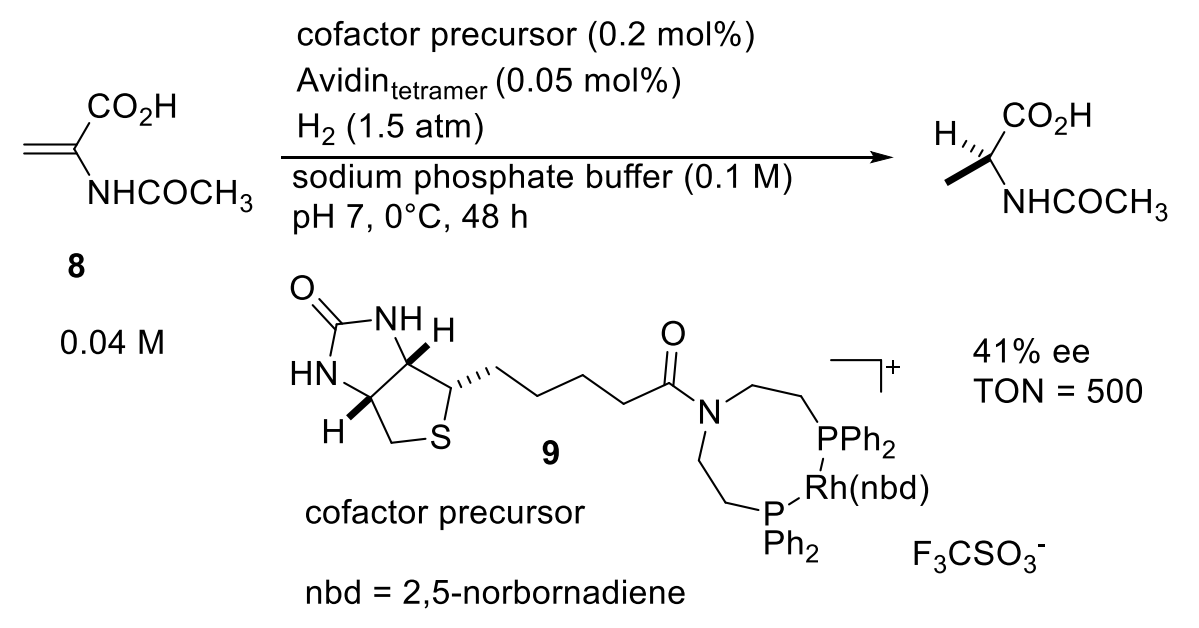

Catalytic enantioselective oxidation of sulfides by various oxidants in the presence of bovine serum albumin (BSA) was investigated by Sugimoto and Kokubo et al. in the late 70 's. ${ }^{113-115}$ In one publication, the effect of stoichiometric metal additives, namely $\mathrm{Cu}(\mathrm{II})$, $\mathrm{MoO}_{4}{ }^{2-}$, or $\mathrm{WO}_{4}{ }^{2-}$, in combination with $t-\mathrm{BuOOH}$ was reported, though the results were less promising than other systems tested in terms of yield and selectivity. ${ }^{113}$ In 1983, T. Kokubo et al. investigated the asymmetric $\mathrm{OsO}_{4}$-catalyzed dihydroxylation of alkenes with BSA as a scaffold with remarkable success (Scheme 4). ${ }^{116}$ An ee of 68 at a TON of 40 in the dihydroxylation of $\alpha$-methylstyrene 10 with $t-\mathrm{BuOOH}$ as oxidant was reported.

Scheme 4. Asymmetric dihydroxylation of $\alpha$-methylstyrene with $\mathrm{OsO}_{4} / t-\mathrm{BuOOH}$ in the presence of bovine serum albumin (BSA).<smiles>C=C(C)c1ccccc1</smiles>

10

$100 \mathrm{mM}$
$\mathrm{OsO}_{4}(0.2 \mathrm{~mol} \%)$

$\underset{t-\mathrm{BuOOH}(100 \mathrm{mM})}{\mathrm{BSA}}$

carbonate buffer $(50 \mathrm{mM})$ $\mathrm{pH} 10.9,25^{\circ} \mathrm{C}, 8 \mathrm{~h}$

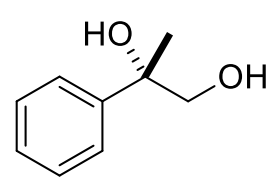

$68 \%$ ee

$\mathrm{TON}=40$

Cytochromes P450 have long attracted the attention of chemists. The ability of these enzymes to catalyze regio- and stereo-selective oxidative processes using molecular oxygen and reducing equivalents from $\mathrm{NAD}(\mathrm{P}) \mathrm{H}$ has so far been impossible to mimic reliably with synthetic models. The sophisticated redox machinery required to transfer 
electrons from reduced nicotinamide cofactors to the heme center and generate an active iron-oxo species has contributed to the interest in these systems, ${ }^{117}$ but it also hampers the application of P450 variants in synthetic processes. ${ }^{118}$ Hemoglobin, another heme-containg metalloprotein, has been shown to catalyze P450-type oxidations when supported by an NADPH-cytochrome P450 reductase containing FAD and FMN cofactors. ${ }^{119}$ Kokubo, Sassa, and Kaiser reported in 1987 on a catalytically competent 7cyanoisoalloxazine-hemoglobin conjugate. ${ }^{120}$ The flavin-substituted hemoglobin hybrid, named flavohemoglobin, catalyzed the p-hydroxylation of aniline $\mathbf{1 1}$ in the absence of NADPH-cytochrome P450 reductase with a higher rate than the reconstituted system and with a $K_{m}$ value similar to that of the hemoglobin scaffold (Table 2, Scheme 5). The flavin derivative was attached to cysteine $\beta-93$ through a glycine-aminoethanethiol-linker. The X-ray structure (1988) of flavohemoglobin revealed that: i) the flavin derivative is readily accessible to NADPH ii) the center of the isoalloxazine and the heme of the same subunit are $14 \AA$ apart iii) the flavins of neighbouring subunits are in close contact, possibly enabling electron transfer between subunits. ${ }^{121}$ Natural flavohemoglobins exist, for example in E. coli. ${ }^{122}$

Table 2. Comparison of catalytic paramters of flavohemoglobin with hemoglobin and reductase complemented hemoglobin.

\begin{tabular}{llll}
\hline Entry & Protein & $\begin{array}{l}k_{\text {aat }}^{\text {app }} \\
\left(\mathrm{min}^{-1}\right)\end{array}$ & $\begin{array}{l}K_{\mathrm{m}}^{\text {app }} \\
(\mathrm{mM})\end{array}$ \\
\hline 1 & flavohemoglobin & 0.169 & 5.3 \\
2 & hemoglobin & 0.127 & 5.3 \\
3 & + P450-reductase & 0.022 & 5.6 \\
\hline
\end{tabular}

Scheme 5: Hydroxylation of aniline 11 catalyzed by flavohemoglobin, reductasecomplemented hemoglobin or the non-modified parental protein.

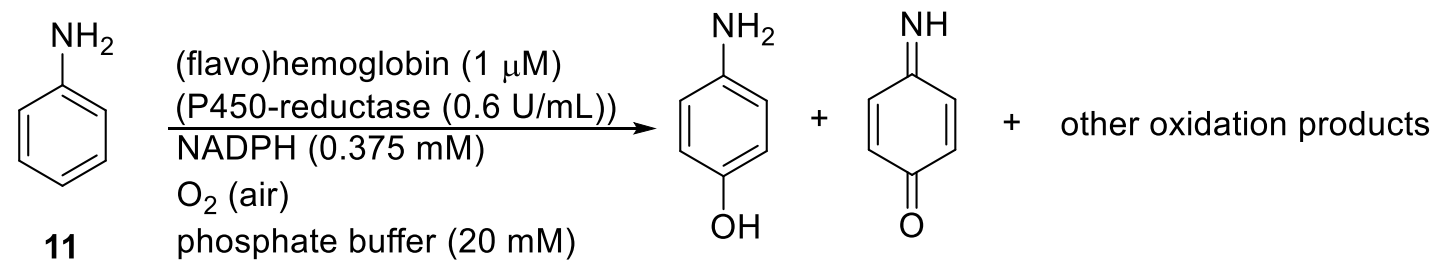
$\mathrm{pH} 7.5,37^{\circ} \mathrm{C}$ 
Although enzymes are frequently highly substrate-specific, this is by no means a general feature. The introduction of specificity to a natural metalloenzyme by complementation with a molecular recognition element was demonstrated by Corey and Schultz in 1987. Upon attachment of an oligonucleotide via a disulfide bridge, the $\mathrm{Ca}$ (II)-dependent staphylococcal nuclease cleaved single-stranded DNA in proximity to the attachment site. Only superstoichiometric conditions were reported. ${ }^{123}$ In a similar manner, various oligonucleotide binding proteins or protein domains were converted to oligonucleotide cleaving proteins via covalent modification with EDTA or phenanthroline complexes of $\mathrm{Fe}(\mathrm{II})$ or $\mathrm{Cu}(\mathrm{II})$, respectively. ${ }^{124-127}$ The combination of a reducing agent such as a thiol or ascorbic acid with molecular oxygen resulted in oxidative cleavage of the oligonucleotide backbone. ${ }^{128}$ The systems were typically employed in superstoichiometric amounts relative to the oligonucleotide.

The ability to raise monoclonal antibodies against any hapten inspired ambitious research into the generation of antibody-based artificial metalloenzymes. It was envisioned that these could possess the ability to discriminate substrates and hence provide specificity toward cleavage motifs. ${ }^{129}$ Iverson and Lerner first reported in 1989 on a specific antibody-based ArM hydrolase for peptide substrates. ${ }^{130}$ Monoclonal antibodies were raised against a peptide (trien) $\mathrm{Co}$ (III) complex 12 (trien = triethylenetetramine). Substitution of the hapten for other metal(trien) complexes led to active peptidases that could distinguish between structurally related substrates 13-18 and cleaved a specific peptide bond in the small set of peptidic substrates investigated 17-18; Scheme 6. The antibody ArM design was based on the prospective exchange of a coordinatively inert octahedral $\mathrm{Co}$ (III) complex used as the hapten against a kinetically more labile complex used for catalysis. Various metal(trien) complexes were tested employed, and a turnover number of 400 with a turnover frequency of $6 \times 10^{-4} \mathrm{~s}^{-1}$ was reported. 
Scheme 6. Metal-dependent antibodies for specific cleavage of peptidic substrates. a) Kinetically inert cobalt(III) complex employed as hapten; b) peptidic structures not accepted as substrates; c) cleavage of peptidic substrates with antibody 28F11 in the presence of $\mathrm{Zn}(\mathrm{II})$ trien.

a)

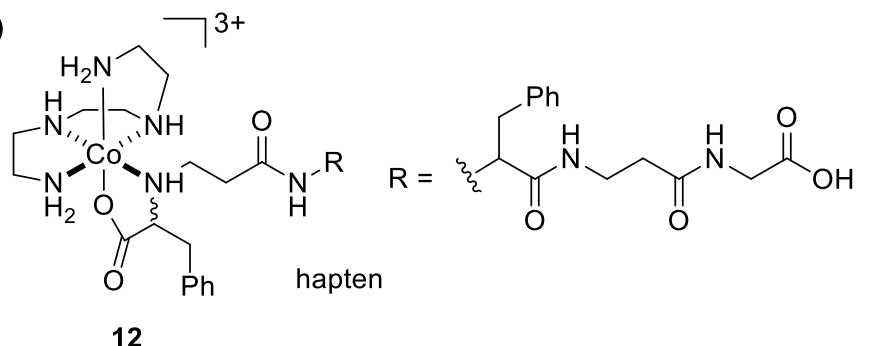

b) unsuitable substrates<smiles>[R]NC(=O)CNC(=O)Cc1ccccc1</smiles>

13<smiles>[R]NC(=O)CNC([13CH2])=O</smiles><smiles>[2H]NC(=O)CCNC(=O)Cc1ccccc1</smiles><smiles>[R]NC(=O)CCNC(=O)CCc1ccccc1</smiles>

c)<smiles>[R]NC(=O)CNC(=O)CCc1ccccc1</smiles>

$28 \mathrm{~F} 11(0.25 \mathrm{~mol} \%, 10 \mu \mathrm{M})$ sodium phosphate buffer $(75 \mathrm{mM})$ $\mathrm{pH} 6-8,8 \mathrm{~d}$

18

$2 \mathrm{mM}$ each<smiles>O=C(O)CNC(=O)CCc1ccccc1</smiles>

$\mathrm{H}_{2} \mathrm{~N}^{-\mathrm{R}}$<smiles>O=C(O)CNC(=O)CCCc1ccccc1</smiles>

full conversion

Following Kaiser's work demonstrating that hemoglobin could be converted into a reductase-independent hydroxylase, Sasaki and Kaiser decorated Fe(III) coproporphyrin with four identical fifteen-residue peptides. ${ }^{131}$ In the presence of acetylflavin and NADPH, the resulting 'helichrome' hydroxylated aniline with $k_{c a t}$ and $K_{m}$ values of $0.02 \mathrm{~min}^{-1}$ and $K_{\mathrm{m}}=5.0 \mathrm{mM}$, respectively. The unmodified Fe(III) coproporphyrin showed only negligible hydroxylase activity under the same conditions. The study, published in 1989 constitutes, to the best of our knowledge, the first report of a de novo 'heme'-enzyme.

Cochran and Schultz raised in 1990 monoclonal antibodies against $N$ methylmesoporphyrin IX 19 as a hapten (Figure 2). ${ }^{132} \mathrm{~N}$-methylporphyrins displays outof-plane distortion and can be considered as a transition state model for the metalation of the porphyrin, a reaction typically catalyzed by ferrochelatase in the conversion of protoporphyrin to heme. Three purified antibodies were specific for the hapten, and two of these catalyzed $\mathrm{Zn}(\mathrm{II})$ - and $\mathrm{Cu}(\mathrm{II})$-porphyrin complex formation. Further studies revealed that the same antibody was effectively inhibited by iron(III) mesoporphyrin 20 . 
Intriguingly, the resulting construct catalyzed the oxidation of a range of typical chromogenic peroxidase substrates (using $\mathrm{H}_{2} \mathrm{O}_{2}$ as a stoichiometric oxidant) with significantly higher rates than iron(III) mesoporphyrin itself. ${ }^{133}$ Notably, ABTS and pyrogallol red were converted by the construct, but not by iron(III) mesoporphyrin. In a related study, Harada and coworkers reported several years later that antigen binding fragments in combination with meso-tetrakis(4-carboxyphenyl)porphyrin (TCPP) complexes of $\mathrm{Mn}(\mathrm{III})$ and $\mathrm{Fe}(\mathrm{III})$ catalyzed the oxidation of pyrogallol with $\mathrm{H}_{2} \mathrm{O}_{2}$ exclusively while other substrates tested by Cochran and Schulz such as hydroquinone, resorcinol, catechol and ABTS with a higher redox potential were not converted. ${ }^{134}$

In 1990, E. Keinan et al. raised antibodies against the water soluble Sn(IV) porphyrin complex meso-tetrakis(4-carboxyvinylphenyl)porphinato tin(IV)dihydroxide $\left(\mathrm{Sn}(\mathrm{TCP})(\mathrm{OH})_{2}\right)$ 21, Figure 2. ${ }^{135}$ Antibody metallation with $\mathrm{Mn}(\mathrm{III})(\mathrm{TCP})$ cofactor 22 led to an ArM that catalyzed the epoxidation of styrene in the presence of iodosobenzene. The highest activity was observed under heterogeneous conditions in $\mathrm{CH}_{2} \mathrm{Cl}_{2}$, but no enantioinduction was detected.

a)

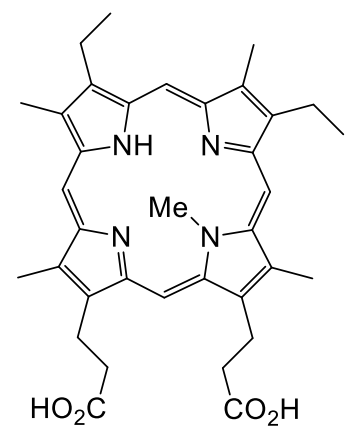

19 b)

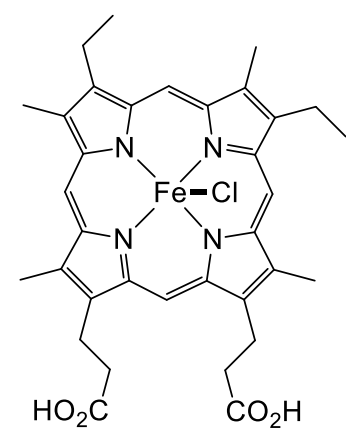

20

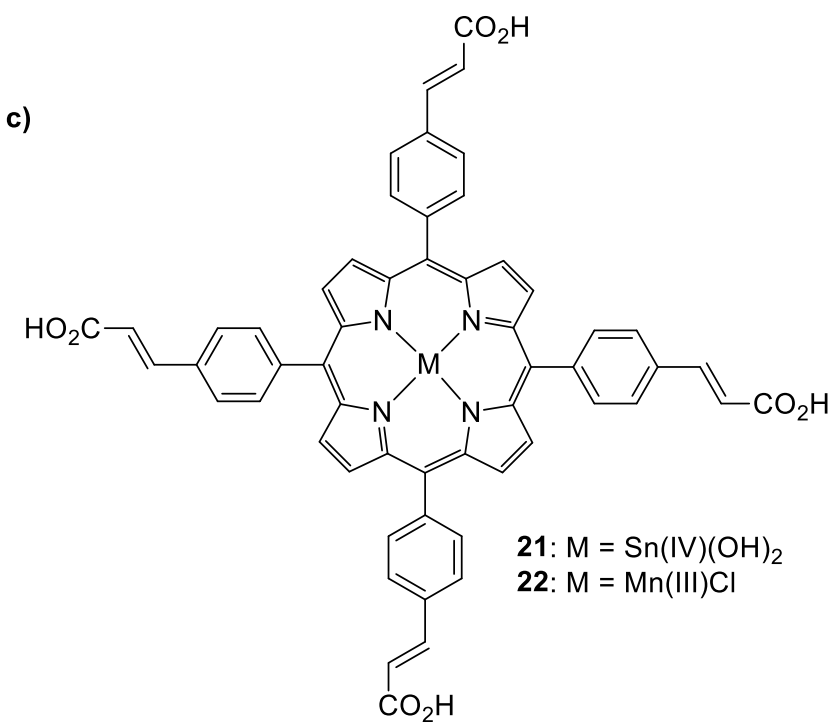

Figure 2. Haptens and cofactor precursors for monoclonal antibody-based, metalloporphyrin-dependent artificial metalloenzymes. a) $\mathrm{N}$-methylated porphyrin as a transition state mimic for ferrochelatase afforded an antibody for $\mathrm{Zn}$ (II) and $\mathrm{Cu}(\mathrm{II})$ mesoporphyrin formation; b) the same antibody formed an active oxidase upon loading with $\mathrm{Fe}(\mathrm{III})$ mesoporphyrin; c) water soluble $\mathrm{Sn}(\mathrm{TCP})(\mathrm{OH})_{2}$ used as a hapten to raise 
monoclonal antibodies that were subsequentely combined with $\mathrm{Mn}(\mathrm{TCP}) \mathrm{Cl}$ to yield an artificial epoxidase.

Despite the prevalence of non-covalent cofactor incorporation in early ArM efforts, work on covalent incorporation was also actively pursued. Germanas and Kaiser reported an artificial oxidase based on a covalently bound $\mathrm{Cu}$ (II)-bipyridine complex linked to the cysteine in the active site of papain. The construct catalyzed the air-oxidation of ascorbic acid and more lipophilic derivatives at 15 to 26 fold higher rates compared to the free cofactor. ${ }^{136}$ Although no catalysis was probed, in 1993, Gray, Imperiali, and coworkers demonstrated photoinduced electron transfer between a covalently linked Ru-center and heme in a cytochrome c mutant. The heme-bearing mutant beared a Ru(bipy)2-fragment coordinated to a bipyridylalanine-bearing peptide constructed by semisynthesis. ${ }^{137}$

In 1993, Lerner, Janda, and coworkers disclosed a strategy to generate an antibodybased ArM hydrolase using a hapten that contained a methylpyridinium unit 23, rather than a metal moiety (Scheme 7). ${ }^{138}$ Based on the activation of picolinic acid esters by Lewis acids coordinated to the pyridine nitrogen atom, it was envisioned that the methylpyridinium-substituted hapten would select for antibodies that address to scaffold design criteria. First, the methyl group in the hapten would act as a placeholder for a metal ion. Second, the positive charge would elicit the expression of carboxylate residues to serve as additional ligands near the prospective metal binding site and thereby increase metal affinity. The ester moiety envisaged as a cleavage site, or more specifically, the expected tetrahedal intermediate, was simulated with a hydroxyl functional group. Upon metallation with $\mathrm{Zn}(\mathrm{II})$, the resulting antibody-based ArM showed a $>10,000$-fold rate acceleration against background and a $>1,000$-fold rate acceleration against $\mathrm{Zn}(\mathrm{II})$ in equivalent concentration. The affinity of the antibody for $\mathrm{Zn}(\mathrm{II})$ and the substrate complexed to $\mathrm{Zn}(\mathrm{II})$ was modest, whereas the affinity for the substrate itself was substantially higher. 
Scheme 7. Monoclonal antibodies catalyze the hydrolysis of a specific picolinic acid ester in the presence of $\mathrm{Zn}(\mathrm{II})$. a) $\mathrm{N}$-methyl pyridinium employed as the hapten; b) substrates not accepted by the antibody; c) hydrolysis of the substrate by the antibody in the presence of $\mathrm{Zn}(\mathrm{II})$.

a)<smiles>C[n+]1ccccc1C(O)Cc1ccc(NC(=O)CCCC(=O)ON2C(=O)CCC2=O)cc1</smiles>

hapten $\quad 23$

c) b) unsuitable substrates
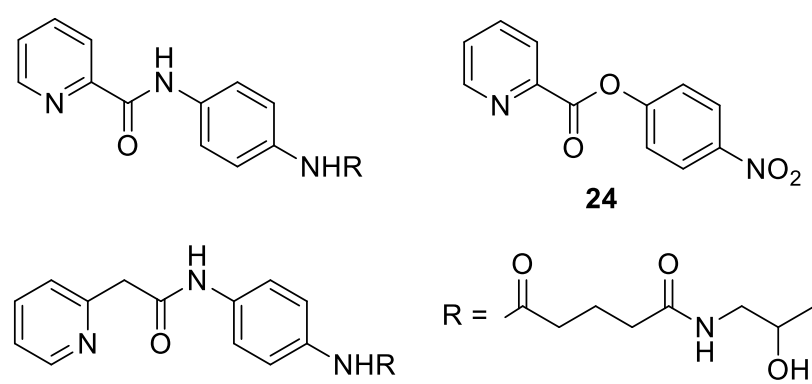<smiles>[R]=CCCCC(=O)NCC(O)CO</smiles><smiles>[R]Nc1ccc(OC(=O)c2ccccn2)cc1</smiles>

antibody $\lg \mathrm{G} 84 \mathrm{~A} 3(5$ or $10 \mu \mathrm{M})$

$\underset{\mathrm{Zn}(\mathrm{II})(100-300 \mu \mathrm{M})}{\mathrm{MOPS}(12.5 \mathrm{mM}), \mathrm{NaCl}(75 \mathrm{mM})}$ $\mathrm{pH} 7.0,25^{\circ} \mathrm{C}$<smiles>O=C(O)c1ccccn1</smiles><smiles>[R]Nc1ccc(O)cc1</smiles>
$25-300 \mu \mathrm{M}$

Imperiali and Roy reported in 1994 on an artificial transaminase generated by reassembly of the subtilisin-cleaved bovine ribonuclease $A$ (RNase $A$ ) with a synthetic peptide fragment carrying a pyridoxal derivative, Figure 3. One reassembled construct displayed eighteen-fold rate acceleration for the conversion of L-alanine to pyruvate under single turnover conditions compared to the pyridoxal-derivative carrying the peptide fragment alone. Accelerating effects of metal ions observed with pyridoxal models had been studied previously and consequently their addition was probed in this complex system. ${ }^{139} \mathrm{Cu}(\mathrm{II})$-ions had either beneficial or detrimental effects on the rate depending on the peptide fragment employed. ${ }^{140}$ In a subsequent study, multiple turnovers could be realized in the conversion of pyruvate to alanine through the addition of L-phenylalanine accompanied by a moderate enantioselectivity. ${ }^{141}$ 
a)

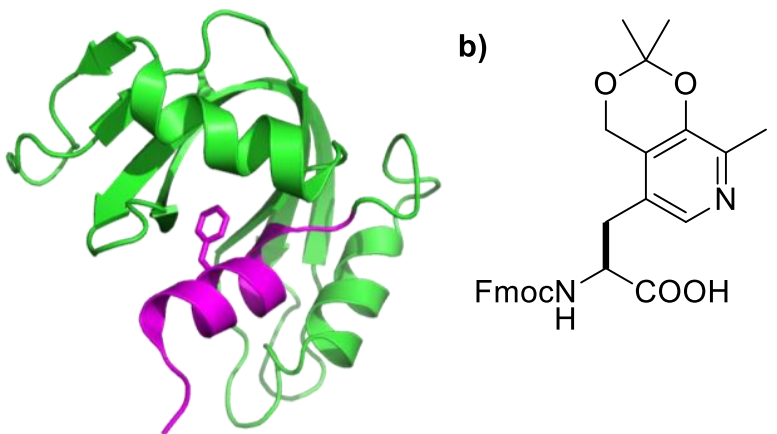

c)<smiles>Cc1ncc(CC(C)NC(C)C)c(C=O)c1O</smiles>

d)<smiles></smiles>

Figure 3. An artificial transaminase based on RNase A. RNase A is cleaved by subtilisin into fragments termed S-protein ${ }^{140}$ and S-peptide (magenta). Reassembly of S-protein with suitable synthetic S-peptides affords functional supramolecular constructs. a) The side chain of 8-Phe targeted for cofactor introduction is displayed in stick mode (PDB ID 3DH5); b) unnatural amino acid used to introduce the pyridoxal mimic into the synthetic S-peptide; c) S-peptide bearing the pyridoxal mimic as a side chain resulting from deprotection and oxidation; d) postulated interaction of $\mathrm{Cu}(\mathrm{II})$-ions with the Schiff-base formed by condensation of side chain functionality with L-alanine.

Craik and coworkers engineered a metal binding site into trypsin in order to change its substrate specificity. ${ }^{142} \mathrm{~A}$ double mutation to introduce histidines in the S2' pocket $(\mathrm{N} 143 \mathrm{H}-\mathrm{E} 151 \mathrm{H})$ allowed selective cleavage of the substrate AGPYAXSS, containing tyrosine at P1. Cleavage occured exclusively upon addition of either $\mathrm{Zn}(\mathrm{II})$ or $\mathrm{Ni}(\mathrm{II})$ and if the peptide contained a histidine at P2' $(\mathrm{X}=\mathrm{H}$; Figure 4). WT-trypsin was also able to cleave this substrate in the presence of $\mathrm{Zn}(\mathrm{II})$ at 10 -fold lower rate, although cleavage after tyrosine is highly disfavored in the absence of zinc. This unexpected result was rationalized by complexation of the substrate with the participation of glutamate 151 . Indeed, exchange of glutamate for glutamine led to an inactive mutant towards AGPYAHSS. 


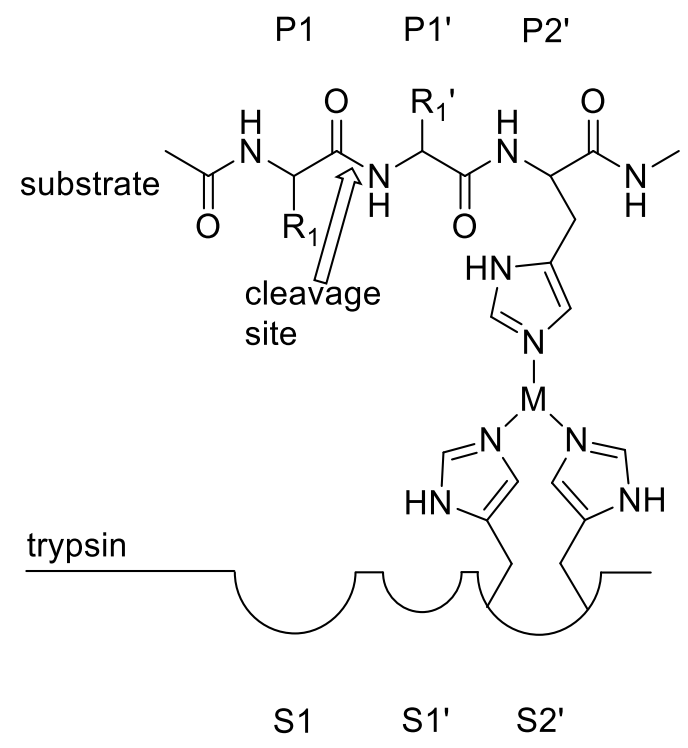

Figure 4. Modifying the substrate profile of trypsin through an engineered metal binding site for substrate coordination. Adapted with permission from ref. ${ }^{142}$. Copyright 1995 American Chemical Society.

Starting in 1997, Davies and Distefano reported covalent scaffold modifications to anchor transition metal complexes inside fatty acid binding proteins. lodoacetamido1,10-phenanthroline was reacted with a unique cysteine residue inside the cavity $(\mathrm{V}=$ $600 \AA^{3}$ ) of adipocyte lipid binding protein (ALBP) resulting, after complexation with $\mathrm{Cu}(\mathrm{II})$, in ALBP-Phen-Cu(II) (PDB ID 1A18) for the stereoselective hydrolysis of racemic esters such as $\mathbf{2 5}$ and $\mathbf{2 6}$ although only modest activity was observed (Scheme 8). ${ }^{143-144}$ In a subsequent study, the position of the phenanthroline inside the protein cavity was varied by site directed mutagenesis. The resulting selectivities and activities were moderately but significantly affected (Figure 5). ${ }^{145}$ 


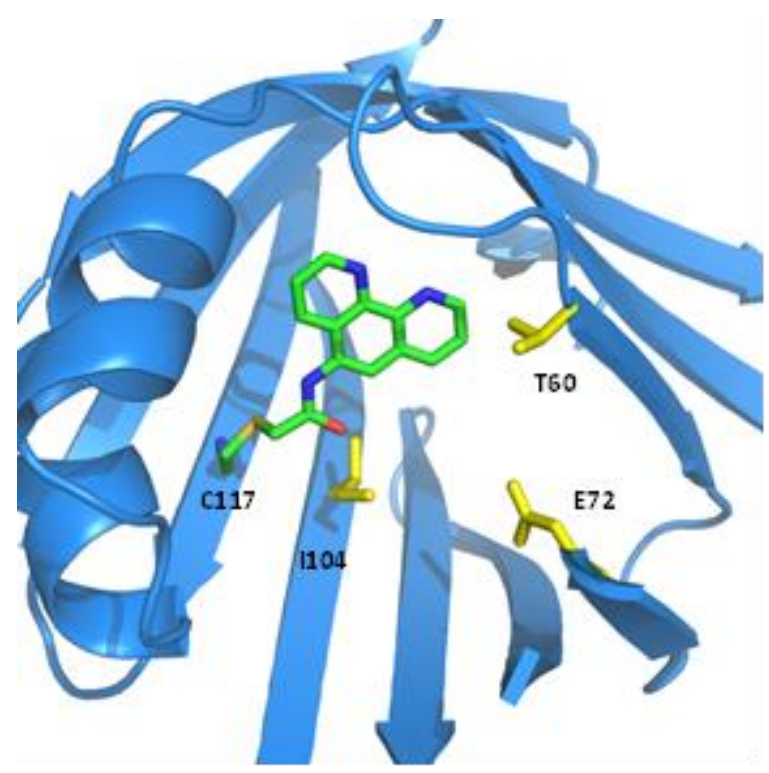

Figure 5. Cartoon representation of ALBP protein (PDB: 1A18) studied by Distefano. ${ }^{143-}$ 145 Highlighted 1,10-phenanthroline (coloured in green $\mathrm{C}$, blue $\mathrm{N}$ and red $\mathrm{O}$ ) linked to Cys117. Side chains of aminoacids mutated to cysteine in susequent constructs with alternative phenanthroline positions are highlighted as yellow sticks.

Scheme 8. Kinetic resolution of racemic amino acid esters catalyzed by a $\mathrm{Cu}$ (II)phenanthroline complex anchored covalently to a cysteine residue in the cavity of ALBP.

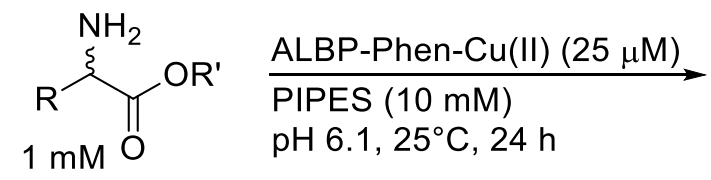

25: $\mathrm{R}=\mathrm{CH}_{3}, \mathrm{R}^{\prime}=\mathrm{CH}\left(\mathrm{CH}_{3}\right)_{2}$

26: $\mathrm{R}=\mathrm{CH}_{2} \mathrm{C}_{6} \mathrm{H}_{4} \mathrm{OH}, \mathrm{R}^{\prime}=\mathrm{CH}_{3}$<smiles>[R]C(N)C(=O)O[NH2+]O</smiles>

$$
\begin{array}{ll}
86 \% \text { ee }(S) & 39 \% \text { ee }(S) \\
\text { TON } \sim 1 & \text { TON } \sim 8 \\
\mathrm{R}=\mathrm{CH}_{3} & \mathrm{R}=\mathrm{CH}_{2} \mathrm{C}_{6} \mathrm{H}_{4} \mathrm{OH}
\end{array}
$$

Another set of constructs resulted from immobilisation of a pyridoxamine-derived cofactor by cysteine linkage via disulfide bond formation in ALBP and the closely related intestinal fatty acid binding protein (IFABP). ${ }^{146}$ A 1998 study scrutinized the effect of $\mathrm{Cu}(\mathrm{II}), \mathrm{Ni}(\mathrm{II})$, and $\mathrm{Zn}(\mathrm{II})$ on the catalytic performance resulting in rate acceleration but also erosion of enantioselectivity for the transamination of keto-carboxylic acids with phenylalanine as a sacrificial donor. ${ }^{147}$

Inspired by the phytase inhibition by transition metal oxoanions and the structures of vanadium chloroperoxidases, Sheldon and coworkers doped phytase from Aspergillus ficuum with vanadate. ${ }^{148}$ The resulting ArM oxidized thioanisole 27 in the presence of 
$\mathrm{H}_{2} \mathrm{O}_{2}$ at considerably increased rates relative to free vanadate and provided an ee of up to $66 \%(S)-28$, Scheme 9 . Unexpectedly, phytase even in the absence of vanadate also catalyzed the reaction, albeit at reduced rates and enantioselectivity. ${ }^{149-150}$ Subsequent studies examined a range of protein hosts doped with various transition metal oxoanions, including $\mathrm{MoO}_{4}^{2-}, \mathrm{ReO}_{4}^{-}$, and $\mathrm{WO}_{4}^{2-}$. Although significant enantiomeric excess and rate acceleration was observed in the oxidation of thioanisole, none of the systems tested could improve on the original phytase-vanadate system.

Scheme 9. Sulfoxidation of thioanisole with $\mathrm{H}_{2} \mathrm{O}_{2}$ catalyzed by vanadate-doped phytase.<smiles>CSc1ccccc1</smiles>

27 $5 \mathrm{mM}$ phytase $(\sim 0.18 \mu \mathrm{M})$

$\underset{\mathrm{Na}_{2} \mathrm{O}_{2}(5.5 \mathrm{mM})}{\longrightarrow}$ formate buffer $(100 \mathrm{mM})$ $\mathrm{pH} 5.1,4{ }^{\circ} \mathrm{C}, 3 \mathrm{~h}$<smiles></smiles>

28 full conversion $66 \%$ ee $(S)$

Finn, Lerner, and Barbas, III, published in 1998 a study on the effect of metal ions on rate and enantioselectivity of antibody catalyzed aldol reactions. ${ }^{151}$ The antibodies (33F12 and 38C2) were originally raised against a hapten able to form a covalent intermediate with a reactive lysine residue in the antibody active site via reactive immunization. ${ }^{152-153} \mathrm{~A}$ wide range of metal ions was examined, but substantial effects were only observed for $\mathrm{Pd}(\mathrm{II})$ salts: rate enhancements of 2.3-2.6 fold with variable enantioselectivity. The authors concluded that a direct binding of $\mathrm{Pd}$ in the active site seemed unlikely given the moderate effect and favoured instead an allosteric interaction. Following Whiteside's - at the time two-decade old - lead, Chan and coworkers published in 1999 a study in which a more rigid and, importantly, enantiopure pyrphos ligand was biotinylated and the corresponding $\mathrm{Rh}(\mathrm{I})$-complex 29 incorporated into avidin. ${ }^{154}$ The authors studied the effect of hydrogen pressure, temperature and stereochemistry of the pyrphos moiety on the catalysis outcome in the hydrogenation of 
itaconic acid 30, Scheme 10. Although stereoselectivity was improved in the presence of avidin and could even be inverted compared to the protein free cofactor, only moderate enantioselectivities were reported.

Scheme 10. Asymmetric hydrogenation of itaconic acid catalyzed by an enantiopure biotinylated Rh-diphosphine complex in the presence of avidin.

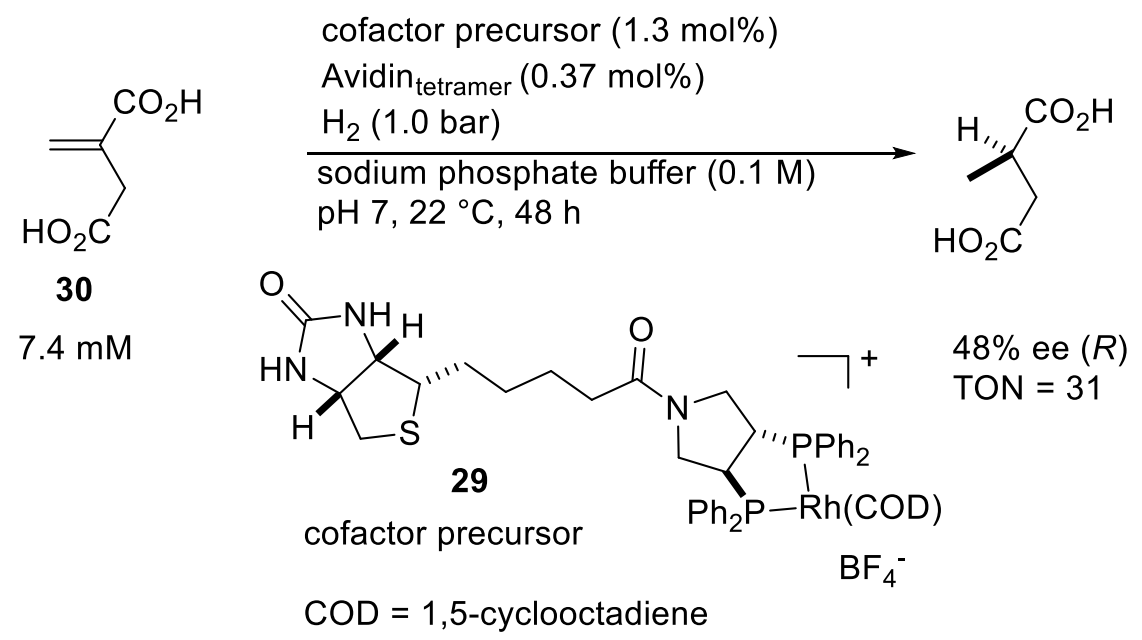

Nimri and Keinan reported in the same year on antibodies raised against a modified hapten compared to Keinan's previous design from 1990 (Figure 2 c). ${ }^{155}$ Apart from a variation of the porphyrin scaffold (TCPP instead of TCP), the axial hydoxo-ligands of the tin center were exchanged for bulky $\alpha$-naphthoxy-groups with the intention of eliciting a substrate binding site in the antibody scaffold. Antibody metallation with TCPP-Ru(II)$\mathrm{CO}$ led to an active and enantioselective ArM sulfoxidase in the presence of iodosobenzene. A $k_{c a t}$ of $24 \mathrm{~min}^{-1}$, a $K_{\mathrm{M}}$ of $10 \mathrm{mM}$, and an ee of $43 \%$ were obtained for the oxidation of thioanisole 27 . A significantly higher $k_{\text {cat-value }}\left(174 \mathrm{~min}^{-1}\right)$ was determined for the electron-rich substrate 4-methoxythioanisole, albeit at the expense of a diminished enantioselectivity ( $27 \%$ ee).

Marchetti and coworkers studied the biphasic rhodium-catalyzed hydroformylation of alkenes in the presence of a range of protein scaffolds. The initial study was published in 2000 and followed by a more detailed investigation in $2002 .^{156-157}$ The most successful system reported was generated by combining human serum albumin with 
[Rh(acac)(CO)2]. A TON of 741,000 was observed at a TOF of $30,000 \mathrm{~h}^{-1}$. At higher catalyst loadings ( $\mathrm{S}: \mathrm{C}=10,400: 1$ ) good recyclability was demonstrated. 1,1diarylethenes were not viable ArM substrates despite their reactivity toward the common TPPTS-Rh(I) system (TPPTS = triphenylphosphine-3,3',3"-trisulfonic acid trisodium salt). A branched : linear-ratio of $90: 10$ was observed for styrene, whereas only a qualitative comment on stereoinduction (i.e. very low, but observable) was made. Stereoselectivity in biphasic hydroformylation reactions is generally considered to be challenging. ${ }^{158}$

In 2002, Nicholas, Janda and coworkers published an application of a monoclonal antibody for the generation of an artificial metalloenzyme. ${ }^{159}$ Whereas previously antibodies were raised against metal complexes or ligands for the generation of ArMs, the authors relied on an antibody raised for a metal-free aldolase. Addition of a copper(II)-bis-imidazole complex afforded a catalytic metalloantibody for the hydrolysis of picolinic ester $24\left(k_{\text {cat }}=2.3 \mathrm{~min}^{-1}, K_{\mathrm{m}}=2.2 \mathrm{mM}\right){ }^{152-153}$

The advent of increasingly convenient site directed mutagenesis in the late 70's opened new opportunities to optimize natural enzymes enzymes for biocatalysis. ${ }^{160-161}$ The possibilities for biocatalyst development were further expanded by the development of directed evolution methods involving iterative rounds of random mutagenesis or gene shuffling followed by screening or selection. ${ }^{162} \mathrm{~A}$ wide range of site-directed and random mutagenesis strategies are now commonly used to rapidly optimize biocatalyst activity, while limiting the screening effort. ${ }^{163-164}$

Despite these advances, the considerable effort required to express, purify, modify, and evaluate protein scaffolds for ArM catalysis posed and continues to pose a considerable obstacle to ArMs optimization via mutagenesis. In 2002, Reetz proposed in conceptual articles the application of directed evolution protocols to hybrid catalyst development for non-biological reactions such as hydroformylation, olefin hydrogenation, metathesis, and 
allylic substitution. ${ }^{165-166}$ In contrast, Ward and coworkers initially focused on a chemogenetic strategy to reduce the number of ArM components (protein scaffolds and cofactors) and simplify ArM optimization. This strategy involves the combination of a small set of protein mutants with a small set of cofactor variants to generate ArM diversity. ${ }^{31}$

Many exciting studies on systems related to ArMs but outside the scope of this review as outlined in the introduction were reported during the timeframe discussed in this section. These include active site redesign of natural metalloenzymes to elucidate structurefunction relationships, ${ }^{110}$ and early efforts on de-novo designed coiled-coil and helical bundle metallopeptides that would later be used for ArM catalysis. ${ }^{167-169}$ Considering the widened opportunities for rational design guided by structural information and molecular modelling, standardized and new molecular biology protocols and kits, the renewed interest in water compatible transition metal catalysts and, a few years later, affordable gene synthesis, the ground was set for further research endeavors in the field of artificial metalloenzymes. 


\section{Reduction Chemistry}

\subsection{Hydrogenation}

The discovery of homogeneous, transition metal phosphine complexes capable of promoting the addition of molecular hydrogen to carbon-carbon double bonds ultimately precipitated the entire field of asymmetric transition metal catalysis. ${ }^{101,170}$ Factors contributing to the importance of this reaction for organic synthesis include its i) perfect atom economy, ii) high reaction rates, iii) high tunability via ligand design, and iv) ability to generate valuable, chiral products. Asymmetric hydrogenation has also been extensively explored as a benchmark reaction for artificial metalloenzymes.

As previously noted, Whitesides' seminal example of asymmetric hydrogenation using a biotinylated $\mathrm{Rh}(\mathrm{I})$-bisphosphine complex embedded within avidin constituted not only the first example of ArM-catalyzed hydrogenation, but also the first example of asymmetric catalysis using an ArM and the first example of ArM formation via non-covalent cofactor anchoring. This work was first revisited by Chan and coworkers in 1999 (Scheme 10). ${ }^{2}$, 154 M. T. Reetz later demonstrated that $\mathrm{Cu}$-, Pd-, and Rh-complexes of maleimidesubstituted dipyridine compounds (Figure 6) could readily alkylate the active site cysteine of papain, a cysteine protease. Only preliminary catalytic activity was reported for these ArMs, which were reported to catalyze hydrogenation with low enantioselectivity. ${ }^{165-166}$

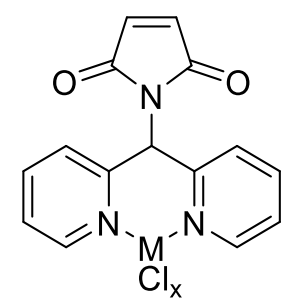

$\mathrm{M}=\mathrm{Cu}, \mathrm{x}=2$

$M=P d, x=2$

$M=R h, x=3$ 
Figure 6: Dipyridine complexes by Reetz. ${ }^{165}$

Initial efforts in the Ward group on building an artificial hydrogenase aimed at improving the original Whitesides' system. Instead of avidin ( $\mathrm{pl}=10.4)$, streptavidin $(\mathrm{pl}=6.2)$ with an anticipated improved affinity for cationic complexes such as $[R h(C O D)(34)]^{+}$was used. Position $\mathrm{S} 112^{171}$ was targeted for mutagenesis and the resulting 20 isoforms combined with 22 biotinylated ligands with variable spacer units and two different bisphosphine chelating groups 33, 35 precomplexed with $\left[\mathrm{Rh}(\mathrm{COD})_{2}\right] \mathrm{BF}_{4}$ for individual experiments. ${ }^{44,172-177}$ A mix of two dehydroamino acid derivatives as substrates was hydrogenated simultaneously to yield amino acid derivatives 31,32 . Results (Scheme 11 and Table 3) can be summarized as follows:

i) Generally, the "chemical" Rh-complex library contributed more to diversity than the "genetic" Sav-mutant library.

ii) The more flexible bisphosphine $\mathbf{3 3}$ scaffold afforded more active and selective ArMs than the rigid six-membered chelate formed with 35.

iii) The two substrates displayed similar reactivity and selectivity profiles. This suggested a broad substrate scope of the artificial transfer hydrogenase, reminiscent of homogeneous catalysts.

iv) Mutation at position S112X enabled an inversion of enantioselectivity (Table 3, entries 13 and 14) which could be optimized by choosing suitable ligand, mutant $(X=H, K, R$; Table 3, entries 2-4) and linker combinations.

Scheme 11: Biotinylated rhodium diphosphine complexes anchored within Sav catalyze the asymmetric hydrogenation of dehydroamino acid derivatives. To optimize the reaction, a library of biotinylated rhodium complexes with varying spacers and ligand head groups a) was combined with a Sav site-saturation mutagenesis library of position S112. Both conversion and enantioselectivity for each protein-ligand combination are summarized in a fingerprint display b). Enantiopure amino acid spacer with flexible head group $33 \mathrm{c}$ ). Adapted with permission from ref. ${ }^{176}$ Copyright Wiley VCH 2005. 
a)

ligand (1.0 mol\%)

$=\mathrm{NHAc}_{\mathrm{Ph}}^{\mathrm{CO}_{2} \mathrm{H}}+\mathrm{NHAC}_{\mathrm{NH}}^{\mathrm{CO}_{2} \mathrm{H}}$

$\left[\mathrm{Rh}(\mathrm{COD})_{2}\right] \mathrm{BF}_{4}(0.9 \mathrm{~mol} \%)$

streptavidin S112X (0.33 mol\%)

$-\underset{\mathrm{NHAc}}{\mathrm{CO}_{2} \mathrm{H}}+{ }_{\mathrm{Ph}}^{\mathrm{NHHC}_{\mathrm{H}}}$

MES buffer $(0.1 \mathrm{M})$

pH 5.5, RT, $15 \mathrm{~h}$

31

32<smiles>CC(=O)CCCC[C@H]1SC[C@@H]2NC(=O)N[C@@H]21</smiles><smiles>[R]N(CCc1ccccc1)CCc1ccccc1</smiles>

$\mathrm{R}^{\prime}=\mathrm{H}(33)$

$\mathrm{R}^{\prime}=$ Biot, Biot-1 (34)

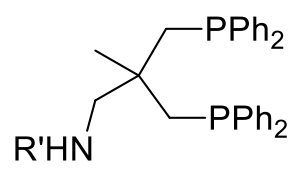

$\mathrm{R}^{\prime}=\mathrm{H}(35)$

$\mathrm{R}^{\prime}=$ Biot, Biot-2 (36)<smiles>[R]C(=O)C(C)NCc1ccccc1</smiles>

Biot- $3^{n}$

$n=1-5$

Biot $_{\mathrm{NH}}$<smiles>[R]C(=O)c1cccc(N)c1</smiles>

Biot-4

$q=$ ortho-, meta- . para-

$R=33$, Biot $-3^{n}-1 \quad R=33$, Biot $-4^{q}-1$

$R=35$, Biot $-3^{n}-2 \quad R=35$, Biot $-4^{q}-2$

Biot-3 ${ }^{1}-1$ (37) Biot-4 ${ }^{\text {meta }}-1$ (40)

Biot- $3^{1}-2$ (38) Biot-4 ${ }^{\text {ortho }}-1$ (41)

Biot- $3^{4}-2$ (39)

b)

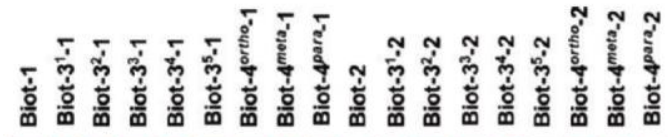

WT Sav

S112A

S112C

S112D

S112F

S112G

$\mathrm{S} 112 \mathrm{H}$

s112I

S112K

S112L

S112M

S112N

S112P

S112Q

S112R

S112T

S112V

s112W

S112Y

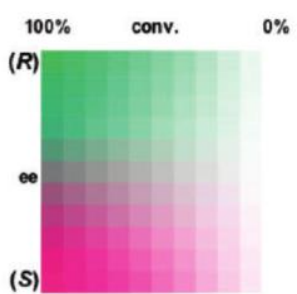

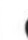

c)<smiles>O=C([C@@H]1CCCN1)N(CCc1ccccc1)CCc1ccccc1</smiles><smiles>[R]N[C@@H](Cc1ccccc1)C(=O)N(CCc1ccccc1)CCc1ccccc1</smiles>

$\mathrm{R}^{\prime}=$ Biot

Table 3. Selected results for chemogenetic optimization of the artificial hydrogenase based on the biotin-(strept)avidin technology.

\begin{tabular}{lllllll}
\hline Entry & Ligand & Protein & $\mathbf{3 1}$ & $\mathbf{3 1}$ & $\mathbf{3 2}$ & $\mathbf{3 2}$ \\
ee $(\%)$ & Conv. $(\%)$ & ee $(\%)$ & Conv. (\%) \\
\hline 1 & $\mathbf{3 4}$ & WT Sav & $94(R)$ & quant. & $93(R)$ & 84 \\
2 & $\mathbf{4 0}$ & S112H & $58(S)$ & quant. & $81(S)$ & 88 \\
3 & $\mathbf{4 0}$ & S112K & $63(S)$ & quant. & $88(S)$ & 89 \\
4 & $\mathbf{4 0}$ & S112R & $63(S)$ & quant. & $86(S)$ & 71 \\
5 & $\mathbf{3 8}$ & S112W & $59(S)$ & 96 & $33(S)$ & 8 \\
6 & $\mathbf{3 9}$ & S112Q & $87(S)$ & quant. & $92(S)$ & 77 \\
7 & $\mathbf{4 2}$ & WT Avi & $87(S)$ & quant. & $89(S)$ & quant. \\
8 & $\mathbf{4 2}$ & WT Sav & $86(S)$ & quant. & $91(S)$ & quant.
\end{tabular}




\begin{tabular}{|c|c|c|c|c|c|c|}
\hline 9 & 42 & WT Sav & $87(S)$ & quant. & $86(S)$ & 94 \\
\hline 10 & 42 & WT Sav & $83(S)$ & 90 & $87(S)$ & 85 \\
\hline 11 & 42 & WT Sav & $76(S)$ & 76 & $89(S)$ & 36 \\
\hline 12 & 42 & S112W & $95(S)$ & quant. & $95(S)$ & quant. \\
\hline 13 & 43 & $\mathrm{~S} 112 \mathrm{H}$ & $87(S)$ & quant. & $78(S)$ & 65 \\
\hline 14 & 43 & S112M & $73(R)$ & quant. & $87(R)$ & quant. \\
\hline
\end{tabular}

In early studies, van Koten and Klein-Gebbink demonstrated that lipase inhibitors, such as nitrophenol phosphonate esters, can be used to selectively anchor metallopincers within Cutinase (44). ${ }^{178-180}$ Cutinase from Fusarium solani pisi is a $21 \mathrm{kDa}$ lipase containing a Ser ${ }_{120}-$ Asp $_{175}-\mathrm{His}_{188}$ catalytic triad that hydrolyses fatty acids. Phosphonate esters function as transition-state analogues for this reaction and react irreversibly with Ser 120 . A pincer-metal complex linked to a phosphonate moiety (45 or $\mathbf{4 6}$ ) may thus be suitable for covalent anchoring to cutinase. (Scheme 12). M. T. Reetz and coworkers discussed related studies with an esterase in 2002, but the resulting construct suffered from low hydrolytic stability. They suggested to improve hydrolytic stabilty by exchanging a nitrophenoxy-group at phosphorus for an ethoxy group, a strategy later realized by van Koten and Klein-Gebink. ${ }^{165}$

Scheme 12. Covalent anchoring of pincer-metal complexes via nucleophilic substitution of an activated phosphonate ester Ser 120 in the active site of cutinase 44. The anchoring is conveniently monitored by the release of para-nitrophenolate. 


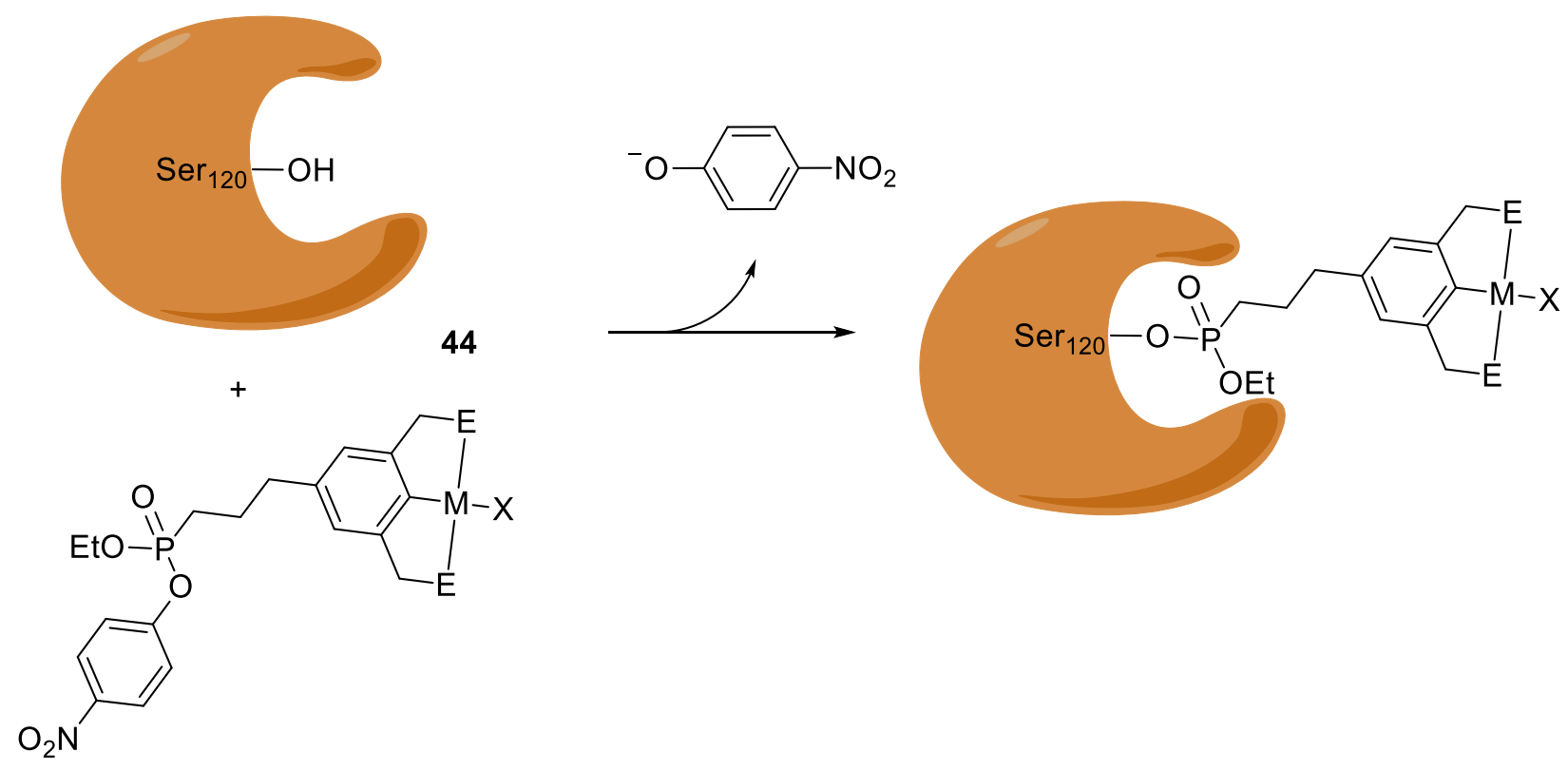

45: $\mathrm{M}=\mathrm{Pt}, \mathrm{X}=\mathrm{Cl}, \mathrm{E}=\mathrm{NMe}_{2}$

46: $M=P d, X=B r, E=S M e$

van Koten and Klein-Gebbink subsequently extended their approach with Pd- and Ptpincer complexes to Rh-based systems for the creation of artificial hydrogenases. ${ }^{181}$ Building on the work of Kühn et al. concerning the hydrogenation of acetophenone in aqueous media with rhodium $\mathrm{N}$-heterocyclic carbenes (NHCs), ${ }^{182}$ Klein-Gebbink covalently linked the lipase inhibitor $\mathbf{4 7}$ within Cutinase $\mathbf{4 4}$ and CalB (33.5 kDa, lipase from Candida antarctica), Scheme $13 .{ }^{183}$

Scheme 13. Covalent anchoring of a $\mathrm{Rh}(\mathrm{NHC})$ in serine-hydrolases for the creation of artificial hydrogenases. 


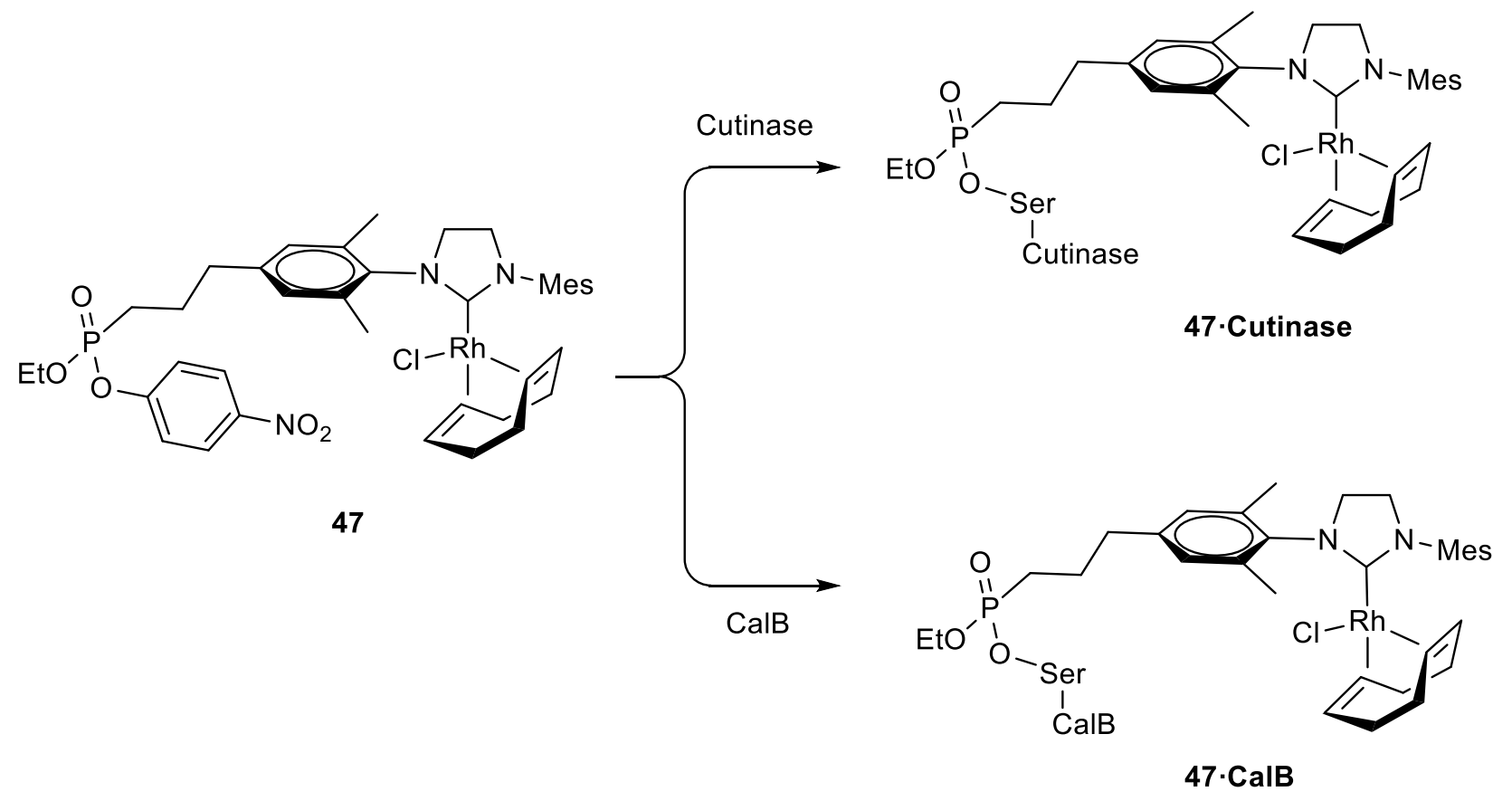

The resulting hybrids 47. Cutinase and 47. CalB (obtained using Cutinase and CalB respectively), were tested in the hydrogenation of acetophenone 48 , and methyl 2acetamidoacrylate 49 (Scheme 14). Acetophenone was reduced in 90\% yield (18 TON) with the free Rh-NHC catalyst (Table 4, entry 1), while the Rh-ArMs showed a reduced catalytic activity, yielding 1-phenylethanol $\mathbf{5 0}$ in $27 \%$ and $0 \%$ yield for Rh-cutinase 47. Cutinase and 47. CalB, respectively (Table 4, entries 2 and 3). For the hydrogenation of the olefinic substrate, both artificial hydrogenases afforded complete conversion to methyl-acetylalaninate $\mathbf{5 1}$, (Table 4, entries 5 and 6 ), highlighting the preferred reduction of olefins over ketones. ${ }^{184}$ Accordingly, 47.CalB was fully chemoselective for the hydrogenation of olefin 49 (Table 4, entries 3 and 6), highlighting the benefit of the deep binding pocket provided by the active site in CalB to discriminate between both substrates. Similar results were observed for 47.Cutinase at shorter reaction times (Table 4, entries 7-10). Unfortunately, no enantioselectivity was observed for any of the systems reported. These examples highlight the potential of second coordination sphere interactions provided by a host protein to discriminate between similarly reactive substrates. 
Table 4. Selected results for the catalytic hydrogenation of acetophenone $\mathbf{4 8}$ and methyl 2-acetamidoacrylate 49 with 47. Cutinase and 47. CalB.

\begin{tabular}{llllllll}
\hline Entry & Protein & Sub. & $\mathrm{T}(\mathrm{h})$ & $\begin{array}{l}\text { Ratio } \\
{[\mathrm{Rh}][\text { Prot] }]}\end{array}$ & $\begin{array}{l}\text { ee } \\
(\%)\end{array}$ & $\begin{array}{l}\text { Conv. } \\
(\%)\end{array}$ & TON \\
\hline 1 & - & $\mathbf{4 8}$ & 20 & - & rac. & 90 & 18 \\
2 & cutinase & $\mathbf{4 8}$ & 20 & 1 & rac. & 27 & 5.4 \\
3 & CalB & $\mathbf{4 8}$ & 20 & 1 & rac. & 0 & 0 \\
4 & - & $\mathbf{4 9}$ & 20 & - & rac. & $>99$ & 20 \\
5 & cutinase & $\mathbf{4 9}$ & 20 & 1 & rac. & $>99$ & 20 \\
6 & CalB & $\mathbf{4 9}$ & 20 & 1 & rac. & $>99$ & 20 \\
7 & - & $\mathbf{4 8 + 4 9}$ & 20 & - & rac. & $71,93^{\mathrm{a}}$ & $14,19^{\mathrm{b}}$ \\
8 & cutinase & $\mathbf{4 8 + 4 9}$ & 20 & 1 & rac. & $15,78^{\mathrm{a}}$ & $3,16^{\mathrm{b}}$ \\
9 & - & $\mathbf{4 8 + 4 9}$ & 0.66 & - & rac. & $15,70^{\mathrm{a}}$ & $3,14^{\mathrm{b}}$ \\
10 & cutinase & $\mathbf{4 8 + 4 9}$ & 0.66 & 1 & rac. & $0,63^{\mathrm{a}}$ & $0,13^{\mathrm{b}}$ \\
\hline
\end{tabular}

${ }^{a}$ Conversion for 1-phenylethanol 50 and methyl acetylalaninate 51, respectively. ${ }^{\mathrm{b}} \mathrm{TON}$ for 1-phenylethanol 50 and methyl acetylalaninate $\mathbf{5 1}$, respectively.

Scheme 14. Hydrogenation reaction catalalyzed by Cutinase and CalB.<smiles>CC(=O)c1ccccc1</smiles>

48<smiles>C=C(NC(C)=O)C(=O)OC</smiles>

49
$\mathrm{H}_{2} 40$ bar, cat $50 \mu \mathrm{M}$, Phosphate buffer $\mathrm{pH}=8.5$

$\mathrm{CH}_{2} \mathrm{Cl}_{2}(5 \mathrm{vol} \%)$, $25^{\circ} \mathrm{C}, 20 \mathrm{~h}$ or $40 \mathrm{~min}$<smiles>CC(O)c1ccccc1</smiles>

50<smiles>COC(=O)C(C)NC(C)=O</smiles>

51

Papain was used by de Vries and coworkers as a scaffold for covalent attachment of a monodentate phosphite ligand (Scheme 15) that was subsequently metallated by $[\mathrm{Rh}(\mathrm{COD})]^{+}$to generate an hydrogenase, but only very modest enantioselectivity was observed for the reduction of methyl-2-acetamidoacrylate. ${ }^{185}$

Scheme 15. Immobilization of a bulky phosphite ligand by thioether formation with the reactive site cysteine of papain and subsequent complexation to $\mathrm{Rh}(\mathrm{I})$.

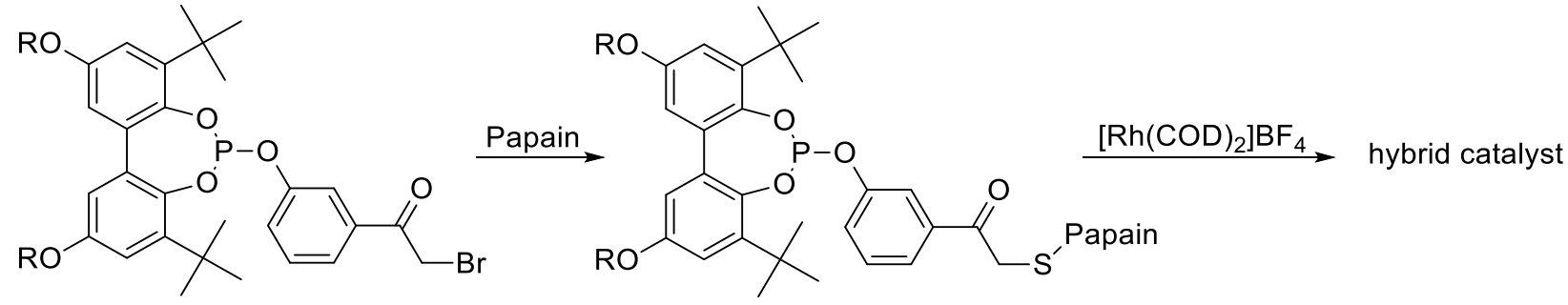

$\mathrm{R}=-\left(\mathrm{CH}_{2} \mathrm{CH}_{2} \mathrm{O}\right) \mathrm{CH}_{3}$ 
Kamer demonstrated that a non-catalytic cysteine residue in apo-photoactive yellow protein (PYP) could be selectively acylated with a carboxylic imidazolide-substituted bisphosphine. This phosphine could also be metallated with $\left[\mathrm{Rh}(\mathrm{cod})(\mathrm{MeCN})_{2}\right] \mathrm{BF}_{4} \mathbf{5 2}$ and subsequently reacted with PYP to generate an artificial hydrogenase, which catalyzed the reduction of dimethyl itaconate (53) with full conversion but low ee (Scheme 16). ${ }^{186}$

Scheme 16. Hydrogenation of itaconic acid methyl ester catalyzed by $\mathbf{5 2 .}$
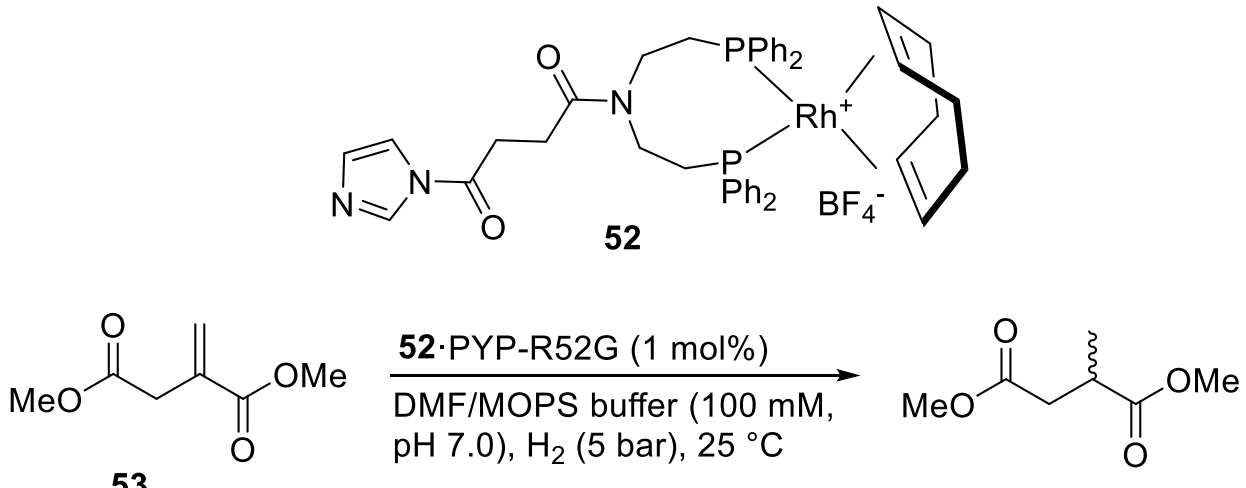

$>99 \%$ conversion, $6 \%$ ee

Harada and coworkers elicited a monoclonal antibody 1 G8 against an achiral rhodium complex 54, Scheme $17 .{ }^{187}$ In the hydrogenation of the 2-acetamidoacrylic acid $\mathbf{8}$, the antibody $1 \mathrm{G} 8$ in combination with the hapten $\mathbf{5 4}$ afforded the reduction product with > $98 \%$ ee $(S)$ and a TON of 854 . In contrast, racemic product was obtained with either $\mathbf{5 4}$ or $54 \cdot \mathrm{BSA}$ (BSA = bovine serum albumin) accompanied by lower TONs, Table 5.

Table 5. Selected results for the hydrogenation of $\mathbf{8}$ catalyzed by an antibody loaded with hapten 54.

\begin{tabular}{llll}
\hline Entry & Protein $^{\mathrm{a}}$ & $\begin{array}{l}e e \\
(\%)\end{array}$ & TON \\
\hline 1 & No protein & 0 & 409 \\
2 & Antibody 1G8 & $>98(S)$ & 854 \\
3 & BSA & 0 & 446 \\
\hline
\end{tabular}

Scheme 17. Combination of hapten $\mathbf{5 4}$ with the antibody results in a highly selective and active hydrogenation catalyst. 
<smiles>C=C(NC(=O)OC)C(=O)O</smiles>

$15.6 \mathrm{mM}$
$54(4.2 \mu \mathrm{M})$

Antibody $1 \mathrm{G} 8$

$\mathrm{H}_{2}$

Phosphate buffer (100 mM)

$\mathrm{pH} 7,37^{\circ} \mathrm{C}, 12 \mathrm{~h}$

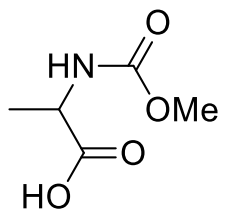

$\mathrm{HO}$

8<smiles>O=C(O)CCC(=O)N1CCCP(c2ccccc2)(c2ccccc2)(P(C2=CC3CCC2C3)(c2ccccc2)(c2ccccc2)P(c2ccccc2)c2ccccc2)C1</smiles>

54

A number of researchers have explored the formation of ArMs by substituting the catalytic $\mathrm{Zn}$ ion located in a Hisз binding site of carbonic anhydrase with different metals. For example, Kazlauskas created a cis-stilbene hydrogenase by metallation of apohCAll with $\left[\mathrm{Rh}(\mathrm{cod})_{2}\right] \mathrm{BF}_{4}{ }^{188}$ In addition to $\mathrm{Rh}$ incorporation in the CA active site, $\mathrm{Rh}$ also bound to the surface of the scaffold (Rh : hCAII $=6.5$ by ICP-MS), leading to cis/trans isomerization (hydrogenation : isomerization $=6.3$ ), Scheme 18. Site-directed mutagenesis was used to remove 9 histidine residues on the surface of hCAll that were believed to be involved in non-specific Rh-binding. The resulting ArM, 9*His-hCAll-[Rh], was found to have a reduced $\mathrm{Rh}$ : hCAll ratio of 1.8 , yielded an increased hydrogenation : isomerization ratio of 20.6, and displayed improved specificity for cisstilbene, Table 6.

Table 6. Hydrogenation and cis/trans isomerization of cis-stilbene catalyzed by 9*hCAll[Rh].

\begin{tabular}{llll}
\hline Entry & Catalyst & Rh / hCAll Ratio. & $\mathbf{5 5 ~ / 5 6 ~}$ \\
\hline 1 & {$\left[\right.$ Rh $\left.(\mathrm{cod})_{2}\right] \mathrm{BF}_{4}$} & - & 6.3 \\
2 & hCAll-[Rh] & 6.5 & 3.5 \\
3 & 9*His-hCAll-[Rh] & 1.8 & 20.6 \\
\hline
\end{tabular}

Scheme 18. Hydrogenation of stilbene catalyzed by Rh-substituted hCAll.

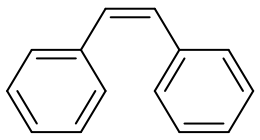

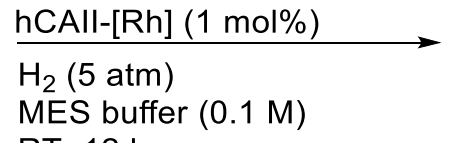

$\mathrm{RT}, 12 \mathrm{~h}$

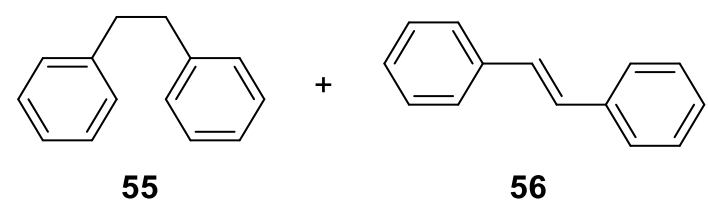

55 
Eppinger designed cofactors comprised of not only a catalytically active metal complex and a reactive group (epoxide) to covalently link the cofactor to protein scaffolds, but also a non-covalent amino acid recognition motif to steer the cofactor's orientation within the scaffold. ${ }^{189}$ Half-sandwich ruthenium and rhodium cofactors were constructed and linked to cysteine proteases from the papain family to generate ArM hydrogenases. Ketone hydrogenation could be achieved with up to $64 \%$ ee for $p$-chloroacetophenone as substrate (Table 7 and Scheme 19).

Table 7. Hydrogenation of aromatic ketones catalyzed by protein affinity labels.

\begin{tabular}{lllllll}
\hline Entry & Catalyst & Substrate & $\mathrm{H}_{2}($ bar $)$ & $t(\mathrm{~h})$ & Yield (\%) & ee $(\%)$ \\
\hline 1 & $\mathbf{5 7}$ & $\mathbf{6 0}$ & 25 & 65 & 4 & $4(R)$ \\
2 & 57. Papain & $\mathbf{6 0}$ & 75 & 96 & 89 & $24(R)$ \\
3 & 58.Papain & $\mathbf{6 0}$ & 35 & 65 & 41 & $20(R)$ \\
4 & 59.Papain & 60 & 96 & 75 & 44 & $20(R)$ \\
5 & 57. Papain & $\mathbf{6 1}$ & 75 & 96 & 12 & $64(R)$ \\
\hline
\end{tabular}

Scheme 19. Hydrogenation of ketones catalyzed by Rh/Ru-substituted Papain.

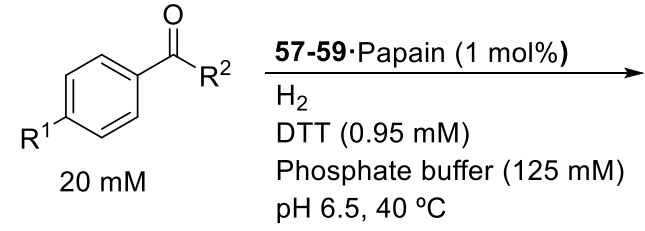

60: $\mathrm{R}^{1}=\mathrm{H}, \mathrm{R}^{2}=\mathrm{CF}_{3}$ 61: $\mathrm{R}^{1}=\mathrm{Cl}, \mathrm{R}^{2}=\mathrm{CH}_{3}$

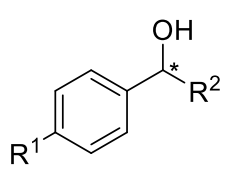
58: $\mathrm{R}^{3}={ }^{i} \mathrm{Pr}, \mathrm{Ar}=\mathrm{C}_{5}\left(\mathrm{CH}_{3}\right)_{4}, \mathrm{M}=\mathrm{Rh}$ 59: $\mathrm{R}^{3}=\mathrm{Ph}, \mathrm{Ar}=\mathrm{C}_{6} \mathrm{H}_{5}, \mathrm{M}=\mathrm{Ru}$

Knölker-type $\left[\eta^{4}\right.$-(cyclopentadienone) $\left.\mathrm{Fe}(\mathrm{CO})_{3}\right]$ complexes catalyze the hydrogenation of polarized C-X double bonds $(\mathrm{X}=\mathrm{O}, \mathrm{N}) \cdot{ }^{190}$ Renaud, Ward and coworkers investigated the potential of biotinylated Knölker-type complexes (Figure 7) to catalyze the enantioselective hydrogenation of aromatic ketones and imines inside Sav. ${ }^{191}$ A library of seven catalysts was synthesized with a biotin anchor tethered to the cyclopentadienone moiety via various linkers. Hydrogenation of $\alpha, \alpha, \alpha$-trifluoroacetophenone afforded the corresponding secondary alcohol with 20 TON but only $9 \%$ ee. The best enantioselectivity (34\% ee $(R)$-product) was obtained in the conversion of p-methoxy-acetophenone albeit with only a single turnover. 


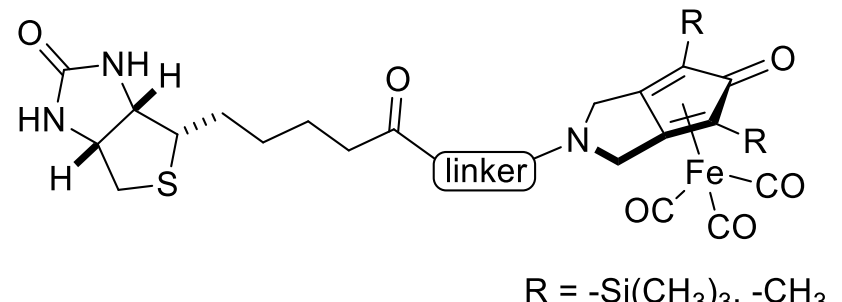

Figure 7. Biotinylated Knölker-type complexes.

\subsection{Hydrogen Generation: Towards Artificial Hydrogenases}

Today, scientists face the challenge of finding a sustainable source of energy to support tomorrow's societal needs. In this context, the valorization of solar energy is regarded by many as the "Holy Grail". However, efficient ways to convert solar energy into electricity or to a fuel, for storage and transportation, remains challenging. The development of artificial photosynthesis would allow conversion of sunlight into a fuel. Hydrogen $\left(\mathrm{H}_{2}\right)$ is one of the most explored potential fuel candidates. ${ }^{60}$ Interestingly, its production from light and water has been observed in a living organism, and biocatalytic hydrogen production is catalyzed by hydrogenases. These are classified according to the nature of their active site, namely [FeFe]-, [NiFe]-, and [Fe]-hydrogenases. They catalyze the generation of $\mathrm{H}_{2}$ from protons and electrons provided by the electron transport chain of photosynthesis under near thermodynamic equilibrium conditions (i.e. no overpotential required) with high catalytic rates (TOF up to $20^{\prime} 000 \mathrm{~s}^{-1}$ ). ${ }^{68}$ Interestingly, hydrogenases operate both in the forward and reverse reaction and approach the efficiency of platinum. The technological applications of natural hydrogenases are impaired by i) their biosynthesis, which requires a complex maturation machinery, ii) their air sensitivity, and iii) their high molecular weight, which limits the number of active sites that can be immobilized on an electrode..$^{58}$ 
The former limitation has been recently addressed by Fontecave and coworkers with the [FeFe]-hydrogenase HydA. The formation of its di-iron catalytic site (H-cluster) requires a complete maturation machinery, involving at least HydE, HydG and HydF. HydE and HydG provide the exogeneous ligands ( $\mathrm{CO}, \mathrm{CN}^{-}$, aza-propanedithiol), and $\mathrm{HydF}$ is the host protein in which the di-iron complex is ultimately assembled. In the last step, the nearly-mature di-iron complex is transferred to apo-HydA. Fontecave and coworkers demonstrated that a hydrogenase could be maturated in vitro, without the need of the entire maturation machinery. By loading an inactive artificial di-iron cofactor into apoHydF, they could transfer the synthetic complex into the apo form of the hydrogenase HydA, reconstituting a fully active HydA (Scheme 20, path a). ${ }^{192}$ This work unambiguously settled the controversy concerning the nature of the central atom of the bridging dithiolate ligand: catalytic activity was detected only in the presence of a nitrogen atom at this position ( $\mathrm{X}$ in Scheme 20). Building on these results, Happe and Fontecave demonstrated that the use of HydF could even be avoided, that is, a direct loading of a synthetic complex into apo-HydA is possible (Scheme 20, path b). ${ }^{193}$ Building upon this strategy, $\mathrm{Hu}$ and coworkers reported the direct reconstitution of an [Fe]-hydrogenase by loading its apo-form with a synthetic complex (Scheme 20, path c). ${ }^{194}$

Scheme 20. Reconstitution of apo-hydrogenases with synthetic cofactors affords functional hydrogenases. 
a)
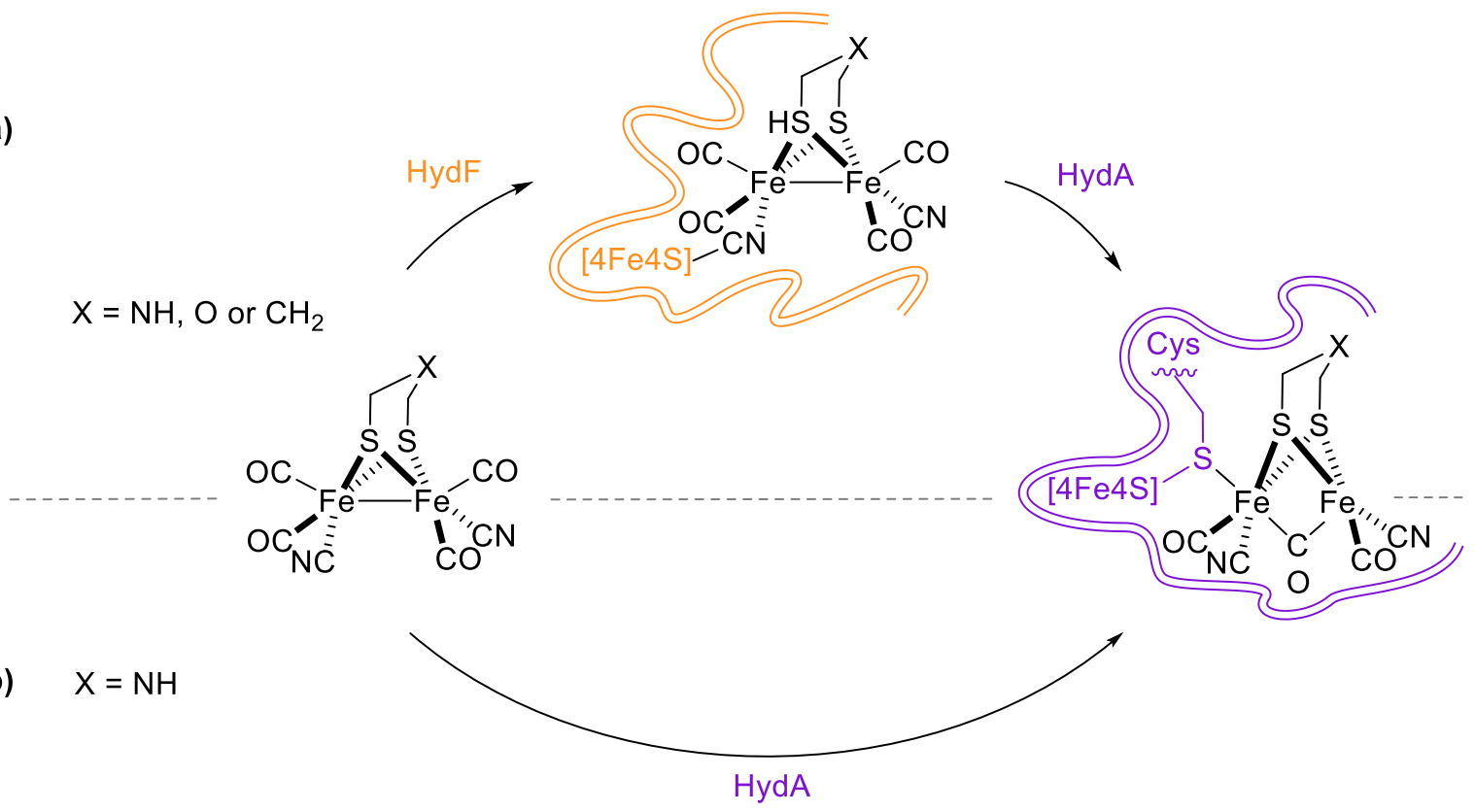

c)
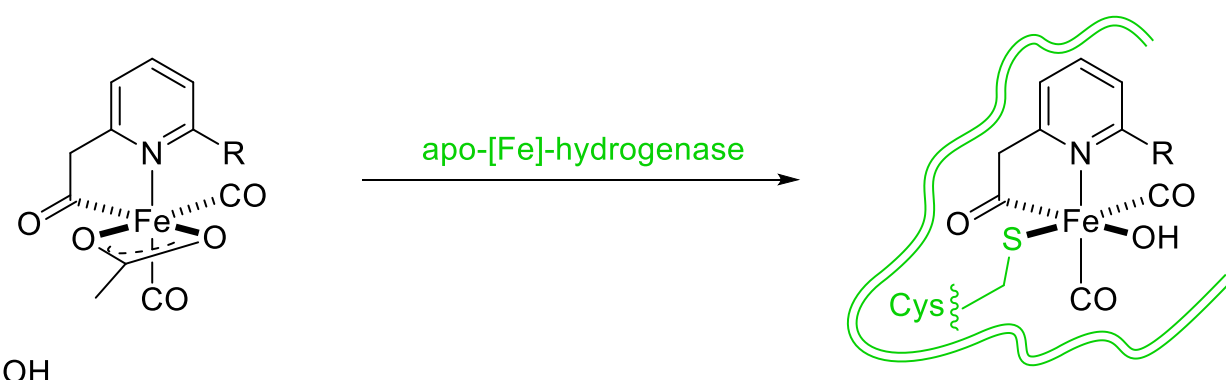

$\mathrm{R}=\mathrm{OMe}$ or $\mathrm{OH}$

Besides shedding light on a long controversy concerning the key features of the cofactor, this methodology demonstrated that it is indeed possible to generate an active hydrogenase without the need of its complex maturation machinery. These results are of particular interest as: i) they allow the expression of the hydrogenase in a heterologous organism and ii) they open the possibility of introducing a fully synthetic cofactor within an apo-hydrogenase. The former feature should allow large screening campaigns of hydrogenases (e.g. homologous, directed evolution), to identify variants with higher activity and/or oxygen-resistance. The later was recently explored by $\mathrm{Hu}$ and Lubitz. They demonstrated that subtle variations of the cofactor lead, in most cases, to inactive hydrogenases, thus allowing to establish structure-activity relationships for the cofactor. ${ }^{195}$ 
The strategy described relies on a highly evolved scaffold, optimized for hydrogen production from its constituents (i.e. presence of proton- and electron-channels leading to and from the active site). The drawbacks of this strategy lie in the complexity and the size of the scaffold. For technological applications, one would favor a scaffold reduced to its minimum size and with a structure that is stable over a wide range of conditions. With large scale applications in mind, some groups explored the possibility of assembling synthetic complexes within various protein scaffolds to produce hydrogen. Only a limited number of catalysts and protein scaffolds have been used so far. Alternatively, the metal-substitution strategy to repurpose natural metalloenzymes for hydrogenase activity has also been used. In this section, we summarize the reported studies fitting into either category, with a particular emphasis on the catalytic activity of the resulting artificial hydrogenases. Several recent papers have also reviewed other aspects of artificial hydrogenases. ${ }^{57,59,61,66,68,196}$

Hayashi et al. inserted synthetic complexes that mimic the active site of [FeFe]hydrogenases into various host proteins. They datively anchored a di-iron complex into the active site of apo-cytochrome c. ${ }^{197}$ This protein naturally contains a $\mathrm{Fe}$ protoporphyrin(IX) cofactor that is covalently attached to the protein via thioether linkage at a Cys- $\mathrm{X}_{2}$-Cys motif. After removal of the heme, the Cys- $\mathrm{X}_{2}$-Cys motif of the apocytochrome $c$ could bind catalytically-inactive $\left[\mathrm{Fe}_{2}(\mathrm{CO})_{9}\right] 62$ (Scheme 21) to afford an active artificial hydrogenase containing a $\left[(\mu-\mathrm{S})_{2} \mathrm{Fe}_{2}(\mathrm{CO})_{6}\right]$-moiety. When irradiated in the presence of the photosensitizer (PS hereafter) $[R u(b p y) 3]^{2+}$ and ascorbate as sacrificial electron donor, in Tris $\cdot \mathrm{HCl}$ at $\mathrm{pH} 4.7$, the ArM produced hydrogen (82 TON in 2h), with a maximum observed TOF of $0.035 \mathrm{~s}^{-1}$ (Table 8 , entry 1). Notably, the electron transport from the PS to the active site is proposed to be the limiting factor in the reaction. Although the structure of this artificial hydrogenase is poorly defined, the protein environment provides robustness to the catalytic activity. When compared to 62 bound 
to a synthetic heptapeptide containing the Cys- $\mathrm{X}_{2}-$ Cys motif and a His residue to mimic the active site of cytochrome $c$, the entire protein scaffold performed better (i.e. $\sim 4$ fold higher TOF and $\sim 8$ fold higher TON), demonstrating a protective role of the protein environment.

Next, Hayashi et al. selected a more rigid scaffold to engineer an artificial hydrogenase. The di-iron cofactor $\left[(\mu-\mathrm{S})_{2} \mathrm{Fe}_{2}(\mathrm{CO})_{6}\right]$-moiety was anchored via a maleimide linker to the cysteine of apo-nitrobindin Q96C (Figure 8). ${ }^{198}$ As suggested by the docked structure, the synthetic complex 63 , (Scheme 21 ) is embedded in the cavity formed by the $\beta$-barrel of nitrobindin, surrounded by a well-defined protein environment. Upon irradiation, the 63. nitrobin generated hydrogen with a maximum TOF of $0.038 \mathrm{~s}^{-1}$ and up to 130 TON after $6 \mathrm{~h}$ of irradiation (120 after $2 \mathrm{~h}$ ) (Table 8, entry 2). Under similar conditions, the free cofactor 63 performed c.a. 3 fold faster. This phenomenon is most likely due to a decreased accessibility of the complex inside the protein, decreasing the rate of electron transfer from the PS. Despite this decrease in rate, it is clear that the protein provides a stabilizing environment to 63 since its deactivation is slower than in solution. Compared to $62 \cdot$ cytochrome $c$, the activity of $63 \cdot$ nitrobin was less sensitive to the $\mathrm{pH}$ : raising the $\mathrm{pH}$ to 7.8 decreased the activity of the former by $93 \%$ versus $72 \%$ for the latter (Table 8 , entry 3). In addition, due to the well-defined environment around the active site, improving catalytic activity by rationally mutating residues around at the $\beta$-barrel cavity can be envisioned. 


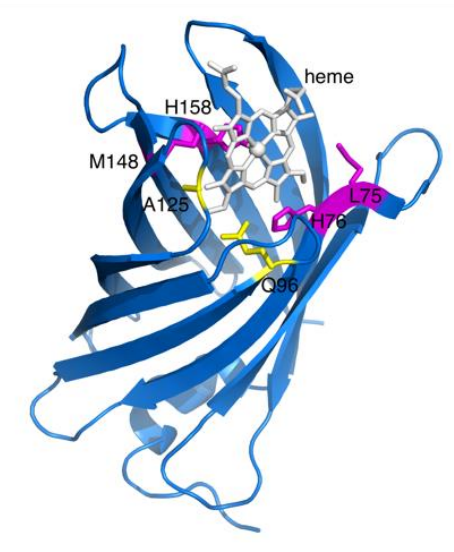

Figure 8. Nitrobindin (PDB code 3EMM) was employed to create ArMs for hydrogenation, ${ }^{198}$ ring-closing metathesis, ${ }^{199}$ phenylacetylene polymerization ${ }^{200}$ and benzylic oxidation. ${ }^{201}$ To afford ArMs, nitrobindin was produced in absence of the heme cofactor. Residues highlighted in yellow were mutated to cysteine residues to covalently attach a catalyst. Improved substrate accommodation was achieved by replacing bulky residues flanking the active site cavity (magenta) with smaller hydrophobic residues.

Scheme 21. Dative and covalent anchoring of $\left[\mathrm{Fe}_{2}(\mathrm{CO})_{6}\right]$ afford [FeFe]-hydrogenase mimics, upon irradiation in the presence of $\left[\mathrm{Ru}(\mathrm{bpy})_{3}\right]^{2+}$ as photosensitizer.

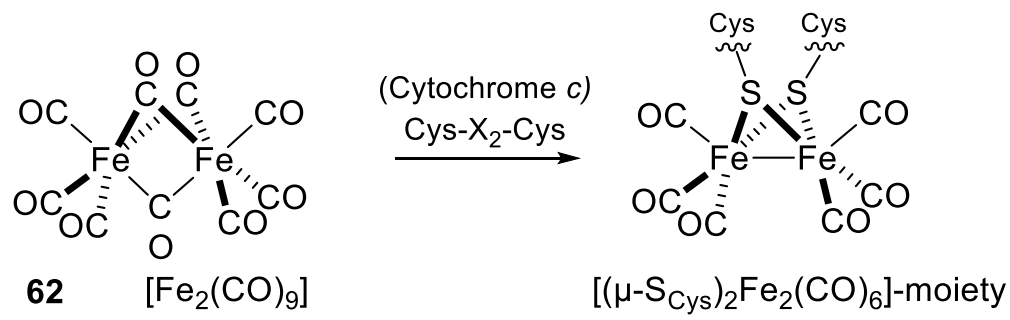

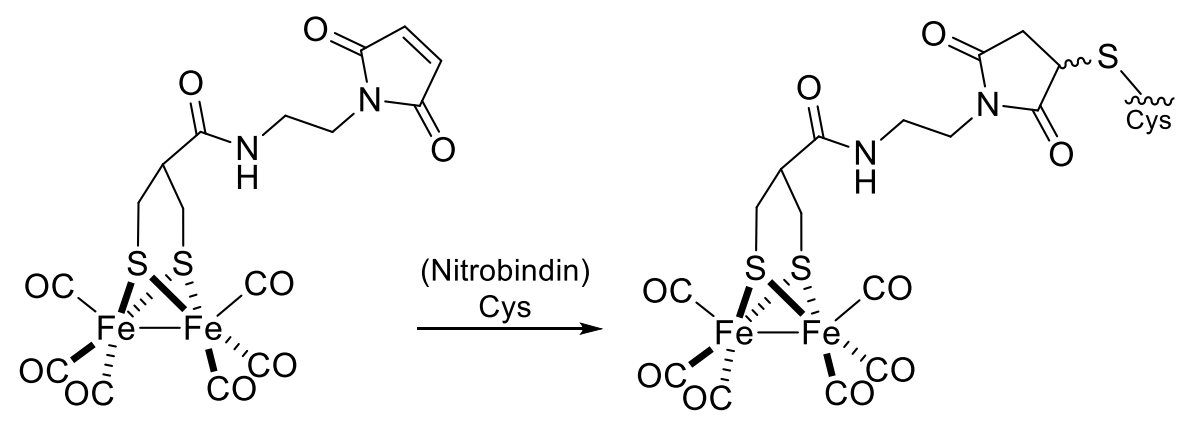

$63\left[(\mu-\mathrm{S})_{2} \mathrm{Fe}_{2}(\mathrm{CO})_{6}\right]$

Another example of an artificial hydrogenase containing a biomimetic-center was recently reported by the group of Shafaat. This work is reminiscent of the pioneering work from the groups of Moura and LeGall. ${ }^{202-203}$ In this example, the aim was not to mimic the active site of the [FeFe]-hydrogenases, but those of [FeNi]-hydrogenases. For these systems, the nickel, coordinated by four cysteinate residues, is the redox-active 
metal operating during the proton reduction. The first coordination sphere is reminiscent of rubredoxin. An iron to nickel substitution in the active site of rubredoxin yields an enzyme, termed NiRd, able to produce dihydrogen, Scheme 22, a). When irradiated in presence of $\left[\mathrm{Ru}(\mathrm{bpy})_{3}\right]^{2+}$ and ascorbate, in phosphate buffer at $\mathrm{pH} 6.5$, NiRd generated hydrogen at a rate of $0.0083 \mathrm{~s}^{-1}$ and afforded approximately 70 TON over $8 \mathrm{~h}$ (Table 8 , entry 4). Using $\mathrm{Ti}(\mathrm{III})$-citrate as a light-independent electron source, NiRd yielded up to 300 TON in $8 \mathrm{~h}$, at $22{ }^{\circ} \mathrm{C}$ at $\mathrm{pH} 9.4$ (Table 8 , entry 5), suggesting that, with a strong reductant, NiRd can generate hydrogen at $\mathrm{pH}>7$. Importantly, most of the catalyst can be recycled, indicating that the inactivation is not due to protein degradation. However, this system requires a high overpotential $(540 \mathrm{mV}$ at $\mathrm{pH} 3-5)$. It is proposed that mutagenesis of residues close to the Ni-center may help to improve the catalytic properties of this artificial hydrogenase.

Scheme 22. Metal substitution in natural metalloenzymes yield artificial hydrogenases. The iron of rubredoxin can be replaced with nickel a). The iron in a heme protein can be substituted by cobalt either by demetallation followed by incubation with excess of $\left.\left[\mathrm{Co}(\mathrm{Ac})_{2}\right] \mathrm{b}\right)$, or by removing the heme from the enzyme and inserting a [CoPP $\left.(\mathrm{IX})\right]$ complex c). 
a)

(Rubredoxin) Demetallation,

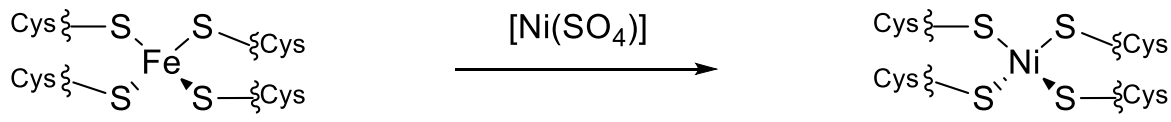

$$
\begin{aligned}
& {\left[\mathrm{Fe}(\mathrm{Cys})_{4}\right] \quad\left[\mathrm{Ni}(\mathrm{Cys})_{4}\right]}
\end{aligned}
$$

b) (Cytochrome $\left.c_{552}\right)$

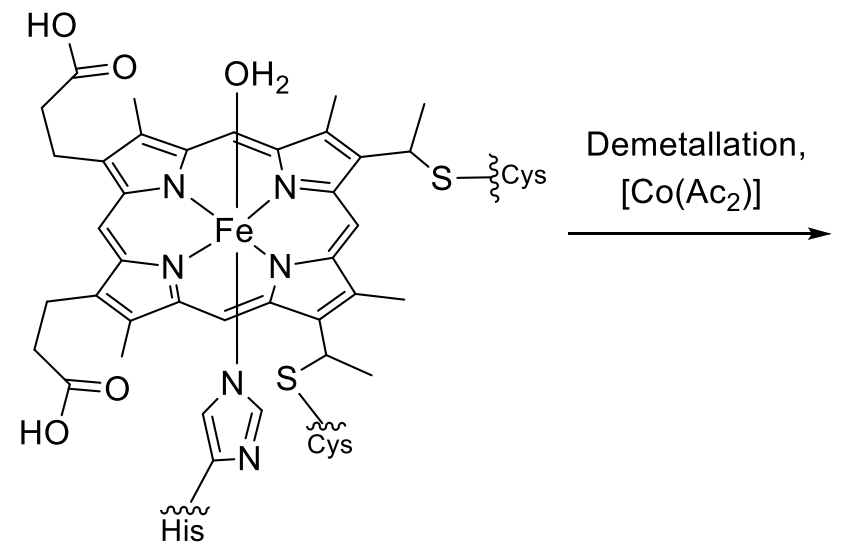

$\left[\mathrm{Fe}(\mathrm{PP}(\mathrm{IX}))\left(\mathrm{H}_{2} \mathrm{O}\right) \mathrm{His}\right]$

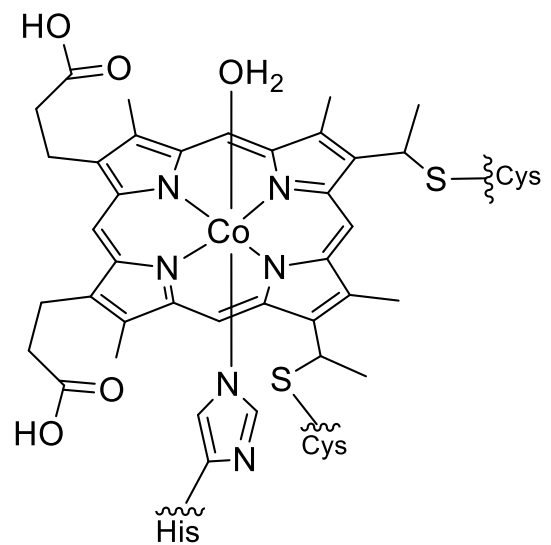

$\left[\mathrm{Co}(\mathrm{PP}(\mathrm{IX}))\left(\mathrm{H}_{2} \mathrm{O}\right) \mathrm{His}\right]$

c)
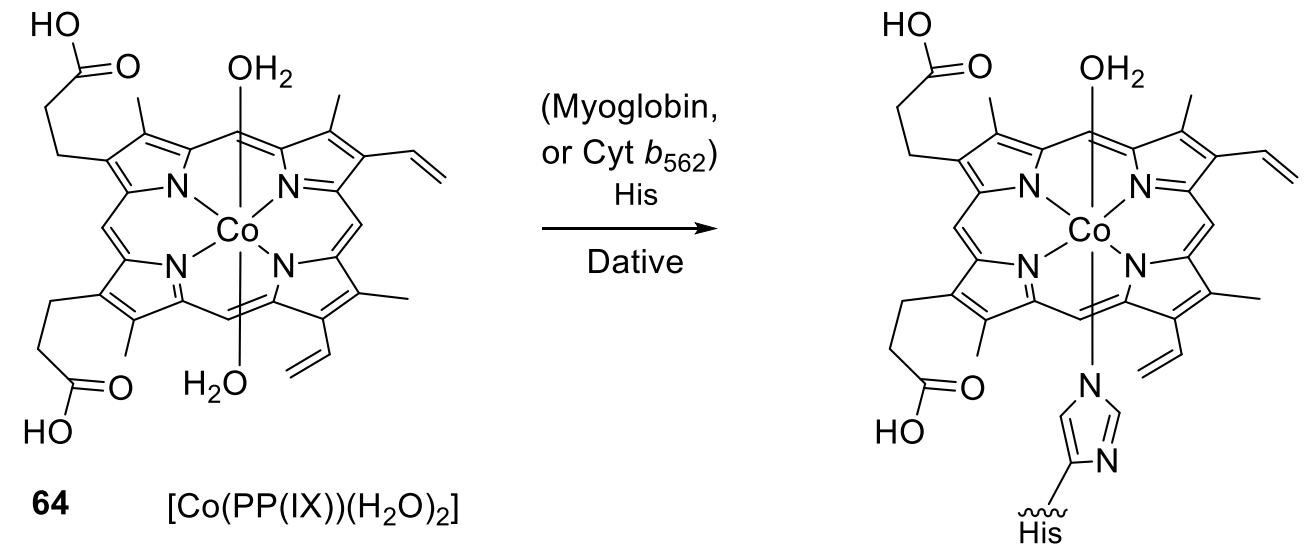

Following in Hayashi's footsteps, other groups have designed artificial hydrogenases based on heme-proteins. This family of proteins has been used extensively for their ability to bind heme moiety substituted by other metals as well as other planar complexes containing non-porphyrin ligands. ${ }^{204}$ In addition, the potential of Coporphyrins and cobaloximes for hydrogen production in aqueous solutions has been known since the 80 's. ${ }^{205-206}$ The latter usually require a smaller overpotential than the former, and both exhibit promising oxygen-tolerance properties. 
Bren and coworker demonstrated that substituting iron by cobalt in enzymes containing iron-protoporphyrin(IX) affords efficient artificial hydrogenases. The iron of the hemeprotein cytochrome $C_{552}$ from Hydrogenobacter thermophilus (Ht c-552) was substituted with cobalt, taking advantage of the thioethers linking the protoporphryrin(IX) ligand and the cysteines of the protein that anchor the porphyrin even under forcing conditions (Scheme 22 b). ${ }^{61}$ In this scaffold, the histidine residue acting as axial ligand was conserved. However, the distal methionine was mutated to alanine (M61A) to keep a free coordination site for the proton reduction. Though no data was presented for photocatalysis, the electrocatalysis experiments showed remarkable stability for proton reduction: 11,000 TON after $6 \mathrm{~h}$ and up to 27,000 TON in $24 \mathrm{~h}$ at pH 7.0 (Table 8, entry 6). The major drawback of this system lies in the high overpotential that is required (i.e. $830 \mathrm{mV})$. On the other hand, comparing the performance of Co.Ht c-552 and CoMP11Ac, an eleven aminoacid proteolytic fragment of the horse cytochrome c containing a cobalt-substituted heme, highlights the beneficial effect of a full protein environment (for a related structure, see Fe-microperoxidase-8 217). ${ }^{207}$ CoMP11-Ac exhibits interesting proton reduction activity coupled with a remarkable oxygen tolerance. Although cobalt possesses an identical first coordination sphere, it is exposed to the solvent in CoMP11Ac but buried in the protein in Co.Ht $c-552$. The surrounding protein environment results in a longer catalyst lifetime ( $\sim 24 \mathrm{~h}$ against $\sim 4 \mathrm{~h})$, allowing to reach a $\sim 10$ fold higher TONs for the former. The presence of a defined protein environment however did not lead to a decrease of the overpotential required ( $830 \mathrm{vs} 850 \mathrm{mV})$.

Ghirlanda and coworkers used a cobalt-substituted myoglobin termed 64.Mb (i.e. dative anchoring via a His and no cysteine thioether linkages, Scheme 22 c). ${ }^{208}$ Upon irradiation at $\mathrm{pH} 7.0$ in the presence of ascorbate and a photosensitizer, $64 \cdot \mathrm{Mb}$ catalyzes the production of hydrogen in up to $518 \mathrm{TON}$ in $12 \mathrm{~h}$ (Table 8 , entry 7 ). This corresponds to a 4.3 fold increase of TON compared to the free cofactor 64 , highlighting 
the effect of the host protein. With this system, the maximum TON was observed at $\mathrm{pH}$ 7.0. Upon lowering the $\mathrm{pH}$, the cofactor is released from $64 \cdot \mathrm{Mb}$, and raising the $\mathrm{pH}$ decreases the proton concentration. In addition to the axial H93 ligation to the Co, second coordination sphere residues $\mathrm{H} 64$ and $\mathrm{H} 97$ form hydrogen bonds with the carboxylates of the cofactor 64 . Mutating these residues positively affects the catalytic activity. The corresponding TONs are $234(64 \cdot \mathrm{Mb}), 331(64 \cdot \mathrm{Mb} \mathrm{H} 64 \mathrm{~A})$ and $512(64 \cdot \mathrm{Mb}$ H64A-H97A) at $\mathrm{pH}$ 6.5. This increase may arise from a flexibilization of the protein structure in the proximity of the catalyst, facilitating interactions of the protein-bound cofactor with the photosensitizer (i.e. facilitating the electron transfer). (Figure 15 for $\mathrm{Mb}$ active site).

More recently, Ghirlanda and coworkers applied a similar strategy to anchor 64 within cytochrome $b_{562 .}{ }^{209}$ In this system, the metal of the heme is anchored via $\mathrm{H} 102$ and M7 (Figure 9). Mutation of the methionine-7 to an alanine (M7A) results in a 2.5 fold increase in photocatalytic activity (305 vs $125 \mathrm{TON}$ ), as it liberates one coordination site for catalysis. Continuous removal of hydrogen increased $64 \cdot b_{562}$ M7A TON to 1450 (Table 8 , entry 8). Even in the presence of air, $\mathbf{6 4} \cdot b_{562}$ M7A afforded up to 400 TON. Upon catalyst stalling, addition of fresh photosensitizer $\left(\left[\mathrm{Ru}(\mathrm{bpy})_{3}\right]^{2+}\right)$ partially restored catalytic activity, while addition of fresh $64 \cdot b_{562}$ M7A did not.

Next, 64. $b_{562}$ M7D and 64. $b_{562}$ M7E mutations were investigated. The authors speculated that the presence of a carboxylic acid in the vicinity of the catalytic center could enhance hydrogen production, similar to protonated amines. ${ }^{210-211}$ Although better than the WT, the activity of these carboxylate-bearing mutants did not surpass that of the M7A mutant, suggesting that these residues do not behave as proton relays. 


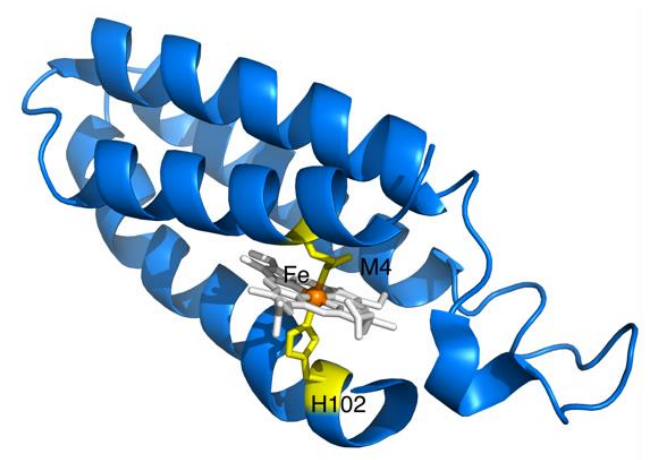

Figure 9 Mutation of the coordinating methionine of a cobalt-substituted Cytochrome $b_{562}$ (PDB code 1QPU) affords an artificial hydrogenase. ${ }^{209}$

Artero and coworkers explored a similar strategy using cobalt complexes. Cobaloximes 65 and 66 (Scheme 23) were inserted into the apo-form of the sperm whale myoglobin. ${ }^{204}$ The cobaloximes were shown to occupy the heme-site, where cobalt was coordinated by $\mathrm{H} 93$ and a water molecule. Modeling with 66 suggested that the coordinated water molecule could form a hydrogen bond with the distal histidine (H64). EPR parameters obtained for $\mathbf{6 5} \cdot \mathrm{Mb}$ suggest that the cobalt is exposed to a hydrophobic environment. This environment may account for the difference in redox potential (of the $\mathrm{Co}(\mathrm{I}) / \mathrm{Co}(\mathrm{II})$ couple) between $65 \cdot \mathrm{Mb}$ and 65 .imidazole. This observation suggests that the second coordination sphere from the protein indeed influences the redox-properties of a protein-bound synthetic complex. Both $65 \cdot \mathrm{Mb}$ and $66 \cdot \mathrm{Mb}$ catalyzed dihydrogen production under neutral aqueous solution with a low overpotential ( 200 mV). 66. Mb performed better than $65 \cdot \mathrm{Mb}$, and at $\mathrm{pH} 7.0,66 \cdot \mathrm{Mb}$ converted up to $65 \%$ of the electron donor $[\mathrm{Eu}(\mathrm{EGTA})]^{2+}$ to $\mathrm{H}_{2}$, corresponding to $3.2 \mathrm{TON}$, within 5 min. For comparison free cofactor 66 was deactivated after 2.5 TON, indicating that Mb provided modest catalyst protection.

Photochemical hydrogen production by cobaloxime-Mb ArMs was also performed using deazaflavin (DAF hereafter) and tris buffer as electron donor. At $\mathrm{pH} 7.0,66 \cdot \mathrm{Mb}$ performed up to 5 TON in 15 min (Table 8 , entry 9). In this case however, the free cofactor 66 outperformed the artificial hydrogenase, TON 8.3. Other heme-binding 
proteins were also investigated as scaffolds to generate ArM hydrogenases using either 65 or 66. These included: rat heme oxygenase 1 (HO1 hereafter) and Corynebacterium diphteriae heme oxygenase (HmuO hereafter). ${ }^{212}$ The resulting artificial hydrogenases 66. $\mathrm{HO} 1$ and $66 \cdot \mathrm{HmuO}$ were more active than $66 \cdot \mathrm{Mb}$ both under thermal- and photochemical conditions. 66. $\mathrm{HO} 1$ converted up to $82 \%$ of the electron donor $[\mathrm{Eu}(\mathrm{EGTA})]^{2+}$ into $\mathrm{H}_{2}$ within 5 min, corresponding to $6.2 \mathrm{TON}$ (Table 8, entry 10). Both TON and TOF were higher than that of 66 free in solution. However, these did not outperform the free catalyst 66 under photocatalytic conditions: at $10 \mu \mathrm{M}$ concentration, 66 afforded 20 TON in 15 min, versus 6.3 and 15.3 for $66 \cdot \mathrm{HO} 1$ and $66 \cdot \mathrm{HmuO}$ respectively (Table 8 , entries 11 and 12). Despite the low overpotential required and the shielding effect provided by the protein, these artificial hydrogenases suffered from a poor affinity for the host.

Scheme 23. Cobaloximes and nickel phosphines are synthetic complexes with high hydrogen production catalytic activity. Cobaloximes can be anchored via a histidine or a methionine residue of the apo-heme protein. 

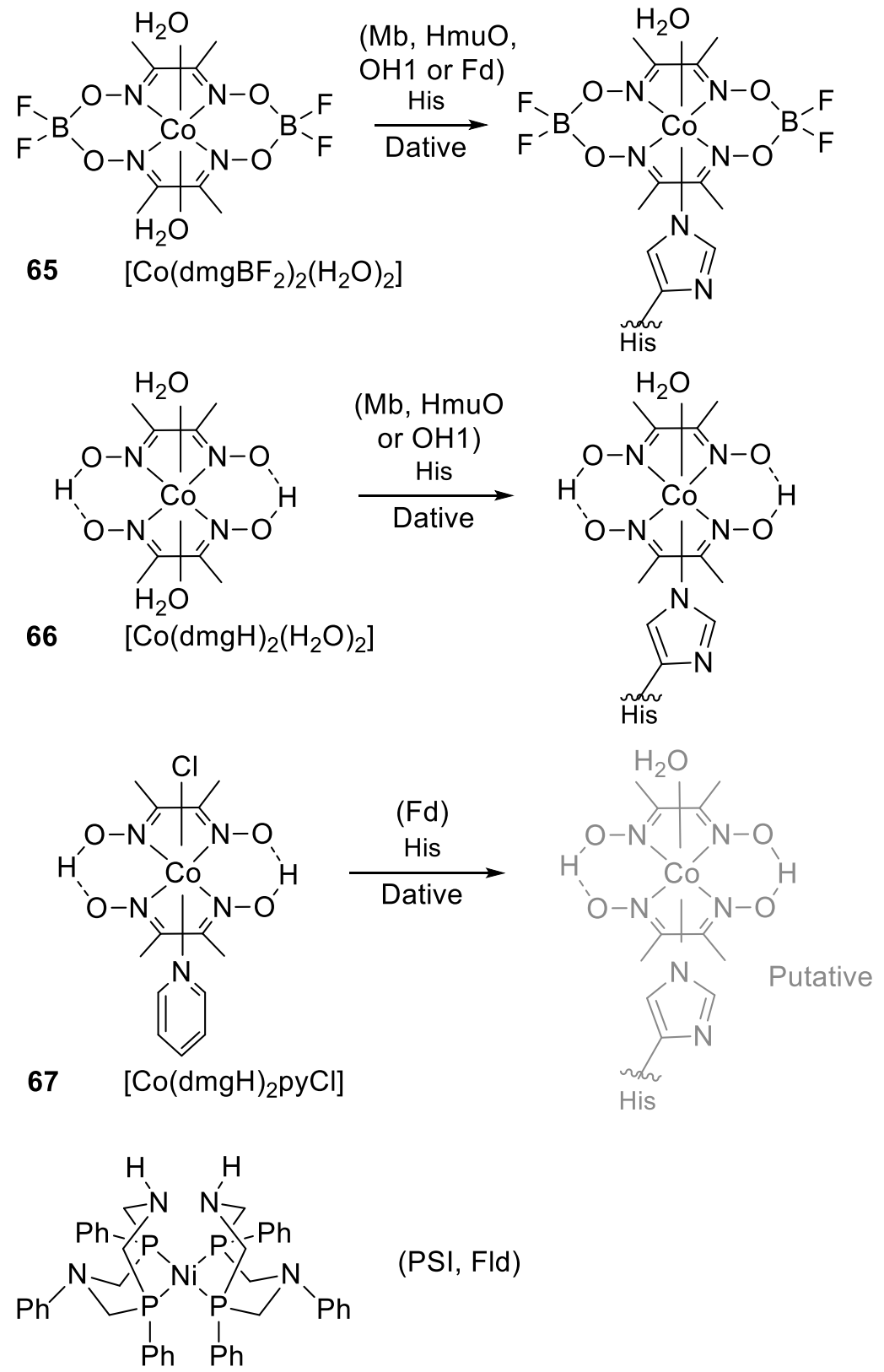

$68 \quad\left[\mathrm{Ni}\left(\mathrm{P}_{2}{ }^{\mathrm{Ph}} \mathrm{N}_{2}{ }^{\mathrm{Ph}}\right)_{2}\right]^{2+}$

The artificial hydrogenases of Artero and coworkers proved to be better catalysts than the free cobaloximes at $\mathrm{pH} 7.0$ in the case of thermal catalysis (using $[\mathrm{Eu}(\mathrm{EGTA})]^{2+}$ as electron donor), while in photocatalysis, the free catalysts performed better. This could arise from the shielding effect of the protein, obstructing interaction between the PS and the anchored catalyst. In addition, the deactivation of the catalyst occurred rapidly. The authors hypothesize that $\mathrm{Co}(\mathrm{III})-\mathrm{H}$ intermediate may reduce the oxime ligand. A faster electron transfer to the catalyst could shorten the lifetime of this intermediate thereby 
preventing ligand degradation. One way to achieve this would be to maintain the PS and the catalyst in close vicinity, thus favouring fast electron transfer.

This issue has been elegantly addressed by Utschig and coworkers. In a first attempt, Utschig, Tiede and coworkers made use of the direct interaction between the synthetic complexes 67 and 68 with photosystem I (PSI hereafter). ${ }^{213-214}$ This natural component of the photosynthetic electron transport chain possesses both a light-harvesting center and a series of electron relays, scaffolded within a large protein assembly. They demonstrated that 67 and 68 interact with PSI in a non-covalent manner. In contrast to other artificial hydrogenases described herein, the interaction between PSI and the two complexes were not unambiguously defined: the authors hypothesize that interaction may occur at the hydrophobic patches of PSI (and possibly at a histidine residue in the case of 67). Following incubation of 67 with PSI, affording 67.PSI, ascorbate (as sacrificial electron source) and cytochrome $\mathrm{C}_{6}$ as electron transport (to reduce the oxidized PSI) were added, and dihydrogen evolution could be detected upon irradiation. Relative to the cobalt content, this system performed 2080 TON in $1.5 \mathrm{~h}$, with a maximum TOF of $1.13 \mathrm{~s}^{-1}$, at $\mathrm{pH} 6.3$ (Table 8, entry 13). Under similar conditions, 68.PSI performed 1870 TON in $3 \mathrm{~h}$ (Table 8, entry 14). For both 67 and 68, analysis of the catalytic mixture upon completion of the reaction revealed that approximately $90 \%$ of the metal was lost. The poorly defined and weak interactions between PSI and those catalysts combined with possible catalyst degradation pathways may lead to leaching during catalysis. To overcome this limitation, the authors combined 68 with apoflavodoxin $(F / d)$, a protein known to interact via electrostatic interactions with the $F_{B}$ cluster of PSI. The authors hypothesized that $\mathbf{6 8}$ could be inserted is the FMN pocket of apo-flavodoxin. The metal content of the assembly was quantified, confirming this hypothesis. Irradiation of PSI in the presence of 30 equivalents of 68 -flavodoxin led to the rapid production of dihydrogen relative to $\mathrm{PSI}$, improving the photon to hydrogen 
conversion. However, when converted to catalyst concentration (ie. 30 eq. vs. PSI), only 94 TON were obtained after $4 \mathrm{~h}$ (Table 8 , entry 15). Despite its efficiency and elegant design, this biomimetic artificial hydrogenase is challenging to handle because of the membrane-bound nature of the proteins.

To reduce the complexity of the above system, Utschig and coworkers recently reported a simpler design, in which both the synthetic PS and the catalyst are anchored on a ferredoxin protein, acting as scaffold naturally containing an electron relay. ${ }^{215-216}$ This latter feature, as well as the defined and stable structure of the scaffold, differentiates their work with previous report from Hayashi and coworkers, in which a PS and a catalyst were attached on a peptide. ${ }^{217}$ Ferredoxin is a small electron carrier protein containing a [2Fe-2S]-cluster. The cofactors $\mathbf{6 5}$ or $\mathbf{6 7}$ were datively anchored at $\mathrm{H} 90$ and the $\left[\mathrm{Ru}(\mathrm{bpy})_{3}\right]^{2+}$-photosensitizer linked to $\mathrm{C} 18$ of ferredoxin. Only $40 \%-50 \%$ of the artificial hydrogenase included the covalently-bound PS, to afford 65.ferredoxin.[Ru(bpy $\left.)_{3}\right]$ and $67 \cdot f e r r e d o x i n \cdot\left[R u(b p y)_{3}\right]$ respectively. Both ArMs produced dihydrogen under irradiation and in the presence of ascorbate at $\mathrm{pH} 6.3$. In $6 \mathrm{~h}$, 65.ferredoxin.[Ru(bpy $\left.)_{3}\right]$ and $67 \cdot f e r r e d o x i n \cdot\left[R u(b p y)_{3}\right]$ yielded 210 and 650 TON respectively relative to the PS, with a maximum $0.047 \mathrm{~s}^{-1}$ TOF observed for the latter (Table 8, entries 16 and 17). Upon removal of the [2Fe-2S]-cluster from $65 \cdot$ ferredoxin $\left[\mathrm{Ru}(\mathrm{bpy})_{3}\right]$, complete loss of photocatalytic activity resulted. Spectroscopic analysis suggested that electron transfer from $\mathrm{Ru}(\mathrm{II})^{*}$ to cobalt does not occur. The authors elegantly demonstrated that this could be traced back to the loss of the [2Fe-2S]-electron relay, substituting it by its redox inactive [2Ga-2S]-congener. The quaternary structure of $\mathbf{6 5}$. ferredoxin was maintained but no photocatalytic dihydrogen evolution could be observed, suggesting that the extended distance between the cofactor and the PS prevents electron transfer in the absence of the electron relay station. The [2Fe-2S]-cluster is separated from the Ru PS and the cobalt cofactor by 
approximately $15 \AA$ and $12.5 \AA$, respectively. Anchoring the PS and the cofactor to a rigid scaffold not only keeps them in close vicinity, but also maintains a suitable distance between them, thus avoiding fast charge recombination after the electron transfer. This increase of the lifetime of the charge-separated state, in which $\mathrm{Co}(\mathrm{I})$ is a key intermediate, empowers the proton reduction. For $\mathbf{6 5}$-ferredoxin·[Ru(bpy)3], the lifetime of this state was determined to be $\sim 6 \mathrm{~ms}$.

Finally, based on the observation that apo-flavodoxin can bind synthetic complexes, it was loaded with 65 and covalently modified by a $[R u(b p y) 3]^{2+}-$ moiety $\sim 10 \AA$ away from the FMN-binding site. This PS-catalyst distance is considerably shorter than within the ferredoxin host resulting in a faster direct electron transfer ( 3000 times, based on distance alone), as well as a faster charge recombination. In contrast to the ferredoxin construct, only 85 TON were achieved by 65 -flavodoxin. $\left[\mathrm{Ru}(\mathrm{bpy})_{3}\right]$ in $6 \mathrm{~h}$ (Table 8 , entry 18). This corresponds to $40 \%$ of the activity of 65 -ferredoxin.[Ru(bpy $\left.)_{3}\right]$, highlighting the superiority of assemblies in which the PS and the catalyst are far enough to slow down back-donation (within milliseconds), but in which an electron relay favours the first electron transfer event (within microseconds). Accordingly, the difference in activity of 65.ferredoxin.[Ru(bpy $\left.)_{3}\right]$ and $65 \cdot f l a v o d o x i n \cdot\left[R u(b p y)_{3}\right]$ correlates well with the lifetime of the charge-separated state containing $\mathrm{Co}(\mathrm{l})$ : for $65 \cdot f l a v o d o x i n \cdot\left[\mathrm{Ru}(\mathrm{bpy})_{3}\right]$ and $65 \cdot$ ferredoxin $\left[\mathrm{Ru}(\mathrm{bpy})_{3}\right]$ the lifetimes are $\sim 800 \mu \mathrm{s}$ and $\sim 6 \mathrm{~ms}$ respectively.

Table 8. Selected results for dihydrogen production by artificial hydrogenases.

\begin{tabular}{|c|c|c|c|c|c|c|c|c|c|c|c|c|}
\hline Entry & Cof. & Protein $^{a}$ & $P S^{b}$ & $\begin{array}{l}\text { Elec. } \\
\text { donor }\end{array}$ & $\begin{array}{l}\text { [Cof] } \\
(\mu \mathrm{M})\end{array}$ & $\begin{array}{l}\text { Ratio } \\
{[\text { PS] }} \\
{[\text { Cof] }}\end{array}$ & $\begin{array}{c}\mathrm{t} \\
(\mathrm{h})\end{array}$ & $\mathrm{pH}$ & $\begin{array}{c}\mathrm{T} \\
\left({ }^{\circ} \mathrm{C}\right)\end{array}$ & $\begin{array}{l}\text { TOF } \\
\left(s^{-1}\right)\end{array}$ & TON & Ref \\
\hline 1 & 65 & cyt $c$ & {$\left[\mathrm{Ru}(\mathrm{bpy})_{3}\right]^{2+}$} & asc. $^{c}$ & 14 & 10 & 2 & 4.7 & 25 & 0.035 & 82 & 197 \\
\hline 2 & 66 & NB & {$\left[\mathrm{Ru}(\mathrm{bpy})_{3}\right]^{2+}$} & asc. $^{c}$ & 7.8 & 18 & 6 & 4.7 & 25 & 0.038 & 130 & 198 \\
\hline 3 & 66 & NB & {$\left[\mathrm{Ru}(\mathrm{bpy})_{3}\right]^{2+}$} & asc. $^{c}$ & 7.8 & 18 & 6 & 7.8 & 25 & nd & 36.4 & 198 \\
\hline 4 & $\mathrm{Ni}$ & $\mathrm{Rd}$ & {$\left[\mathrm{Ru}(\mathrm{bpy})_{3}\right]^{2+}$} & asc. $^{c}$ & 2 & 500 & 8.3 & 6.5 & 4 & 0.008 & $70^{1}$ & 203 \\
\hline 5 & $\mathrm{Ni}$ & $\mathrm{Rd}$ & - & {$[\text { Ti }(\text { citrate })]^{\mathrm{d}}$} & 2.5 & - & 8 & 9.4 & 22 & nd & 300 & 203 \\
\hline 6 & Co & $c-552$ & - & - e & 0.1 & - & 24 & 7.0 & r.t. & nd & 27000 & 61 \\
\hline 7 & 64 & $\mathrm{Mb}$ & {$\left[\mathrm{Ru}(\mathrm{bpy})_{3}\right]^{2+}$} & asc. $^{\mathrm{c}}$ & 2.5 & 400 & 12 & 7.0 & r.t. & 0.025 & 518 & 208 \\
\hline 8 & 64 & $b-562$ & {$\left[\mathrm{Ru}(\mathrm{bpy})_{3}\right]^{2+}$} & asc. $^{c}$ & 4 & 250 & 25 & 7.0 & r.t. & $0.025^{\mathrm{h}}$ & $1450^{g}$ & 209 \\
\hline 9 & 66 & $\mathrm{Mb}$ & DAF & Tris & 30 & 0.5 & 0.25 & 7.0 & r.t. & $0.015^{i}$ & 5 & 204 \\
\hline 10 & 63 & $\mathrm{HO1}$ & - & {$\left[\mathrm{Eu}\left(\mathrm{EGTA}_{\mathrm{f}}\right]^{2-}\right.$} & 40 & - & 0.08 & 7.0 & r.t. & $0.067^{j}$ & 6.2 & 212 \\
\hline 11 & 66 & $\mathrm{HO1}$ & DAF & Tris & 10 & 0.5 & 0.25 & 7.0 & r.t. & $0.015^{k}$ & 6.3 & 212 \\
\hline
\end{tabular}




\begin{tabular}{|c|c|c|c|c|c|c|c|c|c|c|c|c|}
\hline 12 & 66 & $\mathrm{HmuO}$ & DAF & Tris & 10 & 0.5 & 0.25 & 7.0 & r.t. & $0.058^{k}$ & 15.3 & 212 \\
\hline 13 & 67 & PSI & PSI & asc. $^{c, g}$ & 0.152 & 0.4 & 1.5 & 6.3 & r.t. & 1.13 & $2080^{m}$ & 213 \\
\hline 14 & 68 & PSI & PSI & asc..$^{c, g}$ & 0.060 & 1 & 3 & 6.3 & r.t. & 0.73 & $1870^{m}$ & 214 \\
\hline 15 & 68 & Fld & PSI & asc. $^{c, g}$ & 2 & 0.033 & 4 & 6.3 & r.t. & 0.042 & $94^{\mathrm{m}}$ & 214 \\
\hline 16 & 65 & $\mathrm{Fd}$ & $c-\left[R u(b p y)_{3}\right]^{2+v}$ & asc. $^{c}$ & 2 & 0.36 & 6 & 6.3 & r.t. & 0.014 & $210^{n}$ & 216 \\
\hline 17 & 67 & $\mathrm{Fd}$ & $c-\left[R u(b p y)_{3}\right]^{2+v}$ & asc. $^{c}$ & 2 & 0.42 & 6 & 6.3 & r.t. & 0.047 & $650^{n}$ & 215 \\
\hline 18 & 65 & Fld & $c-\left[R u(b p y)_{3}\right]^{2+v}$ & asc. $^{c}$ & 1.7 & 1 & 6 & 6.3 & r.t. & 0.008 & $85^{n}$ & 215 \\
\hline
\end{tabular}

Entries highlighted in gray correspond to non-photocatalytic experiments. ${ }^{a}$ apo-cytochrome $c$ (cyt $c$ ); apo-nitrobindin (NB); rubredoxin (Rd); apo-Ht cytrochrome $c_{552}$ M61A (c-552); myoglobin (Mb); apo-cytochrome $b_{562}$ M7A (b-562) ; apo-rat heme oxygenase 1 (HO1); apo-Corynebacterium diphteriae heme oxygenase (HmuO); photosystem I (PSI) ; apo-flavodoxin (FId) ; ferredoxin (Fd). ${ }^{b}$ deazaflavin (DAF); $\left[\mathrm{Ru}(\mathrm{bpy})_{3}\right]^{2+}$ free in solution $\left(\left[\mathrm{Ru}(\mathrm{bpy})_{3}\right]^{2+}\right.$ ) or covalently attached to the protein scaffold $(\mathrm{c}-$ $\left[\mathrm{Ru}(\mathrm{bpy})_{3}\right]^{2+}$ ). ${ }^{\mathrm{c}}$ ascorbate $100 \mathrm{mM}$ (asc.); ${ }^{\mathrm{d}}\left[\mathrm{Ti}(\mathrm{III})\right.$ citrate], $39 \mathrm{mM}$ ([Ti(citrate)]). e Electocatalysis. ${ }^{\dagger} 600 \mu \mathrm{M} .{ }^{\mathrm{g}} \mathrm{Cyt} c_{6}(4-20 \mu \mathrm{M}) \mathrm{was}$ added as an electron carrier. ${ }^{\mathrm{h}}$ Derived from Fig. 5 of ref $\left[{ }^{209}\right] .{ }^{i}$ Minimal value, estimated from Fig. 11 of ref $\left[{ }^{204}\right] .{ }^{j}$ Minimal value, estimated their Fig. 7 of ref $\left.{ }^{212}\right] .{ }^{k}$ Minimal value, estimated from Fig. S7 of ref $\left.{ }^{212}\right] .{ }^{1}$ The 40 TON observed in the absence of catalyst were substracted from the 110 TON for NiRd, depicted in Fig.3. ${ }^{203} \mathrm{~m}$ Re-calculated relative to the metal cofactor. ${ }^{\mathrm{n}}$ Calculated relative to the PS, considering the metal cofactors embedded in a scaffold not containing a PS have no catalytic activity, based on the fact that solution of PS and cat at $1 \mu \mathrm{M}$ did not yield the photocatalytic production of $\mathrm{H}_{2}$.

In summary, the artificial hydrogenases reported to date show that anchoring a catalytically competent proton-reduction catalyst within a protein scaffold can impart compatibility with aqueous media at neutral $\mathrm{pH}$ and increase both TOF and TON. In some cases however, the artificial hydrogenases are less efficient than the cofactor alone. This is especially valid for photocatalytic systems whereby the PS/catalyst interactions are hampered, eventually leading to slow catalytic rates or catalyst degradation. The recent studies from Utschig and coworkers offer promising avenues to overcome this issue.

Some advantageous aspects of artificial hydrogenases remain to be systematically explored. For example, very few reports on random mutagenesis or directed evolution schemes have been published, although such avenues are often suggested in the outlook of these publications. Only a handful of modifications in the direct environment of the metal have been tested either by mutating residues or by testing different scaffolds from a same family (e.g. heme-binding proteins). None of these examples led to a dramatic improvement of catalytic activity however. In contrast, directed evolution could be used to tune the protein environment, rather than the PS or the catalyst. ${ }^{218}$ Finally, in a biomimetic spirit, artificial hydrogenases could be improved by engineering facilitated pathway for proton/electron delivery/removal at the metal center, and gas release pathways, reminiscent of the channels and electron relays present in natural hydrogenases. 


\subsection{Transfer Hydrogenation}

Background. Catalytic asymmetric transfer hydrogenation (ATH) provides a powerful means for reducing unsaturated substrates including ketones, imines, nitro compounds, nitriles, oximes, $\alpha, \beta$-unsaturated carbonyl compounds, heterocycles, alkenes, and alkynes. ${ }^{219-227}$ It requires neither hazardous hydrogen gas nor pressure vessels. Instead, a number of cheap, non-toxic, and easy to handle reductants, including formic acid, formate salts or isopropanol, have been used as hydrogen donors. Recent advances and trends in ATH using homogeneous, heterogeneous, organo- and transition-metal catalysts were recently reviewed. ${ }^{228}$

A major breakthrough in ATH was reported by Noyori and coworkers in 1995: enantiopure TsDPEN-Ru(II)-based complexes $($ TsDPEN $=\mathrm{N}$-( $p$-toluenesulfonyl)-1,2diphenylethylenediamine) were found to be outstanding homogeneous catalysts for the asymmetric reduction of a variety of substrates..$^{229-231}$ Building upon this finding, some of the most effective catalysts reported to date are $d^{6}$-pianostool complexes of rhodium, iridium and ruthenium. As amply demonstrated by Xiao and coworkers, closely related homogenous catalysts are efficient for the asymmetric reduction of prochiral ketones and cyclic imines in water. ${ }^{232-234}$ This is obviously an important feature in the context of ArMs.

In nature, $\mathrm{NAD}(\mathrm{P}) \mathrm{H}$-dependent enzymes including ketoreductases, imine reductases (IRED), and ene reductases can be used for the asymmetric reduction of $\mathrm{C}=\mathrm{O}, \mathrm{C}=\mathrm{N}$ and activated $\mathrm{C}=\mathrm{C}$ bonds respectively. While both keto- 235 and ene-reductases ${ }^{236}$ are well known and widely used on industrial scale, ${ }^{163}$ IREDs were only recently discovered by Nagasawa in $2011 .{ }^{237}$ These have been further exploited by, among others, the Turner and Hauer groups. ${ }^{238,239}$ 
In this section, we summarize the progress in artificial transfer hydrogenases (ATHases) for the asymmetric reduction of prochiral ketones, enones, imines as well as $N A D(P)^{+}$ and its analogs. For several groups, ATHase has provided a fertile playground to benchmark various challenging concepts including: catalyst immobilization, directed evolution, enzyme cascades, allosteric regulation etc. These are presented at the end of this section.

Transfer Hydrogenation of ketones. To assemble an artificial metalloenzyme for the asymmetric transfer hydrogenation of prochiral ketones, the Ward group set out to adapt Noyori's homogeneous $d^{6}$-pianostool complexes bearing a Ts-DPEN-ligand. ${ }^{230}$ Several $\operatorname{Ir}(I I I), \operatorname{Rh}(\mathrm{III})$ and $\mathrm{Ru}(\mathrm{II}) \mathrm{d}^{6}$-pianostool complexes were prepared by complexation of a achiral biotinylated $N$-arylsulfonamide-1,2-ethylenediamine ligands $(69, q=$ ortho, meta, para) to either $\left[\eta^{5}-\mathrm{Cp}{ }^{*} \mid \mathrm{rCl}\left(\mathrm{H}_{2} \mathrm{O}\right)_{2}\right]^{+},\left[\eta^{5}-\mathrm{Cp}{ }^{*} \mid r C l\left(\mathrm{H}_{2} \mathrm{O}\right)_{2}\right]^{+}$, or $\left[\left(\eta^{6} \text {-arene }\right) \mathrm{RuCl}\left(\mathrm{H}_{2} \mathrm{O}\right)_{2}\right]^{+}$. The resulting pianostool complexes $\left[\left(\eta^{n} \text {-arene }\right) \mathrm{M}(69) \mathrm{Cl}\right]^{+}$were combined with an Sav sitesaturation mutagenesis library Sav $\mathrm{S} 112 \mathrm{X}$ as well as selected single- and double point mutants (Scheme 24). ${ }^{18,240}$ The aminoacid positions subjected to mutagenesis were selected based on their estimated proximity to the catalytic metal. Ward and coworkers first screened all cofactors $\left[\left(\eta^{n} \text {-arene }\right) \mathrm{M}(69) \mathrm{Cl}\right]^{+}$with a subset of Sav isoforms and only the best biotinylated catalysts were then screened with the entire set of proteins. The best catalyst.protein combinations were evaluated toward various substrates. Selected results are summarized in Table 9.

Noteworthy features for the ATHases included (Scheme 24 and Table 9):

i) Complexes bearing a para-substituted spacer (70) outperform those with ortho- and meta-spacers.

ii) Exchange of the capping arene ligand from benzene to p-cymene led to stereoinversion; this is most pronounced with mutants Sav S112K ((S)- 
selective) and Sav S112A ((R)-selective), respectively (Table 9, entries 6 vs. 3).

iii) Aryl alcohols $\mathbf{7 1 - 7 3}$ were obtained with good to very good ee (>90\%) whereas reduction of dialkyl ketones resulted in only modest ees.

An X-crystal structure of the most $(S)$-selective artificial transfer hydrogenase (ATHase hereafter) [ $\eta^{6}$-(benzene)Ru(70)Cl].Sav S112K was determined (PDB 2QCB,

Figure 10). ${ }^{241}$ The following features are apparent:

i) The Ru-center is located in the biotin-binding vestibule in close proximity to residues $\mathrm{S} 112 \mathrm{~K}_{\mathrm{A}}, \mathrm{L} 124_{\mathrm{A}}, \mathrm{S} 112 \mathrm{~K}_{\mathrm{B}}, \mathrm{K} 121_{\mathrm{B}}$ (subscripts $\mathrm{A}$ and $\mathrm{B}$ refer to Sav monomers).

ii) A $\quad(S)-\mathrm{Ru}-\mathrm{Cl}$ absolute configuration was determined for $\left[\eta^{6}\right.$ (benzene)Ru(70)Cl].Sav $\mathrm{S} 112 \mathrm{~K}$. This configuration is reminiscent of the homogeneous catalytic system as both ArM and homogeneous catalyst, (S)reduction products are formed preferentially in the presence of an (S)-Ru-Cl moiety. This suggests that both catalysts rely on a similar enantioselection mechanism.

iii) The short $R u_{A} \cdots \cdot \cdot R u_{B}$ distance (4.44 $\AA$ ) suggests that it is unlikely that two neighboring cofactors can fit within a biotin-binding vestibule (which contains two biotin binding sites): the maximum activity and selectivity is achieved in the presence of two cofactors occupying one Sav tetramer.

iv) The overall Sav structure in the complex-bound Sav vs. apo-Sav is virtually identical $(\mathrm{RMSD}=0.276 \AA$ ) .

From the crystal structure, it was concluded that site-saturation mutagenesis libraries in position K121 and L124 may allow to further fine-tune the catalytic performance of the ATHase. Thus, the following libraries K121X, L124X, S112A-K121X, S112KK121X, S112A-L124X and S112K-L124X were produced to afford eighty double 
mutants and forty single mutants. This Sav library was combined with both (S)- and $(R)$-selective cofactors $\quad\left[\eta^{6}\right.$-(benzene $\left.) \mathrm{Ru}(\mathbf{7 0}) \mathrm{Cl}\right] \quad$ and $\quad\left[\eta^{6}-(p\right.$-cymene $\left.) \mathrm{Ru}(\mathbf{7 0}) \mathrm{Cl}\right]$ respectively. The resulting ATHase were screened for the reduction of aryl-alkyl and dialkylketones, Scheme 24. To speed-up the screening effort, the Sav mutants were tested in catalysis in semi-purified form. With this procedure, ATHases could be obtained that produced up to $97 \%$ ee $(R)$ and $92 \%(S)$ for aryl-alkylkalcohols $\mathbf{7 1 , 7 2}$ and 73 (Table 9, entries 15-18) and up to ee $90 \%(R)$ for dialkylalcohols 74 and 75 (Table 9, entries 19-21).

Scheme 24: An artificial transfer hydrogenase based on biotinylated Noyori-type $\mathrm{d}^{6}$ pianostool complexes anchored within Sav catalyzes the asymmetric reduction of ketones. 
<smiles>CC(=O)c1ccc(C)cc1</smiles><smiles>O=C1CCCc2ccccc21</smiles><smiles>CC(=O)CCc1ccccc1</smiles><smiles>CC(=O)CCOCc1ccccc1</smiles><smiles>Cc1ccc([C@@H](C)O)cc1</smiles>

$71 \mathrm{OH}$<smiles>CC1CCCc2ccccc21</smiles>

72<smiles>C[C@@H](O)c1ccccn1</smiles><smiles>C[C@@H](O)CCc1ccccc1</smiles>

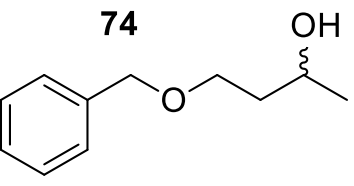

75<smiles></smiles>

$\left[\eta^{n}-\left(C_{n} R_{n}\right) M{ }_{2}\right]_{2}$ $\mathrm{NEt}_{3}, i-\mathrm{PrOH}$, reflux<smiles>C[C@@H]1SC[C@@H]2NC(=O)N[C@H]12</smiles><smiles>[M]Cl</smiles>

$69=$ ortho, meta, para (70)

$\eta^{n}-\left(C_{n} R_{n}\right)$<smiles>Cc1c(C)c(C)c(C)c(C)c1C</smiles><smiles>c1ccccc1</smiles><smiles>Cc1ccc(C(C)C)cc1</smiles><smiles>Cc1cc(C)cc(C)c1</smiles><smiles>Cc1cc(C)c(C)cc1C</smiles><smiles>CCCCCC</smiles>

$M \quad \operatorname{Ir}(\mathrm{III}), \operatorname{Rh}(\mathrm{III})$

$\mathrm{Ru}(\mathrm{II})$

Table 9. Summary of the catalytic performance of ATHase for the reduction of prochiral ketones. ${ }^{a}$

\begin{tabular}{cccccc} 
Entry & Complex & Protein & Product & ee. $(\%)$ & Conv. $(\%)$ \\
\hline 1 & {$\left[\eta^{6}-(p\right.$-cymene $\left.) \mathrm{Ru}(\mathbf{7 0}) \mathrm{Cl}\right]$} & WT Sav & $\mathbf{7 1}$ & $89(R)$ & 95 \\
2 & {$\left[\eta^{6}-(\right.$ benzene $\left.) \mathrm{Ru}(\mathbf{7 0}) \mathrm{Cl}\right]$} & WT Sav & $\mathbf{7 1}$ & $29(R)$ & 38 \\
3 & {$\left[\eta^{6}-(p\right.$-cymene $\left.) \mathrm{Ru}(\mathbf{7 0}) \mathrm{Cl}\right]$} & $\mathrm{S} 112 \mathrm{~A}$ & $\mathbf{7 1}$ & $91(R)$ & 98 \\
4 & {$\left[\eta^{6}-(\right.$ benzene $\left.) \mathrm{Ru}(\mathbf{7 0}) \mathrm{Cl}\right]$} & $\mathrm{S} 112 \mathrm{~A}$ & $\mathbf{7 1}$ & $41(R)$ & 74 \\
5 & {$\left[\eta^{6}-(p\right.$-cymene $\left.) \mathrm{Ru}(\mathbf{7 0}) \mathrm{Cl}\right]$} & $\mathrm{S} 112 \mathrm{~K}$ & $\mathbf{7 1}$ & $10(S)$ & 34 \\
6 & {$\left[\eta^{6}-(\right.$ benzene) $\mathrm{Ru}(\mathbf{7 0}) \mathrm{Cl}]$} & $\mathrm{S} 112 \mathrm{~K}$ & $\mathbf{7 1}$ & $63(S)$ & 24 \\
7 & {$\left[\eta^{6}-(p\right.$-cymene $\left.) \mathrm{Ru}(\mathbf{7 0}) \mathrm{Cl}\right]$} & $\mathrm{P} 64 \mathrm{G}$ & $\mathbf{7 1}$ & $94(R)$ & 92 \\
8 & {$\left[\eta^{6}-(\right.$ benzene $\left.) \mathrm{Ru}(\mathbf{7 0}) \mathrm{Cl}\right]$} & $\mathrm{P} 64 \mathrm{G}$ & $\mathbf{7 1}$ & $44(S)$ & 44 \\
9 & {$\left[\eta^{6}-(p\right.$-cymene $\left.) \mathrm{Ru}(\mathbf{7 0}) \mathrm{Cl}\right]$} & $\mathrm{S} 112 \mathrm{Y}$ & $\mathbf{7 2}$ & $97(R)$ & 79 \\
10 & {$\left[\eta^{6}-(\right.$ benzene $\left.) \mathrm{Ru}(\mathbf{7 0}) \mathrm{Cl}\right]$} & $\mathrm{S} 112 \mathrm{~A}$ & $\mathbf{7 2}$ & $51(S)$ & 44 \\
11 & {$\left[\eta^{6}-(\right.$ benzene $\left.) \mathrm{Ru}(\mathbf{7 0}) \mathrm{Cl}\right]$} & $\mathrm{S} 112 \mathrm{R}$ & $\mathbf{7 3}$ & $70(S)$ & 95
\end{tabular}




$\begin{array}{cccccc}12 & {\left[\eta^{6}-(p \text {-cymene }) \mathrm{Ru}(\mathbf{7 0}) \mathrm{Cl}\right]} & \mathrm{S} 112 \mathrm{~F} & \mathbf{7 3} & 76(R) & 95 \\ 13 & {\left[\eta^{6}-(p \text {-cymene }) \mathrm{Ru}(\mathbf{7 0}) \mathrm{Cl}\right]} & \mathrm{S} 112 \mathrm{~A} & \mathbf{7 4} & 48(R) & 98 \\ 14 & {\left[\eta^{6}-(p \text {-cymene)Ru(70)Cl] }\right.} & \mathrm{S} 112 \mathrm{~A} & \mathbf{7 5} & 69(R) & 97 \\ 15 & {\left[\eta^{6}-(p \text {-cymene }) \mathrm{Ru}(\mathbf{7 0}) \mathrm{Cl}\right]} & \mathrm{L} 124 \mathrm{~V} & \mathbf{7 1} & 96(R) & 97 \\ 16 & {\left[\eta^{6}-(p \text {-cymene }) \mathrm{Ru}(\mathbf{7 0}) \mathrm{Cl}\right]} & \mathrm{L} 124 \mathrm{~V} & \mathbf{7 2} & 87(R) & 20 \\ 17 & {\left[\eta^{6}-(\text { benzene }) \mathrm{Ru}(\mathbf{7 0}) \mathrm{Cl}\right]} & \mathrm{S} 112 \mathrm{~A}-\mathrm{K} 121 \mathrm{~N} & \mathbf{7 2} & 92(S) & 54 \\ 18 & {\left[\eta^{6}-(\text { benzene }) \mathrm{Ru}(\mathbf{7 0}) \mathrm{Cl}\right]} & \mathrm{S} 112 \mathrm{~A}-\mathrm{K} 121 \mathrm{~N} & \mathbf{7 3} & 92(S) & \text { quant. } \\ 19 & {\left[\eta^{6}-(p \text {-cymene }) \mathrm{Ru}(\mathbf{7 0}) \mathrm{Cl}\right]} & \mathrm{S} 112 \mathrm{~A}-\mathrm{K} 121 \mathrm{~T} & \mathbf{7 4} & 88(R) & \text { quant. } \\ 20 & {\left[\eta^{6}-(p \text {-cymene }) \mathrm{Ru}(\mathbf{7 0}) \mathrm{Cl}\right]} & \mathrm{S} 112 \mathrm{~A}-\mathrm{K} 121 \mathrm{~W} & \mathbf{7 4} & 84(R) & \text { quant. } \\ 21 & \left.\left[\eta^{6} \text {-(benzene }\right) \mathrm{Ru}(\mathbf{7 0}) \mathrm{Cl}\right] & \mathrm{S} 112 \mathrm{~A}-\mathrm{K} 121 \mathrm{~T} & \mathbf{7 5} & 90(R) & \text { quant. }\end{array}$

${ }^{2}$ The catalytic runs were performed at $55^{\circ} \mathrm{C}$ for $64 \mathrm{~h}$ using the mixed buffer $\mathrm{HCO}_{2} \mathrm{Na}(0.48 \mathrm{M})+\mathrm{B}(\mathrm{OH})_{3}(0.41 \mathrm{M})+\mathrm{MOPS}(0.16 \mathrm{M})$ at $\mathrm{pH}_{\text {initial }}=6.25$. $\mathrm{Ru} /$ substrate/formate ratio 1:100:4000 (i.e., 100 equiv. substrate vs. $\mathrm{Ru}$ ).

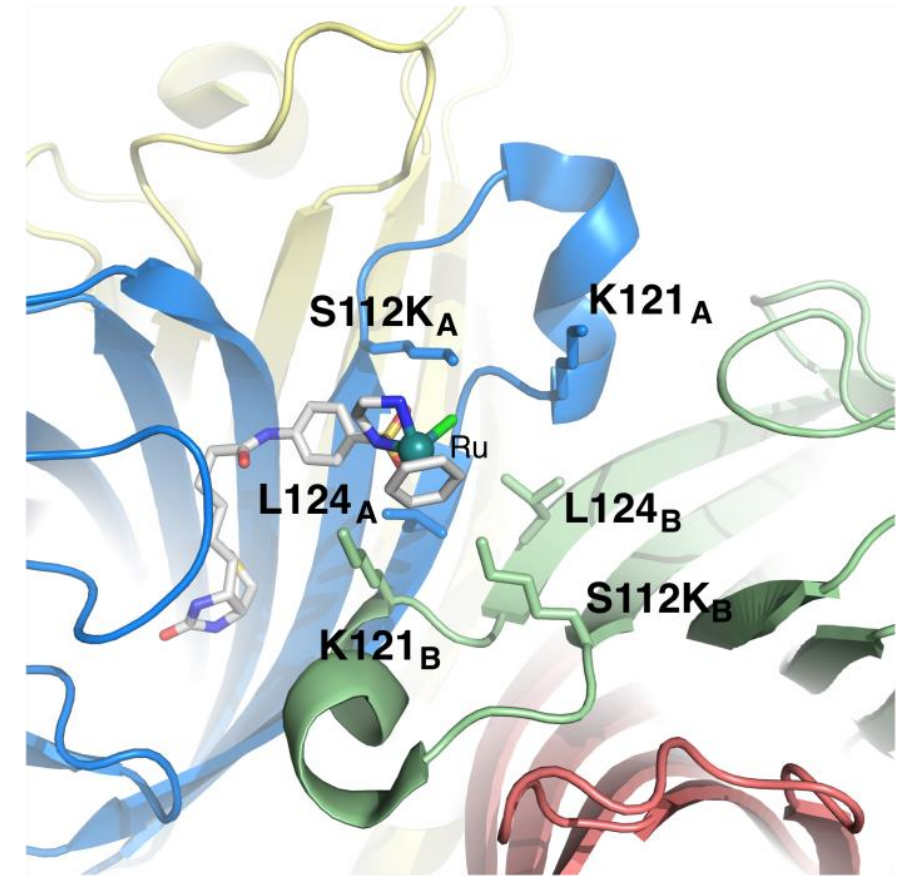

Figure 10: X-ray crystal structure of [ $\eta^{6}$-(benzene)Ru(70)Cl]-Sav-S112K tetramer (PDB code $2 \mathrm{QCB}$ ) reveals the ruthenium location in the biotin-binding vestibule. Optimization of the artificial transfer hydrogenase is achieved by mutagenesis of residues $\mathrm{S} 112$ and K121 and L124 located in proximity of the metal in the Sav monomer (blue)-monomer (yellow) interface. For simplicity the cofactor in Sav monomer B was removed.

The asymmetric reduction of trifluoroacetophenone 60 was evaluated by Salmain and coworkers. Previously, they demonstrated that the active site of papain (PAP) could be used to anchor organometallic cofactors via a covalent linkage to the Cys25. ${ }^{242-243}$ They applied this strategy to anchor $d^{6}$-pianostool complexes $(R u(I I)$ and $R h(I I I))$ via a maleimide moiety. Upon covalent anchoring of either 77 or 78 in PAP (Scheme 25), respectively 99 and 82 TON were obtained after 60 h. Low enantioselectivity was observed (15\% for $(R)-76$ at best), ${ }^{244}$ which was proposed to stem from the high 
conformational flexibility of the cofactor within the protein-cavity. Attempts to address this challenge by shortening the linker led to test cofactors 79 and 80 . The ArM 80.PAP performed best, with 48 TON in $24 \mathrm{~h}$ and up to $9 \%$ ee in favor of $(S)-76$. The free 80 afforded 100 TON in 1.25 h. ${ }^{245}$

Scheme 25. Covalent anchoring of 77-80 in PAP affords ArMs that catalyze the transfer hydrogenation of trifluoroacetophenone 60 .<smiles>O=C(c1ccccc1)C(F)(F)F</smiles>

$5-10 \mathrm{mM}$

60

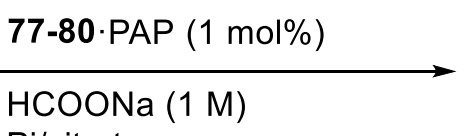

$\mathrm{Pi} /$ citrate

$\mathrm{pH} 4.5-8.0,40^{\circ} \mathrm{C}, 72 \mathrm{~h}$<smiles>OC(c1ccccc1)C(F)(F)F</smiles>

up to $15 \%$ ee for $(R)$-product

76

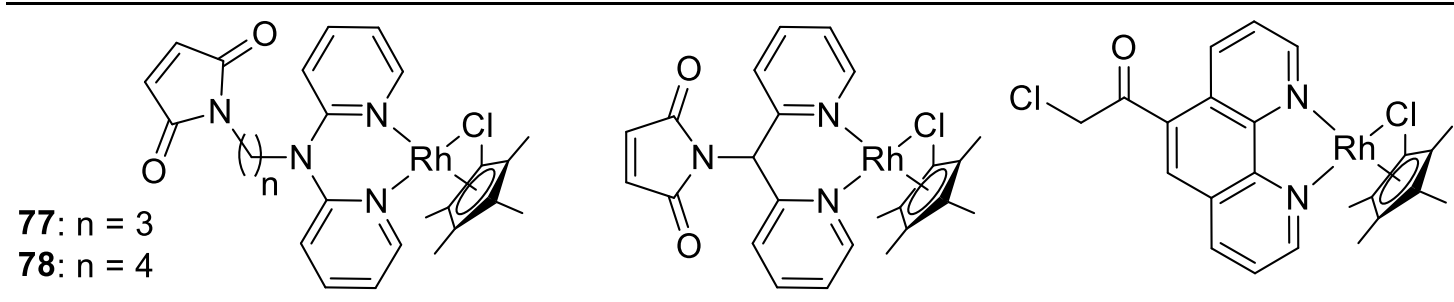

$\left[\left(\eta^{5}-\mathrm{C} p^{*}\right) \operatorname{Rh}\left(\mathrm{N}(\mathrm{Py})_{2}\right) \mathrm{Cl}\right] \quad\left[\left(\eta^{5}-\mathrm{C} p^{*}\right) \mathrm{Rh}\left(\mathrm{Me}(\mathrm{Py})_{2}\right) \mathrm{Cl}\right] 79 \quad\left[\left(\eta^{5}-\mathrm{C} p^{*}\right) \mathrm{Rh}(\mathrm{Phen}) \mathrm{Cl}\right] \mathbf{8 0}$

Moving away from ArMs based on covalent anchoring, Salmain and coworkers designed ATHases based on the "Trojan horse" strategy relying on bovine $\beta$-lactoglobulin ( $\beta$-LG hereafter). This $\beta$-barrel protein binds long fatty acids with submicromolar affinity, with the carboxylate group pointing towards the solvent. The authors coupled different fatty acids to the dipyridylamine of the $\left[\left(\eta^{5}-\mathrm{Cp}{ }^{*} \mathrm{Rh}\left(\mathrm{N}(\mathrm{Py})_{2}\right) \mathrm{Cl}\right)\right.$-moiety, resulting in $\mathbf{8 1 - 8 3}$, Scheme 26. $246-247$ The resulting ArMs catalyzed the transfer hydrogenation of trifluoroacetophenone 60. The ATHase 81· $\beta$-LG, led to full substrate conversion (i.e. 2550 TONs), but only $7 \%$ ee in favor of $(R)-76.83 \cdot \beta-L G(A)$ was the most enantioselective ArM based on the lactoglobulin scaffold achieving $32 \%$ ee for $(R)-76$.

Although the authors identified the EF loop of $\beta-L G$ and L39 as a position to mutate, no attempt to genetically improve the catalytic performance of the artificial transfer hydrogenase was reported. ${ }^{248}$ 
Scheme 26. Supramolecular anchoring of 81-83 into $\beta-L G$ affords ArMs that catalyze the transfer hydrogenation of trifluoroacetophenone.

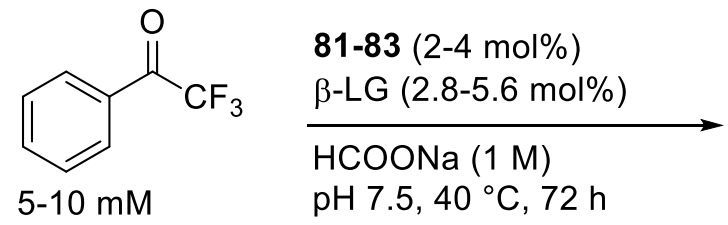

60<smiles>OC(c1ccccc1)C(F)(F)F</smiles>

up to $32 \%$ ee for $(R)$-product

76

$$
\begin{gathered}
{\left[\left(\eta^{5}-\mathrm{Cp}^{*}\right) \operatorname{Rh}\left(\mathrm{FA}-\mathrm{N}(\mathrm{Py})_{2}\right) \mathrm{Cl}\right]} \\
\mathbf{8 1 :} \mathrm{n}=8 \\
\mathbf{8 2}: \mathrm{n}=10 \\
\mathbf{8 3}: \mathrm{n}=16
\end{gathered}
$$

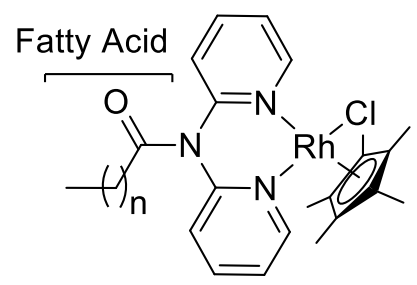

Protein Crystals. The asymmetric transfer hydrogenation of acetophenone derivatives was also investigated by Ueno and Kitagawa et al. in $2014 .^{249}$ In this study, a pianostool catalyst precursor was soaked into a protein crystal to generate a heterogeneous ArM. A tetragonal crystal and an orthorhombic crystal of the hen egg white lysozyme (HEWL, hereafter) were used for ArM formation. After treatment of the crystals with glutaraldehyde to cross-link the monomers, the resulting protein crystals were soaked with a solution of $\left[\mathrm{Ru} \text { (benzene) } \mathrm{Cl}_{2}\right]_{2} \mathbf{8 6}$, Scheme 27 . For the transfer hydrogenation of isobutyrophenone 84 using sodium formate as a hydride source, $\mathbf{8 6} \cdot \mathrm{HEWL}$ (tetragonal) and 86. HEWL (orthorhombic) afforded the corresponding alcohol in $23 \%$ ee $(R)-85$ and $36 \%$ ee (S)-85 respectively, Table 10. When using dissolved HEWL and 86, the ATHase conversion decreased to $7 \%$ (0.3 TON) compared to $38 \%$ ( $3.3 \mathrm{TON}$ ) and $46 \%$ (4.0 TON) conversions obtained using either $\mathbf{8 6} \cdot \mathrm{HEWL}$ (tetragonal) and $\mathbf{8 6} \cdot \mathrm{HEWL}$ (orthorhombic) respectively. Based on Sadler's report, ${ }^{250}$ it seems reasonable to speculate that the Rupianostool complex is coordinated to H15 of HEWL. These results suggest that the formation of catalytic compartments upon incorporation of $\mathrm{Ru}(\mathrm{II})$ complexes favour the ATH and affords different enantiomers depending on the crystal form used (tetragonal 
vs. orthorhombic).

Table 10. Selected results for transfer hydrogenation of isobutyrophenone $\mathbf{8 4}$ catalyzed by a ruthenium complex immobilized within and hen egg white lysozyme (HEWL) protein crystal. ${ }^{249}$

\begin{tabular}{ccccccccc}
\hline Entry & Cofactor & Protein & Sub. & $\mathrm{pH}$ & $\mathrm{T}\left({ }^{\circ} \mathrm{C}\right)$ & {$[\mathrm{Ru}](\mathrm{mM})$} & ee $(\%)$ & $\mathrm{TON}$ \\
\hline 1 & $\mathbf{8 6}$ & HEWL_solution & $\mathbf{8 4}$ & 7.5 & 35 & 2.6 & $24(R)$ & 0.3 \\
2 & $\mathbf{8 6}$ & HEWL_tetragonal & $\mathbf{8 4}$ & 7.5 & 35 & 1.3 & $23(R)$ & 3.3 \\
3 & $\mathbf{8 6}$ & HEWL_orthorhombic & $\mathbf{8 4}$ & 7.5 & 35 & 1.3 & $36(S)$ & 4.0 \\
\hline
\end{tabular}

Scheme 27. Cross-Linked Egg Hen White Lysozyme crystals catalyze the ATH of isobutyrophenone in the presence of $\left[\mathrm{Ru}(\text { benzene }) \mathrm{Cl}_{2}\right]_{2}$.<smiles>CC(C)C(=O)c1ccccc1</smiles>

$11.3 \mathrm{mM}$

84
[Ru(benzene) $\left.\mathrm{Cl}_{2}\right]_{2} 86$

HEWL crystal

HCOONa (3.3 M)

Borate buffer (300 mM)

$\mathrm{pH} 7.5,35^{\circ} \mathrm{C}$

$24 \mathrm{~h}$<smiles>CC(C)[C](O)c1ccccc1</smiles>

85

Transfer Hydrogenation of Imines. Besides the ATH of ketones, the Ward group developed ATHases for the reduction of cyclic imines. In an initial screening, the complex $\left[\eta^{5}-\left(\mathrm{Cp} p^{*}\right) \operatorname{Ir}(70) \mathrm{Cl}\right]$ outperformed complexes $\left[\eta^{6}-(\right.$ arene $\left.) \mathrm{Ru}(70) \mathrm{Cl}\right]$ (which were most active in the asymmetric transfer hydrogenation of ketones) and [ $\eta^{5}$ $\left.\left(\mathrm{Cp}^{*}\right) \mathrm{Rh}(\mathbf{7 0}) \mathrm{Cl}\right] .{ }^{251}$ For the reduction of the salsolidine precursor $\mathbf{8 8}, 57 \%$ ee in favor of $(R)$-amine 87 was obtained with $\left[\eta^{5}-\left(\mathrm{Cp}^{*}\right) \operatorname{Ir}(\mathbf{7 0}) \mathrm{Cl}\right] \cdot$ WT Sav. Genetic optimization of the ArM was achieved by screening the site-saturation mutagenesis libraries in position S112X and K121X as well as double mutants thereof. The following trends are apparent (Scheme 28):

i) Artificial transfer hydrogenase $\left[\eta^{5}-\left(\mathrm{Cp} \mathrm{p}^{*}\right) \operatorname{Ir}(70) \mathrm{Cl}\right]$.Sav $\mathrm{S} 112 \mathrm{~A}$ yielded $91 \%$ ee for $(R)-87$ with $>100 \mathrm{TON}$ at $\mathrm{pH} 6.5,5^{\circ} \mathrm{C}$ in $24 \mathrm{~h}$.

ii) The opposite enantiomer (S)-87 was obtained with ee $78 \%$ at $5^{\circ} \mathrm{C}$ with $\left[\eta^{5}\right.$ $\left.\left(\mathrm{Cp}{ }^{\star}\right) \operatorname{Ir}(70) \mathrm{Cl}\right] \cdot$ Sav S112K.

iii) The double mutant $\left[\eta^{5}-\left(C p^{*}\right) \operatorname{Ir}(70) \mathrm{Cl}\right]$.Sav S112A-K121A displayed a 7.6 -fold 
improved catalytic efficiency compared to WT Sav for substrate 89.252

iv) Reducing the ArM concentration to $17 \mu \mathrm{M}$ for the reduction of 88 resulted in TON > 4'000.

Scheme 28: Artificial transfer hydrogenases for the reduction of cyclic imines result from incorporation of an iridium $\mathrm{d}^{6}$-pianostool complex within Sav isoforms.

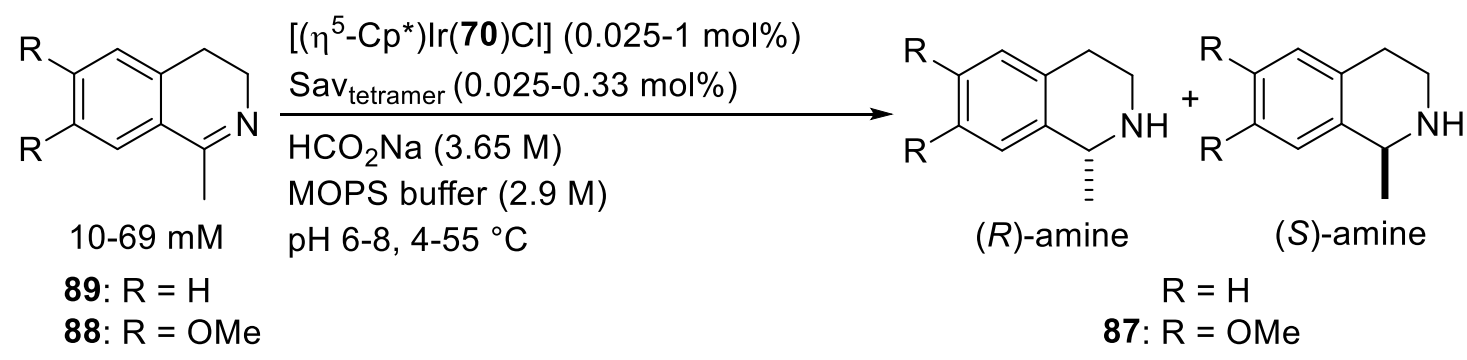

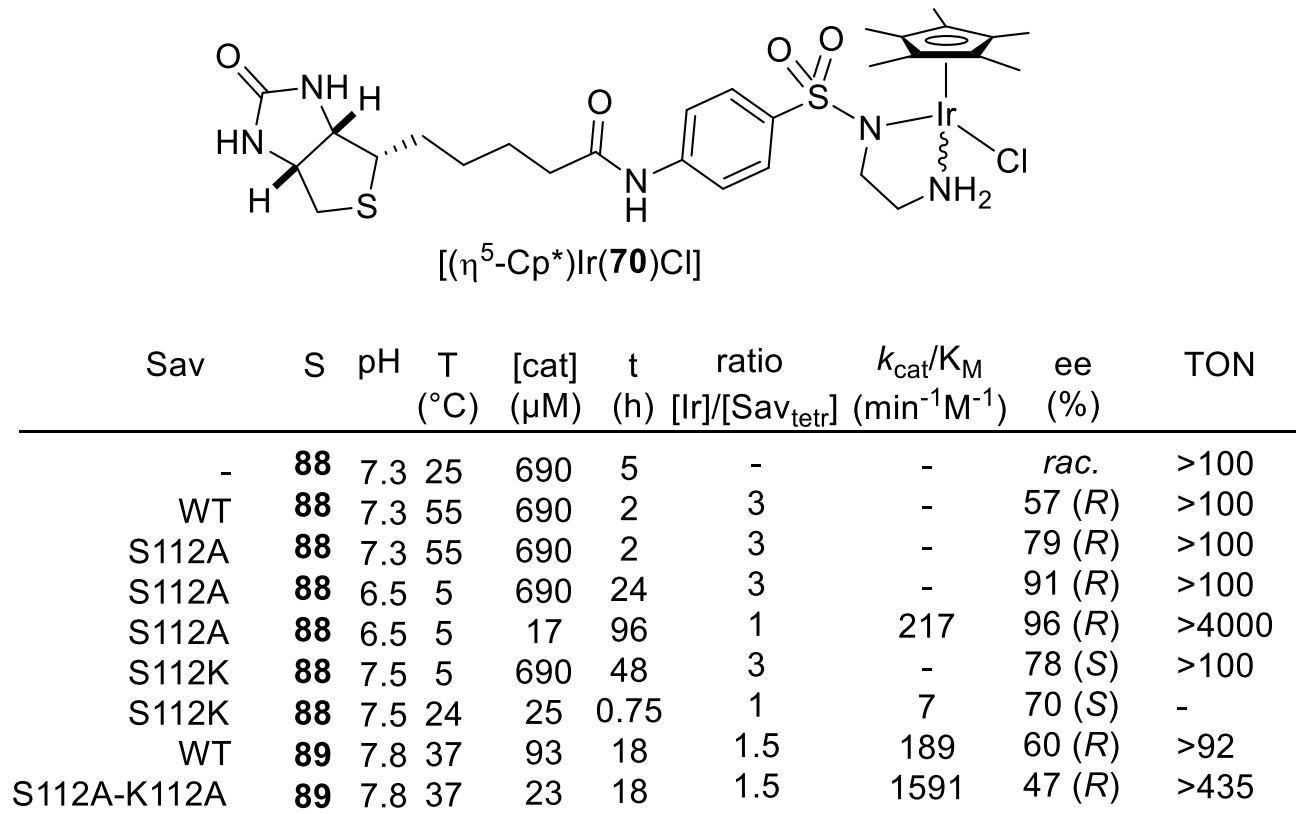

To compute the transition state for the reduction of isoquinoline $\mathbf{8 8}$ in the presence of either $\left[\eta^{5}-\left(C p^{*}\right) \operatorname{Ir}(70) C l\right] \cdot S a v S 112 A / K$, Ward, Maréchal and coworkers relied on a custom tailored $\mathrm{QM} / \mathrm{MM}$ strategy. ${ }^{253}$ The computed results nicely corroborated the catalysis results:

i) In the transition state for $\left[\eta^{5}-\left(C p^{*}\right) \operatorname{Ir}(70) \mathrm{Cl}\right] \cdot$ Sav $\mathrm{S} 112 \mathrm{~A}$, the imine cofactor is located in the biotin-binding site opposite to the position of the biotinylated cofactor (see below).

ii) Residue $\mathrm{K} 121^{\mathrm{B}}$ forms a cation- $\pi$ with the electron-rich arene moiety of the substrate 88. 
iii) The computed difference in transition-state free energy $\left(1.21 \mathrm{kcal} \cdot \mathrm{mol}^{-1}\right)$ is in line with the enantioselectivity observed at room temperature.

Varying the Cofactor: Protein Ratio In order to investigate the influence of adjacent cofactors, Ward and Maréchal analyzed the ATHase structure, reaction rates and resulting enantioselectivites as a function of $\mathrm{Ir}$ : Sav ratios for both $\left[\eta^{5}-\left(\mathrm{Cp}{ }^{*}\right) \operatorname{Ir}(\mathbf{7 0}) \mathrm{Cl}\right]$. Sav S112A and $\left[\eta^{5}-\left(C p^{*}\right) \operatorname{Ir}(70) \mathrm{Cl}\right] \cdot$ Sav $\mathrm{S} 112 \mathrm{~K} .{ }^{254}$ For $\left[\eta^{5}-\left(\mathrm{C} p^{*}\right) \operatorname{Ir}(70) \mathrm{Cl}\right] \cdot$ Sav S112A, increasing the Ir-cofactor: Sav tetramer ratio from 1:1 to $4: 1$ caused an erosion in ee for the formation of $(R)$-amine 87 from 96 to $45 \%$ in the transfer hydrogenation of $\mathbf{8 8}$. This erosion was accompanied by a twentyfold decrease in catalytic efficiency $\left(k_{\mathrm{cat}} / K_{\mathrm{M}}=0.22\right.$ $\min ^{-1} \mathrm{mM}^{-1}$ to $\left.0.011 \mathrm{~min}^{-1} \cdot \mathrm{mM}^{-1}\right)$. In contrast, the catalytic efficiency of the $(S)$-selective ATHase $\left[\eta^{5}-\left(\mathrm{Cp}^{*}\right) \operatorname{Ir}(\mathbf{7 0}) \mathrm{Cl}\right] \cdot$ Sav $\mathrm{S} 112 \mathrm{~K}$ decreased only 1.5 -fold. The ee increased from $70 \%(S)-87$ to $78 \%(S)-87$ at Sav tetramer saturation. Analysis of the X-ray structure of $\left[\eta^{5}-\left(\mathrm{C} p^{*}\right) \operatorname{Ir}(\mathbf{7 0}) \mathrm{Cl}\right]$. Sav $\mathrm{S} 112 \mathrm{~K}$ revealed two equally populated metal cofactor positions, allowing to fit up to four cofactors without leading to significant steric clash. Importantly, the absolute configuration at the metal was found to be opposite that found for the $\left[\eta^{5}-\left(C p^{*}\right) \operatorname{Ir}(70) C l\right] \cdot$ Sav S112A.

As mentioned above, enantiopure 1,2-aminosulfonamides, such as TsDPEN combined with $d^{6}$-pianostool moieties are privileged catalysts for asymmetric transfer hydrogenation. ${ }^{231}$ Building upon this, Gandolfi-Rimoldi and coworkers investigated the properties of Ru complexes chelated with chiral 1,3-aminosulfonamides for the ATH of prochiral ketone in water. ${ }^{255}$ Inspired by the work of Ward and coworkers based on 1,2aminosulfonamides, ${ }^{38}$ Rimoldi extended this work to biotinylated substituted 1,3aminosulfonamides for the reduction of prochiral imines. Both enantiopure and achiral bidentate ligands were evaluated, Figure 11.256 
<smiles>[R]C(N)CCNS(=O)(=O)c1ccc(NC(=O)CCCC[C@@H]2SC[C@@H]3NC(=O)N[C@H]23)cc1</smiles>
90: $p-(R)-B i o t, \mathrm{R}=\mathrm{Ph}$
95: $o-(S)-B i o t, \mathrm{R}=\mathrm{Ph}$
91: $p-(S)-B i o t, \mathrm{R}=\mathrm{Ph}$
70a: $p$-Biot, $\mathrm{R}=\mathrm{H}$
92: $m-(R)-B i o t, \mathrm{R}=\mathrm{Ph}$
96: $m-$ Biot, $\mathrm{R}=\mathrm{H}$
93: $m-(S)-B i o t, \mathrm{R}=\mathrm{Ph}$
97: o-Biot, $\mathrm{R}=\mathrm{H}$
94: $\mathrm{o}-(\mathrm{R})-$ Biot, $\mathrm{R}=\mathrm{Ph}$

Figure 11. Biotinylated 1,3 aminosulfonamides. All six diastereoisomers $\mathbf{9 0 - 9 5}$ as well as the achiral ligands $\mathbf{7 0 a}, \mathbf{9 6}, 97$ were used for the preparation of $d^{6} \mathrm{Ir}$ piano-stool complexes. ArMs formed after supramolecular interaction with streptavidin were tested in the ATHase of salsolidine precursor $\mathbf{8 8}$.

Biotinylated 1,3-aminosulfonamides $\mathbf{7 0 a}, \mathbf{9 0 - 9 7}$ were used as ligands for the preparation of $d^{6}$ Ir-pianostool complexes and tested for their ATHase properties for the reduction of the salsolidine precursor $\mathbf{8 8}$, Scheme 29. The free cofactor 90 (Table 11, entry 1) displayed high activity and very low enantioselectivity $(6 \%$ ee $(S)-87)$. Upon incorporation within WT Sav, the cofactors $\mathbf{9 0 - 9 5}$ led to nearly racemic 87 (up to $18 \%$ $(R)-87$, Table 11, entries 2-7). Various Sav S112-mutants were tested and led to an improvement in enantioselectivity, Table 11.240-241, 251

Table 11. Selected results for the asymmetric transfer hydrogenation of prochiral imine 88 in MOPS buffer using sodium formate as a hydride source.

\begin{tabular}{|c|c|c|c|c|c|c|c|}
\hline Entry & Protein & Ligand & Sub (mM) & {$[\mathrm{Ir}](\mu \mathrm{M})$} & $\mathrm{ee}^{\mathrm{a}(\%)}$ & Conv(\%) & TON \\
\hline 1 & - & 90 & 28 & 280 & -6 & $>99$ & 100 \\
\hline 2 & SavWT & 90 & 28 & 280 & 5 & 58 & 58 \\
\hline 3 & SavWT & 91 & 28 & 280 & 18 & 83 & 83 \\
\hline 4 & SavWT & 92 & 28 & 280 & 5 & 99 & 99 \\
\hline 5 & SavWT & 93 & 35 & 350 & 8 & 76 & 76 \\
\hline 6 & SavWT & 94 & 28 & 280 & rac. & $>99$ & 100 \\
\hline 7 & SavWT & 95 & 35 & 350 & rac. & $>99$ & 100 \\
\hline 8 & S112R & 90 & 28 & 280 & -12 & 43 & 43 \\
\hline 9 & S112C & 91 & 28 & 280 & 65 & 60 & 60 \\
\hline 10 & $\mathrm{~S} 112 \mathrm{C}$ & 93 & 35 & 350 & 40 & 26 & 26 \\
\hline 11 & S112Y & 92 & 28 & 280 & -47 & 72 & 72 \\
\hline 12 & $\mathrm{~S} 112 \mathrm{M}$ & 94 & 28 & 280 & 9 & 95 & 95 \\
\hline 13 & S112E & 95 & 28 & 280 & 18 & 73 & 73 \\
\hline 14 & S112C & $70 a$ & 10 & 140 & 83 & 25 & 18 \\
\hline 15 & S112C & 96 & 10 & 140 & 52 & 15 & 11 \\
\hline 16 & S112C & 97 & 10 & 140 & 56 & 15 & 11 \\
\hline
\end{tabular}

Scheme 29. ATHase of imine 88 based on six-membered ring aminosulfonamide chelating ligands. 


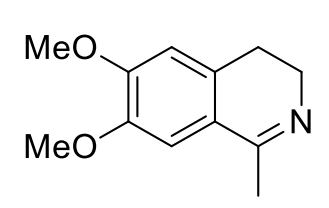

10-35 mM

88

$$
\begin{aligned}
& {\left[\left(\eta^{5}-\mathrm{Cp}^{*}\right) \operatorname{Ir}(\mathbf{7 0 a}, \mathbf{9 0 - 9 7}) \mathrm{Cl}\right](1 \mathrm{~mol} \%)} \\
& \mathrm{Sav}_{\text {tetramer }}(0.33 \mathrm{~mol} \%) \\
& \mathrm{HCO}_{2} \mathrm{Na}(3.0 \mathrm{M}) \\
& \operatorname{MOPS} \text { buffer }(1.2 \mathrm{M})
\end{aligned}
$$

$\mathrm{pH} 6.5-7.0,30-40{ }^{\circ} \mathrm{C}, 24 \mathrm{~h}$

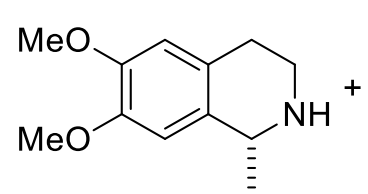

$(R)$-amine

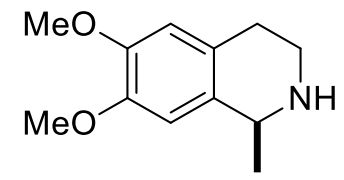

(S)-amine

87

To rationalize these results, a docking study was carried out with S112C and S112Y mutants in combination with $\left[\eta^{5}-\mathrm{C} p^{*} \operatorname{Ir}(91) \mathrm{Cl}\right]$ and $\left[\eta^{5}-\mathrm{Cp}{ }^{*} \operatorname{Ir}(\mathbf{9 2}) \mathrm{Cl}\right]$ catalysts respectively. As for previous studies by Maréchal and coworkers, ${ }^{254}$ the host protein dictates the absolute configuration at iridium, which in turn determines the preferred approach of one prochiral face of the substrate 88. Ward and Maréchal coined this chiral relay mechanism "induced lock-and-key" as the host protein favours one metal absolute configuration upon incorporation within Sav. With the diastereopure cofactor in place, the approach of the prochiral substrate is dictated by the Sav host.

\section{A Dual Anchoring Strategy for ATHAse Based on the Biotin-Streptavidin}

Technology. Although incorporation of ArMs in Sav is best achieved via a biotin anchor, additional dative interactions between the metal cofactor and engineered amino acid side chains can be envisaged. This strategy may contribute to firmly localize the metal within the shallow biotin-binding vestibule. To evaluate the potential of this strategy, Ward designed a biotinylated $\mathrm{Cp}^{*}$ ligand, thus ensuring localization of a $\mathrm{d}^{6}$-pianostool moiety but leaving the remaining three coordination sites available for coordination to amino acid residues and for catalysis. Accordingly, Ward and coworkers used cofactor $\left[(98) \mathrm{MCl}_{2}\left(\mathrm{H}_{2} \mathrm{O}\right)\right](\mathrm{M}=\mathrm{Rh}(\mathrm{III}), \operatorname{Ir}(\mathrm{III}))$ inspired by structure-based modeling. ${ }^{257}$ The presence of the ethyl spacer projects the metal in proximity to both Sav S112 and Sav K121 positions. The authors hypothesized that the imidazole side chains of mutations $\mathrm{S} 112 \mathrm{H}$ and $\mathrm{K} 121 \mathrm{H}$ may coordinate the metal thereby influencing the ArMs activity and selectivity. As a model reaction, the asymmetric transfer hydrogenation of imine $\mathbf{8 8}$ was 
selected. The reaction's stereoselectivity was very similar for complexes $\left[(98) \mid \mathrm{ICl}_{2}\left(\mathrm{H}_{2} \mathrm{O}\right)\right]$ and $\left[(98) \mathrm{RhCl}_{2}\left(\mathrm{H}_{2} \mathrm{O}\right)\right]$ in the presence and absence of WT Sav (rac-87 and $6 \%(S)-87$, respectively). When $\left[(\mathbf{9 8}) \mathrm{RhCl}_{2}\left(\mathrm{H}_{2} \mathrm{O}\right)\right] \cdot$ Sav $\mathbf{S} 112 \mathrm{H}$ was tested, (S)-87 was produced with $55 \%$ ee and $>100 \mathrm{TON}$ at $55{ }^{\circ} \mathrm{C}$ and $\mathrm{pH} 5$, Scheme 30 a). As suggested by docking, [(98) RhCl $\left.2\left(\mathrm{H}_{2} \mathrm{O}\right)\right] \cdot$ Sav $\mathrm{K} 121 \mathrm{H}$ leads to stereoinversion; $(R)-87$ is obtained with $79 \%$ ee and $>100$ TON under identical conditions. Decreasing the temperature leads to erosion in ee and TON. X-ray crystal structures were solved for both $\left[(98) \mathrm{RhCl}_{2}\left(\mathrm{H}_{2} \mathrm{O}\right)\right] \cdot \operatorname{Sav} \mathrm{S} 112 \mathrm{H}$ and $\left[(98) \mathrm{RhCl}_{2}\left(\mathrm{H}_{2} \mathrm{O}\right)\right] \cdot$ Sav $\mathrm{K} 121 \mathrm{H}$ (Scheme $30 \mathrm{~b}$ ) and c).

Scheme 30: A dual-anchoring strategy allows to localize and activate the biotinylated cofactor $\left[(98) \mathrm{MCl}_{2}\left(\mathrm{H}_{2} \mathrm{O}\right)\right]$ within Sav. a) The imine reductase is activated by introduction of a coordinating His-residue either at position Sav S112 or Sav K121; band c) as highlighted by a crystal structure. Adapted with permission from ref. ${ }^{38}$ Copyright 2016 American Chemical Society.

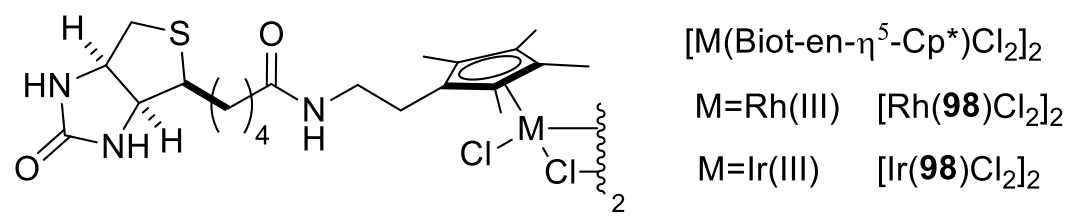

a)

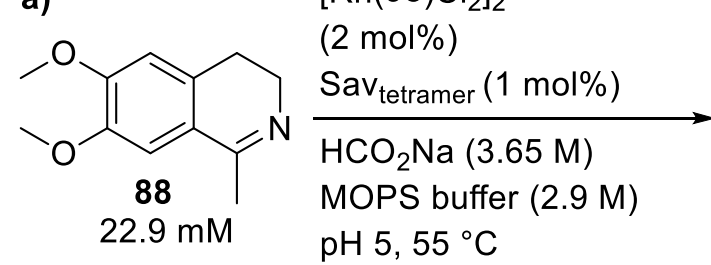

b)

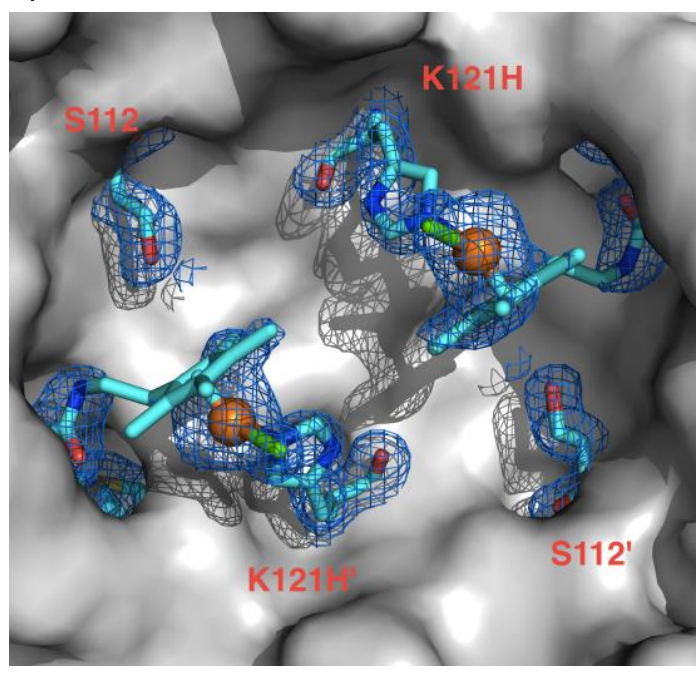<smiles>COc1cc2c(cc1OC)C(Br)=C(C)NCC2</smiles>

c)

Sav $\quad$ ee $(\%)$ TON
WT rac.
S112H $55(S)>100$
K121H $79(R)>100$
S112H
S121H

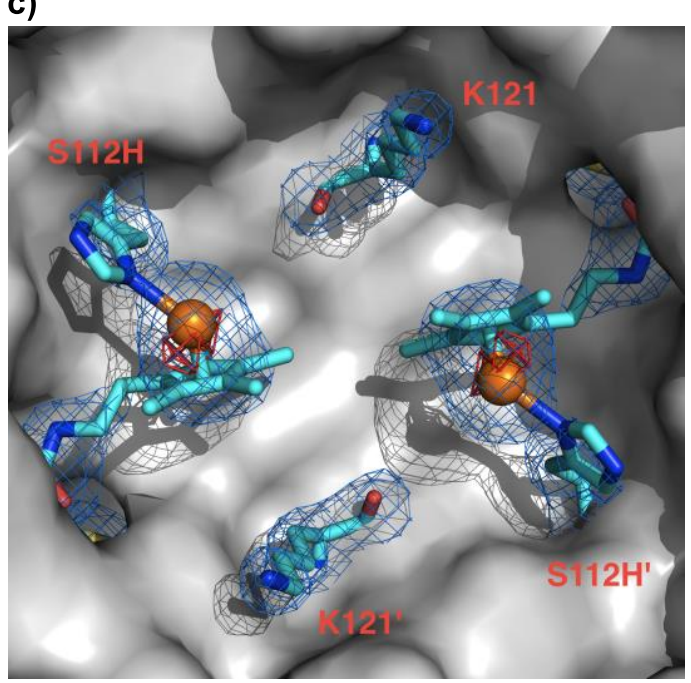


Transfer Hydrogenation of Imines, Bidentate Ligand Screening. Iridium pianostool complexes bearing a biotinylated arene cap allow for the screening of a bidentate ligand library within the Sav scaffold. This easily accessible chemical diversity component may lead to a rapid identification of ATHases with improved activity and selectivity. To test this hypothesis, Ward and coworkers preincubated complexes $\left.\left[(\mathbf{9 8}) \mathrm{M}_{2} \mathrm{Cl}_{2}\right)\right]_{2}(\mathrm{M}=\mathrm{Rh}, \mathrm{Ir})$ in the presence of eight bidentate ligands (diamines, amino acids and amino amides) at room temperature followed by addition of WT Sav. ${ }^{258}$ The reaction was initiated by addition of the substrate 1-phenyl-3,4-dihydroisoquinoline and 1.5 M sodium formate in a MOPS-buffered solution ( $\mathrm{pH}$ 7.8). All Rh-based ATHases displayed very limited activity and yielded virtually racemic product. The bidentate ligand glycineamide in conjunction with $\left[(98) \mid \mathrm{rCl}_{2}\left(\mathrm{H}_{2} \mathrm{O}\right)\right] \cdot$ WT Sav was most active (372 TON) and most selective albeit yielding the corresponding imine in $43 \%(S)$-ee. Encouraged by the promising result obtained with glycineamide, the amide derivatives of all 20 natural amino acids were screened in the presence $\left[(98) \mid r \mathrm{Cl}_{2}\left(\mathrm{H}_{2} \mathrm{O}\right)\right] \cdot$ WT Sav. The amides of L-proline $(67 \%$ ee), Lvaline (63 \% ee), L-leucine (63\% ee), L-arginine (61\% ee), L-isoleucine (65\% ee) and L-threonine (63\% ee) displayed improved selectivity for (S)-product. Further genetic fine-tuning with a focused Sav mutant library did not further contribute to improve the ee significantly. 258

Transfer Hydrogenation of Imines, ATHase Immobilized on Silica Nanoparticles. Silica nanoparticles are used in biocatalysis to immobilize enzymes, to protect these against denaturation and to improve the reaction rates. Ward and coworkers tethered the ATHase $\left[\eta^{5}-\left(C p^{*}\right) \operatorname{Ir}(70) C l\right] \cdot S a v$ S112A, Sav S112K and Sav S112A-K121A via imine formation to an aldehyde group at the surface of a silica nanoparticle (SNP). The protein-functionalized SNP surface was further treated with a protective silica layer. ${ }^{259}$ The immobilized ATHase $\left[\eta^{5}-\left(\mathrm{C} \mathrm{p}^{*}\right) \operatorname{Ir}(\mathbf{7 0}) \mathrm{Cl}\right]$.Sav $\mathrm{S112A}$ had a 4 -fold increased TON vs. 
the free enzyme (TON: 4294 vs. 1154) in the asymmetric transfer hydrogenation of cyclic imine 88. Upon lowering the catalyst loading to $0.0013 \mathrm{~mol} \% 16990$ TON were achieved. The selectivity of complex $\left[\eta^{5}-\left(C p^{*}\right) \operatorname{Ir}(70) C l\right] \cdot S a v$ S112A for $(R)-87$ increased from $79 \%$ ee to $90 \%$ ee upon immobilization. The opposite effect was observed with $(S)$-selective mutant S112K where the ee decreased from $66 \%$ ee to $56 \%$ ee upon immobilization. The most active mutant tested was S112A-K121A which afforded up to 46'747 TON (in 24 hours) at a catalyst loading of $0.0075 \mathrm{~mol} \%$.

Neutralizing Cellular Glutathione for ATHases. Natural evolution of function relies on mutagenesis and selection. In contrast to homogenous catalysts, ArMs bear the potential to be genetically optimized by mutagenesis. Directed evolution relies on the efficient high-throughput screening of genetic diversity to identify and characterize functionally evolved mutants. Parallel in vivo expression of Sav in E. coli (e.g. in 96-well plates) followed by cofactor addition would allow directed evolution of the corresponding ArMs. A challenge in the development of HTS methods for ArMs optimization is the presence of glutathione (GSH) in millimolar concentrations in aerobic E. coli cells. ${ }^{260}$ The soft acid character of the precious metals in ArMs favors their coordination to GSH. One way to decrease the cellular GSH content is to treat cell lysates with GSH scavengers such as electrophiles or oxidants. Ward and coworkers evaluated the potency of various GSH scavengers to recover artificial transfer hydrogenase activity in cellular media. ${ }^{261}$ From all the GSH scavengers tested, diamide 99, phenylvinylsulfone 100 and 2bromoacetophenone 101 led to the best recovery of activity. Up to $90 \%$ initial activity and similar ee were obtained with $\left[\eta^{5}-\left(\mathrm{C} p^{*}\right) \operatorname{Ir}(70) \mathrm{Cl}\right]$.Sav $\mathrm{S} 112 \mathrm{~A}$ for substrate 88 after incubation with 99 . With $10 \mathrm{mM} 99$ and only $2 \mathrm{~h}$ preincubation time, $>50 \%$ of the pure protein's activity and very similar ee's were obtained. When cell lysates were used, very good results could be obtained with $\left[\eta^{5}-\left(C p^{*}\right) \operatorname{Ir}(70) \mathrm{Cl}\right] \cdot$ Sav $\mathrm{S} 112 \mathrm{~K}(64 \%$ pure protein activity, - $68 \%$ ee) whereas the corresponding ArM with mutant Sav S112A yielded 
reduced ee and TON.

Scheme 31. Biotinylated Ir-pianostool complexes anchored within Sav are inactivated by physiological concentrations $(\sim 1 \mathrm{mM})$ of glutathione. Electrophiles and oxidizing agents react with glutathione and restore ATHase activity. Adapted with permission from ref. ${ }^{38}$ Copyright 2016 American Chemical Society.

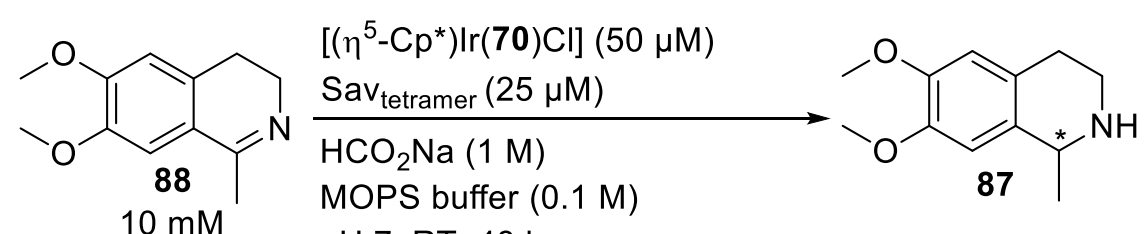

$10 \mathrm{mM} \quad \mathrm{pH} 7, \mathrm{RT}, 48 \mathrm{~h}$<smiles>CN(C)C(=O)N=NC(=O)N(C)C</smiles>

99: DiAm<smiles>C=CS(=O)(=O)c1ccccc1</smiles>

100: PheViSul<smiles>O=C(CBr)c1ccccc1</smiles>

101: BrPheOne
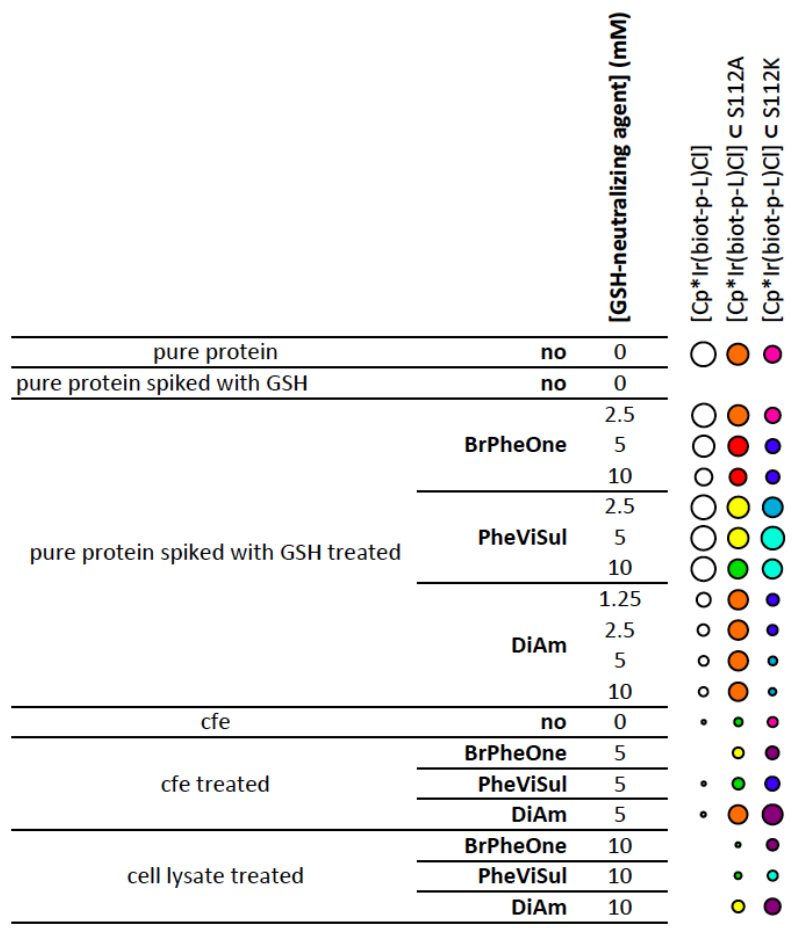

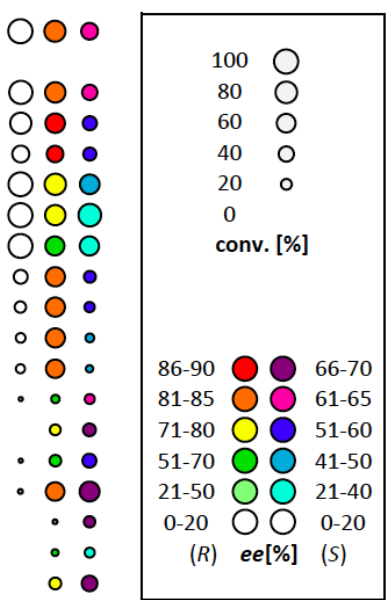

Transfer Hydrogenation of Imines, High-Throughput Screening. Ward and coworkers extended the glutathione scavenger strategy to implement a high-throughput genetic screening of artificial transfer hydrogenases. ${ }^{262}$ To parallelize Sav mutant expression, a 24-well deep well plate format was introduced. In six milliliter medium, sufficient Sav $(\simeq>0.5 \mathrm{mg})$ can be produced to run $1-2$ catalytic reactions. Accordingly, 
twenty-eight amino acids within a $15 \AA$ distance to the metal were selected for mutagenesis. Instead of introducing all 20 amino acids at each position, the effort was reduced to 12 amino acids: $A, V, L, D, E, Q, K, H, M, Y, S, P$ as representatives of the different types of amino acids (acidic, basic, polar, hydrophobic). The autoinduction medium Zyp-5052 was used to express all Sav isoforms, Scheme 32. After $24 \mathrm{~h}$ expression, cell free extracts of the mutants were prepared and biotin-4-fluorescein titration was applied to determine the number of free biotin-binding sites per well. To generate an artificial transfer hydrogenase, Sav was coupled to a biotinylated threelegged iridium pianostool complex $\left[\mathrm{Cp}^{*} \operatorname{Ir}(\mathbf{7 0}) \mathrm{Cl}\right]$, after the treatment of the cell-free extracts with 99. To produce an artificial metathase the cell free extracts containing Sav were combined to a biotinylated second-generation Grubbs-Hoveyda catalyst following immobilization of Sav on Sepharose-iminobiotin beads.

The two procedures summarized above allow to screening of 335 Sav mutants within 20 days (including mutagenesis, expression and activity screening).

Scheme 32. a) Streamlined Sav library production, isolation and screening for ATHase activity in cell-free extracts relying on diamide treatment; b) metathesis activity in cell free extracts using a reversible imminobiotin-sepharose immobilization. Adapted with permission from ref. ${ }^{262}$ Copyright MacMillan 2016. 


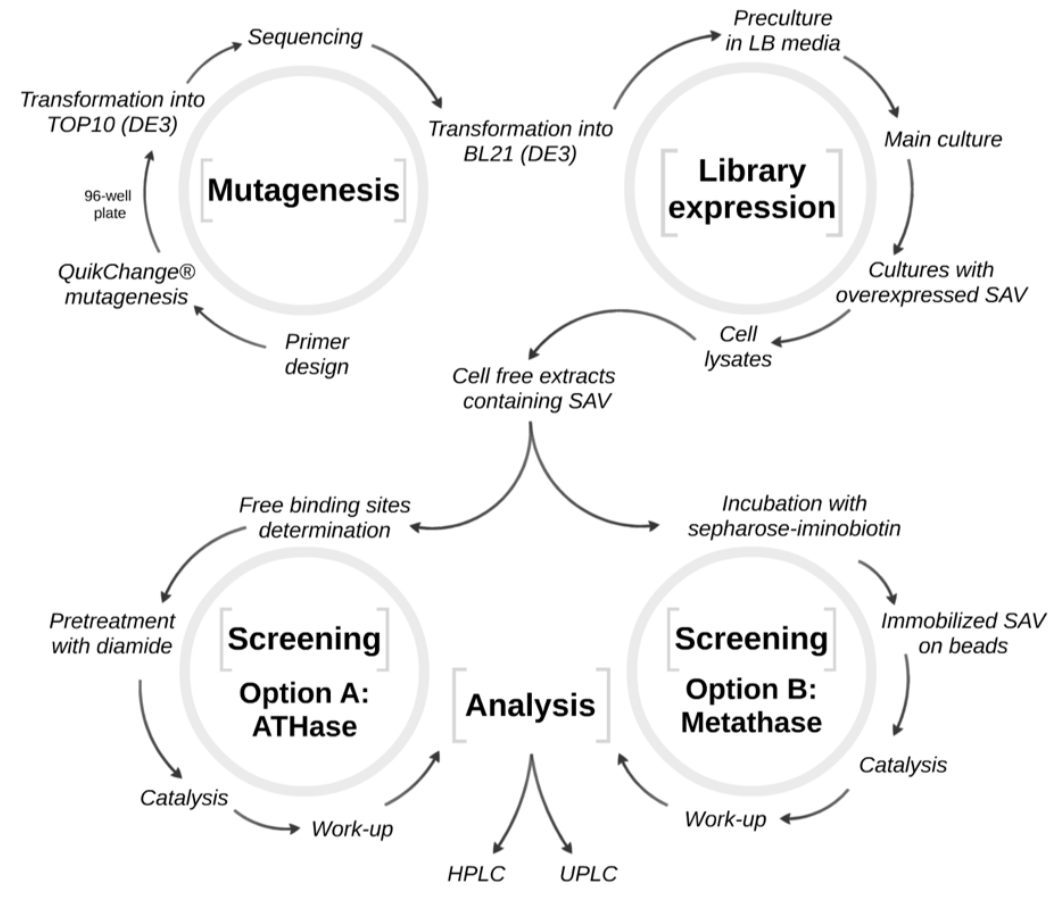

The streamlined protocol allows the preparation of cell lysates and corresponding CFEs containing the overexpressed Sav isoforms. The simple preincubation of either cell lysates or CFEs with 5 mM diamide 99 (for ATH) or the immobilization of Sav from CFEs on the iminobiotin-Sepharose beads (for olefin metathesis) allows to restore most of the catalytic activity.

Transfer Hydrogenation of Imines, Cascade with Amine Oxidase. In the Ward group, initial efforts towards the creation of cascade reactions aimed at combining an artificial transfer hydrogenase with a natural amine oxidase. ATHase $\left[\eta^{5}-\left(C p^{*}\right) \operatorname{Ir}(70) C l\right] \cdot S a v$ S112T is moderately $(R)$-selective (59 \% ee) for imine $89 .{ }^{263}$ The ATHase was combined with monoamineoxidase MAO-N which has very high selectivity for the oxidation of $(S)$ amine 102, Scheme 33. Unfortunately, shortly after the reaction had started, the ATHase was inhibited by the hydrogen peroxide produced by the MAO upon oxidation of the amine substrate. Addition of catalase restored activity and allowed the dynamic kinetic resolution to afford $(R)-102$ in $>99 \%$ ee. The same strategy was applied for the one pot dynamic kinetic resolution of pyrrolidines 103 and 105 which were obtained in essentially 
enantiopure $(R)$-form thanks to the exquisite $(S)$-selectivity of MAO-N. Similarly, tertiary imine 104 was reduced to the corresponding $(R)$-amine 105 with $>99 \%$ ee and 65 TON. Cyclic imine 104 is in equilibrium with the ring-open keto form 106 at $\mathrm{pH}$ 7.5. Interestingly, the nature of the Sav mutant determines which substrate is preferentially reduced: $\left[\eta^{5}-\left(C p^{*}\right) \mid r(70) C l\right] \cdot S a v S 112 A-K 121 T$ produces preferentially the imine 104 (76 : 11). In contrast, $\left[\eta^{5}-\left(\mathrm{Cp}^{*}\right) \operatorname{Ir}(\mathbf{7 0}) \mathrm{Cl}\right]$. Sav $\mathrm{S} 112 \mathrm{G}$ favors the reduction of the keto form of 104, yielding the corresponding alcohol $107(3: 79)$.

Transfer Hydrogenation of Enone and Nicotinamide Regeneration. Many enzymedriven reactions utilize $\mathrm{NAD}(\mathrm{P}) \mathrm{H}$ as cofactor which increases the production costs of biocatalytic transformations. Several enzymatic $\mathrm{NAD}(\mathrm{P}) \mathrm{H}$ regeneration systems are known. Additionally, $\mathrm{NAD}(\mathrm{P}) \mathrm{H}$ regeneration systems based on organometallic catalysts were developed. However only few of them actually work in cascade reactions in the presence of $\mathrm{NAD}(\mathrm{P}) \mathrm{H}$-dependent enzymes. Ward and coworkers applied the ATHase $\left[\eta^{5}-\left(\mathrm{Cp}^{*}\right) \operatorname{Ir}(\mathbf{7 0}) \mathrm{Cl}\right] \cdot$ WT Sav to recycle NADH in a cascade with $\mathrm{NADH}$-dependent hydroxybiphenyl monooxygenase (HbpA, Scheme 34). ${ }^{263}$ In this reaction, hydroxybiphenyl 108 was converted to the corresponding catechol 109 with TON > 99 in the presence of $\mathrm{O}_{2}$ as oxidant. No catalase was required since the reaction's byproduct is water.

Scheme 33. Enzyme cascades combining an ATHase and an amine oxidase afford enantiopure amines. This can be applied for the synthesis of isoquinolines, $a-b)$ and pyrrolidines, nicotine, c) and pipecolic acid d). Addition of either horseradish peroxidase or catalase prevents the oxidation of the iridium cofactor by hydrogen peroxide resulting from MAO activity. 
a)

MAO-N

ATHase

catalase

N9<smiles>CC1NCCc2ccccc21</smiles>

$\mathrm{HCO}_{2} \mathrm{Na}$

$\underset{\text { MOPS-buffer }}{\stackrel{\mathrm{O}_{2} \text { (air) }}{\longrightarrow}}$

$\mathrm{pH} 7.8,37^{\circ} \mathrm{C}$<smiles>C[C@H]1NCCc2ccccc21</smiles>

b)

MAO-N

ATHase<smiles>[O-]C1CCC([C@@H]2CCCN2)CC1C1=NCCC1</smiles>

catalase

$\mathrm{HCO}_{2} \mathrm{Na}$

$\mathrm{O}_{2}$ (air)

MOPS-buffer $\mathrm{pH} 7.8,37^{\circ} \mathrm{C}$<smiles>C1CCC(C2CCCN2)CC1</smiles>

c)

MAO-N

ATHase

$\overbrace{N}$

catalase

$\mathrm{HCO}_{2} \mathrm{Na}$

$\mathrm{O}_{2}$ (air)

MOPS-buffer

$\mathrm{pH} 7.8,37^{\circ} \mathrm{C}$<smiles></smiles>

$\overbrace{N=104}^{>}$<smiles>C=C</smiles><smiles>CNCCCC(=O)c1cccnc1</smiles>

d)

LAAO

ATHase<smiles>NCCCC[C@H](N)C(=O)O</smiles>

DAAO

$\mathrm{HCO}_{2} \mathrm{Na}$

$\underset{\text { MOPS-buffer }}{\stackrel{\mathrm{O}_{2} \text { (air) }}{\longrightarrow}}$

$\mathrm{pH} 7.8,37^{\circ} \mathrm{C}$<smiles>O=C(O)C1CCCCN1</smiles>

Scheme 34. ATHases can be used to recycle NADH using formate as reductant. The $\mathrm{NADH}$-recycling ATHase can be applied in a cascade with HbpA monooxygenase to produce dihydroxy biphenyl. 

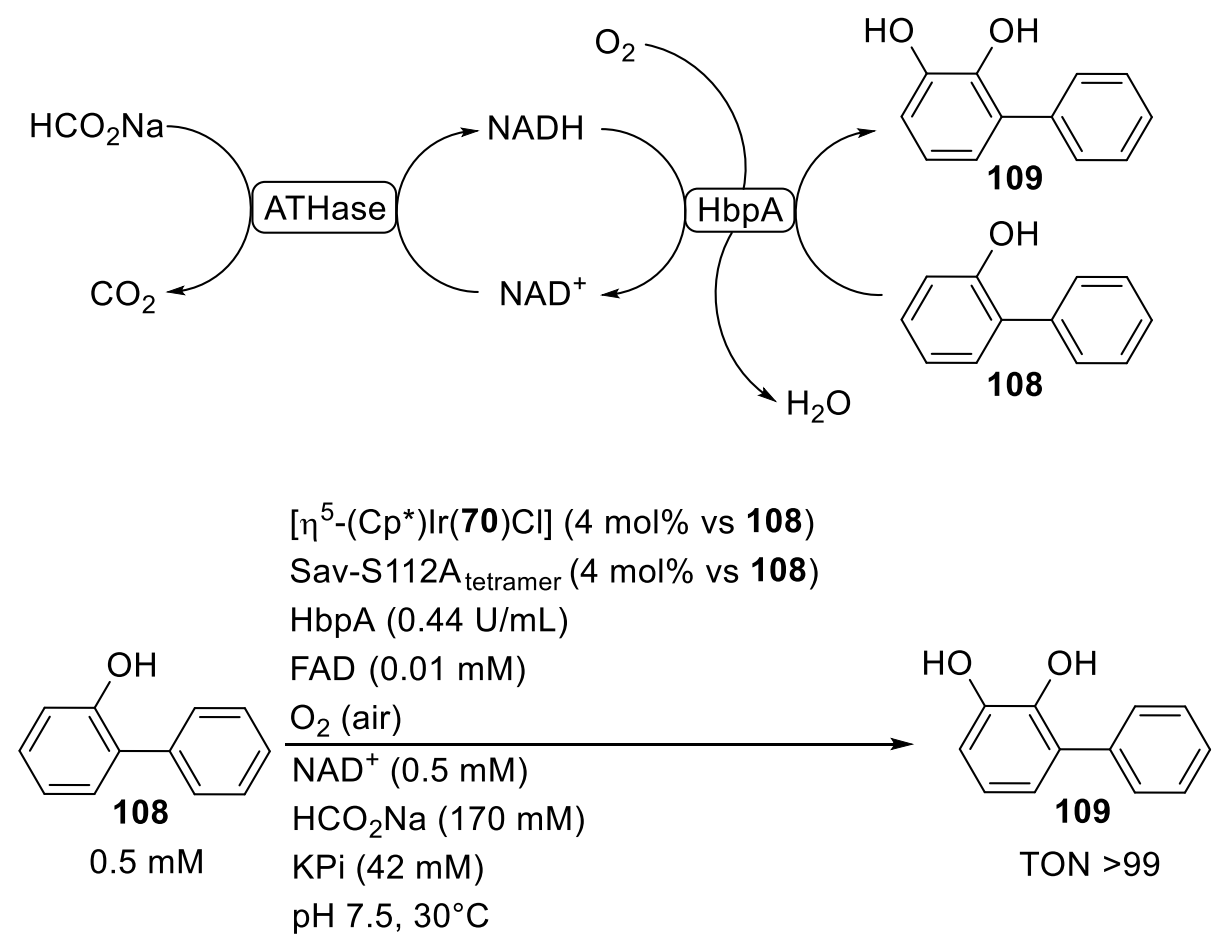

The NADH regeneration employing ArMs and sodium formate as hydride source (Scheme 35) was also investigated by Salmain and coworkers. The Papain scaffold was used to host the precious metal $d^{6}$-pianostool complexes using a covalent anchoring strategy via a maleimide moiety. ${ }^{242-243}$ They evaluated the catalytic transfer hydrogenation performance for the reduction of NAD 111 into NADH 110. The authors showed that the artificial transfer hydrogenase $77 \cdot$ PAP has comparable catalytic activity to the free cofactor 77 and to the benchmark complex $\left[\left(\eta^{5}-\mathrm{Cp}^{*}\right) \mathrm{Rh}(\mathrm{bpy}) \mathrm{H}_{2} \mathrm{O}\right]^{2+} .{ }^{264}$ Disappointingly, no attempt was reported by the coauthors to couple this NADH regeneration ArM with natural $\mathrm{NADH}$-consuming enzymes.

Scheme 35. Covalent anchoring of 77 in PAP yields an ArM that catalyzes the reduction of $\mathrm{NAD}^{+}$to $\mathrm{NADH}$ using formate as hydride source. 


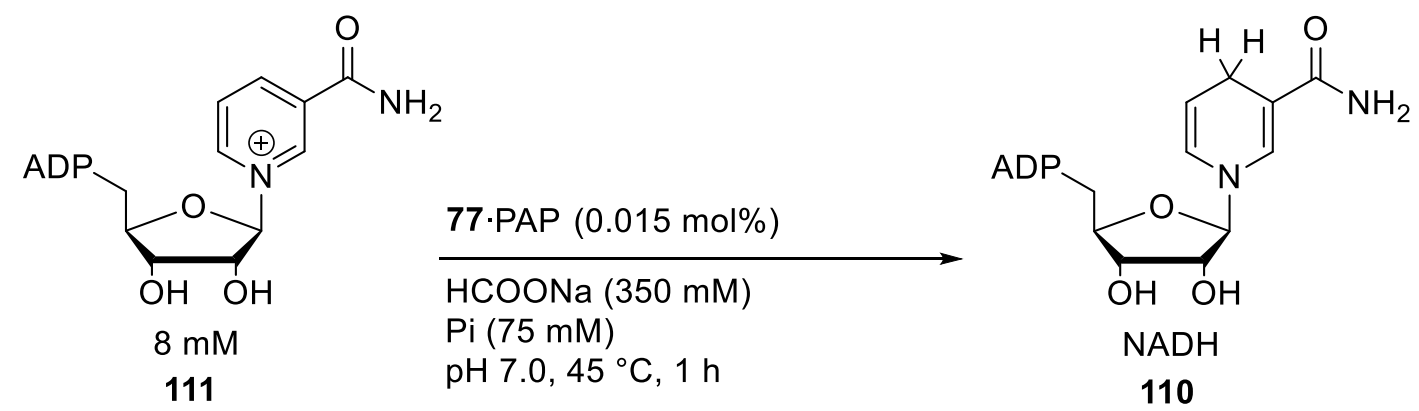

Transfer Hydrogenation of Enones, Regeneration of NADH Mimics. Mimics of $\mathrm{NAD}(\mathrm{P}) \mathrm{H}$ are attractive in biocatalysis as the natural $\mathrm{NAD}(\mathrm{P}) \mathrm{H}$ cofactors are costly. Nonenzymatic regeneration systems based on organometallic catalysts are only moderately active when applied in cascades as they are typically inhibited by enzymes. Based on a previous finding that ATHase $\left[\eta^{5}-\left(\mathrm{C} p^{*}\right) \operatorname{Ir}(\mathbf{7 0}) \mathrm{Cl}\right] \cdot$ Sav S112A regenerates NADH using sodium formate as hydride source, Ward and coworkers set out to investigate whether NADH mimics could be regenerated. The ATHases were applied in a cascade with enereductase TsOYE of the old yellow enzyme family which was previously shown to accept NADH mimics as reducing equivalents. ${ }^{265}$ Various ATHase isoforms with point mutations at positions Sav S112, K121 and L124 were tested towards the reduction of five NAD ${ }^{+}$ mimics ( $\mathrm{mNAD}^{+}$hereafter). The model substrate $\mathrm{N}$-ethyl-2-methylmaleimide 113 was converted by TSOYE to the corresponding enantiopure unsaturated imide 114, Scheme 36. Only the ketone-bearing $m N A D^{+} 112$ afforded high turnover numbers $(100-1000$ TON) and enantioselectivity ( 90\% ee for $(R)$-product). Sav-mutant S112K showed the highest conversion $(\sim 100 \%)$. The protein prevents the inactivation of the organometallic cofactor by TsOYE. The $(R)$-selectivity of the cascade could be increased to $98 \%$ ee when the Ir-catalyst concentration was reduced to $5 \mu \mathrm{M}$ and the substrate was added slowly. This strategy helps to minimize the reduction of the substrate by the ATHase, which leads to an erosion of ee. The maximum TON achieved was $>1980$. Other substrates tested included ketoisophorone 115 and 2-methylcyclohexenone 116 which 
were converted into the corresponding products with up to $86 \%$ ee $((R)$-product) and $94 \%$ ee $((R)$-product), respectively, and TONs ranging between 550 and 1655 .

Scheme 36. An ATHase for the recycling of NADH-mimics in the presence of an ene reductase. a) Structure of $\mathrm{NAD}^{+}$and $\mathrm{mNAD}^{+} ; \mathrm{b}-\mathrm{c}$ ) the ATHase can be applied in an enzyme cascade in the presence of ene-reductase TSOYE to afford highly enantioenriched $\alpha, \beta$-saturated ketones from the corresponding enones.

a)<smiles>NC(=O)c1ccc[n+](Cc2ccccc2)c1</smiles><smiles>CC(=O)c1ccc[n+](Cc2ccccc2)c1</smiles><smiles>Nc1ncnc2c1ncn2C1OC2(COP(=O)([O-])[O-])C(O)C1C2O[N+](=O)[O-]</smiles>
mNAD 112

b)

c)

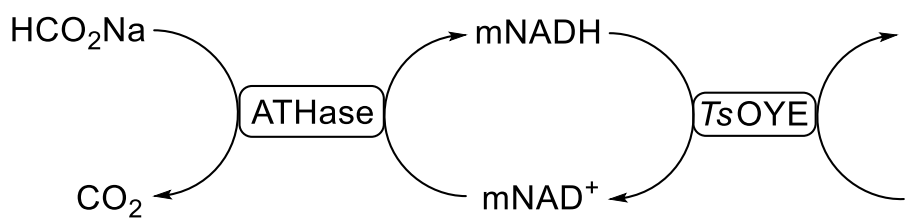

$$
\text { [ } \left.\eta^{5}-\mathrm{Cp}{ }^{*} \operatorname{Ir}(70) \mathrm{Cl}\right]
$$

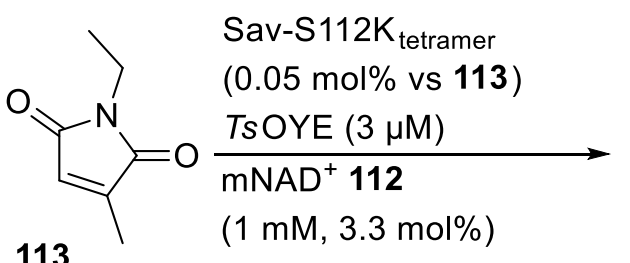

113 $30 \mathrm{mM}$ $\mathrm{HCO}_{2} \mathrm{Na}(2 \mathrm{M})$ MOPS buffer $(0.6 \mathrm{M})$ $\mathrm{pH} 7,30^{\circ} \mathrm{C}$<smiles>O=C(O)c1ccc[n+](Cc2ccccc2)c1</smiles>

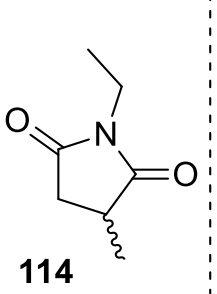

114<smiles>N#Cc1ccc[n+](Cc2ccccc2)c1</smiles>

114 113 up to $98 \%$ ee $(R) \quad 115: 86 \%$ ee $(R), 951$ TON up to $>1980$ TON) $116: 94 \%$ ee $(R), 1655$ TON<smiles>CC1=CCCCC1=O</smiles><smiles>CCN1C(=O)C=C(C)C1=O</smiles>

Ward and coworkers demonstrated that ATHase $\left[\eta^{5}-\left(C p^{*}\right) \operatorname{Ir}(\mathbf{7 0}) \mathrm{Cl}\right]$.Sav can be applied in the diasteroselective transfer hydrogenation of $\mathrm{NAD}^{+}$with sodium formate. ${ }^{266}$ In 
phosphate buffer $(\mathrm{pH} 7.5)$ and in the absence of Sav, the reduction of $\mathrm{NAD}^{+}$by $\mathrm{DCO}_{2} \mathrm{Na}$ proceeded with a diastereomeric excess de $=38 \%$. For $\left[\eta^{5}-\left(\mathrm{Cp} p^{*}\right) \operatorname{Ir}(70) \mathrm{Cl}\right] \cdot \mathrm{Sav}$ S112A and $\left[\eta^{5}-\left(C p^{*}\right) \operatorname{Ir}(70) \mathrm{Cl}\right] \cdot$ Sav S112K, the de increased to $87 \%$ and $90 \%$ respectively. In stark contrast to the reduction of either ketones or imines, both ATHases yielded the same enantiomer as determined by ${ }^{1} \mathrm{H}-\mathrm{NMR}$.

Transfer Hydrogenation of Imines, NADH-dependent ATHase. Living organisms rely widely on $\mathrm{NAD}(\mathrm{P}) \mathrm{H}$ as redox cofactor to modulate redox reactions. The artificial transfer hydrogenases developed in the Ward group utilize formate as hydride source. To integrate an ATHase into an in vivo cascade, it would be desirable to use $\mathrm{NAD}(\mathrm{P}) \mathrm{H}$ as hydride source. To address this challenge, Ward and coworkers screened a number of bis-imino Ir-Cp* complexes for the reduction of 1-methyl-dehydroisoquinoline 89 using NADH as hydride source. ${ }^{267}$ The most active ligand identified was 4,7-dihydroxy-1,10phenantroline (117). Complex $[(98) \operatorname{Ir}(117) \mathrm{Cl}]^{+}$afforded $\sim 200 \mathrm{TON}$ in $20 \mathrm{~h}$. Next, to recycle the spent $\mathrm{NADPH}$, glucose dehydrogenase $(\mathrm{GDH})$ was added to the cascade for the reduction of imine 89. By screening various Sav isoforms, $[(\mathbf{9 8}) \operatorname{Ir}(\mathbf{1 1 7}) \mathrm{Cl}] \cdot \mathrm{Sav} \mathrm{K} 112 \mathrm{R}$ yielded the highest conversion in 14 hours (up to 961 TON). Unfortunately, amine 102 was produced in low ee $(13 \%(R)-102)$, Scheme 37 . To upgrade the ee via a dynamic kinetic resolution, monoamine oxidase (MAO-N) and catalase were added to the ATHase-GDH cascade. The four-enzyme cascade yielded amine $(R)-102$ with $>99 \%$ ee and $>99$ TON, Scheme 37 .

Scheme 37: A biotinylated $[(98) \operatorname{Ir}(117) \mathrm{Cl}]^{+}$cofactor anchored within Sav can rely on NADPH as reducing agent for the asymmetric transfer hydrogenation of imines. ${ }^{267}$ This ATHase was integrated in a four-enzyme cascade to produce enantioenriched 102 , relying on glucose as hydride source (blue frame) and MAO-N to upgrade the enantioselectivity of the ATHase (red frame). Adapted with permission from ref. ${ }^{267}$ Copyright 2016 American Chemical Society. 

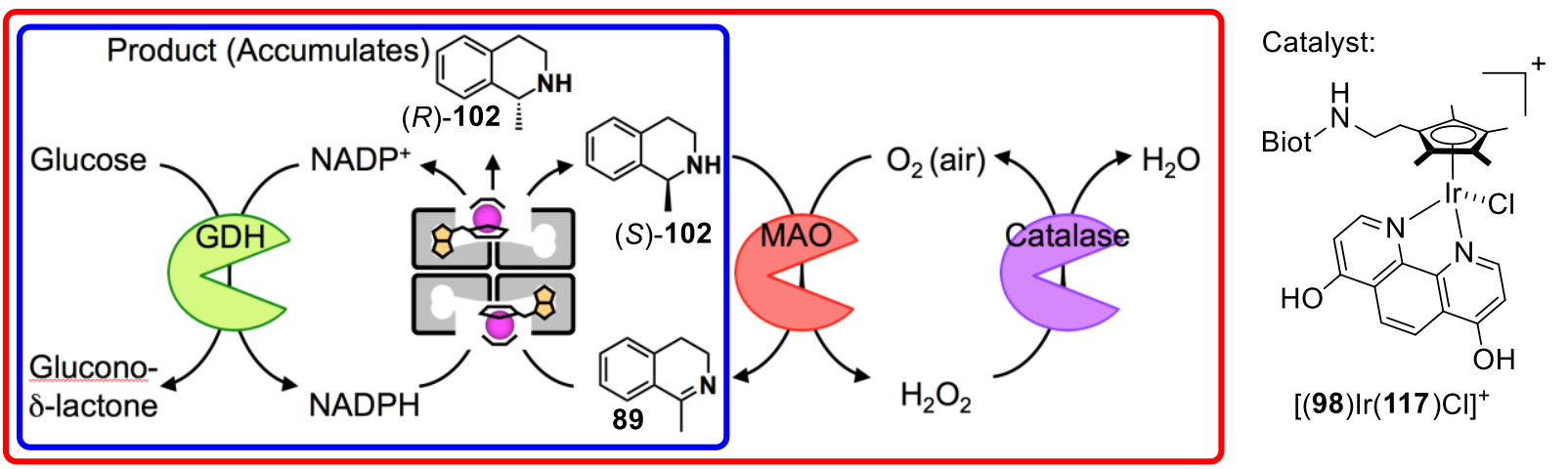

\begin{tabular}{|cccc|}
\hline Sav & Hydride source & TON $_{\text {Ir }}$ ee $(\%)$ \\
\hline no Sav & NAD+/glucose & 75 & $1(R)$ \\
WT & NAD+/glucose & 202 & $17(S)$ \\
K121R & NAD+/glucose & 679 & $13(S)$ \\
K121R & NADP+/glucose & 961 & $13(S)$ \\
\hline
\end{tabular}

$50 \mu \mathrm{M}[(\mathbf{9 8}) \operatorname{lr}(\mathbf{1 1 7}) \mathrm{Cl}]-S a v(0.1 \mathrm{~mol} \%)$,

$0.1 \mathrm{mg} / \mathrm{mL} \mathrm{GDH}, 1 \mathrm{mM} \mathrm{NAD}(\mathrm{P})^{+}$

(2 mol\%), $50 \mathrm{mM}$ substrate $89,60 \mathrm{mM}$

glucose, $0.3 \mathrm{M}$ MOPS ( $\mathrm{pH} 7.9$ ), $37^{\circ} \mathrm{C}$

\begin{tabular}{ccccc} 
Sav & $\begin{array}{c}\text { MAO-N } \\
(\mathrm{mg} / \mathrm{mL})\end{array}$ & $\begin{array}{c}\text { Time } \\
(\mathrm{h})\end{array}$ & $\begin{array}{c}\text { Conv. } \\
(\%)\end{array}$ & $\begin{array}{l}\text { ee } \\
(\%)\end{array}$ \\
\hline no Sav & 0.2 & 12 & 6 & $>99(R)$ \\
K121R & 0.2 & 12 & 89 & $75(R)$ \\
K121R & 0.2 & 24 & $>99$ & $>99(R)$ \\
K121R & - & 24 & $>99$ & $13(R)$ \\
\hline
\end{tabular}

$100 \mu \mathrm{M}[(\mathbf{9 8}) \operatorname{lr}(\mathbf{1 1 7}) \mathrm{Cl}]-\mathrm{Sav}(0.2 \mathrm{~mol} \%), 0.1$

$\mathrm{mg} / \mathrm{mL} \mathrm{GDH}, 0.2 \mathrm{mg} / \mathrm{mL} \mathrm{MAO}, 500 \cup$ catalase,

$1 \mathrm{mM} \mathrm{NADP}^{+}(2 \mathrm{~mol} \%), 50 \mathrm{mM}$ substrate 89 ,

$100 \mathrm{mM}$ glucose, $0.3 \mathrm{M}$ MOPS $(\mathrm{pH} 7.9), 37^{\circ} \mathrm{C}$

Transfer Hydrogenation of Imines, Allosteric regulation. In living organisms, enzymatic activity is typically (cross)-regulated via weak molecular interactions. Molecular or physical (e.g. optical, magnetic, temperature etc.) tools with the ability to control artificial metalloenzyme's activity would be highly desirable to regulate enzyme cascade in vivo. Ward and coworkers developed a latent artificial transfer hydrogenase that is activated by a protease, Scheme $38 .{ }^{268}$ As cofactor, a biotinylated Ir-Cp* complex $\left[(98) \mid \mathrm{rCl}_{2}\left(\mathrm{H}_{2} \mathrm{O}\right)\right]$ was selected. As demonstrated previously, activation by an additional ligand is required to ensure ATHase activity. Inspired by the work of Hilvert and coworkers $^{269}$ they screened and identified a Ser-Gly-Phe tripeptide (SGF) that leads to significant enhancement of the catalytic activity upon coordination to $\left[(\mathbf{9 8}) \mathrm{IrCl}_{2}\left(\mathrm{H}_{2} \mathrm{O}\right)\right]{ }^{269}$ Fused to the $C$-terminus of Sav and flanked by a protease-recognition sequence, the tripeptide becomes available to activate the cofactor upon digestion of the $C$-terminus by protease Factor Xa. While $\left[(98) \mathrm{IrCl}_{2}\left(\mathrm{H}_{2} \mathrm{O}\right)\right] \cdot$ WT Sav was only moderately active for the reduction of pentafluoroacetophenone 118 (29 TON), addition of SGF led to a fiftyfold increase in activity (1431 TON). Next, the SGF peptide was fused to the C-terminus of Sav preceeded by the Factor Xa protease cleavage site. Incubation of the ATHase with 
Factor Xa prior to addition of formate and the ketone $\mathbf{1 1 8}$ led to significantly improved TONs (compare 23 for the undigested to 1778 TON, Scheme 38). Such irreversible activation is widespread amongst enzymes and is commonly referred to zymogens.

Scheme 38: An artificial transfer hydrogenase is upregulated by a protease. A zymogen is formed upon incorporation of $\left[(\mathbf{9 8}) \mathrm{IrCl}_{2}\left(\mathrm{H}_{2} \mathrm{O}\right)\right]$ into Sav K121A bearing an SGF tripeptide at its $C$-terminus. Incubation of the zymogen with the protease Factor $\mathrm{Xa}$ releases the SGF ligand to afford $[(\mathbf{9 8}) \operatorname{Ir}(\mathrm{SGF}) \mathrm{Cl}] \cdot$ Sav K121A which displays significant ATHase activity b). ${ }^{268}$ Adapted with permission from ref. ${ }^{268}$ Copyright Wiley VCH 2016.

a)

$$
\mathrm{L}=\mathrm{Cl}^{-}, \mathrm{H}_{2} \mathrm{O}
$$

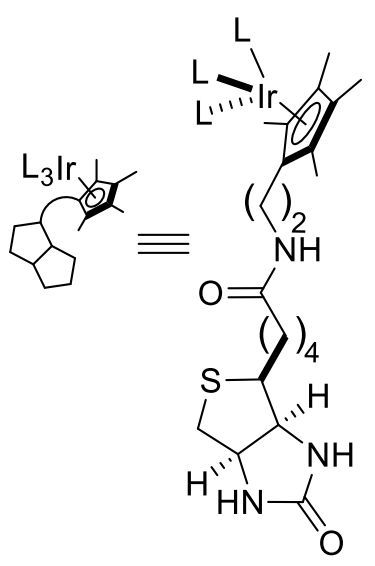

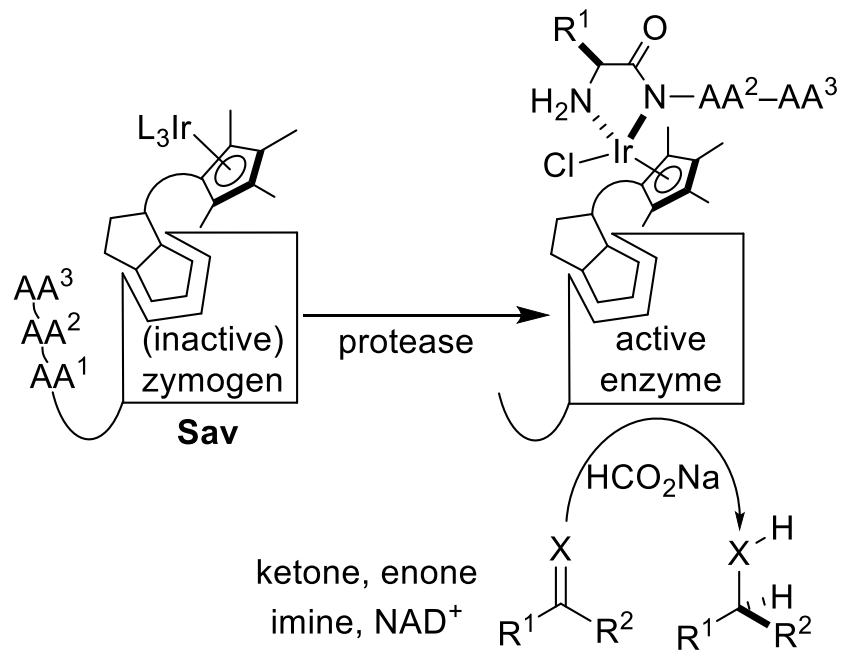

b)<smiles>CC(=O)c1c(F)c(F)c(F)c(F)c1F</smiles>

Sav-K121A-SGF $(100 \mu \mathrm{M})$ $\left[(98) \mid r C l_{2}\right]_{2}(25 \mu \mathrm{M})$

FactorXa $(5 \mu \mathrm{g})$ $\mathrm{HCO}_{2} \mathrm{Na}(1.5 \mathrm{M})$ MOPS $0.6 \mathrm{M} \mathrm{pH} 7.8$ $100 \mathrm{mM}$ $37^{\circ} \mathrm{C}, 24 \mathrm{~h}$

\begin{tabular}{cccc} 
Sav-mutant & FactorXa & TON & ee $(\%)$ \\
\hline K121A-SGF & - & 23 & - \\
K121A-SGF & + & 1778 & $39(R)$ \\
no protein & - & 8 & -
\end{tabular}

reaction procedure:

1) mix Sav + cofactor in MOPS

2) add Factor $X a$

3) incubate $12 \mathrm{~h}$

4) add substrate and formate

5 ) incubate for $24 \mathrm{~h}$

\section{Transfer Hydrogenation of Imines using Ribonuclease $\mathbf{S}$ as host protein.}

Ribonuclease A digestion by subtilisin affords a clove-shaped S-protein as well as an $\alpha$ helical S-peptide. The S-protein and the S-peptide bind to each other with nanomolar affinity to form a functional RNase S enzyme. Sträter, Ward and coworkers set out to engineer RNase $S$ into an artificial metalloenzyme. ${ }^{270}$ S-peptide variants with metal binding capacity including non-natural amino acids were produced by solid-phase 
synthesis. Incubation of metallated S-peptides with S-protein may allow to engineer RNase $\mathrm{S}$ isoforms displaying new-to-nature activities. Tuning of reaction activity and selectivity may be possible via second coordination sphere interactions stemming mainly from the S-protein. This concept was tested with the asymmetric transfer hydrogenation of the cyclic imine $\mathbf{8 8}$. The authors speculated that two histidine residues provided by the host protein may activate the cofactor. The RNase S crystal structure allowed to identify two residues (K7 and Q11) in the proximity of the $\alpha$-helical S-peptide. Thus RNase $S$ $\mathrm{K} 7 \mathrm{H}-\mathrm{R} 10 \mathrm{Q}-\mathrm{Q} 11 \mathrm{H}$ isoform was synthesized and incubated with $\left[\eta^{5}-\left(\mathrm{Cp}^{*}\right) \mid \mathrm{rCl}{ }_{2}\right] 2$, $\left[\eta^{5}-\right.$ $\left.\left(\mathrm{Cp}^{*}\right) \mathrm{RhCl}_{2}\right]_{2}$ or $\left[\eta^{6}-(p \text {-cymene }) \mathrm{RuCl}_{2}\right]_{2}$ prior to complexation with the S-protein. The iridium RNase S K7H-R10Q-Q11H complex was most active affording 28 TON. The corresponding WT RNase S however yielded 70 TON under the same conditions, suggesting that the metal does not bind to the two-histidines introduced in the S-peptide. The enantioselectivity was very low (4-8\% ee (S)-87) for both S-peptide triple mutant and WT. When the WT S-peptide Ir complex was used in the absence of S-protein, the ee increased minimally to $22 \%(S)-87$ at the cost of a lower activity (10 TON), suggesting a modest protein acceleration. The best ee obtained with the RNase $S$ system was $39 \%(S)$-amine 87 obtained with RNase S mutant H12A in which the only histidine within the WT S-peptide was replaced by an alanine.

Transfer Hydrogenation of Imines, hCAll as host protein. Most artificial metalloenzymes developed in the Ward group are based on the (strept)avidin-biotin technology to anchor a transition metal complex within a protein environment. Human carbonic anhydrase II (hCAll) is another attractive scaffold for ArM design. It is a monomeric protein which binds with sub-nanomolar affinity numerous arylaminosulfonamide derivatives. ${ }^{271}$ In an initial effort to build an ArM from hCAll, Ward and coworkers tethered pianostool complex $\left[\eta^{6}-\left(\mathrm{C}_{6} \mathrm{Me}_{6}\right) \mathrm{Ru}(\text { bispyridine }) \mathrm{Cl}\right]^{+}$to a benzene sulfonamide anchor. ${ }^{272}$ The Ru-cofactor did not afford any transfer hydrogenation activity 
but bound to hCAll with nanomolar affinity. A second arylsulfonamide cofactor was based on iridium complexes $\left[\eta^{5}-(\mathrm{Cp} *) \operatorname{Ir}(\right.$ pico $\left.) \mathrm{Cl}\right](\mathbf{1 1 9 - 1 2 0}) .{ }^{273}$ In the asymmetric transfer hydrogenation of cyclic imine 88 inside WT hCAll, this ArM afforded 9 TON and up to 70 ee for (S)-salsolidine 87, Scheme 39. A crystal structure of complex $\left[\eta^{5}-\left(\mathrm{Cp}^{*}\right) \operatorname{Ir}(\mathbf{p i c o}) \mathrm{Cl}\right]$ 119.WT hCAll was solved which served as a model for a computational enzyme redesign. In a collaboration with the Baker group, Ward and coworkers relied on the Rosetta design algorithm to identify mutants that may stabilize the Ir-cofactor within hCAll. ${ }^{274}$ The hypothesis was that cofactor stabilization and localization might increase the relative concentration of the active catalytic species vs. unproductive conformations of the ATHase. Rosetta predicted four hCAll constructs containing up to 8 mutations (d1 - d4) that were predicted to display increased affinity. Binding assays of the mutated hCAll revealed that indeed the designs had on average a $\sim 50$-fold increased affinity vs. WT hCAll $\left(K_{d}=\sim 0.33-0.46 \mathrm{nM}\right.$ vs. $\left.21 \mathrm{nM}\right)$. Gratifyingly, the imine reduction activity was also positively affected: up to 98 TON with $74 \%$ ee $(S)-87$ with the hCA II d1 construct. The best enantioselectivity was obtained with the design hCAll $\mathbf{d} 4$ and afforded $92 \%$ ee (S)-87 and 78 TON. Substituting a single methyl- by a propyl group on the $\mathrm{Cp}^{*}$ cap in the

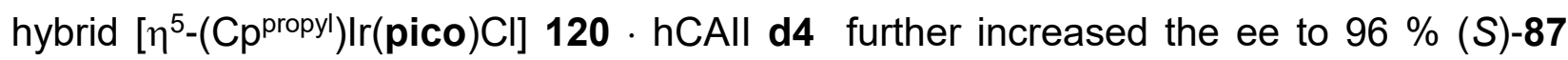
and 59 TON at $4^{\circ} \mathrm{C}$, Scheme 39.

Scheme 39, Rosetta-optimization of an ATHase based on human carbonic anhydrase II. a) Reaction conditions; b) structure of the pianostool complex and computationallydesigned mutants predicted to increase the affinity of $\left[\eta^{5}-\mathrm{Cp}{ }^{*} \mid \mathrm{I}(\mathbf{p i c o}) \mathrm{Cl}\right]$ for $\mathrm{hCA} \| \mathrm{l}$ and $\mathrm{c}$ ) X-ray crystal structure of the WT ATHase crystal structure (PDB 3zp9) used as template for computational mutagenesis with the Rosetta design algorithm (complex stabilizing residues displayed in purple). Adapted from ref. ${ }^{274}$ Copyright 2015 American Chemical Society. 

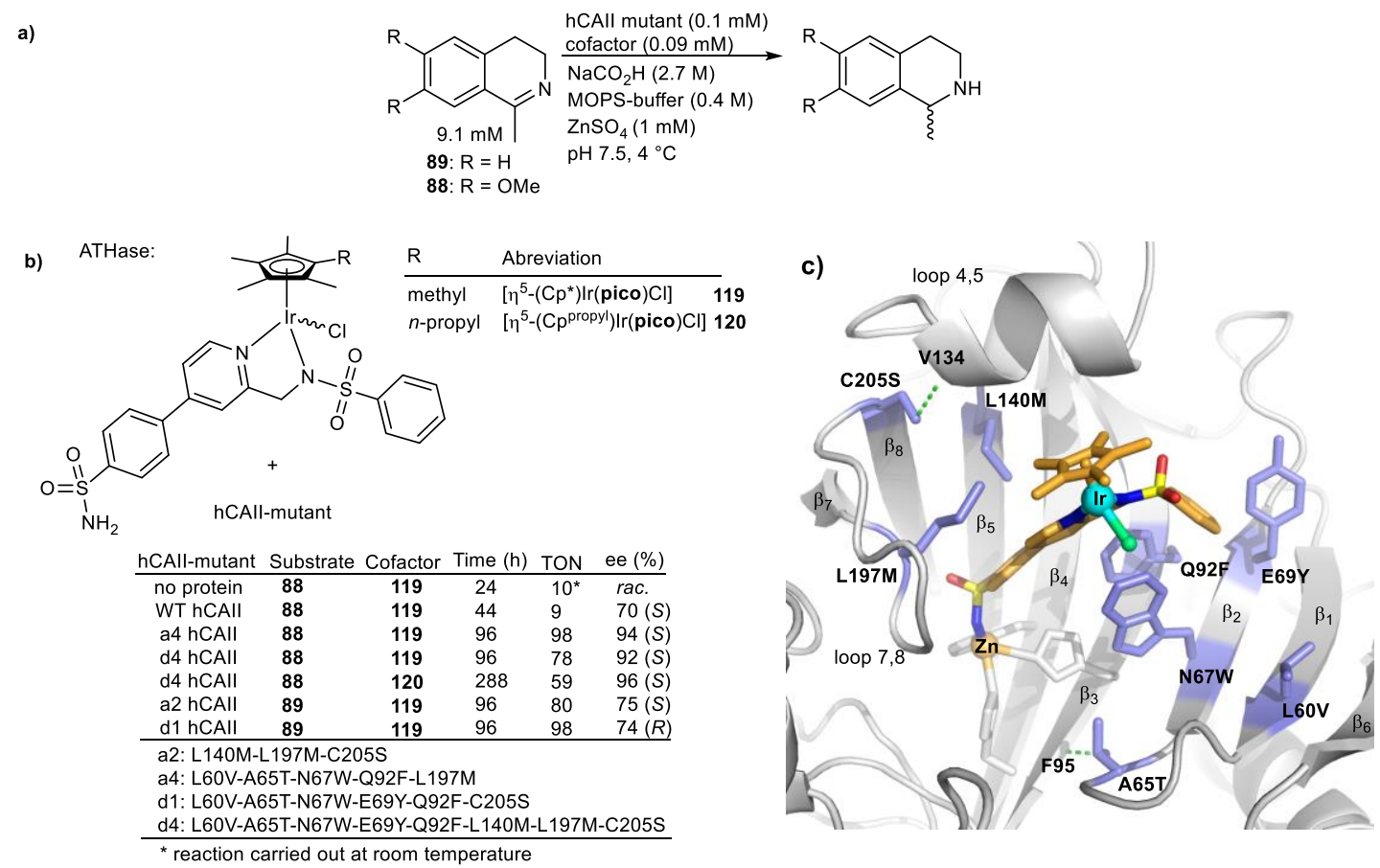

Transfer Hydrogenation of Enones. Noyori-type pianostool complexes have been widely applied in the asymmetric reduction of enones. ${ }^{275}$ To test whether ATHase $\left[\eta^{5}\right.$ $\left.\left(C p^{*}\right) \operatorname{Ir}(70) C l\right] \cdot W T$ Sav chemoselectively reduces enones to the corresponding ketones, Ward and coworkers designed the profluorescent enone 121. Upon Michael addition of a hydride, a spontaneous E1cB elimination leads to the release of fluorescent umbelliferone, Scheme 40 a). ${ }^{276}$ As little as $1 \mu \mathrm{M}$ of $\left[\eta^{5}-\left(\mathrm{Cp} \mathrm{p}^{*}\right) \operatorname{Ir}(\mathbf{7 0}) \mathrm{Cl}\right] \cdot \mathrm{WT}$ Sav sufficed to observe the appearance of the fluorescent product. Screening purified Sav mutants in positions S112X and K121X led to the identification of $\left[\eta^{5}-\left(\mathrm{C} p^{*}\right) \operatorname{Ir}(\mathbf{7 0}) \mathrm{Cl}\right] \cdot$ Sav K121F with a twenty fold improved activity vs. WT.

With in vivo-applications in mind, Ward and coworkers encapsulated the best ATHase $\left[\eta^{5}-\left(\mathrm{C} p^{*}\right) \operatorname{Ir}(\mathbf{7 0}) \mathrm{Cl}\right] \cdot S a v \mathrm{~K} 121 \mathrm{~F}$ within a polymersome. The polymersome consisted of block-co-polymers poly(2-methyloxazoline)- $\beta$-poly(dimethylsiloxane)- $\beta$-poly(2methyloxazoline) (PMOXA-PDMS-PMOXA) developed by Meier and coworkers Scheme 40 b). ${ }^{277}$ Upon incorporation inside the capsule, the ATHase activity was reduced however. Activity could be improved upon incorporation of the bacterial outer membrane 
protein ompF into the polymersome which assists small molecule trafficking across the membrane.

Scheme 40. An artificial transfer hydrogenase consisting of Sav and $\left[\left(\eta^{5}-\mathrm{Cp} \mathrm{p}^{*}\right) \operatorname{lr}(\mathbf{7 0}) \mathrm{Cl}\right]$ reduces enones. a) The reduced ketone spontaneously undergoes an $\mathrm{E} 1 \mathrm{cB}$ elimination to release umbelliferone, thus allowing high-throughput genetic optimization of ATHase activity; b) the best ATHase-K121F is active inside a polymersome equipped with bacterial pore protein ompF. Adapted with permission from ref. ${ }^{38}$ Copyright 2016 American Chemical Society.

a)<smiles>O=C1CCCC=C1COc1ccc2ccc(=O)oc2c1</smiles>
$\left[\left(\eta^{5}-\mathrm{Cp}{ }^{*}\right) \operatorname{lr}(70) \mathrm{Cl}\right](1 \mathrm{~mol} \%)$

$0.1 \mathrm{mM}$

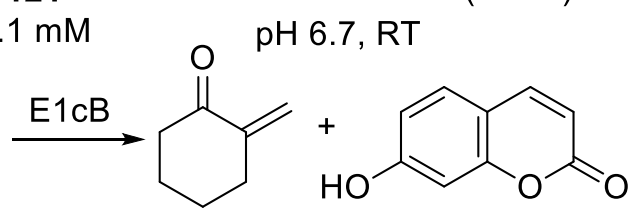
$\mathrm{SAV}_{\text {tetramer }}(0.5 \mathrm{~mol} \%)$

$\mathrm{HCO}_{2} \mathrm{Na}(1.4 \mathrm{M})$ MOPS buffer $(0.1 \mathrm{M})$ $\mathrm{pH}$ 6.7, RT $\lambda_{\mathrm{ex}}=323 \mathrm{~nm}, \lambda_{\mathrm{em}}=470 \mathrm{~nm}$
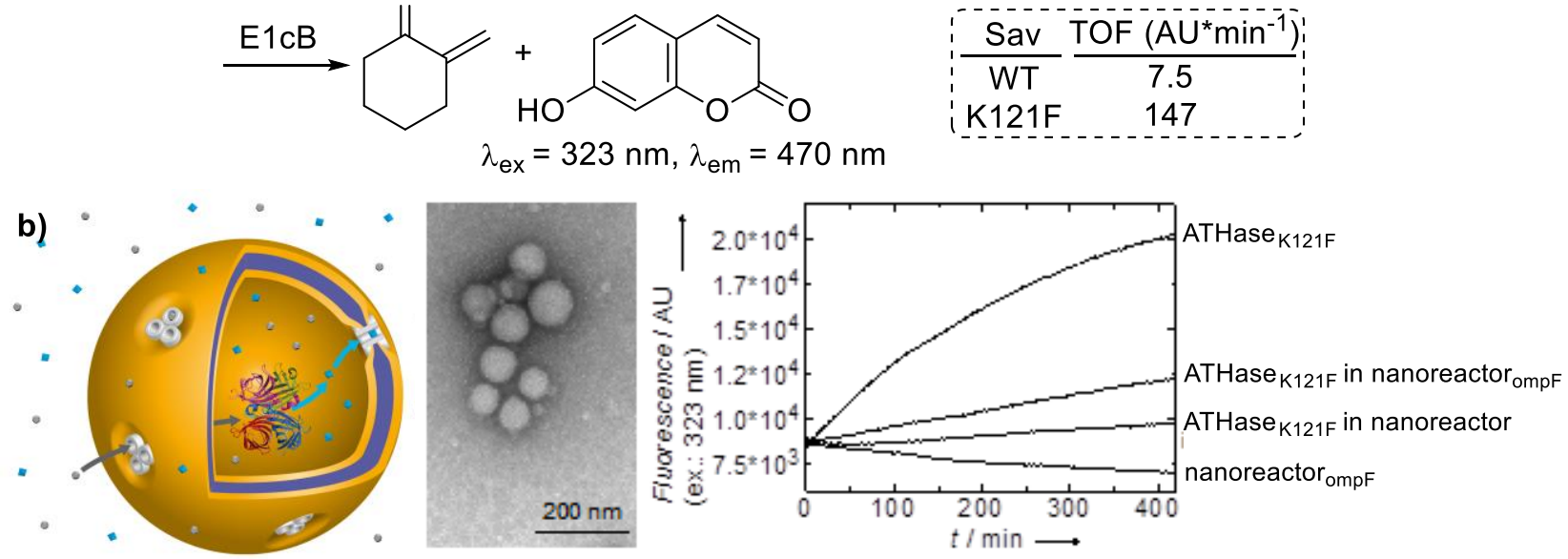

\subsection{Hydroformylation}

Hydroformylation of olefins is widely used to synthesize aldehydes in both commodity and fine chemicals due to its perfect atom economy and the availability of olefins and syngas. ${ }^{278}$ Both linear and branched aldehydes can be accessed, in the latter case leading to a stereogenic center $\alpha$ to the aldehyde, presenting the opportunity for catalyst control over both regio- and enantioselectivity. ${ }^{279}$ As noted in section 3 , early studies by Marchetti established that ArMs generated via metallation of HSA with $\mathrm{Rh}(\mathrm{acac})(\mathrm{CO})_{2}$ catalyze styrene hydroformylation with a branched-to-linear ratio of $~ 90: 10 .{ }^{157}$ Building on extensive work showing that the active site $\mathrm{Zn}$ of carbonic anhydrase could be substituted with different metals, ${ }^{280}$ Kazlauskas replaced the active site $\mathrm{Zn}$ of hCAll with 
$\left[\mathrm{Rh}(\mathrm{acac})(\mathrm{CO})_{2}\right]$ to generate a hydroformylase. ${ }^{281}$ The branched aldehyde product of styrene hydroformylation was favored by the free cofactor and ArMs generated using WT hCAll, Scheme 41. Analysis of this ArM using ICP-MS indicated that it possessed a $\mathrm{Rh} / \mathrm{scaffold}$ ratio of 5.4 , which was believed to result from non-specific Rh-binding sites on the scaffold surface. Targeted mutagenesis and chemical modification of surface histidine residues was therefore carried out, and ArMs generated from the resulting hCAll variants had Rh/scaffold ratios of 1.2 and 1.4. The hydroformylation of styrene catalyzed by the modified ArMs reversed its regioselectivity to favor the linear product (linear/branched ratio up to 8.4 , Scheme 41 ).

Scheme 41. Hydroformylation of styrene catalyzed by a Rh-substituted hCAll.

\begin{tabular}{|c|c|c|c|c|c|}
\hline \multicolumn{6}{|c|}{ 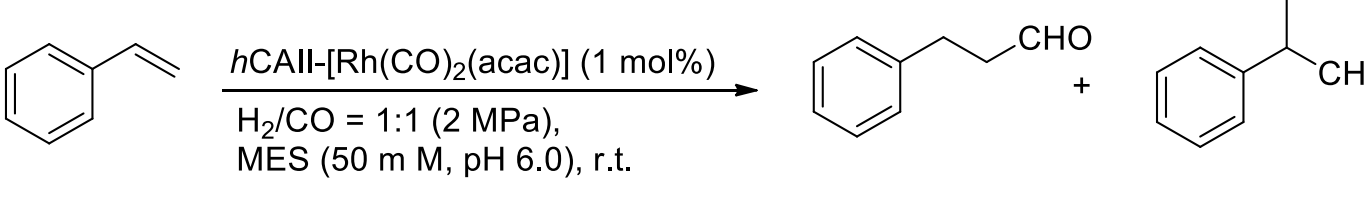 } \\
\hline \multicolumn{2}{|l|}{ Catalyst } & & h/hCAll Ratio & $\underline{\text { Conversion } \%}$ & Linear/Branched \\
\hline \multicolumn{2}{|c|}{$\mathrm{Rh}(\mathrm{CO})_{2}(\mathrm{acac})$} & & - & 39 & 0.21 \\
\hline \multicolumn{2}{|c|}{$h \mathrm{CAll}-\left[\mathrm{Rh}(\mathrm{CO})_{2}(\mathrm{acac})\right]$} & & 5.4 & 50 & 0.39 \\
\hline \multicolumn{2}{|c|}{$9^{*} \mathrm{His}-h \mathrm{CAll}-\left[\mathrm{Rh}(\mathrm{CO})_{2}(\mathrm{acac})\right]$} & & 1.2 & 50 & 3.0 \\
\hline \multicolumn{3}{|c|}{ DEPC-H4/10R-H17F-[Rh(CO) $\left.{ }_{2}(\mathrm{acac})\right]$} & 1.4 & 74 & 8.4 \\
\hline
\end{tabular}

More recently, Hartwig reported detailed characterization of rhodium- and iridiumsubstituted hCAll ArMs. ${ }^{282}$ Metallation of apo hCAll was monitored using a colorimetric assay, which indicated that metallation was significantly impacted by the ligands on the metal precursors used but suggested that surface histidine residues had only a minor impact. $\left[\mathrm{Rh}(\mathrm{nbd})_{2}\right] \mathrm{BF} 4$ and $\left[\mathrm{Rh}(\mathrm{acac})(\mathrm{CO})_{2}\right](\mathrm{nbd}=$ norbornadiene and acac $=$ acetylacetonate) afforded $71 \%$ and $>90 \%$ metallation, and the $\mathrm{Rh} /$ scaffold ratio was approximately $1: 1$ even with surface histidines present. A elegant series of HSQC NMR experiments, which had been previously used to study the catalytic mechanism of hCAll, ${ }^{283}$ indicated that Rh was only coordinated by two of the three His residues in the active site. Multiple ligand substitution reactions of $h C A l l-\left[R h(n b d)_{2}\right]$ were also examined. 


\subsection{Small Molecule Reductases}

Natural enzymes performing reduction of small molecules are located in the super-group of the oxidoreductases (Enzyme Commission number: E.C. 1) and act on nitrite, nitric oxide, nitrous oxide, elemental nitrogen, sulfite, elemental sulfur as well as dioxygen, chlorate and perchlorate. Enzymes involved in these transformations are amongst others flavodiiron proteins ${ }^{284}$, heme proteins ${ }^{285-286}$ and enzymes depending on copper ${ }^{287}$, molybdenum ${ }^{288-290}$ and vanadium. ${ }^{291}$ Beside the large variety of natural small molecule reductases, researchers have engineered artificial metalloenzymes for the reduction of nitrite, nitric oxide, dioxygen and carbon dioxide.

Inspired by the structural homology of heme copper oxidases (HCOs) and nitric oxide reductases (NORs), Lu designed and engineered a copper binding site in sperm whale myoglobin $(\mathrm{Mb})$ by introducing two histidine residues $(\mathrm{L} 29 \mathrm{H}, \mathrm{F} 43 \mathrm{H})$ into the distal heme pocket. Metal binding in the resulting scaffold $\left(\mathrm{Cu}_{B} \mathrm{Mb}\right)$ was supported by UV-Vis and EPR, and increased $\mathrm{O}_{2}$ affinity was observed when $\mathrm{Ag}(\mathrm{I})$ (as a $\mathrm{Cu}(\mathrm{I})$ mimic) bound. ${ }^{292}$ NO reduction (Equation 1) was catalyzed by $\mathrm{Cu}_{\mathrm{B}} \mathrm{Mb}-\mathrm{Cu}(\mathrm{I})$, with a turnover number close to a native enzyme $\left(\sim 2 \mathrm{~mol} \mathrm{NO} \cdot \mathrm{mol} \mathrm{CuBMb}^{-1} \cdot \mathrm{min}^{-1}\right) \cdot{ }^{293} \mathrm{Lu}$ later designed a heme/non-heme $\mathrm{Fe}$ binding site in $\mathrm{Mb}$ by incorporating the $\mathrm{L} 29 \mathrm{H}-\mathrm{F} 43 \mathrm{H}-\mathrm{V} 68 \mathrm{E}$ mutations. ${ }^{294}$ The binding of $\mathrm{Fe}(\mathrm{II})$ in the new artificial enzyme (FeвMb) was supported by the crystal structure of $\mathrm{Fe}(\mathrm{II})-\mathrm{Fe} \mathrm{BMb}$, in which the non-heme iron was coordinated with three histidines, one $\mathrm{O}$ atom of glutamate and one water molecule. Thirty percent conversion was observed for $\mathrm{NO}$ reduction catalyzed by $\mathrm{Fe}(\mathrm{II})-\mathrm{Fe} \mathrm{BMb}$. The catalytic activity was further enhanced ( 100\% increase) by introducing a second glutamate into the second coordination sphere of $\mathrm{Fe}_{\mathrm{B}}$ binding site (I107E), which was believed to facilitate proton delivery via a hydrogen binding network. The same group reported an 
alternate binding pocket $(\mathrm{Fe} \mathrm{Bm}(-\mathrm{His}))$ for $\mathrm{Cu}, \mathrm{Fe}$ and $\mathrm{Zn}$ ions, consisting of two histidines and one glutamate (L29E-F43H-H64). Both FeBMb(-His)-Cu and FeBMb(-His)Fe catalyzed the reduction of NO, while the former ArM had better activities (32\% vs $6 \%$ conversion after $20 \mathrm{~h}){ }^{295}$

$2 \mathrm{NO}+2 \mathrm{e}^{-}+2 \mathrm{H}^{+} \longrightarrow \mathrm{N}_{2} \mathrm{O}+\mathrm{H}_{2} \mathrm{O} \quad$ (Equation 1)

In 2006, Watanabe and coworkers studied the electron transfer between an artificial metalloenzyme and a natural enzyme. For this purpose, they incorporated a Fesalophen (122 or 123) into heme oxygenase (HO). This enzyme converts heme to biliverdin using electrons provided by NADPH/cytochrome P450 reductase (CPR, Scheme 42). ${ }^{296}$ The crystal structure of $\mathbf{1 2 3} \cdot \mathrm{HO}$ highlighted the presence of a hydrogen bond between the propionic acid carboxyl group and R177 of HO. Accordingly, the electron transfer rate from CPRred to $\mathbf{1 2 3} \cdot \mathrm{HO}$ is 3.5 -fold faster than that of $\mathbf{1 2 2} \cdot \mathrm{HO}$, although the redox potential of $\mathbf{1 2 3} \cdot \mathrm{HO}$ is lower than that of $\mathbf{1 2 2} \cdot \mathrm{HO}$ (Table 12).

Table 12. Catalytic $\mathrm{NADPH}$ and $\mathrm{O}_{2}$ consumption by $\mathrm{HO}$ seconstituted with $\mathrm{Fe}$-salophen complexes. ${ }^{a}$

\begin{tabular}{|c|c|c|c|c|c|c|c|}
\hline Entry & Cofactor & Protein & [Cof] $(\mu \mathrm{M})$ & $\begin{array}{c}-\mathrm{d}[\mathrm{NADPH}] / \mathrm{dt} \\
(\mu \mathrm{M} / \mathrm{min})\end{array}$ & $\begin{array}{c}-\mathrm{d}\left[\mathrm{O}_{2}\right] / \mathrm{dt} \\
(\mu \mathrm{M} / \mathrm{min})\end{array}$ & $-\mathrm{d}[\mathrm{NADPH}] / \mathrm{d}\left[\mathrm{O}_{2}\right]$ & Ref \\
\hline 1 & 122 & No Protein & 2 & 24 & 4.8 & 0.20 & 296 \\
\hline 2 & 123 & No Protein & 2 & 31 & 12 & 0.39 & 296 \\
\hline 3 & 122 & $\mathrm{HO}$ & 2 & 21 & 21 & 1.0 & 296 \\
\hline 4 & 123 & $\mathrm{HO}$ & 2 & 5.5 & 5.1 & 0.93 & 296 \\
\hline
\end{tabular}

Scheme 42. Dioxygen reduction catalyzed by $\mathrm{HO}$ reconstituted with Fe-salophen coupled with cytochrome $\mathrm{P} 450$ reductase (CPR). 


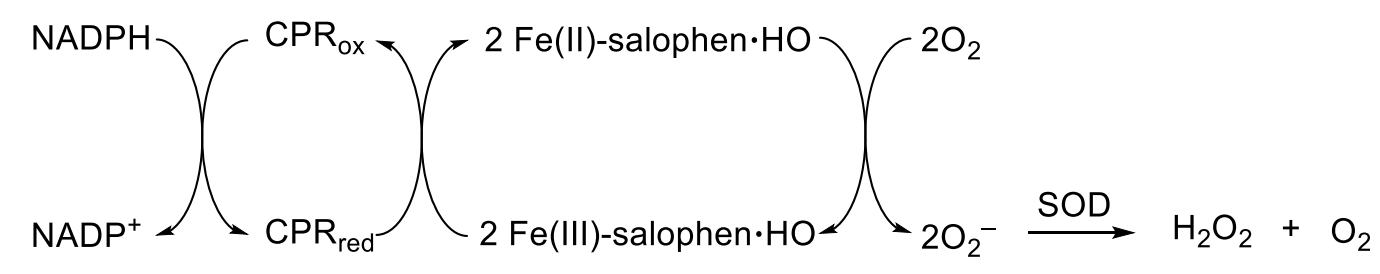

Fe-salophen $\cdot \mathrm{HO}(2 \mu \mathrm{M}), \mathrm{CPR}(1 \mu \mathrm{M})$, Superoxide dismutase (SOD) (100 units)

NADPH $(100 \mu \mathrm{M})$, Tris- $\mathrm{HCl}(10 \mathrm{mM}), \mathrm{pH} 7.4,15^{\circ} \mathrm{C}$

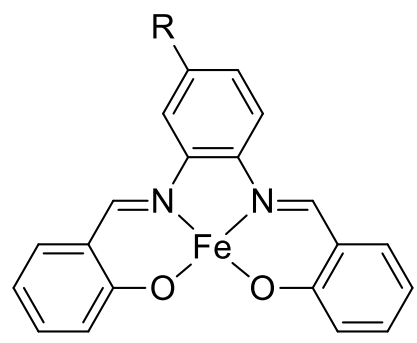

[Fe-salophen]

122: $\mathrm{R}=\mathrm{H}$

123: $\mathrm{R}=\mathrm{CH}_{2} \mathrm{CH}_{2} \mathrm{COOH}$

An artificial $\mathrm{CO}_{2}$ reductase, based on two covalently-anchored metal complexes within [(gp5 $\left.\beta f)_{3}\right]_{2}$ (sections 5.8 and 7.4), was designed by Ueno et al. in $2011 .{ }^{297}$ A maleimide$\mathrm{Re}(\mathrm{bpy})(\mathrm{CO})_{3} \mathrm{Cl}$ complex 124 and a succinimide- $\mathrm{Ru}(\mathrm{bpy})_{3}$ complex 125 were conjugated to a cysteine and a lysine residue respectively (Scheme 43 and Figure 12). In the presence of 1-benzyl-1,4-nicotinamide as a sacrificial reductant, the electron-transfer from the photo-reduced Ru-moiety to the Re-moiety for the reduction of $\mathrm{CO}_{2}$ to $\mathrm{CO}$ was investigated. The reaction efficiency depends on the distance between the Ru-moiety and Re-moiety: the turnover frequency of 124-125·[(gp5 $\left.\beta f)_{3}\right]_{2}$ was 3.3 times higher than a mixture consisting of 124·[(gp5 $\left.\beta f)_{3}\right]_{2}$ and $\mathrm{Ru}(\mathrm{bpy})_{3}-\mathrm{COOH} 126$ (Table 13).

Table 13. Selected results for the photocatalytic reduction of $\mathrm{CO}_{2}$ by $\mathrm{Ru}$ and $\mathrm{Re}$ complexes covalently anchored to $\left[(g p 5 \beta f)_{3}\right]_{2} .^{a}$

\begin{tabular}{|c|c|c|c|c|c|c|c|c|}
\hline Entry & Cof1 & Cof2 & Protein & $\begin{array}{c}\text { [Cof1] } \\
(\mu \mathrm{M})\end{array}$ & $\begin{array}{c}\text { [Cof2] } \\
(\mu \mathrm{M})\end{array}$ & $\begin{array}{c}\text { [1-benzyl-1,4- } \\
\text { nicotinamide] }(\mathrm{mM})\end{array}$ & $\begin{array}{l}\text { TOF } \\
\left(\mathrm{s}^{-1}\right) \\
\end{array}$ & Ref \\
\hline 1 & 124 & 125 & {$\left[(\mathrm{gp} 5 \beta \mathrm{ff})_{3}\right]_{2}(\mathrm{~K} 41 \mathrm{C})$} & 70 & 20 & 100 & 2.8 & 297 \\
\hline 2 & 124 & 125 & {$\left[(\mathrm{gp} 5 \beta \mathrm{ff})_{3}\right]_{2}(\mathrm{~N} 57 \mathrm{C})$} & 72 & 20 & 100 & 1.2 & 297 \\
\hline 3 & 124 & 125 & {$\left[(\mathrm{gp} 5 \beta \mathrm{ff})_{3}\right]_{2}(\mathrm{D} 69 \mathrm{C})$} & 80 & 20 & 100 & 1.5 & 297 \\
\hline 4 & 124 & 126 & $\begin{array}{c}{\left[(\mathrm{gp} 5 \beta \mathrm{f})_{3}\right]_{2}} \\
(\mathrm{~K} 41 \mathrm{C})\end{array}$ & 70 & 20 & 100 & 0.8 & 297 \\
\hline
\end{tabular}

${ }^{a}$ Reactions were carried out in a solution of $1: 1 \mathrm{DMF} / \mathrm{MOPS}(40 \mathrm{mM}, \mathrm{pH} 7.0)$ at $25^{\circ} \mathrm{C}$. 
Scheme 43. Photocatalytic reduction of $\mathrm{CO}_{2}$ catalyzed by $\mathrm{Ru}$ and $\mathrm{Re}$ complexes anchored to $\left[(\mathrm{gp} 5 \beta \mathrm{f})_{3}\right]_{2}$ with 1-benzyl-1,4-dihydronicotinamide as the stoichiometric reductant.

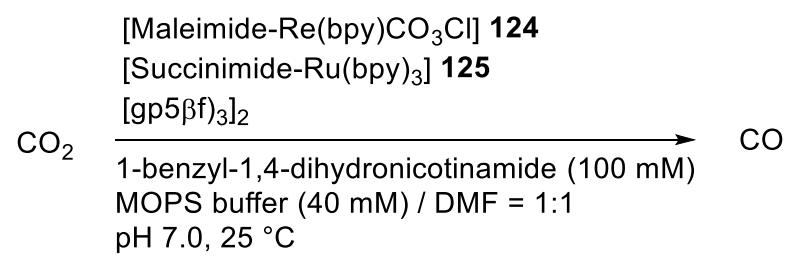<smiles></smiles>

[Maleimide- $\left.\operatorname{Re}(\mathrm{bpy})(\mathrm{CO})_{3} \mathrm{Cl}\right]$ 124<smiles></smiles>

[Succinimide-Ru(bpy) $)_{3}$ ]

125<smiles></smiles>

[Ru(bpy $\left.)_{3}-\mathrm{COOH}\right]$

126

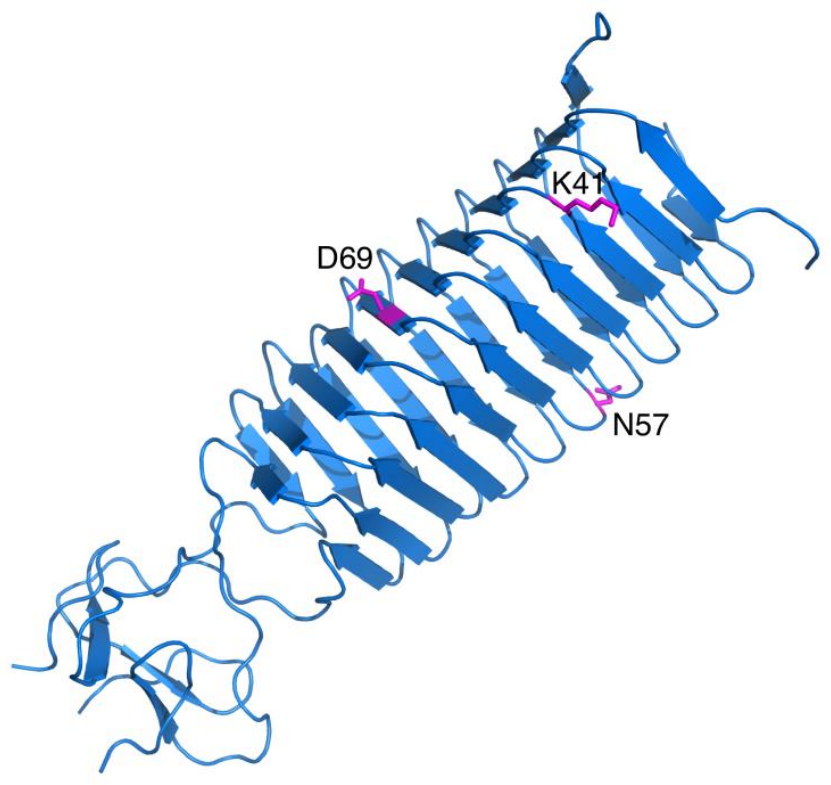

Figure 12. The bionanotube $\left[(\mathrm{gp} 5 \beta \mathrm{ff})_{3}\right]_{2}$ (PDB code $\left.3 \mathrm{~A} 1 \mathrm{M}\right)$ was covalently functionalized at selected positions (magenta) with a $\mathrm{Sc}(\mathrm{bpy})$ complex to afford a clickase ${ }^{298}$, an epoxide ring forming metalloenzyme ${ }^{299}$ and a $\mathrm{CO}_{2}$ reductase. ${ }^{297}$

One year later, Pecoraro et al. engineered an artificial nitrite reductase based on a previously designed $\alpha$-helical coiled-coil motif (section 7.1). ${ }^{300}$ The construct (TRIL23H) 3 is able to bind $\mathrm{Cu}(\mathrm{I})$ and $\mathrm{Cu}(\mathrm{II})$ with picomolar and nano/micromolar affinities 
respectively. Binding occurs via coordination to three histidine residues (mutation L23H). The nature of the active site, a structural analogue of copper nitrite reductase, was characterized by spectroscopy. The designed artificial metalloenzyme $\mathrm{Cu}(\mathrm{I} / \mathrm{II})(\mathrm{TRIL23H}) 3^{+/ 2+}$ catalyzes the reduction of nitrite to nitric oxide with ascorbate as electron donor, Equation 2. Kinetic investigations revealed similar rates for the oxidation of ascorbate by $\mathrm{Cu}(\mathrm{II})(\mathrm{TRIL23H}) 3^{2+}$ and for the oxidation of $\mathrm{Cu}(\mathrm{I})(\mathrm{TRIL23H}) 3^{+}$by nitrite $\left(k_{\text {ascorbate }}=4.6 \cdot 10^{-4} \mathrm{~s}^{-1}\right.$ and $k \mathrm{cu}=5.2 \cdot 10^{-4} \mathrm{~s}^{-1}$ at $\mathrm{pH}$ 5.8). This suggests that the electron transfer from $\mathrm{Cu}(\mathrm{I})(\mathrm{TRIL} 23 \mathrm{H}) 3^{+}$to nitrite with simultaneous formation of $\mathrm{Cu}(\mathrm{II})(\mathrm{TRIL23H}) 3^{2+}$ is the rate-limiting step of the catalytic cycle. Under optimized conditions, the artificial nitrite reductase exceeded 5 turnovers and formed predominantly $\mathrm{NO}$ as product (i.e. almost no formation of $\mathrm{N}_{2} \mathrm{O}$ ).

$\mathrm{NO}_{2}^{-}+\mathrm{e}^{-}+2 \mathrm{H}^{+} \longrightarrow \mathrm{NO}+\mathrm{H}_{2} \mathrm{O} \quad$ (Equation 2) 


\section{C-C Bond Formation}

\subsection{Allylic Alkylation}

Allylic alkylation is a $\mathrm{C}-\mathrm{C}$ bond forming reaction catalyzed by a range of transition metal complexes, though Pd-phosphine complexes are most commonly used for synthetic applications. ${ }^{301}$ These catalysts activate heteroatom-substituted allyl compounds to attack by a soft nucleophiles via a metal-allyl intermediates. Though no natural enzyme has been reported to catalyze this reaction, terpene synthases rely on allyl cation intermediates that react in a similar fashion with an intramolecular carbon nucleophile to create a C-C bond. ${ }^{302}$ Researchers have demonstrated that Ru-catalyzed allylic substitution proceeds even inside of cells, making this reaction particularly attractive for in vivo applications. ${ }^{303-305}$ Encapsulating the transition metal within a protein scaffold could help to protect the metal in a biological environment, induce substrate specificity, and enable selective cell or even organelle targeting.

Toward this end, Ward and coworkers generated a panel of ArMs by incorporating biotinylated Pd-bisphosphine complexes into different Sav variants and investigated their activity toward asymmetric allylic alkylation of 1,3-diphenylallylacetate using malonate as a nucleophile. ${ }^{306}$ In total, fourteen Pd complexes were screened against 20 Sav isoforms bearing mutations at S112X and two additional positions (Scheme 44 and Table 14). Didodecyldimethlyammonium bromide (DMB) was added to suppress 1,3diphenylallylacetate hydrolysis (Scheme 44). With this modification, ArMs containing ligands 37 (which yielded rac-product), 41 (mostly (R)-selective), and 42 (mostly (S)selective) were identified. Replacement of DMB by DMSO was possible in case of ligand 41 and led to increased enantioselectivity and conversion (i.e. $95 \%$ ee, TON 45, Table 14 , entry 3). The (S)-selectivity was increased to $82 \%$ ee upon combining $S 112 \mathrm{G}$ and V47G mutations. 
Scheme 44. A biotinylated bisphosphine palladium complex anchored within streptavidin affords an artificial allylic alkylase.

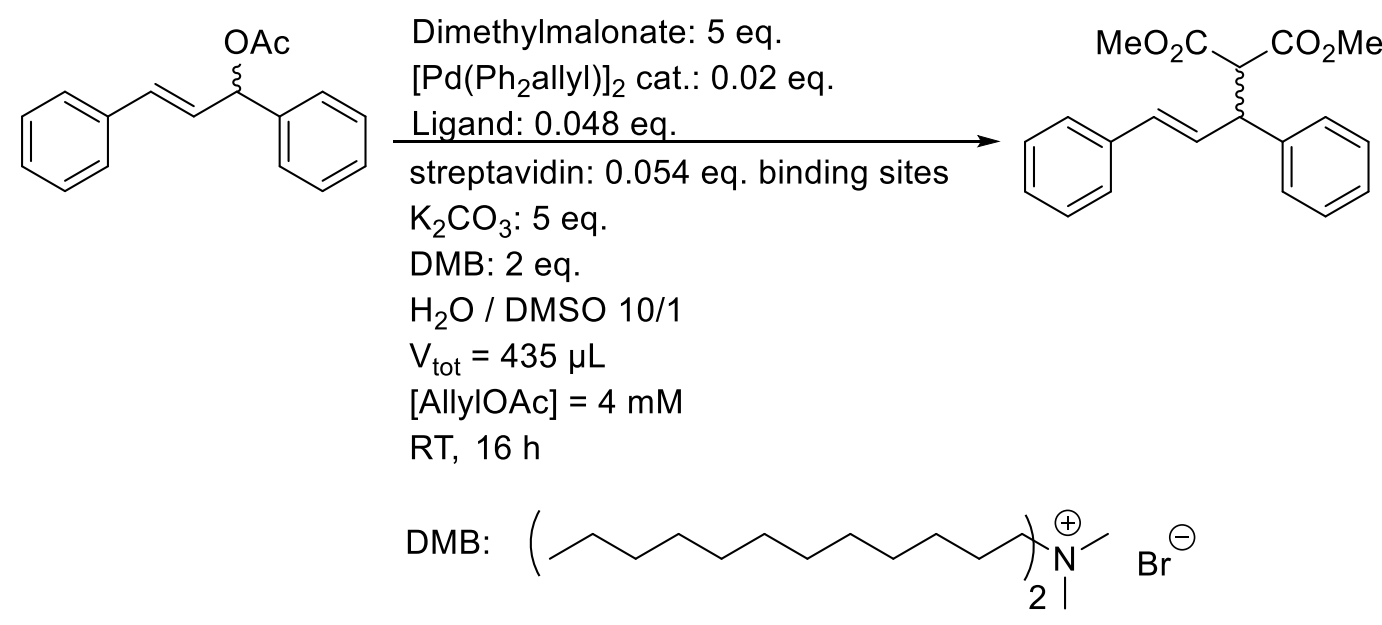

Table 14. Selected results of the catalytic performance of the allylic alkylase based on the biotin-streptavidin technology.

\begin{tabular}{cllll}
\hline Entry & Ligand $^{\mathrm{a}}$ & Protein & ee $(\%)$ & Conv. $(\%)$ \\
\hline 1 & $\mathbf{4 1}$ & $\mathrm{S} 112 \mathrm{~A}$ & $90(R)$ & 95 \\
2 & $\mathbf{4 1}$ & $\mathrm{S} 112 \mathrm{~A}^{\mathrm{b}}$ & $93(R)$ & 20 \\
3 & $\mathbf{4 1}$ & $\mathrm{S} 112 \mathrm{~A}^{\mathrm{c}}$ & $95(R)$ & 90 \\
4 & $\mathbf{4 1}$ & $\mathrm{S} 112 \mathrm{Q}$ & $31(S)$ & 96 \\
5 & $\mathbf{4 2}$ & $\mathrm{S} 112 \mathrm{Y}$ & $80(R)$ & 87 \\
6 & $\mathbf{4 2}$ & $\mathrm{S} 112 \mathrm{G}$ & $54(S)$ & 96 \\
7 & $\mathbf{4 2}$ & $\mathrm{S} 112 \mathrm{G}-\mathrm{V} 47 \mathrm{G}$ & $82(S)$ & 92 \\
\hline
\end{tabular}

\subsection{Suzuki Cross-Coupling}

Carbon-carbon cross-coupling reactions offer a highly versatile means to assemble functional molecules. The palladium-catalyzed Suzuki-Miyaura cross-coupling reaction of aromatic halides and aryl boronic acids to afford biaryls is particularly notable in this regard. ${ }^{307}$ The importance of biaryls to the agrochemical, pharmaceutical, and polymer industries, coupled with the bioorthogonality of the Suzuki-Miyaura cross-coupling in general have led to extensive development of catalysts for this reaction. Researchers have also started to apply this and closely-related reactions for chemical biology applications, ${ }^{308-311}$ although these efforts are limited by the high catalyst loadings required, presumably due to catalyst inactivation under biologically relvant conditions ${ }^{308}$. 
Anchoring Pd-catalysts within a protein scaffold could potentially i) protect the Pdcatalyst from inactivation in a biological reaction medium and ii) control the stereochemistry of the cross-coupling reaction.

To date, three studies have been reported on ArM Suzukiases. The first of these, reported by Ueno, Watanabe, and coworkers, was generated by loading $[\mathrm{Pd}(\mathrm{allyl}) \mathrm{Cl}]_{2}$ 127 into apo-ferritin (Scheme 45). ${ }^{312}$ Ferritin is an iron storage protein consisting of 24 self-assembled four helix-bundle subunits. The crystal structure of 127-apo-ferrtin reveals two dinuclear Pd complexes located at the so-called accumulation center and threefold channel, respectively (Figure 13). Localization of the Pd centers is ensured via coordination to cysteine, histidine, and glutamic acid residues. The resulting ArMs catalyzed the Suzuki-Miyaura cross-coupling between 4-iodoaniline 128 and phenylboronic acid 129 with up to TOF $=3500$ /hour (Scheme 45 and Table 15, entry 1 ).

Figure 13. Ferritin (PDB code 1DAT) was engineered to carry out Suzuki-Miyaura crosscoupling ${ }^{312}$ and phenylacetylene polymerization reactions. ${ }^{313}$ Crystal structure analysis of $\mathrm{Pd}$ - and $\mathrm{Rh}$-bound ferritin indicated metal binding to amino acid side chains in the "threefold channel" (magenta) and the "accumulation center" (red). Only a cross-section of ferritin is displayed for clarity.

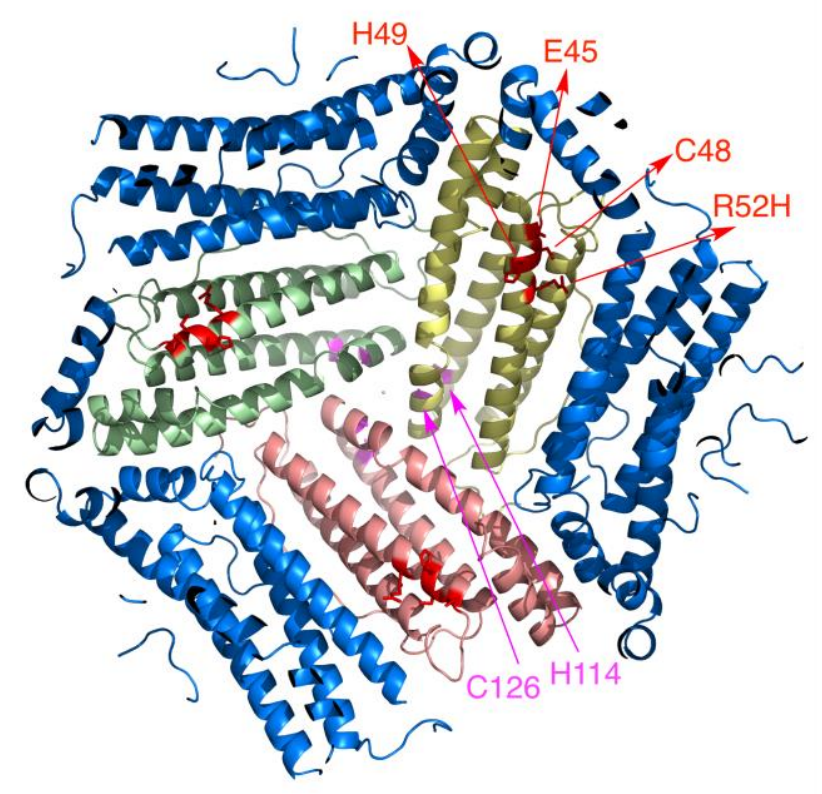


Several mutations were introduced around the Pd binding site in 127-apo-ferrtin to decipher the role of the coordination geometry on the catalytic activity (Figure 13). ${ }^{314}$ Among the mutants, the ferritin $\mathrm{E} 45 \mathrm{C}-\mathrm{R} 52 \mathrm{H}$ variant gave the highest TOF $=4300 /$ hour (Table 15, entry 7 ).

Table 15. Suzuki-Miyaura coupling reaction catalyzed by a Pd(allyl) · ferritin ArM.

\begin{tabular}{|c|c|c|c|c|c|c|c|}
\hline Entry & Cofactor & Protein & $\begin{array}{l}\mathrm{NaOH} \\
(\mathrm{mM})\end{array}$ & $\begin{array}{l}\mathrm{T} \\
\left({ }^{\circ} \mathrm{C}\right)\end{array}$ & $\begin{array}{l}{[\mathrm{Pd}] /[\mathrm{Fr}]} \\
\text { determined by ICP }\end{array}$ & $\begin{array}{l}\text { TOF per Pd(allyl) } \cdot \mathrm{Fr} \\
\left(\mathrm{h}^{-1}\right)\end{array}$ & Ref \\
\hline 1 & 127 & $\operatorname{Fr}(\mathrm{WT})$ & 4.5 & 50 & 103 & 3500 & 312 \\
\hline 2 & 127 & $\operatorname{Fr}(\mathrm{H} 49 \mathrm{~A})$ & 4.5 & 50 & 99 & 3400 & 312 \\
\hline 3 & 127 & $\mathrm{Fr}(\mathrm{C} 48 \mathrm{~A}-\mathrm{H} 49 \mathrm{~A})$ & 4.5 & 50 & 54 & 1900 & 312 \\
\hline 4 & 127 & $\operatorname{Fr}(\mathrm{H} 114 \mathrm{~A})$ & 4.5 & 50 & 78 & 900 & 312 \\
\hline 5 & 127 & $\operatorname{Fr}(\mathrm{C} 126 \mathrm{~A})$ & 4.5 & 50 & 37 & 830 & 312 \\
\hline 6 & 127 & $\operatorname{Fr}(\mathrm{E} 45 \mathrm{C}-\mathrm{C} 48 \mathrm{~A})$ & 4.5 & 50 & 98 & 4200 & 314 \\
\hline 7 & 127 & $\operatorname{Fr}(\mathrm{E} 45 \mathrm{C}-\mathrm{R} 52 \mathrm{H})$ & 4.5 & 50 & 154 & 4300 & 314 \\
\hline 8 & 127 & $\mathrm{Fr}(\mathrm{E} 45 \mathrm{C}-\mathrm{H} 49 \mathrm{~A} / \mathrm{R} 52 \mathrm{H})$ & 4.5 & 50 & 154 & 4200 & 314 \\
\hline
\end{tabular}

Scheme 45. Suzuki-Miyaura coupling reaction catalyzed by a $[\mathrm{Pd}($ allyl)Cl]2-loaded ferritin.

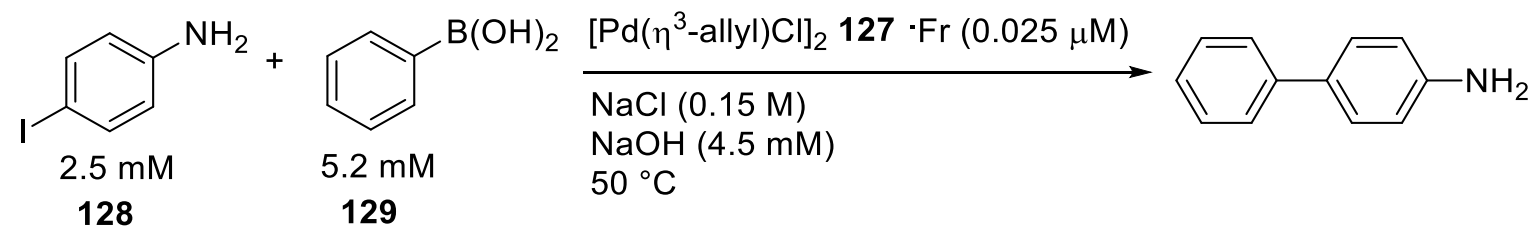

Based on the promising results obtained with the asymmetric allylic alkylases outlined above, Ward and coworkers screened a number of biotinylated NHC- and monophosphine ligands in the presence of $\left[\mathrm{Pd}\left(\eta^{3}-\text { cinnamyl }\right) \mathrm{Cl}\right]_{2}$ for Suzuki crosscoupling to afford enantioenriched binaphtyls (Scheme 46). ${ }^{315}$ Anchored within WT Sav, the monophosphine complexes $\left.\left[\mathrm{Pd}\left(\eta^{3} \text {-cinnamyl)Cl(Biot-Et-P(t-Bu}\right)_{2}\right)\right] 131$ and $\left[\mathrm{Pd}\left(\eta^{3}-\right.\right.$ cinnamyl)Cl(Biot-Pr-P(t-Bu$\left.\left.)_{2}\right)\right] 132$ yielded binaphtyl 135 with 78 and 73 TON, respectively. The NHC-complex $\left[\mathrm{Pd}\left(\eta^{3}\right.\right.$-cinnamyl $) \mathrm{Cl}($ Biot-L $\left.)\right] \mathbf{1 3 0}$ was less active (45 TON) and afforded rac-135. For the tert-butyl phosphine complexes, the ethyl and propyl spacers yielded opposite product enantiomers in $58 \%$ ee $((R)-135)$ and $10 \%$ ee $((S)$ 135), respectively. Screening a panel of ArMs generated by combining different Sav 
variants with $\left[\mathrm{Pd}\left(\eta^{3}-\right.\right.$ cinnamyl $\left.) \mathrm{Cl}\left(\mathrm{Biot}-\mathrm{Et}-\mathrm{P}(t-\mathrm{Bu})_{2}\right)\right] \mathbf{1 3 1}$ led to the identification of Sav S112Y-K121E, which produced $(R)-135$ with $90 \%$ ee and 50 TON at $4{ }^{\circ} \mathrm{C}$. Mutant K121A yielded the $(S)-135$ with $47 \%$ ee and 32 TON.

Scheme 46. An artificial Suzukiase for the synthesis of enantioenriched binaphtyls based on the biotin-streptavidin technology. Insert: X-ray crystal structure of $\left[\mathrm{Pd}\left(\eta^{3}\right.\right.$ cinnamyl) $\mathrm{Cl}(\mathrm{Biot}-\mathrm{Et}-\mathrm{P}(t-\mathrm{Bu}) 2)]$ 131.Sav S112Y K121E. Adapted from ref. ${ }^{315}$ - Published by The Royal Society of Chemistry.

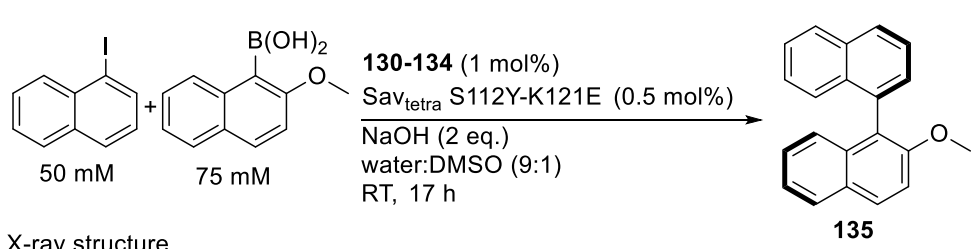

X-ray structure

Sav-S112Y-K121E - 131 (cinnamyl modelled, magenta):

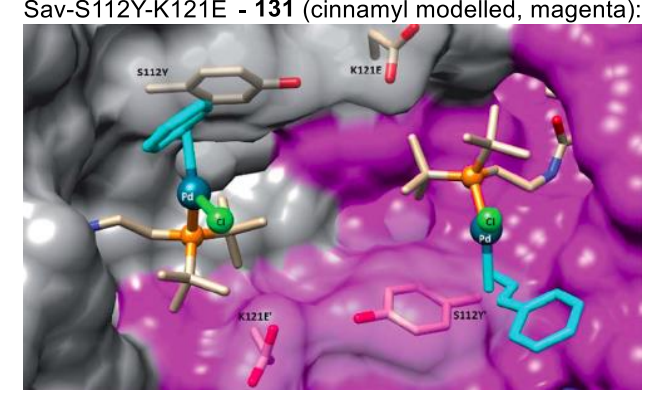

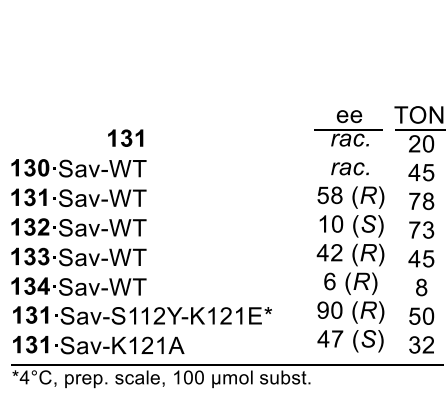

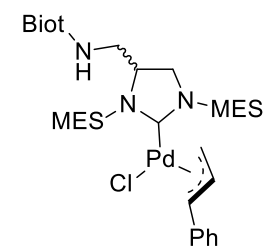

$\left[\mathrm{Pd}\left(\eta^{3}\right.\right.$-cinnamyl $) \mathrm{Cl}($ Biot-L $\left.)\right] 130$

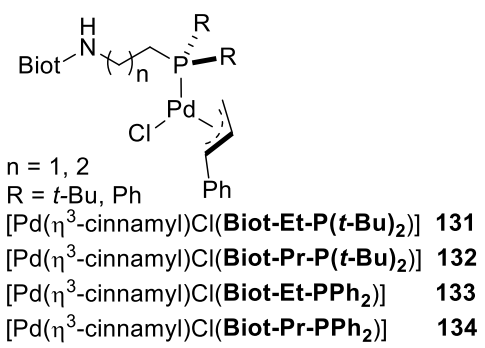

\subsection{Heck Reaction}

The Heck reaction is an extremely powerful means of forging C-C bonds between widely available aryl halides and olefins. Moreover, substituted olefins can give rise to regioand enantiomeric products, which necessitates the development of catalysts that can impart selectivity to these transformations. Filice and Palomo therefore took on the challenge of developing an ArM Heckase.${ }^{316}$ Covalent modification of a variety of lipases, including CAL-B, was achieved using phosphonate-substituted Pd-pincer complex 136 (Figure $14 \mathrm{a}$ ) in analogy to the previous work of Gebbink and van Koten (Scheme 12). ${ }^{181,}$ 183 Optimization of reaction conditions and immmobilization methods led to the finding that 136.CAL-B immobilized on aldehyde-activated Sephabeads (136.CAL-B-CHO-SP) catalyzed a model Heck reaction with high efficiency (Figure $14 \mathrm{~b}$ ). This system was compatible with remarkably high temperatures $\left(70-120{ }^{\circ} \mathrm{C}\right)$ and organic solvent 
concentrations (75-100\% DMF). Further optimization of the SP surface using different alkyl amine capping agents (methyl, octyl, etc.) led to the development of 136.SP-CAL$\mathrm{B}-\mathrm{C}_{8}$, which had higher activity toward the model Heck reaction than 136.CAL-B-CHOSP. Even more remarkably, this catalyst provided high enantioselectivity $(96.6 \%$ ee) in the Heck coupling of 2,3-dihydrofuran 137 with phenyl iodide at $120{ }^{\circ} \mathrm{C}$ in $75 \%$ DMF, though no conversion was observed at $70{ }^{\circ} \mathrm{C}$ or with phenyl bromide (Figure $14 \mathrm{c}$ ). Beyond highlighting the potential for ArMs to catalyze selective Heck reactions, this study provides compelling support for further exploration of immobilized ArMs.

a)<smiles>CCOP(=O)(CCCc1cc(CS(=O)(=O)c2ccccc2)c(Br)c(SP(c2ccccc2)c2ccccc2)c1)Oc1ccc([N+](=O)[O-])cc1</smiles>

b)<smiles>C=CC(=O)OCC</smiles>

c)

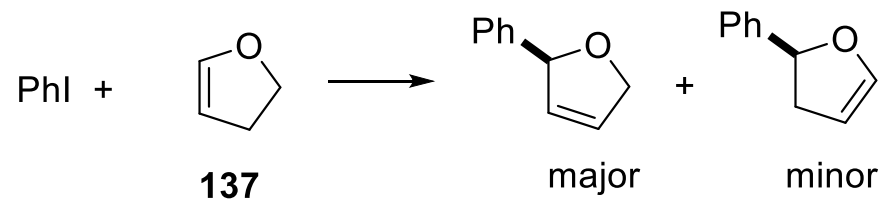

Figure 14. Structure of phosphonate-substituted Pd-pincer complex used to generate ArM Heckase a). Model Heck reaction used to optimize immobilized ArM Heckases b). ArM-catalyzed asymmetric Heck reaction between 2,3-dihydrofuran and iodobenzene C). ${ }^{316}$

\subsection{C-H Activation}

Carbon-carbon bond formation via carbon-hydrogen $(\mathrm{C}-\mathrm{H})$ bond functionalization remains a highly attractive yet equally challenging transformation in organic synthesis. ${ }^{317}$ By eliminating the need for prefunctionalized starting materials, these reactions can 
enable new disconnection strategies, reduce synthetic manipulations, and decrease waste. All of these benefits, however, require a catalyst to activate a single $\mathrm{C}-\mathrm{H}$ bond in the presence of many other, often similarly reactive, $\mathrm{C}-\mathrm{H}$ bonds, and functionalize the resulting metallated position with the desired regio- and enatioselectivity. The impressive levels of selectivity exhibited by a number of natural enzymes that catalyze $\mathrm{C}-\mathrm{H}$ bond functionalization clearly demonstrates the potential for protein scaffolds to control these transformations. ${ }^{318} \mathrm{~A}$ number of researchers have therefore explored the possibility of using ArMs to control the selectivity of synthetic $\mathrm{C}-\mathrm{H}$ functionalization catalysts.

Rovis and Ward, for example, hypothesized that incorporating a biotinylated Rh-complex [(98) $\left.\mathrm{RhCl}_{2}\left(\mathrm{H}_{2} \mathrm{O}\right)\right]$ into Sav could provide a chiral environment for enantioselective hydroarylation reactions ${ }^{319-320}$ catalyzed by $\left[\eta^{5}-\left(\mathrm{Cp}^{*}\right) \mathrm{RhCl}_{2}\right]_{2 .}{ }^{321}$ One such reaction, involving hydroarylation of methyl acrylate with pivaloyl-protected benzhydroxamic acid 138 and subsequent cyclization (i.e. benzanulation), provides regioisomeric isoquinolones 139 and 140 (Scheme 47 a)). While this reaction proceeded poorly using the free cofactor in water, addition of acetate buffer increased TON from 5 to 80 and provided 139 and 140 in a 4:1 ratio. This was hypothesized to result from acetate participation in a rate limiting concerted metallation-deprotonation step (CMD) of the overall C-H functionalization process (Scheme $47 \mathrm{~b}$ ). Incorporating $\left[(98) \mathrm{RhCl}_{2}\left(\mathrm{H}_{2} \mathrm{O}\right)\right]$ into WT Sav decreased TON to 40, but the regioisomeric ratio (rr) and ee values increased to $9: 1$ and $50 \%$ (favoring $R-139$ ), respectively. Sav variants bearing a carboxylate residue in the proximity of the $\mathrm{Rh}$ cofactor (i.e. $\mathrm{S} 112 \mathrm{D} / \mathrm{E}$ or $\mathrm{K} 121 \mathrm{D} / \mathrm{E}$ ) were then examined to determine if these could replace acetate and allow to carry out the desired reaction at neutral $\mathrm{pH}$. Indeed, Sav K121D provided an ArM that catalyzed benzanulation of 138 with improved TON and $\operatorname{rr}$ (up to 89 and 15:1, respectively), but the ee remained virtually identical to WT Sav. Promising single point mutations were then combined to generate Sav variants N118K-K121E and S112Y-K121E, which, upon 
metallation, provided $(R)$-139 with 50 TON, 64\% ee, 15:1 rr and 47 TON, $82 \%$ ee, and 19:1 rr, respectively.

The role of glutamate $\mathrm{K} 121 \mathrm{E}$ as general base in the rate limiting ortho- $\mathrm{C}_{\text {aryl }} \mathrm{H}$ deprotonation step was investigated. A kinetic isotope effect (KIE) of 4.8 was observed for substrate 138 with $\left[(98) \mathrm{RhCl}_{2}\left(\mathrm{H}_{2} \mathrm{O}\right)\right]$.Sav $\mathrm{S} 112 \mathrm{Y}-\mathrm{K} 121 \mathrm{E}$. The $\mathrm{KIE}$ of the corresponding WT Sav ArM was only 2.8. To highlight the rate accelerating effect of the Sav, the protein/cofactor ratio was varied and the enantioselectivity was determined using substrate 138. Strikingly, the artificial benzannulase $\left[(98) \mathrm{RhCl}_{2}\left(\mathrm{H}_{2} \mathrm{O}\right)\right]$.Sav $\mathrm{S} 112 \mathrm{Y}$ K121E retained a high ee even in the presence of a large excess of cofactor; a rate acceleration of $\sim 100$-fold was determined.

Scheme 47. An artificial benzannulase for the synthesis of enantioenriched dihydroisoquinolones based on the biotin-streptavidin technology. Reaction conditions and substrate scope and postulated transition state of the CMD step are displayed in a) and $b$ ), respectively. Adapted with permission from ref. ${ }^{38}$ Copyright ACS Publications 2016.

a)

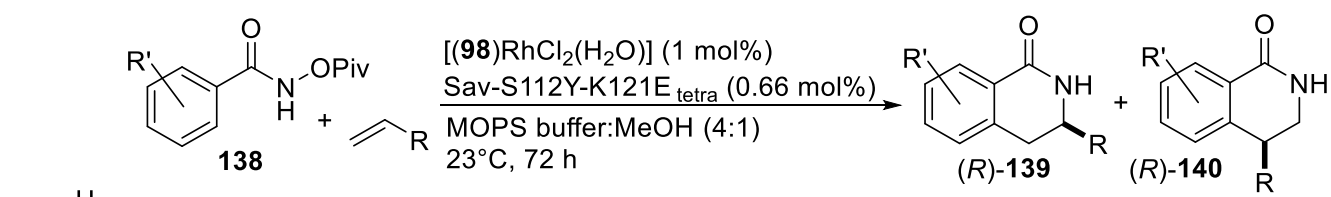

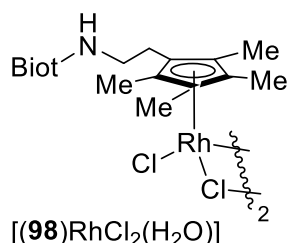

b) Postulated transition state:

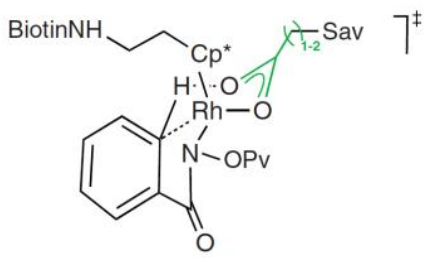

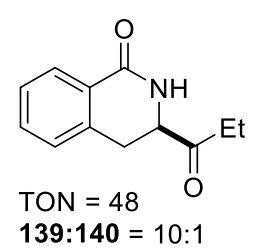

ee $=12 \%$

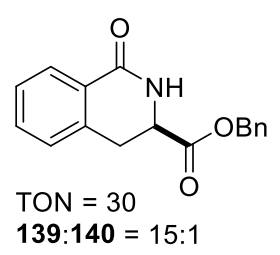

ee $=46 \%$
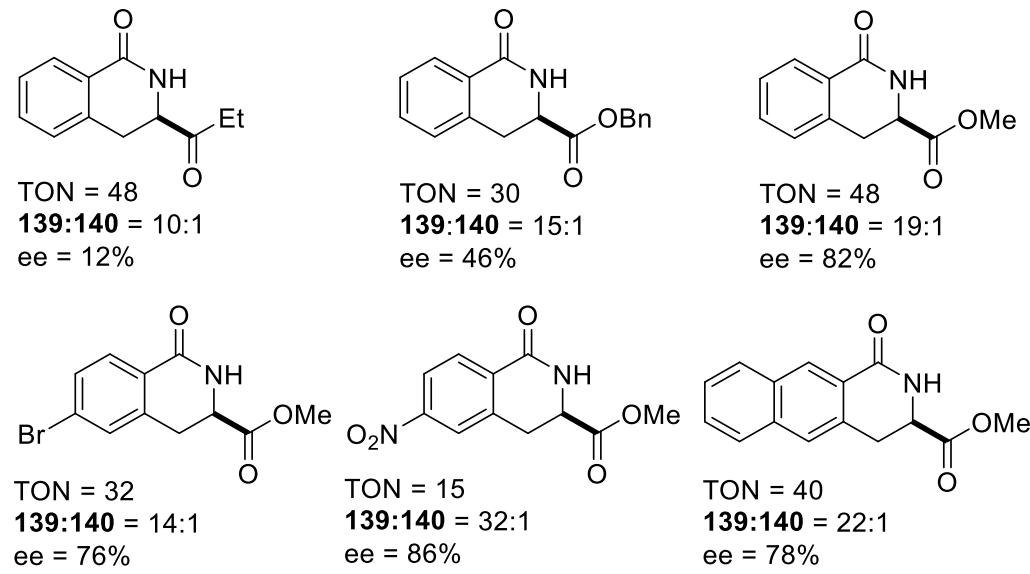

Metal porphyrin complexes catalyze a range of $\mathrm{C}-\mathrm{H}$ insertion reactions via generation of highly reactive metal-oxo, -peroxy, -carbene, and -nitrene intermediates upon reaction with suitable precursors for these species. ${ }^{322}$ While oxo insertion reactions catalyzed by 
heme-dependent oxygenases and peroxygenases have been extensively studied, ${ }^{323}$ reactions of these enzymes with carbene and nitrene precursors has only recently been explored in detail. ${ }^{324}$ As discussed in the review by Fasan and coworkers elsewhere in this issue, this has been exploited to enable carbene insertion into olefins (cyclopropanation) ${ }^{12}$ and nitrene insertion into $\mathrm{C}-\mathrm{H}$ bonds using cytochromes $\mathrm{P} 450$, myoglobin, and other heme enzymes. ${ }^{325-326}$ To obtain systems with further expanded function, a number of researchers have incorporated unnatural porphyrins and other heme-like cofactors into heme proteins and enzymes to generate ArMs. ${ }^{55}$ These efforts take advantage of well-formed active sites that evolved to accommodate a planar (heme) cofactors and small molecule substrates. While this approach has also been extensively explored for oxo-insertion reactions (section 6.1), significantly less has been done for carbene and nitrene insertion reactions.

Despite the ability of heme enzymes to catalyze carbene insertions into olefins, analogous insertions into $\mathrm{C}-\mathrm{H}$ bonds using these enzymes have not been reported. Hartwig, Clark and coworkers therefore investigated the activity of ArMs generated by metallating eight different apo-myoglobin variants containing a different mutation at the axial ligand position (H93X) in the presence of protoporphyrin IX (PPIX) cofactors containing different noble metals. Of these, an ArM generated from (PPIX)Ir(Me) catalyzed both cyclopropanation (vide infra) and intramolecular carbene insertion using diazo carbene precursors. ${ }^{327}$ In the later case, reaction of diazoester 141 to form the corresponding chiral dihydrobenzofuran, which has not been reported for natural heme enzymes, was examined. Stepwise targeted mutagenesis of the myoglobin active site led to ArMs with good enantioselectivity reactions of multiple substrates $(86 \%$ ee for $\mathrm{C}-\mathrm{H}$ insertion, Figure 15). Variants were identified that catalyzed intramolecular carbene insertion in one particular substrate to provide either product enantiomer with up to $84 \%$ and $50 \%$ ee (Scheme 48 a). 


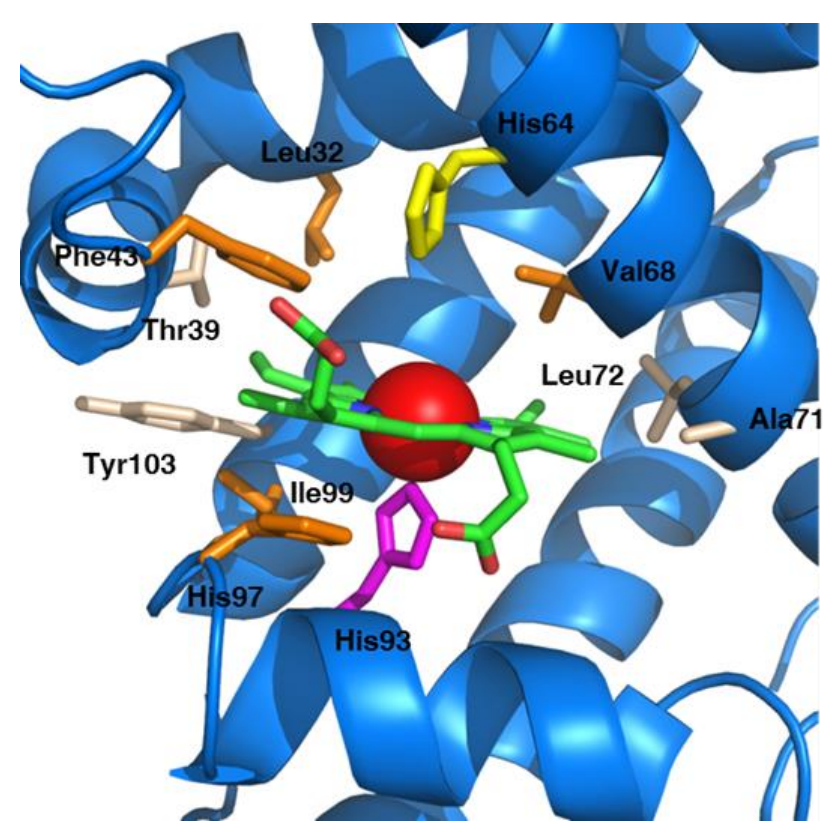

Figure 15. Cartoon representation of Myoglobin's active site with its natural cofactor (PDB: 1MBI). Highlighted in magenta and yellow are the axial (H93) and distal (H64) histidines, respectively. Highlighted in orange are additional amino acids modified to evolve the ArMs as $\mathrm{C}-\mathrm{H}$ activase, cyclopropanase ${ }^{327}$ and dihydrogenase. ${ }^{208}$ Highlighted in beige are amino acids mutated to modify the affinity or the orientation of the artificial cofactors for the evolution of sulfoxidase ${ }^{328}{ }^{329-330}$ and peroxidase. ${ }^{331-333} \mathrm{Heme}$ displayed in green $(\mathrm{C})$, red $(\mathrm{O})$ and blue $(\mathrm{N})$.

The same group also reported that a thermostable cytochrome P450 from Sulfolobus solfataricus (CYP119) could be reconstituted with (PPIX) $\operatorname{lr}(\mathrm{Me})$ to generate a thermostable $\operatorname{ArM}\left(\mathrm{T}_{\mathrm{m}}=69^{\circ} \mathrm{C}\right) .{ }^{334}$ Intramolecular carbene insertion using diazoester 141 was again selected as a model reaction (Scheme $48 \mathrm{~b})$. A catalytic efficiency $\left(k_{\mathrm{cat}} / K_{\mathrm{M}}\right)$ of $0.071 \mathrm{~min}^{-1} \cdot \mathrm{mM}^{-1}$ was observed for the single mutant C317G, which was improved by introducing hydrophobic and uncharged residues into the ArM active site (Figure 16). The quadruple mutant (L69V-T213G-V254L-C317G) showed a more than 4000 -fold higher catalytic efficiency $\left(k_{\mathrm{cat}} / K_{\mathrm{M}}=269 \mathrm{~min}^{-1} \cdot \mathrm{mM}^{-1}\right)$ than the initial wild type construct, accompanied by an initial turnover frequency of $43 \mathrm{~min}^{-1}$ and a high enantioselectivity (94\% ee). 


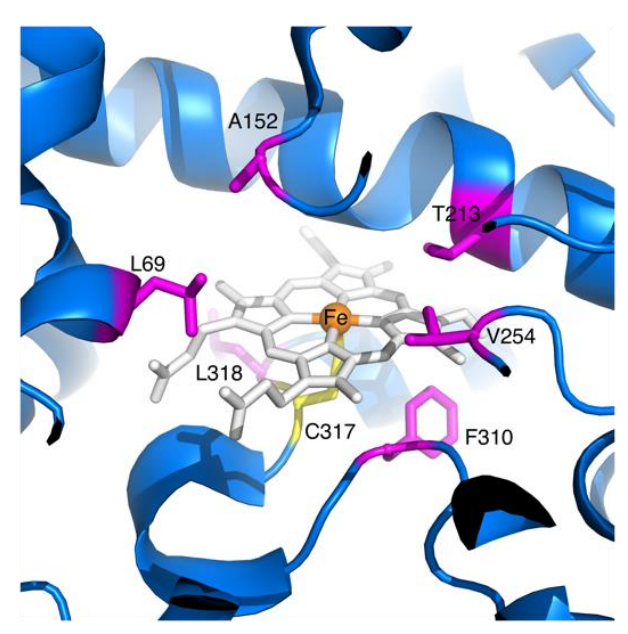

Figure 16. Cytochrome P450 Cyp119 (PDB code 1IO8) catalyzes carbene insertion into $\mathrm{C}-\mathrm{H}$ bonds. ${ }^{334}$ Residues in proximity to the heme cofactor that were subjected to mutagenesis are highlighted in magenta and yellow.

ArMs optimized for this model reaction also catalyzed the intramolecular carbene insertion into a variety of activated primary, secondary and sterically hindered $\mathrm{C}-\mathrm{H}$ bonds with high turnover numbers and enantioselectivities, Scheme 48 b). Intramolecular carbene insertion into an unactivated primary $\mathrm{C}-\mathrm{H}$ bond, (Scheme $48 \mathrm{c}$ ) and intermolecular reaction between phthalan 143 and ethyl diazoacetate 142 to provide 144 was also observed (Scheme $48 \mathrm{~d}$ ). The latter is particularly challenging since diazo coupling $\mathbf{1 4 5}$ or formal insertion of the carbene into the $\mathrm{O}-\mathrm{H}$ bond of water to form alcohol 146 can occur. Diazoester 141 was transformed into the corresponding dihydrobenzofuran on a preparative scale ( $1.0 \mathrm{~g}$ substrate, $55 \%$ isolated yield, $93 \%$ ee), whereby the ArM exceeded 3200 turnovers. On a smaller scale (10 mg substrate) a TON > 35,000 was achieved. Supported on sepharose beads, the ArMs could be recycled at least 4 times without erosion of enantioselectivity and retaining $64 \%$ of its initial activity.

Scheme 48. C-H insertion reactions catalyzed by heme-substituted ArMs. Intramolecular insertion into activated $\mathrm{C}-\mathrm{H}$ bonds catalyzed by a) myoglobin variants and b) P450-CYP119 variants; c) intramolecular insertion into unactivated $\mathrm{C}-\mathrm{H}$ bonds by a P450-CYP119 variant; d) intermolecular insertion into activated $\mathrm{C}-\mathrm{H}$ bonds by a P450CYP119 variant. TON: turnover number, e.r.: enantiomeric ratio, d.r.: diastereomeric ratio (trans : cis), ${ }^{*}$ with $0.0025 \mathrm{~mol} \%$ catalyst. 
a)<smiles>[R]COc1c([R])cccc1C(=N)C(=O)O[Z]</smiles>
$\operatorname{Ir}(\mathrm{Me})-\mathrm{mOCR}-\mathrm{Mb}(0.5 \mathrm{~mol} \%)$ $10 \mathrm{mM}$ Tris, pH 8.0, 8 vol\% MeCN<smiles>[R]COC(=O)C1c2cccc([R])c2OC1[R]</smiles>

141: $\mathrm{R}=\mathrm{H}, \mathrm{R}^{\prime}=\mathrm{H}, \mathrm{R}^{\prime \prime}=\mathrm{Me}$

\section{Substrate}

$\mathrm{R}=\mathrm{H}, \mathrm{R}^{\prime}=\mathrm{Me}, \mathrm{R}^{\prime \prime}=\mathrm{Me}$

$\mathrm{R}=\mathrm{OMe}, \mathrm{R}^{\prime}=\mathrm{H}, \mathrm{R}^{\prime \prime}=\mathrm{Me}$

$\mathrm{R}=\mathrm{OMe}, \mathrm{R}^{\prime}=\mathrm{H}, \mathrm{R}^{\prime \prime}=\mathrm{Me}$

\section{Mutant}

H93G-H64L-F43L-199F

H93G-H64L-V68A-L32F-H97Y

H93A-H64A-F43W-V68G

$\begin{array}{ll}\text { ee } \% & \text { TON } \\ 84 & 92 \\ -77 & 144 \\ 68 & 7260^{*}\end{array}$

b)<smiles>[R]COc1ccc([R])cc1C(=N)C(=O)OC</smiles>

Ir(Me)-PIX-CYP119 C317G (0.17 mol\%)

$100 \mathrm{mM} \mathrm{NaPi}, 100 \mathrm{mM} \mathrm{NaCl}, \mathrm{pH} 6.0$

2 vol\% DMF, room temp., $16 \mathrm{~h}$<smiles>[R]c1ccc2c(c1)C(C(=O)OC)C([R])O2</smiles>

141: $R=H, R^{\prime}=H$

Substrate

$\mathrm{R}=\mathrm{H}, \mathrm{R}^{\prime}=\mathrm{H}$

$\mathrm{R}=\mathrm{H}, \mathrm{R}^{\prime}=\mathrm{H}$

$\mathrm{R}=\mathrm{OMe}, \mathrm{R}^{\prime}=\mathrm{H}$

$\mathrm{R}=\mathrm{OMe}, \mathrm{R}^{\prime}=\mathrm{H}$

$\mathrm{R}=\mathrm{Cl}, \mathrm{R}^{\prime}=\mathrm{H}$

$\mathrm{R}=\mathrm{H}, \mathrm{R}^{\prime}=\mathrm{Me}$

$\mathrm{R}=\mathrm{H}, \mathrm{R}^{\prime}=\mathrm{Me}$

$\mathrm{R}=\mathrm{H}, \mathrm{R}^{\prime}=\mathrm{Ph}$

$\mathrm{R}=\mathrm{H}, \mathrm{R}^{\prime}=\mathrm{Ph}$

\section{Mutant}

L69V-T213G-V254L

L69W-T213G-F310G

L69Y-T213G-A152W

T213A-V254L

L69Y-T213G-A152W

L69W-T213G-L318G

L69F-T213G-V254L

T213G-V254L

L69W-T213G

$\begin{array}{ll}\text { ee } \% & \text { de } \% \\ 94 & \\ -93 & \\ -98 & \\ 87 & \\ 94 & \\ 73 & >92 \\ -77 & >92 \\ -61 & -92 \\ 90 & -85\end{array}$

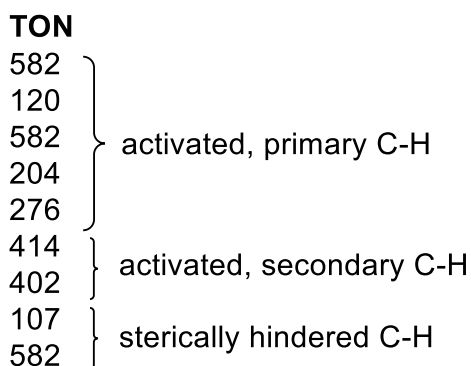

c)<smiles>CCc1ccccc1C(=N)C(=O)OC</smiles>

Ir(Me)-PIX-CYP119 C317G (1 mol\%)

$100 \mathrm{mM} \mathrm{NaPi}, 100 \mathrm{mM} \mathrm{NaCl}, \mathrm{pH} 6.0$

2 vol\% DMF, $37^{\circ} \mathrm{C}, 16 \mathrm{~h}$<smiles>COC(=O)C1CCc2ccccc21</smiles>

$\begin{array}{lll}\text { Mutant } & \text { ee\% } & \text { TON } \\ \text { L69V-T213G-V254L } & 90 & 31\end{array}$

d)<smiles>c1ccc2c(c1)[CH+]OC2</smiles>

143<smiles>CCOC(=O)C=[W]</smiles>

142 (10 eq.)
Ir(Me)-PIX-CYP119 (0.17 mol\%)

$100 \mathrm{mM} \mathrm{NaPi}, 100 \mathrm{mM} \mathrm{NaCl}, \mathrm{pH} 6.0$ 2 vol\% DMF, room temp., $16 \mathrm{~h}$

1

144<smiles>CCOC(=O)C=CC(=O)OCC</smiles>

$\begin{array}{llll}\text { Mutant } & \text { ee\% } & \text { yield } \% & \text { ratio 144:145 } \\ \text { L69V-T213A-V254L-A152W } & 68 & 55 & 120: 1\end{array}$

The work by Hartwig clearly represents a major step towards the use of ArMs as a widely applicable synthetic tool. Indeed, in view of the large number of heme-binding 
proteins and the diversity of reactions catalyzed by metalloporphyrins, the potential of such metal-subsituted hemoproteins is huge.

Although the protocol reported by the authors requires: i) E. coli culture under Fedepleted conditions, ii) affinity purification of the protein, iii) addition of the preciousmetal containing heme cofactor (in default vs. a rough estimate concentration of the apohemoprotein) and iv) catalysis under inert atmosphere, all of these technical challenges are readily amenable to automation.

\subsection{Olefin Metathesis}

Transition metal catalyzed olefin metathesis has become a highly versatile tool for $\mathrm{C}-\mathrm{C}$ bond formation. ${ }^{335}$ The development of $Z$ - and $E$-selective cross metathesis catalysts has enabled construction of a wide range of molecules containing a double bond. Moreover, the bioorthogonality of many olefin metathesis reactions has led to their use in chemical biology, ${ }^{336-338}$ particularly for selective functionalization of biopolymers. ${ }^{339-340}$ More recently, olefin metathesis has been considered as a means to expand the chemical toolkit of biochemistry given that it is thus far unknown to living organisms. A number of ArM metathases have been developed toward this end.

The first two ArM metathases were introduced in 2011 by Ward et al. and Hilvert et al. in the same issue of Chem. Commun..$^{341-342}$ The former employed (strept)avidin as a host for biotinylated cofactors based on a Grubbs-Hoveyda $2^{\text {nd }}$ generation catalyst $(\mathrm{GH}$-type catalyst). In fact, all the artificial metathase published to date use this type of cofactor. This is most probably due to its stability toward air and water. Two such cofactors 148 and 149 with different linkers were synthesized and anchored within either avidin or streptavidin via a supramolecular interactions. Diallyl tosylamide 147 served as a model substrate for ring closing metathesis (Scheme 49).

Scheme 49. Artificial metathase based on the biotin-(strept)avidin technology. 
<smiles>C=CCN(CC=C)S(=O)(=O)c1ccccc1</smiles>

$15.2 \mathrm{mM}$

147

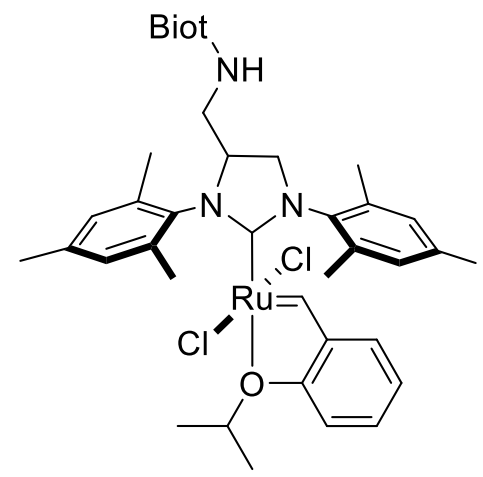

148
148 or 149 (5 mol\%)

(strept)avidin tetramer $(1.7 \mathrm{~mol} \%)$

$\mathrm{H}_{2} \mathrm{O}$ : DMSO (5:1)

$\mathrm{pH} 4-7,40{ }^{\circ} \mathrm{C}, 16 \mathrm{~h}$
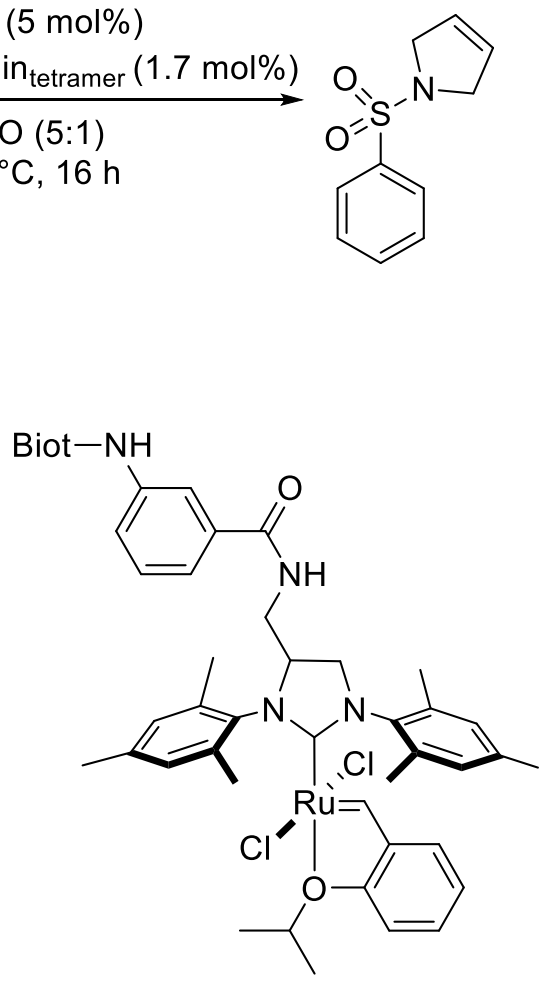

149

Different reaction conditions were explored, and the best yields were obtained at low $\mathrm{pH}$ with high concentrations of $\mathrm{MgCl}_{2}$ (Table 16). Similarly, Matsuo et al. investigated the effect of added chloride ions in aqueous metathesis and found that catalyst stability is significantly enhanced by the addition of $\mathrm{KCl}^{343}$ They proposed that the replacement of the chloride ligands by hydroxy ions may lead to decomposition of the catalyst. This could explain why the addition of chloride salts and lowering of the $\mathrm{pH}$ has a beneficial effect. In a subsequent article, Ward and coworkers tested a large number of biotinylated catalysts where the biotin anchor was placed not at the backbone but on one of the mesityl units of the $\mathrm{NHC}$ ligand. ${ }^{344}$ This strategy improved the activity of the Sav-based metathase for a poor RCM substrate that affords fluorescent umbelliferone 169 upon metathesis.

Table 16. Summary of the results obtained for the artificial metathase system based on the biotin-(strept)avidin technology for substrate 147. 


\begin{tabular}{ccccccc}
\hline Entry & Catalyst & Protein & $\mathrm{pH}^{\mathrm{a}}$ & $\begin{array}{c}\mathrm{MgCl}_{2} \\
{[\mathrm{M}]}\end{array}$ & $\begin{array}{c}\text { Yield } \\
(\%)\end{array}$ & TON \\
\hline 1 & $\mathbf{1 4 8}$ & - & 7 & - & 74 & 15 \\
2 & $\mathbf{1 4 8}$ & Sav & 7 & - & $<1$ & 0 \\
3 & $\mathbf{1 4 9}$ & Sav & 7 & - & 8 & 2 \\
4 & $\mathbf{1 4 9}$ & Sav & 7 & 0.5 & 33 & 7 \\
5 & $\mathbf{1 4 9}$ & Sav & 4 & - & 41 & 8 \\
6 & $\mathbf{1 4 9}$ & Sav & 4 & 0.5 & 71 & 14 \\
7 & $\mathbf{1 4 8}$ & Avi & 7 & - & 17 & 3 \\
8 & $\mathbf{1 4 9}$ & Avi & 7 & - & 6 & 1 \\
9 & $\mathbf{1 4 9}$ & Avi & 7 & 0.5 & 54 & 11 \\
10 & $\mathbf{1 4 8}$ & Avi & 4 & - & 79 & 16 \\
11 & $\mathbf{1 4 8}$ & Avi & 4 & 0.5 & 95 & 19 \\
12 & $\mathbf{1 4 8}$ & - & 4 & 0.5 & 95 & 19 \\
\hline${ }^{a} \mathrm{pH} 7:$ no buffer; $\mathrm{pH}$ 4: acetate $(0.1 \mathrm{M})$ & & &
\end{tabular}

The construct of Hilvert et al., on the other hand, was generated via covalent modification of a small heat-shock protein from Methanocaldococcus jannaschii (MjHSP). ${ }^{342}$ This protein assembles into a spherical substructure with large pores, which allow for the diffusion of small molecules. Similar to streptavidin, the protein displays a remarkable stability towards high temperatures and low pH. GH-type catalyst 150 substituted with a $\alpha$-bromoacetyl group was reacted with the thiol of a surface cysteine in the G41C mutant of MjHSP to yield the artificial metathase 151 (Scheme 50).

Scheme 50. Covalent anchoring strategy to produce a metathase by Hilvert et al. 342 


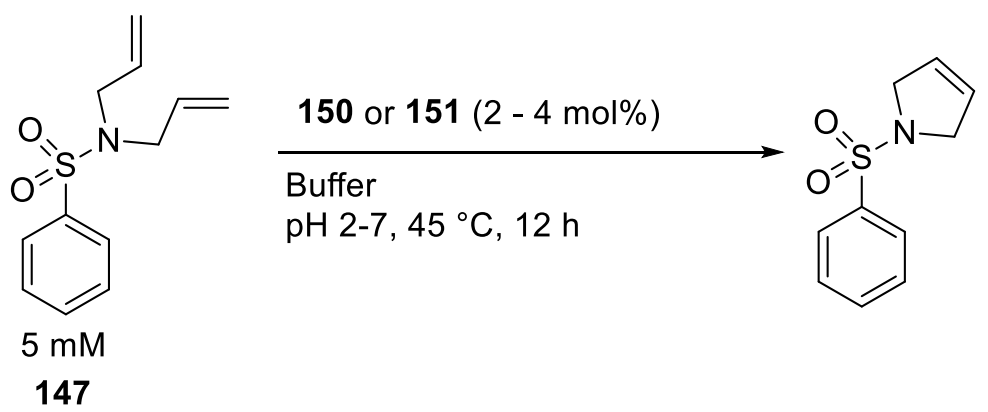

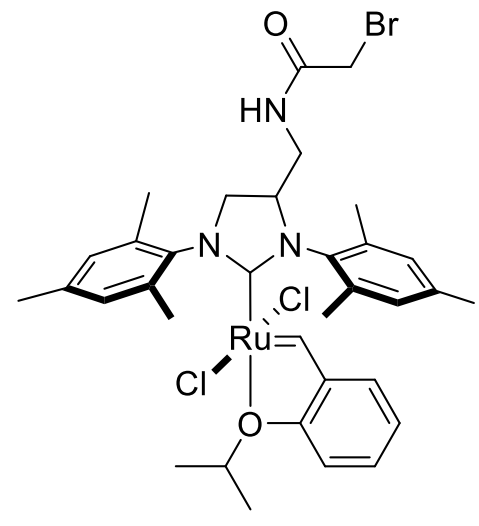

150

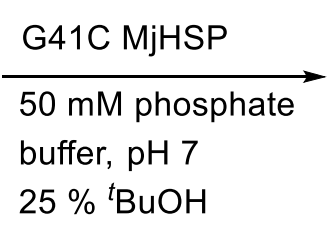

$25 \%{ }^{t} \mathrm{BuOH}$

The same trend observed for the metathase of Ward et al. was also apparent for this system: the lower the $\mathrm{pH}$, the better the performance of the metathase. A total turnover number of 25 could be achieved for ArM 151 at $\mathrm{pH}$ 2, but the free catalyst 150 gave slightly better results (Table 17, compare entries 1-3 with entries 4-6).

Table 17. Selected results for the metathase with substrate 147 based on the heatshock protein MjHSP by Hilvert et al. ${ }^{342}$

\begin{tabular}{ccccc}
\hline Entry & Catalyst & $\mathrm{pH}^{\mathrm{a}}$ & Catalyst loading (mol \%) & TON \\
\hline 1 & $\mathbf{1 5 0}$ & 7.0 & 2 & 2 \\
2 & $\mathbf{1 5 0}$ & 3.9 & 2 & 16 \\
3 & $\mathbf{1 5 0}$ & 2.0 & 2 & 33 \\
4 & $\mathbf{1 5 1}$ & 7.0 & 4 & 3 \\
5 & $\mathbf{1 5 1}$ & 3.9 & 4 & 12 \\
6 & $\mathbf{1 5 1}$ & 2.0 & 4 & 25 \\
\hline${ }^{\mathrm{a}} \mathrm{pH}$ 7.0: & $\mathbf{5 0}$ mM phosphate; $\mathrm{pH}$ 3.9: $50 \mathrm{mM} \mathrm{MES;} \mathrm{pH} \mathrm{2.0:} 10 \mathrm{mM} \mathrm{HCl}$.
\end{tabular}

A covalent anchoring strategy was also used by Matsuo et al. to generate an ArM metathase. ${ }^{345} \mathrm{GH}$ cofactor 152 , which contains an L-phenylalanine moiety bearing an $\alpha$ chloroketone, was used to both covalently anchor the cofactor to $\alpha$-chymotrypsin and 
selectively interact with the $S 1$ site of $\alpha$-chymotrypsin via hydrophobic contacts. Nucleophilic attack of the imidazole of $\mathrm{H} 57$ on the chloroketone resulted in a covalent link between the cofactor and $\alpha$-chymotrypsin to provide 153. Interestingly, the authors showed that the enantiomer of $\mathbf{1 5 2}$ with inverted stereochemistry did not react with the protein. This provided convincing evidence that the functionalization indeed occured inside the active site of $\alpha$-chymotrypsin which is known to only recognizes Lphenylalanine. The authors tested three different substrates for metathesis and reported good turnover numbers when using the glycosylated diene 154. In contrast, they observed only low TONs for the cationic substrate 155 and the lipophylic diallyl tosylate 147 (Table 18, entries 1-6 and Scheme 51).

Scheme 51. Conversion of $\alpha$-Chymotrypsin into a metathase via covalent anchoring.

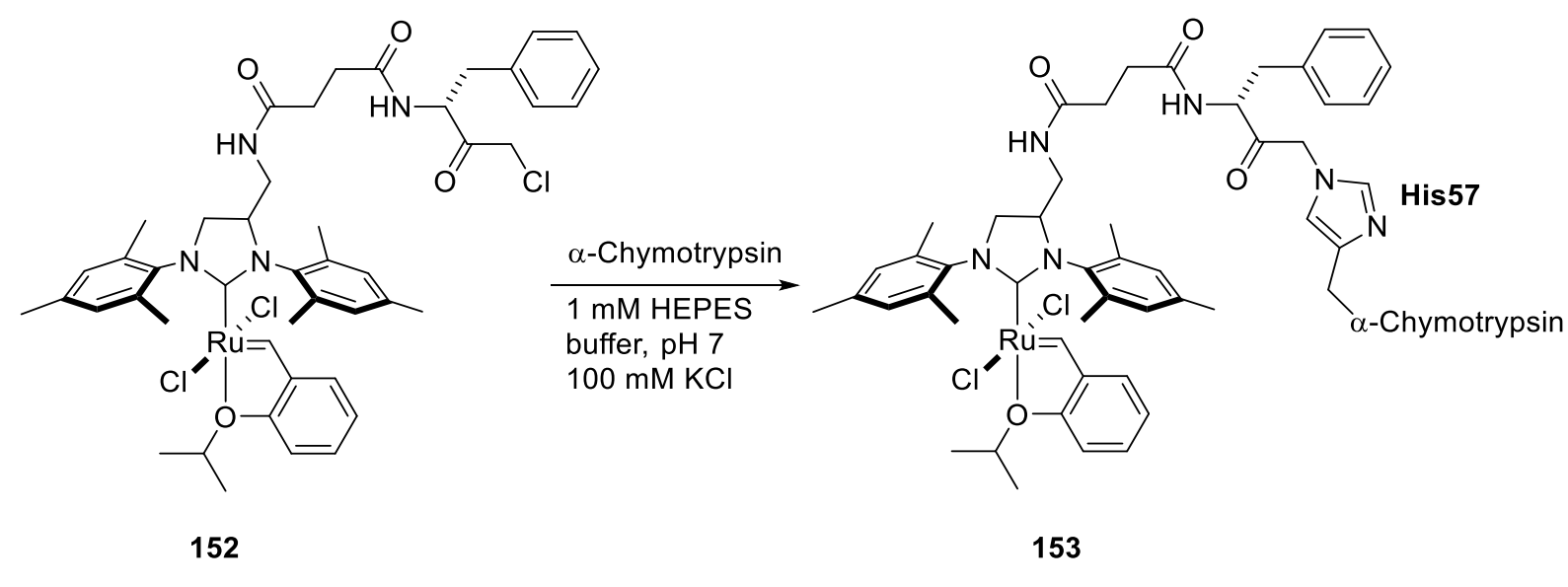

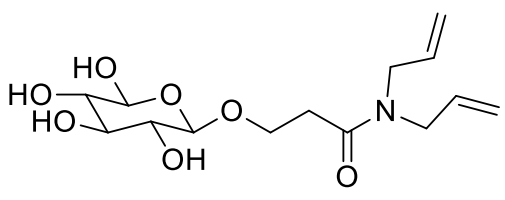

154

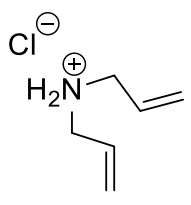

155

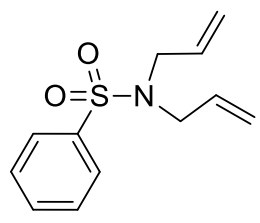

147

Table 18. Selected results for RCM using the metathase based on $\alpha$-chymotrypsin.

\begin{tabular}{cccc}
\hline Entry & Catalyst & Sub. & TON (after 2 h) \\
\hline $1^{\text {a }}$ & $\mathbf{1 5 3}$ & $\mathbf{1 5 4}$ & 20 \\
$2^{\text {a,b }}$ & $\mathbf{1 5 2}$ & $\mathbf{1 5 4}$ & 14
\end{tabular}




\begin{tabular}{|c|c|c|c|}
\hline $3^{c}$ & 153 & 155 & N.D. \\
\hline $4^{\mathrm{c}, \mathrm{d}}$ & 152 & 155 & $<2$ \\
\hline $5^{\mathrm{b}, \mathrm{e}}$ & 153 & 147 & 4 \\
\hline $6^{\mathrm{b}, \mathrm{e}}$ & 152 & 147 & 12 \\
\hline
\end{tabular}

Yet another anchoring strategy was used by Gebbink et al. ${ }^{346}$ to link a GH-type catalyst substituted with a phosphonated alkyl chain to cutinase. The cofactor underwent irreversible transesterification with $\mathrm{S} 120$ in the cutinase active site to form an ArM (Figure 17). The authors first explored a catalyst with a short alkyl chain 156, but this had no metathesis activity. When the chain length was increased (157), the resulting ArM catalyzed both ring closing metathesis of diallyl tosylamide 147 and crossmetathesis of allylbenzene 158. To our knowledge this was the first example of crossmetathesis using an ArM (Table 19).

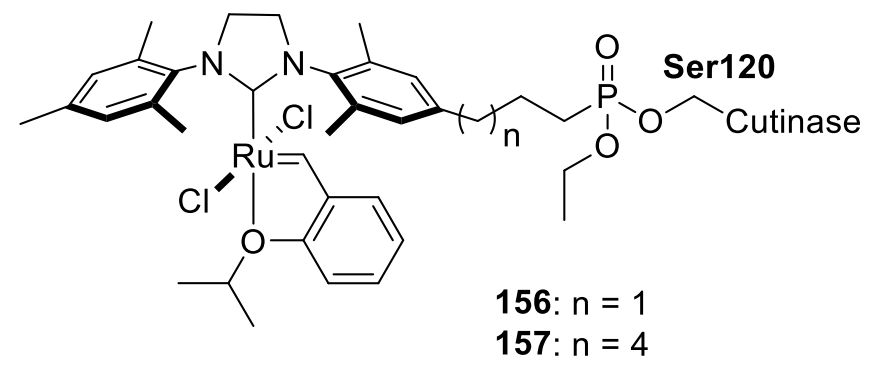

Figure 17. Artificial metathase using cutinase as a host.

Table 19. Selected results for an artificial metathase with a cutinase host.

\begin{tabular}{|c|c|c|c|c|}
\hline Entry & Catalyst & Sub. & Buffer & TON \\
\hline 1 & 156 & 147 & tris- $\mathrm{HCl} \mathrm{pH} 8.5$ & - \\
\hline 2 & 156 & 147 & $\mathrm{HCl} 0.01 \mathrm{M}$ & - \\
\hline 3 & 156 & 147 & acetate $\mathrm{pH} 5$ & $<1$ \\
\hline 4 & Grubbs-Hoveyda II & 147 & acetate $\mathrm{pH} 5$ plus cutinase & 18 \\
\hline 5 & 157 & 147 & tris- $\mathrm{HCl} \mathrm{pH} 8.5$ & - \\
\hline 6 & 157 & 147 & acetate $\mathrm{pH} 5$ & 17 \\
\hline 7 & 156 & 158 & acetate $\mathrm{pH} 5$ & $<1$ \\
\hline 8 & 157 & 158 & Acetate $\mathrm{pH} 5$ & 20 \\
\hline
\end{tabular}

An artificial metathase based on on human carbonic anhydrase II (hCA II) was reported by Ward et al. ${ }^{347}$ The hCA II protein has a strong affinity (typically nM - pM) toward 
arylsulfonamides due to sulfonamide coordination to an active site zinc ion. Three different sulfonamide-substituted catalysts were prepared (159-161), and their activity toward ring closing metathesis of substrate 147 was evaluated. Catalyst 160 , bearing ortho-isopropoxy groups at the NHC aryl groups, performed best. The ArM had similar activity to the free cofactor, but moderate turnover was observed even at $\mathrm{pH} 7.0$, which may be relevant for in vivo applications (Table 20 and Scheme 52).

Scheme 52. Human carbonic anhydrase as host for an artificial metathase.

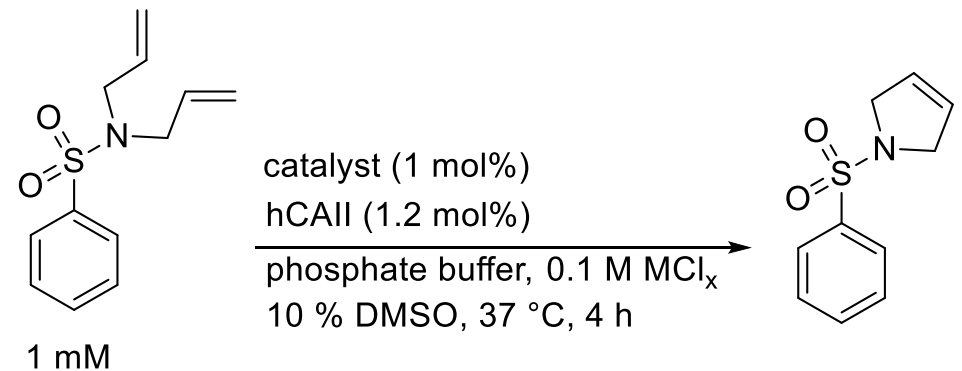

147
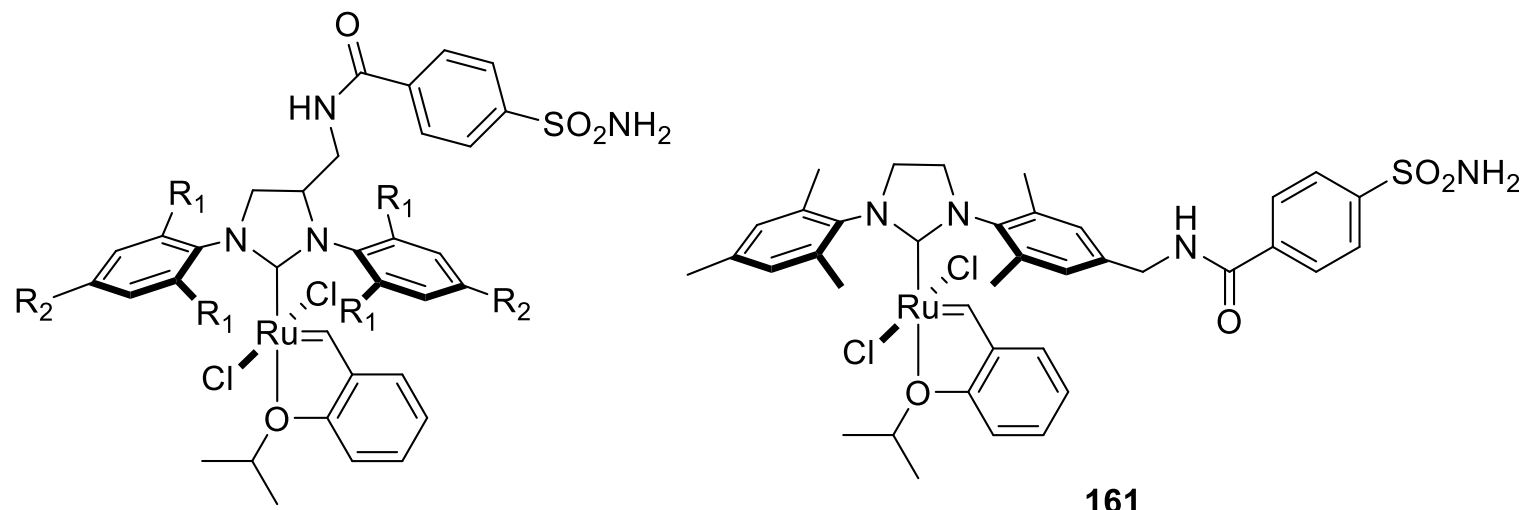

159: $R_{1}=R_{2}=M e$

160: $\mathrm{R}_{1}={ }^{i} \mathrm{Pr}, \mathrm{R}_{2}=\mathrm{H}$

Table 20. Selected results for RCM with an artificial metathase based on hCA II.

\begin{tabular}{|c|c|c|c|c|c|c|c|c|c|c|c|}
\hline Entry & Cat & hCAll & $\mathrm{pH}$ & $\begin{array}{l}\mathrm{MCl}_{\mathrm{x}} \\
\mathrm{mol} / \mathrm{L}\end{array}$ & TON & Entry & Cat & hCAll & $\mathrm{pH}$ & $\begin{array}{c}\mathrm{MCl}_{\mathrm{x}} \\
\mathrm{mol} / \mathrm{L}\end{array}$ & TON \\
\hline 1 & 159 & - & 6.0 & $\mathrm{MgCl}_{2} 0.1$ & 20 & 15 & 160 & WT & 8.0 & - & 21 \\
\hline 2 & 160 & - & 6.0 & $\mathrm{MgCl}_{2} 0.1$ & 48 & 16 & 160 & - & 7.0 & $\mathrm{NaCl} 1.5$ & 32 \\
\hline 3 & 161 & - & 6.0 & $\mathrm{MgCl}_{2} 0.1$ & 25 & 17 & 160 & WT & 7.0 & $\mathrm{NaCl} 1.5$ & 21 \\
\hline 4 & 159 & WT & 6.0 & $\mathrm{MgCl}_{2} 0.1$ & 13 & 18 & 160 & WT & 7.0 & $\mathrm{NaCl} 0.5$ & 32 \\
\hline 5 & 160 & WT & 6.0 & $\mathrm{MgCl}_{2} 0.1$ & 45 & 19 & 160 & WT & 7.0 & $\mathrm{NaCl} 1.0$ & 29 \\
\hline 6 & 161 & WT & 6.0 & $\mathrm{MgCl}_{2} 0.1$ & 16 & 20 & 160 & $191 \mathrm{~A}$ & 7.0 & - & 18 \\
\hline 7 & 160 & WT & 6.0 & $\mathrm{NaCl} 0.2$ & 40 & 21 & 160 & F131A & 7.0 & - & 16 \\
\hline
\end{tabular}




\begin{tabular}{|c|c|c|c|c|c|c|c|c|c|c|c|}
\hline 8 & 160 & WT & 7.0 & $\mathrm{NaCl} 0.2$ & 28 & 22 & 160 & L198F & 7.0 & - & 18 \\
\hline 9 & 160 & - & 7.0 & - & 23 & 23 & 160 & L198H & 7.0 & - & 22 \\
\hline 10 & 160 & WT & 7.0 & - & 14 & 24 & 160 & L198H & 7.0 & $\mathrm{NaCl} 0.15$ & 28 \\
\hline $11^{\mathrm{a}}$ & 160 & WT & 7.0 & - & 20 & 25 & 160 & L198A & 7.0 & - & 15 \\
\hline 12 & 160 & - & 5.0 & $\mathrm{MgCl}_{2} 0.5$ & 85 & 26 & 160 & L198Q & 7.0 & - & 14 \\
\hline 13 & 160 & WT & 5.0 & $\mathrm{MgCl}_{2} 0.5$ & 78 & 27 & 160 & $\mathrm{~K} 170 \mathrm{~A}$ & 7.0 & - & 15 \\
\hline 14 & 160 & WT & 6.0 & - & 23 & & & & & & \\
\hline
\end{tabular}

Okuda and Schwanenberg reported the first artificial metathase for ring opening metathesis polymerization (ROMP). In their original publication, the authors described a strategy to engineer the $\beta$-barrel protein FhuA via modification of an internal cysteine mutant (K545C) of the protein (Figure 18). ${ }^{348}$ Two additional positions (N548V and E501F) were also mutated to ensure cysteine accessibility and improve catalyst performance. Both maleimide- and $\alpha$-bromoacetyl-functionalized GH-type catalysts reacted with the internal cysteine residue in the FhuA triple mutant to generate ArM metathases. Of the metathases evaluated, 166.FhuA, generated from maleimide functionalized GH-catalyst 166, provided the highest activity for polymerization of 7oxanorbornene 162, but higher activity was observed for the free catalyst. In a subsequent publication, the authors performed chemical optimization of the linker length. ${ }^{349}$ Gratifyingly, shortening the linker increased the efficiency of the metathase, and modest selectivity towards cis-double bonds was observed in the polymer product (Table 21, entries 1-8 and Scheme 53). 


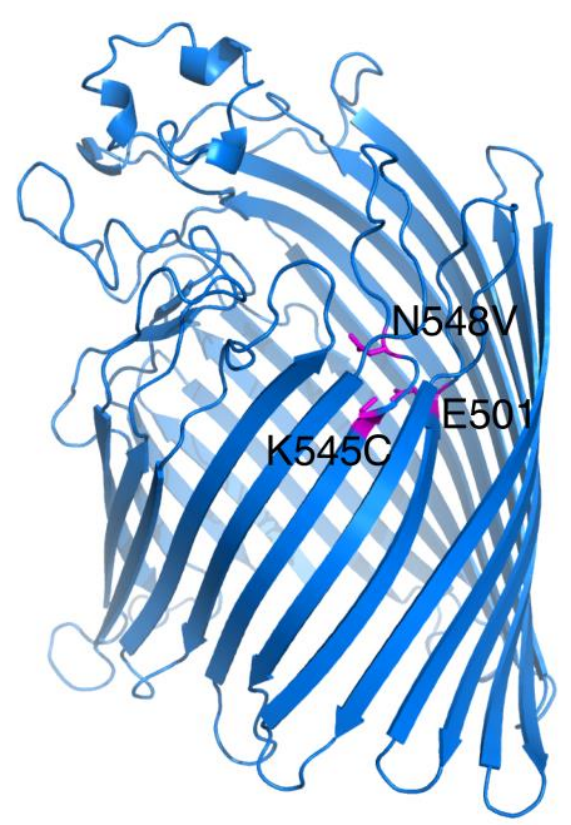

Figure 18. An artificial metathase ${ }^{349}$ and a Diels-Alderase ${ }^{350}$ were generated based on the FhuA scaffold (PDB code 1BY3). Metal catalysts were covalently tethered to the protein scaffold via mutation $\mathrm{K} 545 \mathrm{C}$.

Scheme 53. Artificial metathase based on the FhuA barrel protein. 


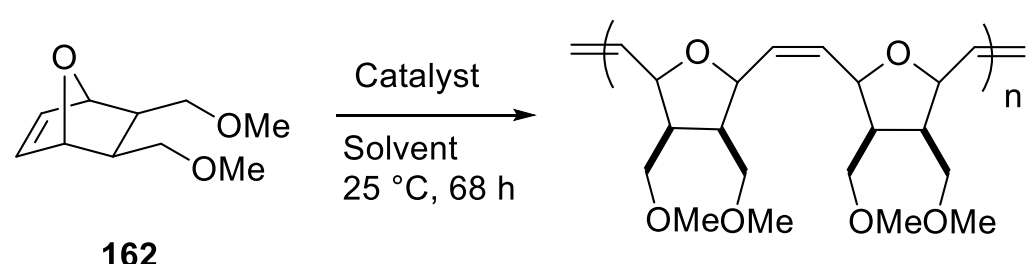

162

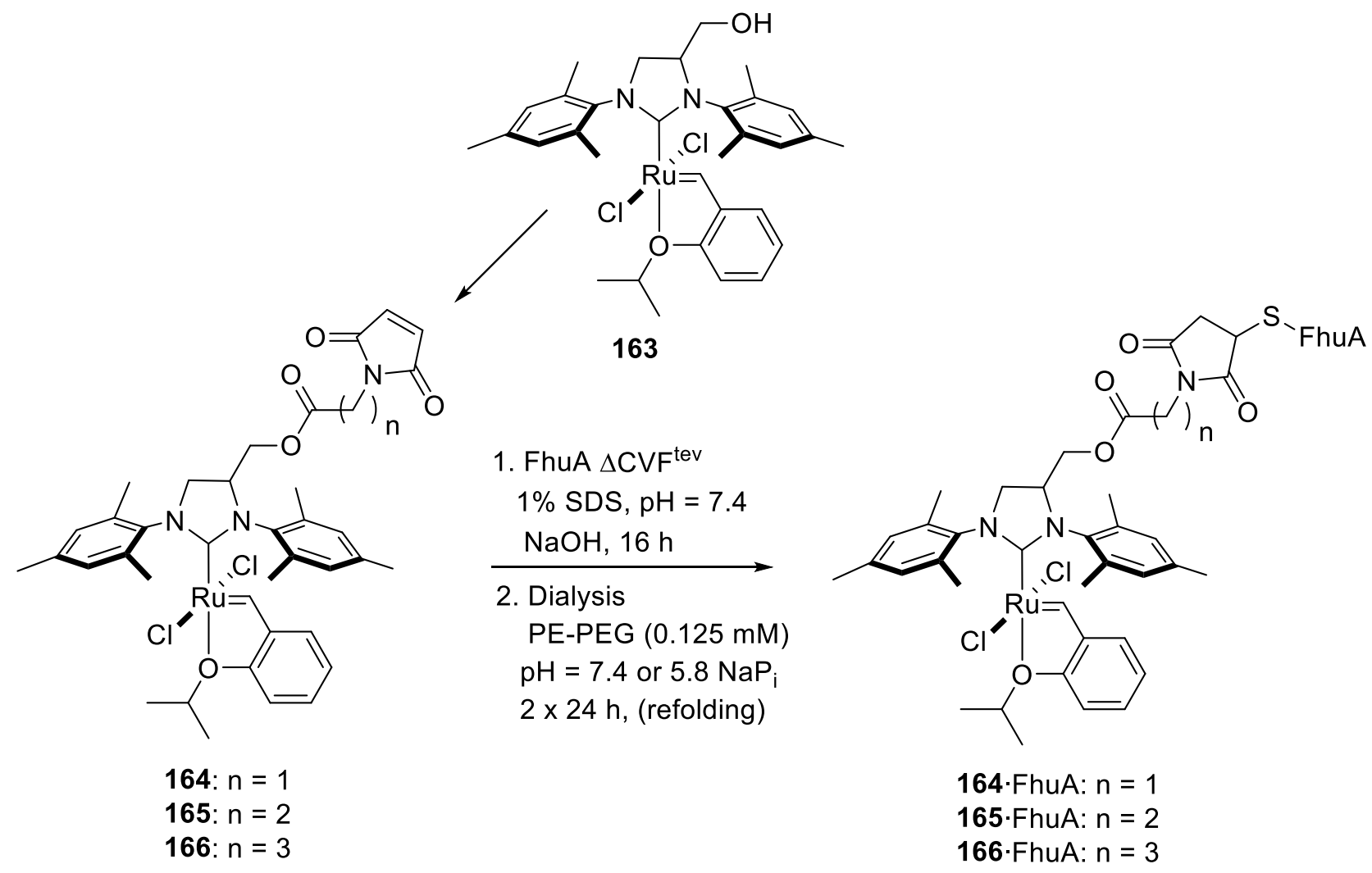

The same authors then examined a cysteine mutant of nitrobindin as a protein scaffold for their second generation metathases. ${ }^{199}$ Low bioconjugation yields were observed presumably due to the small size of the barrel interior relative to the sterically demanding GH-type catalysts. A cofactor bearing a longer linker 166 , on the other hand, reacted to form the desired ArM 166. Nb1. Enlarging the cavity of the nitrobindin 1 scaffold led to higher bioconjugation yields. This mutant (nitrobindin 2) enabled formation of multiple metathases $164 \cdot \mathrm{Nb2}, 165 \cdot \mathrm{Nb} 2$ and $166 \cdot \mathrm{Nb2}$. The ArM generated using the cofactor bearing the longest linker $166 \cdot \mathrm{Nb} 2$ again proved to be most active. The metathase also catalyzed ring closing metathesis with 2,2-diallyl-1,3-propanediol 167, but no protein acceleration was observed for this reaction (Table 21, entries 9-17 and Scheme 54).

Scheme 54. Second generation metathase based on a nitrobindin scaffold. 


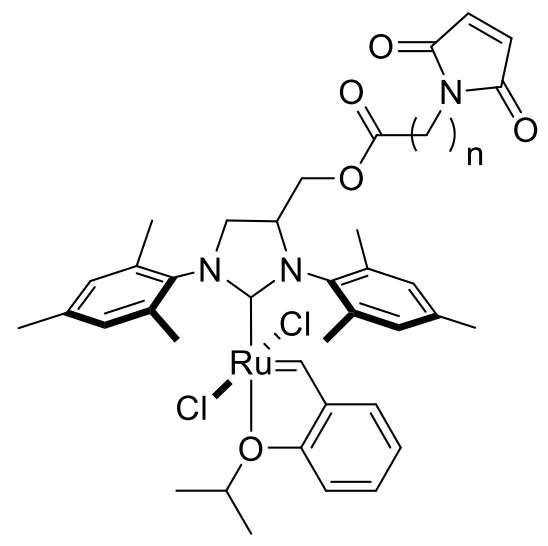

164: $\mathrm{n}=1$

165: $n=2$

166: $n=3$
NB-SH

$\mathrm{H}_{2} \mathrm{O}$, DMSO (1-10\%)

Tris- $\mathrm{HCl} 10 \mathrm{mM} \mathrm{pH} 7.5$

$50 \mathrm{mM} \mathrm{NaCl}$

$60 \mathrm{~min}, 25^{\circ} \mathrm{C}$

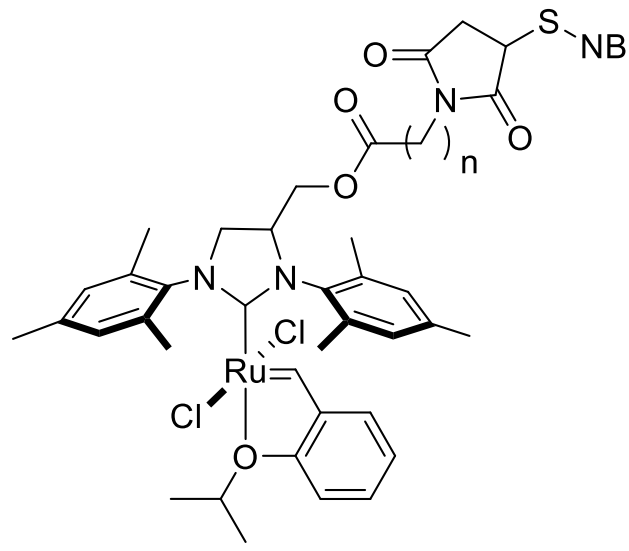

166. NB1: $\mathrm{n}=3$

164.NB2: $\mathrm{n}=1$

165.NB2: $n=2$

166.NB2: $\mathrm{n}=3$

Table 21. Selected results for the artificial metathase based on FhuA and Nitrobindin with substrates 162 and 167.

\begin{tabular}{|c|c|c|c|c|c|c|c|c|c|c|c|c|}
\hline Entry & Catalyst & Sub. & $\begin{array}{c}\text { Conversion } \\
(\%)\end{array}$ & cis/trans & TON & Ref & Entry & Catalyst & Sub. & Conversion & TON & Ref \\
\hline $1^{\mathrm{a}}$ & 163 & 162 & 70 & $48 / 52$ & 530 & 348 & $14^{\mathrm{c}, \mathrm{e}, \mathrm{f}}$ & 163 & 167 & $>99$ & 100 & 199 \\
\hline $2^{\mathrm{a}}$ & $163+$ FhuA & 162 & 0 & n.d. & n.d & 348 & $15^{\mathrm{d}, \mathrm{e}, \mathrm{f}}$ & $165 \cdot \mathrm{Nb} 2$ & 167 & 89 & 89 & 199 \\
\hline $3^{a}$ & 166.FhuA & 162 & 37 & $56 / 44$ & 365 & 348 & $16^{\mathrm{d}, \mathrm{e}, \mathrm{f}}$ & $166 \cdot \mathrm{Nb} 2$ & 167 & $>99$ & 100 & 199 \\
\hline $4^{b}$ & 163 & 162 & 99 & $50 / 50$ & 990 & 349 & $17^{\mathrm{d}, \mathrm{e}, \mathrm{g}}$ & $166 \cdot \mathrm{Nb} 2$ & 167 & 57 & 178 & 199 \\
\hline $5^{b}$ & 164.FhuA & 162 & 41 & $58 / 42$ & 555 & 349 & & & & & & \\
\hline $6^{b}$ & 165.FhuA & 162 & 24 & $56 / 44$ & 325 & 349 & & & & & & \\
\hline $7^{c}$ & 163 & 162 & 41 & $70 / 30$ & 4100 & 199 & & & & & & \\
\hline $8^{d}$ & 163 & 162 & $<5$ & n.d. & n.d & 199 & & & & & & \\
\hline $9^{d}$ & $166 \cdot \mathrm{Nb} 1$ & 162 & 10 & $40 / 60$ & 1100 & 199 & & & & & & \\
\hline $10^{\mathrm{d}}$ & $164 \cdot \mathrm{Nb} 2$ & 162 & $<5$ & n.d. & n.d. & 199 & & & & & & \\
\hline $11^{d}$ & $165 \cdot$ NB2 & 162 & 19 & $42 / 58$ & 2100 & 199 & & & & & & \\
\hline $12^{d}$ & $166 \cdot$ NB2 & 162 & 78 & $43 / 57$ & 9700 & 199 & & & & & & \\
\hline $13^{\mathrm{d}, \mathrm{e}}$ & $166 \cdot N B 2$ & 162 & 80 & $48 / 52$ & 9900 & 199 & & & & & & \\
\hline
\end{tabular}

a phosphate buffer pH 7.4, 10\% THF, $0.125 \mathrm{mM} \mathrm{PE-PEG;}{ }^{b}$ phosphate buffer $\mathrm{pH} 5.8,10 \%$ THF, $0.125 \mathrm{mM}$ PE-PEG; ${ }^{\mathrm{c}}$ in THF, $12 \mathrm{~h}$, $0.01 \mathrm{~mol} \%$ catalyst; ${ }^{\mathrm{d}} 0.008 \mathrm{~mol} \%$ catalyst, MES buffer $\mathrm{pH} 6.0,0.2 \mathrm{M} \mathrm{NaCl}, 25^{\circ} \mathrm{C}, 12 \mathrm{~h}$; e performed at $40{ }^{\circ} \mathrm{C} ;{ }^{\dagger}[\mathrm{Sub}]=125 \mathrm{mM}$; [cat] $=1.25 \mathrm{mM} ;{ }^{9} 0.3 \mathrm{~mol} \%$ catalyst.

A breakthrough in the field of artificial metalloenzymes and metathases in particular was achieved in the groups of Ward and Panke. ${ }^{351}$ Relying on the biotin-streptavidin couple, they selectively assembled an ArM metathase within the periplasm of Escherichia coli. 
The secretion of streptavidin into the periplasm was achieved by fusing Sav with the signal peptide OmpA. The E. coli strain combined a biotinylated GH-type catalyst 171 and periplasmic streptavidin as the protein host. This approach offers several important benefits. First, the metathase is not exposed to metabolites that could potentially interfere with the reaction or poison the catalyst. Glutathione, for example, is known to inhibit many precious metal catalysts, ${ }^{261}$ but in the periplasm, this metabolite is only present in low concentrations and primarily in its oxidized form. The latter was shown to be significantly less harmful to $d^{6}$-metal complexes. Second, conducting metathesis reactions in vivo substantially sped up genetic optimization of the ArM metathases. A screening protocol was designed using microtiter plates and substrate 168, which yielded fluorescent umbelliferone 169 upon RCM. Saturation mutagenesis libraries for twenty different amino acid positions were generated and over 3000 clones were screened. A quintuple mutant (47A-49K-114Q-119G-121R) with a cell-specific activity 5.4 times higher than the wild type metathase was identified. The activity of the purified ArM was also evaluated on two additional water soluble RCM substrates. The evolved metathase had increased activity over free catalyst as well as two benchmark, commercial catalysts toward uncharged diol substrate 167 . When the positively-charged diallylsulfonamide derivative $\mathbf{1 7 0}$ was tested with the quintuple mutant, however, a lower activity than the wild type was observed. The authors hypothesized that this may be due to electrostatic repulsion of the quarternary ammonium ion and the positively charged guanidinium group of arginine K121R. Consequently, a new round of saturation mutagenesis was performed at this position and a new clone (47A-49K/114Q-119G121L) was found with leucine as an apolar residue at the 121 position. Upon removing this charge, the new mutant brought a significant improvement for the positively charged substrate 170 (Table 22 and Scheme 55). 
Scheme 55. In vivo directed evolution of an artificial metathase based on the biotinstreptavidin technology.

a)<smiles>C=CC(=O)Oc1cc(O)ccc1C=C</smiles>
$10 \mathrm{mM}$

168
$171(2.1 \mu \mathrm{M})$

Sav-expressing E-coli

Ac Buffer $\mathrm{pH} 4,5 \%$ DMSO, $0.5 \mathrm{M} \mathrm{MgSO}_{4}, 37^{\circ} \mathrm{C}$<smiles>O=c1ccc2ccc(O)cc2o1</smiles>

Fluorescent

169 b)

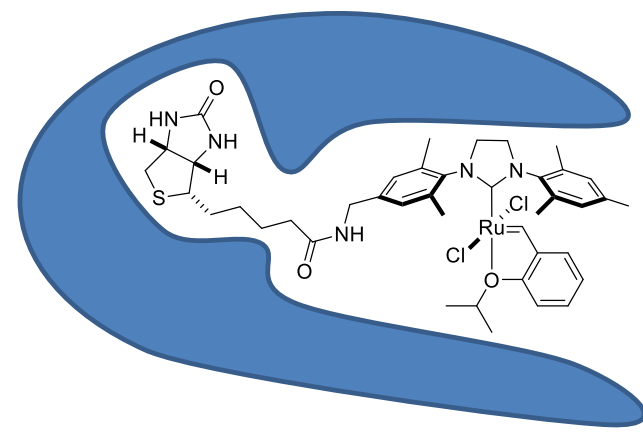

representation of catalyst $\mathbf{1 7 1}$ inside streptavidin c)<smiles>C=CCN(CC=C)S(=O)(=O)c1ccc(CCNC(C)C)cc1</smiles><smiles>C=CCC(CO)(CO)CC=C</smiles>

167

d)

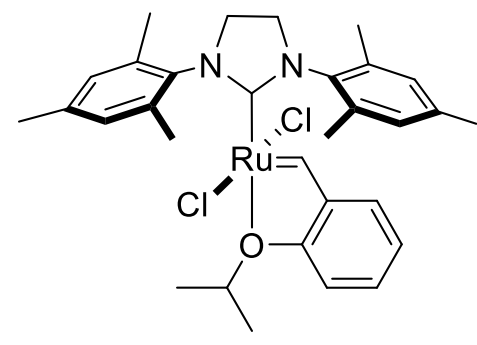

172

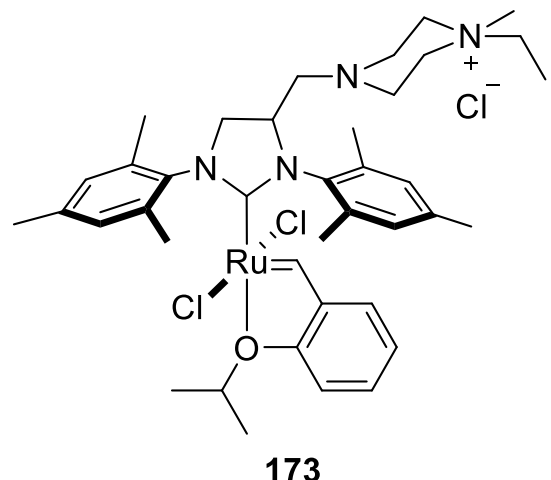

173

Table 22. In vitro performance of artificial metathases obtained by directed evolution.

\begin{tabular}{ccccc}
\hline Entry & Cat & $\begin{array}{c}\text { SAV } \\
\text { mutant }\end{array}$ & Sub & TON \\
\hline $1^{\text {a }}$ & $\mathbf{1 7 2}$ & - & $\mathbf{1 6 7}$ & 230 \\
$2^{\mathrm{a}}$ & $\mathbf{1 7 3}$ & - & $\mathbf{1 6 7}$ & 340 \\
$3^{\mathrm{a}}$ & $\mathbf{1 7 1}$ & - & $\mathbf{1 6 7}$ & 155 \\
$4^{\mathrm{a}}$ & $\mathbf{1 7 1}$ & Wild Type & $\mathbf{1 6 7}$ & 445 \\
$5^{\mathrm{a}}$ & $\mathbf{1 7 1}$ & $(47 \mathrm{~A} / 49 \mathrm{~K} / 114 \mathrm{Q} / 119 \mathrm{G} / 121 \mathrm{R})$ & $\mathbf{1 6 7}$ & 645 \\
$6^{\mathrm{a}}$ & $\mathbf{1 7 1}$ & $(47 \mathrm{~A} / 49 \mathrm{~K} / 114 \mathrm{Q} / 119 \mathrm{G} / 121 \mathrm{~L})$ & $\mathbf{1 6 7}$ & 455 \\
$7^{\mathrm{b}}$ & $\mathbf{1 7 2}$ & - & $\mathbf{1 7 0}$ & 18 \\
$8^{\mathrm{b}}$ & $\mathbf{1 7 3}$ & - & $\mathbf{1 7 0}$ & 30 \\
$9^{\mathrm{b}}$ & $\mathbf{1 7 1}$ & - & $\mathbf{1 7 0}$ & 32 \\
$10^{\mathrm{b}}$ & $\mathbf{1 7 1}$ & Wild Type & $\mathbf{1 7 0}$ & 53 \\
$11^{\mathrm{b}}$ & $\mathbf{1 7 1}$ & $(47 \mathrm{~A} / 49 \mathrm{~K} / 114 \mathrm{Q} / 119 \mathrm{G} / 121 \mathrm{R})$ & $\mathbf{1 7 0}$ & 46 \\
$12^{\mathrm{b}}$ & $\mathbf{1 7 1}$ & $(47 \mathrm{~A} / 49 \mathrm{~K} / 114 \mathrm{Q} / 119 \mathrm{G} / 121 \mathrm{~L})$ & $\mathbf{1 7 0}$ & 89 \\
\hline
\end{tabular}


${ }^{a}$ conditions: deuterated acetate buffer $\mathrm{pH} 4,1.5 \%$ DMSO-d6, [cat] = $50 \mu \mathrm{M}$, [sub] = $50 \mathrm{mM}$; ${ }^{\mathrm{b}}$ conditions:

acetate buffer $\mathrm{pH} 4,1.5 \% \mathrm{DMSO}$, [cat] $=50 \mu \mathrm{M}$, [sub] $=10 \mathrm{mM}$.

However, when performing catalysis in the periplasm, the metathase's activity droped by ca 1 order of magnitude (e.g. 89 TON in vitro vs 7 TON in cellulo for substrate 170). The authors speculate that this may be caused by several factors including: i) the very low concentration of ArM in the periplasm; ii) the gel-like medium present in the periplasm and iii) the presence of non-innocent metabolites in the periplasm.

In conclusion, it has been shown that metathesis is a versatile reaction for ArMs. Within the past five years, the efficiency of metathases rose from a TON of 20 to hundreds of turnovers. Furthermore, all of the common metathesis reactions including crossmetathesis, ring closing metathesis, as well as ring opening metathesis polymerization have been achieved by artificial metathases. It has also been shown that such metathases under certain conditions can also work inside cells, which raises fascinating perspectives for their potential use in vivo. Yet, some major hurdles have to be overcome for such hybrid catalysts to be applicable as real alternatives to their organometallic counterparts. Since these systems rely on $\mathrm{GH}$-type cofactors, they remain fragile toward reactive cell metabolites, especially thiols including GSH. This problem could be solved by either chemical engineering of more stable metathesis catalysts or by biological engineering of highly shielded active sites. The second challenge is the modest reactivity, compared to established commercial catalysts. However, taking into account the powerful tools offered by enzyme engineering, it is only a matter of time until highly efficient metathases can be developed for in vivo applications. 


\subsection{Cyclopropanation}

As noted in section 5.4 , several heme enzymes have been reported to catalyze olefin cyclopropanation via carbene insertion into olefin substrates. Metal substituted heme proteins also catalyze this reaction. Indeed, (PPIX) Ir(Me)-substituted myoglobin (see active site in Figure 15) catalyzed cyclopropanation reactions of an internal alkene 174 and an unactivated aliphatic olefin 175, neither of which has been reported for natural heme enzymes (Scheme 56 a-b). To facilitate in vivo generation of ArMs containing heme cofactors, Brustad and Snow recently reported an orthogonal P450-Fe-DPIX pair and demonstrated that the resulting ArMs could catalyze carbene insertion into olefins to generate cyclopropanes (Scheme 56 c), Figure 19). ${ }^{352}$

Scheme 56. Cyclopropanation reactions catalyzed by heme-substituted ArMs: a) aromatic olefins and b) aliphatic olefins catalyzed by myoglobin variants; c) styrene cyclopropanation catalyzed by $\mathrm{P} 450 \mathrm{BM} 3$ variants. 
a)<smiles>CC=Cc1ccccc1</smiles><smiles>CCOC(=O)C=[W]</smiles>
$\operatorname{lr}(\mathrm{Me})-\mathrm{mOCR}-\mathrm{Mb}(0.5 \mathrm{~mol} \%)$

$10 \mathrm{mM}$ Tris, $\mathrm{pH} 8.0,8$ vol\% MeCN<smiles>CCOC(=O)[C@H](C)c1ccccc1</smiles>

174

142 (6 eq.)

Mutant

H93A-H64V-F43Y-V68V-H97F

$\begin{array}{lll}\text { ee } \% & \text { de } \% & \text { TON } \\ 40 & 94 & 20\end{array}$

b)

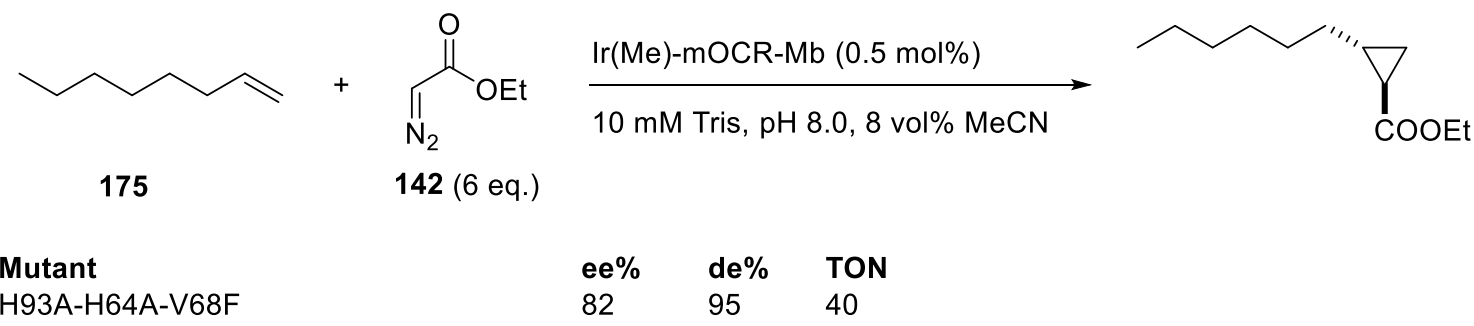

c)

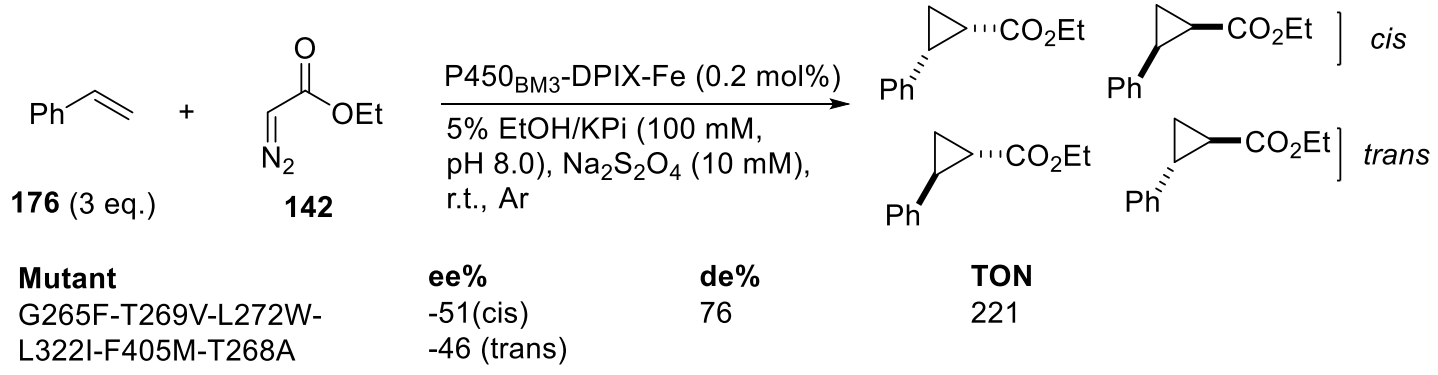

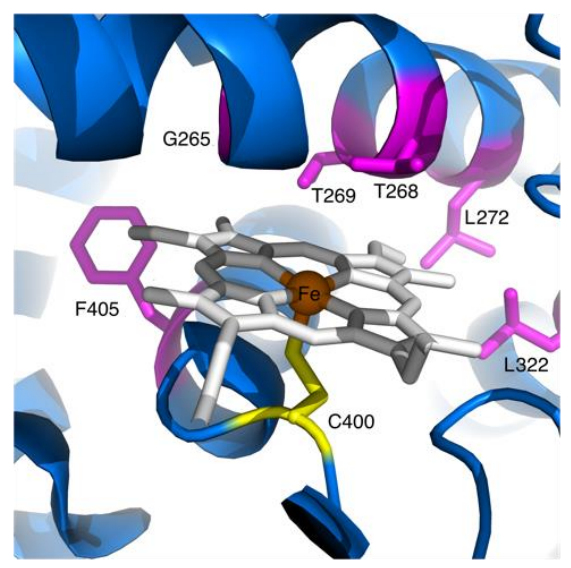

Figure 19. Cytochrome P450BM3 (PDB code 2IJ2) was evolved (mutant P450BM3 G265F-T269V-L272W-L322I-F405M-T268A) to preferentially bind a synthetic heme derivative, DPIX-Fe, which bears two methyl groups instead of the bulkier vinyl groups. ${ }^{352}$ The ArM is a cyclopropanation catalyst.

Prior to any reported studies on carbene insertion chemistry using metal-substituted heme enzymes, Lewis reported that ArMs containing a dirhodium cofactor could catalyze cyclopropanation of 4-methoxystyrene and insertion into the $\mathrm{Si}-\mathrm{H}$ bond of 
diphenylmethylsilane using diazoacetate carbene precursors (Scheme 57). The dirhodium ArMs were constructed by genetically encoding a $p$-azidophenylalanine residue at different sites within tHisF and phytase scaffolds, followed by strain-promoted azide-alkyne cycloaddition (SPAAC) of bicyclononyne (BCN)-substituted dirhodium cofactor (177).$^{10}$ Neither of the carbene insertion reactions investigated proceeded with significant enantioselectivity, likely as a result of the dirhodium center projecting out of the scaffolds investigated. Significant levels of formal carbene insertion into the $\mathrm{O}-\mathrm{H}$ bond of water were also observed, but these ArMs accepted donor-acceptor carbenes, which has not yet been reported using heme protein scaffolds.

To determine if a protein scaffold could be used to correct the chemo- and enantioselectivity problems encountered by initial dirhodium ArM constructs, bioconjugation of $\mathbf{1 7 7}$ to several additional scaffolds was pursued. Gratifyingly, incorporating 177 into a prolyl oligopeptidase (POP) $)^{353}$ scaffold from Pyrococcus furiosus, which has a large active site capable of completely encapsulating the bulky dirhodium cofactor, led to modest enantioselectivity for styrene cyclopropanation ( $38 \%$ ee). ${ }^{354}$ Targeted mutagenesis of residues in the POP active site led to dirhodium ArMs that catalyzed styrene cyclopropanation with up to $92 \%$ ee and improved selectivity for cyclopropanation over competing formal insertion into the $\mathrm{O}-\mathrm{H}$ bond of water (Scheme 57 b)). Key residues introduced into the POP scaffold included a histidine (H328), believed to coordinate to one of the Rh centers in 177 , and two phenylalanines (F99, F594) across the active site relative to the coordinating histidine (Figure 20).

Scheme 57. Bicyclononyne-substituted dirhodium cofactor a). Dirhodium ArMs catalyzed cyclopropanation b) and $\mathrm{Si}-\mathrm{H}$ insertion reactions $\mathrm{c}$ ). 
a)

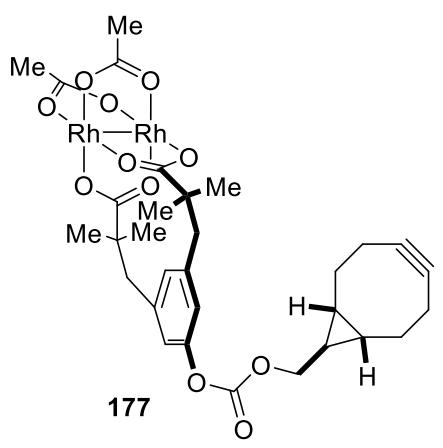

b)

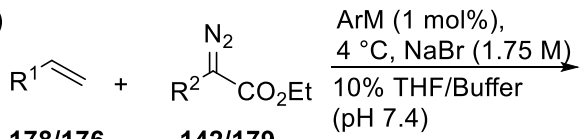
178/176 $\stackrel{\text { ArM }}{177 \cdot \text { tHisF-Z176 }} \frac{\text { Substrate }}{178 / 142}$ $177 \cdot \mathrm{POP}-\mathrm{A}_{4} \mathrm{Z} 477$ $177 \cdot \mathrm{POP}-\mathrm{A}_{4} \mathrm{Z} 477-$ H328-F99-F594

c)

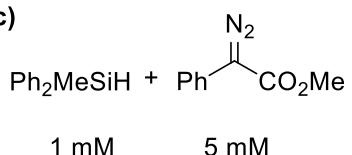

177-tHisF-Z176

(1 $\mathrm{mol} \%)$

$10 \% \mathrm{THF} / \mathrm{KP}_{\mathrm{i}}$ $(100 \mathrm{mM}, \mathrm{pH}=7.5)$

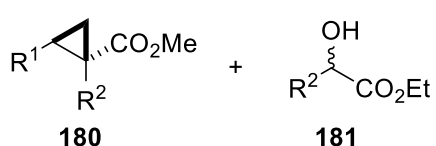
81

25

74 $\underline{180 / 181}$

0.6

2.4

178: $\mathrm{R}^{1}=4-\mathrm{MeOPh}$; 176: $R^{1}=P h$ 142: $R^{2}=H$ 179: $\mathrm{R}^{2}=4-\mathrm{MeOPh}$

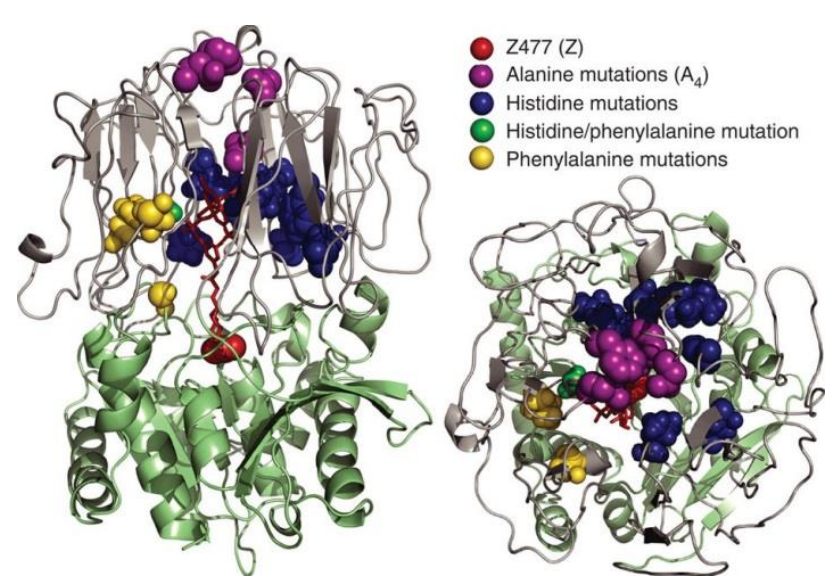

Figure 20. Homology model of Pfu POP. 355 The hydrolase domain is shown in green, the propeller domain is shown in grey and cofactor 177 linked at Z477 is shown in red. In magenta are highlighted alanine mutations introduced to widen the pore and thereby enabling access of the cofactor to the active site. Additional mutations introduced into Pfu POP are shown as coloured spheres. Adapted from ref. ${ }^{354}$, Rights Managed by Nature Publishing Group.

\subsection{Polymerization (non-ROMP)}

The stereochemistry, molecular weight $\left(M_{\mathrm{w}}\right)$, and polydispersity $\left(M_{\mathrm{w}} / M_{\mathrm{n}}\right)$ of polymers are critical factors that can be influenced by the secondary coordination sphere of metal catalysts. Researchers have also explored the potential to control polymer properties using interactions provided by either a protein scaffold or a protein assembly. The welldefined interiors of these systems could provide a hydrophobic environment to favor polymerization, orient substrates, and influence polymer size and polydispersity. ArM polymerases that lead to the formation of $\mathrm{C}-\mathrm{C}$ bonds via a variety of mechanisms, 
including ATRP, acetylene polymerization, and ROMP have been developed. The latter metathesis-type polymerization is presented in section 5.5.

In 2009, Ueno and Watanabe et al. introduced $[\mathrm{Rh}(\mathrm{nbd}) \mathrm{Cl}]_{2} 184(\mathrm{nbd}=$ norbornadiene) into apo-ferritin and evaluated Rh-loaded capsule as catalyst for the polymerization of phenylacetylene 182 (Scheme 58). ${ }^{313}$ The crystal structure of 184-apo-ferrtin revealed one rhodium ion at the threefold channel and two rhodium ions in the accumulation center (Figure 13) via coordination of histidine and cysteine residues. The polyphenylacetylene 183 produced by 184 -apo-ferritin displayed an average molecular weight $\left(M_{\mathrm{w}}\right)=13.1 \pm 1.5 \cdot 10^{3} \mathrm{~g} / \mathrm{mol}$ and a polydispersity $\left(M_{\mathrm{w}} / M_{\mathrm{n}}\right)=2.6 \pm 0.3$. For comparison, the polymer produced by free $\left[\mathrm{Rh}(\mathrm{nbd}) \mathrm{Cl}_{2} 2184\right.$ had $M_{\mathrm{w}}=63.7 \pm 4 \cdot 10^{3}$ $\mathrm{g} / \mathrm{mol}$ and $M_{\mathrm{w}} / M_{\mathrm{n}}=21.4 \pm 0.4$ (Table 23, entries 1 and 2).

Hayashi and coworkers covalently linked a maleimide-substituted $\mathrm{Cp}{ }^{*} \mathrm{Rh}(\mathrm{cod})$ complex (185) to the interior of apo-nitrobindin $(\mathrm{Nb})$ to perform the polymerization of phenyl acetylene 182 (Scheme 58). ${ }^{200} \mathrm{Nb}$ contains an Fe-protoporphyrin IX 222 cofactor in a cavity formed by eight $\beta$-strands. In order to covalently anchor the pianostool cofactor, Q96, located at the entrance of the cavity, was mutated to a cysteine. The resulting artificial metalloenzyme was tested for alkyne polymerization. The free cofactor, 185, yielded the thermodynamically preferred cis-poly(phenylacetylene) 183 with trans : cis = $7:$ 93. In contrast, $185 \cdot \mathrm{Nb}(\mathrm{Q} 96 \mathrm{C})$ afforded 183 with trans : cis $=53: 47$ (Table 23, entries 3 and 4).

Next, they genetically optimized the artificial polymerase to improve the trans-selectivity (Scheme 58). They selected aminoacid residues within $6 \AA$ from the computed position of the Rh center. Gratifyingly, 185·Nb (H76L-Q96C-H158L) produced 183 with trans : cis $=82: 18$ (Table 23, entry 5). ${ }^{356}$ Molecular dynamic simulations of $\mathbf{1 8 5} \cdot \mathrm{Nb}$ variants suggested that mutations which lock the orientation of the Rh-moiety and guide the 
access of the monomer enhance trans-stereoselectivity.

Scheme 58. Polymerization of phenylacetylene catalyzed by Rh(I)-modified proteins.

a)

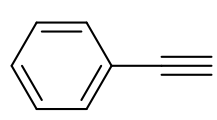

$1.5 \mathrm{mM}$ 182

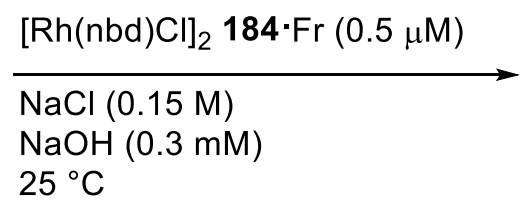

$\mathrm{NaOH}(0.3 \mathrm{mM})$

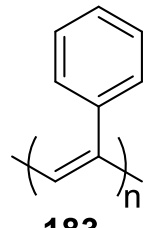

183

b)

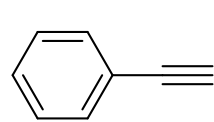

$1 \mathrm{M}$

182

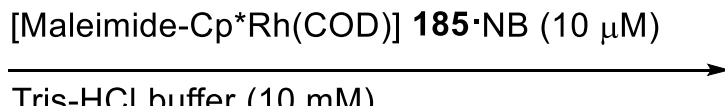

$\mathrm{pH} 8,25^{\circ} \mathrm{C}$

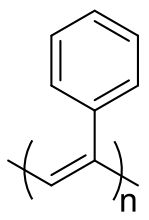

183

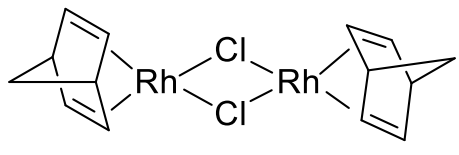

$[\mathrm{Rh}(\mathrm{nbd}) \mathrm{Cl}]_{2}$

184

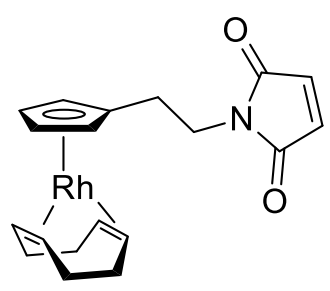

[Maleimide-Cp* Rh(COD)]

185

In 2011, Bruns and coworkers reported that horseradish peroxidase (HRP) was able to catalyze atom transfer radical polymerization (ATRP) using $\mathrm{N}$-isopropyl acrylamide (NIPAAm, 187) as the monomer and alkylbromide (186) as initiator (Table 23, entry 6). ${ }^{357}$ In 2014, Bruns and coworkers constructed an ArM ATRPase comprised of copper complex 189 and the group II chaperonin thermosome (THS) from the archaea Thermoplasma acidophilum as a protein scaffold. ${ }^{358}$ THS is a hexadecameric protein complex and can switch between an open and a closed state by consumption of ATP. In its closed state, the protein possesses two cavities of $130 \mathrm{~nm}^{2}$ each that can host a polymerization event. In its open state, the pores are large enough to allow the polymer to exit the capsule. The ATRPase, 189-THS C363A-K316C-C364A catalyzed the polymerization of 187 under ATRP conditions (Scheme 59). This ATRPase yielded Poly- 
NIPAAm (PNIPAAm, 188) with a lower $M_{\mathrm{w}} / M_{\mathrm{n}}$ and $M_{\mathrm{n}}$ compared to the catalyst bound on the surface of bovine serum albumin, a globular protein (BSA-189). These results indicate that the protein cage not only improves the polymerization process, but also limits the diffusion of monomers into the active site of the polymerase (Table 23, entries 7 and 8).

Scheme 59. N-isopropyl acrylamide (NIPAAm) atom transfer radical polymerization (ATRP) catalyzed by 189 ArMs.

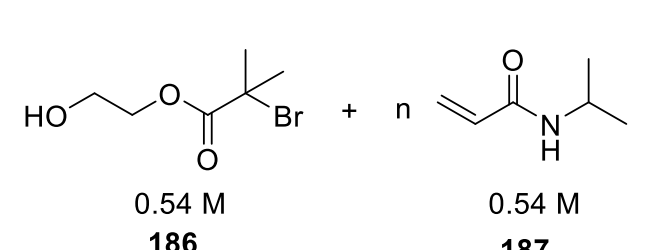

187

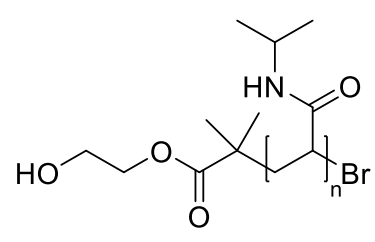

188<smiles>CCN1CCN(CC)C2(C1)N(CC)CCN2CCC(=O)OCCOC(=O)c1ccc(/C=N/Nc2ccc(N3C(=O)C=CC3=O)cn2)cc1</smiles>

Table 23. Selected results for the polymerization catalyzed by ArMs.

\begin{tabular}{|c|c|c|c|c|c|c|c|c|c|c|}
\hline Entry & Cofactor & Sub & Protein & $\begin{array}{c}\mathrm{T} \\
\left({ }^{\circ} \mathrm{C}\right)\end{array}$ & $\begin{array}{c}t \\
(h)\end{array}$ & $\begin{array}{c}\text { [Metal] } \\
(\mu \mathrm{M})\end{array}$ & $\begin{array}{c}M_{\mathrm{n}} \\
(\mathrm{g} / \mathrm{mol})\end{array}$ & $M_{\mathrm{w}} / M_{\mathrm{n}}$ & trans:cis & Ref \\
\hline 1 & 184 & 182 & No Protein & 25 & 3 & 30.0 & 63700 & 21.4 & - & 313 \\
\hline 2 & 184 & 182 & Fr (WT) & 25 & 3 & 28.8 & 13100 & 2.6 & - & 313 \\
\hline 3 & 185 & 182 & No Protein & 25 & 24 & 10.0 & 22900 & 2.6 & $7: 93$ & 200 \\
\hline 4 & 185 & 182 & $\mathrm{Nb}(\mathrm{Q} 96 \mathrm{C})$ & 25 & 24 & 10.0 & 42600 & 2.2 & $53: 47$ & 200 \\
\hline 5 & 185 & 182 & $\mathrm{Nb}$ (H76L-Q96C-H158L) & 25 & 24 & 10.0 & 38900 & 2.4 & $82: 18$ & 356 \\
\hline 6 & 222 & 187 & HRP & r.t & 2.5 & 16.2 & 99900 & 1.44 & - & 357 \\
\hline 7 & 189 & 187 & THS & r.t. & 20 & 16.2 & 1500 & 1.11 & - & 358 \\
\hline 8 & 189 & 187 & BSA & r.t. & 20 & 16.2 & 42600 & 1.94 & - & 358 \\
\hline
\end{tabular}

\subsection{Diels-Alder Reaction}

Diels-Alder reactions are widely used for the construction of six-membered rings due the predictable regio- and stereospecificity of these reactions. ${ }^{359} \operatorname{Copper}(\mathrm{II})$-catalyzed DielsAlder reactions of azachalcones with cyclopentadiene (Scheme 60 a) have been extensively employed in fundamental studies on the design of a wide range of catalysts, ${ }^{360}$ including ArMs. An early example, particularly notable for its high 
enantioselectivity, was reported by Reetz. ArM Diels-Alderases were constructed via non-covalent binding of a $\mathrm{Cu}(\mathrm{II})$ phthalocyanine complex (Figure 22, 190) to various serum albumins. Up to $91 \%$ conversion, $91: 9$ endo/exo ratio, and $98 \%$ ee could be obtained using this system (Table 24, entry 1-6), although the rate of the ArM-catalyzed reaction was slower than that catalyzed by cofactor alone. In a separate effort, Reetz also demonstrated that a His2Asp $\mathrm{Cu}(\mathrm{II})$ binding site could be introduced into tHisF, the thermostable synthase subunit of the glutaminase synthase enzyme complex from Thermotoga maritima, to generate an ArM Diels-Alderase. ${ }^{361}$ EPR spectroscopy was used to confirm $\mathrm{Cu}(\mathrm{II})$ binding in the designed site, and eliminating potential metalbinding cysteine and histidine residues from the scaffold surface improved the enantioselectivity of this system (up to $46 \%$ ee, Table 24 , entries $7-8$ and Figure 21 ).

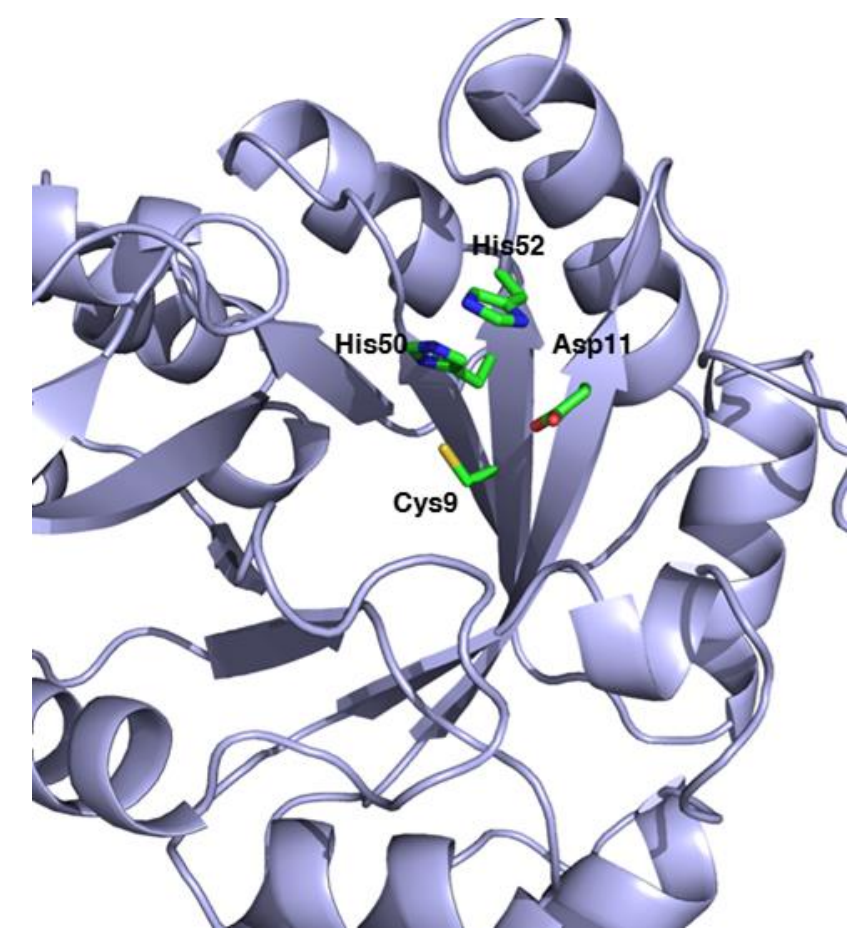

Figure 21. Designed putative metal binding site in the thermostable protein tHisF for the evolution of Diels-Alderase at the top of the TIM barrel (based on the crystal structure PDB: 1THF). Highlighted are the existing aspartate residue in thisF and the two histidines introduced to create the 2-His-1-carboxylate motif. The cysteine residue in the middle of the TIM barrel was replaced with alanine to prevent metal binding.

Scheme 60. Model Diels-Alder reactions catalyzed by ArMs. 
a)<smiles>O=C(/C=C/[CH+]c1ccccc1)c1ccccn1</smiles>

b)

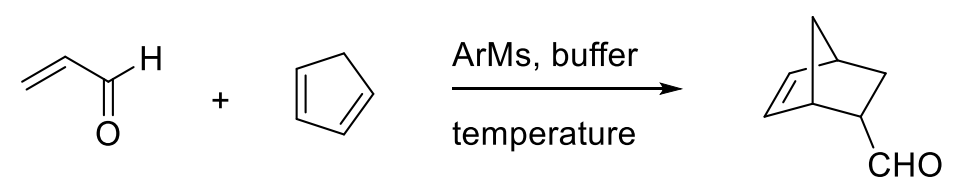

Scaffold-specific interactions have also been used to anchor catalysts into protein scaffolds to generate ArMs that catalyze the Diels-Alder reaction displayed in Scheme 60 a. For example, Niemeyer reconstituted apo myoglobin using a heme cofactor substituted with both ssDNA and a Cu(II)-bipy complex (Figure 22, 191). ${ }^{362}$ The resulting ArM catalyzed the Diels-Alder reaction with improved enantioselectivity relative to the heme-ssDNA cofactor alone $(18 \%$ ee for endo product and $10 \%$ for exo, Table 24 , entries 9-10). More recently, Mahy and Ricoux demonstrated that a testosteronesubstituted $\mathrm{Cu}(\mathrm{II})$-phenanthrene complex (Figure 22, 192) could be incorporated into a neocarzinostatin variant engineered to bind testosterone with improved affinity relative to the WT enzyme. ${ }^{363}$ The scaffold exhibited tighter binding affinity to the $\mathrm{Cu}(\mathrm{II})$ phenanthroline-testerone cofactor $\left(K_{d}=3 \mu \mathrm{M}\right)$ than toward testosterone $\left(K_{d}=13 \mu \mathrm{M}\right)$, and docking experiments suggested that the added phenanthroline ligand enhanced the complementarity of the cofactor to the protein. The resulting ArM catalyzed the reaction displayed in Scheme 60 a) with an increased endo : exo ratio compared to cofactor alone, but with lower conversion and no enantioselectivity (Table 24, entries 11-12).

Several approaches to generate ArM Diels-Alderases via covalent modification of scaffold proteins have also been reported. For example, Salmain constructed a DielsAlderase by covalently linking a chloroacetamide-substituted [( $\eta^{6}$-arene)ruthenium(II)]complex to papain via cysteine alkylation (Figure 22, 193). ${ }^{364}$ The TOF of the Diels-Alder reaction between cyclopentadiene and acrolein (a rare example not involving aza- 
chalcones, Scheme $60 \mathrm{~b}$ ) was increased more than threefold with the ArM relative to the free cofactor. Kamer ${ }^{353}$ and later Okuda and Hayashi ${ }^{365}$ have demonstrated that bidentate and tridentate nitrogen ligands (Figure 23, 194-202) can be introduced into protein scaffolds to generate ArM Diels-Alderases for the reaction shown in Scheme 60 a) following metallation with $\mathrm{Cu}(\mathrm{II})$. Modest enantioselectivity was observed in the former case (Table 24, entries 13-15) ${ }^{353}$ while improved conversion relative to free cofactor was observed in the latter (Table 24, entries 16-17) ${ }^{365}$. A similar tridentate ligand 196 was used to generate an improved ArM Diels-Alderase via bioconjugation to an engineered variant of the transmembrane protein ferric hydroxamate uptake component $A(F h u A) .{ }^{350}$ The endo-selectivity was improved to $98 \%$ by the 196 . FhuA compared to $54 \%$ and $66 \%$ obtained for the free copper ion and 196 respectively (Table 24, entries 18-19).

Filice showed that a similar approach could be used to generate immobilized ArM DielsAlderases. A lipase from $G$. thermocatenulatus (GTL) containing cysteine mutation in a cleft distal to the active site was immobilized on hydrophobic sepharose. $\mathrm{A} \mathrm{Cu}(\mathrm{II})$ cofactor derived from ligand $\mathbf{2 0 0}$ was used to alkylate the distal cysteine in GTL to generate an ArM, which catalyzed the reaction shown in Scheme 60 a) with up to $92 \%$ ee (Table 24, entries 20-22). Both the support and immobilizing orientation had a large impact on the selectivity of the reaction, and the native activity of the lipase was maintained after cofactor incorporation in the distal site..$^{366}$ 

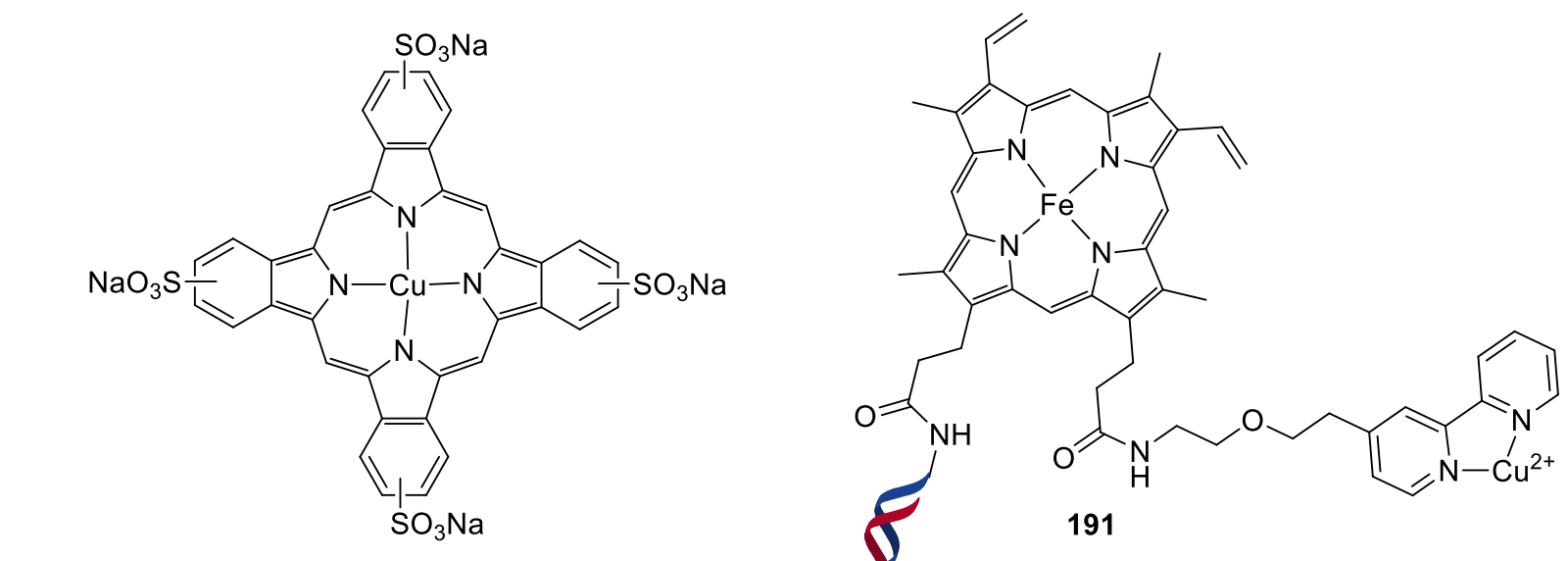

190
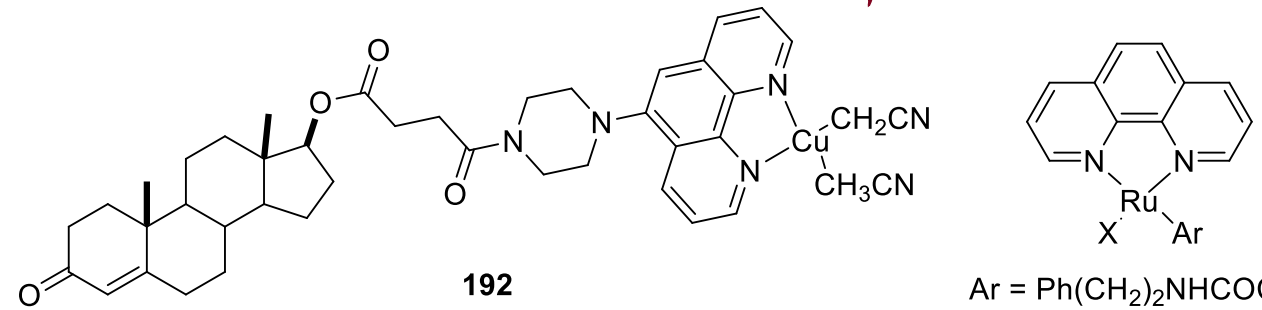

$\mathrm{Ar}=\mathrm{Ph}\left(\mathrm{CH}_{2}\right)_{2} \mathrm{NHCOCH}_{2} \mathrm{Cl}$, p-cymene, benzene $\mathrm{X}=\mathrm{Cl}, \mathrm{H}_{2} \mathrm{O}$

193

Figure 22. Cofactors used to construct an artificial Diels-Alderase.<smiles>[R]c1cc(-c2ccccn2)nc(-c2ccccn2)c1</smiles>

$\mathrm{R}=$<smiles>COCCN1C(=O)C=CC1=O</smiles><smiles>O=C(ON1C(=O)CCC1=O)c1ccc(-c2ccccn2)nc1</smiles>

194

195<smiles>O=C(CCN1C(=O)C=CC1=O)N(Cc1ccccn1)Cc1ccccn1</smiles><smiles>O=C(CBr)NCc1ccc(-c2ccccn2)nc1</smiles><smiles>[X]CC(=O)Nc1cc2cccnc2c2ncccc12</smiles>

200: $X=1$ 201: $\mathrm{X}=\mathrm{Br}$<smiles>O=C1C=CC(=O)N1c1cc2cccnc2c2ncccc12</smiles>

202

Figure 23. Bidentate and tridentate nitrogen cofactors used to form ArM Diels-Alderases.

Concurrent with much of this work, Roelfes conducted a number of studies on the development of $\mathrm{Cu}(\mathrm{II})$-bipyridine and related ArMs that catalyze the Diels-Alder reaction and other Lewis Acid catalyzed processes. Initial studies showed that the lactococcal 
multidrug resistance regulator $(\mathrm{LmrR})$, a dimeric transcription repressor, could be alkylated with an haloacetamide-substituted bipyridine (199) and phenanthroline ligands 201 at the dimer interface to generate Diels-Alderases following metallation with $\mathrm{Cu}(\mathrm{II}) .{ }^{367}$ High conversion and enantiomeric excess (both $>90 \%$ ) were observed for the reaction displayed in Scheme 60 a) (Table 24, entries 23-24). Point mutants of this ArM also catalyzed enantioselective hydration of azachalcones with a slightly lower conversion and enantiomeric excess (up to $84 \%$ ee) as discussed in chapter 7 (Scheme 93). .368

Table 24. Selected results for the Diels-Alderase.

\begin{tabular}{|c|c|c|c|c|c|c|c|c|c|c|c|c|}
\hline Ent. & Cof. & Protein & $\mathrm{pH}$ & $\begin{array}{c}\mathrm{T} \\
\left({ }^{\circ} \mathrm{C}\right)\end{array}$ & $\begin{array}{l}{[\mathrm{Cof}]} \\
(\mu \mathrm{M})\end{array}$ & $\begin{array}{c}\mathrm{t} \\
\text { (day) }\end{array}$ & [Cof]/[Prot] & $\begin{array}{l}\mathrm{Y} . \\
(\%)\end{array}$ & Endo/Exo & $\begin{array}{c}\text { ee } \\
(\%)^{b}\end{array}$ & $\mathrm{TON}^{\mathrm{d}}$ & Ref \\
\hline 1 & 190 & BSA & 4.0 & 5 & 0.4 & 3 & $1: 1.2$ & 78 & $96: 4$ & 93 & 39 & 369 \\
\hline 2 & 190 & HSA & 4.0 & 5 & 0.4 & 3 & $1: 1.2$ & 89 & $91: 9$ & 85 & 45 & 369 \\
\hline 3 & 190 & PSA & 4.0 & 5 & 0.4 & 3 & $1: 1.2$ & 87 & $89: 11$ & 68 & 44 & 369 \\
\hline 4 & 190 & RSA & 4.0 & 5 & 0.4 & 3 & $1: 1.2$ & 69 & $88: 12$ & 7 & 35 & 369 \\
\hline 5 & 190 & SSA & 4.0 & 5 & 0.4 & 3 & $1: 1.2$ & 76 & $87: 13$ & 75 & 38 & 369 \\
\hline 6 & 190 & CSA & 4.0 & 5 & 0.4 & 3 & $1: 1.2$ & 72 & $78: 22$ & 1 & 36 & 369 \\
\hline 7 & $\mathrm{CuSO}_{4}$ & - & 7.5 & 12 & 115 & 4 & - & 44 & $87: 13$ & 1 & 4 & 361 \\
\hline 8 & $\mathrm{CuSO}_{4}$ & tHisF-HHD-4xAla & 7.5 & 12 & 115 & 4 & $1: 1.3$ & 73 & $93: 7$ & 46 & 6 & 361 \\
\hline 9 & 191 & - & 7.4 & 4 & 100 & 3 & - & 6 & $>99: 1$ & 0 & 0.6 & 362 \\
\hline 10 & 191 & apo-Mb & 7.4 & 4 & 100 & 3 & $1: 1$ & 71 & $90: 10$ & $\begin{array}{l}18 \\
10^{\mathrm{a}}\end{array}$ & 7 & 362 \\
\hline 11 & 192 & - & 7.5 & 4 & 114 & 3 & - & 98 & $84: 16$ & - & 36 & 363 \\
\hline 12 & 192 & NCS-3.24 & 7.5 & 4 & 114 & 3 & $1.1: 1$ & 83 & $81: 19$ & - & 33 & 363 \\
\hline 13 & $\begin{array}{l}202- \\
\mathrm{Cu}^{2+}\end{array}$ & - & 6.0 & 4 & 56 & 3 & - & 27 & $85: 15$ & - & 3 & 353 \\
\hline 14 & $\begin{array}{l}202- \\
\mathrm{Cu}^{2+}\end{array}$ & $\begin{array}{c}\text { SCP- } \\
\text { 2LV83C }\end{array}$ & 6.0 & 4 & 56 & 3 & $1: 1.1$ & 20 & $88: 12$ & 25 & 2 & 353 \\
\hline 15 & $\begin{array}{l}202- \\
\mathrm{Cu}^{2+}\end{array}$ & $\begin{array}{c}\text { SCP- } \\
\text { 2LA100C }\end{array}$ & 6.0 & 4 & 56 & 3 & $1: 1.1$ & 43 & $92: 8$ & - & 5 & 353 \\
\hline 16 & $\begin{array}{l}\text { 198- } \\
\mathrm{Cu}^{2+}\end{array}$ & - & 7.0 & 4 & 100 & 3 & - & 11 & $85: 15$ & - & 1 & 365 \\
\hline
\end{tabular}




\begin{tabular}{|c|c|c|c|c|c|c|c|c|c|c|c|c|}
\hline 17 & $\begin{array}{l}198- \\
\mathrm{Cu}^{2+}\end{array}$ & $\begin{array}{c}\mathrm{Nb}-\mathrm{Q} 96 \mathrm{C} / \\
\mathrm{M} 75 \mathrm{~L} / \mathrm{M} 148 \mathrm{~L} / \mathrm{H} 76 \mathrm{~L} / \mathrm{H} 158 \mathrm{~L}\end{array}$ & 7.0 & 4 & 100 & 3 & $1: 1.1$ & 22 & $90: 10$ & - & 2 & 365 \\
\hline 18 & $\begin{array}{l}195- \\
\mathrm{Cu}^{2+}\end{array}$ & - & $7.4^{\mathrm{c}}$ & 4 & 10 & 3 & - & 12 & $66: 34$ & - & 12 & 350 \\
\hline 19 & $\begin{array}{l}195- \\
\mathrm{Cu}^{2+}\end{array}$ & FhuA & $7.4^{c}$ & 4 & 10 & 3 & $1: 1$ & 64 & $98: 2$ & - & 64 & 350 \\
\hline 20 & $\begin{array}{l}200- \\
\mathrm{Cu}^{2+}\end{array}$ & - & 6.0 & 4 & 2.4 & 3 & - & 28 & $92: 8$ & $<5$ & 118 & 366 \\
\hline 21 & $\begin{array}{l}200- \\
\mathrm{Cu}^{2+}\end{array}$ & GTL-S114C & 6.0 & 4 & 2.4 & 3 & $1: 1$ & 99 & $99: 1$ & 18 & 416 & 366 \\
\hline 22 & $\begin{array}{l}200- \\
\mathrm{Cu}^{2+}\end{array}$ & GTL-S196C & 6.0 & 4 & 2.4 & 3 & $1: 1$ & 98 & $94: 6$ & 92 & 412 & 366 \\
\hline 23 & $\begin{array}{l}201- \\
\mathrm{Cu}^{2+}\end{array}$ & - & 7.0 & 4 & 30 & 3 & - & 20 & $93: 7$ & 0 & 7 & 367 \\
\hline 24 & $\begin{array}{l}201- \\
\mathrm{Cu}^{2+}\end{array}$ & LmrR-M89C & 7.0 & 4 & 30 & 3 & $1: 1.1$ & 93 & $95: 5$ & 97 & 31 & 367 \\
\hline
\end{tabular}

${ }^{a}$ For both endo and exo; ${ }^{b}$ Positive and negative ee values correspond to the $(R)$ - and $(S)$-enantiomers respectively; ${ }^{c}$ Buffer contains $0.125 \mathrm{mM}$ polyethylene polyethylene glycol and $20 \%(\mathrm{v} / \mathrm{v}) \mathrm{THF}$. ${ }^{\mathrm{d}}$ TON calculated from original papers by reviewer.

\subsection{Huisgen [3+2] Cycloaddition}

Ueno and coworkers have explored the use of self-assembled protein scaffolds for ArM catalysis. ${ }^{370}$ For example, the tubular structure formed by the triple-stranded $\alpha$-helical assembly of three subunits of gene product $5,(\mathrm{gp} 5)_{3}$, from bacteriophage $\mathrm{T} 4$, was used to generate an ArM that catalyzes a Huisgen [3+2] cycloaddition. ${ }^{298} \mathrm{~A}$ protease resistant fragment from the $C$-terminal region of $(\mathrm{gp} 5)_{3}$, termed $(\mathrm{gp} 5 \beta)_{3}$, was fused to a foldon (f) domain that promotes trimerization of bacteriophage $\mathrm{T} 4$ fibritin to generate a stable tubular scaffold. A succinimide moiety conjugated with flavin 204 was introduced at lysines located on the outer-surface of the $\left[(\mathrm{gp} 5 \mathrm{\beta f})_{3}\right]_{2}$ (Scheme 61 and Figure 12). Upon addition of copper ions, the artificial metalloenzyme catalyzed the azide-alkyne $[3+2]$ cycloaddition. The hybrid catalyst $204 \cdot\left[(\mathrm{gp} 5 \beta \mathrm{f})_{3}\right]_{2}$ catalyzed the "click reaction" reaction faster than $\mathbf{2 0 5}$ or of a mixture of $\mathbf{2 0 5}$ and [(gp5 $\beta f) 3]_{2}$ (Table 25).

Scheme 61. $\mathrm{Cu}(\mathrm{I})$-catalyzed cycloaddition catalyzed by the copper-flavin complex conjugated to $\left[(\mathrm{gp} 5 \beta \mathrm{f})_{3}\right]_{2}$. 


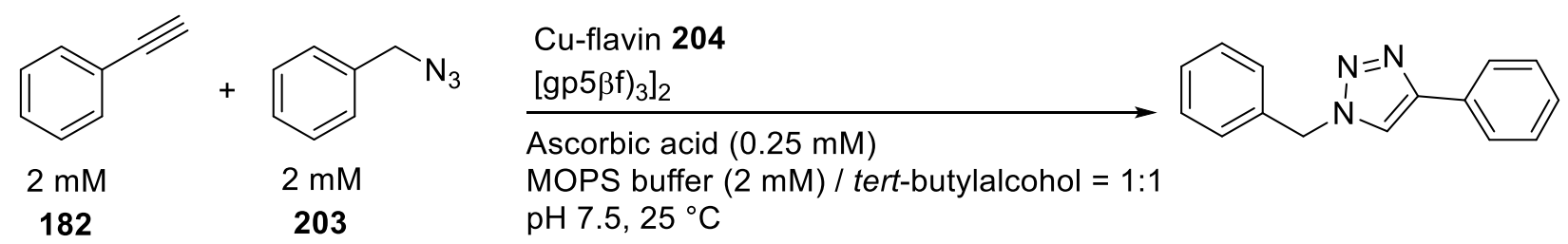<smiles></smiles><smiles>[Y]CNCCCC</smiles>

204

Cu-flavin

205

Table 25. Selected results for the $\mathrm{Cu}(\mathrm{I})$-catalyzed cycloaddition of substrate 182 and 203 in the presence of $\left[(g p 5 \beta f)_{3}\right]_{2 .}{ }^{a}$

\begin{tabular}{cccccccc}
\hline Entry & Cofactor & Protein $^{\mathrm{a}}$ & $\mathrm{t}(\mathrm{h})$ & {$[$ Cof] $(\mu \mathrm{M})$} & {$[$ Ascorbic acid] $(\mathrm{mM})$} & TON & Ref \\
\hline 1 & 204 & {$\left[(\mathrm{gp} 5 \beta \mathrm{f})_{3}\right]_{2}$} & 5 & 250 & 0.25 & 5.86 & ${ }^{298}$ \\
2 & 205 & {$\left[(\mathrm{gp} 5 \beta \mathrm{\beta f})_{3}\right]_{2}$} & 5 & 250 & 0.25 & 0.14 & ${ }^{298}$ \\
3 & 205 & No Protein & 5 & 250 & 0.25 & 0.62 & ${ }^{298}$ \\
\hline \multicolumn{2}{l}{ Reactions were carried out in a solution of $1: 1$ tert-butylalcohol/MOPS $(2 \mathrm{mM}, \mathrm{pH} 7.5)$ at $5^{\circ} \mathrm{C}}$.
\end{tabular}

\subsection{Friedel-Crafts Reaction}

Although the Friedel-Crafts reaction was introduced more than 130 years ago, it still represents an attractive tool to alkylate aromatic compounds. ${ }^{371}$ Initially, it required $\geq 1.0$ equivalent of Lewis acid, and alkyl halides. Today however, alkyl alcohols, ethers, tosylamides, or styrenes can be used instead of alkyl halides, and catalytic asymmetric Friedel-Crafts reactions have been developed. ${ }^{371-373}$

Artificial metalloenzymes that catalyze the Friedel-Crafts reaction have been developed by Roelfes et al. A BpyAla residue was genetically encoded into LmrR to eliminate the need for covalent modification of the scaffold. ${ }^{374}$ Metallation with $\mathrm{Cu}(\mathrm{II})$ provided an ArM that catalyzed the Friedel-Crafts alkylation of a variety of indoles (Scheme 62) with conversions as high as $94 \%$ and high enantioselectivity (up to $83 \%$ ee, Table 26 , entries 2-7). Interestingly, when the ligand was placed outside of the hydrophobic pocket, the 
opposite enantiomer was formed (Table 26, entry 3). More recently, Roelfes demonstrated that the hydrophobic cavity of dimeric LmrR was capable of binding an unsubstituted $\mathrm{Cu}(\mathrm{II})$ phenanthroline cofactor directly to form ArMs through supramolecular assembly. ${ }^{375}$ The binding affinity of the cofactor was measured by tryptophan fluorescence quenching, which showed the dissociation constant $\left(K_{\mathrm{d}}\right)$ was much higher when an interfacial tryptophan residue (W96A) was removed (45 $\mu \mathrm{M}$ compared to $2.6 \mu \mathrm{M})$. Fluorescence decay also showed decreased lifetime when the scaffold was saturated with $\mathrm{Cu}(\mathrm{II})$, suggesting cofactor binding at the hydrophobic pore. The enantioselectivity of these ArMs toward Friedel-Crafts alkylations was significantly higher (up to $94 \%$ ee) (Table 26, entries 8-11) than the covalently linked systems noted above. These studies constitute one of the few cases in which covalent scaffold modification, metal binding to a scaffold residue (albeit an unnatural amino acid), and non-covalent scaffold binding have all be used to generate ArM catalysts, all of which provided high enantioselectivity.

Scheme 62. Friedel-Crafts reaction catalyzed by LmrR-Cu ArMs.
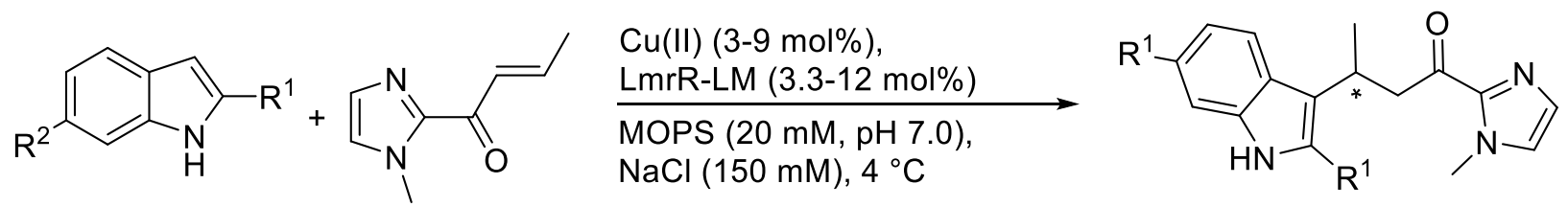

206: $R^{1}=H, R^{2}=$ OMe

207: $\mathrm{R}^{1}=\mathrm{H}, \mathrm{R}^{2}=\mathrm{H}$

208: $R^{1}=H, R^{2}=\mathrm{Cl}$

209: $R^{1}=M e, R^{2}=H$

Table 26. Selected results for the asymmetric Friedel-Crafts reaction based on $\mathrm{Cu}$ (phen)-cotaining ArMs

\begin{tabular}{ccccccccc}
\hline Entry & Protein & Sub. & $\mathrm{t}(\mathrm{h})$ & $\begin{array}{c}\text { Ratio } \\
{[\text { Cof]/[Prot] }}\end{array}$ & Conversion (\%) & ee (\%) & TON $^{c}$ & Ref $^{2}$ \\
\hline $1^{\text {a }}$ & - & $\mathbf{2 0 6}$ & 72 & - & 98 & 0 & 10.9 & 374 \\
2 & LmrR_LM (M89X) & $\mathbf{2 0 6}$ & 72 & $1 / 1.25$ & 27 & $49(S)$ & 3 & 374 \\
3 & LmrR_LM (F93X) & $\mathbf{2 0 6}$ & 72 & $1 / 1.25$ & 36 & $22(R)$ & 4 & 374
\end{tabular}




\begin{tabular}{ccccccccc}
4 & LmrR_LM (M89XE107A) & $\mathbf{2 0 6}$ & 72 & $1 / 1.25$ & 22 & $66(S)$ & 2.4 & 374 \\
5 & LmrR_LM (M89XF93W) & $\mathbf{2 0 7}$ & 72 & $1 / 1.25$ & 16 & $55(S)$ & 1.8 & 374 \\
6 & LmrR_LM (M89XF93W) & $\mathbf{2 0 8}$ & 72 & $1 / 1.25$ & 3 & $50(S)$ & 0.3 & 374 \\
7 & LmrR_LM (M89XF93W) & $\mathbf{2 0 9}$ & 72 & $1 / 1.25$ & 94 & $83(S)$ & 10.4 & 374 \\
$8^{\text {b }}$ & LmrR_LM & $\mathbf{2 0 6}$ & 16 & $1 / 1.33$ & 90 & $84(S)$ & 5 & 375 \\
$9^{\text {b }}$ & LmrR_LM & $\mathbf{2 0 7}$ & 64 & $1 / 1.33$ & Full & $94(S)$ & 11.1 & 375 \\
$10^{\text {b }}$ & LmrR_LM & $\mathbf{2 0 8}$ & 64 & $1 / 1.33$ & 19 & $64(S)$ & 2.1 & 375 \\
$11^{\text {b }}$ & LmrR_LM & $\mathbf{2 0 7}$ & 64 & $1 / 1.33$ & Full & $93(S)$ & 11.1 & 375 \\
$12^{\text {b }}$ & LmrR_LM & $\mathbf{2 0 6}$ & 16 & $1 / 1.33$ & 53 & $<5$ & 5.9 & 375 \\
\hline
\end{tabular}

${ }^{\mathrm{a}} \mathrm{Cu}\left(\mathrm{NO}_{3}\right)_{2}$ only. ${ }^{\mathrm{b}}$ None covalent binding with $\mathrm{Cu}(\mathrm{phen}) .{ }^{\mathrm{c}} \mathrm{Calculated}$ based on the concentration of the limiting substrate. 


\section{Oxygen Insertion Chemistry}

\subsection{Peroxidation or Oxygenation}

Dioxygen is widely used as a terminal oxidant in biological processes. Although the reaction of organic compounds with dioxygen is generally thermodynamically favorable, kinetic barriers slow the oxidation of most organic compounds. This can be traced back to spin considerations: organic compounds exist mostly as spin-paired species whereas dioxygen has a triplet ground-state, thus rendering the reaction spin-forbidded. ${ }^{376}$ To overcome the high energetic barrier, nature typically generates metal- $\mathrm{O}_{2}$ species in the active site of metalloenzymes such as cytochrome P450, methane monooxygenase and tyrosinase etc. Inspired by these metalloenzymes relying on dioxygen for oxygenation and oxidation reactions, heme analogues or copper complexes have been exploited as a cofactors to create numerous artificial oxidases. This section summarizes oxidation reactions catalyzed by artificial oxidases using peroxides and molecular oxygen as oxidant. Oxygen-atom insertion reactions are described in the following sections.

Shortly after the initial reports of catalytic antibodies, Schultz and Cochran described a class of metallo-catalytic antibodies which they coined "hemoabzymes". ${ }^{133,} 377$ Shortly thereafter, Imanaka and Mahy joined these efforts. ${ }^{378-379}$ This term "hemoabzyme" stems from their composition: a porphyrin ("hemo-"), inserted into an anti-body ("-ab-") that has been elicited in mice against a protein-conjugated heme hapten. Progress achieved relying on this strategy has been reviewed recently. ${ }^{62-63}$

In 1990, Schultz and coworkers used N-methyl-mesoporphyrin IX (19) as the hapten. This molecule was selected as a transition-state analogue for porphyrin metalation. The metallation of the mesoporphyrin IX was accelerated by monoclonal anti-19 to afford the hemoabzyme 20 Ab-7G12. Peroxidase degradation catalyzed by this metallo-antibody was quantified using o-dianisidine oxidation (210) (Scheme 63). ${ }^{133,377}$ The hemoabzyme 
20.Ab-7G12 displayed saturation kinetics and was $>4$ times more efficient than the [Fe(MPIX)] 20 (Table 27, entries 1 and 2).

Scheme 63. Antibodies raised against 19 catalyze the oxidation of o-dianisidine $\mathbf{2 1 0}$ upon loading with cofactor 20.<smiles>COc1cc(-c2ccc(N)c(OC)c2)ccc1N</smiles>

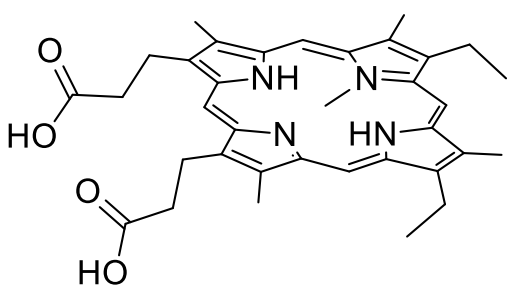

N-M-MPIX 19
$20(0.05 \mathrm{~mol} \%)$ Ab-7G12 (0.13 mol\%)

$\mathrm{H}_{2} \mathrm{O}_{2}(0.1-1.7 \mathrm{mM})$ Tris/Acetate $(90 \mathrm{mM})$ $\mathrm{pH} 8.0,10^{\circ} \mathrm{C}$<smiles>COC1=C/C(=C2/C=CC(=N)C(OC)=C2)C=CC1=N</smiles>

In 1999, Kawamura-Konishi and coworkers also utilized the same set of hapten 19 and catalyst $\mathbf{2 0}$ to generate an ArM peroxidase. ${ }^{380}$ The affinity between $\mathbf{2 0}$ and the isolated antibody 2B4 was $K_{\mathrm{D}}=0.064 \mu \mathrm{M}$. In the presence of hydrogen peroxide, oxidation of ABTS 211, o-dianisidine 210, and pyrogallol 212 was investigated (Scheme 64). The ArM exhibited higher peroxidase activity for o-dianisidine 210 and ABTS 211 than the ferric mesoporphyrin itself, while such enhancement was not observed for pyrogallol 212 (Table 27, entries 3 and 4). The authors hypothesize that the antibody imposed a certain degree of substrate preference to the cofactor.

Scheme 64. Peroxidase activity of iron porphyrin derivatives in the presence of an antibody elicited against $N$-methylmesoporphyrin 19. 

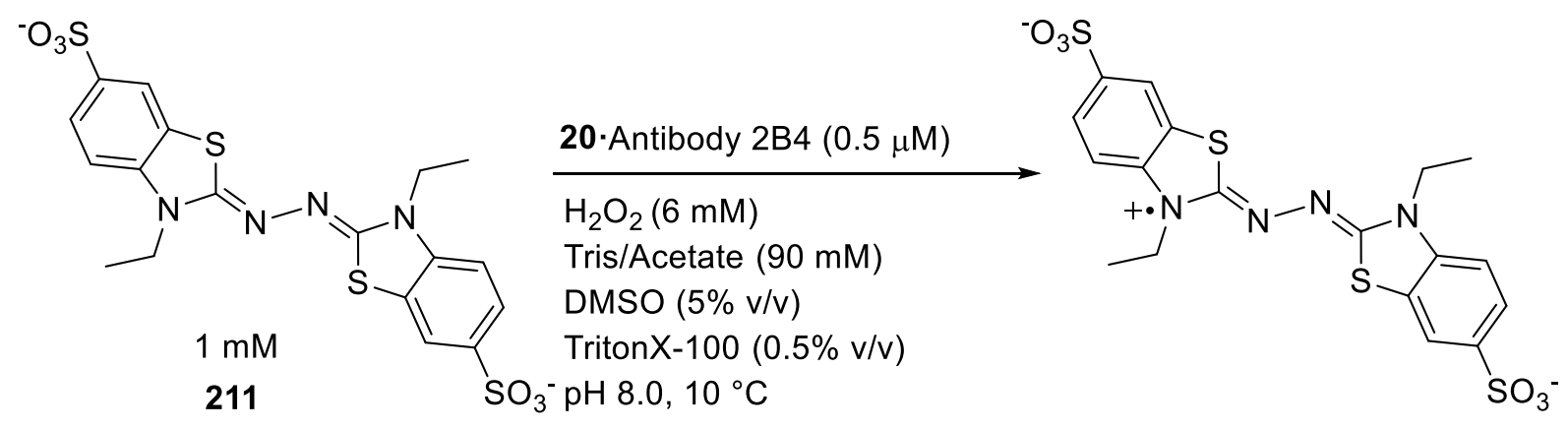<smiles>COc1cc(-c2ccc(N)c(OC)c2)ccc1N</smiles>

210
20-Antibody 2B4 (0.3-0.5 $\mu \mathrm{M})$ $\mathrm{H}_{2} \mathrm{O}_{2}$ (1.1-33.3 mM) Tris/Acetate $(90 \mathrm{mM})$ DMSO (5\% v/v) TritonX-100 (0.5\% v/v) $\mathrm{pH} 8.0,10^{\circ} \mathrm{C}$<smiles>Oc1cccc(O)c1O</smiles>

$1 \mathrm{mM}$

212
20-Antibody 2B4 (0.5 $\mu \mathrm{M})$

$\mathrm{H}_{2} \mathrm{O}_{2}(6 \mathrm{mM})$

Tris/Acetate (90 mM)

DMSO (5\% v/v)

TritonX-100 (0.5\% v/v)

$\mathrm{pH} 8.0,10^{\circ} \mathrm{C}$

In 1995, the group of Imanaka immunized mice using TpCPP as a hapten (Scheme 65). ${ }^{378}$ Both monoclonal antibodies as well as the light chain (L) of one of these antibodies (L-Ab-13-1) were isolated. Incorporating 213 into L-Ab-13-1 afforded an ArM that was more thermostable and displayed a higher peroxidase activity than the complex of 213 with the complete antibody. The peroxidase activity of $213 \cdot \mathrm{L}-\mathrm{Ab}-13-1$ was significantly higher than other hemoabzymes, and remains among the highest reported to date (Table 27, entry 5).

Scheme 65. Antibodies raised against TpCPP bind 213 to afford hemoabzymes with peroxidase activity. 
<smiles>Oc1cccc(O)c1O</smiles>

$1.2 \mathrm{mM}$

212

$$
\begin{aligned}
& 213(0.4 \mathrm{~mol} \%) \\
& \stackrel{\mathrm{L}-\mathrm{Ab}-13-1(0.7 \mathrm{~mol} \%)}{\longrightarrow} \\
& \mathrm{H}_{2} \mathrm{O}_{2}(5 \mathrm{mM}) \\
& \text { Tris/Acetate }(90 \mathrm{mM})
\end{aligned}
$$

$\mathrm{pH} 8.0,37^{\circ} \mathrm{C}$<smiles>Cc1cc2cccc(O)c(=O)c2c(O)c1O</smiles>

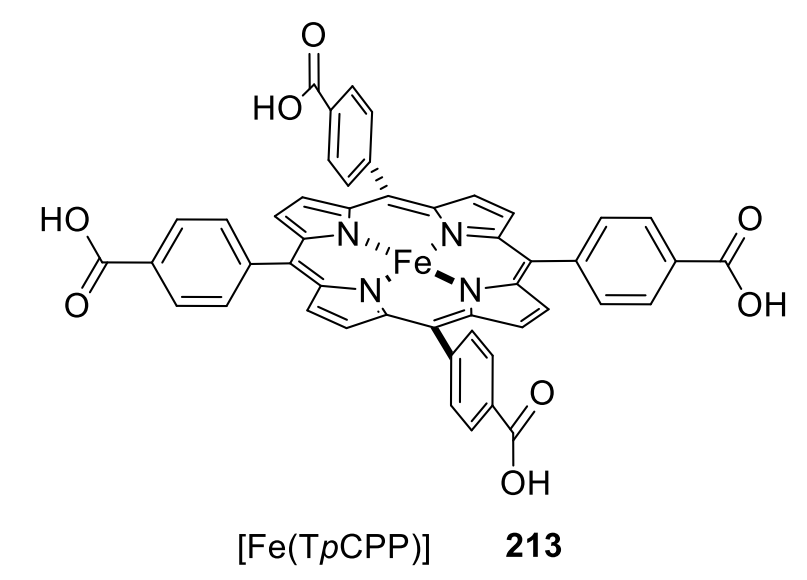

In 1996, Mahy and coworkers selected the tetra-aryl porphyrin 214 as a hapten (Scheme 66). ${ }^{379}$ Two $\operatorname{lgG} 1$ monoclonal antibodies, $\mathrm{Ab}-14 \mathrm{H} 7$ and $\mathrm{Ab}-13 \mathrm{G} 10$, bind 214 with a dissociation $K_{D}=5.5 \times 10^{-9} \mathrm{M}$ and $K_{D}=2.9 \times 10^{-9} \mathrm{M}$ respectively. ${ }^{379}$ These are the highest affinity values reported for porphyrin/Ab-antiporphyrin interactions. ${ }^{381}$ The protein pocket provided a beneficial effect on the peroxidase activity of 214 . Indeed, both 214 $\cdot \mathrm{Ab}-14 \mathrm{H} 7$ and $214 \cdot \mathrm{Ab}-13 \mathrm{G} 10$ showed $\sim 5$ times higher $k_{\text {cat }} / K_{\mathrm{M}}$ than 214 alone at $\mathrm{pH}$ 5.0 (Table 27, entries 6-8). 214 Ab-13G10 showed even higher activity at pH 4.6 (Table 27, entry 9).

Scheme 66. Supplementation of a synthetic o-carboxyphenyl-porphyrin 214 or 215 with their cognate antibodies affords artificial peroxidases. 

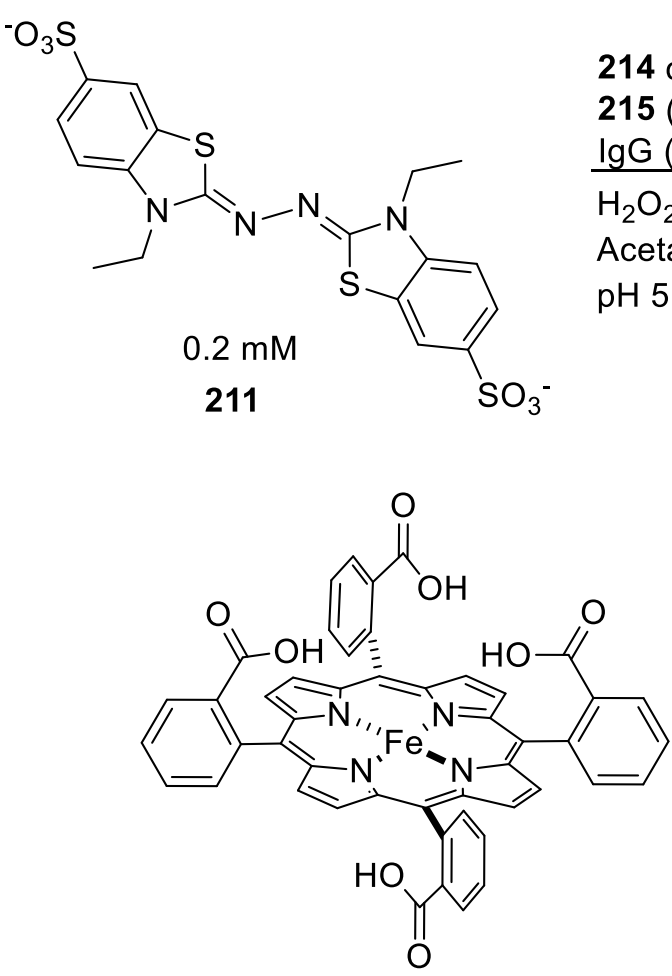

[Fe(ToCPP, $\alpha, \alpha, \alpha, \beta$-isomer)] 214
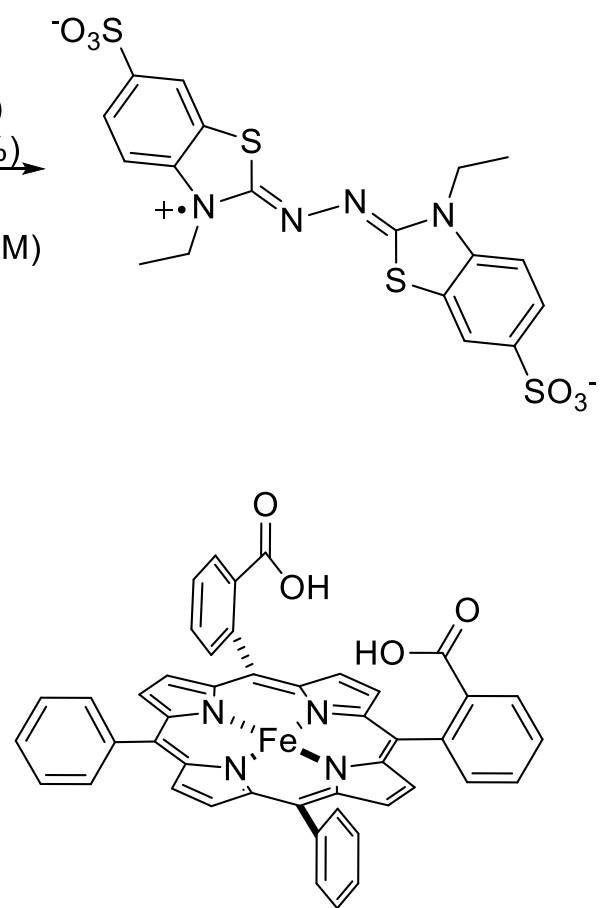

[Fe(DoCPP, $\alpha, \alpha$-isomer) $) 215$

Harada and coworkers elicited monoclonal antibodies $03-1$ and $12 \mathrm{E} 11 \mathrm{G}$ against the anionic porphyrin 213 and the cationic porphyrin 216, respectively (Scheme 67). ${ }^{134,382}$ The dissociation constant between the antibody 03-1 and Fe-meso-tetrakis(4carboxyphenyl)porphyrin (TCPP) 213 was $1.5 \times 10^{-7} \mathrm{M}$ and the antibody 12E11G bound to Fe-meso-tetrakis(4-N-methylpyridyl)porphyrin (TMPyP) 216 with $K_{d}$ of $2.6 \times 10^{-7} \mathrm{M}$. In the presence of hydrogen peroxide, the resulting ArMs catalyzed the oxidation of pyrogallol 212 with higher catalytic performance than the free cofactor (Table 27, entries 10-13).

Scheme 67. Oxidation of pyrogallol catalyzed by iron porphyrin derivatives in the presence of an antibody. 
2<smiles>Oc1cccc(O)c1O</smiles>

0.25-2 mM

212

Fe-TCPP 213·Antibody 03-1

or

Fe-TMPyP 216-Antibody 12E11G

$\mathrm{H}_{2} \mathrm{O}_{2}(5-800 \mathrm{mM})$

Tris-acetate buffer or PBB buffer (90-100 mM)<smiles>O=c1c(O)cccc2cc(O)c(O)c(O)c12</smiles>

$4 \%$ DMSO

$\mathrm{pH} 9$

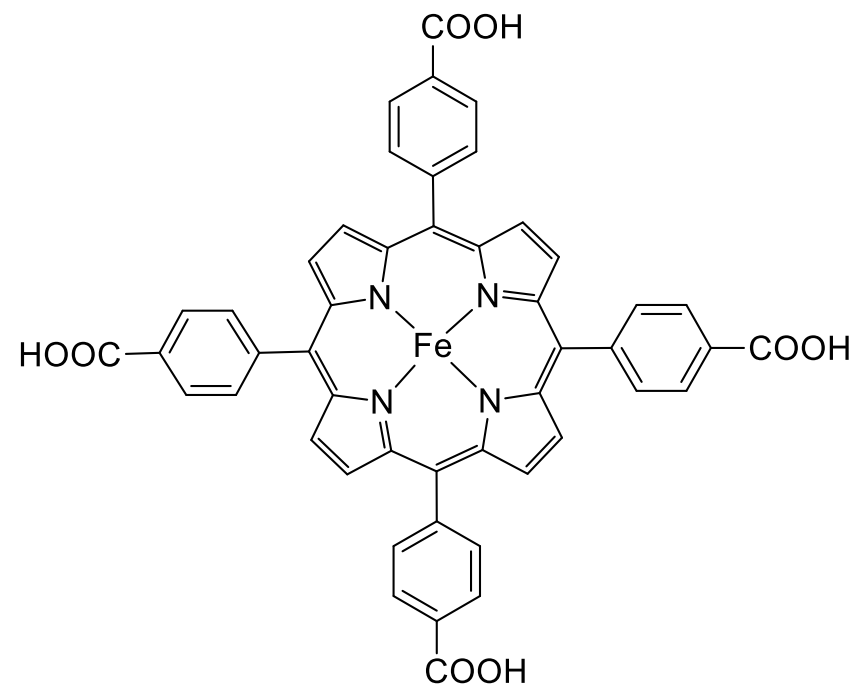

[Fe-TCPP]

213

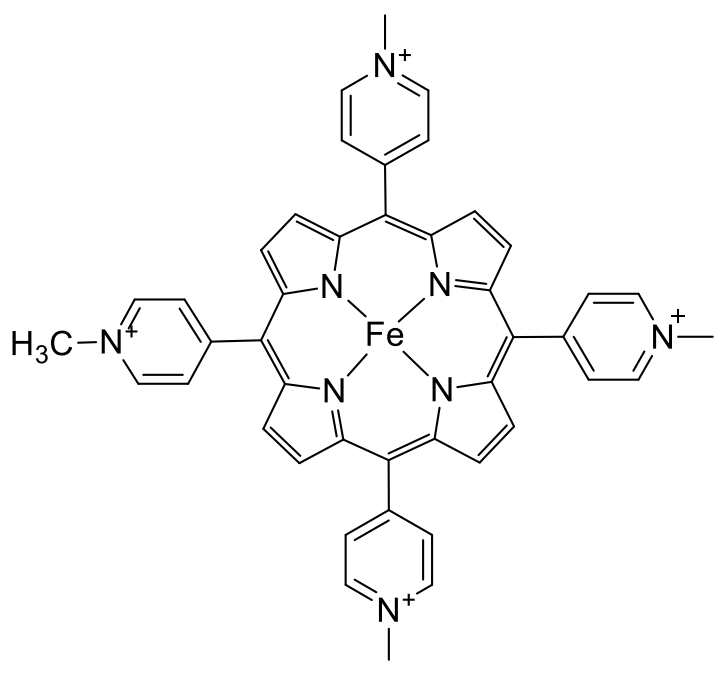

[Fe-TMPyP]

216

In 2002, Mahy and coworkers investigated the impact of added imidazole on the peroxidase activity of their hemoabzyme to mimic the histidine ligation found in natural peroxidases. ${ }^{383}$ The effect was deleterious in the case of hindered porphyrins: the peroxidase activity of $\mathbf{2 1 4} \cdot \mathrm{Ab}-13 \mathrm{G} 10$ decreased by fifty percent upon addition of $50 \mathrm{mM}$ imidazole. (Scheme 66) However, for 215.Ab-13G10, addition of $50 \mathrm{mM}$ imidazole increased the $k_{\mathrm{cat}} / K_{\mathrm{M}}$ by a factor $\sim 15$ (Table 27, entries 14 and 5 ). Under these conditions, 215 $\mathrm{Ab}-13 \mathrm{G} 10$ displayed higher $k_{\text {cat }}$ and $k_{\text {cat }} / K_{\mathrm{M}}$ than 214·Ab-13G10 (Table 27, entries 8, 9 and 15).

To further improve catalytic activity, microperoxidase 8 (MP8, 217), which contains an intramolecular imidazole-moiety, was also examined as a catalyst. ${ }^{384}$ MP8 is a digestion product of the horse cytochrome $c$ and consists of a heme [Fe(PPIX)] linked to an octapeptide via two thioether linkages and provides a histidine ligated to iron. The $\lg _{1}$ monoclonal antibody Ab-3A3 binds 217 with a dissociation constant $K_{D} \sim 10^{-7} \mathrm{M} .217$ 
alone catalyzes peroxide degradation as well as monooxygenation reactions; however, its performance is limited by dimerization and by its oxidative degradation during catalysis. Upon integration within the antibody, the authors hoped to alleviate these challenges and to improve catalytic efficiency by providing a well-defined second coordination sphere environment for enantioselective monooxygenation. They investigated 217-Ab-3A3 for peroxidase activity toward both o-dianisidine (210) and ABTS (211) (Scheme 68). The 217.Ab-3A3 showed a $k_{\mathrm{cat}} / K_{\mathrm{M}} \sim 3.3 \times 10^{4} \mathrm{M}^{-1} \cdot \mathrm{s}^{-1}$ with 210 as substrate. This corresponds to the highest catalytic efficiency reported to date for an hemoabzyme (Table 27, entry 17). This represents a $\sim 50 \%$ improvement over the free cofactor 217 (Table 27, entry 16).

Scheme 68. Peroxidase activity of $\mathbf{2 1 7}$ is enhanced upon binding to $A b-3 A 3$.
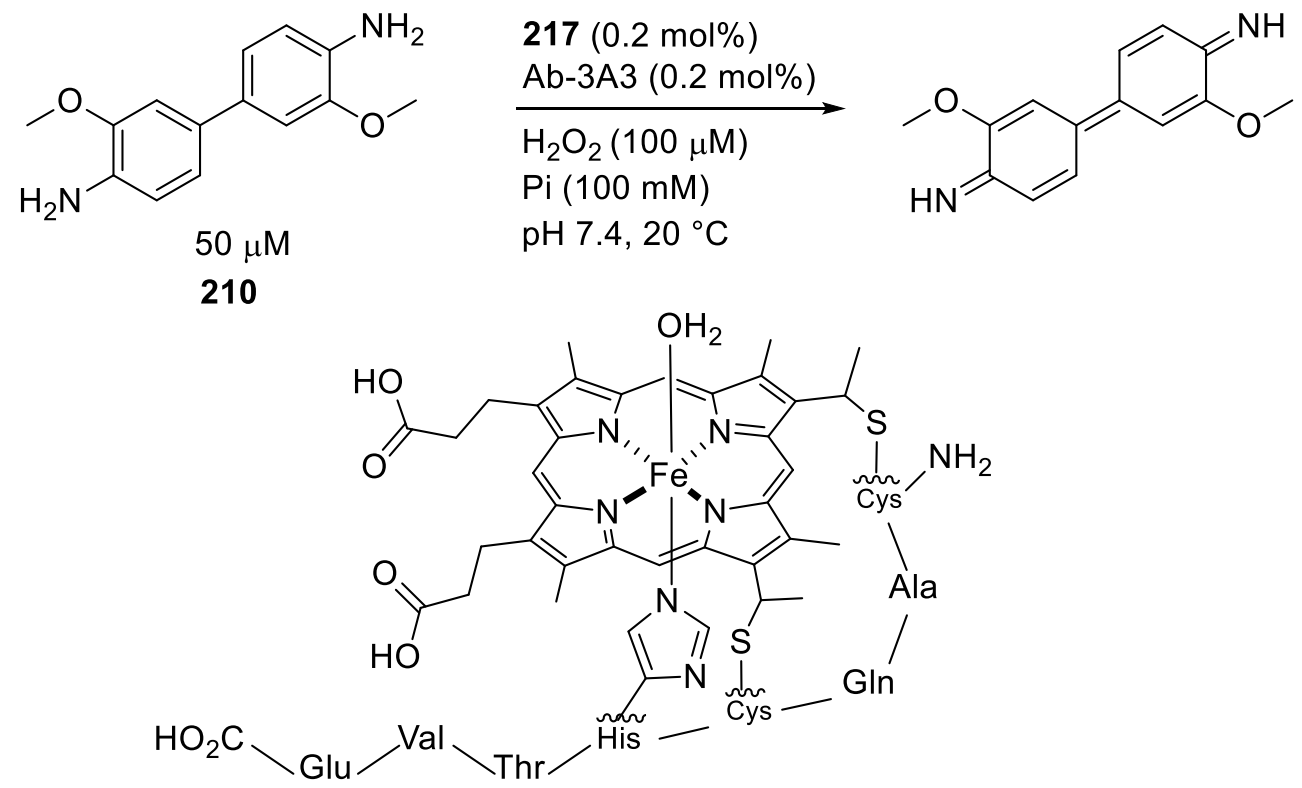

Microperoxidase $8 \quad 217$

In the presence of hydrogen peroxide and a nitrite anion, 217.Ab-3A3 also catalyzes the nitration of phenol 218 to yield in para-nitrophenol p-219 and ortho-nitrophenol o-219 with an $11: 8$ regioselectivity (Scheme 69). ${ }^{385}$ Upon incorporation into the antibody Ab$3 A 3$, both the activity ( 36 TON vs. 19 TON) and the selectivity increased: the $\mathbf{0 - 2 1 9}$ was 
favored by a factor two over $\mathbf{p - 2 1 9}$.

Scheme 69. Supramolecular assembly of 217 with Ab-3A3 yields an ArM for the nitration of phenol. (The catalyst loading is reported vs. the hydrogen peroxide concentration)

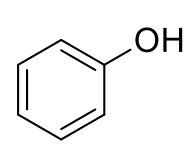

$1 \mathrm{mM}$

218

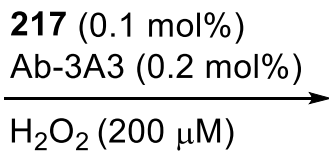

$\mathrm{NO}_{2}^{-}(20 \mathrm{mM})$

$\mathrm{Pi}(100 \mathrm{mM})$

$\mathrm{pH} 7.4$, r.t., $25 \mathrm{~min}$<smiles>O=[N+]([O-])c1ccc(O)cc1</smiles>

p-219<smiles>O=[N+]([O-])c1ccccc1O</smiles>

$0-219$

In 2004, Mahy and coworkers reported a "Trojan Horse" strategy to assemble ArMs. In the previous hemoabzymes, antibodies were raised against a molecule that is directly involved in the reaction (e.g. the catalyst, a structural analog of a reaction intermediate or transition state). In the "Trojan Horse" strategy, an anchor moiety was used as hapten. This constitutes a versatile means to elicit an host-anchor couple for assembling ArMs, alleviating the requirement of natural protein-cofactor specific interactions. As proof of principle, they tethered a porphyrin to estradiol (220, Scheme 70) and incorporated this cofactor into $\mathrm{Ab}-7 \mathrm{~A} 3$, an antibody raised against estradiol. ${ }^{386-388}$ The resulting antibody'porphyrin conjugate $220 \cdot \mathrm{Ab}-7 \mathrm{~A} 3$ had an affinity $K_{\mathrm{D}}=4 \cdot 10^{-7} \mathrm{M}$ and displayed peroxidase activity twofold improved compared to the free cofactor $\mathbf{2 2 0}$. 387

Scheme 70. A Trojan Horse anchoring strategy affords an "Hemoabzyme" with peroxidase activity. 
<smiles>CCn1/c(=N/N=C\O)sc2cc([S+](=O)(=O)[O-])ccc21</smiles>

211

[Fe(TMPyP)-est.] 220

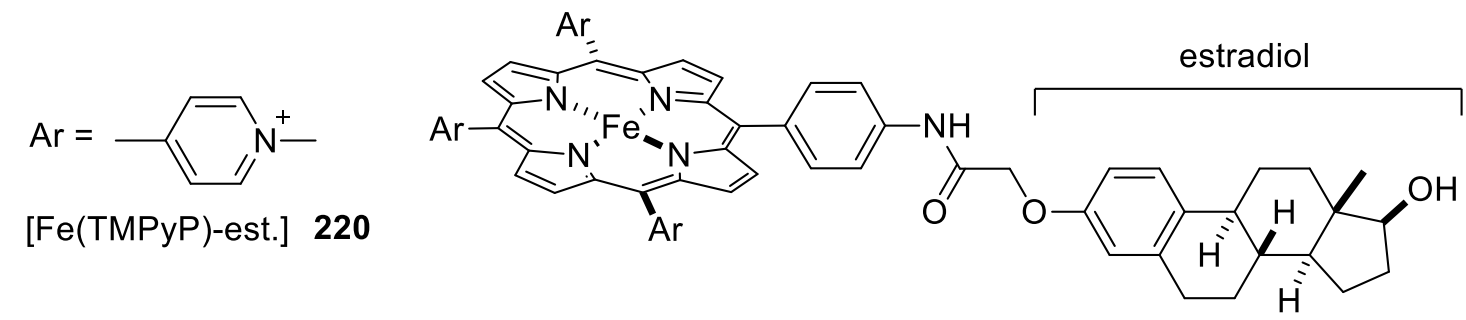

$220(1 \mathrm{~mol} \%)$ Ab-7A3 (2.5 mol\%)

$\mathrm{H}_{2} \mathrm{O}_{2}(0.1-1.7 \mathrm{mM})$ Pi-citrate $(50 \mathrm{mM})$ $\mathrm{pH} 4.4,22^{\circ} \mathrm{C}$

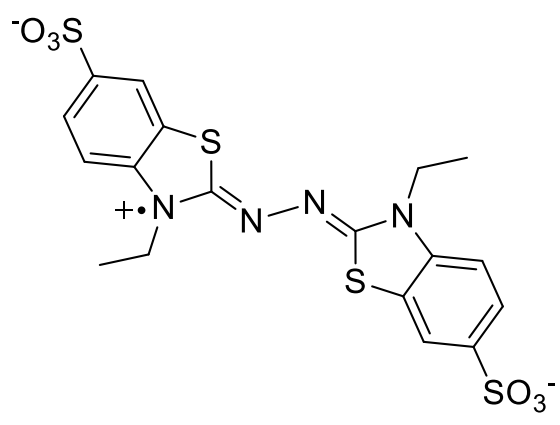

Table 27. Selected results for the peroxidase activity of "hemoabzymes".

\begin{tabular}{|c|c|c|c|c|c|c|c|c|c|c|c|}
\hline Entry & Cof. & Protein & Sub. & $\mathrm{pH}$ & $\begin{array}{c}\mathrm{T} \\
\left({ }^{\circ} \mathrm{C}\right)\end{array}$ & $\begin{array}{l}{[\mathrm{Cof}]} \\
(\mu \mathrm{M})\end{array}$ & $\begin{array}{c}{\left[\mathrm{H}_{2} \mathrm{O}_{2}\right]} \\
(\mathrm{mM})\end{array}$ & $\begin{array}{c}K_{\mathrm{M}} \\
\left(\mathrm{mM}^{-1}\right)\end{array}$ & $\begin{array}{l}k_{\text {cat }} \\
\left(\mathrm{s}^{-1}\right)\end{array}$ & $\begin{array}{c}k_{\mathrm{cat}} / K_{\mathrm{M}} \\
\left(\mathrm{s}^{-1} \cdot \mathrm{M}^{-1}\right)\end{array}$ & Ref \\
\hline 1 & 20 & - & 210 & 8.0 & 10 & 0.5 & 5 & 43 & 2.77 & 64 & 133 \\
\hline 2 & 20 & Ab-7G12 & 210 & 8.0 & 10 & 0.5 & 5 & 24 & 6.57 & 274 & 133 \\
\hline 3 & 20 & - & $210^{b}$ & 8.0 & 10 & 0.3 & $\begin{array}{c}0.0103- \\
0.613\end{array}$ & 43 & 5.5 & 128 & 380 \\
\hline 4 & 20 & $\mathrm{Ab}-2 \mathrm{~B} 4$ & $210^{b}$ & 8.0 & 10 & 0.3 & $\begin{array}{c}0.0103- \\
0.613\end{array}$ & 25 & 1.3 & 51 & 380 \\
\hline 5 & 213 & L-Ab-13-1 & 212 & 8.0 & 37 & 0.5 & 5 & 2.3 & 11.12 & 4833 & 378 \\
\hline 6 & 214 & - & 211 & 5.0 & 20 & 0.2 & 1 & 42 & 0.85 & 21 & 379 \\
\hline 7 & 214 & $\mathrm{Ab}-14 \mathrm{H} 7$ & 211 & 5.0 & 20 & 0.2 & 1 & 9 & 1.05 & 119 & 379 \\
\hline 8 & 214 & $A b-13 G 10$ & 211 & 5.0 & 20 & 0.2 & 1 & 16 & 1.67 & 105 & 379 \\
\hline 9 & 214 & $A b-13 G 10$ & 211 & 4.6 & 20 & 0.2 & 0.7 & 16 & 9.33 & 222 & 389 \\
\hline 10 & 213 & - & 212 & 9.0 & - & 0.5 & 5 & - & 0.15 & - & 134 \\
\hline 11 & 213 & $A b-03-1$ & 212 & 9.0 & - & 0.5 & 5 & 4.0 & 0.83 & 208 & 134 \\
\hline 12 & 216 & - & 212 & 9.0 & r.t. & 0.5 & 50 & - & 1.38 & - & 382 \\
\hline 13 & 216 & $A b-12 E 11 G$ & 212 & 9.0 & r.t. & 0.5 & 50 & 8.6 & 11.3 & 1318 & 382 \\
\hline 14 & 215 & $A b-13 G 10$ & 211 & 5.0 & 19 & 0.3 & 0.7 & 34 & 0.53 & 15.7 & 383 \\
\hline 15 & 215 & $A b-13 G 10$ & 211 & 5.0 & 19 & 0.3 & 0.7 & $10^{a}$ & $2.53 a$ & $253 a$ & 383 \\
\hline 16 & 217 & - & 210 & 7.4 & 20 & 0.1 & 0.1 & 0.4 & 9.83 & 24580 & 384 \\
\hline 17 & 217 & $A b-3 A 3$ & 210 & 7.4 & 20 & 0.1 & 0.1 & 0.45 & 14.75 & 32780 & 384 \\
\hline
\end{tabular}

Many hemoproteins, including myoglobin, cytochrome b5, horseradish peroxidase, and cytochromes P450 possess a Fe-protoporphyrin IX cofactor (FePPIX, 222). Since FePPIX is bound in the pocket of hemoproteins via only non-covalent and dative interactions, it can readily be removed under acidic conditions. The resulting apohemoprotein can be reconstituted with synthetic FePPIX analogues to generate ArMs. ${ }^{52}$ Hayashi and coworkers varied the propionate side chain of PPIX, hypothesizing that this 
could affect substrate-binding. ${ }^{331}$ A double-winged Fe-PPIX derivative (223) that possessed two aromatic rings and eight carboxylates (Figure 24) was synthesized and used to reconstitute apo-Mb. Compared to $222 \cdot \mathrm{Mb}, 223 \cdot \mathrm{Mb}$ displayed a higher $k_{\text {cat }}$ and a lower $K_{M}$ for the oxidation of guaiacol (221) with hydrogen peroxide (Table 28, entries 1 and 2 and Scheme 71), suggesting that the dendridic wedges act as substrate-binding moieties. Further improvements to catalytic activity were realized using the Mb H64D variant. ${ }^{332}$ Reconstituting this scaffold with $\mathbf{2 2 2}$ and 223 led to ArMs that oxidized 221 with $\mathrm{kcat}_{\mathrm{K}} / \mathrm{K}_{\mathrm{M}}$ 96- and 434-fold higher than the ArMs generated using the wt Mb scaffold (Figure 24, Table 28, entries 3-6).

While reconstituting Mb with double-winged Fe-PPIX cofactors led to ArMs with reduced $K_{\mathrm{M}}$, the improvement for $K_{\text {cat }}$ was modest (Table 28, entries 3-6). Since the chemical modification of both propionates of $\mathbf{2 2 2}$ decreased the reactivity of the corresponding oxoferryl intermediate, the single-winged Fe-PPIX cofactor 224 was also prepared (Figure 24). ${ }^{390}$ When bound to Mb, 224 can form hydrogen bonds between its unmodified propionate and Mb R45 to lock the orientation of the cofactor. Accordingly, 224.Mb (H64D) showed 20-fold higher $k_{\text {cat }}$ and 3.7-fold higher $k_{\text {cat }} / K_{M}$ for guaiacol 221 oxidation compared with 223·Mb (H64D) (Table 28, entries 6 and 7).

Hayashi and coworkers also reconstituted Mb with Fe-porphycene 225, a constitutional isomer of Fe-PPIX (Figure 24). ${ }^{333}$ Fe-porphycene 225 binds to myoglobin (Mb) more tightly than Fe-PPIX due to a stronger interaction between the porphycene Fe center and with His93. This strong electron $\sigma$-donation also increases the peroxidase activity of the ArM. In the presence of hydrogen peroxide, the rate of guaiacol oxidation catalyzed by $\mathbf{2 2 5} \cdot \mathrm{Mb}$ is eleven-fold higher than that observed with native $\mathrm{Mb}(\mathbf{2 2 2} \cdot \mathrm{Mb})$ (Table 28 , entries 8 and 9). (see active site in Figure 15). The same group also reconstituted HRP with Fe-porphycene 225 since the active species responsible for the peroxidase activity has a longer lifetime in HRP compared to Mb (Figure 24). ${ }^{391}$ In the presence of hydrogen 
peroxide, 225.HRP oxidized the guaiacol 221 with a comparable rate to native HRP (222·HRP). (Table 28, entries 10 and 11).

Finally, Fe-corrole 226 was also used to reconstitute both Mb and HRP. Hayashi and coworkers hypothesized that the high-valent oxidation states of this cofactor might be better stabilized due to the trianionic character of the corrole (Figure 24). The resulting Mb- and HRP-based ArMs were used to catalyze guaiacol oxidation in the presence of hydrogen peroxide. The catalytic activity decreased in the following order: $222 \cdot \mathrm{HRP}>$ 226 $\cdot \mathrm{HRP}>\mathbf{2 2 6} \cdot \mathrm{Mb}>>\mathbf{2 2 2} \cdot \mathrm{Mb}$ (Table 28, entries 12-15). ${ }^{392}$

Table 28. Selected results for the peroxidase activity by reconstituted hemoproteins with iron porphyrin derivatives.

\begin{tabular}{|c|c|c|c|c|c|c|c|c|c|c|c|c|}
\hline Ent. & Cof. & Protein $^{a}$ & Sub. & $\mathrm{pH}$ & $\begin{array}{c}\mathrm{T} \\
\left({ }^{\circ} \mathrm{C}\right)\end{array}$ & $\begin{array}{l}{[\mathrm{Cof}]} \\
(\mu \mathrm{M})\end{array}$ & $\begin{array}{c}{\left[\mathrm{H}_{2} \mathrm{O}_{2}\right]} \\
(\mathrm{mM})\end{array}$ & $\begin{array}{c}\mathrm{K}_{\mathrm{M}} \\
\left(\mathrm{mM}^{-1}\right)\end{array}$ & $\begin{array}{l}k_{\mathrm{cat}} \\
\left(\mathrm{s}^{-1}\right)\end{array}$ & $\begin{array}{c}k_{\text {cat }} / \mathrm{K}_{\mathrm{M}} \\
\left(\mathrm{s}^{-1} \mathrm{M}^{-1}\right)\end{array}$ & $\begin{array}{l}\text { TOF } \\
\left(\mathrm{s}^{-1}\right)\end{array}$ & Ref \\
\hline 1 & 222 & $\mathrm{Mb}(\mathrm{WT})$ & 221 & 7.0 & 20 & 1 & 9.7 & 32 & $\begin{array}{l}0.3 \\
6\end{array}$ & 11 & - & 331 \\
\hline 2 & 223 & Mb (WT) & 221 & 7.0 & 20 & 1 & 9.7 & 7.4 & 1.1 & 149 & - & 331 \\
\hline 3 & 222 & $\mathrm{Mb}$ (WT) & 221 & 6.0 & 25 & 2 & 100 & 54 & 2.8 & 53 & - & 332 \\
\hline 4 & 223 & $\mathrm{Mb}(\mathrm{WT})$ & 221 & 6.0 & 25 & 2 & 100 & 3.4 & 6.2 & 1800 & - & 332 \\
\hline 5 & 222 & $\mathrm{Mb}(\mathrm{H} 64 \mathrm{D})$ & 221 & 6.0 & 25 & 2 & 15 & 1.8 & 9.0 & 5100 & - & 332 \\
\hline 6 & 223 & $\mathrm{Mb}(\mathrm{H} 64 \mathrm{D})$ & 221 & 6.0 & 25 & 2 & 15 & 0.052 & 1.2 & 23000 & - & 332 \\
\hline 7 & 224 & $\mathrm{Mb}$ (H64D) & 221 & 6.0 & 25 & 4 & 100 & 0.29 & 24 & 85000 & - & 390 \\
\hline 8 & 222 & $\mathrm{Mb}$ (WT) & 221 & 7.0 & 20 & 1 & 20 & - & - & - & 0.021 & 333 \\
\hline 9 & 225 & $\mathrm{Mb}$ (WT) & 221 & 7.0 & 20 & 1 & 20 & - & - & - & 0.230 & 333 \\
\hline 10 & 222 & HRP (WT) & 221 & 7.0 & 25 & 0.1 & 4 & - & - & - & 40 & 391 \\
\hline 11 & 225 & HRP (WT) & 221 & 7.0 & 25 & 0.1 & 4 & - & - & _- & 38 & 391 \\
\hline 12 & 222 & $\mathrm{Mb}(\mathrm{WT})$ & 221 & 7.0 & 20 & 2 & 5 & - & - & - & $\sim 0$ & 392 \\
\hline 13 & 226 & Mb (WT) & 221 & 7.0 & 20 & 2 & 5 & - & - & - & 0.43 & 392 \\
\hline 14 & 222 & HRP (WT) & 221 & 7.0 & 20 & 2 & 5 & - & - & - & 11 & 392 \\
\hline 15 & 226 & HRP (WT) & 221 & 7.0 & 20 & 2 & 5 & - & - & - & 1.6 & 392 \\
\hline
\end{tabular}

Scheme 71. Oxidation of guaiacol performed by myoglobin and horseradish peroxidae.<smiles>COc1ccccc1O</smiles>

0.025-20 mM 221
Fe-Porphrinoid 222-226 $\mathrm{Mb}$ or HRP

$\mathrm{H}_{2} \mathrm{O}_{2}$ (4-100 mM)

Buffer (20-100 mM)

$\mathrm{pH} 6,7$

$20-25^{\circ} \mathrm{C}$<smiles>COC1=CC(=C2C=CC(=O)C(OC)=C2)C=CC1=O</smiles> 


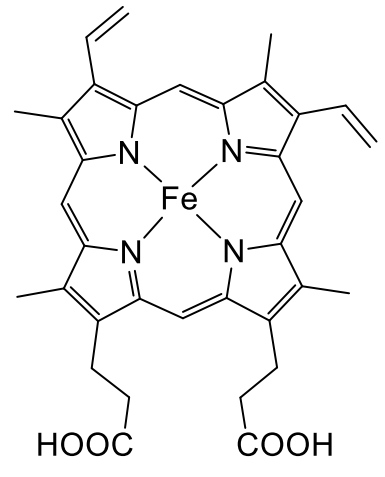

[Fe-protoporphyrin IX] 222

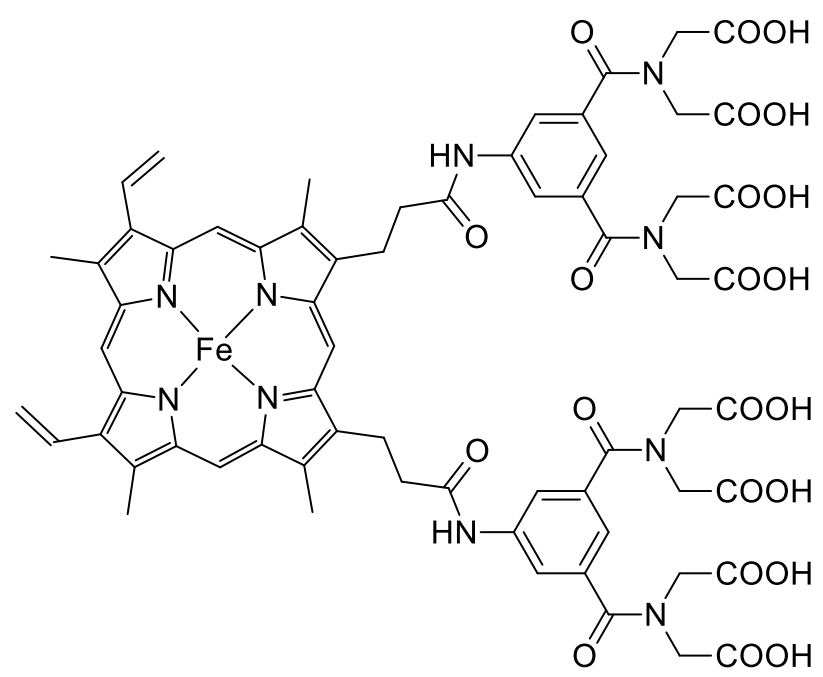

[Fe-double winged protoporphyrin IX]

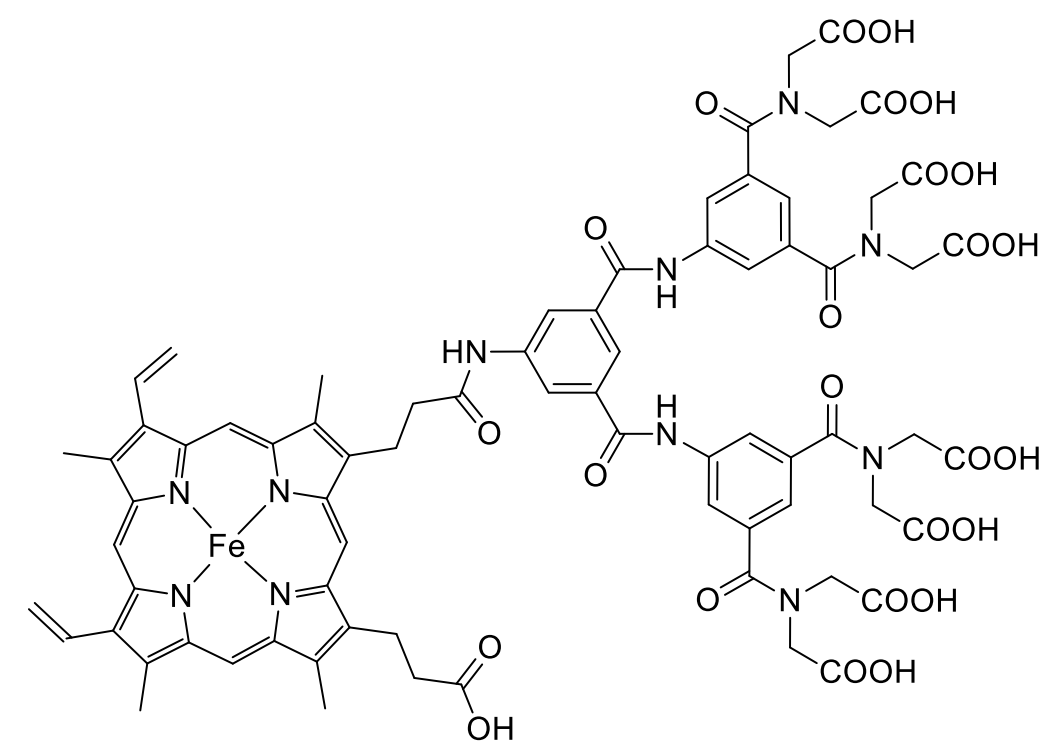

[Fe-single winged protoporphyrin IX]

224

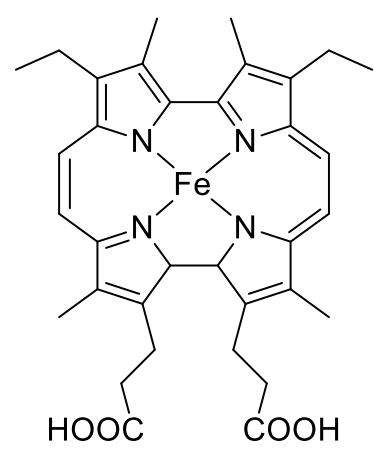

[Fe-porphycene] 225

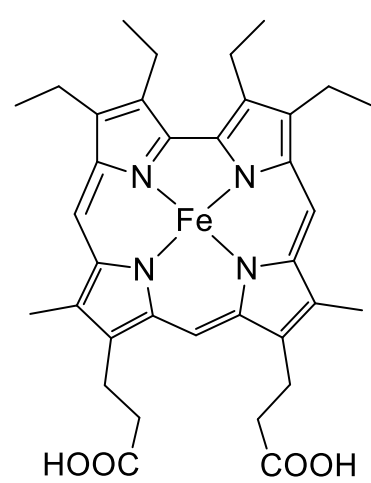

[Fe-corrole] 226

Figure 24. Cofactors used for the oxidation of guaiacol and thioanisole in the presence of apo heme proteins. 
De novo designed proteins have also been used as scaffolds to generate ArM oxidases and oxygenases via metallation with both metal ions and metal porphyrin complexes. DeGrado and Kaplan, for example, designed a phenol oxidase based on DFtet, a fourchain heterotetrameric helix bundle from the family of the dueferri (DF) proteins. ${ }^{393}$ The de novo-designed metalloenzyme contains two Fe-ions in its active site and its catalytic activity depends on the presence of dioxygen. Phenol oxidase activity occurs via formation of an oxo-bridged di-Fe(III) species (Scheme 72). Combinations of different monomeric units and introduction of mutations in the active site (i.e. increasing the size of cavity in the active site) led to highly active variants. The engineered metalloenzymes catalyze the oxidation of 4-aminophenol (227) to the corresponding benzoquinone monoimine (228). Catalytic efficiencies $\left(K_{\mathrm{cat}} / K_{\mathrm{M}}\right)$ of up to $1540 \mathrm{M}^{-1} \cdot \mathrm{min}^{-1}$ along with a $\sim 1000$-fold rate enhancement relative to the background reaction were achieved, and the best variant $\left(\mathrm{G}_{4}-\mathrm{DF}\right.$ tet $)$ provided over 100 turnovers.

Scheme 72. Oxidation of 4-aminophenol (227) using an engineered di-iron metalloenzyme $\mathrm{G}_{4}-\mathrm{DF}_{\text {tet. }}$

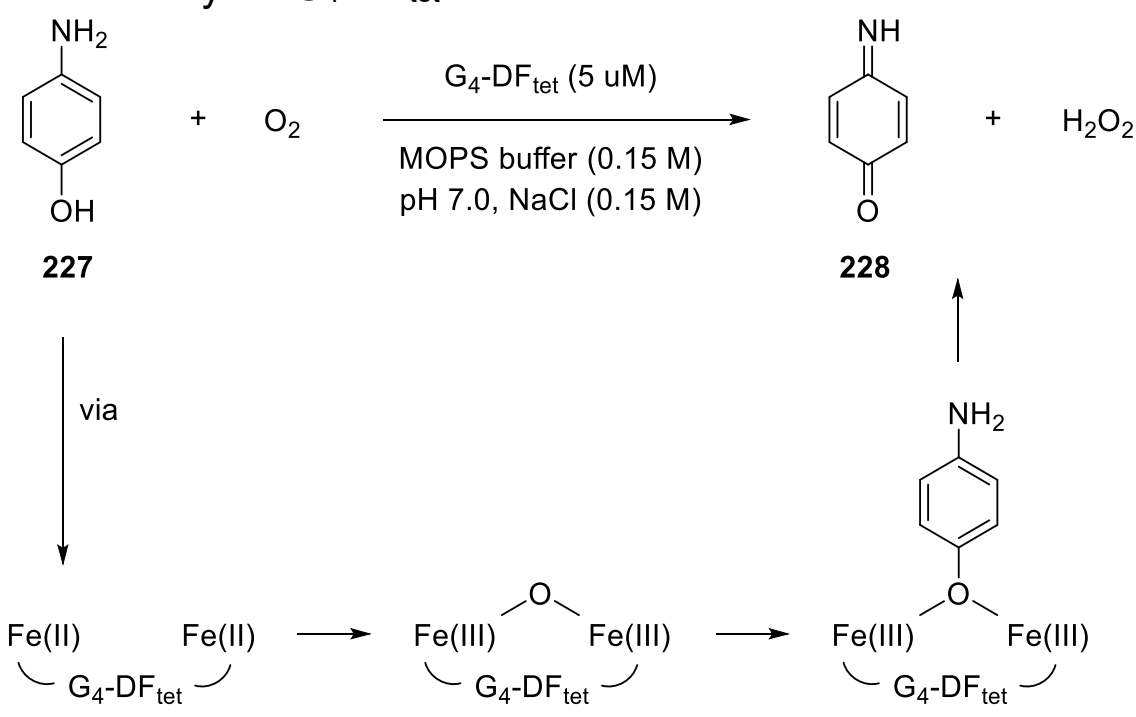

Lombardi et al. also engineered an artificial oxidase using the DF1 scaffold (PDB entry 1EC5), a well-characterized metalloprotein of the dueferri protein family. ${ }^{394}$ DF1 is a 
dimeric protein in which each monomer adopts an helix-loop-helix structure. ${ }^{395}$ The active site consists of two Fe-ions coordinated by two glutamates and one histidine each (Figure 25). Introducing mutations beneficial for the catalytic activity of the $\mathrm{G}_{4}-\mathrm{DF}_{\text {tet }}$ analogue led to a destabilization of the protein fold, but this issue was solved by mutating the interhelical turn. An NMR structure of the new DF3 variant was determined (PDB entry $2 \mathrm{KIK}$ ), and the designed artificial metalloenzyme displayed oxidase activities towards various substrates (Table 29).

Table 29. Oxidase activity of de novo-designed artificial di-iron oxo-proteins.

\begin{tabular}{|c|c|c|c|c|c|c|c|}
\hline Entry & Protein & Substrate & $\begin{array}{c}K_{\mathrm{M}} \\
(\mathrm{mM})\end{array}$ & $\begin{array}{c}k_{\text {cat }} \\
\left(\mathrm{min}^{-1}\right)\end{array}$ & $\begin{array}{c}k_{\text {cat }} / K_{\mathrm{M}} \\
\left(\mathrm{M}^{-1} \cdot \mathrm{min}^{-1}\right)\end{array}$ & TON & Ref \\
\hline 1 & DF3 & 3,5-di-tert-butylcatechol & $2.09 \pm 0.31$ & $13.2 \pm 1.2$ & 6315 & & 394 \\
\hline 2 & DF3 & 227 & $1.97 \pm 0.27$ & $2.72 \pm 0.19$ & 1380 & $>50$ & 394 \\
\hline 3 & DF3 & p-phenylenediamine & $8.87 \pm 2.58$ & $0.73 \pm 0.03$ & 83 & & 394 \\
\hline 4 & $\mathrm{G}_{4}-\mathrm{DF}_{\text {tet }}$ & 227 & $0.83 \pm 0.06$ & $1.30 \pm 0.10$ & 1540 & $>100$ & 393 \\
\hline
\end{tabular}

Reaction conditions: HEPES buffer (100 mM, pH 7.0), $100 \mathrm{mM} \mathrm{NaCl}$.

a)

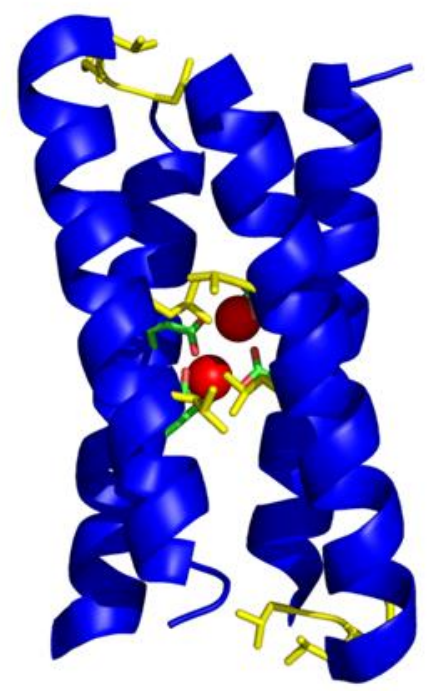

b)

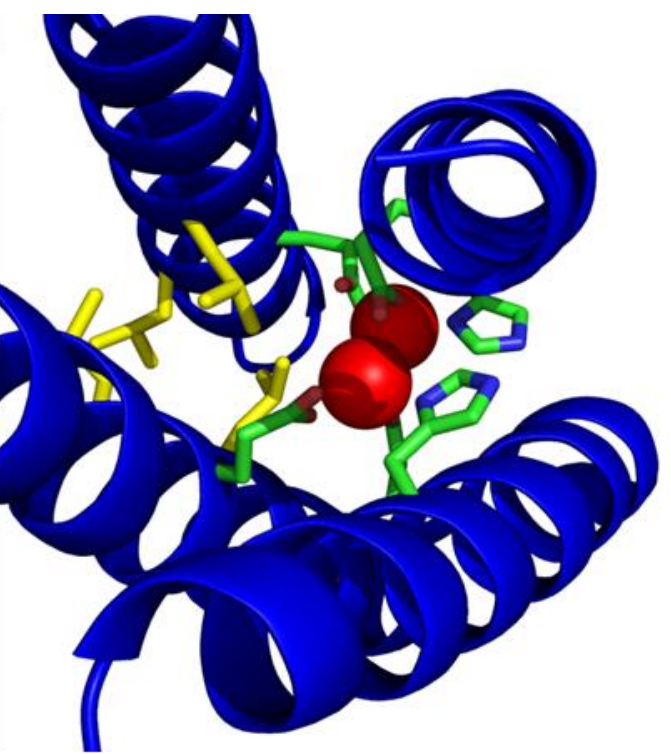

Figure 25. Cartoon representation of DF1 structures (PDB: 1EC5). Side view of the designed four helix bundles. Highlighted, in yellow, the amino acid mutations in the turn and in proximity of the active site, introduced to stabilize the protein scaffold and to allow substrates to approach the metal ions, respectively a). Zoom into the active site of Due Ferro protein. Iron centers are depicted in red. Coordinating residues (two His and four Glu) are represented as stick and coloured by element b).

DeGrado et al. repurposed a de novo-designed metalloprotein originally designed to oxidize hydroquinones in order to catalyze selective $N$-hydroxylation of arylamines. ${ }^{396}$ DFsc, a single-chain four-helix bundle protein from the dueferri family (PDB entry $2 \mathrm{HZ}$ ), 
was selected as template for the redesign. Four Ala $\rightarrow$ Gly mutations (analogous to the $\mathrm{G}_{4}-\mathrm{DF}_{\text {tet }}$ construct) afforded a highly active hydroquinone oxidase (G4DFsc). Inspection of the crystal structure of AurF (PDB entry 2JCD), an $N$-oxygenase containing a di-iron catalytic center, suggested the incorporation of a third metal-binding His residue in the scaffold. Following the introduction of three additional stabilizing mutations, a functional $N$-hydroxylase was created (3His-G4DFsc, PDB entry 2LFD). Both enzymes displayed high affinity for $\mathrm{Fe}(\mathrm{II})\left(\mathrm{K}_{d}=70 \pm 3 \mu \mathrm{M}\right.$ and $30 \pm 2 \mu \mathrm{M}$ for G4DFsc and 3His-G4DFsc respectively). G4DFsc had a high catalytic activity towards the oxidation of 4aminophenol (227), whereas no $N$-hydroxylase activity was observed. The opposite trend was observed for 3His-G4DFsc. This construct showed high activity towards the selective $N$-hydroxylation of $p$-anisidine $(229$, Scheme 73$)$ thus highlighting the flexibility of de-novo designed metalloproteins and the power to repurpose the reaction specificity by introduction of single mutations. Recently, DeGrado et al. identified the actual active species of the two due-ferri scaffolds (G4DFsc and 3His-G4DFsc) and suggested mechanisms explaining their different reactivities. ${ }^{397}$

Scheme 73: Selective $N$-hydroxylation of $p$-anisidine 229 with the de-novo designed metalloprotein 3His-G4DFsc. The $N$-hydroxylated product 230 is thought to undergo disproportionation to form $p$-nitrosoanisole 231, which reacts with another molecule of $p$ anisidine 229 via a nucleophilic aromatic substitution to yield 4-nitroso-4 methoxydiphenylamine 232 .

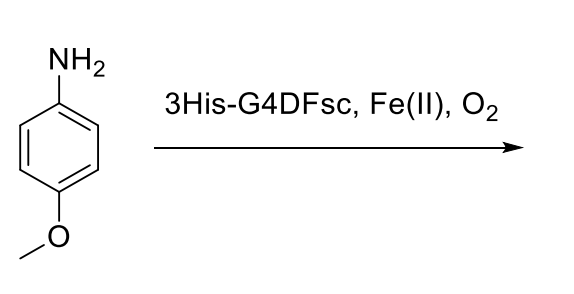

229

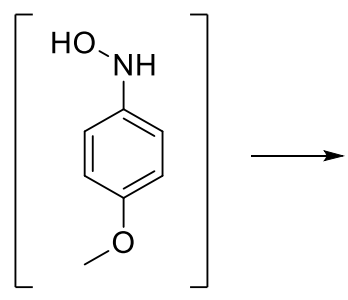

230

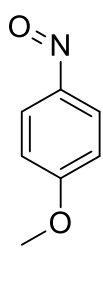

231

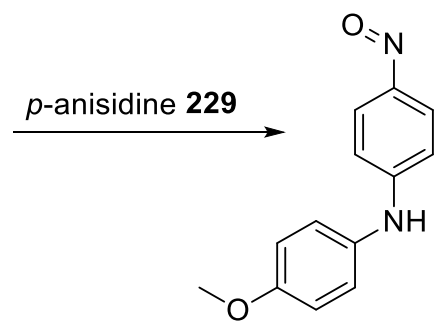

232

In 2008, Mahy and coworkers inserted the porphyrin [Fe(TpCCP)] (213) into xylanase $A$ (XIn) via supramolecular interactions. ${ }^{398}$ This protein possesses a hydrophobic pocket 
that may host a $[\mathrm{M}(\mathrm{TpCCP})]-$ complex. Even though modeling studies suggested that the porphyrin does not entirely fit into the cleft, the host-guest affinity was in the micromolar range $\left(K_{D}=0.5 \mu \mathrm{M}\right)$, ensuring a high concentration of the desired ArM during catayltic experiments. The peroxidase activity of this ArM was determined via its ability to promote the oxidation o-dianisidine 210, Scheme 63. Compared to 213 alone, 213.XIn displayed an 1.8 fold higher $k_{\text {cat }}$ but a 3 -fold lower $k_{\text {cat }} / K_{M}$, due to a lower affinity for the substrate (i.e. $K_{M} 5$ times higher) (Table 30 , entries 1 and 2 ).

Table 30. Selected results for the peroxidase activity by $213 \cdot X \ln$.

\begin{tabular}{cccccccccccc}
\hline Entry & Cof. & Protein & Sub. & $\mathrm{pH}$ & $\begin{array}{c}\mathrm{T} \\
\left({ }^{\circ} \mathrm{C}\right)\end{array}$ & $\begin{array}{c}{[\mathrm{Cof}]} \\
(\mu \mathrm{M})\end{array}$ & $\begin{array}{c}{\left[\mathrm{H}_{2} \mathrm{O}_{2}\right]} \\
(\mathrm{mM})\end{array}$ & $\begin{array}{c}\mathrm{K}_{\mathrm{M}} \\
\left(\mathrm{mM}^{-1}\right)\end{array}$ & $\begin{array}{c}k_{\text {cat }} \\
\left(\mathrm{s}^{-1}\right)\end{array}$ & $\begin{array}{c}k_{\text {cat }} / \mathrm{K}_{\mathrm{M}} \\
\left(\mathrm{s}^{-1} \mathrm{M}^{-1}\right)\end{array}$ & $\begin{array}{c}\text { Ref } \\
\text { Ref }\end{array}$ \\
\hline 1 & $\mathbf{2 1 3}$ & - & $\mathbf{2 1 0}$ & 7.5 & 20 & 1.2 & 2.4 & 0.16 & 0.49 & 3041 & 398 \\
2 & $\mathbf{2 1 3}$ & XIn & $\mathbf{2 1 0}$ & 7.5 & 20 & 1.2 & 2.4 & 0.8 & 0.87 & 1083 & 398
\end{tabular}

In 2012, Itoh and Fujieda et al. prepared artificial dicopper oxidase by substitution of the di-zinc moiety of $\beta$-lactamase. ${ }^{399}$ This artificial metalloenzyme catalyzed the oxidation of catechol under aerobic conditions. Based on molecular dynamics simulations, they redesigned the copper binding site to more closely mimic the dicopper active site of natural catechol oxidases (Figure 26). The resulting triple mutant displayed 87-fold higher $k_{\mathrm{cat}} / K_{\mathrm{M}}$ values for the 4-tert-butylcatecol $\mathbf{2 3 3}$ oxidation compared to the wild type $\beta$-lactamase (Scheme 74 and Table 31).

Table 31. Selected results for catechol oxidation by dicopper reconstituted $\beta$-lactamase.

\begin{tabular}{|c|c|c|c|c|c|c|c|c|c|c|}
\hline Entry & Cofactor & Protein $^{a}$ & Sub. & $\mathrm{pH}$ & $\mathrm{T}\left({ }^{\circ} \mathrm{C}\right)$ & $\begin{array}{c}{[\mathrm{ArM}]} \\
(\mu \mathrm{M})\end{array}$ & $\begin{array}{c}\mathrm{K}_{\mathrm{M}} \\
\left(\mathrm{mM}^{-1}\right)\end{array}$ & $\begin{array}{l}k_{\mathrm{cat}} \\
\left(\mathrm{s}^{-1}\right)\end{array}$ & $\begin{array}{l}k_{\mathrm{cat}} / \mathrm{K}_{\mathrm{M}} \\
\left(\mathrm{s}^{-1} \mathrm{M}^{-1}\right)\end{array}$ & Ref \\
\hline 1 & Copper ion & $\beta$-lactamase (WT) & 233 & 7.0 & 25 & 20 & 7.7 & 1.1 & 1.4 & 399 \\
\hline 2 & Copper ion & $\begin{array}{c}\beta \text {-lactamase } \\
\text { (D88G-S185H-P224G) }\end{array}$ & 233 & 7.0 & 25 & 20 & 3.2 & 40 & 125 & 399 \\
\hline
\end{tabular}

Scheme 74. Oxidation of catechol derivatives catalyzed by dicopper-reconstituted $\beta$ lactamases. 
<smiles>CC(C)(C)c1ccc(O)c(O)c1</smiles>

1-10 mM dicopper $\beta$-lactamase

$\mathrm{O}_{2}$

Phosphate buffer (20 mM)

$\mathrm{pH} 7,25^{\circ} \mathrm{C}$<smiles>CC(C)(C)C1=CC(=O)C(=O)C=C1</smiles>

233

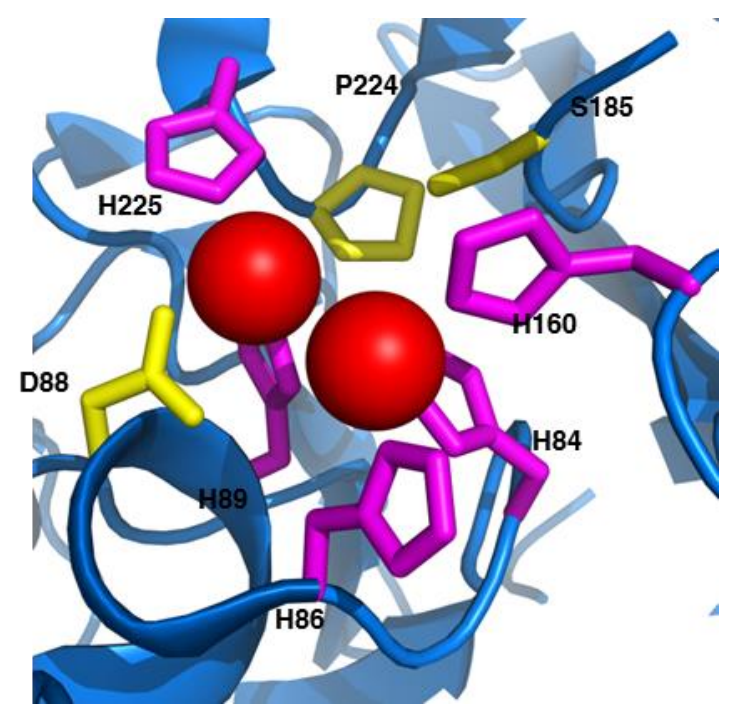

Figure 26. Active site structure of copper-substituted metallo $\beta$-Lactamase (PDB: 2FU7). Highlighted, in yellow, the amino acid position mutated to convert $\beta$-lactamase in catechol oxidase (D88G, S185H, P224G). In magenta, the five coordinating histidine residues (displayed as spheres).

In 2015, Ward and coworkers constructed an artificial copper oxidase by mining the pdb to identify proteins containing latent facial triad motifs, i.e. proteins would contain a metal binding site following a single point mutation. Following mutagenesis and metallation, the resulting ArMs might be expeted to possess radically different catalytic activity compared to the wild-type proteins. The algorithm "Search of Three-dimensional Atom Motifs in Protein Structure" (STAMPS) ${ }^{400}$ was used to identify thirteen proteins with a putative facial triad motifs. ${ }^{401}$ Among the identified proteins, only 6phosphogluconolactonase (6-PGLac hereafter), afforded peroxidase activity toward odianisidine in the presence of $\mathrm{H}_{2} \mathrm{O}_{2}$ upon metallation $\mathrm{CuSO}_{4}$ (Scheme 75). Using glucose oxidase with glucose and $\mathrm{O}_{2}$ in the presence of $\mathrm{Cu} \cdot 6$-PGLac led to slightly improved activity. A dramatic increase in activity was observed using $t$ - $\mathrm{BuOOH}$ as 
oxidant. Michaelis-Menten kinetics were determined $K_{\mathrm{M}}=11 \mu \mathrm{M}, k_{\text {cat }}=78 \cdot 10^{3} \cdot \mathrm{s}^{-1}$, and the $k_{\text {cat }}$ obtained was four orders of magnitude lower than natural horseradish peroxidase $\left(7.7 \cdot 10^{7} \mathrm{M}^{-1} \mathrm{~s}^{-1}\right)$. Although the authors anticipated that the copper binding sites was the predicted triad (His67, His104, Asp131), it was unambiguously demonstrated that the catalytically active copper center was bound to only two histidine residues (i.e. $\mathrm{H} 67$ and $\mathrm{H} 104$ ). These results were validated by $\mathrm{X}$-ray, EPR and mutagenesis studies.

Scheme 75. A single point mutation of 6-phosphogluconolactonase yields a facial triad (H67-H104-N131D). Addition of $\mathrm{CuSO}_{4}$ leads to an artificial peroxidase. ${ }^{401}$ a) A colorimetric assay was applied to quantify the peroxidase activity of Cu-PGLac in the presence of $t-\mathrm{BuOOH} ; \mathrm{b})$ the crystal structure of the artificial peroxidase (PDB code 4tm7) highlights copper coordination to only two histidines $\mathrm{H} 67$ and $\mathrm{H} 104 ; \mathrm{c}$ ) mutagenesis highlights the requirement of both histidines but not of the aspartate D121.

a)<smiles>COc1cc(-c2ccc(N)c(OC)c2)ccc1N</smiles>
$25^{\circ} \mathrm{C}$

b)

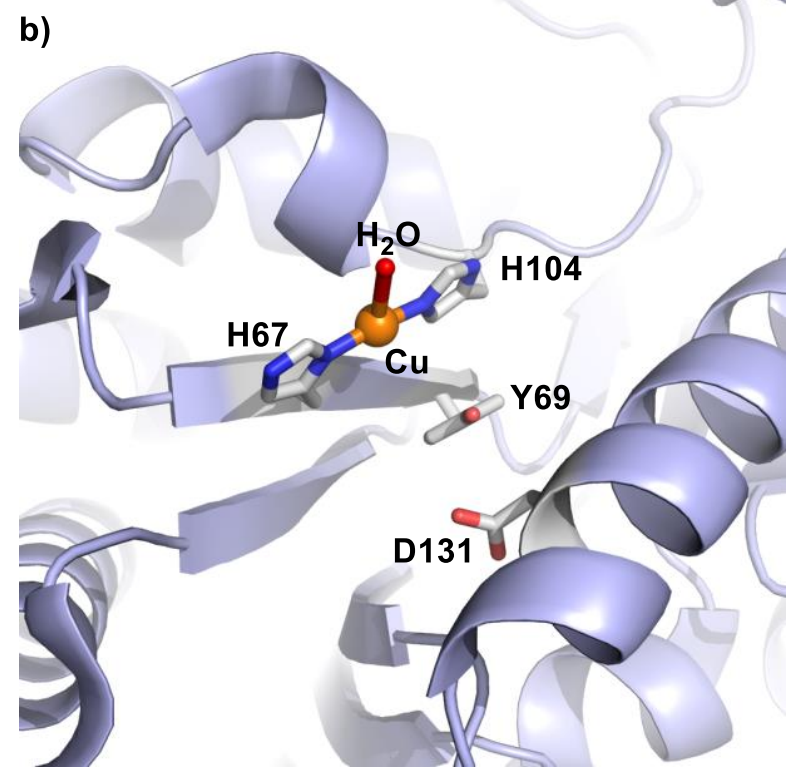

c)

\begin{tabular}{lc} 
Enzyme & $k_{\text {cat }} / K_{\mathrm{M}} \times 10^{3}\left(\mathrm{M}^{-1} \mathrm{~s}^{-1}\right)$ \\
\hline Cu-6-PGLac & \\
WT & 6.9 \\
H67F & N.D. \\
H104F & N.D. \\
D131A & 7.7 \\
Horseradish Peroxidase & 71000
\end{tabular}

In addition to supramolecular anchoring and dative anchoring, a non-natural ligand was directly introduced into the amino acid sequence. In 2008, Schultz and Lee incorporated 
the unnatural amino acid (2,2'-bipyridine-5-yl)alanine (Bpy-Ala, 237, Figure 27) into the catabolite activator protein (CAP), a dsDNA binding protein of E. coli (Figure 27). ${ }^{402}$ The engineered construct (CAP K26Bpy-Ala) showed a high affinity towards a 50-bp doublestranded DNA containing the 22-bp CAP recognition sequence $\left(K_{d}=1.90 \mathrm{nM}\right.$ vs. 0.85 $\mathrm{nM}$ for the wild type CAP). In the presence of $\mathrm{Cu}(\mathrm{II})$ or $\mathrm{Fe}(\mathrm{II})$, cAMP and 3mercaptopropionic acid or ascorbic acid as a reducing agent, site specific DNA cleavage activity was observed. Thus, a DNA binding protein was repurposed into an artificial metalloenzyme. Additional DNA-cleaving ArMs are summarized in section 6.8.

a)

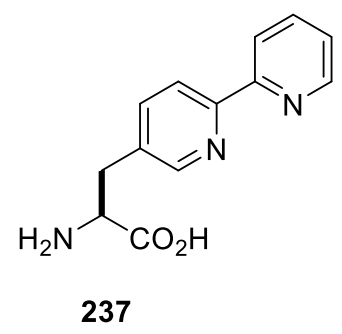

b)

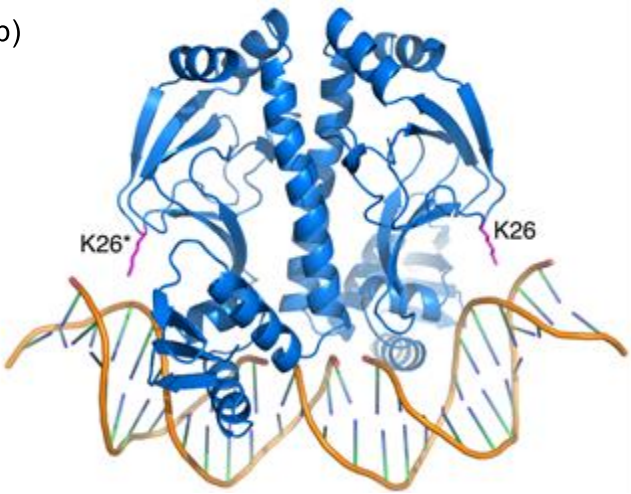

Figure 27: The unnatural metal binding amino acid (2,2'-bipyridine-5-yl)alanine (Bpy-Ala 237) was introduced in artificial zinc-finger domains. a) Structure of Bpy-Ala. b) Catabolite activator protein CAP (PDB code 2CGP) was mutated to bear Bpy-Ala in position 26. Upon addition of $\mathrm{Cu}^{2+}$ or $\mathrm{Fe}^{2+}$ and a reducing agent cleavage of the DNA substrate was achieved.

\subsection{Sulfoxidation}

Enantiopure sulfoxides are important building blocks for organic synthesis and have found applications as chiral auxiliaries and ligands in enantioselective catalysis. ${ }^{403-405}$ Enantioselective oxidation of sulfides has gained considerable attention as an easy way of generating enantiopure sulfoxides. ${ }^{404,}$, $406-407$ Most commonly used sulfoxidation catalysts rely on titanium, manganese, iron, or vanadium. ${ }^{404,408-409}$ The mechanism of asymmetric induction in these processes resembles that of several natural enzymes as 
the prochiral sulfide does not coordinate to the metal prior to oxidation. Instead, a metalactivated oxygen moiety (e.g. a metal-oxo, -peroxo, etc.) is delivered to a suitablypositioned sulfide. Accordingly, sulfoxidation is an attractive reaction to scrutinize the role of second coordination sphere interactions that could be imparted by a host protein containing a suitable sulfoxidation catalyst. In this context, the asymmetric sulfoxidation of thioanisole-type substrates has become a benchmark reaction to evaluate the performance of artificial sulfoxidases, Scheme 76. Most of the ArMs previously described for their peroxidase activity have also been tested as sulfoxidases.

Scheme 76. Thioanisole 27 is used as a benchmark substrate to evaluate the performance of artificial sulfoxidases. For reaction conditions and results, please refer to Table 32. 


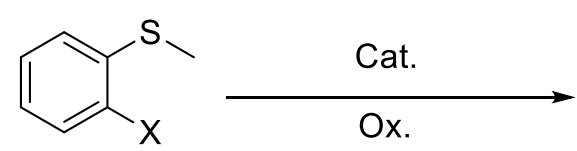

Sulfide

27: $X=H$

238: $X=\mathrm{Cl}$

239: $\mathrm{X}=\mathrm{Br}$

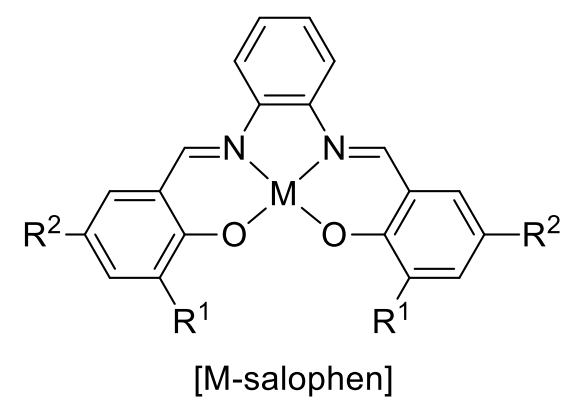

243: $M=C r, R^{1}=H, R^{2}=t-B u$

244: $M=M n, R^{1}=M e, R^{2}=H$

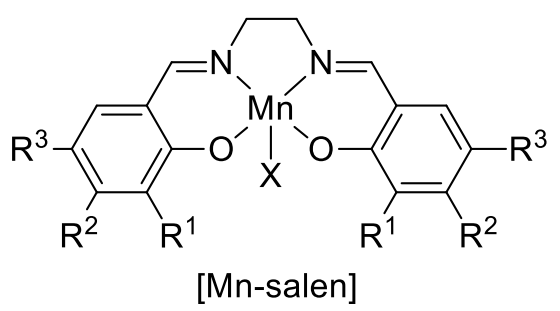

245: $R^{1}=M e, R^{2}=R^{3}=H$, no $X$ 246: $R^{1}=E t, R^{2}=R^{3}=H$, no $X$

247: $\mathrm{R}^{1}=n-\mathrm{Pr}, \mathrm{R}^{2}=\mathrm{R}^{3}=\mathrm{H}$, no $\mathrm{X}$

248: $X=B r, R^{2}=\left(\mathrm{CH}_{2}\right)_{3} \mathrm{SS}(\mathrm{O})_{2} \mathrm{Me}, \mathrm{R}^{1}=\mathrm{R}^{3}=\mathrm{H}$

249: $X=B r, R^{1}=R^{2}=R^{3}=H$

250: $X=\mathrm{Cl}, \mathrm{R}^{3}=\mathrm{COOH}, \mathrm{R}^{1}=\mathrm{R}^{2}=\mathrm{H}$

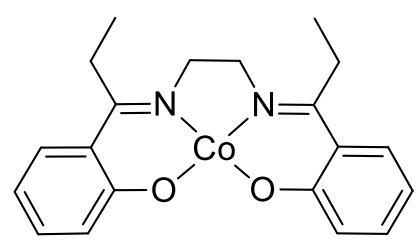

[Co-salen] 251<smiles>[X]c1ccccc1S(C)(=O)=O</smiles>

28

242

241

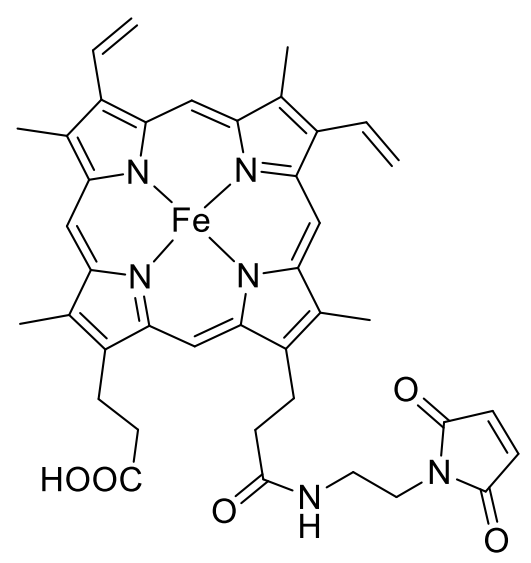

[Fe-Protoporphyrin IX] 252

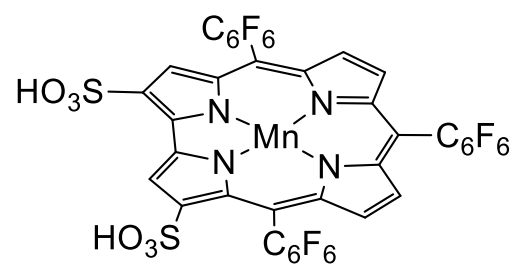

[Mn-corrole] 253

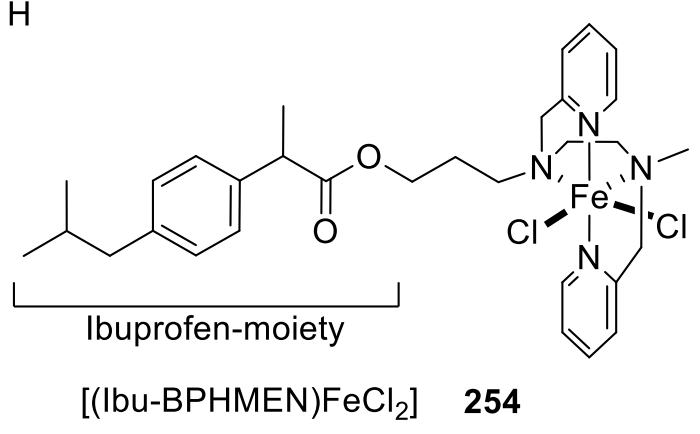

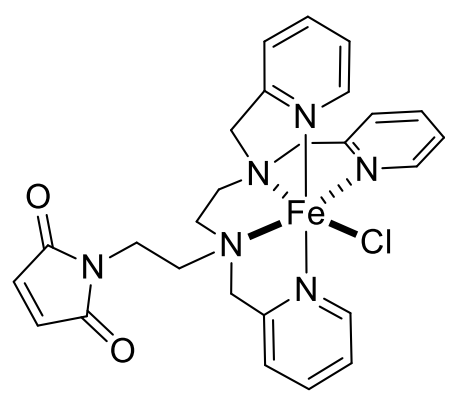

$\left[\mathrm{Fe}\left(\mathrm{M}-(\mathrm{Py}) \operatorname{en}(\mathrm{Py})_{2}\right)(\mathrm{L})\right] 255$ 
The first examples of ArM sulfoxidases were reported by the groups of Sheldon in 1998 and Keinan in 1999 (see chapter 3 and Table 32, entries 1-2), and a similar antibodybased strategy was later used by Mahy and coworkers. Among the hemoabzymes that were investigated, 217.Ab-3A3 displayed the highest peroxidase activity, Scheme 68. Mahy and coworkers later showed that this ArM catalyzes the sulfoxidation of thioanisole 27 in the presence of $\mathrm{H}_{2} \mathrm{O}_{2} \cdot{ }^{410}$ The ArM 217. Ab-3A3 performed better than 217 alone, with 82 and 38 TON respectively (Table 32, entries 3-4). The ArM was also more enantioselective, with $45 \%$ ee vs. $23 \%$ ee in favor of the $(R)-28$. Those results were obtained in presence of $5 \% t-\mathrm{BuOH}$, which significantly improved both activity and enantioselectivity of $\mathbf{2 1 7}$, with and without Ab-3A3.

The hemoabzymes with anti-estradiol antibodies were also tested for the sulfoxidation of thioanisole 27 in presence of $\mathrm{H}_{2} \mathrm{O}_{2}$. First, 220. Ab-7A3 was twice as active as $\mathbf{2 2 0}$ alone, and afforded (S)-28 with $8 \%$ ee. (Table 32, entries 5-6). ${ }^{386}$ Substitution of the $N$ methylpyridinium groups by $p$-sulfonatophenyl groups yielded an $25 \%$ less active artificial peroxidase affording similar enantioselectivity: up to $10 \%$ ee for $(S)-28 .{ }^{411}$ Upon incorporation of the sulfonated cofactor within neocarzinostatin (NCS), the enantioselectivity slightly increased (i.e. $13 \%$ ee), but was accompanied with a decrease in activity (i.e. 6 TON). ${ }^{412}$

Better results were obtained with the ArM resulting from incorporation of an iron porphyrin within xylanase, 213.XIn. Upon addition of exogeneous imidazole, 213.XIn afforded (S)-28 with up to 145 TON and $40 \%$ ee (Table 32, entries $7-8$ )..$^{413-414}$ The authors speculate that the added imidazole mimics the effect of an axial histidine on catalysis, reminiscent of the activity observed with $217 \cdot A b-3 A 3$. In summary, 213.XIn and 217.Ab-3A3 are the most active and enantioselective artificial sulfoxidases reported by the Mahy group and display enantioselectivities of $40 \%$ ee $(S)-\mathbf{2 8}$ and $45 \%(R)-\mathbf{2 8}$, respectively. 
Watanabe, Ueno and coworkers reported the formation of an ArM sulfoxidase by incorporating an Fe-porphyrin cofactor into a (gp27-gp5) 3 ( $\mathrm{gp}=$ gene product) scaffold from bacteriophage T4. The structure of this protein consists of a $\beta$-helical needle made of the gp5 trimer and a cup-shaped structure composed of the gp27 trimer. A cysteine residue was introduced at the bottom of the cup to react with a maleimide moiety of FePPIX 252 (Scheme 76 and Figure 12). ${ }^{415}$ The oxidation of the thioanisole 27 was investigated in the presence of hydrogen peroxide. The catalytic efficiency was enhanced tenfold in the presence of (gp27-gp5)3, compared to the free cofactor 252 (Table 32, entries 9-10), which was attributed to the hydrophobic environment of the cup structure.

ArM sulfoxidases have also been generated using metal-salen and -salophen cofactors. For example, Watanabe and coworkers reconstituted myoglobin (Mb) with various Schiff-base complexes, ${ }^{328}$ including Cr-salophen 243, which has a similar size and shape to the native Fe-PPIX cofactor (222) of Mb. The reconstituted Mb ArM catalyzed the enantioselective oxidation of thioanisole 27 (Scheme 76). Mutations H64D and A71G were introduced into the Mb scaffold to improve substrate access to the active site and to improve the affinity for $\mathbf{2 4 3}$, respectively. The resulting ArM oxidized thioanisole $\mathbf{2 7}$ in the presence of hydrogen peroxide to afford $\mathbf{2 8}$ with $13 \%$ ee (Table 32, entries 11-12). A crystal structure of $244 \cdot \mathrm{Mb} A 71 \mathrm{G}$ was obtained, and based on this structure, the salophen ligand was replaced with a salen ligand to create a larger substrate access pathway. ${ }^{416}$ Modeling suggested that the location of the metal complex in Mb depends on the nature of the 3,3'-substituents of the salen moiety. Gratifyingly, the enantioselectivity for the thioanisole $\mathbf{2 7}$ oxidation was indeed influenced by the nature of the complexes 245-247. The highest ee (32\%) was obtained with 245.Mb (Table 32, entry 13). 
Lu later reported on a dual anchoring strategy to fix the orientation of a $\mathrm{Mn}$ (salen) cofactor bearing two methane thiosulfonate groups $(\mathbf{2 4 8}$, Scheme $\mathbf{7 6})$ within an apo myoglobin scaffold containing two cysteine mutations L72C-Y103C (Figure 15). The resulting ArM catalyzed the sulfoxidation of thioanisole with higher enantioselectivity (51\% ee) than an analogous system with only one anchoring point $M b(Y 103 C)$ (Table 32, entries 14-15). ${ }^{329}$ In both of these systems, sulfoxidation was accompanied by overoxidation to the corresponding sulfone 242. By selecting alternate anchoring sites within Mb T39C-L72C, Lu also showed that the chemoselectivity of the ArMs could be enhanced. ${ }^{330}$ Increased activity (52\% yield), enantioselectivity $(60 \%$ ee), and chemoselectivity ( $100 \%$ sulfoxide) were obtained for reactions catalyzed by $\mathbf{2 4 8} \cdot \mathrm{Mb}$ T39C-L72C (Table 32, entry 16). Subsequent studies on this system suggested that polar residues in the ArM active site led to its improved activity, and the need for substrates to enter the active site via a hydrophobic region of the scaffold was believed to favor entry of sulfide over sulfoxide to impart chemoselectivity. In addition, residues in the secondary coordination sphere of the ArM active site were shown to impact the $\mathrm{pH}$ dependence of ArM catalysis relative to cofactor alone. ${ }^{417}$

In 2009, Ménage and coworkers inserted Mn-salen complexes (250, Scheme 76 ) into human serum albumin (HSA hereafter) to catalyze the oxidation of sulfide $\mathbf{2 7}$ to the corresponding sulfoxide $28 .{ }^{418}$ Serum albumins have been used in the past as host to catalyze a variety of reactions. ${ }^{27,91,93}$ The choice of HSA as a host for ArM formation was based on its ability to bind a variety of small hydrophobic molecules. Indeed, facile ArM formation was realized by incubating HSA with one equivalent of cofactor 250 , and 1:1 HSA:250 binding stoichiometry was observed $\left(K_{D}=8 \mu \mathrm{M}\right)$. The resulting ArM catalyzed the oxidation of $\mathbf{2 7}$ in the presence of aqueous $\mathrm{NaOCl}(2 \mathrm{eq})$ at $\mathrm{pH} 5.2$ to provide a mixture of sulfoxide $28(7 \%)$ and sulfone $242(31 \%)$. The free Mn-salen complexes afforded almost exclusively the sulfone 242 (60\%). When combined with 
HSA, however, the resulting ArM (250.HSA) led to formation of sulfoxide $\mathbf{2 8}$ exclusively (97\%, i.e. 97 TON) (Table 32, entry 17), although racemic product was obtained. No catalysis was observed when hydrogen peroxide was used instead of hypochlorite, and addition of excess $\mathbf{2 5 0}$ relative to BSA led to decreased chemoselectivity. Interestingly, the ArM remained efficient (i.e. $95 \%$ conversion) and chemoselective (i.e. $92: 3$ ratio for 28 : 242) upon recycling the ArM up to four times. In contrast, HSA alone lost its selectivity upon recycling. In the absence of cofactor, HSA is unspecifically oxidized by $\mathrm{HOCl}$ as confirmed by SDS-PAGE, which led to a gradual erosion of the chemoselectivity.

Liang and coworkers also developed an artificial sulfoxidase by incorporating a cobaltsalen cofactor into a serum albumin scaffold,. ${ }^{419}$ 251.BSA (Scheme 76) achieved 98 TON for the sulfoxidation of thioanisole 27 with up to $50 \%$ ee in favor of the $(R)-28$ (Table 32, entry 18). Improved enantioselectivity was obtained with substrate 238 : up to $87 \%$ ee was obtained for $(R)-240$ (Table 32 , entry 19 ). Unfortunately, the increase in enantioselectivity was accompanied with a loss of activity and chemoselectivity (sulfoxide vs sulfone).

Mn-corroles have also been combined with serum albumins to afford ArM sulfoxidases. In 2005, Gross and coworkers inserted a sulfonated manganese corrole 253 within various serum albumins, Scheme 76 . Human serum albumin was shown to bind 253 with a dissociation constant in the nanomolar range. In terms of catalysis, however, the best results were obtained with bovine serum albumin (BSA). In presence of hydrogen peroxide, 253·BSA achieved 42 TON for thioanisole 27 sulfoxidation, with up to $52 \%$ ee in favor of the (S)-28 (Table 32, entry 20). The enantioselectivity increased with 0 halogen-bearing substrates albeit at the cost of reduced activity: sulfoxidation of 2bromo-thioanisole 239 proceeded in $74 \%$ ee (S)-241 but only 8 TON (Table 32, entry 21). The iron-containing corrole was also tested, but the corresponding ArMs had lower 
activity and selectivity. These same authors later evaluated ArMs generated from incorporation of metal-corrole complexes into other serum albumins. Interestingly, 253.RSA (rabbit serum albumin) was used to complete the synthesis of armodafinil 257 , a FDA-approved eugeroic drug: up to $70 \%$ ee $(R)-257$ could be achieved (Scheme 77 and Table 32, entry 22). ${ }^{420}$

Scheme 77. Binding of a Mn-corrole to various serum albumins afford an artificial sulfoxidases for armodafinil synthesis.

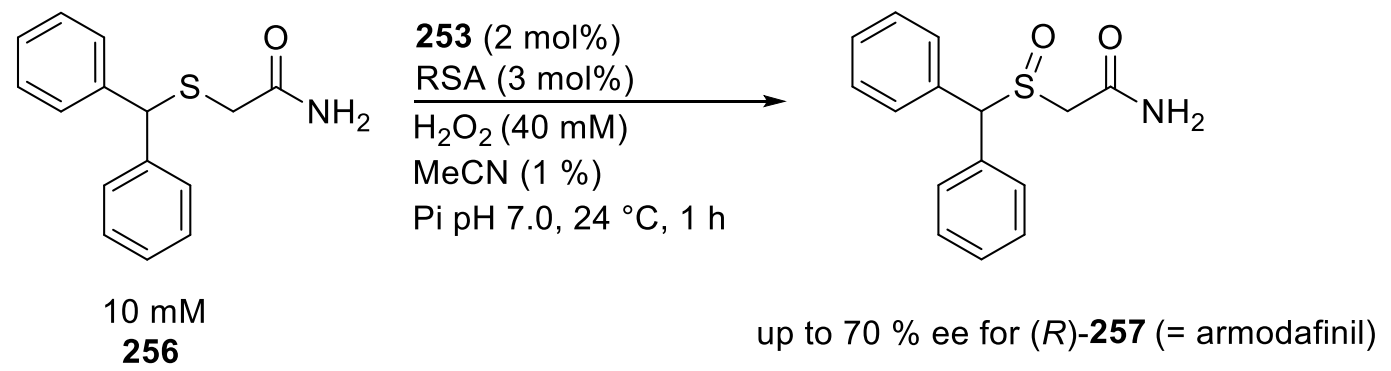

Building on the 253.BSA ArM reported by Gross and coworkers, Mahy and Gross later reported an ArM sulfoxidase that used water as an oxygen source. ${ }^{421-422}$ Upon irradiation, a $\left[\mathrm{Ru}(\mathrm{bpy})_{3}\right]^{2+}$-photosensitizer sequentially abstracts two electrons from $\left[\mathrm{Mn}(\mathrm{III})(\right.$ Corrole $\left.)\left(\mathrm{OH}_{2}\right)\right] 253$ to yield $[\mathrm{Mn}(\mathrm{V})($ Corrole $)(\mathrm{O})]$ in the presence of $\left[\mathrm{Co}(\mathrm{III})\left(\mathrm{NH}_{3}\right)_{5} \mathrm{Cl}\right]^{2+}$ as an electron acceptor. The active $[\mathrm{Mn}(\mathrm{V})($ Corrole $)(\mathrm{O})]$ transfers its oxygen to thioanisole 27 . Isotope-labeling confirmed that water is indeed the oxygen source in the sulfoxide 28 (21 TON $16 \%$ ee $(R)$-28, Table 32, entry 23). Strinkingly, when $\mathrm{H}_{2} \mathrm{O}_{2}$ was used as oxidant in the presence of 253.BSA, the opposite enantiomer (S)-28 was produced. This clearly demonstrates that, depending on the oxidant, that the active species are not identical. ${ }^{421}$

Ward and coworkers investigated the propensity of vanadyl-loaded Sav to promote the asymmetric sulfoxidation of aryl-alkyl thioethers. ${ }^{423}$ In the presence of the Sav scaffold (twofold excess of biotin-binding sites vs. $\mathrm{VO}^{2+}$ ), vanadate sulfoxidase activity increased from 28 to 50 TON for thioanisole 27 (Scheme 78 and Table 32, entries 24 and 26). The 
Sav scaffold a $46 \%$ ee in favor of $(R)-28$. While the $\mathrm{VO}^{2+}$ source did not influence the reaction, the oxidizing agent had a dramatic influence on the observed enantioselectivity. Only $t$ - $\mathrm{BuOOH}$ afforded high activity and enantioselectivity, while $\mathrm{H}_{2} \mathrm{O}_{2}$ afforded (rac)-28 and cumylhydroperoxide yielded the opposite enantiomer (S)-28 (15\% ee). Electron-rich aromatic thioethers yielded good to very good enantioselectivities: $(R)-258$ and $(R)-259$ were produced in 90 and $93 \%$ ee respectively (Table 32, entries 27-28). Dialkyl thioethers 260 and 261 afforded moderate ee. In the presence of biotin, no enantioselectivity was obtained, suggesting that the vanadyl moiety is located within the biotin-binding site. This assumption was confirmed upon mutation of biotin-binding key residue Sav D128A to afford rac-28. The X-band EPR signal obtained with complex $\mathrm{VO}\left(\mathrm{H}_{2} \mathrm{O}\right)_{5} \cdot \mathrm{Sav}$ is very similar to the free $\mathrm{VO}\left(\mathrm{H}_{2} \mathrm{O}\right)_{5}$, suggesting that the protein interacts with the complex only via second coordination sphere interactions. It is interesting to note that, despite the poorly defined localization of the vanadyl moiety within Sav, the resulting sulfoxidase affords very good enantioselectivities, highlighting the flexibility of this facinating protein scaffold.

Scheme 78. Incorporation of $\mathrm{VOSO}_{4}$ within Sav affords an artificial sulfoxidase. Adapted with permission from ref. ${ }^{423}$ Copyright 2016 American Chemical Society.
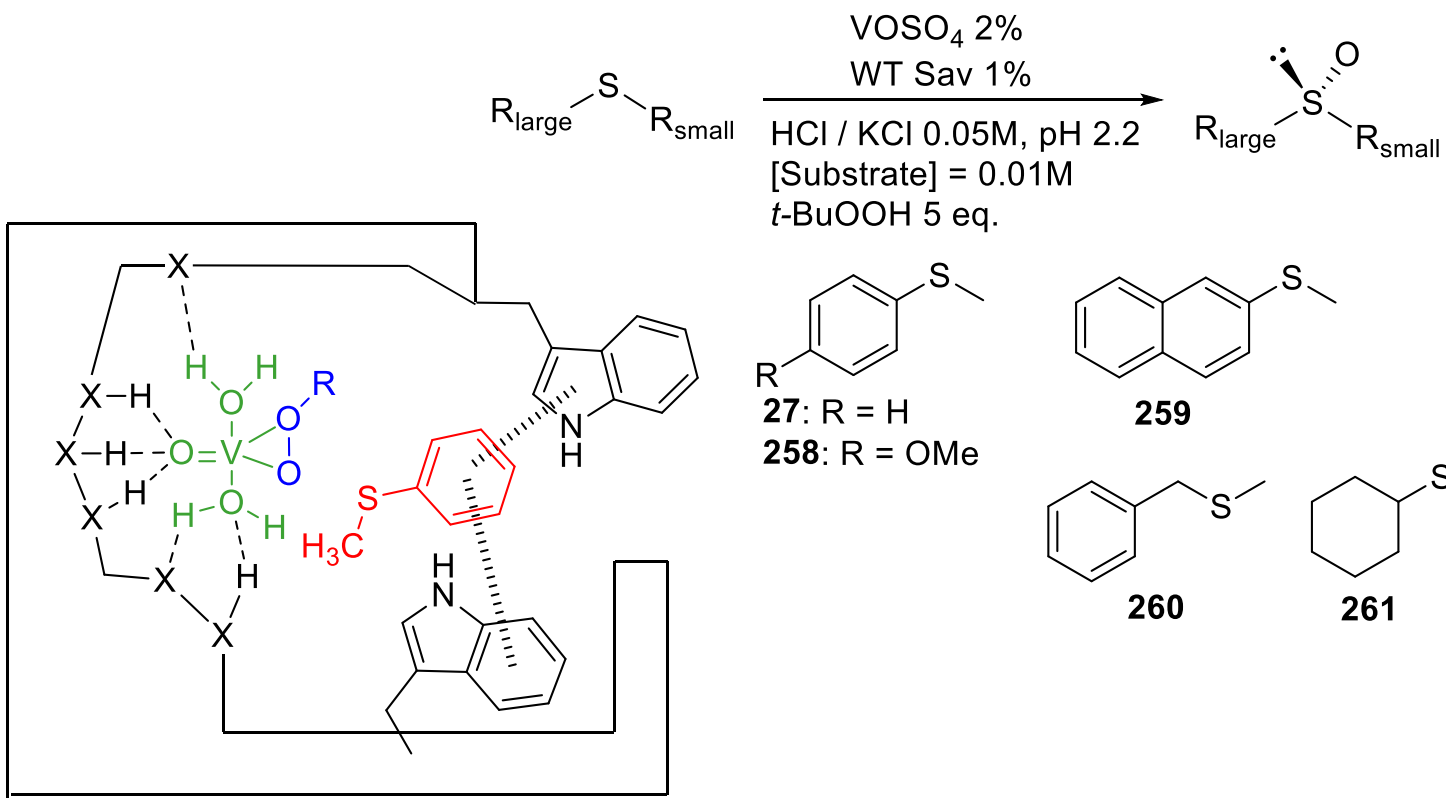<smiles>[R]c1ccc(SC)cc1</smiles>

27: $\mathrm{R}=\mathrm{H}$

258: $R=O M e$<smiles>CSc1ccc2ccccc2c1</smiles>

259<smiles>CSCc1ccccc1</smiles>

260<smiles>CSC1CCCCC1</smiles>

261 
Artificial sulfoxidases based on non-porphyrin iron complexes have been investigated by Ménage and coworkers. For example, Fe complexe 268 (Scheme 79) was incorporated into NikA, a periplasmic nickel-binding protein. ${ }^{424}$ Ménage and coworkers had previously reported on the incorporation of small iron complexes into the pocket of NikA: they characterized the complex.protein assembly as well as investigated the iron-mediated oxygen insertion in an aromatic $\mathrm{C}-\mathrm{H}$ bond of the ligand. ${ }^{425-426}$ The affinity of these complexes for NikA lies in the $\mu \mathrm{M}$ range. Based on the structure of the ArM, docking simulations of various substrates into the cofactor-loaded cavity were performed. The substrates evaluated all contained an $\mathrm{R} 1-\mathrm{S}-\mathrm{CH}_{2}-\mathrm{X}$ moiety. The main selection criterion was the $\mathrm{Fe} \cdots . . \mathrm{S}$ distance, to favour an $\mathrm{Fe} \cdots . . . . \mathrm{S}$ transition state. The docking revealed that a family of molecules, containing an $\mathrm{R}_{1}-\mathrm{S}-\mathrm{CH}_{2}-\mathrm{C}(\mathrm{O})-\mathrm{NH}-\mathrm{R}_{2}$ motif $\left(\mathrm{R}_{1}, \mathrm{R}_{2}\right.$ aromatic groups), met this criterion. The simplest molecule, with $\mathrm{R}_{1}=3$-amino-phenyl and $R_{2}=$ a-naphthyl, was selected as the starting point for substrate design. This skeleton is reminiscent of omeprazole and modafinil, drugs containing an enantiopure sulfoxide moiety (Scheme 79). In the absence of protein, oxidation of 262 yielded neither sulfoxide 264 nor sulfone. Instead, the dichlorinated sulfoxide species 265 was isolated. When 268. NikA was added to a reaction mixture containing sulfide 262 (in a ratio ArM:substrate: $\mathrm{NaOCl} 1: 255: 600)$, it afforded $173 \mathrm{TON}$ in $4 \mathrm{~h}$ and a selectivity of $87 \%$ in favor of sulfoxide $\mathbf{2 6 4}$ of (Table 32, entry 29). 268. NikA displayed the highest TOF (43 h1). Under similar conditions, sulfide 263 was selectively converted into sulfoxide with TON = 199 (Table 32, entry 30). Unfortunately these ArMs displayed only very modest enantioselectivity (i.e. $\leq 10 \%$ ).

Scheme 79. Inserting iron complexes 268 into NikA yields an artificial sulfoxidase. 
<smiles>[R]NC(=O)CS[R]</smiles>

$9.4 \mathrm{mM}$

262

263

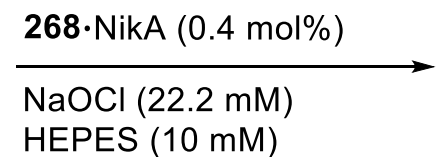

$\mathrm{pH} 7.0$, r.t., $4 \mathrm{~h}$ $\begin{array}{ll}\mathrm{R}_{1} & \mathrm{R}_{2} \\ 4-\mathrm{AcNH}-\mathrm{Ph} & \mathrm{Ph}\end{array}$ 4-Me-Ph

$\mathrm{Ph}$<smiles>[R2][R7]S(=O)C(Cl)(Cl)C(=O)N[R2]</smiles>

Sulfoxide dichlorinated
sulfoxide

$26469 \%$ $26678 \%$

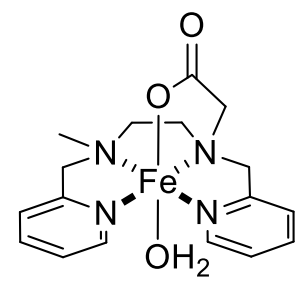

268

The same group subsequently reported another artificial sulfoxidase based on the supramolecular anchoring of 254 in human serum albumin (HSA). ${ }^{427}$ To ensure a more defined localization within HSA, a "Trojan horse" known to interact specifically with HSA was used. The authors functionalized the abiotic cofactor [Fe(BPHMEN) $\left.\mathrm{Cl}_{2}\right]$ with an ibuprofen anchor, resulting in $\mathbf{2 5 4}$, Scheme 76 . Ibuprofen is known to bind to HSA preferentially in its "drug site 2" (IIIA domain). Correspondingly, 254 binds HSA with a $\sim 27 \mu \mathrm{M}$ affinity to afford 254.HSA. When thioanisole 27 was dissolved in an acetatebuffered solution ( $\mathrm{pH} 5.2,2.4$ equ. $\mathrm{NaOCl}$ ), no oxidation was detected. If 254 alone was used, the sulfone 242 was produced exclusively ( $97 \%$ yield). When HSA alone was used as catalyst, a mixture of sulfoxide 28 and sulfone 242 were produced in $45 \%$ and $12 \%$ yield respectively. In the presence of $254 \cdot \mathrm{HSA}$, the sulfoxide 28 and the sulfone 242 were produced in $62 \%$ and $10 \%$ yield respectively. Upon lowering the temperature to $4^{\circ} \mathrm{C}, 1367 \mathrm{TON}$ were obtained with $254 \cdot \mathrm{HSA}$, (TOF $=459 \mathrm{~min}^{-1}$, Table 32, entry 31). The main advantage brought by the incorporation of the cofactor into HSA was the stability and recyclability of the ArM: after four rounds of catalysis, 254.HSA maintained its chemoselectivity for $\mathbf{2 8}$. In contrast, HSA gradually lost its activity and selectivity upon 
recycling. 418 Despite the better defined localization of the cofactor within HSA, no enantioselectivity was observed for the sulfoxidation.

Finally, the groups of Mahy and Banse explored a covalent anchoring strategy for the generation of an artificial non-heme ArM sulfoxidase. $\beta$-lactoglobulin ( $\beta$-LG) was used as a scaffold to covalently anchor the iron-cofactor 255 to Cys 121 , Scheme $76 .{ }^{428}$ This ArM catalyzed the sulfoxidation of thioanisole, with a TON $=2.8$. Starting at $20 \%$ ee in favour of $(R)-28$, the selectivity eroded over the course of the reaction, suggesting a denaturation of the ArM.

Table 32. Selected results for artificial sulfoxidases.

\begin{tabular}{|c|c|c|c|c|c|c|c|c|c|c|c|c|}
\hline Ent. & Cof. & Protein & Sub. & Ox. & $\mathrm{pH}$ & $\begin{array}{c}\mathrm{T} \\
\left({ }^{\circ} \mathrm{C}\right)\end{array}$ & $\begin{array}{l}{[\mathrm{Cof}]} \\
(\mu \mathrm{M})\end{array}$ & $\begin{array}{l}\text { [Ox.] } \\
(\mathrm{mM})\end{array}$ & $\begin{array}{c}e e \\
(\%)\end{array}$ & $\begin{array}{l}\text { TON } \\
(\mathrm{t} / \mathrm{h})\end{array}$ & $\begin{array}{l}\text { TOF } \\
\left(\mathrm{s}^{-1}\right)\end{array}$ & Ref \\
\hline 1 & 269 & Phytase & 27 & $\mathrm{H}_{2} \mathrm{O}_{2}$ & & & 10 & & $66(S)$ & $550(3)$ & & 148 \\
\hline 2 & $\begin{array}{l}\text { TCPP- } \\
\text { Ru(II)- } \\
\text { CO }\end{array}$ & Ab-SN37.4 & 27 & PhlO & 9.0 & 4 & 0.5 & 0.5 & $43(S)$ & $\sim 750$ & & 155 \\
\hline 3 & 217 & - & 27 & $\mathrm{H}_{2} \mathrm{O}_{2}$ & 7.5 & r.t. & 0.3 & 0.05 & $23(R)^{\mathrm{a}}$ & $38(1.5)^{a}$ & & 410 \\
\hline 4 & 217 & $A b-3 A 3$ & 27 & $\mathrm{H}_{2} \mathrm{O}_{2}$ & 7.5 & r.t. & 0.3 & 0.05 & $45(R)^{\mathrm{a}}$ & $82(1.5)^{a}$ & & 410 \\
\hline 5 & 220 & $A b-7 A 3$ & 27 & $\mathrm{H}_{2} \mathrm{O}_{2}$ & 4.4 & r.t. & 5 & 0.25 & - & $5.6(2.6)$ & & 386 \\
\hline 6 & 220 & $A b-7 A 3$ & 27 & $\mathrm{H}_{2} \mathrm{O}_{2}$ & 4.4 & r.t. & 5 & 0.25 & $8(S)$ & $12(2.6)$ & & 386 \\
\hline 7 & 213 & - & 27 & $\mathrm{H}_{2} \mathrm{O}_{2}$ & 7.4 & r.t. & 20 & 3.5 & - & $162(2.3)^{b}$ & & 414 \\
\hline 8 & 213 & $X \ln$ & 27 & $\mathrm{H}_{2} \mathrm{O}_{2}$ & 7.4 & r.t. & 20 & 3.5 & $40(S)$ & $145(2.3)^{b}$ & & 414 \\
\hline 9 & 252 & - & 27 & $\mathrm{H}_{2} \mathrm{O}_{2}$ & 8.0 & 18 & 2 & 0.5 & - & & 0.0006 & 415 \\
\hline 10 & 252 & $(\mathrm{gp} 27-\mathrm{gp} 5)_{3}$ & 27 & $\mathrm{H}_{2} \mathrm{O}_{2}$ & 8.0 & 18 & 2 & 0.5 & - & & 0.0062 & 415 \\
\hline 11 & 243 & - & 27 & $\mathrm{H}_{2} \mathrm{O}_{2}$ & 5.0 & 35 & 10 & 1 & - & & 0.0002 & 328 \\
\hline 12 & 243 & $\begin{array}{l}\mathrm{Mb}(\mathrm{H} 64 \mathrm{D}- \\
\text { A71G) }\end{array}$ & 27 & $\mathrm{H}_{2} \mathrm{O}_{2}$ & 5.0 & 35 & 10 & 1 & $13(S)$ & & 0.001 & 328 \\
\hline 13 & 245 & $\begin{array}{l}\text { Mb (H64D- } \\
\text { A71G) }\end{array}$ & 27 & $\mathrm{H}_{2} \mathrm{O}_{2}$ & 5.0 & 35 & 10 & 1 & $32(S)$ & & 0.008 & 416 \\
\hline 14 & 249 & - & 27 & $\mathrm{H}_{2} \mathrm{O}_{2}$ & 7.0 & 4 & 500 & 10 & - & $1.9(0.17)$ & & 330 \\
\hline 15 & 248 & $\begin{array}{l}\mathrm{Mb}(\mathrm{L} 72 \mathrm{C} / \\
\mathrm{Y} 103 \mathrm{C})\end{array}$ & 27 & $\mathrm{H}_{2} \mathrm{O}_{2}$ & 5.1 & 4 & 130 & 6.5 & $51(S)$ & & 0.007 & 329 \\
\hline 16 & 248 & $\begin{array}{c}\mathrm{Mb}(\mathrm{T} 39 \mathrm{C} / \\
\text { L72C) }\end{array}$ & 27 & $\mathrm{H}_{2} \mathrm{O}_{2}$ & 7.0 & 4 & 500 & 10 & 60 & $5(0.17)$ & & 330 \\
\hline 17 & 250 & HSA & 27 & $\mathrm{NaOCl}$ & 5.2 & r.t. & 12.5 & 2.5 & - & $97(0.17)$ & & 418 \\
\hline 18 & 251 & BSA & 27 & $\mathrm{H}_{2} \mathrm{O}_{2}$ & 5.1 & 0 & 2.7 & 0.4 & $50(R)$ & $98(20)$ & & 419 \\
\hline 19 & 251 & BSA & 238 & $\mathrm{H}_{2} \mathrm{O}_{2}$ & 5.1 & 0 & 2.7 & 0.4 & $87(R)$ & $19(20)$ & & 419 \\
\hline 20 & 253 & BSA & 27 & $\mathrm{H}_{2} \mathrm{O}_{2}$ & 7.0 & 24 & 200 & 15 & $52(S)$ & $42(1.5)$ & & 421 \\
\hline 21 & 253 & BSA & 239 & $\mathrm{H}_{2} \mathrm{O}_{2}$ & 7.0 & 24 & 200 & 15 & $74(S)$ & $8(1.5)$ & & 421 \\
\hline 22 & 253 & RSA & 256 & $\mathrm{H}_{2} \mathrm{O}_{2}$ & 7.0 & r.t. & 200 & 40 & $70(R)$ & $45(1)$ & & 420 \\
\hline 23 & 253 & BSA & 27 & $\mathrm{PS} / \mathrm{hv}^{\mathrm{c}}$ & 7.4 & r.t. & 50 & - & $16(R)$ & $21(0.2)$ & & 422 \\
\hline 24 & - & WT Sav & 27 & $\mathrm{tBuOOH}$ & 2.2 & r.t. & 200 & 50 & $4(R)$ & $3.5(4)$ & & 423 \\
\hline 25 & {$\left[\mathrm{VO}^{2+}\right.$} & - & 27 & $\mathrm{tBuOOH}$ & 2.2 & r.t. & 200 & 50 & - & $27.5(4)$ & & 423 \\
\hline 26 & {$[\mathrm{VO}]^{2+}$} & WT Sav & 27 & $\mathrm{tBuOOH}$ & 2.2 & r.t. & 200 & 50 & $46(R)$ & $47(4)$ & & 423 \\
\hline 27 & {$[\mathrm{VO}]^{2+}$} & WT Sav & 258 & $\mathrm{tBuOOH}$ & 2.2 & r.t. & 200 & 50 & $90(R)$ & $50(4)$ & & 423 \\
\hline 28 & {$[\mathrm{VO}]^{2+}$} & WT Sav & 259 & $\mathrm{tBuOOH}$ & 2.2 & r.t. & 200 & 50 & $93(R)$ & $26.5(4)$ & & 423 \\
\hline 29 & 268 & NikA & 262 & $\mathrm{NaOCl}$ & 7.0 & r.t. & 37 & 22.2 & $\leq 10$ & $173(4)$ & 0.012 & 424 \\
\hline 30 & 268 & NikA & 263 & $\mathrm{NaOCl}$ & 7.0 & r.t. & 37 & 22.2 & $\leq 5$ & $199(4)$ & & 424 \\
\hline 31 & 254 & HSA & 27 & $\mathrm{NaOCl}$ & 5.2 & r.t. & 38 & 45.7 & - & 1367 & 7.65 & 427 \\
\hline
\end{tabular}




\subsection{Alcohol Oxidation}

Numerous natural enzymes, including laccases, glucose oxidases, and alcohol dehydrogenases, catalyze the oxidation of alcohols. ${ }^{429}$ Alcohol dehydrogenases are highly active and enantioselective $\mathrm{NAD}(\mathrm{P}) \mathrm{H}$-dependent enzymes, but they often possess a narrow substrate scope. $\mathrm{NAD}(\mathrm{P}) \mathrm{H}$ cofactor recycling is an important economic issue and can be achieved by enzymatic and non-enzymatic systems. Homogenous catalysts are of course widely used for alcohol oxidation. ${ }^{430}$ Transition metal complexes of ruthenium, palladium, or copper in combination with TEMPO/dioxygen or a peroxide such as $\mathrm{H}_{2} \mathrm{O}_{2}$ or $t-\mathrm{BuOOH}$ are typically used for alcohol oxidation. Artificial metalloenzymes are potentially an attractive alternative for enantioselective alcohol oxidation. As elegantly demonstrated by Noyori, a pianostoolbased asymmetric transfer hydrogenation catalyst, can act either in the reduction- or in the oxidation-direction, depending on the hydride donor : hydride acceptor ratio. ${ }^{431}$ This is reminiscent of natural alcohol dehydrogenases.

To mimic such systems, Ward and coworkers investigated whether biotinylated transition metal pianostool complexes anchored within Sav could catalyze the (asymmetric) oxidation of primary and secondary aromatic alcohols. ${ }^{432}$ Of the four biotinylated piano stool transition metal complexes tested $\left[\eta^{6}\right.$-(benzene) $\left.\mathrm{Ru}(\mathbf{7 0}) \mathrm{Cl}\right]$ displayed highest activity for the oxidation of phenethyl alcohol into acetophenone (200 TON) upon incorporation into WT Sav. On the other hand, no hydride acceptor (electrondeficient ketones, quinones etc.) proved efficient for the oxidation of phenetyl alcohol: only $t$ - $\mathrm{BuOOH}$ led to oxidation, suggesting an alternative mechanism, different from the widely accepted concerted proton and hydride transfer via a six-membered transition state. $^{431}$ 


\subsection{Epoxidation}

Olefin epoxidation is a powerful approach for introducing oxygen atoms into organic compounds due the stereospecificity of this reaction and the potential for subsequent ring opening reactions of epoxides. ${ }^{433}$ While a wide range of olefin epoxidation catalysts have been developed, ${ }^{434}$ high levels of enantioselectivity remain challenging for a number of olefin classes. ${ }^{435}$ Several different ArMs have therefore been explored with the hope of controlling epoxidation selectivity.

For example, Kazlauskas ${ }^{436}$ and Soumillion ${ }^{437}$ independently reported that the active site $\mathrm{Zn}$ of carbonic anhydrase could be replaced with $\mathrm{Mn}$ to generate artificial epoxidases. Specifically, incubating apo hCA II with $\mathrm{Mn}$ (II) salts (chloride or acetate) led to the formation of an hCA.Mn ArM that catalyzed the epoxidation of styrenes in the presence of hydrogen peroxide with a moderate conversion and enantioselectivity (up to $67 \%$ ee). The Kazlauskas system also provided modest enantioselectivity $(52 \%$ ee) on an aliphatic olefin, albeit with low conversion (Scheme 80).

Scheme 80. Epoxidation catalyzed by Mn-substituted hCA II.

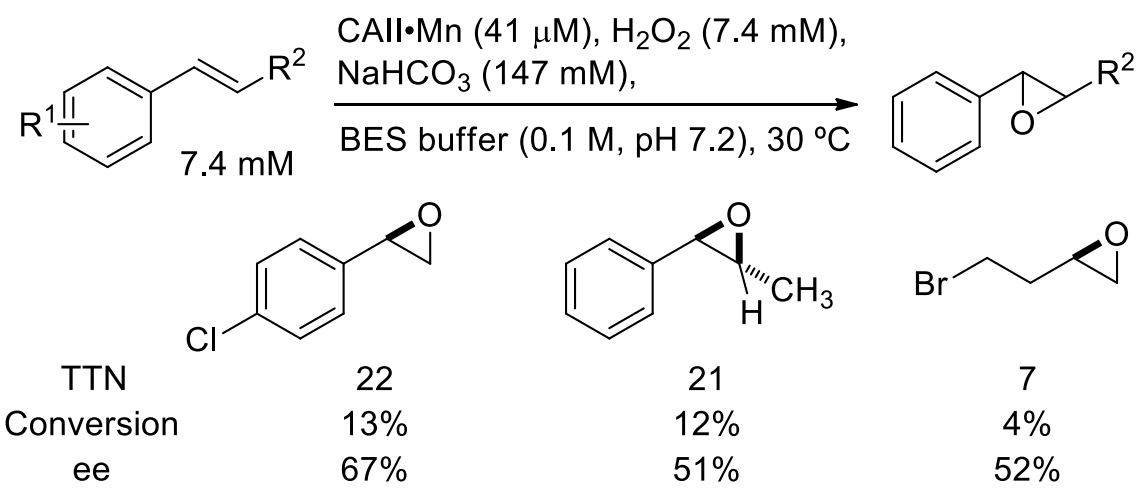

Manganese complexes with multidentate nitrogen ligands are robust catalysts for a range of oxygenation reactions. Reetz incorporated a maleimide-substituted Mn-salen cofactor 272 into papain via cysteine alkylation; the resulting ArM catalyzed the olefin epoxidation, but low enantioselectivity was observed $(<10 \%$ ee, data not shown in the 
paper). ${ }^{165}$ Lewis and coworkers also generated Mn-terpyridine ArMs by linking a maleimide-substituted terpyridine cofactor (273) to cysteine residues in nitrobindin and tHisF. Both benzylic oxidation and olefin epoxidation were catalyzed by these ArMs (Scheme 81). ${ }^{201}$

Scheme 81. Benzyl oxidation and olefin epoxidation catalyzed by $\mathrm{Mn}$ (salen) and Mn(terpy) ArMs.

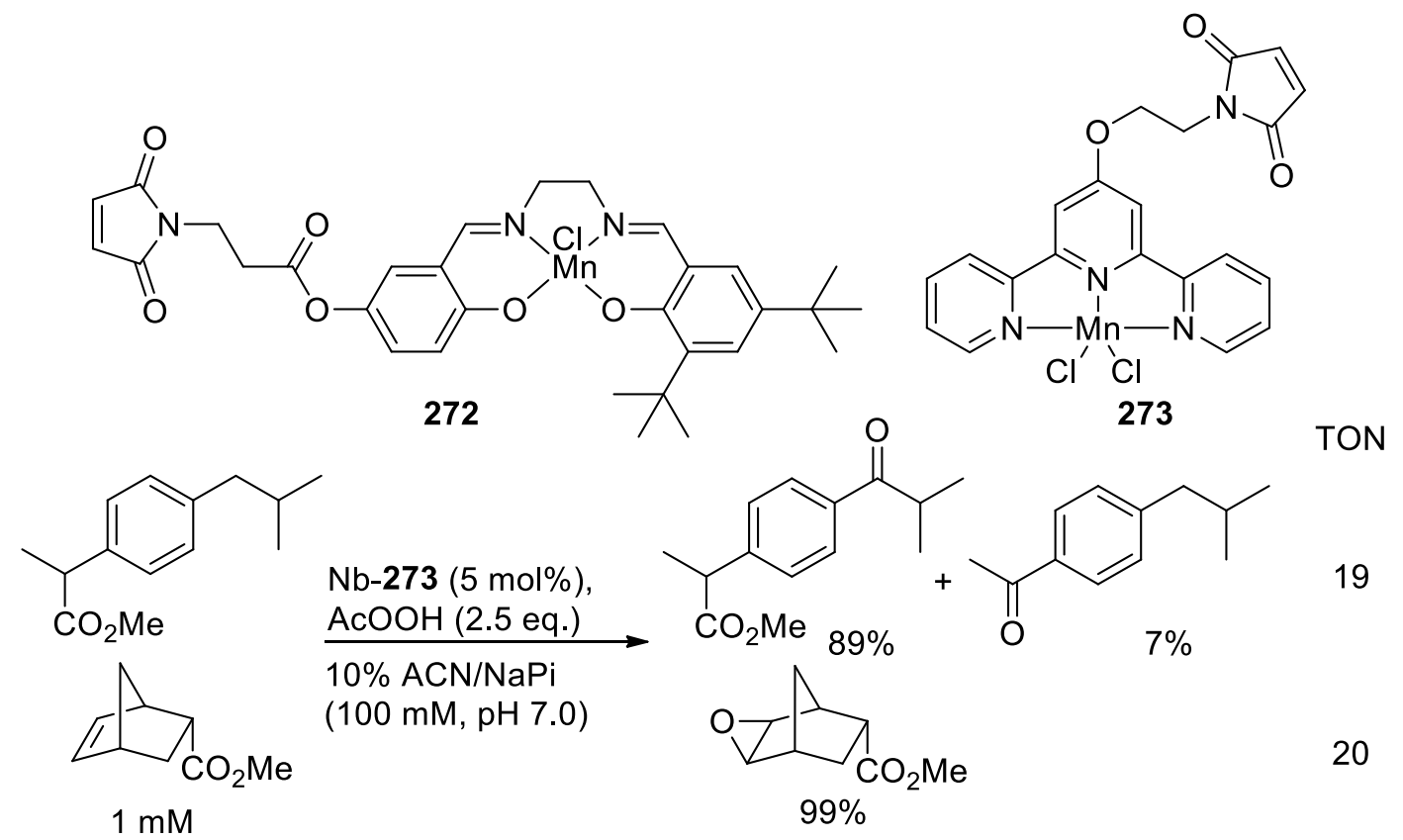

Ab-7A3, an antibody that was raised against estradiol has been used as a scaffold for incorporating estradiol-substituted $\mathrm{Mn}(\mathrm{III})$-porphyrins (Scheme 82 ) by Mahy. ${ }^{411}$ The affinities of $\mathrm{Ab}-7 \mathrm{~A} 3$ for 274 and $283\left(K_{\mathrm{D}}=9.0 \cdot 10^{-6} \mathrm{M}\right.$ and $K_{\mathrm{D}}=1.9 \cdot 10^{-6} \mathrm{M}$, respectively) were lower by approximately 3 orders of magnitude compared to the estradiol alone $\left(K_{\mathrm{D}}=9.5 \cdot 10^{-10} \mathrm{M}\right)$. Spectroscopic data suggested that the metal centers in these cofactors are not coordinated to any residues of the antibody scaffold. Nonetheless, 274.Ab-7A3 and 283.Ab-7A3 catalyzed the epoxidation of styrene, affording 425 and 100 turnovers respectively within one hour, in the presence of $0.2 \%$ ArM vs. the oxidant. Additional products 277 and 278 were also formed, however, and the chemoselectivity favored production of phenylacetaldehyde 277: $25 \%$ and $45 \%$ 
using 274.Ab-7A3 and 283.Ab-7A3, respectively. As both cofactors were mostly located outside of the protein, the presence of the antibody only modestly influenced the catalytic performance of the resulting ArMs.

Mahy and coworkers demonstrated that Xylanase A (XIn hereafter) can host, deep in its pocket, the synthetic iron porphyrin $[\mathrm{Fe}(\mathrm{T} p \mathrm{CPP})] 213\left(K_{\mathrm{D}}=0.5 \cdot 10^{-6} \mathrm{M}\right) \cdot{ }^{398}$ The resulting ArM displays peroxidase and sulfoxidase catalytic activity (sections 6.1 and 6.2). Incorporation of $[\mathrm{Mn}(\mathrm{T} p \mathrm{CPP})] 284$ into $\mathrm{X} \ln \left(K_{\mathrm{D}}=1.5 \cdot 10^{-6} \mathrm{M}\right)$ affords an ArM for the epoxidation of styrene. ${ }^{438}$ The olefins $\mathbf{2 7 5}$ and $\mathbf{2 7 9}$ were converted to the aryloxiranes 276 and 280 in $17 \%$ and $16 \%$ yield respectively (i.e. 23 and 21 TON). The chemoselectivity of the reaction was not affected by the protein scaffold, favouring the epoxide $\mathbf{2 7 6}$ for styrene (65\%). For the electron-rich styrene derivative $\mathbf{2 7 9}$, the carbonyl products $\mathbf{2 8 1}$ and $\mathbf{2 8 2}$ were formed preferentially (70\%). Importantly, the XIn host protein was responsible for enantioselectivity in the $\mathbf{2 8 4} \cdot \mathrm{X}$ In-catalyzed epoxidation, resulting in ee $=\mathbf{8 . 5 \%}$ for $(S)-\mathbf{2 7 6}$ and $\mathbf{8 0 \%}$ for $(R)-\mathbf{2 8 0}$. In addition, an increase of yield was also observed when comparing 284 to $284 \cdot X \ln$.

Scheme 82. Styrene epoxidation catalyzed by ArMs assembled with synthetic Mn(III)porphyrins via a Trojan horse anchoring strategy and supramolecular incorporation. The catalyst loading is reported $v s$. the oxidant. 


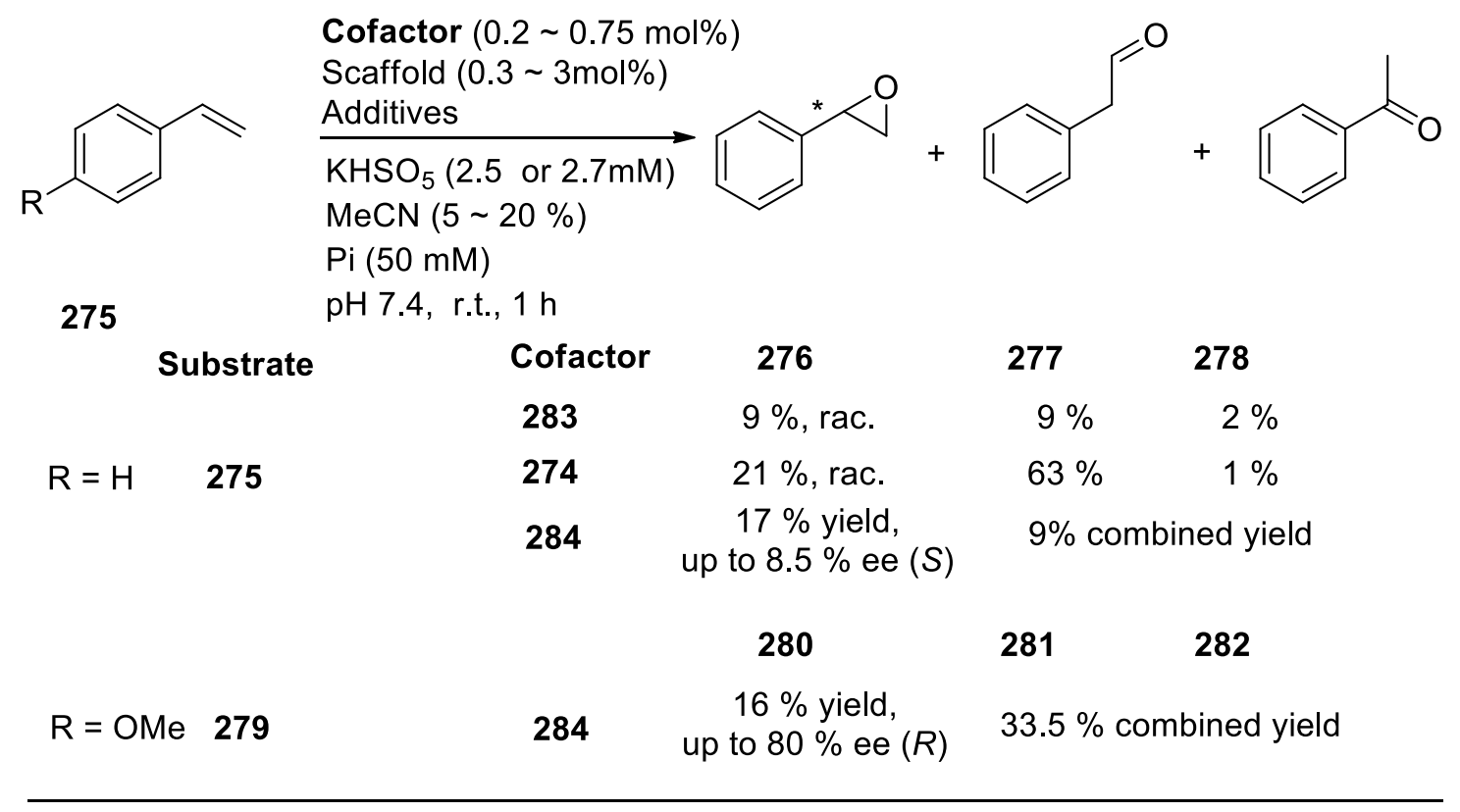
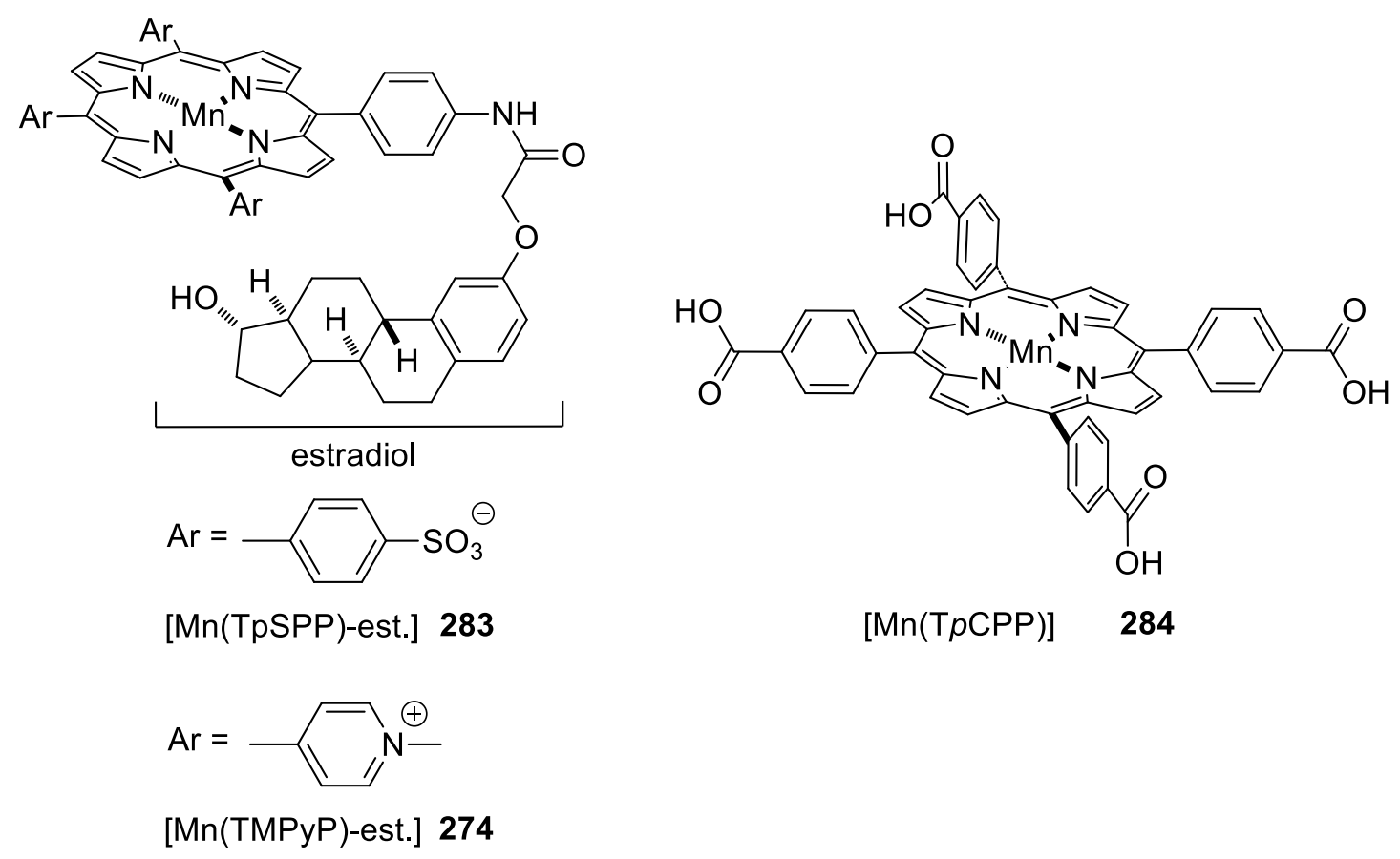

\subsection{Dihydroxylation}

Catalytic asymmetric dihydroxylation of olefins with osmium tetroxide and chiral ligands was discovered by Sharpless in the 1980s. As presented in the historical perspective, an ArM dihydroxylase was reported Kokubo. ${ }^{116}$ Inspired by this report, Ward and coworkers envisaged that the classic cinchona alkaloid ligands typically used for asymmetric dihydroxylation could be replaced with amino acid side chain functionality provided by 
Sav. X-ray analysis of a Sav crystal soaked with excess $\mathrm{K}_{2}\left[\mathrm{OsO}_{2}(\mathrm{OH})_{4}\right]$ revealed metal binding on surface-exposed basic amino acid residues, including $\mathrm{H} 87$ and $\mathrm{H} 127.439$ Incubating WT Sav with 1-2 eq. $\mathrm{K}_{2}\left[\mathrm{OsO}_{2}(\mathrm{OH})_{4}\right]$ yielded a highly enantioselective catalyst for the dihydroxylation of vinyl substrates, Table 33 and Scheme 83. (R)-1,2-dihydroxy2-phenyl propane was obtained from $\alpha$-methylstyrene 10 with $95 \%$ ee. To identify the position of the catalytic site, residues that had osmium-bound in the crystal structure were mutated to alanine. Surprisingly, none of these mutants displayed a significantly eroded ee suggesting that the active osmium is not bound to any of these residues. In stark contrast, mutations within the biotin binding vestibule (e.g. S112, K121) and deep within the biotin binding pocket (e.g. D128) had a significant impact on the enantioselectivity of the artificial dihydroxylase. The ee for 1,2-dihydroxy-3-thiophenyl propane increased from $2 \%(R)$ - to $71 \%(S)$-product when catalysis was performed with mutant S112Y. Mutant D128A afforded the same product with $71 \%(R)$-selectivity, Table 33.

Table 33. Incubation of Sav with $\mathrm{K}_{2}\left[\mathrm{OsO}_{2}(\mathrm{OH})_{4}\right]$ affords an asymmetric dihydroxylase.

\begin{tabular}{|c|c|c|c|c|c|}
\hline Entry & Substrate & Sav mutant & $\begin{array}{c}\mathrm{K}_{2}\left[\mathrm{OsO}_{2}(\mathrm{OH})_{4}\right] \\
(\mathrm{mol} \%)\end{array}$ & $\begin{array}{l}e e \\
(\%) \\
\end{array}$ & TON $^{a}$ \\
\hline 1 & 10 & S112M & 5.0 & $97(R)$ & 16 \\
\hline 2 & 285 & S112Y & 5.0 & $82(S)$ & 14 \\
\hline 3 & 285 & D128A & 2.5 & $77(R)$ & 21 \\
\hline 4 & 286 & S112Y & 5.0 & $71(S)$ & 7 \\
\hline 5 & 286 & D128A & 2.5 & $71(R)$ & 10 \\
\hline 6 & 287 & S112M & 5.0 & $41(1 R, 2 S)$ & 12 \\
\hline 7 & 288 & WT & 2.5 & $90(1 R, 2 S)$ & 26 \\
\hline 8 & 288 & $\mathrm{~S} 112 \mathrm{~T}$ & 2.5 & $92(1 R, 2 S)$ & 16 \\
\hline 9 & 289 & D128A & 2.5 & $45(1 R, 2 S)$ & 13 \\
\hline 10 & 290 & $\mathrm{~S} 112 \mathrm{~T}$ & 2.5 & $68(3 R, 4 R)$ & 6 \\
\hline
\end{tabular}

aBased on the amount of $\mathrm{K}_{2}\left[\mathrm{OsO}_{2}(\mathrm{OH})_{4}\right]$ employed.

Scheme 83. Incubation of Sav with $\mathrm{K}_{2}\left[\mathrm{OsO}_{2}(\mathrm{OH})_{4}\right]$ affords an asymmetric dihydroxylase. 
<smiles>C=C(C)c1ccccc1</smiles>

10<smiles>C=CCOc1ccccc1</smiles>

285<smiles>C=CCSc1ccccc1</smiles>

286<smiles>C1=Cc2ccccc2CC1</smiles>

287<smiles>C/C=C\c1ccccc1</smiles>

288<smiles>COc1ccc2c(c1)OC(C)(C)C=C2</smiles>

289

290

One of the most stringent requirements for ArMs is the preferred use of water as a reaction medium. ${ }^{27} \mathrm{~A}$ few reports, however, outline efforts to create ArMs that operate in the presence of large amounts of organic solvents. ${ }^{20,175,438,440-441}$ To overcome the inherent tendency of proteins to denature in the presence of organic solvents, Tiller and co-worker have investigated the potential of organosoluble polymer enzyme conjugates (PECs hereafter, 294) using poly(2-oxazoline) 291 for the creation of ArMs. ${ }^{442-443}$ PEC formation was achieved by coupling anhydride intermediate 293 with the amino groups present on the surface of host proteins, Scheme 84. The resulting ArMs are soluble in apolar solvents and display activity in both organic- and aqueous media.

Scheme 84. The terminal amino group of poly(2-oxazoline) 291, reacts with pyrometillic dianhydride 292 to afford the oligomer intermediate poly(2-oxazoline) anhydride 293. PECs 294 are generated upon coupling of the anhydride 293 with the amino groups on the surface of the protein scaffold. 
<smiles>[R]C(=O)N(CCNCCN)CCN(C([R])=O)C(C)(CC[AsH3+])c1ccccc1</smiles>

231<smiles>[3H]I</smiles><smiles>[R]C(=O)N(CCC(C)(c1ccccc1)N(CCNCCn1c(=O)c2cc3c(=O)oc(=O)c3cc2c1=O)C([R])=O)c1ccccc1</smiles><smiles>O=c1oc(=O)c2cc3c(=O)oc(=O)c3cc12</smiles>
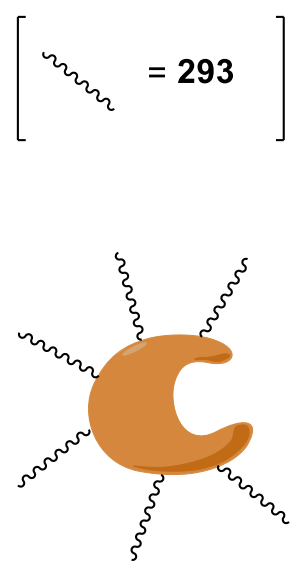

294

Building on the work of Kokubo ${ }^{116}$ and Ward ${ }^{439}$ on osmate-catalyzed dihydroxylation employing ArMs, Tiller and coworkers reported on the use of PECs 294 as chiral scaffolds for the dihydroxylation of alkenes in organic solvents. ${ }^{444}$ The amphiphilic nature of PECs allowed formation of the osmate-PEC ArMs in fairly apolar media. PECderivatives from various proteins were evaluated in the asymmetric dihydroxylation of styrene 176 in water-saturated chloroform using hexacyanoferrate (III) as co-oxidizing agent. (Table 34 and Scheme 85).

Table 34. Selected results for the catalytic dihydroxylation of styrene 176 with PECs in chloroform.

\begin{tabular}{|c|c|c|c|c|c|c|c|}
\hline Entry & Protein & co-oxidant & base & $\mathrm{T}(\mathrm{d})$ & $\begin{array}{c}\text { Ratio } \\
\text { [Os] / [Prot] }\end{array}$ & $\begin{array}{c}e e \\
(\%)\end{array}$ & TON $^{a}$ \\
\hline 1 & Lysozyme & $\mathrm{K}_{3}\left[\mathrm{Fe}(\mathrm{CN})_{6}\right](300 \mathrm{mM})$ & $\mathrm{K}_{2} \mathrm{CO}_{3}(300 \mathrm{mM})$ & 7 & 4.2 & rac. & $<1$ \\
\hline 2 & BSA & $\mathrm{K}_{3}\left[\mathrm{Fe}(\mathrm{CN})_{6}\right](300 \mathrm{mM})$ & $\mathrm{K}_{2} \mathrm{CO}_{3}(300 \mathrm{mM})$ & 7 & 18 & rac. & $<1$ \\
\hline 3 & $\alpha$-chymotripsin & $\mathrm{K}_{3}\left[\mathrm{Fe}(\mathrm{CN})_{6}\right](300 \mathrm{mM})$ & $\mathrm{K}_{2} \mathrm{CO}_{3}(300 \mathrm{mM})$ & 7 & 7.5 & $19(S)$ & $<1$ \\
\hline 4 & Proteinase- $\mathrm{K}$ & $\mathrm{K}_{3}\left[\mathrm{Fe}(\mathrm{CN})_{6}\right](300 \mathrm{mM})$ & $\mathrm{K}_{2} \mathrm{CO}_{3}(300 \mathrm{mM})$ & 6 & 8.3 & $6(S)$ & $<1$ \\
\hline 5 & Lipase (C. rugosa) & $\mathrm{K}_{3}\left[\mathrm{Fe}(\mathrm{CN})_{6}\right](300 \mathrm{mM})$ & $\mathrm{K}_{2} \mathrm{CO}_{3}(300 \mathrm{mM})$ & 7 & 16.7 & $12(S)$ & $<1$ \\
\hline 6 & peroxidase & $\mathrm{K}_{3}\left[\mathrm{Fe}(\mathrm{CN})_{6}\right](300 \mathrm{mM})$ & $\mathrm{K}_{2} \mathrm{CO}_{3}(300 \mathrm{mM})$ & 7 & 12.5 & $12(S)$ & $<1$ \\
\hline 7 & $\mathrm{ADH}$ & $\mathrm{K}_{3}\left[\mathrm{Fe}(\mathrm{CN})_{6}\right](300 \mathrm{mM})$ & $\mathrm{K}_{2} \mathrm{CO}_{3}(300 \mathrm{mM})$ & 7 & 11 & $12(S)$ & $<1$ \\
\hline 8 & laccase & $\mathrm{K}_{3}\left[\mathrm{Fe}(\mathrm{CN})_{6}\right](300 \mathrm{mM})$ & $\mathrm{K}_{2} \mathrm{CO}_{3}(300 \mathrm{mM})$ & 7 & 7.7 & $15(R)$ & $<1$ \\
\hline 9 & laccase & $\mathrm{K}_{3}\left[\mathrm{Fe}(\mathrm{CN})_{6}\right](300 \mathrm{mM})$ & $\mathrm{K}_{2} \mathrm{CO}_{3}(300 \mathrm{mM})$ & 7 & 1.9 & $93(R)$ & 7 \\
\hline $10^{\mathrm{b}}$ & laccase & $\mathrm{K}_{3}\left[\mathrm{Fe}(\mathrm{CN})_{6}\right](300 \mathrm{mM})$ & $\mathrm{K}_{2} \mathrm{CO}_{3}(300 \mathrm{mM})$ & 7 & 1.9 & $98(R)$ & 42 \\
\hline 11 & laccase & $\mathrm{K}_{3}\left[\mathrm{Fe}(\mathrm{CN})_{6}\right](300 \mathrm{mM})$ & $\mathrm{K}_{2} \mathrm{CO}_{3}(300 \mathrm{mM})$ & 3 & 3.8 & $99.4(R)$ & $<1$ \\
\hline $12^{\mathrm{c}}$ & laccase & $t$-BuOOH (110 mM) & $\mathrm{K}_{2} \mathrm{CO}_{3}(300 \mathrm{mM})$ & 7 & 2 & $98(R)$ & 232 \\
\hline
\end{tabular}




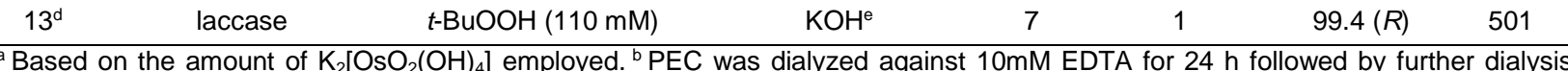
against water. ${ }^{c} 26 \mu \mathrm{M} \mathrm{K}_{2}\left[\mathrm{OsO}_{2}(\mathrm{OH})_{4}\right] .{ }^{\mathrm{d}} 13 \mu \mathrm{M} \mathrm{K}{ }_{2}\left[\mathrm{OsO}_{2}(\mathrm{OH})_{4}\right] .{ }^{e} 10 \mu \mathrm{L} / \mathrm{mL}$ of a saturated methanolic solution. BSA: bovine serum albumin, ADH: Alcohol dehydrogenases (ADH).

Scheme 85. Immobilized artificial dihydroxylase obtained as polymer enzyme conjugate using various protein hosts.<smiles>C=Cc1ccccc1</smiles>

$100 \mathrm{mM}$

176

PEC $(11 \mu \mathrm{M}-105 \mu \mathrm{M})$
$\underset{\mathrm{K}_{2}\left[\mathrm{OsO}_{2}(\mathrm{OH})_{4}\right](200 \mu \mathrm{M})}{\stackrel{\text { co-oxidant }}{\longrightarrow}}$
base
$\mathrm{CHCl}_{3}$ sat. with $\mathrm{H}_{2} \mathrm{O}$
$0^{\circ} \mathrm{C}, 7 \mathrm{~d}$<smiles>OCC(O)c1ccccc1</smiles>

295

1-phenylethane-1,2-diol 295 was obtained in racemic form with enzyme conjugates derived from lysozyme or BSA (Table 34, entries 1 and 2). All other polymer-enzyme conjugates afforded enantioenriched product with $(S)$-configuration (Table 34, entries 3 and 7) except for laccase (Table 34, entry 8). Varying the osmate : laccase ratio from 7.7 to 1.9 improved the yield and ee substantially (7 TON and 93\%) (Table 34, entry 9). Laccase contains four copper ions in its active site. Dialysis against EDTA and subsequent loading with osmate led to a further improvement in yield and ee for the dihydroxylation of styrene (98\% ee $(R)-295$, Table 34 , entry 10$)$.

In a subsequent study, alternative reaction conditions were investigated to overcome the poor solubility of the co-oxidant $\mathrm{K}_{3}\left[\mathrm{Fe}(\mathrm{CN})_{6}\right]$ in $\mathrm{CHCl}_{3} . t-\mathrm{BuOOH}$ in combination with methanolic $\mathrm{KOH}$ as a base led to excellent results for dihydroxylation of styrene with a TON of 501 and even outcompeting the Sharpless system in terms of enantioselectivity $(>99 \%$ ee $(R)$ ) (Table 34 , entries $12-13) .{ }^{445} \mathrm{KMnO}_{4}$ and $\mathrm{FeCl}_{2}$, respectively, were tested in the same study as alternatives to $\mathrm{K}_{2}\left[\mathrm{OsO}_{2}(\mathrm{OH})_{4}\right]$, but resulted in a sharp drop in TON (51 for $\mathrm{KMnO}_{4}$ and 20 for $\mathrm{FeCl}_{2}$ ) and enantioselectivity (26\% ee $(R)$ for $\mathrm{KMnO}_{4}$ and $11 \%$ ee $(R)$ for $\mathrm{FeCl}_{2}$ ).

More challenging substrates were also tested with the $\mathrm{K}_{3}\left[\mathrm{Fe}(\mathrm{CN})_{6}\right] / \mathrm{K}_{2} \mathrm{CO}_{3}$ system: $1-H$ indene 289, 1,2-dihydronaphthalene 287, and (allyloxy)benzene 285 yielded the corresponding vicinal diols in moderate to good ee. (Table 35, entries 1, 3 and 4 and 
Figure 28) The enantiomeric excess observed for substrates $\mathbf{2 8 9}$ and $\mathbf{2 8 7}$ is, the highest ever reported for the osmium catalyzed dihydroxylation to the best of our knowledge. Strikingly, neither the styrene derivative 10 nor 297 afforded the corresponding diol. ${ }^{444}$ These results stand in contrast with those obtained by Ward and coworkers, relying on streptavidin as host protein. ${ }^{439}$ Although selectivities of protein-osmium hybrids are promising, the turnover numbers are modest, with the exception of styrene.

Table 35. Substrate scope for the catalytic dihydroxylation of alkenes with laccase based PEC. ${ }^{a, b}$

\begin{tabular}{|c|c|c|c|c|c|}
\hline Entry & Protein & Sub. & $T$ (d) & $\mathrm{ee}^{\mathrm{c}}(\%)$ & TON $^{d}$ \\
\hline 1 & laccase & 289 & 7 & $71(R)^{\mathrm{e}}$ & 3 \\
\hline 2 & laccase & 10 & 7 & - & - \\
\hline 3 & laccase & 285 & 7 & $87(R)$ & $<1$ \\
\hline 4 & laccase & 287 & 6 & $75(R)^{\mathrm{e}}$ & 11 \\
\hline 5 & laccase & 296 & 7 & - & - \\
\hline 6 & laccase & 297 & 7 & rac. & 1 \\
\hline
\end{tabular}

${ }^{a}$ See Scheme 85 for reaction conditions, ${ }^{b}$ Ratio [Os] / [Prot] $=1.9,{ }^{c}$ positive ee values correspond to the $(R)$-enantiomer. ${ }^{d}$ Based on the amount of $\mathrm{K}_{2}\left[\mathrm{OsO}_{2}(\mathrm{OH})_{4}\right]$ employed. ${ }^{e}$ ee values of $1 R, 2 S$ calculated by comparison of the amounts of the cis enantiomer $(1 R, 2 S$ and $1 S, 2 R)$.<smiles>C1=Cc2ccccc2C1</smiles>

289<smiles>C1=Cc2ccccc2CC1</smiles>

287<smiles>C=C(C)c1ccccc1</smiles>

10<smiles>C=Cc1ccc(C)cc1</smiles>

296<smiles>C=CCOc1ccccc1</smiles>

285<smiles>C=Cc1cccc(Br)c1</smiles>

297

Figure 28. Substrates tested by Tiller in the catalytic dihydroxylation of alkenes with laccase based PEC.

\subsection{Cco Oxidase}

Lu designed and engineered a biosynthetic model of cytochrome $c$ oxidase $(\mathrm{CCO})$ by introducing a heme-copper center into $\mathrm{Mb}(\mathrm{CubMb}){ }^{292} \mathrm{~A}$ tyrosine mutant in the active site (CubMb F33Y or $\mathrm{CubMb}$ G65Y) enabled its catalytic activity for the reduction of $\mathrm{O}_{2}$ to $\mathrm{H}_{2} \mathrm{O}$ and different reactive oxygen species (ROS) with high activity (TON > 1000). ${ }^{446}$ Multiple approaches were used to fine-tune the ArM and thus increase the 
corresponding reduction rates. A point mutation (S92A) was introduced into $\mathrm{CubMb}$ F33Y; this removed hydrogen bonds to the proximal His ligand and a heme propionate, created a more hydrophobic heme pocket, and increased the heme $E^{\circ}$ from 95 to 123 $\mathrm{mV}$. Reconstituting the scaffold with different heme derivatives (Figure 29, 222, 298-301) led to the identification of ArMs with even higher $\mathrm{E}^{\circ}$ (up to $320 \mathrm{mV}$ with $\mathbf{3 0 0}$ ) and better activity (more than threefold TONs after $9 \mathrm{~h}$ compared to CubMb F33Y). ${ }^{447}$ A series of different tyrosine analogs (Figure 30, 302-306) were also introduced into the enzymes in E. coli via stop codon suppression methodology. Unnatural aminoacid $\mathbf{3 0 2}$ mimicked the Tyr-His crosslink in $\mathrm{CcO}$, and the resulting ArM catalyzed the reduction of oxygen to water with eightfold more selectivity and threefold higher TON than CubMb F33Y.448 Tyrosine residues bearing different halogen substituents with decreased $\mathrm{pKa}$ also improved the selectivity and TON (up to 1200) of the ArM, suggesting the enhancement of proton donating ability of the phenol ring of the Tyr was beneficial. ${ }^{449}$ More recently, 3methoxytyrosine (306), a tyrosine analog with similar $\mathrm{pKa}$ but lower $\mathrm{E}^{\circ}$, was incorporated into the ArM, the resulting ArM also showed higher oxidase activity (15.0 vs $6.5 \mu \mathrm{M}$ min $^{-}$ ${ }^{1}$ ) and selectivity ( $82 \%$ vs $51 \%$ to water). ${ }^{450}$

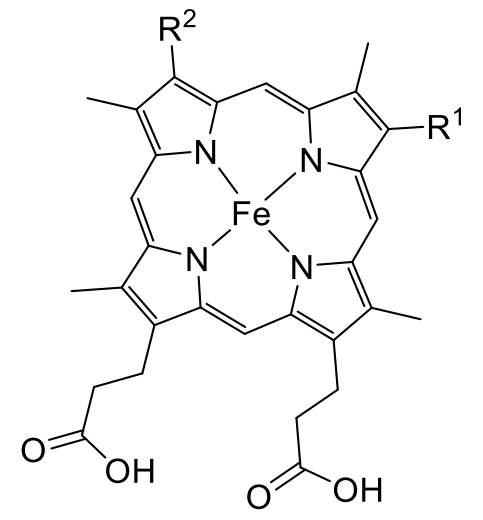

$\begin{array}{lcc} & \mathrm{R}^{1} & \mathrm{R}^{2} \\ \mathbf{2 2 2} & \text { vinyl } & \text { vinyl } \\ \mathbf{2 9 8} & \text { acetyl } & \text { acetyl } \\ \mathbf{2 9 9} & \text { vinyl } & \text { formyl } \\ \mathbf{3 0 0} & \text { formyl } & \text { formyl } \\ \mathbf{3 0 1} & \text { vinyl } & \mathrm{CH}(\mathrm{OH}) \mathrm{CH}_{2} \text { (farnesyl) } \\ & & \end{array}$

Figure 29. Various heme derivatives used to fine-tune the redox potential of the ArMs. 
<smiles>[NH3+]C(Cc1ccc(O)cc1)C(=O)[O-]</smiles><smiles>[NH3+]C(Cc1cc(F)c(O)c(F)c1)C(=O)[O-]</smiles>

304<smiles>[NH3+]C(Cc1ccc(O)c(-n2ccnc2)c1)C(=O)[O-]</smiles>

302<smiles>[NH3+]C(Cc1cc(F)c(O)c(F)c1F)C(=O)[O-]</smiles>

305<smiles>[NH3+]C(Cc1ccc(O)c(Cl)c1)C(=O)[O-]</smiles><smiles>COc1cc(CC([NH3+])C(=O)[O-])ccc1O</smiles>

Figure 30. Various tyrosine analogs incorporated in the artificial oxidase to optimize the activity.

\subsection{C-H oxidation}

As noted in section 5.4, selective functionalization of $\mathrm{C}-\mathrm{H}$ bonds remains a key challenge in catalysis, and ArMs have great potential to improve control over such processes. Toward this end, a Mn(terpy) cofactor (307) was covalently linked to the nitrobindin $(\mathrm{Nb})$ scaffold, a heme protein with a $\beta$-barrel structure, as noted in section 5.5 (Scheme 81) to generate an ArM that catalyzed the oxidation of a broad range of hydrocarbons with good to excellent yields (up to $97 \%$ ). Hoyever, selectivity identical to that of the free cofactor was observed (Scheme 86). ${ }^{201}$

Scheme 86. Selected results for Mn(terpy) ArM catalyzed C-H oxidation. 


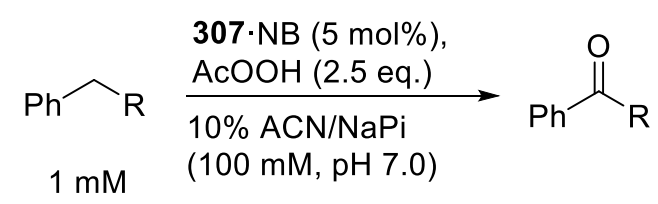
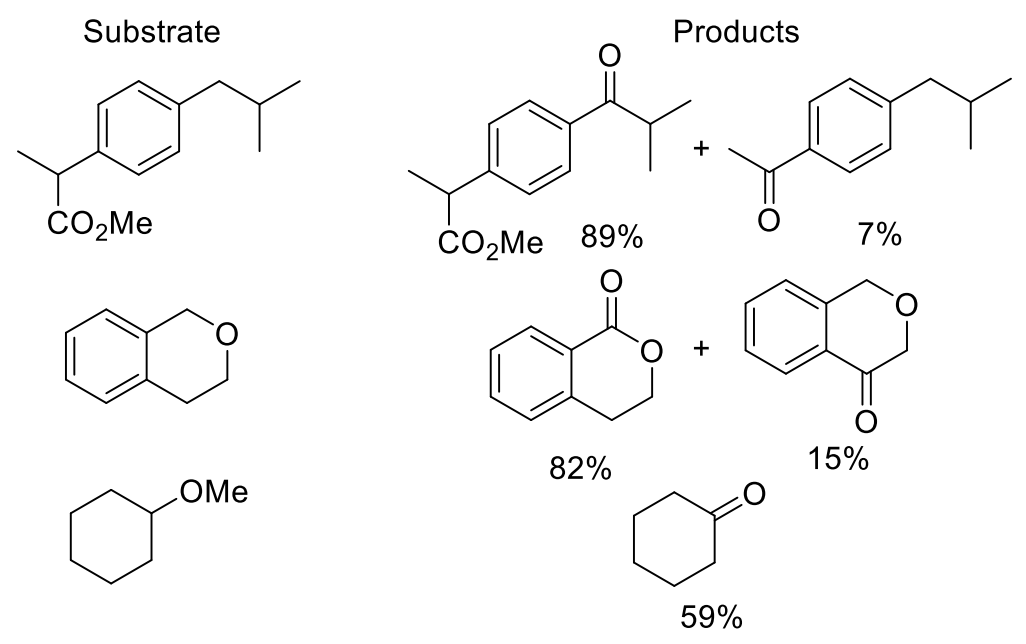

In order to scrutinize the role of both the tetradentate ligand and the metal in $\mathrm{Mb}$, Hayashi and coworkers tested the hydroxylation of ethylbenzene 308 by Mb reconstituted by Fe-porphycene 225 by Mn-protoporphyrin IX 309 and a Mn-porphycene 310, Scheme 87.451 Using hydrogen peroxide as oxidant, only 224.Mb yielded phenylethanol 50 with $\mathrm{TON}=13$ and an ee $=14 \%(S)($ Table 36, entries $1-4)$. No overoxidation to the corresponding acetophenone could be detected.

Table 36. The oxidation reaction by reconstituted Mbs with M-porphyrinoids

\begin{tabular}{cccccccccc}
\hline Entry & Cofactor & Protein & Sub. & $\mathrm{pH}$ & {$[\mathrm{Cof}](\mu \mathrm{M})$} & {$\left[\mathrm{H}_{2} \mathrm{O}_{2}\right](\mathrm{mM})$} & TON & TOF $\left(\mathrm{h}^{-1}\right)$ & Ref \\
\hline 1 & $\mathbf{2 2 2}$ & Mb (WT) & $\mathbf{3 0 8}$ & 8.0 & 20 & 10 & 0 & 0 & 451 \\
2 & $\mathbf{2 2 5}$ & Mb (WT) & $\mathbf{3 0 8}$ & 8.0 & 20 & 10 & 0 & 0 & 451 \\
3 & $\mathbf{3 0 9}$ & Mb (WT) & $\mathbf{3 0 8}$ & 8.0 & 20 & 10 & 0 & 0 & 451 \\
4 & $\mathbf{3 1 0}$ & Mb (WT) & $\mathbf{3 0 8}$ & 8.0 & 20 & 10 & 13 & 33 & 451 \\
\hline
\end{tabular}

Scheme 87. Hydroxylation of ethylbenzene catalyzed by Mb reconstituted with metalloporphyrinoids. 


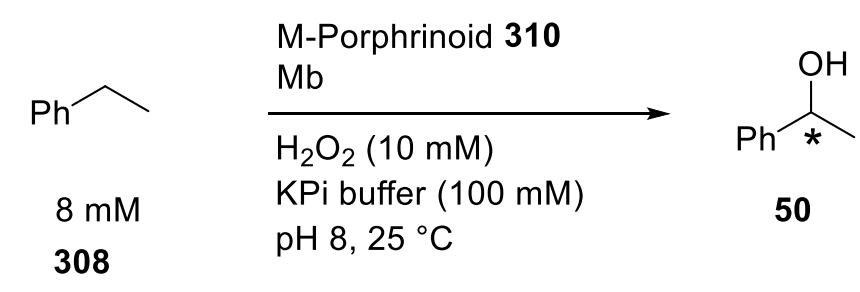

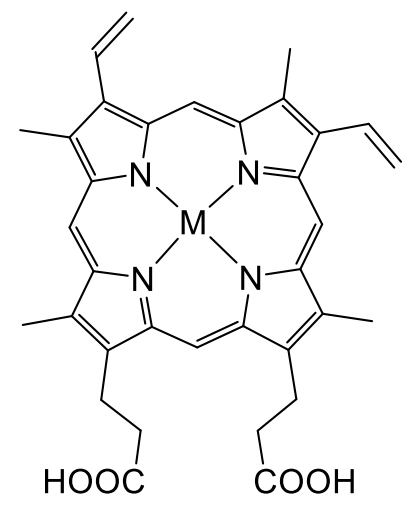

[M-Protoporphyrin IX]

222: $M=F e$

309: $M=M n$

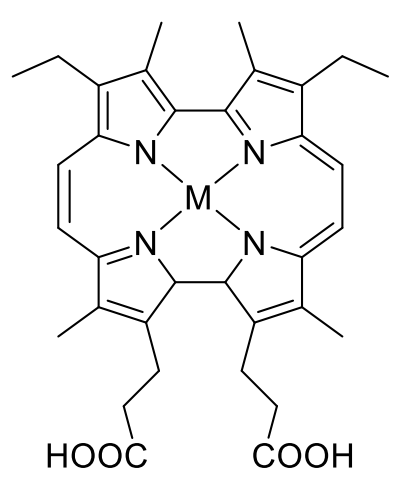

[M-Porphycene]

225: $M=F e$

310: $M=M n$

\subsection{Protein and Nucleic Acid Cleavage}

ArMs have also been designed to catalyze site-selective cleavage of proteins and nucleic acids. Indeed, many of the earliest ArMs developed via covalent modification of protein scaffolds involved modification of protein- and DNA-binding scaffold proteins for this purpose. Unlike most of the systems described above, surface modification of the scaffold is sufficient for selective biopolymer cleavage since the scaffold needs only to maintain cofactors proximal to bound DNA. For example, following iminothiolane treatment, the surface lysine residues on the E. coli Trp repressor protein (trp) were used to install an iodoacetamide-substituted phenanthroline cofactor (Figure 23, 200) that was metallated to generate an ArM nuclease. ${ }^{125}$ Substrate DNA that contained the aroH transcription unit naturally recognized by the trp scaffold was selectively cleaved in the presence of tryptophan and 3-mercaptopropionic acid. A similar approach was used to link an Fe(III)-EDTA cofactor (311) to the $\sigma^{70}$ subunit of $E$. coli RNAP complex. The resulting ArM catalyzed cleavage of nucleic acid and protein components of the RNAP 
complex near the $\sigma^{70}$ binding sites ${ }^{452}$ Haloacetamide-substituted phenanthroline (Figure 23, 200) ${ }^{453}$ or EDTA ligands ${ }^{454}$ and an Fe(III)-EDTA cofactor (Figure 31311$)^{455}$ have been used to generate ArMs for selective biopolymer cleavage via alkylation of cysteine residues on scaffold proteins. ${ }^{15}$ Related systems have been generated via disulfide exchange ${ }^{456}$ and transesterification. ${ }^{457}$ Finally, in order to bypass the need for the covalent scaffold modification, BpyAla was genetically encoded into catabolite activator protein (CAP) near the the DNA binding site of this scaffold. ${ }^{402}$ The BpyAla 237 residue was selectively metallated with $\mathrm{Fe}(\mathrm{II})$ and $\mathrm{Cu}(\mathrm{II})$ to generate $\mathrm{ArM}$ nucleases.

Building on these studies, Nolte recently constructed an ArM containing a Mn-porphyrin cofactor (Figure 31, cofactor 312) that selectively and processively oxidized tri-adenine sites in double stranded DNA (dsDNA). ${ }^{458}$ A trimeric, ring-shaped, DNA-binding clamp protein (gp45) was used as scaffold, and cysteine residues on the clamp were alkylated with a maleimide substituted manganese-phorphyrin complex (312). Supercoiled DNA was quantitatively oxidized by $\mathbf{3 1 2}$ and the reactive position of dsDNA was turned into an aldehyde after oxidation, which was further modified with hydroxylamine-derived biotin. Relying on a biotin-streptavidin pulldown, the reaction site was then visualized by AFM. When the gp45 was closed with an octapeptide, the activity of the ArM was decreased (55\% conversion) and the modification-pattern was changed dramatically, indicating the binding of gp45 to the DNA was the key to processive catalysis. The reaction direction of the ArM could also be guided by clamper-loader complex (gp44/62) like the native polymerase. 

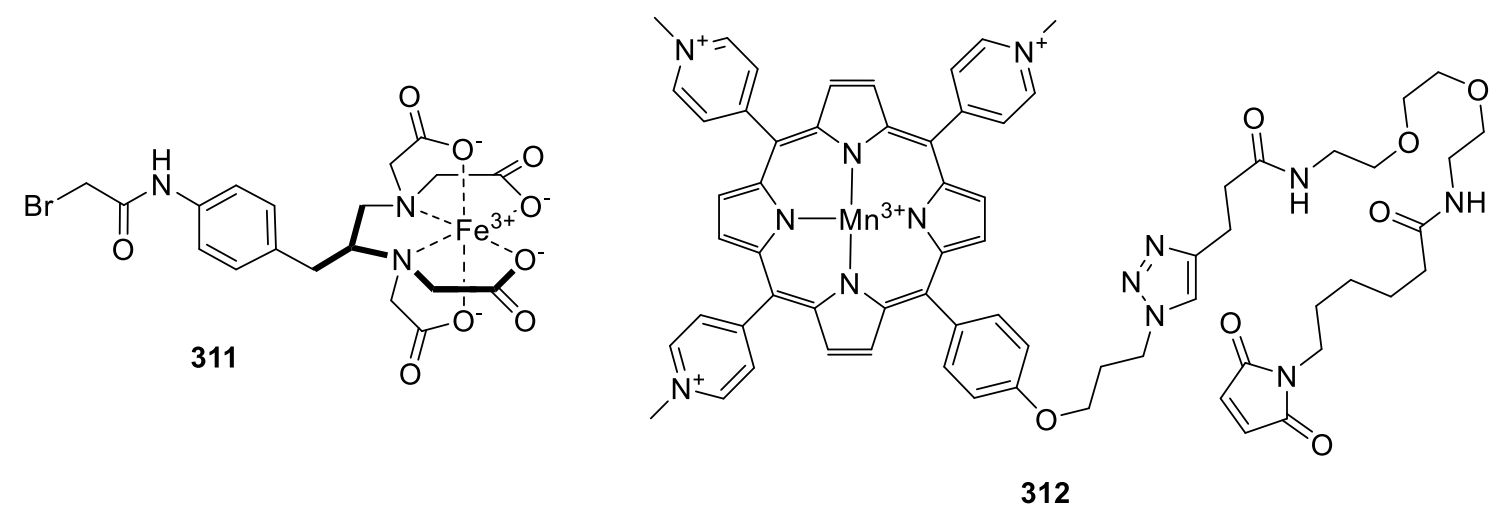

Figure 31. Selected cofactors used for construction of nucleic acid cleaving ArMs. 


\section{Hydration}

A wide range of natural enzymes catalyze an equally diverse range of hydration reactions. Around one-third of the enzymes classified are involved in the addition- or removal of a water molecule from a specific substrate, thus illustrating their importance in nature. Most of these enzymes are hydrolases (E.C. 3), but examples can also be found among the lyases (carbon-oxygen bond cleavage, E.C. 4.2). ${ }^{459}$ Some of these enzymes (e.g. carbonic anhydrase, acetylcholinesterase and fumarase) belong to the fastest and most efficient enzymes known today, operating at the limit of substrate/product diffusion (with $\left.k_{c a t} / K_{M} \approx 10^{8}-10^{9} \mathrm{M}^{-1} \cdot \mathrm{s}^{-1}\right) .460$

In addition to the large variety of natural hydrolytic (metallo)-enzymes, researchers have created ArMs to hydrolyze small model compounds (4-nitrophenyl acetate/phosphate), antibiotics (cefotaxime, ampicillin), or an analogue of the nerve agent cyclosarin. ArMs have also been applied for the hydration of $\mathrm{CO}_{2}$ or $\alpha, \beta$-unsaturated 2-acyl pyridines and were engineered to catalyze epoxide ring-opening reactions, Kemp eliminations, transesterifications, and RNA ligations. The applied metalloenzymes were created by placing a catalytically active metal center (often $\mathrm{Zn}(\mathrm{II})$ ) either in existing proteins or in de novo-designed scaffolds. The catalytic performance and the selectivity of the constructs were subsequently improved by means of genetic engineering. Artificial hydrolases are presented below.

\subsection{Hydrolytic Cleavage}

In 2006, Kim and Benkovic et al. engineered an artificial $\beta$-lactamase for the hydrolysis of the antibiotic cefotaxime (313). ${ }^{461}$ They repurposed the catalytic activity of an existing protein scaffold by applying the SIAFE approach (simultaneous incorporation and adjustment of functional elements) in conjunction with directed evolution. Insertion, 
deletion, and substitution of active site loops led to $\beta$-lactamase activity in the $\alpha \beta / \beta \alpha$ metallo-hydrolase scaffold of glyoxalase II. Subsequent modification of the protein by point mutations resulted in a highly active engineered $\beta$-lactamase (evMBL8, PBD entry 2F50). The designed enzyme completely lost its native activity (hydrolysis of the thioester bond of (S)-D-lactoylglutathione), in favor of the hydrolysis of cefotaxime $\mathbf{3 1 3}$, Scheme 88. The engineered enzyme, whose metal content was $1.63 \pm 0.43 \mathrm{~mol} \mathrm{Zn}$ and $0.46 \pm 0.14 \mathrm{~mol}$ Fe per mol of enzyme, displayed a catalytic efficiency $\left(k_{\text {cat }} / K_{\mathrm{M}}\right)$ of $184 \mathrm{M}^{-}$ $1 \cdot \mathrm{s}^{-1}$.

Scheme 88. An engineered $\beta$-lactamase evMBL8 catalyzes the hydrolysis of cefotaxime 313.

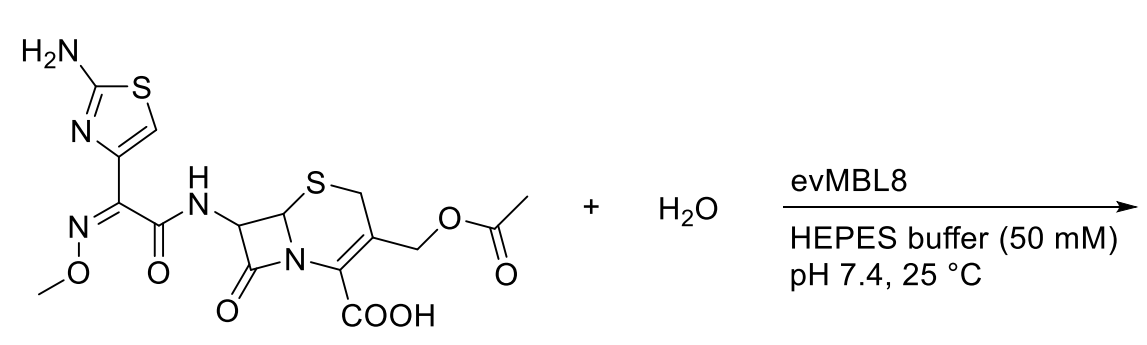

313

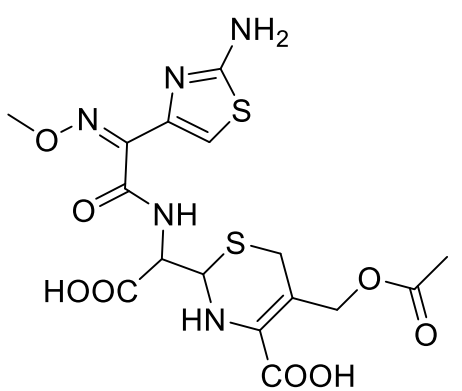

Beside antibiotics, small model compounds have also been examined as substrates for designed ArM hydrolases. For example, Pecoraro has engineered a variety of ArMs that catalyze hydrolysis of 4-nitrophenyl acetate 315.462 The de novo-designed scaffolds consist of a coiled-coil motif with an engineered His $3 \mathrm{Zn}(\mathrm{II})$ binding site. Metallation of this scaffold with $\mathrm{Zn}$ (II) led to an ArM that hydrolyzed ester $\mathbf{3 1 5}$ with a catalytic efficiency only $\sim 100$-fold lower than that of the natural hCAll, Table 37. More generally, the ArM hydrolase $\left([\mathrm{Hg}(\mathrm{II})]\left[\mathrm{Zn}(\mathrm{II})\left(\mathrm{H}_{2} \mathrm{O} / \mathrm{OH}^{-}\right)\right](\mathrm{TRIL9CL23H}) 3^{\mathrm{n}+}\right)$ consists of a three-stranded coiled-coil motif based on the TRI peptide family. The a-helical monomers display the general amino acid sequence Ac-G(LKALEEK) ${ }_{4} \mathrm{G}-\mathrm{NH}_{2}$ in which two leucine residues were mutated to either histidine or cysteine. Upon metallation, this scaffold harbors a catalytically active tetrahedral $\mathrm{Zn}(\mathrm{II})(\mathrm{His})_{3} \mathrm{OH}_{2}$ site (mutation $\mathrm{L} 23 \mathrm{H}$ ) and a structure 
stabilizing trigonal planar $\mathrm{Hg}(\mathrm{II})(\mathrm{Cys})_{3}$ site (mutation L9C) are formed (crystal structure of an analogue: PBD entry 3PBJ, Figure 32).

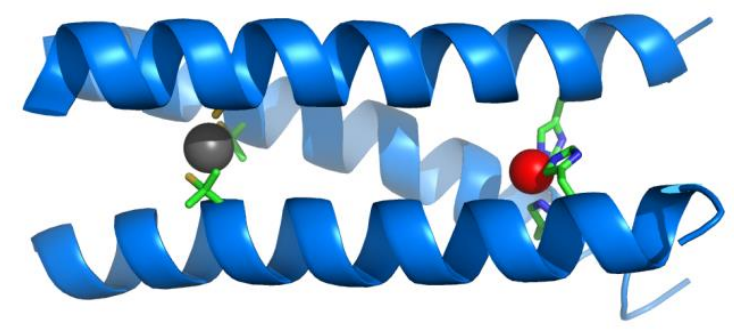

Figure 32. Cartoon representation of de novo-designed three helix bundle proteins. Side view of the trimer found in the asymmetric unit of the crystal structure in TRI peptide structure analogs (PDB:3PBJ). The three helix bundles contain $\mathrm{Zn}(\mathrm{II})$ (red) and $\mathrm{Hg}$ (II) (grey) metal centers coordinated with three His and three Cys, respectively.

Table 37. Saturation kinetic constants for the artificial metallohydrolase $[\mathrm{Hg}(\mathrm{II})]\left[\mathrm{Zn}(\mathrm{II})\left(\mathrm{H}_{2} \mathrm{O} / \mathrm{OH}^{-}\right)\right](\mathrm{TRIL9CL23H}) 3^{\mathrm{n}+}$ and hCAll for the hydrolysis of 4-nitrophenyl acetate $315 .^{\text {a }}$

\begin{tabular}{|c|c|c|c|c|c|c|}
\hline Entry & Protein & $\mathrm{pH}$ & $K_{\mathrm{M}}(\mathrm{mM})$ & $k_{\text {cat }}\left(\mathrm{s}^{-1}\right)$ & $k_{\text {cat }} / K_{\mathrm{M}}\left(\mathrm{M}^{-1} \cdot \mathrm{s}^{-1}\right)$ & Ref \\
\hline 1 & $\begin{array}{c}{[\mathrm{Hg}(\mathrm{II})]\left[\mathrm{Zn}(\mathrm{II})\left(\mathrm{H}_{2} \mathrm{O} / \mathrm{OH}^{-}\right)\right]} \\
(\mathrm{TRIL9CL} 23 \mathrm{H})_{3}{ }^{{ }^{n+}}\end{array}$ & 7.5 & $1.6 \pm 0.4$ & $2.2 \pm 0.5 \cdot 10^{-3}$ & $1.38 \pm 0.04$ & 462 \\
\hline 2 & $\begin{array}{l}{[\mathrm{Hg}(\mathrm{II})]\left[\mathrm{Zn}(\mathrm{II})\left(\mathrm{H}_{2} \mathrm{O} / \mathrm{OH}^{-}\right)\right]} \\
(\mathrm{TRIL9CL23H})_{3}{ }^{\mathrm{n}+}\end{array}$ & 8.0 & $1.7 \pm 0.5$ & $5.4 \pm 1.5 \cdot 10^{-3}$ & $3.1 \pm 0.1$ & 462 \\
\hline 3 & $\begin{array}{c}{[\mathrm{Hg}(\mathrm{II})]\left[\mathrm{Zn}(\mathrm{II})\left(\mathrm{H}_{2} \mathrm{O} / \mathrm{OH}^{-}\right)\right]} \\
(\mathrm{TRIL9CL} 23 \mathrm{H})_{3}{ }^{\mathrm{T}_{+}}\end{array}$ & 8.5 & $1.9 \pm 0.6$ & $12 \pm 4 \cdot 10^{-3}$ & $6.0 \pm 0.1$ & 462 \\
\hline 4 & $\begin{array}{l}{[\mathrm{Hg}(\mathrm{II})]\left[\mathrm{Zn}(\mathrm{II})\left(\mathrm{H}_{2} \mathrm{O} / \mathrm{OH}^{-}\right)\right]} \\
(\mathrm{TRIL9CL} 23 \mathrm{H})_{3}{ }^{\mathrm{n+}}\end{array}$ & 9.0 & $2.1 \pm 0.6$ & $38 \pm 10 \cdot 10^{-3}$ & $17.6 \pm 0.3$ & 462 \\
\hline 5 & $\begin{array}{c}{[\mathrm{Hg}(\mathrm{II})]\left[\mathrm{Zn}(\mathrm{II})\left(\mathrm{H}_{2} \mathrm{O} / \mathrm{OH}^{-}\right)\right]} \\
(\text {TRIL9CL23H })_{3}{ }^{\mathrm{n}^{+}}\end{array}$ & 9.5 & $1.7 \pm 0.5$ & $40 \pm 12 \cdot 10^{-3}$ & $23.3 \pm 0.3$ & 462 \\
\hline 6 & hCAll & 7.4 & $30.5 \pm 2.1$ & n.d. & $2607 \pm 85$ & 463 \\
\hline 7 & hCAll & 8.0 & 20.7 & $53 \pm 10$ & 2550 & 464 \\
\hline 8 & hCAII & 9.0 & 23.9 & $56 \pm 10$ & 2320 & 464 \\
\hline
\end{tabular}

Zastrow and Pecoraro subsequently investigated the influence of the active site location on the catalytic activity of TRI-based ArM hydrolases. ${ }^{465}$ Four coiled-coil motifs were designed in which i) the positions of the $\mathrm{Zn}$ (II)-site and the $\mathrm{Hg}(\mathrm{II})$-site were inverted (TRIL9CL23H and TRIL9HL23C, Table 38, entries 1-2 and 3-4), ii) the Zn(II)-site was moved closer to the $\mathrm{N}$-terminus (TRIL9CL19H, Table 38, entries 5-6), iii) the $\mathrm{Hg}(\mathrm{II})$-site was omitted (TRIL2WL23H, Table 38, entries 7-8). Analysis of these constructs revealed that the maximal rate, the metal binding affinity and the substrate access depended on 
the position of the $\mathrm{Zn}(\mathrm{II})$-site, whereas all designs showed similar maximal catalytic efficiencies for the hydrolysis of $\mathbf{3 1 5}$.

Table 38. Kinetic analysis of four artificial metallohydrolases catalyzing the hydrolysis of 4-nitrophenyl acetate 315 . $^{\mathrm{a}}$

\begin{tabular}{|c|c|c|c|c|c|c|c|c|}
\hline Entry & Protein & $\mathrm{pH}$ & $\begin{array}{l}k_{\text {cat }} \\
\left(\mathrm{s}^{-1}\right)\end{array}$ & $\begin{array}{c}K_{\mathrm{M}} \\
(\mathrm{mM})\end{array}$ & $\begin{array}{c}k_{\text {cat }} / K_{\mathrm{M}} \\
\left(\mathrm{M}^{-1} \cdot \mathrm{s}^{-1}\right)\end{array}$ & $\begin{array}{l}K_{\text {dapp }} \\
(\mu \mathrm{M})\end{array}$ & $\begin{array}{c}\left(k_{\text {cat }}\right)_{\max } \\
\left(\mathrm{s}^{-1}\right)^{\mathrm{b}}\end{array}$ & $\begin{array}{l}\left(k_{\text {cat }} / K_{\mathrm{M}}\right)_{\max } \\
\left(\mathrm{M}^{-1} \cdot \mathrm{s}^{-1}\right)^{\mathrm{b}}\end{array}$ \\
\hline 1 & $\begin{array}{l}{[\mathrm{Hg}(\mathrm{II})]\left[\mathrm{Zn}(\mathrm{II})\left(\mathrm{H}_{2} \mathrm{O} / \mathrm{OH}^{-}\right)\right]} \\
\quad\left(\text { TRIL9CL23H) }{ }_{3}{ }^{n+c}\right.\end{array}$ & 7.5 & 0.0022 & 1.6 & 1.38 & 0.8 & \multirow{2}{*}{$\sim 0.053$} & \multirow{2}{*}{31} \\
\hline 2 & $\begin{array}{c}{[\mathrm{Hg}(\mathrm{II})]\left[\mathrm{Zn}(\mathrm{II})\left(\mathrm{H}_{2} \mathrm{O} / \mathrm{OH}^{-}\right)\right]} \\
\quad(\text { TRIL9CL23H })_{3}{ }^{n+c}\end{array}$ & 9.0 & 0.038 & 2.1 & 17.6 & 0.22 & & \\
\hline 3 & $\begin{array}{c}{\left[\mathrm{Zn}(\mathrm{II})\left(\mathrm{H}_{2} \mathrm{O} / \mathrm{OH}^{-}\right)\right]} \\
{[\mathrm{Hg}(\mathrm{II})](\mathrm{TRIL9HL23C})_{3}{ }^{{ }^{n+}}}\end{array}$ & 7.5 & 0.0005 & 0.9 & 0.6 & $\sim 8$ & \multirow{2}{*}{$\sim 0.030$} & \multirow{2}{*}{24} \\
\hline 4 & $\begin{array}{c}{\left[\mathrm{Zn}(\mathrm{II})\left(\mathrm{H}_{2} \mathrm{O} / \mathrm{OH}^{-}\right)\right]} \\
{[\mathrm{Hg}(\mathrm{II})](\mathrm{TRIL9HL23C})_{3}{ }^{\mathrm{n+}}}\end{array}$ & 9.0 & 0.011 & 1.1 & 9.7 & 0.8 & & \\
\hline 5 & $\begin{array}{c}{[\mathrm{Hg}(\mathrm{II})]\left[\mathrm{Zn}(\mathrm{II})\left(\mathrm{H}_{2} \mathrm{O} / \mathrm{OH}^{-}\right)\right]} \\
(\mathrm{TRIL9CL} 19 \mathrm{H})_{3}{ }^{\mathrm{n}_{+}}\end{array}$ & 7.5 & 0.0014 & 4.2 & 0.33 & 3.7 & \multirow{2}{*}{$\sim 0.076$} & \multirow{2}{*}{27} \\
\hline 6 & $\begin{array}{l}{[\mathrm{Hg}(\mathrm{II})]\left[\mathrm{Zn}(\mathrm{II})\left(\mathrm{H}_{2} \mathrm{O} / \mathrm{OH}^{-}\right)\right]} \\
\quad\left(\text { TRIL9CL19H) }{ }_{3}{ }^{{ }^{+}+}\right.\end{array}$ & 9.0 & 0.010 & 2.3 & 4.5 & 0.4 & & \\
\hline 7 & {$\left[\mathrm{Zn}(\mathrm{II})\left(\mathrm{H}_{2} \mathrm{O} / \mathrm{OH}^{-}\right)\right](\mathrm{TRIL} 2 \mathrm{WL} 23 \mathrm{H})_{3}{ }^{\mathrm{n}+}$} & 7.5 & 0.0011 & 2.7 & 0.41 & 0.6 & \multirow{2}{*}{$\sim 0.055$} & \multirow{2}{*}{25} \\
\hline 8 & {$\left[\mathrm{Zn}(\mathrm{II})\left(\mathrm{H}_{2} \mathrm{O} / \mathrm{OH}^{-}\right)\right](\mathrm{TRIL} 2 \mathrm{WL} 23 \mathrm{H})_{3}{ }^{\mathrm{n}+}$} & 9.0 & 0.016 & 1.8 & 8.9 & 0.24 & & \\
\hline
\end{tabular}

a Reaction conditions: 10-20 $\mu \mathrm{M}$ active $\mathrm{Zn}$ (II)-bound peptide complex; values at pH 7.5 determined in $50 \mathrm{mM} \mathrm{HEPES}$; values at pH 9.0 determined in $50 \mathrm{mM}$ CHES; $25^{\circ} \mathrm{C}$. The error range of the kinetic parameters is not displayed for clarity. ${ }^{\mathrm{b}}$ Determined at optimized $\mathrm{pH} .{ }^{\mathrm{c}}$ Data reported by Pecoraro et al. ${ }^{462}$

Efficient and selective hydrolysis of organophosphates, especially those in nerve agents, has become increasingly important due the serious biological threat that these compounds pose. In 2012, Baker et al. repurposed a mouse adenosine deaminase to catalyze the hydrolysis of such an organophosphate. ${ }^{466}$ A coumarinyl analogue 314 of the nerve agent cyclosarin was efficiently hydrolyzed by the engineered zinc dependent enzyme PT3.3 (Scheme 89), and a catalytic efficiency $\left(k_{c a t} / K_{\mathrm{M}}\right)$ of $\sim 10^{4} \mathrm{M}^{-1} \cdot \mathrm{s}^{-1}$ was determined. This ArM was engineered via a combination of computational design and directed evolution. Initially, the PDB was screened for enzymes containing mononuclear zinc sites. These enzymes are known to catalyze hydrolysis in nature. A calculated model of the transition state for phosphate hydrolysis was subsequently docked into these scaffolds, beneficial hydrogen bonds in the active sites were engineered, and steric clashes were minimized. Out of a set of 12 designed enzymes, one showed a moderate catalytic activity $\left(k_{\text {cat }} / K_{M}=4 \mathrm{M}^{-1} \cdot \mathrm{s}^{-1}\right)$. Saturation mutagenesis of 12 residues surrounding the active site led to the identification of a variant with a $\sim 40$-fold improved catalytic efficiency (PT3.1, PDB entry 3T1G). Random mutagenesis using error-prone 
PCR and a point mutation in the active site (based on analysis of the crystal structure) further increased the activity. Overall, the catalytic efficiency towards the hydrolysis of diethyl 7-hydroxycoumarinyl phosphate 314 was improved by a factor of $10^{7}$. The designed artificial metalloenzyme (PT3.3) exceeded 140 turnovers. Based on a similar in silico design strategy relying on the Rosetta algorithm, Baker et al. have created artificial Diels-Alderases $^{467}$, Retro-Aldolases ${ }^{468}$ and Kemp-Eliminases. ${ }^{469}$ These engineered enzymes do not contain any catalytically active metal, are thus not included in this review. They do, however, demonstrate the huge potential of computational enzyme design combined with directed evolution.

Scheme 89: Hydrolysis of a coumarinyl analogue of cyclosarin 314 catalyzed by an in silico designed artificial metallo-hydrolase PT3.3.

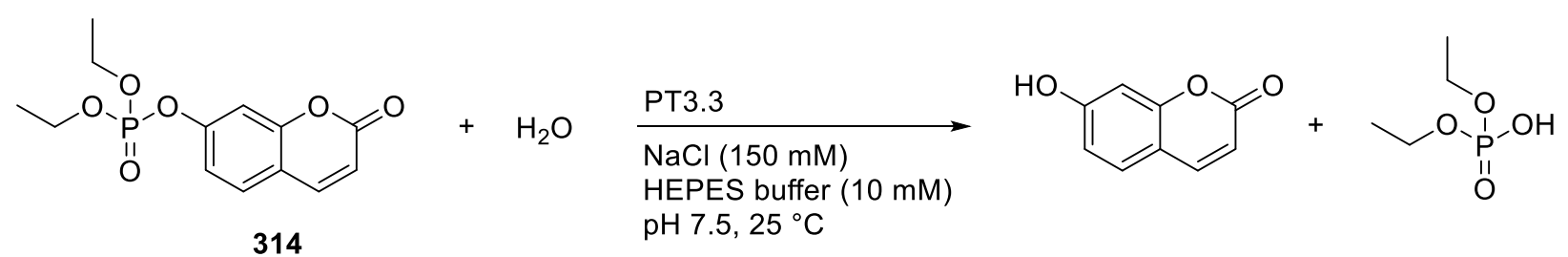

In 2012, Kuhlman reported an $\mathrm{Zn}(\mathrm{II})$-dependent ArM that catalyzed hydrolysis of 4nitrophenyl acetate or phosphate (315 or 316 respectively). ${ }^{470}$ A $5 \mathrm{kDa}$ helical hairpin monomer (Rab4-binding domain of rabenosyn) was used as a starting point to engineer a zinc-mediated homodimer (MID1-zinc). The construct bears two Zn(II)-binding sites at the protein interface. Analysis of the crystal structure (PDB entry 3V1C) revealed that only three out of the four designed histidine residues coordinate to zinc, thus suggesting a possible coordination site that may promote esterase activity. The $\mathrm{Zn}(\mathrm{His})_{3}$ motif, located in a $6.4 \AA$ protein cavity, indeed displayed hydrolase activity towards 4nitrophenyl acetate $\left(315, k_{\text {cat }} / K_{M}=630 \mathrm{M}^{-1} \cdot \mathrm{s}^{-1}, \max . \mathrm{TON}=50\right)$ and 4-nitrophenyl phosphate $316\left(k_{\mathrm{cat}} / K_{\mathrm{M}}=14 \mathrm{M}^{-1} \cdot \mathrm{s}^{-1}\right)$, Scheme 90 . Mutagenesis of the three zinc- 
coordinating histidines to alanines led to a complete loss of esterase activity, suggesting that indeed the $\mathrm{Zn}(\mathrm{His})_{3}$ motif is required for catalysis.

Scheme 90: Hydrolytic activity of MID1-zinc towards 4-nitrophenyl acetate (315) and 4nitrophenyl phosphate (316).<smiles>[R]Oc1ccc([N+](=O)[O-])cc1</smiles><smiles>[R]C(C)=O</smiles>

Similar to the previous report from Kim and Benkovic et al., Tezcan engineered an ArM $\beta$-lactamase to hydrolyze an antibiotic. The Tezcan system, however, involved $\mathrm{Zn}(\mathrm{II})$ mediated self-assembly of four engineered cytochrome cb562 units, Figure 33.471 To stabilize the resulting $D_{2}$ symmetric tetramer, a total of 16 surface mutations including the introduction of zinc-coordination sites, hydrophobic interactions, and disulfide bonds were introduced. The designed supramolecular protein assemblies harbor eight $\mathrm{Zn}(\mathrm{II})$ ions (4 structural zinc sites and 4 catalytic zinc sites). Saturation mutagenesis of four individual amino acid positions surrounding the catalytic zinc sites led to the identification of a highly active variant (Zn8:A104/G57 AB34, PDB entry 4U9E). This ArM $\beta$ lactamase catalyzed the hydrolysis of ampicillin 317 and 4-nitrophenyl acetate 315 with catalytic efficiencies $\left(K_{c a t} / K_{M}\right)$ of $35090 \mathrm{M}^{-1} \cdot \mathrm{min}^{-1}$ and $296 \mathrm{M}^{-1} \cdot \mathrm{s}^{-1}$ respectively, Scheme 91. In vivo $\beta$-lactamase activity was demonstrated by expression and secretion of this construct into the periplasm of $E$. coli. Colonies successfully grew on LB-agar plates containing ampicillin $(0.8 \mathrm{mg} / \mathrm{l})$.

Scheme 91. An evolved artificial metallo $\beta$-lactamase $\mathrm{Zn}_{8}:{ }^{A 104 / G 57} \mathrm{AB} 34$ catalyzes the hydrolysis of ampicillin 317 and 4-nitrophenyl acetate 315. 
<smiles>CC1(C)S[C@@H]2C(NC(=O)C(N)c3ccccc3)C(=O)N2[C@H]1C(=O)O</smiles>

317<smiles>CC(=O)Oc1ccc([N+](=O)[O-])cc1</smiles>

$\underset{\mathrm{Zn}}{\stackrel{\mathrm{A}}{ } \cdot{ }^{\mathrm{A} 104 / \mathrm{G} 57} \mathrm{AB}_{4}}$ $\mathrm{pH} 9,25^{\circ} \mathrm{C}$<smiles>CC1(C)S[C@H](C(NC(=O)C(N)c2ccccc2)C(=O)O)NC1C(=O)O</smiles><smiles>CC(=O)O[N+](=O)c1ccc(O)cc1</smiles>

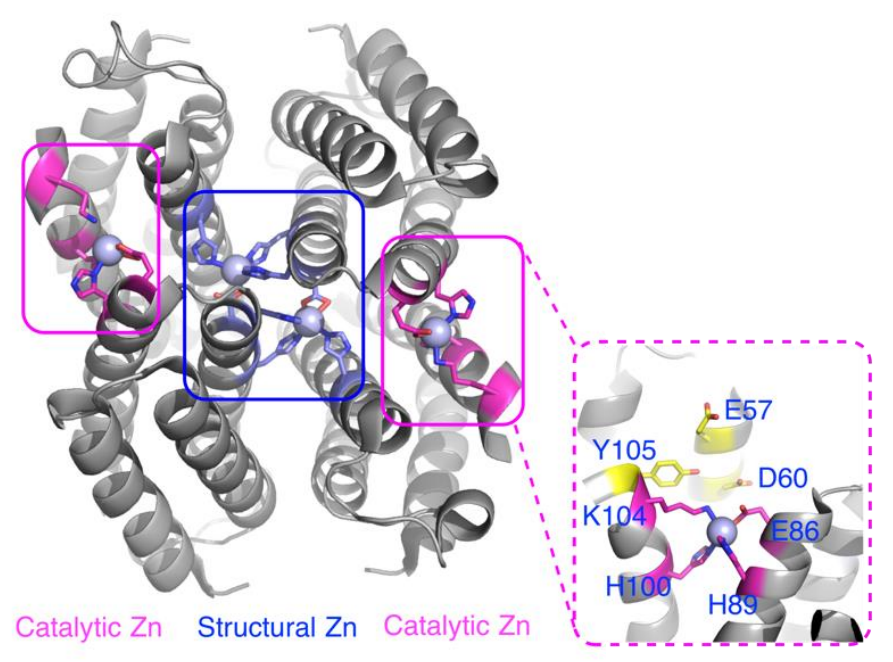

Figure 33. Cytochrome cb562 was engineered (PDB code 4U9E) to accommodate two structural and two catalytic zinc-binding sites affording $\beta$-lactamase activity. ${ }^{471}$

\subsection{Ligation Reaction}

In 2007, Szostak and Seelig introduced de novo RNA-ligase activity into human retinoidX-receptor (hRXRa). ${ }^{472}$ mRNA display-based screening of more than $10^{12}$ randomized two zinc-finger domains revealed highly active mutants towards the ligation of a 5'triphosphorylated RNA with the terminal 3'-hydroxyl group of a second RNA, Scheme $92 .{ }^{473}$ After 17 rounds of evolution, ligases performing several turnovers accompanied with a more than $2 \cdot 10^{6}$ fold rate enhancement were identified. Importantly, no initial catalytic activity or knowledge of the reaction mechanism was required to engineer this ligase activity. Structure determination of a highly active variant (ligase 10C, PDB entry 
2LZE) revealed substantial differences compared to the initial protein (hRXRa) ${ }^{474}$ The helical DNA recognition domain was replaced by a long unstructured loop and the protein adopted a cyclic structure, Figure 34 . The artificial ligase still contained two zincfinger domains, although four of the eight initial cysteine coordination sites were replaced by aspartate, glutamate or histidine. The enzyme maintained its high activity even at temperatures up to $65^{\circ} \mathrm{C} .4^{475}$
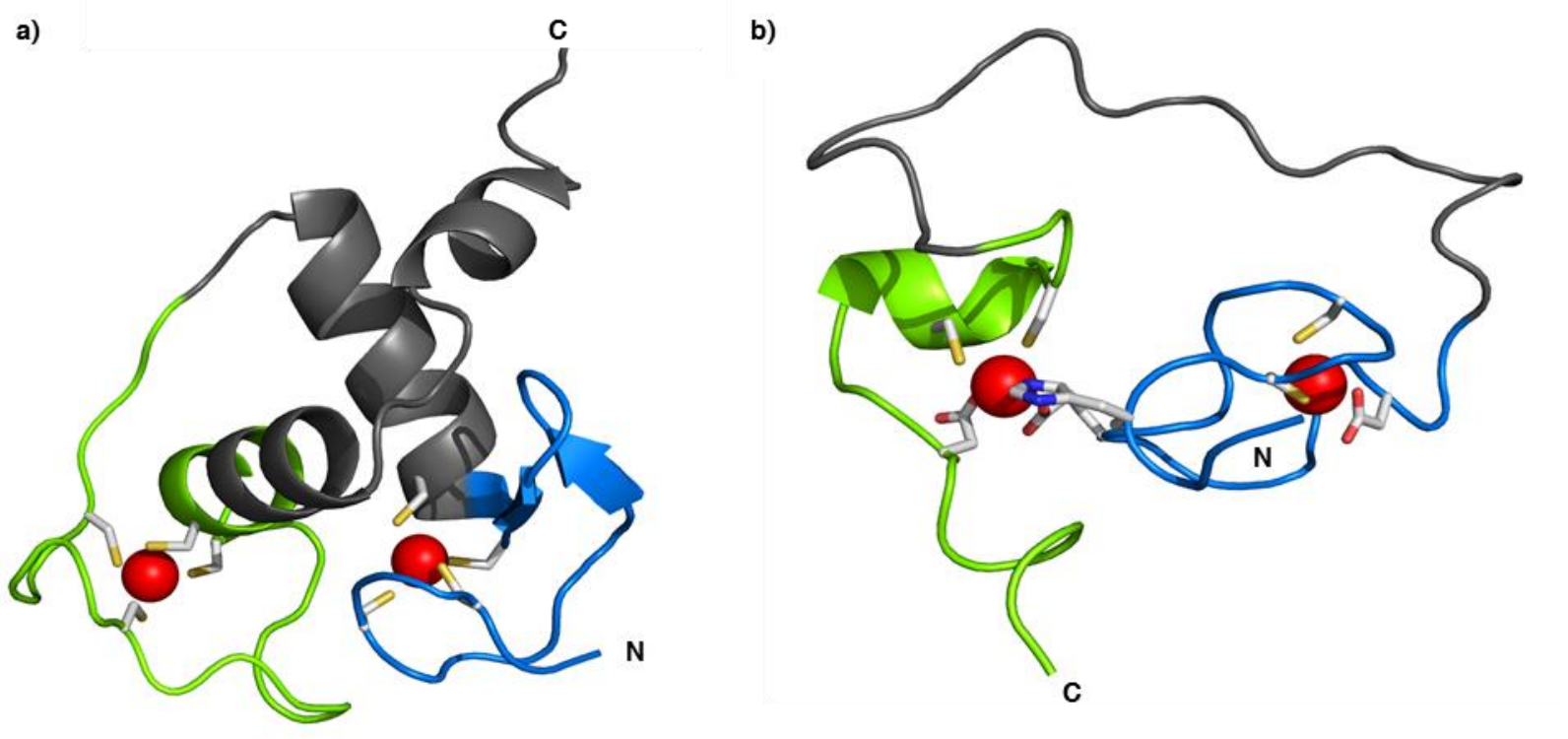

Figure 34. Cartoon representation of changes resulting from directed evolution of $h X R X a$ (PDB: 1RXR) to the ligase C10 (PDB: 2LZE). a) Comparison of the 3D structure of $h R X R a$ and $b$ ) the artificially evolved ligase. $\mathrm{N}$ and $\mathrm{C}$ termini omitted for clarity; the two zinc finger regions (Zn-I and $\mathrm{Zn}-\mathrm{II}$ ), in each scaffold, are highlighted in blue and green, respectively. Zinc-coordinating residues are shown as stick.

Scheme 92. In vitro selection of artificial ligase enzymes by mRNA display. A DNA library is transcribed and the corresponding mRNA modified with puromycin $(P)$ followed by in vitro translation. The zinc-finger proteins (linked to their genotype) catalyze the ligation of a 5'-triphosphate-activated RNA (PPP-substrate) with the terminal 3'-hydroxyl group of a second RNA (HO-substrate) bearing a biotin anchor (B). The mRNA is reverse-transcribed and the linked strands (Product) are immobilized on streptavidin (Sav)-coated beads. After selection, the constructs are released from the beads by UVirradiation of a photocleavable linker (PC). DNA is amplified/mutated by PCR and subjected to the next round of selection. Adapted with permission from ref. ${ }^{472}$ Copyright Macmillan Publishers Limited 2007. 


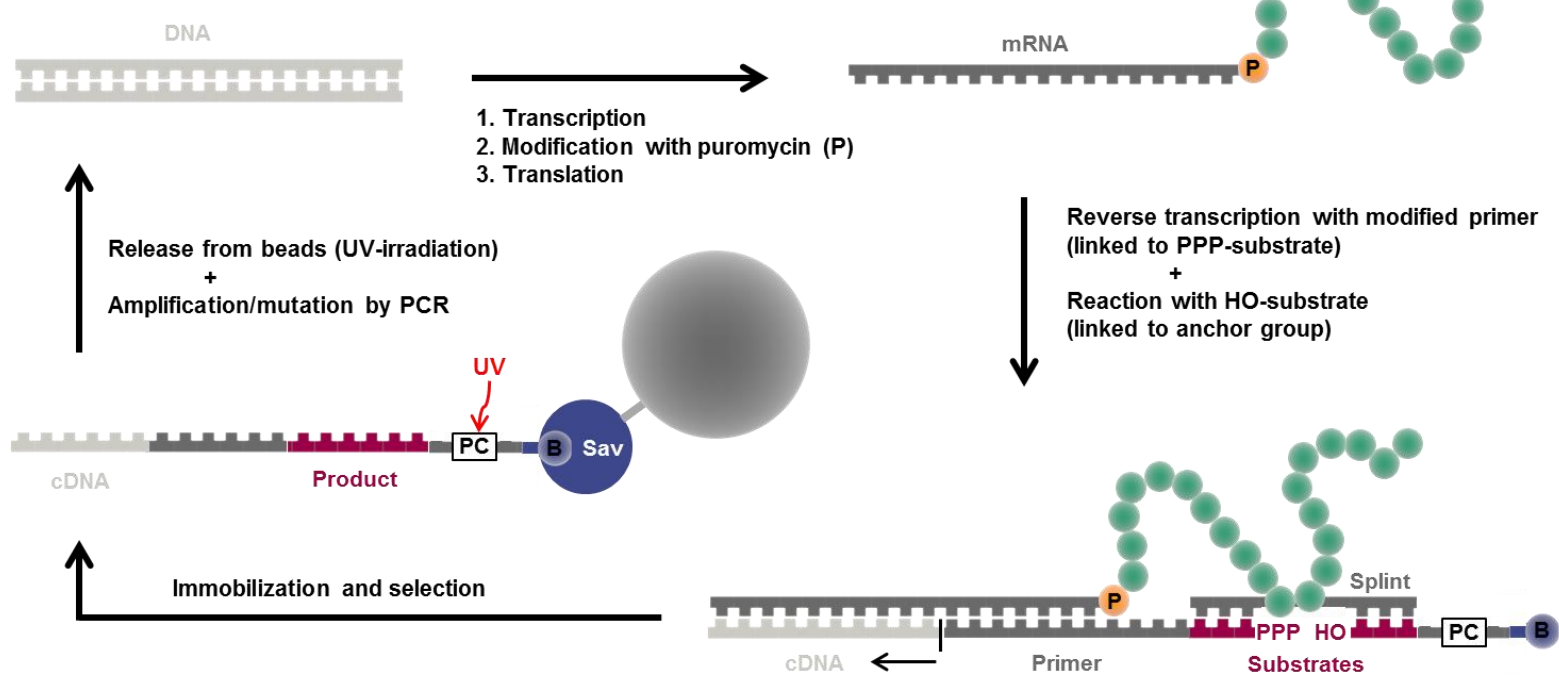

\subsection{Hydration of $\mathrm{C}=\mathrm{C}$ and $\mathrm{C}=\mathrm{O}$ Double Bonds}

In 2013, Roelfes et al. applied their previously designed LmrR-Cu(phen) Diels-Alderase (section 5.8) in the hydration of $\alpha, \beta$-unsaturated 2-acyl pyridine (Scheme 93). ${ }^{368}$ Slightly lower conversion and enantiomeric excess (up to $84 \%$ ee) were observed compared to the Diels-Alder reaction. The point mutants of this ArM also suggested that the two residues (F93, D100) at the front entrance had a crucial impact on both the activity and the selectivity.

Scheme 93. Selected results for hydration of $\alpha, \beta$-unsaturated 2-acyl pyridines.<smiles>[R]C=CC(=O)c1ccccn1</smiles><smiles>CC(C)(C)[C@H](O)CC(=O)c1ccccn1</smiles>

$82 \%$ yield, $75 \%$ ee
$80 \%$ yield, $84 \%$ ee<smiles>[R]C(O)CC(=O)c1ccccn1</smiles><smiles>CCCCC[C@H](O)CC(=O)c1ccccn1</smiles>

$90 \%$ yield, $57 \%$ ee<smiles>[X]CC(=O)Nc1cc2cccnc2c2ncccc12</smiles><smiles>O=C(C[C@@H](O)C1CCCCC1)c1ccccn1</smiles>

$40 \%$ yield, $64 \%$ ee 
A similar strategy was applied by Pecoraro et al. The previously designed ArM $[\mathrm{Hg}(\mathrm{II})]\left[\mathrm{Zn}(\mathrm{II})\left(\mathrm{H}_{2} \mathrm{O} / \mathrm{OH}^{-}\right)\right](\mathrm{TRIL9CL23H}) 3^{\mathrm{n+}}$ (section 7.1), a highly active hydrolase for 4nitrophenyl acetate 315 , displayed $\mathrm{CO}_{2}$ hydration activity (Table 39 , entry 1 ). In order to generalize their approach of de novo-designed ArMs, they switched from a threestranded coiled-coil motif to a single-stranded antiparallel three-helix bundle $\left(\alpha_{3} \mathrm{D}\right.$-motif, originally designed by DeGrado et al. ${ }^{476}$ ). Being single-stranded, this 73 amino acid protein allows the introduction of unique mutations (rather than mutations that are repeated with three-fold symmetry). The potential to improve the catalytic performance of ArMs derived from this scaffold is therefore expected to be higher. Indeed, Pecoraro et al. engineered $\mathrm{CO}_{2}$ hydration activity into this scaffold by mutagenesis (4 mutations) and elongation of the C-terminus (4 residues). ${ }^{477}$ Three leucine residues were replaced by histidines to form the catalytically active $\mathrm{Zn}(\mathrm{II})(\mathrm{His})_{3} \mathrm{O}$-site and an existing histidine was replaced by valine to avoid undesired $\mathrm{Zn}$ (II)-binding. The engineered protein $\left(\alpha_{3} \mathrm{DH}_{3}\right)$ bound $\mathrm{Zn}(\mathrm{II})$ with nanomolar affinity $\left(K_{\mathrm{d}}=59 \pm 9 \mathrm{nM}\right.$ at $\left.\mathrm{pH} 9.0\right)$ to form a highly active ArM (Table 39, entries 2-5 and Figure 35).

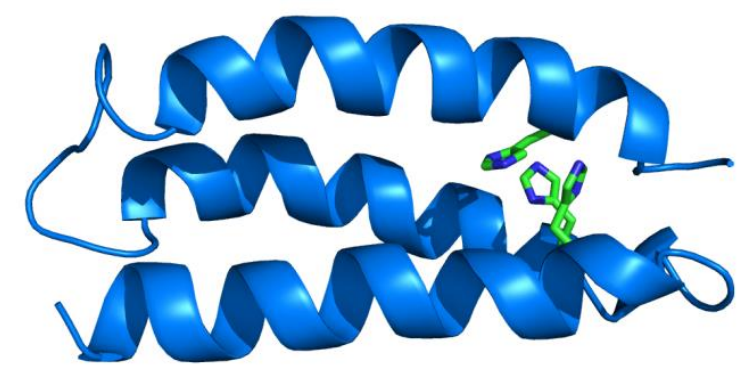

Figure 35. Side view of $\alpha_{3} \mathrm{DH}_{3}$ model built on $\alpha_{3} \mathrm{D}$ peptide structure (PDB: 2A3D). Highlighted, in each single chain of the three helix bundle, the His introduced for the coordination with $\mathrm{Zn}(\mathrm{II})$ ion (not displayed). Coordinating residues are represented as stick and coloured by element.

Table 39. Kinetics for $\mathrm{CO}_{2}$ hydration by natural and artificial metalloenzymes ${ }^{\mathrm{a}}$

\begin{tabular}{ccccccc}
\hline Entry & Protein & $\mathrm{pH}$ & $K_{\mathrm{M}}(\mathrm{mM})$ & $k_{\text {cat }}\left(\mathrm{s}^{-1}\right)$ & $k_{\text {cat }} / K_{\mathrm{M}}\left(\mathrm{M}^{-1} \cdot \mathrm{s}^{-1}\right)$ & $R^{2}$ \\
\hline 1 & {$[\mathrm{Hg}(\mathrm{II})]\left[\mathrm{Zn}(\mathrm{II})\left(\mathrm{H}_{2} \mathrm{O} / \mathrm{OH}-\right)\right](\mathrm{TRIL9CL23H})_{3}{ }^{\mathrm{n}+}$} & 9.5 & $10.0 \pm 2.4$ & $(1.8 \pm 0.4) \cdot 10^{3}$ & $(1.8 \pm 0.3) \cdot 10^{5}$ & 462 \\
2 & {$[\mathrm{Zn}(\mathrm{II})] \mathrm{a}_{3} \mathrm{DH}_{3}$} & 9.5 & $3.5 \pm 0.6$ & $134 \pm 8$ & $(3.8 \pm 0.5) \cdot 10^{4}$ & 477
\end{tabular}




\begin{tabular}{|c|c|c|c|c|c|c|}
\hline 3 & {$[\mathrm{Zn}(\mathrm{II})] \mathrm{a}_{3} \mathrm{DH}_{3}$} & 9.0 & $4.9 \pm 1.0$ & $103 \pm 8$ & $(2.1 \pm 0.3) \cdot 10^{4}$ & 477 \\
\hline 4 & {$[\mathrm{Zn}(\mathrm{II})] \mathrm{a}_{3} \mathrm{DH}_{3}$} & 8.5 & $7.2 \pm 1.1$ & $82 \pm 6$ & $(1.1 \pm 0.1) \cdot 10^{4}$ & 477 \\
\hline 5 & {$[\mathrm{Zn}(\mathrm{II})] \mathrm{a}_{3} \mathrm{DH}_{3}$} & 8.0 & $6.2 \pm 1.7$ & $39 \pm 4$ & $(0.63 \pm 0.1) \cdot 10^{4}$ & 477 \\
\hline 6 & hCAll & 8.8 & 8.9 & $8.2 \cdot 10^{5}$ & $9.2 \cdot 10^{7}$ & 478 \\
\hline 7 & hCAIII & 9.0 & 20 & $8 \cdot 10^{3}$ & $4 \cdot 10^{5}$ & 479 \\
\hline
\end{tabular}

\subsection{Lyases}

In 2011, DeGrado et al. engineered Kemp-eliminase activity into the $C$-terminal domain (last 75 residues) of calmodulin $(\mathrm{CaM})$, a $\mathrm{Ca}^{2+}$ binding EF-hand regulatory protein. ${ }^{480}$ Although the artificial enzyme does not contain a catalytically active metal center, its activity is allosterically regulated by the addition of $\mathrm{Ca}^{2+}$ ions. Upon binding of $\mathrm{Ca}^{2+}$, CaM undergoes a structural rearrangement and opens a hydrophobic pocket. De Grado et al. placed a general base (mutation F92E) at the bottom of the hydrophobic pocket (Figure 36), guided by computational design. This mutation afforded an active Kemp-eliminase (cCaM-F92E, PDB entry 2KZ2, Scheme 94$)$. A catalytic efficiency $\left(k_{\mathrm{cat}} / K_{\mathrm{M}}\right)$ of $5.8 \pm 0.3$ $\mathrm{M}^{-1} \cdot \mathrm{s}^{-1}$ was determined for cCaM-F92E, whereas the natural CaM showed no activity. The engineered protein exceeded 40 turnovers.

Scheme 94. Kemp elimination catalyzed by an engineered calmodulin variant cCaMF92E.
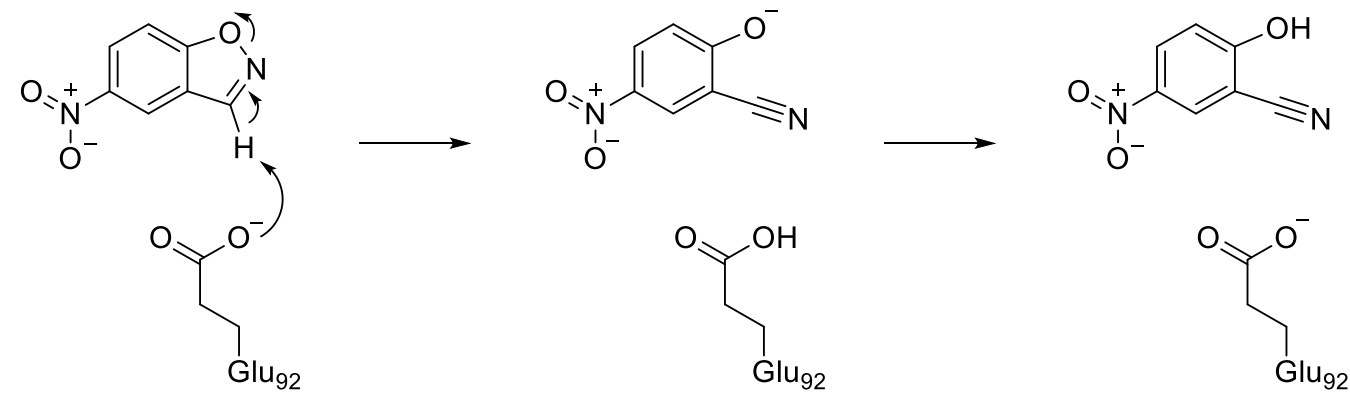


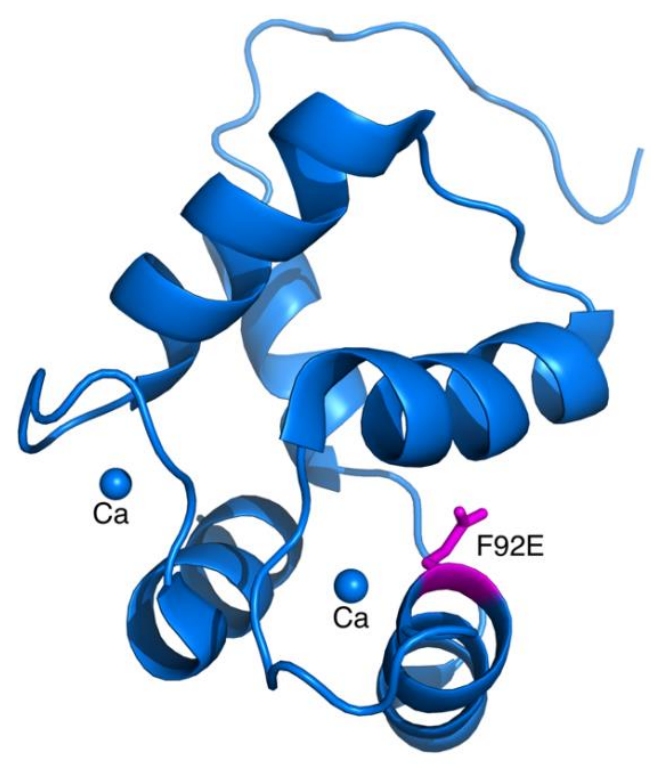

Figure 36. The C-terminal domain of calmodulin (PDB code $2 \mathrm{KZ2}$ ) is a $\mathrm{Ca}^{2+}$-dependent Kemp-Eliminase. ${ }^{480}$

Beside Kemp-eliminases, researchers have also designed ArMs to catalyze epoxide ring-opening reactions. In 2012, for example, Ueno et al. engineered such an artificial construct by covalently linking maleimide-substituted bipyridine cofactor 319 to a cysteine residue in $\left[(\mathrm{gp} 5 \mathrm{\beta f})_{3}\right]_{2}$ (sections 5.9 and 6.2). ${ }^{299}$ Metallation of this scaffold via addition of scandium ions led to the formation of $319 \cdot\left[(\mathrm{gp} 5 \beta \mathrm{\beta f})_{3}\right] 2$, which catalyzed the ring-opening of epoxide $\mathbf{3 1 6}$ with aniline as nucleophile. The reaction efficiency depended on the position of the bipyridine ligand 319 (Table 40). The ArM 319. $\left[(\mathrm{gp} 5 \beta \mathrm{f})_{3}\right]_{2}(\mathrm{G} 18 \mathrm{C})$ gave the highest TON (8.4) and ee (17\%). In contrast, trace amounts of racemic aminoalcohol $\mathbf{3 1 8}$ were produced by the mixture of $\left[(\mathrm{gp} 5 \beta \mathrm{ff})_{3}\right]_{2}$ lacking the critical cysteine residue and cofactor 320, Scheme 95.

Table 40. Selected results for the epoxide ring-opening reaction catalyzed by a $\mathrm{Sc}(\mathrm{bpy})$ complex anchored to $\left[(\mathrm{gp} 5 \beta \mathrm{f})_{3}\right] \mathrm{2}^{{ }^{\mathrm{a}}}$

\begin{tabular}{|c|c|c|c|c|c|c|c|c|}
\hline Entry & Cofactor1 & Protein & [Cof] $(\mu \mathrm{M})$ & Sub1. & Sub2. & $e e(\%)$ & TON & Ref \\
\hline 1 & 319 & {$\left[(\mathrm{gp} 5 \beta \mathrm{f})_{3}\right]_{2}(\mathrm{G} 18 \mathrm{C})$} & 200 & 316 & 317 & $17(1 R, 2 R)$ & 8.4 & 299 \\
\hline 2 & 319 & {$\left[(\mathrm{gp} 5 \beta \mathrm{f})_{3}\right]_{2}(\mathrm{~L} 47 \mathrm{C})$} & 200 & 316 & 317 & $9(1 S, 2 S)$ & 2.6 & 299 \\
\hline 3 & 319 & {$\left[(\mathrm{gp} 5 \beta \mathrm{f})_{3}\right]_{2}(\mathrm{~N} 51 \mathrm{C})$} & 200 & 316 & 317 & $1(1 S, 2 S)$ & 1.6 & 299 \\
\hline 4 & 320 & {$\left[(\mathrm{gp} 5 \beta \mathrm{f})_{3}\right]_{2}$} & 200 & 316 & 317 & - & trace & 299 \\
\hline
\end{tabular}


Scheme 95. Epoxide ring-opening reaction catalyzed by a Sc(bpy) complex covalently anchored to $\left[(\mathrm{gp} 5 \beta \mathrm{f})_{3}\right] 2$.

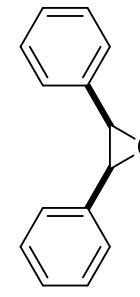

$4 \mathrm{mM}$

316

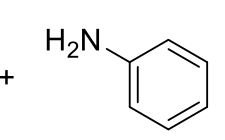

$4 \mathrm{mM}$

317
Sc(bpy) 319

$\left.[\mathrm{gp} 5 \beta \mathrm{f})_{3}\right]_{2}$

MOPS buffer $(10 \mathrm{mM}) / \mathrm{MeCN}=9: 1$ $\mathrm{pH} 7.5,40^{\circ} \mathrm{C}$

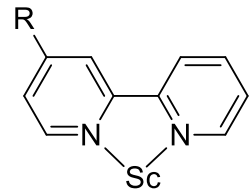

Sc(bpy)<smiles>OC(c1ccccc1)[C@H](Nc1ccccc1)c1ccccc1</smiles>

$(1 R, 2 R)$<smiles>O[C@H](c1ccccc1)C(Nc1ccccc1)c1ccccc1</smiles>

$(1 S, 2 S)$
318

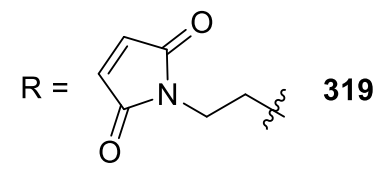

$\mathrm{R}=\mathrm{H} \quad 320$

As previously noted (section 4.1), Kamer has shown that a cysteine residue of photoactive yellow protein (PYP) can be selectively acylated with acylimidazolesubstituted reagents, and this approach has been used to incorporate phosphine ligands into PYP (Figure 37 a). ${ }^{441}$ The analogous reaction could also be achieved using the corresponding $\left[\mathrm{PdCl}\left(\eta^{3}-\mathrm{C}_{3} \mathrm{H}_{5}\right)\right]_{2}$ complexes of phosphines 234 and 235 (Figure $37 \mathrm{~b}$ ), and the resulting ArMs catalyzed allylic amination of 1,3-di-phenylprop-2-enyl acetate with benzylamine (Figure $37 \mathrm{c}$ ). No enantioselectivity was observed in this transformation, but the authors also noted that no conversion was observed using PYP lacking phosphine modification in the presence of $\left[\mathrm{PdCl}\left(\eta^{3}-\mathrm{C}_{3} \mathrm{H}_{5}\right)\right]_{2}$, showing that the observed amination reactions results from intact ArM. Denaturation of the PYP scaffold in the presence of the organic solvent required for substrate solubility was suggested as an explanation for the lack of enantioselectivity in this transformation. These authors later reported a two-step procedure for incorporating phosphines into proteins, though no catalysis was reported. ${ }^{481}$ 
a)<smiles>[R]C(=O)SCP</smiles>

b)<smiles>CC(C)(C)c1ccc(-c2ccccc2)cc1</smiles><smiles>[R5]CCCC(=O)n1ccnc1</smiles>

c)<smiles>CC(=O)O[C@H](/C=C/[PH2+]c1ccccc1)c1ccccc1</smiles>

Figure 37. a) Covalent modification of PYP using acylimidazole reagents. b) Acylimidazole-substituted phosphine ligands used to generate Pd-allyl ArMs. c) Allylic amination catalyzed by PYP-phosphine Pd-allyl ArMs. ${ }^{441}$

In addition to the 20 natural amino acids, researchers have also incorporated a variety of unnatural amino acids ${ }^{81}$ into designed ArM hydrolases. In 2013, Baker et al. designed an ArM relying on the unnatural amino acid (2,2'-bipyridin-5yl)alanine (Bpy-Ala, 237, Figure 26, see also the work of Schultz et al. in section 6.1). ${ }^{482}$ The engineered constructs bound divalent metal ions $\mathrm{Co}^{2+}, \mathrm{Zn}^{2+}, \mathrm{Fe}^{2+}$ and $\mathrm{Ni}^{2+}$. The highest affinity was determined for $\mathrm{Zn}^{2+}\left(\mathrm{K}_{\mathrm{d}} \sim 40 \mathrm{pM}\right)$. Analysis of the crystal structures of the nickel and cobalt-bound variants revealed an octahedral coordination provided by Bpy-Ala, a bidentate glutamate, an aspartate, and a water molecule. These constructs however do not display any catalytic activity.

Finally, an ArM transesterase that mimics the catalytic activity of an RNAse was generated by Mahy and coworkers using a "Trojan horse" strategy. The affinity of testosterone for variant 3.24 of neocarzinostatin (NCS hereafter) was previously exploited to anchor testosterone-linked metal cofactors to NCS. ${ }^{412}$ A testosteronesubstituted $\mathrm{Zn}$ complex, [Zn(N,N-(2-pyridylmethyl)2) Cl] 323, was prepared and used to 
generate an ArM transesterase upon binding to NCS $\left(K_{D}=4.0 \mu M\right){ }^{483}$ The zinc-moiety of cofactor $\mathbf{3 2 3}$ is rapidly aquated and the $\mathrm{Zn}(\mathrm{II})$ ion reduces the $\mathrm{p} K_{\mathrm{a}}$ of the bound water, leading to hydrolase activity. Docking studies suggest that the testosterone-moiety of 323 could bind the site 2 of NCS in a fashion that is reminiscent to the interaction in the (unsubstituted) testosterone-NCS complex. The lowest-energy docked $\mathbf{3 2 3}$ structure suggests that the catalytic-moiety is located in the site 1 of NCS, thus exerting a significant influence on the catalytic performance and paving the way for improvement through mutagenesis.

Scheme 96. Supramolecular anchoring of a $\left[\mathrm{N}\left(\mathrm{CH}_{2} \mathrm{Py}\right)_{2} \mathrm{ZnCl}\right]-$ moiety, via a testosterone "Trojan Horse", into neocarzinostatin (NCS) affords an artificial metalloenzyme displaying RNAse-like activity.

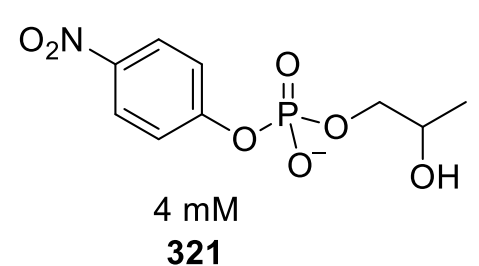

321

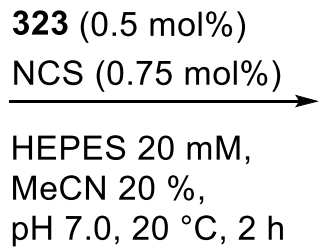

$\mathrm{pH} 7.0,20{ }^{\circ} \mathrm{C}, 2 \mathrm{~h}$<smiles>CC1COP(=O)([O-])O1</smiles>

322

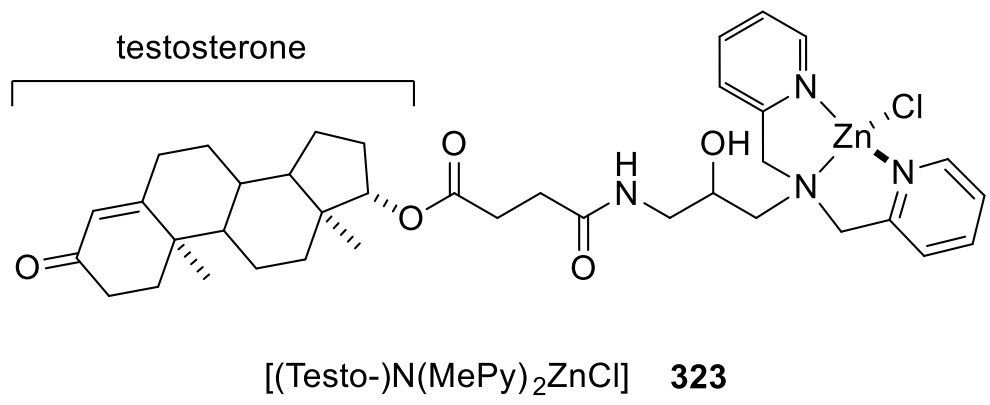

The ArM 323.NCS did not hydrolyze common DNA model compounds, such as bis $(p-$ nitrophenyl)phosphate. It did, however, catalyze the transesterification of phosphate $\mathbf{3 2 1}$ into 322, Scheme 96 . The involvement of a vicinal hydroxy-moiety is reminiscent to the activity of RNAse enzymes. The highest activity achieved was TOF $=3 \cdot 10^{-4} \mathrm{~s}^{-1}$, at $\mathrm{pH}$ 7.0. This is $\sim 800$ fold faster than the cofactor $\mathbf{3 2 3}$ alone, highlighting the positive influence of the NCS host protein. Saturation kinetics were determined for 323.NCS: $K_{M}$ $=22 \mu \mathrm{M}$ and a $k_{\text {cat }}=3 \cdot 10^{-4} \mathrm{~s}^{-1}$ resulting in an efficiency $k_{\mathrm{cat}} / K_{\mathrm{M}}=13.6 \mathrm{M}^{-1} \cdot \mathrm{s}^{-1}$. 
Unfortunately, the protein rapidly denatures in solution, thus limiting the lifetime of 323.NCS. 


\section{Outlook}

The studies highlighted in this review showcase the wide range of metal complexes, protein scaffolds, and linkage strategies that have been used to generate ArMs to date. This diversity of components and methodologies has led to systems that catalyze an impressive range of challenging chemical reactions, many of which are not found in nature. Moreover, a range of approaches has been developed to optimize ArMs for chemo-, regio-, site-, and enantioselective catalysis. Early efforts toward this end involved altering cofactor linkage sites within scaffold proteins, ${ }^{145}$ altering cofactor structure, ${ }^{154}$ and exploring different scaffold/cofactor combinations to enable chemogenetic ArM optimization. ${ }^{177}$ Point mutations were later introduced into putative ArM active sites of scaffold proteins to improve ArM selectivity, ${ }^{173,416}$ and iterative targeted mutagenesis was subsequently reported. ${ }^{484}$ We anticipate that, despite the more pronounced effect of chemical variation of the cofactor on both activity and selectivity, the genetic optimization and the possibility to apply directed evolution schemes may be the method of choice for the optimization of ArMs in the close future, thanks to its ease of parallelization.

Despite these advances and many more since, ${ }^{39}$ ArM catalysis remains rather underdeveloped when compared to homogeneous transition metal catalysis or enzyme catalysis. Because of this, Whitesides' pronouncement regarding the practicality of $\mathrm{ArMs}^{2}$ remains true to this day. As noted in the introduction, fundamental advances in protein engineering ${ }^{485}$ and aqueous organometallic chemistry ${ }^{486}$ contributed to a resurgence in ArM research around the year 2000. Further improvements in ArM efficiency will require innovations that specifically address and exploit the hybrid structures of ArMs ${ }^{87}$ For example, while many studies have demonstrated the potential for protein scaffolds to control the selectivity of organometallic catalysts, the catalysts 
used are typically well-known from the organometallic literature and remain unmodified upon incorporation into protein scaffolds. The activity and selectivity of cofactors designed to interact synergistically with scaffold proteins via ligand exchange, ${ }^{321}$ electron transfer, ${ }^{296}$ or other means could be more extensively tuned or even uniquely activated via incorporation into proteins. Similarly, while a range of bioconjugation techniques have been used for cofactor incorporation, only a handful of these are compatible with complex media, including cell lysate (in vitro) or cytosol (in vivo). Transitioning to efficient bioorthogonal methods ${ }^{354,487}$ for covalent $^{354}$, non-covalent ${ }^{351}$, dative ${ }^{471}$, and substitutive $^{352}$ cofactor incorporation will ensure that ArM libraries can be readily generated as efficiently as for natural enzymes.

Just as methodology must be adapted to suit different aspects of the unique composition or ArMs, so too must our understanding of the structure and function of these catalysts, which currently lags far behind that of transition metal catalysts and enzymes. ArM characterization typically involves a battery of spectroscopy, mass spectrometry, and, in some cases, X-ray crystallography to ensure the desired composition. Evidence for specific scaffold-cofactor interactions (e.g. dative ligation of metal centers) is often presented, ${ }^{257,354}$ and many examples in which scaffold accelerated catalysis have been reported. ${ }^{44,321}$ On the other hand, the exact contributions to catalysis of the former and the origins of the latter remain unclear. Substrate binding interactions within ArM active sites remain almost completely unexplored. These are precisely the types of phenomena that natural enzymes have evolved to harness, ${ }^{488}$ so understanding how they have emerged in ArMs (albeit to only a primordial extent at this point) could improve our ability to design and evolve comparably efficient systems. Given the importance of protein scaffolds to the activity of natural metal cofactors, ${ }^{489}$ it is reasonable to hypothesize that large improvements in the activity and selectivity of synthetic catalysts could be achieved using properly designed protein scaffolds. Toward this end, far deeper 
biophysical studies into the nature of ArM catalysis, mirroring efforts in enzymology, are required. Similarly, significant improvements in computational approaches to design and simulate the structure and conformational dynamics or proteins containing synthetic metal catalysts will be required to provide insight into the molecular level events that occur during ArM catalysis. ${ }^{274,482,490}$

Advances in cofactor design, activation, and bioconjugation, along with improved understanding of ArM catalysis would facilitate development of what is perhaps the most important methodological hurdle limiting ArM catalysis: directed evolution. ${ }^{491}$ It is difficult to overstate the impact that directed evolution has had on biocatalysis in industry using natural enzymes (see also the introduction to this issue of Chemical Reviews.), ${ }^{163}$ and yet such efforts toward ArMs remain in their infancy. Reports to date have demonstrated that iterative targeted mutagenesis of residues proximal to metal cofactors (or at least their presumed location during catalysis) can improve ArM selectivity and activity. ${ }^{7}$ While similar approaches have of course been used to optimize natural enzymes, the true power of directed evolution and the great improvements and surprises in the activity of evolved enzymes have been realized not solely via mutation of active site residues but from functional screens and selections conducted on diverse populations of enzymes containing mutations throughout their structure. ${ }^{491}$

Unfortunately, random mutagenesis methods remain unexplored in part due to the small ArM library sizes that can be generated using existing cofactor incorporation methods, ${ }^{492}$ while targeted mutagenesis (outside of the putative ArM active site) is hindered by a lack of fundamental understanding of how distal scaffold mutations impact cofactor selectivity. Toward the latter point, for example, it is not obvious that phylogenetic tools used to generate targeted "smart libraries" of natural enzymes are applicable to ArMs given that the function of the two are completely unrelated. ${ }^{163}$ Nonetheless, adapting the full arsenal of library methodologies that are available for enzyme evolution, ranging 
from random mutagenesis and gene shuffling ${ }^{485}$ to combinatorial codon mutagenesis ${ }^{493}$ and chimeragenesis ${ }^{494}$, to ArMs will ensure that the latter can be evolved with the efficiency of the former. Genome mining to identify diverse homologues of relevant scaffolds and computations tools to identify new scaffolds based on sequence but (predicted) structural homology could also be highly beneficial for identifying new ArM scaffolds. ${ }^{495-496}$ Based on the success of evolved enzymes for practical applications, this would go a long way to establish whether ArMs can in fact have practical utility.

Despite the need for significant advances in our ability to engineer and understand ArMs, hints of their potential utility have already begun to emerge. The many enantioselective transformations highlighted above have certainly proven their worth for fine chemical synthesis. The few studies reported on the activity of immobilized ArMs suggest that significant improvements in the practicality of ArM catalysis could be realized using different immobilization procedures. ${ }^{259,} 262,316,334$ A key goal of future ArM research must be to develop such transformations that cannot be accomplished using small molecule or enzyme catalysts. In such cases, the added complexity of ArM formation relative to other systems might be offset by savings in other aspects of a process. Tandem processes involving enzyme and ArM catalysis have also been developed, ${ }^{263}$ and these illustrate the unique ability of ArMs to shield transition metals from species that would otherwise lead to catalyst death. Taking this possibility to the extreme, ArM catalysis in vivo ${ }^{351,497}$ could ultimately be used to augment metabolic pathways with synthetic reactions to expand the scope of biosynthesis ${ }^{498}$. Obviously much work remains before these possibilities can be realized, but recent progress in ArM catalysis and other areas of protein engineering and organometallic chemistry should encourage those willing to take on the challenges that lie ahead. 


\section{References}

1. Yamamura, K.; Kaiser, E. T., Studies on the Oxidase Activity of Copper(li) Carboxypeptidase A. J. Chem. Soc., Chem. Commun. 1976, 830-831.

2. Wilson, M. E.; Whitesides, G. M., Conversion of a Protein to a Homogeneous Asymmetric Hydrogenation Catalyst by Site-Specific Modification with a Diphosphinerhodium(I) Moiety. J. Am. Chem. Soc. 1978, 100, 306-307.

3. Chen, K.; Arnold, F. H., Tuning the Activity of an Enzyme for Unusual Environments: Sequential Random Mutagenesis of Subtilisin E for Catalysis in Dimethylformamide. Proc. Natl. Acad. Sci. U. S. A. $1993,90,5618-5622$.

4. Stemmer, W. P. C., Rapid Evolution of a Protein in Vitro by DNA Shuffling. Nature 1994, 370, 389391.

5. Powell, K. A.; Ramer, S. W.; Cardayré, S. B. d.; Stemmer, W. P. C.; Tobin, M. B.; Longchamp, P. F.; Huisman, G. W., Directed Evolution and Biocatalysis. Angew. Chem., Int. Ed. 2001, 40, 3948-3959.

6. Bloom, J. D.; Arnold, F. H., In the Light of Directed Evolution: Pathways of Adaptive Protein Evolution. Proc. Natl. Acad. Sci. U. S. A. 2009, 106, 9995-10000.

7. Reetz, M. T., Biocatalysis in Organic Chemistry and Biotechnology: Past, Present, and Future. J. Am. Chem. Soc. 2013, 135, 12480-12496.

8. Savile, C. K.; Janey, J. M.; Mundorff, E. C.; Moore, J. C.; Tam, S.; Jarvis, W. R.; Colbeck, J. C.; Krebber, A.; Fleitz, F. J.; Brands, J., Biocatalytic Asymmetric Synthesis of Chiral Amines from Ketones Applied to Sitagliptin Manufacture. Science 2010, 329, 305-309.

9. Hermanson, G. T., Bioconjugate Techniques. 3rd ed.; Elsevier: Oxford, 2013.

10. Yang, H.; Srivastava, P.; Zhang, C.; Lewis, J. C., A General Method for Artificial Metalloenzyme Formation through Strain-Promoted Azide-Alkyne Cycloaddition. ChemBioChem 2014, 15, 223227.

11. Jing, Q.; Okrasa, K.; Kazlauskas, R. J., Manganese-Substituted Alpha-Carbonic Anhydrase as an Enantioselective Peroxidase. Top. Organomet. Chem. 2009, 25, 45-61.

12. Coelho, P. S.; Brustad, E. M.; Kannan, A.; Arnold, F. H., Olefin Cyclopropanation Via Carbene Transfer Catalyzed by Engineered Cytochrome P450 Enzymes. Science 2013, 339, 307-310.

13. Renata, H.; Wang, Z. J.; Arnold, F. H., Expanding the Enzyme Universe: Accessing Non-Natural Reactions by Mechanism-Guided Directed Evolution. Angew. Chem., Int. Ed. 2015, 54, 3351-3367.

14. Bordeaux, M.; Tyagi, V.; Fasan, R., Highly Diastereoselective and Enantioselective Olefin Cyclopropanation Using Engineered Myoglobin-Based Catalysts. Angew. Chem., Int. Ed. 2015, 54, 1744-1748.

15. Qi, D.; Tann, C.-M.; Haring, D.; Distefano, M. D., Generation of New Enzymes Via Covalent Modification of Existing Proteins. Chem. Rev. 2001, 101, 3081-3111.

16. Thomas, C. M.; Ward, T. R., Design of Artificial Metalloenzymes. Appl. Organomet. Chem. 2005, 19, 35-39.

17. Thomas, C. M.; Ward, T. R., Artificial Metalloenzymes: Proteins as Hosts for Enantioselective Catalysis. Chem. Soc. Rev. 2005, 34, 337-346.

18. Letondor, C.; Ward, T. R., Artificial Metalloenzymes for Enantioselective Catalysis: Recent Advances. ChemBioChem 2006, 7, 1845-1852.

19. Creus, M.; Ward, T. R., Designed Evolution of Artificial Metalloenzymes: Protein Catalysts Made to Order. Org. Biomol. Chem. 2007, 5, 1835-1844.

20. Mao, J.; Ward, T. R., Artificial Metalloenzymes for Enantioselective Catalysis Based on the BiotinAvidin Technology. Chimia 2008, 62, 956-961.

21. Heinisch, T.; Ward, T. R., Design Strategies for the Creation of Artificial Metalloenzymes. Curr. Opin. Chem. Biol. 2010, 14, 184-199.

22. Heinisch, T.; Ward, T. R., Latest Developments in Metalloenzyme Design and Repurposing. Eur. J. Inorg. Chem. 2015, 3406-3418.

23. Dürrenberger, M.; Ward, T. R., Recent Achievments in the Design and Engineering of Artificial Metalloenzymes. Curr. Opin. Chem. Biol. 2014, 19, 99-106. 
24. Koehler, V.; Wilson, Y. M.; Lo, C.; Sardo, A.; Ward, T. R., Protein-Based Hybrid Catalysts-Design and Evolution. Curr. Opin. Biotechnol. 2010, 21, 744-752.

25. Pordea, A.; Ward, T. R., Artificial Metalloenzymes: Combining the Best Features of Homogeneous and Enzymatic Catalysis. Synlett 2009, 3225-3236.

26. Ringenberg, M. R.; Ward, T. R., Merging the Best of Two Worlds: Artificial Metalloenzymes for Enantioselective Catalysis. Chem. Commun. 2011, 47, 8470-8476.

27. Steinreiber, J.; T.R., W., Artificial Metalloenzymes as Selective Catalysts in Aqueous Media. Coord. Chem. Rev. 2008, 252, 751-766.

28. Steinreiber, J.; Ward, T. R., Artificial Metalloenzymes for Enantioselective Catalysis Based on the Biotin-Avidin Technology. In Topics in Organometallic Chemistry, Springer Berlin Heidelberg: 2008; Vol. 25, pp 93-112.

29. Ward, T. R., Artificial Metalloenzymes for Enantioselective Catalysis Based on the Noncovalent Incorporation of Organometallic Moieties in a Host Protein. Chem. - Eur. J. 2005, 11, 3798-3804.

30. Ward, T. R., Artificial Metalloenzymes: Enantioselective Catalysis and Beyond. Chimia 2010, 64, 850-852.

31. Ward, T. R., Artificial Metalloenzymes Based on the Biotin-Avidin Technology: Enantioselective Catalysis and Beyond. Acc. Chem. Res. 2011, 44, 47-57.

32. Ward, T. R.; Collot, J.; Gradinaru, J.; Loosli, A.; Skander, M.; Letondor, C.; Joseph, E.; Klein, G., Exploiting the Second Coordination Sphere: Proteins as Host for Enantioselective Catalysis. Chimia 2003, 57, 586-588.

33. Davies, C. L.; Dux, E. L.; Duhme-Klair, A. K., Supramolecular Interactions between Functional Metal Complexes and Proteins. Dalton Trans. 2009, 10141-10154.

34. Yu, F. T.; Cangelosi, V. M.; Zastrow, M. L.; Tegoni, M.; Plegaria, J. S.; Tebo, A. G.; Mocny, C. S.; Ruckthong, L.; Qayyum, H.; Pecoraro, V. L., Protein Design: Toward Functional Metalloenzymes. Chem. Rev. 2014, 114, 3495-3578.

35. Zastrow, M. L.; Pecoraro, V. L., Designing Functional Metalloproteins: From Structural to Catalytic Metal Sites. Coord. Chem. Rev. 2013, 257, 2565-2588.

36. Pamies, O.; Dieguez, M.; Bäckvall, J. E., Artificial Metalloenzymes in Asymmetric Catalysis: Key Developments and Future Directions. Adv. Synth. Catal. 2015, 357, 1567-1586.

37. Hoarau, M.; Hureau, C.; Gras, E.; Faller, P., Coordination Complexes and Biomolecules: A Wise Wedding for Catalysis Upgrade. Coord. Chem. Rev. 2016, 308, 445-459.

38. Heinisch, T.; Ward, T. R., Artificial Metalloenzymes Based on the Biotin-Streptavidin Technology: Challenges and Opportunities. Acc. Chem. Res. 2016, 49, 1711-1721.

39. Hyster, T. K.; Ward, T. R., Genetic Optimization of Metalloenzymes: Enhancing Enzymes for NonNatural Reactions. Angew. Chem., Int. Ed. 2016, 55, 7344-7357.

40. Mao, J.; Ward, T. R., Proteins as Host for Enantioselective Catalysis: Artificial Metalloenzymes Based on the Biotin-Streptavidin Technology. John Wiley \& Sons Ltd.: 2010; pp 361-376.

41. Praneeth, V. K. K.; Ward, T. R., Metal-Catalyzed Organic Transformations inside a Protein Scaffold Using Artificial Metalloenzymes. John Wiley \& Sons, Inc.: 2013; pp 203-219.

42. Wilson, Y. M.; Duerrenberger, M.; Ward, T. R. In Organometallic Chemistry in Protein Scaffolds, Wiley-VCH Verlag GmbH \& Co. KGaA: 2013; pp 215-241.

43. Chatterjee, A.; Ward, T. R., Recent Advances in the Palladium Catalyzed Suzuki-Miyaura CrossCoupling Reaction in Water. Catal. Lett. 2016, 146, 820-840.

44. Collot, J.; Humbert, N.; Skander, M.; Klein, G.; Ward, T. R., Artificial Metalloenzymes for Enantioselective Catalysis: The Phenomenon of Protein Accelerated Catalysis. J. Organomet. Chem. 2004, 689, 4868-4871.

45. Creus, M.; Ward, T. R., Design and Evolution of Artificial Metalloenzymes: Biomimetic Aspects. Prog. Inorg. Chem. 2012, 57, 203-253.

46. Koehler, V.; Ward, T. R., Concurrent Cross Metathesis and Enzymatic Oxidation. Enabling OffEquilibrium Transformations. ChemCatChem 2014, 6, 2191-2193.

47. Pordea, A.; Ward, T. R., Chemogenetic Protein Engineering: An Efficient Tool for the Optimization of Artificial Metalloenzymes. Chem. Commun. (Cambridge, U. K.) 2008, 4239-4249. 
48. Quinto, T.; Koehler, V.; Ward, T. R., Recent Trends in Biomimetic Nadh Regeneration. Top. Catal. 2014, 57, 321-331.

49. Ward, T. R., Artificial Enzymes Made to Order: Combination of Computational Design and Directed Evolution. Angew. Chem., Int. Ed. 2008, 47, 7802-7803.

50. Ward, T. R., Directed Evolution of Iridium-Substituted Myoglobin Affords Versatile Artificial Metalloenzymes for Enantioselective C-C Bond-Forming Reactions. Angew. Chem., Int. Ed. 2016, 55, 14909-14911.

51. Hayashi, T.; Hisaeda, Y., New Functionalization of Myoglobin by Chemical Modification of HemePropionates. Acc. Chem. Res. 2002, 35, 35-43.

52. Hayashi, T.; Sano, Y.; Onoda, A., Generation of New Artificial Metalloproteins by Cofactor Modification of Native Hemoproteins. Isr. J. Chem. 2015, 55, 76-84.

53. Inaba, H.; Kitagawa, S.; Ueno, T., Protein Needles as Molecular Templates for Artificial Metalloenzymes. Isr. J. Chem. 2015, 55, 40-50.

54. Maity, B.; Fujita, K.; Ueno, T., Use of the Confined Spaces of Apo-Ferritin and Virus Capsids as Nanoreactors for Catalytic Reactions. Curr. Opin. Chem. Biol. 2015, 25, 88-97.

55. Ueno, T.; Abe, S.; Yokoi, N.; Watanabe, Y., Coordination Design of Artificial Metalloproteins Utilizing Protein Vacant Space. Coord. Chem. Rev. 2007, 251, 2717-2731.

56. Yamaguchi, H.; Harada, A., Functionalized Antibodies as Biosensing Materials and Catalysts. Chem. Lett. 2008, 37, 1184-1189.

57. Artero, V.; Berggren, G.; Atta, M.; Caserta, G.; Roy, S.; Pecqueur, L.; Fontecave, M., From Enzyme Maturation to Synthetic Chemistry: The Case of Hydrogenases. Acc. Chem. Res. 2015, 48, 23802387.

58. Caserta, G.; Roy, S.; Atta, M.; Artero, V.; Fontecave, M., Artificial Hydrogenases: Biohybrid and Supramolecular Systems for Catalytic Hydrogen Production or Uptake. Curr. Opin. Chem. Biol. 2015, 25, 36-47.

59. Faiella, M.; Roy, A.; Sommer, D.; Ghirlanda, G., De Novo Design of Functional Proteins: Toward Artificial Hydrogenases. Biopolymers 2013, 100, 558-571.

60. Fukuzumi, S., Artificial Photosynthetic Systems for Production of Hydrogen. Curr. Opin. Chem. Biol. 2015, 25, 18-26.

61. Kandemir, B.; Chakraborty, S.; Guo, Y. X.; Bren, K. L., Semisynthetic and Biomolecular Hydrogen Evolution Catalysts. Inorg. Chem. 2016, 55, 467-477.

62. Mahy, J. P.; Marechal, J. D.; Ricoux, R., Various Strategies for Obtaining Oxidative Artificial Hemoproteins with a Catalytic Oxidative Activity: From "Hemoabzymes" to "Hemozymes"? J. Porphyrins Phthalocyanines 2014, 18, 1063-1092.

63. Mahy, J. P.; Marechal, J. D.; Ricoux, R., From "Hemoabzymes" to "Hemozymes": Towards New Biocatalysts for Selective Oxidations. Chem. Commun. (Cambridge, U. K.) 2015, 51, 2476-2494.

64. Marchi-Delapierre, C.; Rondot, L.; Cavazza, C.; Ménage, S., Oxidation Catalysis by Rationally Designed Artificial Metalloenzymes. Isr. J. Chem. 2015, 55, 61-75.

65. Mulfort, K. L.; Utschig, L. M., Modular Homogeneous Chromophore-Catalyst Assemblies. Acc. Chem. Res. 2016, 49, 835-843.

66. Onoda, A.; Hayashi, T., Artificial Hydrogenase: Biomimetic Approaches Controlling Active Molecular Catalysts. Curr. Opin. Chem. Biol. 2015, 25, 133-140.

67. Onoda, A.; Hayashi, T.; Salmain, M., Artificial Metalloenzymes Containing an Organometallic Active Site. In Bioorganometallic Chemistry: Applications in Drug Discovery, Biocatalysis, and Imaging, Wiley-VCH Verlag GmbH \& Co. KGaA: Weinheim, 2014; pp 305-337.

68. Simmons, T. R.; Berggren, G.; Bacchi, M.; Fontecave, M.; Artero, V., Mimicking Hydrogenases: From Biomimetics to Artificial Enzymes. Coord. Chem. Rev. 2014, 270, 127-150.

69. Bailey, J. B.; Subramanian, R. H.; Churchfield, L. A.; Tezcan, F. A., Metal-Directed Design of Supramolecular Protein Assemblies. Methods Enzymol. 2016, 580, 223-250.

70. Ball, Z. T., Designing Enzyme-Like Catalysts: A Rhodium(li) Metallopeptide Case Study. Acc. Chem. Res. 2013, 46, 560-570.

71. Ball, Z. T., Molecular Recognition in Protein Modification with Rhodium Metallopeptides. Curr. Opin. Chem. Biol. 2015, 25, 98-102. 
72. Chino, M.; Maglio, O.; Nastri, F.; Pavone, V.; DeGrado, W. F.; Lombardi, A., Artificial Diiron Enzymes with a De Novo Designed Four-Helix Bundle Structure. Eur. J. Inorg. Chem. 2015, 33713390.

73. Golynskiy, M. V.; Seelig, B., De Novo Enzymes: From Computational Design to Mrna Display. Trends Biotechnol. 2010, 28, 340-345.

74. Huang, P. S.; Boyken, S. E.; Baker, D., The Coming of Age of De Novo Protein Design. Nature 2016, 537, 320-327.

75. Korendovych, I. V.; DeGrado, W. F., Catalytic Efficiency of Designed Catalytic Proteins. Curr. Opin. Struct. Biol. 2014, 27, 113-121.

76. Maglio, O.; Nastri, F.; de Rosales, R. T. M.; Faiella, M.; Pavone, V.; DeGrado, W. F.; Lombardi, A., Diiron-Containing Metalloproteins: Developing Functional Models. C. R. Chim. 2007, 10, 703-720.

77. Mocny, C. S.; Pecoraro, V. L., De Novo Protein Design as a Methodology for Synthetic Bioinorganic Chemistry. Acc. Chem. Res. 2015, 48, 2388-2396.

78. Nastri, F.; Chino, M.; Maglio, O.; Bhagi-Damodaran, A.; Lu, Y.; Lombardi, A., Design and Engineering of Artificial Oxygen-Activating Metalloenzymes. Chem. Soc. Rev. 2016, 45, 5020-5054.

79. Sontz, P. A.; Song, W. J.; Tezcan, F. A., Interfacial Metal Coordination in Engineered Protein and Peptide Assemblies. Curr. Opin. Chem. Biol. 2014, 19, $42-49$.

80. Tebo, A. G.; Pecoraro, V. L., Artificial Metalloenzymes Derived from Three-Helix Bundles. Curr. Opin. Chem. Biol. 2015, 25, 65-70.

81. Xiao, H.; Schultz, P. G., At the Interface of Chemical and Biological Synthesis: An Expanded Genetic Code. Cold Spring Harbor Perspect. Biol. 2016, 8, 1-18.

82. Zastrow, M. L.; Pecoraro, V. L., Designing Hydrolytic Zinc Metalloenzymes. Biochemistry 2014, 53, 957-978.

83. Wieczorek, B.; Dijkstra, H. P.; Egmond, M. R.; Klein Gebbink, R. J. M.; van Koten, G., Incorporating Ece-Pincer Metal Complexes as Functional Building Blocks in Semisynthetic Metalloenzymes, Supramolecular Polypeptide Hybrids, Tamoxifen Derivatives, Biomarkers and Sensors. J. Organomet. Chem. 2009, 694, 812-822.

84. Rosati, F.; Roelfes, G., Artificial Metalloenzymes. ChemCatChem 2010, 2, 916-927.

85. Bos, J.; Roelfes, G., Artificial Metalloenzymes for Enantioselective Catalysis. Curr. Opin. Chem. Biol. 2014, 19, 135-143.

86. Drienovská, I.; Roelfes, G., Artificial Metalloenzymes for Asymmetric Catalysis by Creation of Novel Active Sites in Protein and DNA Scaffolds. Isr. J. Chem. 2015, 55, 21-31.

87. Lewis, J. C., Artificial Metalloenzymes and Metallopeptide Catalysts for Organic Synthesis. ACS Catal. 2013, 3, 2954-2975.

88. Lewis, J. C., Metallopeptide Catalysts and Artificial Metalloenzymes Containing Unnatural Amino Acids. Curr. Opin. Chem. Biol. 2015, 25, 27-35.

89. Palomo, J. M.; Filice, M., New Emerging Bio-Catalysts Design in Biotransformations. Biotechnol. Adv. 2015, 33, 605-613.

90. Ilie, A.; Reetz, M. T., Directed Evolution of Artificial Metalloenzymes. Isr. J. Chem. 2015, 55, 51-60.

91. Reetz, M. T., Artificial Metalloenzymes as Catalysts in Stereoselective Diels-Alder Reactions. Chem. Rec. 2012, 12, 391-406.

92. Petrik, I. D.; Liu, J.; Lu, Y., Metalloenzyme Design and Engineering through Strategic Modifications of Native Protein Scaffolds. Curr. Opin. Chem. Biol. 2014, 19, 67-75.

93. Deuss, P. J.; den Heeten, R.; Laan, W.; Kamer, P. C. J., Bioinspired Catalyst Design and Artificial Metalloenzymes. Chem. - Eur. J. 2011, 17, 4680-4698.

94. Doble, M. V.; Ward, A. C. C.; Deuss, P. J.; Jarvis, A. G.; Kamer, P. C. J., Catalyst Design in Oxidation Chemistry; from $\mathrm{KmnO}_{4}$ to Artificial Metalloenzymes. Bioorg. Med. Chem. 2014, 22, 5657-5677.

95. Kohler, V.; Ward, T. R., Design of a Functional Nitric Oxide Reductase within a Myoglobin Scaffold. ChemBioChem 2010, 11, 1049-1051.

96. Boersma, A. J.; Megens, R. P.; Feringa, B. L.; Roelfes, G., DNA-Based Asymmetric Catalysis. Chem. Soc. Rev. 2010, 39, 2083-2092.

97. Rioz-Martinez, A.; Roelfes, G., DNA-Based Hybrid Catalysis. Curr. Opin. Chem. Biol. 2015, 25, 8087. 
98. Park, S.; Sugiyama, H., DNA-Based Hybrid Catalysts for Asymmetric Organic Synthesis. Angew. Chem., Int. Ed. 2010, 49, 3870-3878.

99. Hoffmann, R.; Kabanov, A. A.; Golov, A. A.; Proserpio, D. M., Homo Citans and Carbon Allotropes: For an Ethics of Citation. Angew. Chem., Int. Ed. 2016, 55, 10962-10976.

100. Ward, T. R. Artificial Metalloenzymes: Update. http://www.chemie.unibas.ch/ ward/ [Accessed 20 May 2017]

101. Kagan, H. B., Historical Perspective. In Comprehensive Asymmetric Catalysis, Pfaltz, A.; Jacobsen, E. N., Eds. Springer-Verlag: Berlin Heidelberg Germany, 1999; Vol. 1, pp 9-30.

102. Blaser, H. U.; Spindler, F.; Studer, M., Enantioselective Catalysis in Fine Chemicals Production. Appl. Catal., A 2001, 221, 119-143.

103. Akabori, S.; Sakurai, S.; Izumi, Y.; Fujii, Y., An Asymmetric Catalyst. Nature 1956, 178, 323-324.

104. De Corte, S.; Hennebel, T.; De Gusseme, B.; Verstraete, W.; Boon, N., Bio-Palladium: From Metal Recovery to Catalytic Applications. Microb. Biotechnol. 2012, 5, 5-17.

105. Chankeshwara, S. V.; Indrigo, E.; Bradley, M., Palladium-Mediated Chemistry in Living Cells. Curr. Opin. Chem. Biol. 2014, 21, 128-135.

106. Yang, M.; Li, J.; Chen, P. R., Transition Metal-Mediated Bioorthogonal Protein Chemistry in Living Cells. Chem. Soc. Rev. 2014, 43, 6511-6526.

107. Cuatrecasas, P.; Fuchs, S.; Anfinsen, C. B., Catalytic Properties and Specificity of the Extracellular Nuclease of Staphylococcus Aureus. J. Biol. Chem. 1967, 242, 1541-1547.

108. Coleman, J. E., Metal Ion Dependent Binding of Sulphonamide to Carbonic Anhydrase. Nature 1967, 214, 193-194.

109. Tainer, J. A.; Roberts, V. A.; Getzoff, E. D., Metal-Binding Sites in Proteins. Curr. Opin. Biotechnol. 1991, 2, 582-591.

110. Lu, Y.; Berry, S. M.; Pfister, T. D., Engineering Novel Metalloproteins: Design of Metal-Binding Sites into Native Protein Scaffolds. Chem. Rev. 2001, 101, 3047-3080.

111. Darnall, D. W.; Birnbaum, E. R., Rare Earth Metal lons as Probes of Calcium lon Binding Sites in Proteins: Neodynium(lii) Acceleration of the Activation of Trypsinogen. J. Biol. Chem. 1970, 245, 6484-6486.

112. Gomez, J. E.; Birnbaum, E. R.; Darnall, D. W., The Metal Ion Acceleration of the Conversion of Trypsinogen to Trypsin. Lanthanide Ions as Calcium Ion Substitutes. Biochemistry 1974, 13, 37453750.

113. Sugimoto, T.; Kokubo, T.; Miyazaki, J.; Tanimoto, S.; Okano, M., Stereoselective Oxidation of Aromatic Sulfides and Sulfoxides in the Binding Domain of Bovine Serum Albumin. Bioorg. Chem. 1981, 10, 311-323.

114. Sugimoto, T.; Kokubo, T.; Miyazaki, J.; Tanimoto, S.; Okano, M., Stereoselective Formation of Aromatic Sulfoxides by Oxidation of Sulfides and Sulfoxides in the Presence of Bovine Serum Albumin. J. Chem. Soc., Chem. Commun. 1979, 1052-1053.

115. Sugimoto, T.; Kokubo, T.; Miyazaki, J.; Tanimoto, S.; Okano, M., Preparation of Optically Active Aromatic Sulfoxides of High Optical Purity by the Direct Oxidation of the Sulfides in the Presence of Bovine Serum Albumin. J. Chem. Soc., Chem. Commun. 1979, 402-404.

116. Kokubo, T.; Sugimoto, T.; Uchida, T.; Tanimoto, S.; Okano, M., The Bovine Serum Albumin-2Phenylpropane-1,2-Diolatodioxo-Osmium(Vi) Complex as an Enantioselective Catalyst for CisHydroxylation of Alkenes. J. Chem. Soc., Chem. Commun. 1983, 769-770.

117. Hannemann, F.; Bichet, A.; Ewen, K. M.; Bernhardt, R., Cytochrome P450 Systems-Biological Variations of Electron Transport Chains. Biochim. Biophys. Acta, Gen. Subj. 2007, 1770, 330-344.

118. O'Reilly, E.; Kohler, V.; Flitsch, S. L.; Turner, N. J., Cytochromes P450 as Useful Biocatalysts: Addressing the Limitations. Chem. Commun. 2011, 47, 2490-2501.

119. Mieyal, J. J.; Ackerman, R. S.; Blumer, J. L.; Freeman, L. S., Characterization of Enzyme-Like Activity of Human Hemoglobin. Properties of the Hemoglobin-P-450 Reductase-Coupled Aniline Hydroxylase System. J. Biol. Chem. 1976, 251, 3436-3441.

120. Kokubo, T.; Sassa, S.; Kaiser, E. T., Flavohemoglobin: A Semisynthetic Hydroxylase Acting in the Absence of Reductase. J. Am. Chem. Soc. 1987, 109, 606-607. 
121. Kuriyan, J.; Pahler, A.; Simon, R. J.; Kokubo, T.; Kaiser, E. T., The X-Ray Structure of Flavohemoglobin. A Semisynthetic Hydroxylase. J. Am. Chem. Soc. 1988, 110, 6261-6263.

122. Ilari, A.; Bonamore, A.; Farina, A.; Johnson, K. A.; Boffi, A., The X-Ray Structure of Ferric Escherichia Coli Flavohemoglobin Reveals an Unexpected Geometry of the Distal Heme Pocket. J. Biol. Chem. 2002, 277, 23725-23732.

123. Corey, D.; Schultz, P., Generation of a Hybrid Sequence-Specific Single-Stranded Deoxyribonuclease. Science 1987, 238, 1401-1403.

124. Sluka, J.; Horvath, S.; Bruist, M.; Simon, M.; Dervan, P., Synthesis of a Sequence-Specific DNACleaving Peptide. Science 1987, 238, 1129-1132.

125. Chen, C. H.; Sigman, D. S., Chemical Conversion of a DNA-Binding Protein into a Site-Specific Nuclease. Science 1987, 237, 1197-1201.

126. Ebright, R. H.; Ebright, Y. W.; Pendergrast, P. S.; Gunasekera, A., Conversion of a Helix-Turn-Helix Motif Sequence-Specific DNA Binding Protein into a Site-Specific DNA Cleavage Agent. Proc. Natl. Acad. Sci. U. S. A. 1990, 87, 2882-2886.

127. Mazzarelli, J. M.; Ermacora, M. R.; Fox, R. O.; Grindley, N. D. F., Mapping Interactions between the Catalytic Domain of Resolvase and Its DNA Substrate Using Cysteine-Coupled Edta-Iron. Biochemistry 1993, 32, 2979-2986.

128. Tullius, T. D., Physical Studies of Protein-DNA Complexes by Footprinting. Annu. Rev. Biophys. Biophys. Chem. 1989, 18, 213-237.

129. Hilvert, D., Critical Analysis of Antibody Catalysis. Annu. Rev. Biochem. 2000, 69, 751-793.

130. Iverson, B. L.; Lerner, R. A., Sequence-Specific Peptide Cleavage Catalyzed by an Antibody. Science 1989, 243, 1184-1188.

131. Sasaki, T.; Kaiser, E. T., Helichrome: Synthesis and Enzymic Activity of a Designed Hemeprotein. J. Am. Chem. Soc. 1989, 111, 380-381.

132. Cochran, A.; Schultz, P., Antibody-Catalyzed Porphyrin Metallation. Science 1990, 249, 781-783.

133. Cochran, A. G.; Schultz, P. G., Peroxidase-Activity of an Antibody Heme Complex. J. Am. Chem. Soc. 1990, 112, 9414-9415.

134. Harada, A.; Fukushima, H.; Shiotsuki, K.; Yamaguchi, H.; Oka, F.; Kamachi, M., Peroxidation of Pyrogallol by Antibody-Metalloporphyrin Complexes. Inorg. Chem. 1997, 36, 6099-6102.

135. Keinan, E.; Sinha, S. C.; Sinha-Bagchi, A.; Benory, E.; Ghozi, M. C.; Eshhar, Z.; Green, B. S., Towards Antibody-Mediated Metallo-Porphyrin Chemistry. Pure Appl. Chem. 1990, 62, 2013-2019.

136. Germanas, J. P.; Kaiser, E. T., Autoxidation of Ascorbic Acid Catalyzed by a Semisynthetic Enzyme. Biopolymers 1990, 29, 39-43.

137. Wuttke, D. S.; Gray, H. B.; Fisher, S. L.; Imperiali, B., Semisynthesis of Bipyridyl-Alanine Cytochrome C Mutants: Novel Proteins with Enhanced Electron-Transfer Properties. J. Am. Chem. Soc. 1993, 115, 8455-8456.

138. Wade, W. S.; Ashley, J. A.; Jahangiri, G. K.; McElhaney, G.; Janda, K. D.; Lerner, R. A., A Highly Specific Metal-Activated Catalytic Antibody. J. Am. Chem. Soc. 1993, 115, 4906-4907.

139. Martell, A. E., Vitamin B6-Catalyzed Reactions of Alpha-Amino and Alpha-Keto Acids: Model Systems. Acc. Chem. Res. 1989, 22, 115-124.

140. Imperiali, B.; Roy, R. S., Coenzyme-Amino Acid Chimeras: New Residues for the Assembly of Functional Proteins. J. Am. Chem. Soc. 1994, 116, 12083-12084.

141. Roy, R. S.; Imperiali, B., Pyridoxamine-Amino Acid Chimeras in Semisynthetic Aminotransferase Mimics. Protein Eng. 1997, 10, 691-698.

142. Willett, W. S.; Gillmor, S. A.; Perona, J. J.; Fletterick, R. J.; Craik, C. S., Engineered Metal Regulation of Trypsin Specificity. Biochemistry 1995, 34, 2172-2180.

143. Davies, R. R.; Distefano, M. D., A Semisynthetic Metalloenzyme Based on a Protein Cavity That Catalyzes the Enantioselective Hydrolysis of Ester and Amide Substrates. J. Am. Chem. Soc. 1997, $119,11643-11652$.

144. Ory, J. J.; Mazhary, A.; Kuang, H.; Davies, R. R.; Distefano, M. D.; Banaszak, L. J., Structural Characterization of Two Synthetic Catalysts Based on Adipocyte Lipid-Binding Protein. Protein Eng. 1998, 11, 253-261. 
145. Davies, R. R.; Kuang, H.; Qi, D.; Mazhary, A.; Mayaan, E.; Distefano, M. D., Artificial Metalloenzymes Based on Protein Cavities: Exploring the Effect of Altering the Metal Ligand Attachment Position by Site Directed Mutagenesis. Bioorg. Med. Chem. Lett. 1999, 9, 79-84.

146. Kuang, H.; Davies, R. R.; Distefano, M. D., Modulation of the Rate, Enantioselectivity, and Substrate Specificity of Semisynthetic Transaminases Based on Lipid Binding Proteins Using Site Directed Mutagenesis. Bioorg. Med. Chem. Lett. 1997, 7, 2055-2060.

147. Qi, D.; Kuang, H.; Distefano, M. D., Effects of Metal lons on the Rates and Enantioselectivities of Reactions Catalyzed by a Series of Semisynthetic Transaminases Created by Site Directed Mutagenesis. Bioorg. Med. Chem. Lett. 1998, 8, 875-880.

148. van de Velde, F.; Konemann, L.; van Rantwijk, F.; Sheldon, R. A., Enantioselective Sulfoxidation Mediated by Vanadium-Incorporated Phytase: A Hydrolase Acting as a Peroxidase. Chem. Commun. (Cambridge, U. K.) 1998, 1891-1892.

149. van de Velde, F.; Arends, I. W. C. E.; Sheldon, R. A., Vanadium-Catalysed Enantioselective Sulfoxidations: Rational Design of Biocatalytic and Biomimetic Systems. Top. Catal. 2000, 13, 259-265.

150. van de Velde, F.; Könemann, L.; van Rantwijk, F.; Sheldon, R. A., The Rational Design of Semisynthetic Peroxidases. Biotechnol. Bioeng. 2000, 67, 87-96.

151. Finn, M. G.; Lerner, R. A.; Barbas, C. F., Cofactor-Induced Refinement of Catalytic Antibody Activity: A Metal-Specific Allosteric Effect. J. Am. Chem. Soc 1998, 120, 2963-2964.

152. Barbas, C. F.; Heine, A.; Zhong, G.; Hoffmann, T.; Gramatikova, S.; Björnestedt, R.; List, B.; Anderson, J.; Stura, E. A.; Wilson, I. A. et al, Immune Versus Natural Selection: Antibody Aldolases with Enzymic Rates but Broader Scope. Science 1997, 278, 2085-2092.

153. Wagner, J.; Lerner, R. A.; Barbas, C. F., Efficient Aldolase Catalytic Antibodies That Use the Enamine Mechanism of Natural Enzymes. Science 1995, 270, 1797-1800.

154. Lin, C.-C.; Lin, C.-W.; Chan, A. S. C., Catalytic Hydrogenation of Itaconic Acid in a Biotinylated Pyrphos-Rhodium(I) System in a Protein Cavity. Tetrahedron: Asymmetry 1999, 10, 1887-1893.

155. Nimri, S.; Keinan, E., Antibody-Metalloporphyrin Catalytic Assembly Mimics Natural Oxidation Enzymes. J. Am. Chem. Soc. 1999, 121, 8978-8982.

156. Marchetti, M.; Mangano, G.; Paganelli, S.; Botteghi, C., A Protein-Rhodium Complex as an Efficient Catalyst for Two-Phase Olefin Hydroformylation. Tetrahedron Lett. 2000, 41, 3717-3720.

157. Bertucci, C.; Botteghi, C.; Giunta, D.; Marchetti, M.; Paganelli, S., Aqueous Biphasic Hydroformylation Catalysed by Protein-Rhodium Complexes. Adv. Synth. Catal. 2002, 344, 556562.

158. Eckl, R. W.; Priermeier, T.; Herrmann, W. A., Ix. ${ }^{1}$ mono- and Biphasic Asymmetric Hydroformylation with Rhodium Catalysts of the Diphosphine Ligand Naphos and Its Sulfonated Derivatives. J. Organomet. Chem. 1997, 532, 243-249.

159. Nicholas, K. M.; Wentworth, P., Jr.; Harwig, C. W.; Wentworth, A. D.; Shafton, A.; Janda, K. D., A Cofactor Approach to Copper-Dependent Catalytic Antibodies. Proc. Natl. Acad. Sci. U. S. A. 2002, 99, 2648-2653.

160. Smith, M., Synthetic DNA and Biology (Nobel Lecture). Angew. Chem., Int. Ed. 1994, 33, 12141221.

161. Mullis, K. B., The Polymerase Chain Reaction (Nobel Lecture). Angew. Chem., Int. Ed. 1994, 33, 1209-1213.

162. Kuchner, O.; Arnold, F. H., Directed Evolution of Enzyme Catalysts. Trends Biotechnol. 1997, 15, 523-530.

163. Bornscheuer, U. T.; Huisman, G. W.; Kazlauskas, R. J.; Lutz, S.; Moore, J. C.; Robins, K., Engineering the Third Wave of Biocatalysis. Nature 2012, 485, 185-194.

164. Kiss, G.; Çelebi-Ölçüm, N.; Moretti, R.; Baker, D.; Houk, K. N., Computational Enzyme Design. Angew. Chem., Int. Ed. 2013, 52, 5700-5725.

165. Reetz, M. T.; Rentzsch, M.; Pletsch, A.; Maywald, M., Towards the Directed Evolution of Hybrid Catalysts. Chimia 2002, 56, 721-723.

166. Reetz, M. T., Directed Evolution of Selective Enzymes and Hybrid Catalysts. Tetrahedron 2002, 58, 6595-6602. 
167. Kennedy, M. L.; Gibney, B. R., Metalloprotein and Redox Protein Design. Curr. Opin. Struct. Biol. 2001, 11, 485-490.

168. Case, M. A.; McLendon, G. L., Metal-Assembled Modular Proteins: Toward Functional Protein Design. Acc. Chem. Res. 2004, 37, 754-762.

169. Hill, R. B.; Raleigh, D. P.; Lombardi, A.; DeGrado, W. F., De Novo Design of Helical Bundles as Models for Understanding Protein Folding and Function. Acc. Chem. Res. 2000, 33, 745-754.

170. Osborn, J. A.; Jardine, F. H.; Young, J. F.; Wilkinson, G., Preparation and Properties of Tris(Triphenylphosphine)Halorhodium(I) and Some Reactions Thereof Including Catalytic Homogeneous Hydrogenation of Olefins and Acetylenes and Their Derivatives. J. Chem. Soc., A 1966, 1711-1732.

171. Mazurek, S.; Ward, T. R.; Novic, M., Counter Propagation Artificial Neural Networks Modeling of an Enantioselectivity of Artificial Metalloenzymes. Mol. Diversity 2007, 11, 141-152.

172. Skander, M.; Malan, C.; Ivanova, A.; Ward, T. R., Chemical Optimization of Artificial Metalloenzymes Based on the Biotin-Avidin Technology: (S)-Selective and Solvent-Tolerant Hydrogenation Catalysts Via the Introduction of Chiral Amino Acid Spacers. Chem. Commun. (Cambridge, U. K.) 2005, 4815-4817.

173. Skander, M.; Humbert, N.; Collot, J.; Gradinaru, J.; Klein, G.; Loosli, A.; Sauser, J.; Zocchi, A.; Gilardoni, F.; Ward, T. R., Artificial Metalloenzymes: (Strept)Avidin as Host for Enantioselective Hydrogenation by Achiral Biotinylated Rhodium-Diphosphine Complexes. J. Am. Chem. Soc. 2004, 126, 14411-14418.

174. Rusbandi, U. E.; Skander, M.; Ivanova, A.; Malan, C.; Ward, T. R., Second-Generation Artificial Hydrogenases Based on the Biotin-Avidin Technology: Improving Selectivity and Organic Solvent Tolerance by Introduction of an (R)-Proline Spacer. C. R. Chim. 2007, 10, 678-683.

175. Rusbandi, U. E.; Lo, C.; Skander, M.; Ivanova, A.; Creus, M.; Humbert, N.; Ward, T. R., Second Generation Artificial Hydrogenases Based on the Biotin-Avidin Technology: Improving Activity, Stability and Selectivity by Introduction of Enantiopure Amino Acid Spacers. Adv. Synth. Catal. 2007, 349, 1923-1930.

176. Klein, G.; Humbert, N.; Gradinaru, J.; Ivanova, A.; Gilardoni, F.; Rusbandi, U. E.; Ward, T. R., Tailoring the Active Site of Chemzymes by Using a Chemogenetic-Optimization Procedure: Towards Substrate-Specific Artificial Hydrogenases Based on the Biotin-Avidin Technology. Angew. Chem., Int. Ed. 2005, 44, 7764-7767.

177. Collot, J.; Gradinaru, J.; Humbert, N.; Skander, M.; Zocchi, A.; Ward, T. R., Artificial Metalloenzymes for Enantioselective Catalysis Based on Biotin-Avidin. J. Am. Chem. Soc. 2003, $125,9030-9031$.

178. Kruithof, C. A.; Casado, M. A.; Guillena, G.; Egmond, M. R.; van der Kerk-van Hoof, A.; Heck, A. J.; Klein Gebbink, R. J. M.; van-Koten, G., Lipase Active-Site-Directed Anchoring of Organometallics: Metallopincer/Protein Hybrids. Chem. - Eur. J. 2005, 11, 6869-6877.

179. Rutten, L.; Wieczorek, B.; Mannie, J.-P. B. A.; Kruithof, C. A.; Dijkstra, H. P.; Egmond, M. R.; Lutz, M.; Klein Gebbink, R. J. M.; Gros, P.; van-Koten, G., Solid-State Structural Characterization of Cutinase-Ece-Pincer-Metal Hybrids. Chem. - Eur. J. 2009, 17, $4270-4280$.

180. Wieczorek, B.; Snelders, D. J. M.; Dijkstra, H. P.; Versluis, K.; Lutz, M.; Spek, A. L.; Egmond, M. R.; Klein Gebbink, R. J. M.; van-Koten, G., Coordination Chemistry in Water of a Free and a LipaseEmbedded Cationic Ncn-Pincer Platinum Center with Neutral and Ionic Triarylphosphines. Organometallics 2012, 31, 2810-2820.

181. Basauri-Molina, M.; Riemersma, C. F.; Wurdemann, M. A.; Kleijn, H.; Klein Gebbink, R. J. M., Lipase Active Site Covalent Anchoring of $\mathrm{Rh}(\mathrm{Nhc})$ Catalysts: Towards Chemoselective Artificial Metalloenzymes. Chem. Commun. (Cambridge, U. K.) 2015, 51, 6792-6795.

182. Syska, H.; Herrmann, W. A.; Kühn, F. E., Water-Soluble Carbene Complexes as Catalysts for the Hydrogenation of Acetophenone under Hydrogen Pressure. J. Organomet. Chem. 2012, 703, 5662.

183. Wieczorek, B.; Träff, A.; Krumlinde, P.; Dijkstra, H. P.; Egmond, M. R.; van-Koten, G.; Bäckvall, J.E.; Klein Gebbink, R. J. M., Covalent Anchoring of a Racemization Catalyst to Calb-Beads: Towards Dual Immobilization of Dkr Catalysts. Tetrahedron Lett. 2011, 52, 1601-1604. 
184. Shang, G.; Li , W.; Zhang, X., Catalytic Asymmetric Synthesis,Transition Metal-Catalyzed Homogeneous Asymmetric Hydrogenation. John Wiley \& Sons, Inc.: 2010; 343.

185. Panella, L.; Broos, J.; Jin, J.; Fraaije, M. W.; Janssen, D. B.; Jeronimus-Stratingh, M.; Feringa, B. L.; Minnaard, A. J.; de Vries, J. G., Merging Homogeneous Catalysis with Biocatalysis; Papain as Hydrogenation Catalyst. Chem. Commun. 2005, 5656-5658.

186. den Heeten, R.; Munoz, B. K.; Popa, G.; Laan, W.; Kamer, P. C. J., Synthesis of Hybrid TransitionMetalloproteins Via Thiol-Selective Covalent Anchoring of Rh-Phosphine and Ru-Phenanthroline Complexes. Dalton Trans. 2010, 39, 8477-8483.

187. Yamaguchi, H.; Hirano, T.; Kiminami, H.; Taura, D.; Harada, A., Asymmetric Hydrogenation with Antibody-Achiral Rhodium Complex. Org. Biomol. Chem. 2006, 4, 3571-3573.

188. Jing, Q.; Okrasa, K.; Kazlauskas, R. J., Stereoselective Hydrogenation of Olefins Using RhodiumSubstituted Carbonic Anhydrase-a New Reductase. Chem. - Eur. J. 2009, 15, 1370-1376.

189. Reiner, T.; Jantke, D.; Marziale, A. N.; Raba, A.; Eppinger, J., Metal-Conjugated Affinity Labels: A New Concept to Create Enantioselective Artificial Metalloenzymes. ChemistryOpen 2013, 2, 5054.

190. Yan, T.; Feringa, B. L.; Barta, K., Iron Catalysed Direct Alkylation of Amines with Alcohols. Nat. Commun. 2014, 5, 5602.

191. Merel, D. S.; Gaillard, S.; Ward, T. R.; Renaud, J.-L., Achiral Cyclopentadienone Iron Tricarbonyl Complexes Embedded in Streptavidin: An Access to Artificial Iron Hydrogenases and Application in Asymmetric Hydrogenation. Catal. Lett. 2016, 146, 564-569.

192. Berggren, G.; Adamska, A.; Lambertz, C.; Simmons, T. R.; Esselborn, J.; Atta, M.; Gambarelli, S.; Mouesca, J. M.; Reijerse, E.; Lubitz, W. et al, Biomimetic Assembly and Activation of [Fefe]Hydrogenases. Nature 2013, 499, 66-69.

193. Esselborn, J.; Lambertz, C.; Adamska-Venkatesh, A.; Simmons, T.; Berggren, G.; Nothl, J.; Siebel, J.; Hemschemeier, A.; Artero, V.; Reijerse, E. et al, Spontaneous Activation of [Fefe]Hydrogenases by an Inorganic [2fe] Active Site Mimic. Nat. Chem. Biol. 2013, 9, 607-609.

194. Shima, S.; Chen, D. F.; Xu, T.; Wodrich, M. D.; Fujishiro, T.; Schultz, K. M.; Kahnt, J.; Ataka, K.; Hu, X. L., Reconstitution of [Fe]-Hydrogenase Using Model Complexes. Nat. Chem. 2015, 7, 995-1002.

195. Siebel, J. F.; Adamska-Venkatesh, A.; Weber, K.; Rumpel, S.; Reijerse, E.; Lubitz, W., Hybrid [Fefe]Hydrogenases with Modified Active Sites Show Remarkable Residual Enzymatic Activity. Biochemistry 2015, 54, 1474-1483.

196. Utschig, L. M.; Soltau, S. R.; Tiede, D. M., Light-Driven Hydrogen Production from Photosystem ICatalyst Hybrids. Curr. Opin. Chem. Biol. 2015, 25, 1-8.

197. Sano, Y.; Onoda, A.; Hayashi, T., A Hydrogenase Model System Based on the Sequence of Cytochrome C: Photochemical Hydrogen Evolution in Aqueous Media. Chem. Commun. (Cambridge, U. K.) 2011, 47, 8229-8231.

198. Onoda, A.; Kihara, Y.; Fukumoto, K.; Sano, Y.; Hayashi, T., Photoinduced Hydrogen Evolution Catalyzed by a Synthetic Diiron Dithiolate Complex Embedded within a Protein Matrix. ACS Catal. 2014, 4, 2645-2648.

199. Sauer, D. F.; Himiyama, T.; Tachikawa, K.; Fukumoto, K.; Onoda, A.; Mizohata, E.; Inoue, T.; Bocola, M.; Schwaneberg, U.; Hayashi, T. et al, A Highly Active Biohybrid Catalyst for Olefin Metathesis in Water: Impact of a Hydrophobic Cavity in a Beta-Barrel Protein. ACS Catal. 2015, 5, 7519-7522.

200. Onoda, A.; Fukumoto, K.; Arlt, M.; Bocola, M.; Schwaneberg, U.; Hayashi, T., A Rhodium Complex-Linked Beta-Barrel Protein as a Hybrid Biocatalyst for Phenylacetylene Polymerization. Chem. Commun. (Cambridge, U. K.) 2012, 48, 9756-9758.

201. Zhang, C.; Srivastava, P.; Ellis-Guardiola, K.; Lewis, J. C., Manganese Terpyridine Artificial Metalloenzymes for Benzylic Oxygenation and Olefin Epoxidation. Tetrahedron 2014, 70, 42454249.

202. Saintmartin, P.; Lespinat, P. A.; Fauque, G.; Berlier, Y.; Legall, J.; Moura, I.; Teixeira, M.; Xavier, A. V.; Moura, J. J. G., Hydrogen-Production and Deuterium-Proton Exchange-Reactions Catalyzed by Desulfovibrio Nickel(li)-Substituted Rubredoxins. Proc. Natl. Acad. Sci. U. S. A. 1988, 85, 93789380. 
203. Slater, J. W.; Shafaat, H. S., Nickel-Substituted Rubredoxin as a Minimal Enzyme Model for Hydrogenase. J. Phys. Chem. Lett. 2015, 6, 3731-3736.

204. Artero, V.; Bacchi, M.; Berggren, G.; Fontecave, M., Artificial Hydrogenases Based on Cobaloxime and Sperm-Whale Myoglobin. J. Biol. Inorg. Chem. 2014, 19, 8071-8082.

205. Hawecker, J.; Lehn, J. M.; Ziessel, R., Efficient Homogeneous Photochemical Hydrogen Generation and Water Reduction Mediated by Cobaloxime or Macrocyclic Cobalt Complexes. Nouv. J. Chim. 1983, 7, 271-277.

206. Kellett, R. M.; Spiro, T. G., Cobalt(I) Porphyrin Catalysts of Hydrogen Production from Water. Inorg. Chem. 1985, 24, 2373-2377.

207. Kleingardner, J. G.; Kandemir, B.; Bren, K. L., Hydrogen Evolution from Neutral Water under Aerobic Conditions Catalyzed by Cobalt Microperoxidase-11. J. Am. Chem. Soc. 2014, 136, 4-7.

208. Sommer, D. J.; Vaughn, M. D.; Ghirlanda, G., Protein Secondary-Shell Interactions Enhance the Photoinduced Hydrogen Production of Cobalt Protoporphyrin Ix. Chem. Commun. (Cambridge, $U$. K.) 2014, 50, 15852-15855.

209. Sommer, D. J.; Vaughn, M. D.; Clark, B. C.; Tomlin, J.; Roy, A.; Ghirlanda, G., Reengineering Cyt $\mathrm{B}_{562}$ for Hydrogen Production: A Facile Route to Artificial Hydrogenases. Biochim. Biophys. Acta, Bioenerg. 2016, 1857, 598-603.

210. Bediako, D. K.; Solis, B. H.; Dogutan, D. K.; Roubelakis, M. M.; Maher, A. G.; Lee, C. H.; Chambers, M. B.; Hammes-Schiffer, S.; Nocera, D. G., Role of Pendant Proton Relays and Proton-Coupled Electron Transfer on the Hydrogen Evolution Reaction by Nickel Hangman Porphyrins. Proc. Natl. Acad. Sci. U. S. A. 2014, 111, 15001-15006.

211. Helm, M. L.; Stewart, M. P.; Bullock, R. M.; DuBois, M. R.; DuBois, D. L., A Synthetic Nickel Electrocatalyst with a Turnover Frequency above $100,000 \mathrm{~S}^{-1}$ for $\mathrm{H}_{2}$ Production. Science 2011, 333, 863-866.

212. Bacchi, M.; Veinberg, E.; Field, M. J.; Niklas, J.; Matsui, T.; Tiede, D. M.; Poluektov, O. G.; IkedaSaito, M.; Fontecave, M.; Artero, V., Artificial Hydrogenases Based on Cobaloximes and Heme Oxygenase. ChemPlusChem 2016, 81, 1083-1089.

213. Utschig, L. M.; Silver, S. C.; Mulfort, K. L.; Tiede, D. M., Nature-Driven Photochemistry for Catalytic Solar Hydrogen Production: A Photosystem I-Transition Metal Catalyst Hybrid. J. Am. Chem. Soc. 2011, 133, 16334-16337.

214. Silver, S. C.; Niklas, J.; Du, P. W.; Poluektov, O. G.; Tiede, D. M.; Utschig, L. M., Protein Delivery of a Ni Catalyst to Photosystem I for Light-Driven Hydrogen Production. J. Am. Chem. Soc. 2013, 135, 13246-13249.

215. Soltau, S. R.; Dahlberg, P. D.; Niklas, J.; Poluektov, O. G.; Mulfort, K. L.; Utschig, L. M., Ru-ProteinCo Biohybrids Designed for Solar Hydrogen Production: Understanding Electron Transfer Pathways Related to Photocatalytic Function. Chem. Sci. 2016, 7, 7068-7078.

216. Soltau, S. R.; Niklas, J.; Dahlberg, P. D.; Poluektov, O. G.; Tiede, D. M.; Mulfort, K. L.; Utschig, L. M., Aqueous Light Driven Hydrogen Production by a Ru-Ferredoxin-Co Biohybrid. Chem. Commun. (Cambridge, U. K.) 2015, 51, 10628-10631.

217. Sano, Y.; Onoda, A.; Hayashi, T., Photocatalytic Hydrogen Evolution by a Diiron Hydrogenase Model Based on a Peptide Fragment of Cytochrome $C_{556}$ with an Attached Diiron Carbonyl Cluster and an Attached Ruthenium Photosensitizer. J. Inorg. Biochem. 2012, 108, 159-162.

218. Marshall, N. M.; Garner, D. K.; Wilson, T. D.; Gao, Y. G.; Robinson, H.; Nilges, M. J.; Lu, Y., Rationally Tuning the Reduction Potential of a Single Cupredoxin Beyond the Natural Range. Nature 2009, 462, 113-116.

219. Sandoval, C. A.; Noyori, R.; Zhou, Q. L.; Pfaltz, A.; Hou, X. L.; Yamamoto, H., An Overview of Recent Developments in Metal-Catalyzed Asymmetric Transformations In Organic Chemistry Breakthroughs and Perspectives, Wiley-VCH Verlag GmbH \& Co. KGaA: Weinheim, Germany, 2012; pp 335-366.

220. Kitamura, M.; Noyori, R., Hydrogenation and Transfer Hydrogenation. In Ruthenium in Organic Synthesis, Wiley-VCH Verlag GmbH \& Co. KGaA: Weinheim, FRG. , 2004.

221. Gladiali, S.; Alberico, E., Asymmetric Transfer Hydrogenation: Chiral Ligands and Applications. Chem. Soc. Rev. 2006, 35, 226-236. 
222. Xue, D.; Chen, Y.-C.; Cui, X.; Wang, Q.-W.; Zhu, J.; Deng, J.-G., Transfer Hydrogenation of Activated C $=C$ Bonds Catalyzed by Ruthenium Amido Complexes: Reaction Scope, Limitation and Enantioselectivity. J. Org. Chem. 2005, 70, 3584-3591.

223. Everaere, K.; Mortreux, A.; Carpentier, J.-F., Ruthenium(li)-Catalyzed Asymmetric Transfer Hydrogenation of Carbonyl Compounds with 2-Propanol and Ephedrine-Type Ligands. Adv. Synth. Catal. 2003, 345, 67-77.

224. Nixon, T. D.; Whittlesey, M. K.; Williams, J. M. J., Ruthenium-Catalysed Transfer Hydrogenation Reactions with Dimethylamine Borane. Tetrahedron Lett. 2011, 52, 6652-6654.

225. Lee, S.-H.; Nikonov, G. I., Transfer Hydrogenation of Ketones, Nitriles, and Esters Catalyzed by a Half-Sandwich Complex of Ruthenium. ChemCatChem 2015, 7, 107-113.

226. Mai, V. H.; Nikonov, G. I., Transfer Hydrogenation of Nitriles, Olefins, and N-Heterocycles Catalyzed by an N-Heterocyclic Carbene-Supported Half-Sandwich Complex of Ruthenium. Organometallics 2016, 35, 943-949.

227. Ratovelomanana-Vidal, V.; Phansavath, P.; Echeverria, P.-G.; Ayad, T., Recent Developments in Asymmetric Hydrogenation and Transfer Hydrogenation of Ketones and Imines through Dynamic Kinetic Resolution. Synthesis 2016, 48, 2523-2539.

228. Wang, D.; Astruc, D., The Golden Age of Transfer Hydrogenation. Chem. Rev. 2015, 115, 66216686.

229. Hashiguchi, S.; Fujii, A.; Takehara, J.; Ikariya, T.; Noyori, R., Asymmetric Transfer Hydrogenation of Aromatic Ketones Catalyzed by Chiral Ruthenium (Ii) Complexes. J. Am. Chem. Soc. 1995, 117, 7562-7563.

230. Noyori, R.; Hashiguchi, S., Asymmetric Transfer Hydrogenation Catalyzed by Chiral Ruthenium Complexes. Acc. Chem. Res. 1997, 30, 97-102.

231. Ikariya, T.; Murata, K.; Noyori, R., Bifunctional Transition Metal-Based Molecular Catalyst for Asymmetric Syntheses. Org. Biomol. Chem. 2006, 4, 393-406.

232. Zhou, X.; Wu, X.; Yang, B.; Xiao, J., Varying the Ratio of Formic Acid to Triethylamine Impacts on Asymmetric Transfer Hydrogenation of Ketones. J. Mol. Catal. A: Chem. 2012, 357, 133-140.

233. Wang, C.; Li, C.; Wu, X.; Pettman, A.; Xiao, J., Ph-Regulated Asymmetric Transfer Hydrogenation of Quinolines in Water. Angew. Chem., Int. Ed. 2009, 48, 6524-6528.

234. Wu, X.; Xiao, J., Hydrogenation and Transfer Hydrogenation in Water. In Metal-Catalyzed Reactions in Water, first ed.; Wiley-VCH Verlag GmbH \& Co. KGaA, : Weinheim, Germany., 2013; pp 173-242.

235. Pollard, D. J.; Kosjek, B.; Devine, P. N.; Moore, J. C., Advances in the Enzymatic Reduction of Ketones. Acc. Chem. Res. 2007, 40, 1412-1419.

236. Stuermer, R.; Hauer, B.; Hall, M.; Faber, K., Asymmetric Bioreduction of Activated C=C Bonds Using Enoate Reductases from the Old Yellow Enzyme Family. Curr. Opin. Chem. Biol. 2007, 11, 203-213.

237. Mitsukura, K.; Suzuki, M.; Shinoda, S.; Kuramoto, T.; Yoshida, T.; Nagasawa, T., Purification and Characterization of a Novel (R)-Imine Reductase from Streptomyces Sp. Gf3587. Biosci., Biotechnol., Biochem. 2011, 75, 1778-1782.

238. Hussain, S.; Leipold, F.; Man, H.; Wells, E.; France, S. P.; Mulholland, K. R.; Grogan, G.; Turner, N. J., An (R)-Imine Reductase Biocatalyst for the Asymmetric Reduction of Cyclic Imines. ChemCatChem 2015, 7, 579-583.

239. Scheller, P. N.; Fademrecht, S.; Hofelzer, S.; Pleiss, J.; Leipold, F.; Turner, N. J.; Nestl, B. M.; Hauer, B., Enzyme Toolbox: Novel Enantiocomplementary Imine Reductases. ChemBiochem 2014, 15, 2201-2204.

240. Letondor, C.; Pordea, A.; Humbert, N.; Ivanova, A.; Mazurek, S.; Novic, M.; Ward, T. R., Artificial Transfer Hydrogenases Based on the Biotin-(Strept)Avidin Technology: Fine Tuning the Selectivity by Saturation Mutagenesis of the Host Protein. J. Am. Chem. Soc. 2006, 128, 8320-8328.

241. Creus, M.; Pordea, A.; Rossel, T.; Sardo, A.; Letondor, C.; Ivanova, A.; LeTrong, I.; Stenkamp, R. E.; Ward, T. R., X-Ray Structure and Designed Evolution of an Artificial Transfer Hydrogenase. Angew. Chem., Int. Ed. 2008, 47, 1400-1404. 
242. Haquette, P.; Salmain, M.; Svedlung, K.; Martel, A.; Rudolf, B.; Zakrzewski, J.; Cordier, S.; Roisnel, T.; Fosse, C.; Jaouen, G., Cysteine-Specific, Covalent Anchoring of Transition Organometallic Complexes to the Protein Papain from Carica Papaya. ChemBioChem 2007, 8, 224-231.

243. Haquette, P.; Talbi, B.; Canaguier, S.; Dagorne, S.; Fosse, C.; Martel, A.; Jaouen, G.; Salmain, M., Functionalized Cationic $\left(\mathrm{H}^{(6)}\right.$-Arene)Ruthenium(li) Complexes for Site-Specific and Covalent Anchoring to Papain from Papaya Latex. Synthesis, X-Ray Structures and Reactivity Studies. Tetrahedron Lett. 2008, 49, 4670-4673.

244. Madern, N.; Talbi, B.; Salmain, M., Aqueous Phase Transfer Hydrogenation of Aryl Ketones Catalysed by Achiral Ruthenium(li) and Rhodium(lii) Complexes and Their Papain Conjugates. Appl. Organomet. Chem. 2013, 27, 6-12.

245. Madern, N.; Queyriaux, N.; Chevalley, A.; Ghasemi, M.; Nicolotti, O.; Ciofini, I.; Mangiatordi, G. F.; Salmain, M., Piano-Stool D(6)-Rhodium(lii) Complexes of Chelating Pyridine-Based Ligands and Their Papain Bioconjugates for the Catalysis of Transfer Hydrogenation of Aryl Ketones in Aqueous Medium. J. Mol. Catal. B: Enzym. 2015, 122, 314-322.

246. Chevalley, A.; Salmain, M., Enantioselective Transfer Hydrogenation of Ketone Catalysed by Artificial Metalloenzymes Derived from Bovine Beta-Lactoglobulin. Chem. Commun. (Cambridge, U. K.) 2012, 48, 11984-11986.

247. Chevalley, A.; Cherrier, M. V.; Fontecilla-Camps, J. C.; Ghasemia, M.; Salmain, M., Artificial Metalloenzymes Derived from Bovine B-Lactoglobulin for the Asymmetric Transfer Hydrogenation of an Aryl Ketone - Synthesis, Characterization and Catalytic Activity. Dalton Trans. 2014, 43, 5482-5489.

248. Cherrier, M. V.; Engilberge, S.; Amara, P.; Chevalley, A.; Salmain, M.; Fontecilla-Camps, J. C., Structural Basis for Enantioselectivity in the Transfer Hydrogenation of a Ketone Catalyzed by an Artificial Metalloenzyme. Eur. J. Inorg. Chem. 2013, 2013, 3596-3600.

249. Tabe, H.; Abe, S.; Hikage, T.; Kitagawa, S.; Ueno, T., Porous Protein Crystals as Catalytic Vessels for Organometallic Complexes. Chem. Asian J. 2014, 9, 1373-1378.

250. McNae, I. W.; Fishburne, K.; Habtemariam, A.; Hunter, T. M.; Melchart, M.; Wang, F.; Walkinshaw, M. D.; Sadler, P. J., Half-Sandwich Arene Ruthenium(li)-Enzyme Complex. Chem. Commun. (Cambridge, U. K.) 2004, 1786-1787.

251. Durrenberger, M.; Heinisch, T.; Wilson, Y. M.; Rossel, T.; Nogueira, E.; Knorr, L.; Zimbron, M. J.; Pierron, J.; Mutschler, A.; Kersten, K. et al, Artificial Transfer Hydrogenases for the Enantioselective Reduction of Cyclic Imines. Angew. Chem., Int. Ed. 2011, 50, 3026-3029.

252. Schwizer, F.; Kohler, V.; Durrenberger, M.; Knorr, L.; Ward, T. R., Genetic Optimization of the Catalytic Efficiency of Artificial Imine Reductases Based on Biotin-Streptavidin Technology. ACS Catal. 2013, 3, 1752-1755.

253. Munoz Robles, V.; Vidossich, P.; Lledos, A.; Ward, T. R.; Marechal, J.-D., Computational Insights on an Artificial Imine Reductase Based on the Biotin-Streptavidin Technology. ACS Catal. 2014, 4, 833-842.

254. Munoz Robles, V.; Durrenberger, M.; Heinisch, T.; Lledos, A.; Schirmer, T.; Ward, T. R.; Marechal, J.-D., Structural, Kinetic, and Docking Studies of Artificial Imine Reductases Based on BiotinStreptavidin Technology: An Induced Lock-and-Key Hypothesis. J. Am. Chem. Soc. 2014, 136, 15676-15683.

255. Facchetti, G.; Gandolfi, R.; Fusè, M.; Zerla, D.; Cesarotti, E.; Pellizzoni, M. M.; Rimoldi, I., Simple 1,3-Diamines and Their Application as Ligands in Ruthenium(li) Catalysts for Asymmetric Transfer Hydrogenation of Aryl Ketones. New J. Chem. 2015, 39, 3792-3800.

256. Pellizzoni, M. M.; Gandolfi, R.; Fusè, M.; Facchetti, G.; Contini, A.; Isabella, R., Evaluation of Chemical Diversity of Biotinylated Chiral 1,3-Diamines as a Catalytic Moiety in Artificial Imine Reductase. ChemCatChem 2016, 1665-1670.

257. Zimbron, J. M.; Heinisch, T.; Schmid, M.; Hamels, D.; Nogueira, E. S.; Schirmer, T.; Ward, T. R., A Dual Anchoring Strategy for the Localization and Activation of Artificial Metalloenzymes Based on the Biotin-Streptavidin Technology. J. Am. Chem. Soc. 2013, 135, 5384-5388. 
258. Quinto, T.; Schwizer, F.; Zimbron, J. M.; Morina, A.; Koehler, V.; Ward, T. R., Expanding the Chemical Diversity in Artificial Imine Reductases Based on the Biotin-Streptavidin Technology. ChemCatChem 2014, 6, 1010-1014.

259. Hestericova, M.; Correro, M. R.; Lenz, M.; Corvini, P. F. X.; Shahgaldian, P.; Ward, T. R., Immobilization of an Artificial Imine Reductase within Silica Nanoparticles Improves Its Performance. Chem. Commun. (Cambridge, U. K.) 2016, 52, 9462-9465.

260. Fahey, R. C.; Brown, W. C.; Adams, W. B.; Worsham, M. B., Occurrence of Glutathione in Bacteria. J. Bacteriol. 1978, 133, 1126-1129.

261. Wilson, Y. M.; Durrenberger, M.; Nogueira, E. S.; Ward, T. R., Neutralizing the Detrimental Effect of Glutathione on Precious Metal Catalysts. J. Am. Chem. Soc. 2014, 136, 8928-8932.

262. Mallin, H.; Hestericova, M.; Reuter, R.; Ward, T. R., Library Design and Screening Protocol for Artificial Metalloenzymes Based on the Biotin-Streptavidin Technology. Nat. Protoc. 2016, 11, 835-852.

263. Kohler, V.; Wilson, Y. M.; Durrenberger, M.; Ghislieri, D.; Churakova, E.; Quinto, T.; Knorr, L.; Haussinger, D.; Hollmann, F.; Turner, N. J., Synthetic Cascades Are Enabled by Combining Biocatalysts with Artificial Metalloenzymes. Nat. Chem. 2013, 5, 93-99.

264. Haquette, P.; Talbi, B.; Barilleau, L.; Madern, N.; Fosse, C.; Salmain, M., Chemically Engineered Papain as Artificial Formate Dehydrogenase for Nad(P)H Regeneration. Org. Biomol. Chem. 2011, 9, 5720-5727.

265. Okamoto, Y.; Kohler, V.; Paul, C. E.; Hollmann, F.; Ward, T. R., Efficient in Situ Regeneration of Nadh Mimics by an Artificial Metalloenzyme. ACS Catal. 2016, 6, 3553-3557.

266. Quinto, T.; Haussinger, D.; Kohler, V.; Ward, T. R., Artificial Metalloenzymes for the Diastereoselective Reduction of $\mathrm{Nad}^{+}$to $\mathrm{Nadh}_{2}$. Org. Biomol. Chem. 2015, 13, 357-360.

267. Okamoto, Y.; Kohler, V.; Ward, T. R., An Nad(P)H-Dependent Artificial Transfer Hydrogenase for Multienzymatic Cascades. J. Am. Chem. Soc. 2016, 138, 5781-5784.

268. Liu, Z.; Lebrun, V.; Kitanosono, T.; Mallin, H.; Koehler, V.; Haeussinger, D.; Hilvert, D.; Kobayashi, S.; Ward, T. R., Upregulation of an Artificial Zymogen by Proteolysis. Angew. Chem., Int. Ed. 2016, 55, 11587-11590.

269. Mayer, C.; Hilvert, D., A Genetically Encodable Ligand for Transfer Hydrogenation. Eur. J. Org. Chem. 2013, 3427-3431.

270. Genz, M.; Koehler, V.; Krauss, M.; Singer, D.; Hoffmann, R.; Ward, T. R.; Straeter, N., An Artificial Imine Reductase Based on the Ribonuclease S Scaffold. ChemCatChem 2014, 6, 736-740.

271. Krishnamurthy, V. M.; Kaufman, G. K.; Urbach, A. R.; Gitlin, I.; Gudiksen, K. L.; Weibel, D. B.; Whitesides, G. M., Carbonic Anhydrase as a Model for Biophysical and Physical-Organic Studies of Proteins and Protein-Ligand Binding. Chem. Rev. 2008, 108, 946-1051.

272. Monnard, F. W.; Heinisch, T.; Nogueira, E. S.; Schirmer, T.; Ward, T. R., Human Carbonic Anhydrase li as a Host for Piano-Stool Complexes Bearing a Sulfonamide Anchor. Chem. Commun. (Cambridge, U. K.) 2011, 47, 8238-8240.

273. Monnard, F. W.; Nogueira, E. S.; Heinisch, T.; Schirmer, T.; Ward, T. R., Human Carbonic Anhydrase li as Host Protein for the Creation of Artificial Metalloenzymes: The Asymmetric Transfer Hydrogenation of Imines. Chem. Sci. 2013, 4, 3269-3274.

274. Heinisch, T.; Pellizzoni, M.; Durrenberger, M.; Tinberg, C. E.; Kohler, V.; Klehr, J.; Haussinger, D.; Baker, D.; Ward, T. R., Improving the Catalytic Performance of an Artificial Metalloenzyme by Computational Design. J. Am. Chem. Soc. 2015, 137, 10414-10419.

275. Watanabe, M.; Murata, K.; Ikariya, T., Enantioselective Michael Reaction Catalyzed by WellDefined Chiral Ru Amido Complexes: Isolation and Characterization of the Catalyst Intermediate, Ru Malonato Complex Having a Metal-Carbon Bond. J. Am. Chem. Soc. 2003, 125, 7508-7509.

276. Heinisch, T.; Langowska, K.; Tanner, P.; Reymond, J.-L.; Meier, W.; Palivan, C.; Ward, T. R., Fluorescence-Based Assay for the Optimization of the Activity of Artificial Transfer Hydrogenase within a Biocompatible Compartment. ChemCatChem 2013, 5, 720-723.

277. Palivan, C. G.; Goers, R.; Najer, A.; Zhang, X. Y.; Car, A.; Meier, W., Bioinspired Polymer Vesicles and Membranes for Biological and Medical Applications. Chem. Soc. Rev. 2016, 45, 377-411.

278. Franke, R.; Selent, D.; Börner, A., Applied Hydroformylation. Chem. Rev. 2012, 112, 5675-5732. 
279. Breit, B.; Seiche, W., Recent Advances on Chemo-, Regio- and Stereoselective Hydroformylation. Synthesis 2001, 1-36.

280. Bertini, I.; Luchinat, C.; Scozzafava, A., Carbonic Anhydrase: An Insight into the Zinc Binding Site and into the Active Cavity through Metal Substitution. In Biochemistry, Springer Berlin, Heidelberg, 1982; pp 45-92.

281. Jing, Q.; Kazlauskas, R. J., Regioselective Hydroformylation of Styrene Using Rhodium-Substituted Carbonic Anhydrase. ChemCatChem 2010, 2, 953-957.

282. Key, H. M.; Clark, D. S.; Hartwig, J. F., Generation, Characterization, and Tunable Reactivity of Organometallic Fragments Bound to a Protein Ligand. J. Am. Chem. Soc. 2015, 137, 8261-8268.

283. Shimahara, H.; Yoshida, T.; Shibata, Y.; Shimizu, M.; Kyogoku, Y.; Sakiyama, F.; Nakazawa, T.; Tate, S.-I.; Ohki, S.-Y.; Kato, T. et al, Tautomerism of Histidine 64 Associated with Proton Transfer in Catalysis of Carbonic Anhydrase. J. Biol. Chem. 2007, 282, 9646-9656.

284. Romao, C. V.; Vicente, J. B.; Borges, P. T.; Frazao, C.; Teixeira, M., The Dual Function of Flavodiiron Proteins: Oxygen and/or Nitric Oxide Reductases. J. Biol. Inorg. Chem. 2016, 21, 3952.

285. McQuarters, A. B.; Wirgau, N. E.; Lehnert, N., Model Complexes of Key Intermediates in Fungal Nitric Oxide Reductase (P450nor). Curr. Opin. Chem. Biol. 2014, 19, 82-89.

286. Hino, T.; Nagano, S.; Sugimoto, H.; Tosha, T.; Shiro, Y., Molecular Structure and Function of Bacterial Nitric Oxide Reductase. Biochim. Biophys. Acta, Bioenerg. 2012, 1817, 680-687.

287. Peterson, R. L.; Kim, S.; Karlin, K. D., Copper Enzymes. In Comprehensive Inorganic Chemistry li, Second ed.; Elsevier: Amsterdam, 2013; pp 149-177.

288. Maia, L. B.; Moura, J. J. G., Nitrite Reduction by Molybdoenzymes: A New Class of Nitric OxideForming Nitrite Reductases. J. Biol. Inorg. Chem. 2015, 20, 403-433.

289. Kirk, M. L.; Stein, B., Molybdenum Enzymes. In Comprehensive Inorganic Chemistry li Second ed.; Elsevier: Amsterdam, 2013; pp 263-293.

290. Hu, Y. L.; Ribbe, M. W., Nitrogenases-a Tale of Carbon Atom(S). Angew. Chem., Int. Ed. 2016, 55, 8216-8226.

291. Pessoa, J. C.; Garribba, E.; Santos, M. F. A.; Santos-Silva, T., Vanadium and Proteins: Uptake, Transport, Structure, Activity and Function. Coord. Chem. Rev. 2015, 301, 49-86.

292. Sigman, J. A.; Kwok, B. C.; Lu, Y., From Myoglobin to Heme-Copper Oxidase: Design and Engineering of a Cub Center into Sperm Whale Myoglobin. J. Am. Chem. Soc. 2000, 122, 81928196.

293. Zhao, X.; Yeung, N.; Russell, B. S.; Garner, D. K.; Lu, Y., Catalytic Reduction of No to $\mathrm{N}_{2} \mathrm{O}$ by a Designed Heme Copper Center in Myoglobin: Implications for the Role of Metal lons. J. Am. Chem. Soc. 2006, 128, 6766-6767.

294. Lu, Y.; Yeung, N.; Sieracki, N.; Marshall, N. M., Design of Functional Metalloproteins. Nature 2009, $460,855-862$.

295. Lin, Y.-W.; Yeung, N.; Gao, Y.-G.; Miner, K. D.; Lei, L.; Robinson, H.; Lu, Y., Introducing a 2-His-1Glu Nonheme Iron Center into Myoglobin Confers Nitric Oxide Reductase Activity. J. Am. Chem. Soc. 2010, 132, 9970-9972.

296. Ueno, T.; Yokoi, N.; Unno, M.; Matsui, T.; Tokita, Y.; Yamada, M.; Ikeda-Saito, M.; Nakajima, H.; Watanabe, Y., Design of Metal Cofactors Activated by a Protein-Protein Electron Transfer System. Proc. Natl. Acad. Sci. U. S. A. 2006, 103, 9416-9421.

297. Yokoi, N.; Miura, Y.; Huang, C. Y.; Takatani, N.; Inaba, H.; Koshiyama, T.; Kanamaru, S.; Arisaka, F.; Watanabe, Y.; Kitagawa, S. et al, Dual Modification of a Triple-Stranded Beta-Helix Nanotube with $\mathrm{Ru}$ and Re Metal Complexes to Promote Photocatalytic Reduction of $\mathrm{CO}_{2}$. Chem. Commun. (Cambridge, U. K.) 2011, 47, 2074-2076.

298. Yokoi, N.; Inaba, H.; Terauchi, M.; Stieg, A. Z.; Sanghamitra, N. J. M.; Koshiyama, T.; Yutani, K.; Kanamaru, S.; Arisaka, F.; Hikage, T. et al, Construction of Robust Bio-Nanotubes Using the Controlled Self-Assembly of Component Proteins of Bacteriophage T4. Small 2010, 6, 1873-1879.

299. Inaba, H.; Kanamaru, S.; Arisaka, F.; Kitagawa, S.; Ueno, T., Semi-Synthesis of an Artificial Scandium(lii) Enzyme with a Beta-Helical Bio-Nanotube. Dalton Trans. 2012, 41, 11424-11427. 
300. Tegoni, M.; Yu, F. T.; Bersellini, M.; Penner-Hahn, J. E.; Pecoraro, V. L., Designing a Functional Type 2 Copper Center That Has Nitrite Reductase Activity within Alpha-Helical Coiled Coils. Proc. Natl. Acad. Sci. U. S. A. 2012, 109, 21234-21239.

301. Butt, N. A.; Zhang, W., Transition Metal-Catalyzed Allylic Substitution Reactions with Unactivated Allylic Substrates. Chem. Soc. Rev. 2015, 44, 7929-7967.

302. Christianson, D. W., Structural Biology and Chemistry of the Terpenoid Cyclases. Chem. Rev. (Washington, DC, U. S.) 2006, 106, 3412-3442.

303. Voelker, T.; Dempwolff, F.; Graumann, P. L.; Meggers, E., Progress Towards Bioorthogonal Catalysis with Organometallic Compounds. Angew. Chem., Int. Ed. 2014, 53, 10536-10540.

304. Tomas-Gamasa, M.; Martinez-Calvo, M.; Couceiro, J. R.; Mascarenas, J. L., Transition Metal Catalysis in the Mitochondria of Living Cells. Nat. Commun. 2016, 7, 12538.

305. Hsu, H.-T.; Trantow, B. M.; Waymouth, R. M.; Wender, P. A., Bioorthogonal Catalysis: A General Method to Evaluate Metal-Catalyzed Reactions in Real Time in Living Systems Using a Cellular Luciferase Reporter System. Bioconjugate Chem. 2016, 27, 376-382.

306. Pierron, J.; Malan, C.; Creus, M.; Gradinaru, J.; Hafner, I.; Ivanova, A.; Sardo, A.; Ward, T. R., Artificial Metalloenzymes for Asymmetric Allylic Alkylation on the Basis of the Biotin-Avidin Technology. Angew. Chem., Int. Ed. 2008, 47, 701-705.

307. Suzuki, A., Cross-Coupling Reactions of Organoboranes: An Easy Way to Construct C-C Bonds (Nobel Lecture). Angew. Chem., Int. Ed. 2011, 50, 6722-6737.

308. Yusop, R.; Broceta, A. U.; Johansson, E.; Sanchez-Martin, R.; Bradley, M., Palladium-Mediated Intracellular Chemistry. Nat. Chem. 2011, 3, 239-243.

309. Li, J.; Chen, P. R., Moving Pd-Mediated Protein Cross Coupling to Living Systems. ChemBioChem 2012, 13, 1728-1731.

310. Gao, Z.; Gouverneur, V.; Davis, B. G., Enhanced Aqueous Suzuki-Miyaura Coupling Allows SiteSpecific Polypeptide 18f-Labeling. J. Am. Chem. Soc. 2013, 135, 13612-13615.

311. Li, N.; Lim, R. K. V.; Edwardraja, S.; Lin, Q., Copper-Free Sonogashira Cross-Coupling for Functionalization of Alkyne-Encoded Proteins in Aqueous Medium and in Bacterial Cells. J. Am. Chem. Soc. 2011, 133, 15316-15319.

312. Abe, S.; Niemeyer, J.; Abe, M.; Takezawa, Y.; Ueno, T.; Hikage, T.; Erker, G.; Watanabe, Y., Control of the Coordination Structure of Organometallic Palladium Complexes in an Apo-Ferritin Cage. J. Am. Chem. Soc. 2008, 130, 10512-10514.

313. Abe, S.; Hirata, K.; Ueno, T.; Morino, K.; Shimizu, N.; Yamamoto, M.; Takata, M.; Yashima, E.; Watanabe, Y., Polymerization of Phenylacetylene by Rhodium Complexes within a Discrete Space of Apo-Ferritin. J. Am. Chem. Soc. 2009, 131, 6958-6960.

314. Wang, Z. Y.; Takezawa, Y.; Aoyagi, H.; Abe, S.; Hikage, T.; Watanabe, Y.; Kitagawa, S.; Ueno, T., Definite Coordination Arrangement of Organometallic Palladium Complexes Accumulated on the Designed Interior Surface of Apo-Ferritin. Chem. Commun. (Cambridge, U. K.) 2011, 47, 170-172.

315. Chatterjee, A.; Mallin, H.; Klehr, J.; Vallapurackal, J.; Finke, A. D.; Vera, L.; Marsh, M.; Ward, T. R., An Enantioselective Artificial Suzukiase Based on the Biotin-Streptavidin Technology. Chem. Sci. 2016, 7, 673-677.

316. Filice, M.; Romero, O.; Aires, A.; Guisan, J. M.; Rumbero, A.; Palomo, J. M., Preparation of an Immobilized Lipase-Palladium Artificial Metalloenzyme as Catalyst in the Heck Reaction: Role of the Solid Phase. Adv. Synth. Catal. 2015, 357, 2687-2696.

317. Davies, H. M. L.; Du Bois, J.; Yu, J.-Q., C-H Functionalization in Organic Synthesis. Chem. Soc. Rev. 2011, 40, 1855-1856.

318. Lewis, J. C.; Coelho, P. S.; Arnold, F. H., Enzymatic Functionalization of Carbon-Hydrogen Bonds. Chem. Soc. Rev. 2011, 40, 2003-2021.

319. Souillart, L.; Cramer, N., Catalytic C-C Bond Activations Via Oxidative Addition to Transition Metals. Chem. Rev. (Washington, DC, U. S.) 2015, 115, 9410-9464.

320. Fagnou, K.; Lautens, M., Rhodium-Catalyzed Carbon-Carbon Bond Forming Reactions of Organometallic Compounds. Chem. Rev. (Washington, DC, U. S.) 2003, 103, 169-196.

321. Hyster, T. K.; Knorr, L.; Ward, T. R.; Rovis, T., Biotinylated Rh(lii) Complexes in Engineered Streptavidin for Accelerated Asymmetric C-H Activation. Science 2012, 338, 500-503. 
322. Che, C.-M.; Lo, V. K.-Y.; Zhou, C.-Y.; Huang, J.-S., Selective Functionalisation of Saturated C-H Bonds with Metalloporphyrin Catalysts. Chem. Soc. Rev. 2011, 40, 1950-1975.

323. Leak, D. J.; Sheldon, R. A.; Woodley, J. M.; Adlercreutz, P., Biocatalysts for Selective Introduction of Oxygen. Biocatal. Biotransform. 2009, 27, 1-26.

324. Svastits, E. W.; Dawson, J. H.; Breslow, R.; Gellman, S. H., Functionalized Nitrogen Atom Transfer Catalyzed by Cytochrome P-450. J. Am. Chem. Soc. 1985, 107, 6427-6428.

325. Wang, Z. J.; Peck, N. E.; Renata, H.; Arnold, F. H., Cytochrome P450-Catalyzed Insertion of Carbenoids into N-H Bonds. Chem. Sci. 2014, 5, 598-601.

326. Sreenilayam, G.; Fasan, R., Myoglobin-Catalyzed Intermolecular Carbene N-H Insertion with Arylamine Substrates. Chem. Commun. 2015, 51, 1532-1534.

327. Key, H. M.; Dydio, P.; Clark, D. S.; Hartwig, J. F., Abiological Catalysis by Artificial Haem Proteins Containing Noble Metals in Place of Iron. Nature 2016, 534, 534-537.

328. Ohashi, M.; Koshiyama, T.; Ueno, T.; Yanase, M.; Fujii, H.; Watanabe, Y., Preparation of Artificial Metalloenzymes by Insertion of Chromium(lii) Schiff Base Complexes into Apomyoglobin Mutants. Angew. Chem., Int. Ed. 2003, 42, 1005-1008.

329. Carey, J. R.; Ma, S. K.; Pfister, T. D.; Garner, D. K.; Kim, H. K.; Abramite, J. A.; Wang, Z. L.; Guo, Z. J.; Lu, Y., A Site-Selective Dual Anchoring Strategy for Artificial Metalloprotein Design. J. Am. Chem. Soc. 2004, 126, 10812-10813.

330. Zhang, J. L.; Garner, D. K.; Liang, L.; Chen, Q.; Lu, Y., Protein Scaffold of a Designed Metalloenzyme Enhances the Chemoselectivity in Sulfoxidation of Thioanisole. Chem. Commun. 2008, 1665-1667.

331. Hayashi, T.; Hitomi, Y.; Ando, T.; Mizutani, T.; Hisaeda, Y.; Kitagawa, S.; Ogoshi, H., Peroxidase Activity of Myoglobin Is Enhanced by Chemical Mutation of Heme-Propionates. J. Am. Chem. Soc. 1999, 121, 7747-7750.

332. Sato, H.; Hayashi, T.; Ando, T.; Hisaeda, Y.; Ueno, T.; Watanabe, Y., Hybridization of ModifiedHeme Reconstitution and Distal Histidine Mutation to Functionalize Sperm Whale Myoglobin. J. Am. Chem. Soc. 2004, 126, 436-437.

333. Hayashi, T.; Murata, D.; Makino, M.; Sugimoto, H.; Matsuo, T.; Sato, H.; Shiro, Y.; Hisaeda, Y., Crystal Structure and Peroxidase Activity of Myoglobin Reconstituted with Iron Porphycene. Inorg. Chem. 2006, 45, 10530-10536.

334. Dydio, P.; Key, H. M.; Nazarenko, A.; Rha, J. Y.-E.; Seyedkazemi, V.; Clark, D. S.; Hartwig, J. F., An Artificial Metalloenzyme with the Kinetics of Native Enzymes. Science 2016, 354, 102-106.

335. Grubbs, R. H., Handbook of Metathesis. Wiley-VCH: Weinheim, 2003; Vol. 3.

336. Herbert, M. B.; Grubbs, R. H., Z-Selective Cross Metathesis with Ruthenium Catalysts: Synthetic Applications and Mechanistic Implications. Angew. Chem., Int. Ed. 2015, 54, 5018-5024.

337. Koh, M. J.; Khan, R. K. M.; Torker, S.; Yu, M.; Mikus, M. S.; Hoveyda, A. H., High-Value Alcohols and Higher-Oxidation-State Compounds by Catalytic Z-Selective Cross-Metathesis. Nature 2015, 517, 181-186.

338. Nguyen, T. T.; Koh, M. J.; Shen, X.; Romiti, F.; Schrock, R. R.; Hoveyda, A. H., Kinetically Controlled E-Selective Catalytic Olefin Metathesis. Science 2016, 352, 569-575.

339. Lin, Y. A.; Chalker, J. M.; Floyd, N.; Bernardes, G. J. L.; Davis, B. G., Allyl Sulfides Are Privileged Substrates in Aqueous Cross-Metathesis: Application to Site-Selective Protein Modification. J. Am. Chem. Soc. 2008, 130, 9642-9643.

340. Ai, H. W.; Shen, W. J.; Brustad, E.; Schultz, P. G., Genetically Encoded Alkenes in Yeast. Angew. Chem., Int. Ed. 2010, 49, 935-937.

341. Lo, C.; Ringenberg, M. R.; Gnandt, D.; Wilson, Y.; Ward, T. R., Artificial Metalloenzymes for Olefin Metathesis Based on the Biotin-(Strept)Avidin Technology. Chem. Commun. 2011, 47, 1206512067.

342. Mayer, C.; Gillingham, D. G.; Ward, T. R.; Hilvert, D., An Artificial Metalloenzyme for Olefin Metathesis. Chem. Commun. 2011, 47, 12068-12070.

343. Matsuo, T.; Yoshida, T.; Fujii, A.; Kawahara, K.; Hirota, S., Effect of Added Salt on Ring-Closing Metathesis Catalyzed by a Water-Soluble Hoveyda-Grubbs Type Complex to Form N-Containing Heterocycles in Aqueous Media. Organometallics 2013, 32, 5313-5319. 
344. Kajetanowicz, A.; Chatterjee, A.; Reuter, R.; Ward, T. R., Biotinylated Metathesis Catalysts: Synthesis and Performance in Ring Closing Metathesis. Catal. Lett. 2014, 144, 373-379.

345. Matsuo, T.; Imai, C.; Yoshida, T.; Saito, T.; Hayashi, T.; Hirota, S., Creation of an Artificial Metalloprotein with a Hoveyda-Grubbs Catalyst Moiety through the Intrinsic Inhibition Mechanism of Alpha-Chymotrypsin. Chem. Commun. 2012, 48, 1662-1664.

346. Basauri-Molina, M.; Verhoeven, D. G. A.; van Schaik, A. J.; Kleijn, H.; Klein Gebbink, R. J. M., RingClosing and Cross-Metathesis with Artificial Metalloenzymes Created by Covalent Active SiteDirected Hybridization of a Lipase. Chem. - Eur. J. 2015, 21, 15676-15685.

347. Zhao, J. M.; Kajetanowicz, A.; Ward, T. R., Carbonic Anhydrase li as Host Protein for the Creation of a Biocompatible Artificial Metathesase. Org. Biomol. Chem. 2015, 13, 5652-5655.

348. Philippart, F.; Arlt, M.; Gotzen, S.; Tenne, S. J.; Bocola, M.; Chen, H. H.; Zhu, L. L.; Schwaneberg, U.; Okuda, J., A Hybrid Ring-Opening Metathesis Polymerization Catalyst Based on an Engineered Variant of the Beta-Barrel Protein Fhua. Chem. - Eur. J. 2013, 19, 13865-13871.

349. Sauer, D. F.; Bocola, M.; Broglia, C.; Arlt, M.; Zhu, L. L.; Brocker, M.; Schwaneberg, U.; Okuda, J., Hybrid Ruthenium Romp Catalysts Based on an Engineered Variant of Beta-Barrel Protein Fhua Delta Cvftev : Effect of Spacer Length. Chem. Asian J. 2015, 10, 177-182.

350. Osseili, H.; Sauer, D. F.; Beckerle, K.; Arlt, M.; Himiyama, T.; Polen, T.; Onoda, A.; Schwaneberg, U.; Hayashi, T.; Okuda, J., Artificial Diels-Alderase Based on the Transmembrane Protein Fhua. Beilstein J. Org. Chem. 2016, 12, 1314-1321.

351. Jeschek, M.; Reuter, R.; Heinisch, T.; Trindler, C.; Klehr, J.; Panke, S.; Ward, T. R., Directed Evolution of Artificial Metalloenzymes for in Vivo Metathesis. Nature 2016, 537, 661-665.

352. Reynolds, E. W.; McHenry, M. W.; Cannac, F.; Gober, J. G.; Snow, C. D.; Brustad, E. M., An Evolved Orthogonal Enzyme/Cofactor Pair. J. Am. Chem. Soc. 2016, 138, 12451-12458.

353. Deuss, P. J.; Popa, G.; Slawin, A. M. Z.; Laan, W.; Kamer, P. C. J., Artificial Copper Enzymes for Asymmetric Diels-Alder Reactions. ChemCatChem 2013, 5, 1184-1191.

354. Srivastava, P.; Yang, H.; Ellis-Guardiola, K.; Lewis, J. C., Engineering a Dirhodium Artificial Metalloenzyme for Selective Olefin Cyclopropanation. Nat. Commun. 2015, 6, 7789.

355. Harris, M. N.; Madura, J. D.; Ming, L. J.; Harwood, V. J., Kinetic and Mechanistic Studies of Prolyl Oligopeptidase from the Hyperthermophile Pyrococcus Furiosus. J. Biol. Chem. 2001, 276, 1931019317.

356. Fukumoto, K.; Onoda, A.; Mizohata, E.; Bocola, M.; Inoue, T.; Schwaneberg, U.; Hayashi, T., Rhodium-Complex-Linked Hybrid Biocatalyst: Stereo-Controlled Phenylacetylene Polymerization within an Engineered Protein Cavity. ChemCatChem 2014, 6, 1229-1235.

357. Sigg, S. J.; Seidi, F.; Renggli, K.; Silva, T. B.; Kali, G.; Bruns, N., Horseradish Peroxidase as a Catalyst for Atom Transfer Radical Polymerization. Macromol. Rapid Commun. 2011, 32, 1710-1715.

358. Renggli, K.; Nussbaumer, M. G.; Urbani, R.; Pfohl, T.; Bruns, N., A Chaperonin as Protein Nanoreactor for Atom-Transfer Radical Polymerization. Angew. Chem.,Int. Ed. 2014, 53, 14431447.

359. Nicolaou, K. C.; Snyder, S. A.; Montagnon, T.; Vassilikogiannakis, G., The Diels-Alder Reaction in Total Synthesis. Angew. Chem., Int. Ed. 2002, 41, 1668-1698.

360. Fringuelli, F.; Piermatti, O.; Pizzo, F.; Vaccaro, L., Recent Advances in Lewis Acid Catalyzed Diels-Alder Reactions in Aqueous Media. Eur. J. Org. Chem. 2001, 2001, 439-455.

361. Podtetenieff, J.; Taglieber, A.; Bill, E.; Reijerse, E. J.; Reetz, M. T., An Artificial Metalloenzyme: Creation of a Designed Copper Binding Site in a Thermostable Protein. Angew. Chem., Int. Ed. 2010, 49, 5151-5155.

362. Kuo, C.-H.; Fruk, L.; Niemeyer, C. M., Addressable DNA-Myoglobin Photocatalysis. Chem. Asian J. 2009, 4, 1064-1069.

363. Ghattas, W.; Cotchico-Alonso, L.; Marechal, J. D.; Urvoas, A.; Rousseau, M.; Mahy, J. P.; Ricoux, R., Artificial Metalloenzymes with the Neocarzinostatin Scaffold: Toward a Biocatalyst for the DielsAlder Reaction. ChemBioChem 2016, 17, 433-440.

364. Talbi, B.; Haquette, P.; Martel, A.; de Montigny, F.; Fosse, C.; Cordier, S.; Roisnel, T.; Jaouen, G.; Salmain, M., (Eta ${ }^{6}$-Arene) Ruthenium(li) Complexes and Metallo-Papain Hybrid as Lewis Acid Catalysts of Diels-Alder Reaction in Water. Dalton Trans. 2010, 39, 5605-5607. 
365. Himiyama, T.; Sauer, D. F.; Onoda, A.; Spaniol, T. P.; Okuda, J.; Hayashi, T., Construction of a Hybrid Biocatalyst Containing a Covalently-Linked Terpyridine Metal Complex within a Cavity of Aponitrobindin. J. Inorg. Biochem. 2016, 158, 55-61.

366. Filice, M.; Romero, O.; Gutierrez-Fernandez, J.; de las Rivas, B.; Hermoso, J. A.; Palomo, J. M., Synthesis of a Heterogeneous Artificial Metallolipase with Chimeric Catalytic Activity. Chem. Commun. 2015, 51, 9324-9327.

367. Bos, J.; Fusetti, F.; Driessen, A. J. M.; Roelfes, G., Enantioselective Artificial Metalloenzymes by Creation of a Novel Active Site at the Protein Dimer Interface. Angew. Chem., Int. Ed. 2012, 51, 7472-7475.

368. Bos, J.; García-Herraiz, A.; Roelfes, G., An Enantioselective Artificial Metallo-Hydratase. Chem. Sci. 2013, 4, 3578-3582.

369. Reetz, M. T.; Jiao, N., Copper-Phthalocyanine Conjugates of Serum Albumins as Enantioselective Catalysts in Diels-Alder Reactions. Angew. Chem., Int. Ed. 2006, 45, 2416-2419.

370. Ueno, T.; Tabe, H.; Tanaka, Y., Artificial Metalloenzymes Constructed from HierarchicallyAssembled Proteins. Chem. Asian J. 2013, 8, 1646-1660.

371. Rueping, M.; Nachtsheim, B. J., A Review of New Developments in the Friedel-Crafts Alkylation from Green Chemistry to Asymmetric Catalysis. Beilstein J. Org. Chem. 2010, 6, 1-24.

372. Lu, H. H.; Tan, F.; Xiao, W. J., Enantioselective Organocatalytic Friedel-Crafts Alkylations. Curr. Org. Chem. 2011, 15, 4022-4045.

373. Qiu, R. H.; Chen, Y.; Yin, S. F.; Xu, X. H.; Au, C. T., A Mini-Review on Air-Stable Organometallic Lewis Acids: Synthesis, Characterization, and Catalytic Application in Organic Synthesis. RSC Adv. 2012, 2, 10774-10793.

374. Drienovska, I.; Rioz-Martinez, A.; Draksharapu, A.; Roelfes, G., Novel Artificial Metalloenzymes by in Vivo Incorporation of Metal-Binding Unnatural Amino Acids. Chem. Sci. 2015, 6, 770-776.

375. Bos, J.; Browne, W. R.; Driessen, A. J. M.; Roelfes, G., Supramolecular Assembly of Artificial Metalloenzymes Based on the Dimeric Protein Lmrr as Promiscuous Scaffold. J. Am. Chem. Soc. 2015, 137, 9796-9799.

376. Kurtz Jr, D. M., Dioxygen-Binding Proteins. In Comprehensive Coordination Chemistry Ii, Pergamon: Oxford, 2003.

377. Schultz, P. G.; Lerner, R. A., Antibody Catalysis of Difficult Chemical-Transformations. Acc. Chem. Res. 1993, 26, 391-395.

378. Takagi, M.; Kohda, K.; Hamuro, T.; Harada, A.; Yamaguchi, H.; Kamachi, M.; Imanaka, T., Thermostable Peroxidase-Activity with a Recombinant Antibody L-Chain-Porphyrin Fe(lii) Complex. FEBS Lett. 1995, 375, 273-276.

379. Quilez, R.; deLauzon, S.; Desfosses, B.; Mansuy, D.; Mahy, J. P., Artificial Peroxidase-Like Hemoproteins Based on Antibodies Constructed from a Specifically Designed Ortho-Carboxy Substituted Tetraarylporphyrin Hapten and Exhibiting a High Affinity for Iron-Porphyrins. FEBS Lett. 1996, 395, 73-76.

380. Kawamura-Konishi, Y.; Fujie, Y.; Suzuki, H., Kinetics of Formation of Antibody-Ferric Porphyrin Complex with Peroxidase Activity. J. Protein Chem. 1999, 18, 741-745.

381. Mahy, J. P.; Desfosses, B.; de Lauzon, S.; Quilez, R.; Desfosses, B.; Lion, L.; Mansuy, D., Hemoabzymes - Different Strategies for Obtaining Artificial Hemoproteins Based on Antibodies. Appl. Biochem. Biotechnol. 1998, 75, 103-127.

382. Yamaguchi, H.; Tsubouchi, K.; Kawaguchi, K.; Horita, E.; Harada, A., Peroxidase Activity of Cationic Metalloporphyrin-Antibody Complexes. Chem. - Eur. J. 2004, 10, 6179-6186.

383. de Lauzon, S.; Mansuy, D.; Mahy, J. P., Coordination Chemistry of Iron(lii)-Porphyrin-Antibody Complexes - Influence on the Peroxidase Activity of the Axial Coordination of an Imidazole on the Iron Atom. Eur. J. Biochem. 2002, 269, 470-480.

384. Ricoux, R.; Sauriat-Dorizon, H.; Girgenti, E.; Blanchard, D.; Mahy, J. P., Hemoabzymes: Towards New Biocatalysts for Selective Oxidations. J. Immunol. Methods 2002, 269, 39-57.

385. Ricoux, R.; Boucher, J. L.; Mansuy, D.; Mahy, J. P., Microperoxidase 8 Catalyzed Nitration of Phenol by Nitrogen Dioxide Radicals. Eur. J. Biochem. 2001, 268, 3783-3788. 
386. Raffy, Q.; Ricoux, R.; Mahy, J. P., Synthesis of a New Estradiol-Iron Metalloporphyrin Conjugate Used to Build up a New Hybrid Biocatalyst for Selective Oxidations by the 'Trojan Horse' Strategy. Tetrahedron Lett. 2008, 49, 1865-1869.

387. Raffy, Q.; Ricoux, R.; Sansiaume, E.; Pethe, S.; Mahy, J. P., Coordination Chemistry Studies and Peroxidase Activity of a New Artificial Metalloenzyme Built by the "Trojan Horse" Strategy. J. Mol. Catal. A: Chem. 2010, 317, 19-26.

388. Girgenti, E.; Ricoux, R.; Mahy, J. P., Design and Synthesis of a Mn(lii)-Porphyrin Steroid Conjugate Used as a New Cleavable Affinity Label: On the Road to Semi-Synthetic Catalytic Antibodies. Tetrahedron 2004, 60, 10049-10058.

389. de Lauzon, S.; Desfosses, B.; Mansuy, D.; Mahy, J. P., Studies of the Reactivity of Artificial Peroxidase-Like Hemoproteins Based on Antibodies Elicited against a Specifically Designed Ortho-Carboxy Substituted Tetraarylporphyrin. FEBS Lett. 1999, 443, 229-234.

390. Matsuo, T.; Fukumoto, K.; Watanabe, T.; Hayashi, T., Precise Design of Artificial Cofactors for Enhancing Peroxidase Activity of Myoglobin: Myoglobin Mutant H64d Reconstituted with a "Single-Winged Cofactor" Is Equivalent to Native Horseradish Peroxidase in Oxidation Activity. Chem. Asian J. 2011, 6, 2491-2499.

391. Matsuo, T.; Murata, D.; Hisaeda, Y.; Hori, H.; Hayashi, T., Porphyrinoid Chemistry in Hemoprotein Matrix: Detection and Reactivities of Iron(Iv)-Oxo Species of Porphycene Incorporated into Horseradish Peroxidase. J. Am. Chem. Soc. 2007, 129, 12906-12907.

392. Matsuo, T.; Hayashi, A.; Abe, M.; Matsuda, T.; Hisaeda, Y.; Hayashi, T., Meso-Unsubstituted Iron Corrole in Hemoproteins: Remarkable Differences in Effects on Peroxidase Activities between Myoglobin and Horseradish Peroxidase. J. Am. Chem. Soc. 2009, 131, 15124-15125.

393. Kaplan, J.; DeGrado, W. F., De Novo Design of Catalytic Proteins. Proc. Natl. Acad. Sci. U. S. A. 2004, 101, 11566-11570.

394. Faiella, M.; Andreozzi, C.; de Rosales, R. T.; Pavone, V.; Maglio, O.; Nastri, F.; DeGrado, W. F.; Lombardi, A., An Artificial Di-Iron Oxo-Protein with Phenol Oxidase Activity. Nat. Chem. Biol. 2009, 5, 882-884.

395. Lombardi, A.; Summa, C. M.; Geremia, S.; Randaccio, L.; Pavone, V.; DeGrado, W. F., Retrostructural Analysis of Metalloproteins: Application to the Design of a Minimal Model for Diiron Proteins. Proc. Natl. Acad. Sci. U. S. A. 2000, 97, 6298-6305.

396. Reig, A. J.; Pires, M. M.; Snyder, R. A.; Wu, Y.; Jo, H.; Kulp, D. W.; Butch, S. E.; Calhoun, J. R.; Szyperski, T.; Solomon, E. I. et al, Alteration of the Oxygen-Dependent Reactivity of De Novo Due Ferri Proteins. Nat. Chem. 2012, 4, 900-906.

397. Snyder, R. A.; Butch, S. E.; Reig, A. J.; DeGrado, W. F.; Solomon, E. I., Molecular-Level Insight into the Differential Oxidase and Oxygenase Reactivities of De Novo Due Ferri Proteins. J. Am. Chem. Soc. 2015, 137, 9302-9314.

398. Ricoux, R.; Dubuc, R.; Dupont, C.; Marechal, J. D.; Martin, A.; Sellier, M.; Mahy, J. P., Hemozymes Peroxidase Activity of Artificial Hemoproteins Constructed from the Streptomyces Lividans Xylanase a and Iron(lii)-Carboxy-Substituted Porphyrins. Bioconjugate Chem. 2008, 19, 899-910.

399. Fujieda, N.; Hasegawa, A.; Ishihama, K.; Itoh, S., Artificial Dicopper Oxidase: Rational Reprogramming of Bacterial Metallo-Beta-Lactamase into a Catechol Oxidase. Chem. Asian J. 2012, 7, 1203-1207.

400. Amrein, B.; Schmid, M.; Collet, G.; Cuniasse, P.; Gilardoni, F.; Seebeck, F. P.; Ward, T. R., Identification of Two-Histidines One-Carboxylate Binding Motifs in Proteins Amenable to Facial Coordination to Metals. Metallomics 2012, 4, 379-388.

401. Fujieda, N.; Schatti, J.; Stuttfeld, E.; Ohkubo, K.; Maier, T.; Fukuzumi, S.; Ward, T. R., Enzyme Repurposing of a Hydrolase as an Emergent Peroxidase Upon Metal Binding. Chem. Sci. 2015, 6, 4060-4065.

402. Lee, H. S.; Schultz, P. G., Biosynthesis of a Site-Specific DNA Cleaving Protein. J. Am. Chem. Soc. 2008, 130, 13194-13195.

403. Fernandez, I.; Khiar, N., Recent Developments in the Synthesis and Utilization of Chiral Sulfoxides. Chem. Rev. 2003, 103, 3651-3705. 
404. Pellissier, H., Recent Advances in Enantioselective Vanadium-Catalyzed Transformations. Coord. Chem. Rev. 2015, 284, 93-110.

405. Sipos, G.; Drinkel, E. E.; Dorta, R., The Emergence of Sulfoxides as Efficient Ligands in Transition Metal Catalysis. Chem. Soc. Rev. 2015, 44, 3834-3860.

406. Legros, J.; Dehli, J. R.; Bolm, C., Applications of Catalytic Asymmetric Sulfide Oxidations to the Syntheses of Biologically Active Sulfoxides. Adv. Synth. Catal. 2005, 347, 19-31.

407. Wojaczynska, E.; Wojaczynski, J., Enantioselective Synthesis of Sulfoxides: 2000-2009. Chem. Rev. 2010, 110, 4303-4356.

408. Correa, A.; Mancheno, O. G.; Bolm, C., Iron-Catalysed Carbon-Heteroatom and HeteroatomHeteroatom Bond Forming Processes. Chem. Soc. Rev. 2008, 37, 1108-1117.

409. Licini, G.; Conte, V.; Coletti, A.; Mba, M.; Zonta, C., Recent Advances in Vanadium Catalyzed Oxygen Transfer Reactions. Coord. Chem. Rev. 2011, 255, 2345-2357.

410. Ricoux, R.; Lukowska, E.; Pezzotti, F.; Mahy, J. P., New Activities of a Catalytic Antibody with a Peroxidase Activity - Formation of Fe(li)-Rno Complexes and Stereoselective Oxidation of Sulfides. Eur. J. Biochem. 2004, 271, 1277-1283.

411. Sansiaume, E.; Ricoux, R.; Gori, D.; Mahy, J. P., Oxidation of Organic Molecules in Homogeneous Aqueous Solution Catalyzed by Hybrid Biocatalysts (Based on the Trojan Horse Strategy). Tetrahedron: Asymmetry 2010, 21, 1593-1600.

412. Sansiaume-Dagousset, E.; Urvoas, A.; Chelly, K.; Ghattas, W.; Marechal, J. D.; Mahy, J. P.; Ricoux, R., Neocarzinostatin-Based Hybrid Biocatalysts for Oxidation Reactions. Dalton Trans. 2014, 43, 8344-8354.

413. Mahy, J. P.; Raffy, Q.; Allard, M.; Ricoux, R., Various Strategies for Obtaining Artificial Hemoproteins: From "Hemoabzymes" to "Hemozymes". Biochimie 2009, 91, 1321-1323.

414. Ricoux, R.; Allard, M.; Dubuc, R.; Dupont, C.; Marechal, J. D.; Mahy, J. P., Selective Oxidation of Aromatic Sulfide Catalyzed by an Artificial Metalloenzyme: New Activity of Hemozymes. Org. Biomol. Chem. 2009, 7, 3208-3211.

415. Koshiyama, T.; Yokoi, N.; Ueno, T.; Kanamaru, S.; Nagano, S.; Shiro, Y.; Arisaka, F.; Watanabe, Y., Molecular Design of Heteroprotein Assemblies Providing a Bionanocup as a Chemical Reactor. Small 2008, 4, 50-54.

416. Ueno, T.; Koshiyama, T.; Ohashi, M.; Kondo, K.; Kono, M.; Suzuki, A.; Yamane, T.; Watanabe, Y., Coordinated Design of Cofactor and Active Site Structures in Development of New Protein Catalysts. J. Am. Chem. Soc. 2005, 127, 6556-6562.

417. Zhang, J. L.; Garner, D. K.; Liang, L.; Barrios, D. A.; Lu, Y., Noncovalent Modulation of PhDependent Reactivity of a Mn-Salen Cofactor in Myoglobin with Hydrogen Peroxide. Chem. Eur. J. 2009, 15, 7481-7489.

418. Rousselot-Pailley, P.; Bochot, C.; Marchi-Delapierre, C.; Jorge-Robin, A.; Martin, L.; FontecillaCamps, J. C.; Cavazza, C.; Ménage, S., The Protein Environment Drives Selectivity for Sulfide Oxidation by an Artificial Metalloenzyme. ChemBioChem 2009, 10, 545-552.

419. Tang, J.; Huang, F. P.; Wei, Y.; Bian, H. D.; Zhang, W.; Liang, H., Bovine Serum Albumin-Cobalt(li) Schiff Base Complex Hybrid: An Efficient Artificial Metalloenzyme for Enantioselective Sulfoxidation Using Hydrogen Peroxide. Dalton Trans. 2016, 45, 8061-8072.

420. Nigel-Etinger, I.; Mahammed, A.; Gross, Z., Covalent Versus Non-Covalent (Biocatalytic) Approaches for Enantioselective Sulfoxidation Catalyzed by Corrole Metal Complexes. Catal. Sci. Technol. 2011, 1, 578-581.

421. Mahammed, A.; Gross, Z., Albumin-Conjugated Corrole Metal Complexes: Extremely Simple yet Very Efficient Biomimetic Oxidation Systems. J. Am. Chem. Soc. 2005, 127, 2883-2887.

422. Herrero, C.; Quaranta, A.; Ricoux, R.; Trehoux, A.; Mahammed, A.; Gross, Z.; Banse, F.; Mahy, J. P., Oxidation Catalysis Via Visible-Light Water Activation of a $\left[\mathrm{Ru}(\mathrm{Bpy})_{3}\right]^{2+}$ Chromophore BsaMetallocorrole Couple. Dalton Trans. 2016, 45, 706-710.

423. Pordea, A.; Creus, M.; Panek, J.; Duboc, C.; Mathis, D.; Novic, M.; Ward, T. R., Artificial Metalloenzyme for Enantioselective Sulfoxidation Based on Vanadyl-Loaded Streptavidin. J. Am. Chem. Soc. 2008, 130, 8085-8088. 
424. Esmieu, C.; Cherrier, M. V.; Amara, P.; Girgenti, E.; Marchi-Delapierre, C.; Oddon, F.; lannello, M.; Jorge-Robin, A.; Cavazza, C.; Ménage, S., An Artificial Oxygenase Built from Scratch: Substrate Binding Site Identified Using a Docking Approach. Angew. Chem., Int. Ed. 2013, 52, 3922-3925.

425. Cherrier, M. V.; Girgenti, E.; Amara, P.; Iannello, M.; Marchi-Delapierre, C.; Fontecilla-Camps, J. C.; Ménage, S.; Cavazza, C., The Structure of the Periplasmic Nickel-Binding Protein Nika Provides Insights for Artificial Metalloenzyme Design. J. Biol. Inorg. Chem. 2012, 17, 817-829.

426. Cavazza, C.; Bochot, C.; Rousselot-Pailley, P.; Carpentier, P.; Cherrier, M. V.; Martin, L.; MarchiDelapierre, C.; Fontecilla-Camps, J. C.; Ménage, S., Crystallographic Snapshots of the Reaction of Aromatic C-H with $\mathrm{O}_{2}$ Catalysed by a Protein-Bound Iron Complex. Nat. Chem. 2010, 2, 10691076.

427. Rondot, L.; Girgenti, E.; Oddon, F.; Marchi-Delapierre, C.; Jorge-Robin, A.; Ménage, S., Catalysis without a Headache: Modification of Ibuprofen for the Design of Artificial Metalloenzyme for Sulfide Oxidation. J. Mol. Catal. A: Chem. 2016, 416, 20-28.

428. Buron, C.; Senechal-David, K.; Ricoux, R.; Le Caer, J. P.; Guerineau, V.; Mejanelle, P.; Guillot, R.; Herrero, C.; Mahy, J. P.; Banse, F., An Artificial Enzyme Made by Covalent Grafting of an Fe-li Complex into Beta-Lactoglobulin: Molecular Chemistry, Oxidation Catalysis, and ReactionIntermediate Monitoring in a Protein. Chem. - Eur. J. 2015, 21, 12188-12193.

429. Faber, K., Biotransformations in Organic Chemistry. 6th ed.; Springer: 2011.

430. Baeckvall, J.-E., Modern Oxidation Methods, 2nd Completely Revised. Wiley-VCH Verlag GmbH \& Co. KGaA: 2010.

431. Hashiguchi, S.; Fujii, A.; Haack, K.-J.; Matsumura, K.; Ikariya, T.; Noyori, R., Kinetic Resolution of Racemic Secondary Alcohols by Ru-Catalyzed Hydrogen Transfer. Angew. Chem., Int. Ed. 1997, 36, 288-290.

432. Thomas, C. M.; Letondor, C.; Humbert, N.; Ward, T. R., Aqueous Oxidation of Alcohols Catalyzed by Artificial Metalloenzymes Based on the Biotin-Avidin Technology. J. Organomet. Chem. 2005, 690, 4488-4491.

433. Smith, J. G., Synthetically Useful Reactions of Epoxides. Synthesis 1984, 629-656.

434. Xia, Q. H.; Ge, H. Q.; Ye, C. P.; Liu, Z. M.; Su, K. X., Advances in Homogeneous and Heterogeneous Catalytic Asymmetric Epoxidation. Chem. Rev. 2005, 105, 1603-1662.

435. Diez, D.; Nunez, M. G.; Anton, A. B.; Garcia, P.; Moro, R. F.; Garrido, N. M.; Marcos, I. S.; Basabe, P.; Urones, J. G., Asymmetric Epoxidation of Electron-Deficient Olefins. Curr. Org. Synth. 2008, 5, 186-216.

436. Okrasa, K.; Kazlauskas, R. J., Manganese-Substituted Carbonic Anhydrase as a New Peroxidase. Chem. - Eur. J. 2006, 12, 1587-1596.

437. Fernández-Gacio, A.; Codina, A.; Fastrez, J.; Riant, O.; Soumillion, P., Transforming Carbonic Anhydrase into Epoxide Synthase by Metal Exchange. ChemBioChem 2006, 7, 1013-1016.

438. Allard, M.; Dupont, C.; Munoz Robles, V.; Doucet, N.; Lledos, A.; Marechal, J. D.; Urvoas, A.; Mahy, J. P.; Ricoux, R., Incorporation of Manganese Complexes into Xylanase: New Artificial Metalloenzymes for Enantioselective Epoxidation. ChemBioChem 2012, 13, 240-251.

439. Koehler, V.; Mao, J.; Heinisch, T.; Pordea, A.; Sardo, A.; Wilson, Y. M.; Knoerr, L.; Creus, M.; Prost, J.-C.; Schirmer, T. et al, Oso ${ }_{4}$ Streptavidin: A Tunable Hybrid Catalyst for the Enantioselective CisDihydroxylation of Olefins. Angew. Chem., Int. Ed. 2011, 50, 10863-10866.

440. Colonna, S.; Manfredi, A.; Spadoni, M., The Effect of Organic Cosolvents on the Enantioselectivity in the Bovine Serum Albumin Catalyzed Weitz-Scheffer Condensation Tetrahedron Lett. 1987, 28, 1577-1580.

441. Laan, W.; Munoz, B. K.; den Heeten, R.; Kamer, P. C., Artificial Metalloenzymes through CysteineSelective Conjugation of Phosphines to Photoactive Yellow Protein. ChemBioChem 2010, 11, 1236-1239.

442. S. Konieczny; C. P. Fik; N. J. Averesch; Tiller, J. C., Organosoluble Enzyme Conjugates with Poly(2Oxazoline)S Via Pyromellitic Acid Dianhydride. J. Biotechnol. 2012, 159, 195-203.

443. S. Konieczny; C. Krumm; D. Doert; K. Neufeld; Tiller, J. C., Investigations on the Activity of Poly(2Oxazoline) Enzyme Conjugates Dissolved in Organic Solvents. J. Biotechnol. 2014, 181, 55-63. 
444. S. Konieczny; M. Leurs; Tiller, J. C., Polymer Enzyme Conjugates as Chiral Ligands for Sharpless Dihydroxylation of Alkenes in Organic Solvents. ChemBioChem 2015, 16, 83-90.

445. Leurs, M.; Spiekermann, P. S.; Tiller, J. C., Optimization of and Mechanistic Considerations for the Enantioselective Dihydroxylation of Styrene Catalyzed by Osmate-Laccase-Poly(2Methyloxazoline) in Organic Solvents. ChemCatChem 2016, 8, 593-599.

446. Miner, K. D.; Mukherjee, A.; Gao, Y.-G.; Null, E. L.; Petrik, I. D.; Zhao, X.; Yeung, N.; Robinson, H.; $\mathrm{Lu}, \mathrm{Y}$., A Designed Functional Metalloenzyme That Reduces $\mathrm{O}_{2}$ to $\mathrm{H}_{2} \mathrm{O}$ with over One Thousand Turnovers. Angew. Chem., Int. Ed. 2012, 51, 5589-5592.

447. Bhagi-Damodaran, A.; Petrik, I. D.; Marshall, N. M.; Robinson, H.; Lu, Y., Systematic Tuning of Heme Redox Potentials and Its Effects on $\mathrm{O}_{2}$ Reduction Rates in a Designed Oxidase in Myoglobin. J. Am. Chem. Soc. 2014, 136, 11882-11885.

448. Liu, X.; Yu, Y.; Hu, C.; Zhang, W.; Lu, Y.; Wang, J., Significant Increase of Oxidase Activity through the Genetic Incorporation of a Tyrosine-Histidine Cross-Link in a Myoglobin Model of HemeCopper Oxidase. Angew. Chem., Int. Ed. 2012, 51, 4312-4316.

449. Yu, Y.; Lv, X.; Li, J.; Zhou, Q.; Cui, C.; Hosseinzadeh, P.; Mukherjee, A.; Nilges, M. J.; Wang, J.; Lu, Y., Defining the Role of Tyrosine and Rational Tuning of Oxidase Activity by Genetic Incorporation of Unnatural Tyrosine Analogs. J. Am. Chem. Soc. 2015, 137, 4594-4597.

450. Yu, Y.; Zhou, Q.; Wang, L.; Liu, X.; Zhang, W.; Hu, M.; Dong, J.; Li, J.; Lv, X.; Ouyang, H. et al, Significant Improvement of Oxidase Activity through the Genetic Incorporation of a Redox-Active Unnatural Amino Acid. Chem. Sci. 2015, 6, 3881-3885.

451. Oohora, K.; Kihira, Y.; Mizohata, E.; Inoue, T.; Hayashi, T., C(Sp3)-H Bond Hydroxylation Catalyzed by Myoglobin Reconstituted with Manganese Porphycene. J. Am. Chem. Soc. 2013, 135, 1728217285.

452. Traviglia, S. L.; Datwyler, S. A.; Meares, C. F., Mapping Protein-Protein Interactions with a Library of Tethered Cutting Reagents: The Binding Site of $\Sigma^{70}$ on Escherichia Coli Rna Polymerase. Biochemistry 1999, 38, 4259-4265.

453. Bruice, T. W.; Wise, J. G.; Rosser, D. S. E.; Sigman, D. S., Conversion of $\wedge$ Phage Cro into an Operator-Specific Nuclease. J. Am. Chem. Soc. 1991, 113, 5446-5447.

454. Rana, T. M.; Meares, C. F., Specific Cleavage of a Protein by an Attached Iron Chelate. J. Am. Chem. Soc. 1990, 112, 2457-2458.

455. Greiner, D. P.; Miyake, R.; Moran, J. K.; Jones, A. D.; Negishi, T.; Ishihama, A.; Meares, C. F., Synthesis of the Protein Cutting Reagent Iron (S)-1-(P-Bromoacetamidobenzyl) Ethylenediaminetetraacetate and Conjugation to Cysteine Side Chains. Bioconjugate Chem. 1997, 8, 44-48.

456. Platis, I. E.; Ermacora, M. R.; Fox, R. O., Oxidative Polypeptide Cleavage Mediated by Edta-Iron Covalently Linked to Cysteine Residues. Biochemistry 1993, 32, 12761-12767.

457. Erlanson, D. A.; Chytil, M.; Verdine, G. L., The Leucine Zipper Domain Controls the Orientation of Ap-1 in the Nfat.Ap-1.DNA Complex. Chem. Biol. 1996, 3, 981-991.

458. van Dongen, S. F. M.; Clerx, J.; Nørgaard, K.; Bloemberg, T. G.; Cornelissen, J. J. L. M.; Trakselis, M. A.; Nelson, S. W.; Benkovic, S. J.; Rowan, A. E.; Nolte, R. J. M., A Clamp-Like Biohybrid Catalyst for DNA Oxidation. Nat. Chem. 2013, 5, 945-951.

459. McDonald, A. G.; Tipton, K. F., Fifty-Five Years of Enzyme Classification: Advances and Difficulties. FEBS J. 2014, 281, 583-592.

460. Fersht, A. R., Structure and Mechanism in Protein Science: A Guide to Enzyme Catalysis and Protein Folding. W. H. Freeman and Company: New York, 1999.

461. Park, H. S.; Nam, S. H.; Lee, J. K.; Yoon, C. N.; Mannervik, B.; Benkovic, S. J.; Kim, H. S., Design and Evolution of New Catalytic Activity with an Existing Protein Scaffold. Science 2006, 311, 535-538.

462. Zastrow, M. L.; Peacock, A. F. A.; Stuckey, J. A.; Pecoraro, V. L., Hydrolytic Catalysis and Structural Stabilization in a Designed Metalloprotein. Nat. Chem. 2012, 4, 118-123.

463. Innocenti, A.; Scozzafava, A.; Parkkila, S.; Puccetti, L.; De Simone, G.; Supuran, C. T., Investigations of the Esterase, Phosphatase, and Sulfatase Activities of the Cytosolic Mammalian Carbonic Anhydrase Isoforms I, Ii, and Xiii with 4-Nitrophenyl Esters as Substrates. Bioorg. Med. Chem. Lett. 2008, 18, 2267-2271. 
464. Verpoorte, J. A.; Mehta, S.; Edsall, J. T., Esterase Activities of Human Carbonic Anhydrases B and C. J. Biol. Chem. 1967, 242, 4221-4229.

465. Zastrow, M. L.; Pecoraro, V. L., Influence of Active Site Location on Catalytic Activity in De NovoDesigned Zinc Metalloenzymes. J. Am. Chem. Soc. 2013, 135, 5895-5903.

466. Khare, S. D.; Kipnis, Y.; Greisen, P., Jr.; Takeuchi, R.; Ashani, Y.; Goldsmith, M.; Song, Y.; Gallaher, J. L.; Silman, I.; Leader, H. et al, Computational Redesign of a Mononuclear Zinc Metalloenzyme for Organophosphate Hydrolysis. Nat. Chem. Biol. 2012, 8, 294-300.

467. Siegel, J. B.; Zanghellini, A.; Lovick, H. M.; Kiss, G.; Lambert, A. R.; St Clair, J. L.; Gallaher, J. L.; Hilvert, D.; Gelb, M. H.; Stoddard, B. L. et al, Computational Design of an Enzyme Catalyst for a Stereoselective Bimolecular Diels-Alder Reaction. Science 2010, 329, 309-313.

468. Jiang, L.; Althoff, E. A.; Clemente, F. R.; Doyle, L.; Rothlisberger, D.; Zanghellini, A.; Gallaher, J. L.; Betker, J. L.; Tanaka, F.; Barbas, C. F. et al, De Novo Computational Design of Retro-Aldol Enzymes. Science 2008, 319, 1387-1391.

469. Rothlisberger, D.; Khersonsky, O.; Wollacott, A. M.; Jiang, L.; DeChancie, J.; Betker, J.; Gallaher, J. L.; Althoff, E. A.; Zanghellini, A.; Dym, O. et al, Kemp Elimination Catalysts by Computational Enzyme Design. Nature 2008, 453, 190-195.

470. Der, B. S.; Edwards, D. R.; KuhIman, B., Catalysis by a De Novo Zinc-Mediated Protein Interface: Implications for Natural Enzyme Evolution and Rational Enzyme Engineering. Biochemistry 2012, 51, 3933-3940.

471. Song, W. J.; Tezcan, F. A., A Designed Supramolecular Protein Assembly with in Vivo Enzymatic Activity. Science 2014, 346, 1525-1528.

472. Seelig, B.; Szostak, J. W., Selection and Evolution of Enzymes from a Partially Randomized NonCatalytic Scaffold. Nature 2007, 448, 828-831.

473. Seelig, B., Mrna Display for the Selection and Evolution of Enzymes from in Vitro-Translated Protein Libraries. Nat. Protoc. 2011, 6, 540-552.

474. Chao, F. A.; Morelli, A.; Haugner, J. C.; Churchfield, L.; Hagmann, L. N.; Shi, L.; Masterson, L. R.; Sarangi, R.; Veglia, G.; Seelig, B., Structure and Dynamics of a Primordial Catalytic Fold Generated by in Vitro Evolution. Nat. Chem. Biol. 2013, 9, 81-83.

475. Morelli, A.; Haugner, J.; Seelig, B., Thermostable Artificial Enzyme Isolated by in Vitro Selection. Plos One 2014, 9, e112028.

476. Bryson, J. W.; Desjarlais, J. R.; Handel, T. M.; DeGrado, W. F., From Coiled Coils to Small Globular Proteins: Design of a Native-Like Three-Helix Bundle. Protein Sci. 1998, 7, 1404-1414.

477. Cangelosi, V. M.; Deb, A.; Penner-Hahn, J. E.; Pecoraro, V. L., A De Novo Designed Metalloenzyme for the Hydration of $\mathrm{CO}_{2}$. Angew. Chem., Int. Ed. 2014, 53, 7900-7903.

478. Jackman, J. E.; Merz, K. M.; Fierke, C. A., Disruption of the Active Site Solvent Network in Carbonic Anhydrase li Decreases the Efficiency of Proton Transfer. Biochemistry 1996, 35, $16421-$ 16428.

479. Jewell, D. A.; Tu, C. K.; Paranawithana, S. R.; Tanhauser, S. M.; Lograsso, P. V.; Laipis, P. J.; Silverman, D. N., Enhancement of the Catalytic Properties of Human Carbonic Anhydrase-lii by Site-Directed Mutagenesis. Biochemistry 1991, 30, 1484-1490.

480. Korendovych, I. V.; Kulp, D. W.; Wu, Y.; Cheng, H.; Roder, H.; DeGrado, W. F., Design of a Switchable Eliminase. Proc. Natl. Acad. Sci. U. S. A. 2011, 108, 6823-6827.

481. Deuss, P. J.; Popa, G.; Botting, C. H.; Laan, W.; Kamer, P. C. J., Highly Efficient and Site-Selective Phosphane Modification of Proteins through Hydrazone Linkage: Development of Artificial Metalloenzymes. Angew. Chem. Int. Edit. 2010, 49, 5315-5317.

482. Mills, J. H.; Khare, S. D.; Bolduc, J. M.; Forouhar, F.; Mulligan, V. K.; Lew, S.; Seetharaman, J.; Tong, L.; Stoddard, B. L.; Baker, D., Computational Design of an Unnatural Amino Acid Dependent Metalloprotein with Atomic Level Accuracy. J. Am. Chem. Soc. 2013, 135, 13393-13399.

483. Urvoas, A.; Ghattas, W.; Marechal, J. D.; Avenier, F.; Bellande, F.; Mao, W.; Ricoux, R.; Mahy, J. P., Neocarzinostatin-Based Hybrid Biocatalysts with a Rnase Like Activity. Bioorg. Med. Chem. 2014, 22, 5678-5686. 
484. Reetz, M. T.; Peyralans, J. J. P.; Maichele, A.; Fu, Y.; Maywald, M., Directed Evolution of Hybrid Enzymes: Evolving Enantioselectivity of an Achiral Rh-Complex Anchored to a Protein. Chem. Commun. 2006, 4318-4320.

485. Arnold, F. H., Design by Directed Evolution. Acc. Chem. Res. 1998, 31, 125-131.

486. Joó, F.; Kathó, Á., Recent Developments in Aqueous Organometallic Chemistry and Catalysis. J. Mol. Catal. A: Chem. 1997, 116, 3-26.

487. Sletten, E. M.; Bertozzi, C. R., Bioorthogonal Chemistry: Fishing for Selectivity in a Sea of Functionality. Angew. Chem., Int. Ed. 2009, 48, 6974-6998.

488. Garcia-Viloca, M.; Gao, J.; Karplus, M.; Truhlar, D. G., How Enzymes Work: Analysis by Modern Rate Theory and Computer Simulations. Science 2004, 303, 186-195.

489. Ragsdale, S. W., Metals and Their Scaffolds to Promote Difficult Enzymatic Reactions. Chem. Rev. 2006, 106, 3317-3337.

490. Muñoz Robles, V.; Ortega-Carrasco, E.; Alonso-Cotchico, L.; Rodriguez-Guerra, J.; Lledós, A.; Maréchal, J.-D., Toward the Computational Design of Artificial Metalloenzymes: From ProteinLigand Docking to Multiscale Approaches. ACS Catal. 2015, 5, 2469-2480.

491. Romero, P. A.; Arnold, F. H., Exploring Protein Fitness Landscapes by Directed Evolution. Nat. Rev. Mol. Cell Biol. 2009, 10, 866-876.

492. Reetz, M. T.; Rentzsch, M.; Pletsch, A.; Taglieber, A.; Hollmann, F.; Mondiere, R. J.; Dickmann, N.; Hocker, B.; Cerrone, S.; Haeger, M. C. et al, A Robust Protein Host for Anchoring Chelating Ligands and Organocatalysts. ChemBioChem 2008, 9, 552-564.

493. Belsare, K. D.; Andorfer, M. C.; Cardenas, F. S.; Chael, J. R.; Park, H. J.; Lewis, J. C., A Simple Combinatorial Codon Mutagenesis Method for Targeted Protein Engineering. ACS Synthetic Biology 2017, 6, 416-420.

494. Landwehr, M.; Carbone, M.; Otey, C. R.; Li, Y.; Arnold, F. H., Diversification of Catalytic Function in a Synthetic Family of Chimeric Cytochrome P450s. Chem. Biol. 2007, 14, 269-278.

495. Heins, R. A.; Cheng, X.; Nath, S.; Deng, K.; Bowen, B. P.; Chivian, D. C.; Datta, S.; Friedland, G. D.; D'Haeseleer, P.; Wu, D. et al, Phylogenomically Guided Identification of Industrially Relevant Gh1 B-Glucosidases through DNA Synthesis and Nanostructure-Initiator Mass Spectrometry. ACS Chem. Biol. 2014, 9, 2082-2091.

496. Sardo, A.; Wohlschlager, T.; Lo, C.; Zoller, H.; Ward, T. R.; Creus, M., Burkavidin: A Novel Secreted Biotin-Binding Protein from the Human Pathogen Burkholderia Pseudomallei. Protein Expression Purif. 2011, 77, 131-139.

497. Sasmal, P. K.; Streu, C. N.; Meggers, E., Metal Complex Catalysis in Living Biological Systems. Chem. Commun. 2013, 49, 1581-1587.

498. Wallace, S.; Balskus, E. P., Opportunities for Merging Chemical and Biological Synthesis. Curr. Opin. Biotechnol. 2014, 30, 1-8.

Yifan Gu received his B.S. in Chemistry from Peking University in 2011 under Professor Zhangjie Shi. He is a current Ph.D. student under Professor Jared C. Lewis at the University of Chicago. In 2016, he received the Eugene Olshansky Memorial Fellowship from the University of Chicago to continue his research on the use of artificial metalloenzymes in olefin polymerization and photoredox catalysis. His research interests also include cofactor design, artificial metalloenzymes construction, and biocatalysis.

Tillmann Heinisch obtained his $\mathrm{PhD}$ in Chemistry and Protein Crystallography at the University of Basel under Profs. T. Ward and T. Schirmer. After joining the group of Prof. Frances Arnold at Caltech for postdoctoral research, he returned to Basel for a second postdoc. His research interests include the structure-based engineering of artificial metalloenzymes. 
Valentin Köhler studied chemistry at the University of Göttingen, Germany, followed by a PhD thesis with A. Pfaltz in asymmetric transition metal catalysis at the University of Basel. During his postdoctoral studies he focused first on oxidative biocatalysis in the groups of N. J. Turner and S. L. Flitsch (University of Manchester, United Kingdom) before combining synthetic transition metal catalysis and protein control in the investigation of hybrid catalyst systems with Prof. Ward. Since 2014 he holds a permanent position as a scientific coworker at the University of Basel which gratifyingly permits some independent research. His current research interests extend to protein modification and peptide design for unusual applications outside of catalysis.

Vincent Lebrun received his PhD in chemistry in 2014 from the University Grenoble Alpes under the guidance of Dr. O. Sénèque and Dr. J.-M. Latour. During this time, he worked on peptidic models of zinc fingers. He currently is a postdoc fellow in the group of Prof. T. R. Ward, focusing on the use of peptides to control the activity of artificial metalloenzymes.

Jared C. Lewis received his B.S. in chemistry in 2002 from the University of Illinois, working with Eric Oldfield, and his Ph. D. in 2007 from the University of California, Berkeley under the direction of Jonathan Ellman and Robert Bergman. He carried out postdoctoral research in Frances Arnold's laboratory at the California Institute of Technology. He began his independent career in 2011 at the University of Chicago, where he is an Assistant Professor. His research involves engineering and evolving natural and artificial enzymes for selective catalysis.

Yasunori Okamoto received his Ph.D. from Osaka University (Japan) in 2014 under the supervision of Prof. T. Hayashi. During and after his Ph.D., he joined Prof. D. M. Kurtz's group at University of Texas at San Antonio (US) and Prof. S. Aono's group at National Institute of Natural Science (Japan). Since 2014 he is postdoctoral fellow in the group of Prof. T. R. Ward and was recently awarded a JSPS fellowship to implement artificial metalloenzymes in mamalian cells for therapeutic purposes.

Michela M. Pellizzoni received her B.S. degree in Pharmaceutical Biotechnology in 2009 and her M.S. degree in Biotechnology Medicine in 2011 from the University of Milan. She earned her PhD degree in Pharmaceutical Sciences from the University of Milan in 2015 on the development of hybrid systems based on new chiral aminophosphine and diamine ligands and their applications in asymmetric synthesis. She then joined the group of Prof. Ward to work on the development of new catalytic reactions and protein scaffold engineering for in vivo catalysis with ArMs.

Raphael Reuter was born in Weil am Rhein, Germany. He obtained his BSc and MSc in chemistry at the university of Basel and did his PhD from 2008 to 2011 in the group of Prof. Dr. Hermann A. Wegner, working on the synthesis and properties of macrocyclic oligoazobenzenes. From 2012 to 2016 he was a postdoctoral fellow in the group of Prof. Ward on in vivo olefin metathesis. He now works for Dottikon Exclusive Synthesis. 
Fabian Schwizer received his M.Sc. in Chemistry from the University of Basel in 2013 on chemo-genetic engineering of artificial metalloenzymes. He then joined the Wardgroup for a $\mathrm{PhD}$ and is interested to implement in vivo catalysis with artificial metalloenzymes in E. coli cells.

Thomas $\mathbf{R}$ Ward obtained his $\mathrm{PhD}$ in homogeneous catalysis from the ETHZ (1991). Following a postdoc with R. Hoffmann (Cornell University, theoretical chemistry) and C. Floriani (Univ. Lausanne, organometallic chemistry), he initiated his independent career at the University of Berne in 1993. In 2000, he moved to the University of Neuchâtel and initiated his research on artificial metalloenzymes. He moved to the University of Basel in 2008. Since 2016, he is the director of the National Compentence Center in Research "Molecular Systems Engineering". He was recently awarded an ERC advanced grant to realize his DrEAM: the Directed Evolution of Artificial Metalloenzymes for in vivo catalysis. 